\title{
THE CITY OF MORRO BAY, CALIFORNIA \\ SIGN ORDINANCE UPDATE AND EMBARCADERO DISTRICT TOURISM-ORIENTED DIRECTIONAL SIGN PLAN
}

\author{
A Professional Project \\ presented to \\ the Faculty of California Polytechnic State University, \\ San Luis Obispo
}

In Partial Fulfillment

Of the Requirements for the Degree

Master of City and Regional Planning in the College of Architecture

By

Erik Berg-Johansen

June 2013 
(c) 2013

Erik Berg-Johansen

ALL RIGHTS RESERVED 


\section{COMMITTEE MEMBERSHIP}

TITLE:

The City of Morro Bay, California - Sign Ordinance Update and Embarcadero District Tourism-Oriented Directional Sign Plan

AUTHOR: $\quad$ Erik Berg-Johansen

DATE SUBMITTED: June 2013

COMMITTEE CHAIR: Chris Clark, JD, Lecturer, City and Regional Planning

COMMITTEE MEMBER: Rob Livick, Director of Public Services, City of Morro Bay

COMMITTEE MEMBER: Kelly Main, Ph.D. Assistant Professor, City and Regional Planning 


\begin{abstract}
The City of Morro Bay, California - Sign Ordinance Update and Embarcadero District Tourism-Oriented Directional Sign Plan
\end{abstract}

Erik Berg-Johansen

This report includes a Draft Sign Ordinance, a Tourism-Oriented Directional Sign Plan, and a background report for each product. The final products were created thought a process involving extensive research, community outreach, and detailed discussions among City of Morro Bay staff.

\title{
The Sign Ordinance
}

It was discovered that signs are important to business owners and residents due to their effect on both economic and aesthetic issues in communities. This report documents research of scholarly articles, case studies, and community outreach efforts. This report includes survey results and analysis that reveal the opinions of Morro Bay business owners, and also their ideas in regards to the sign ordinance update. According to many business owners, the current sign ordinance is convoluted, virtually unenforced, and unfairly applied. It was the goal of this project to hear what the community desires, and then apply this knowledge to a proposal that residents and business owners in Morro Bay approve of. The proposed sign ordinance aims to be fair and user-friendly, while ultimately enhancing community character and aesthetic quality in the future.

\section{Tourism-Oriented Directional Sign Plan}

The Tourism-Oriented Directional Sign Plan was created to promote tourism in the City of Morro Bay and negate the need for A-frame sign use in the Embarcadero District. The plan includes three alternatives that are intended to spur discussion among the Planning Commission when the proposal is presented. The background report associated with this plan is intended to provide the reasoning behind the proposals, and give readers of the plan background knowledge on directional signs in general. Similar to the sign ordinance background report, this report documents research of scholarly articles, case studies, and community outreach efforts. 
TABLE OF CONTENTS

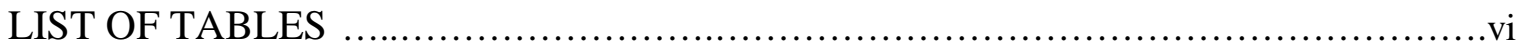

LIST OF FIGURES ................................................................iii

SECTION

I. SIGN ORDINANCE BACKGROUND REPORT .........................ART A

II. DRAFT SIGN ORDINANCE ....................................

III. EMBARADERO DISTRICT TOURISM-ORIENTED ............................RT C DIRECTIONAL SIGN PLAN BACKGROUND REPORT

IV. EMBARADERO DISTRICT TOURISM-ORIENTED ...................PART D DIRECTIONAL SIGN PLAN

\section{APPENDICES}

A. Sign Ordinance Background Report Attachments ..........................

B. TODSP Background Report Attachments ..............................

* Each section (A-D) has its own Table of Contents 


\section{LIST OF TABLES}

\section{PART A}

Table

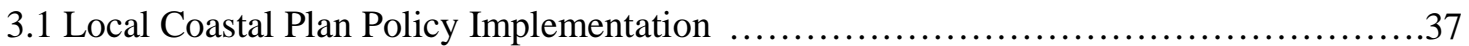

4.1 Compiled Results from Survey \# 5 ..................................................41

\section{PART B}

17.041 Embarcadero District Regulations .25

17.051 Downtown District Regulations . ...........................................28 


\section{LIST OF FIGURES}

\section{PART A}

Figure

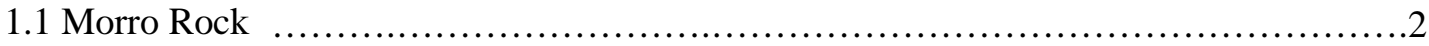

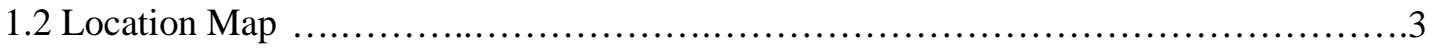

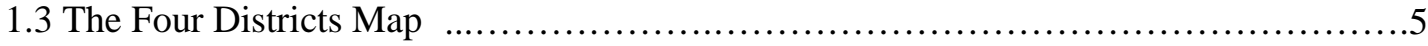

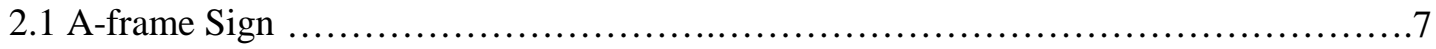

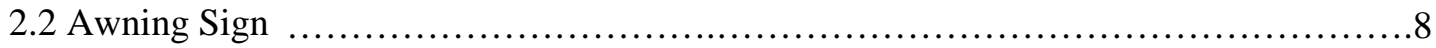

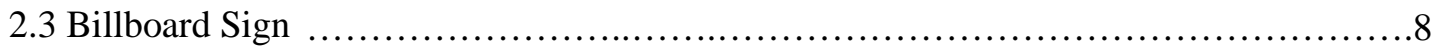

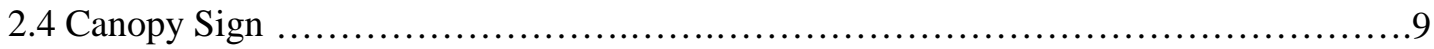

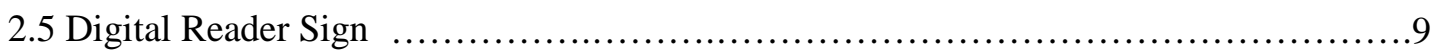

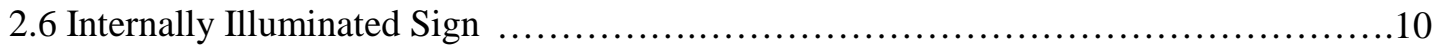

2.7 Externally Illuminated Sign ................................................. 10

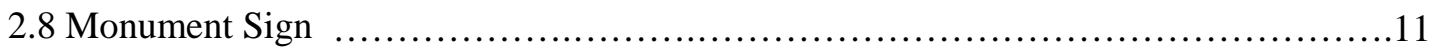

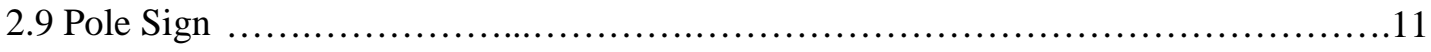

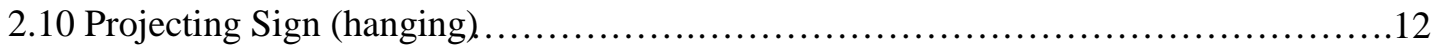

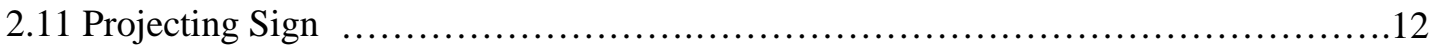

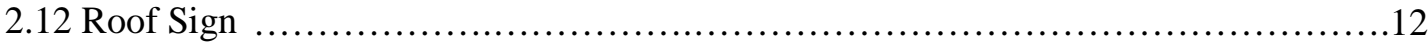

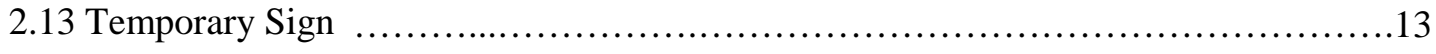

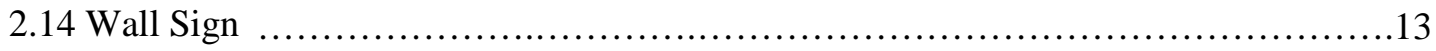

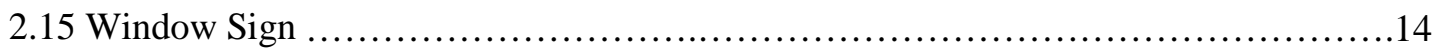

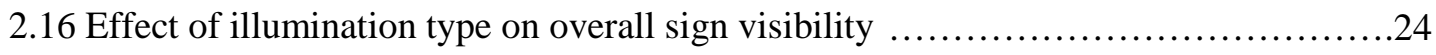

4.1 Combined Survey Results from Surveys 1, 2, and 3 ..............................40

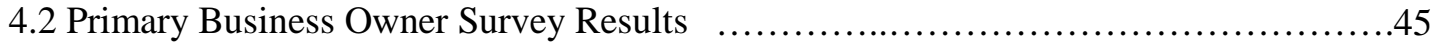

6.1 Current Fee Schedule ........................................................ 57 


\section{PART B}

Figure

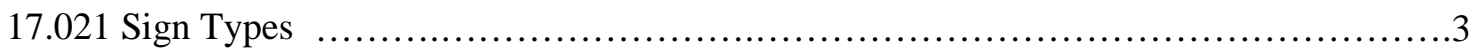

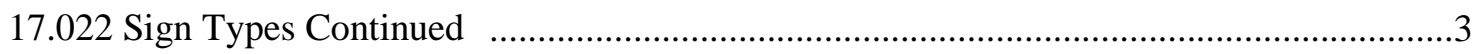

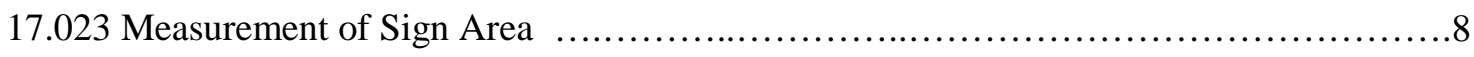

17.024 Measurement of Double and Multi-Faced Signs ...................................8

17.025 Façade Calculations ........................................................

\section{PART C}

Figure

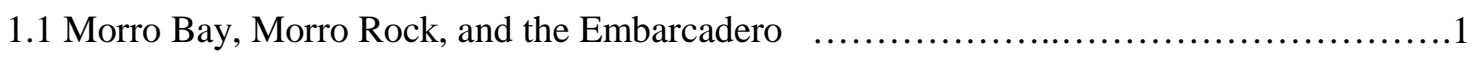

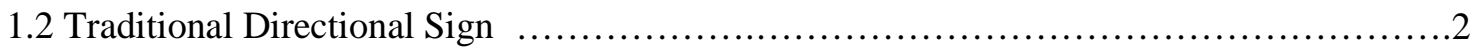

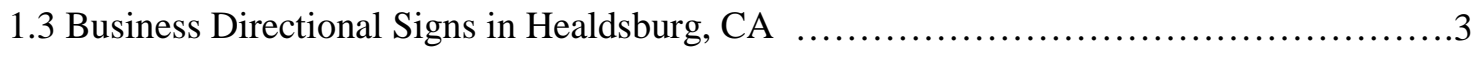

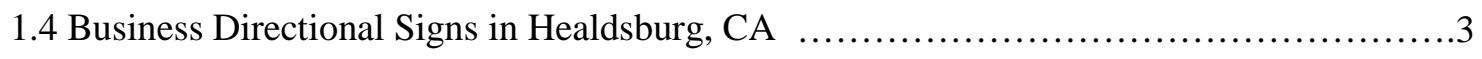

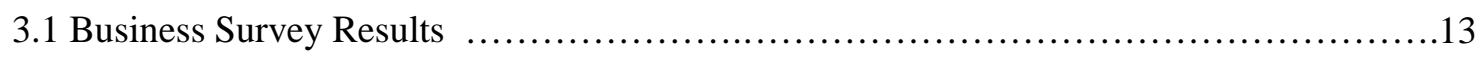

\section{PART D}

Figure

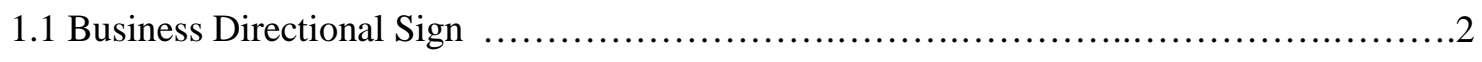

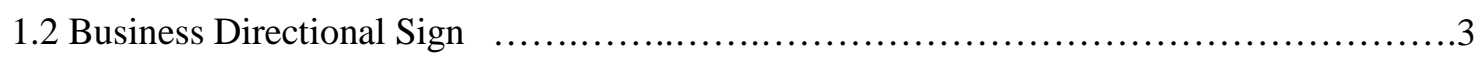

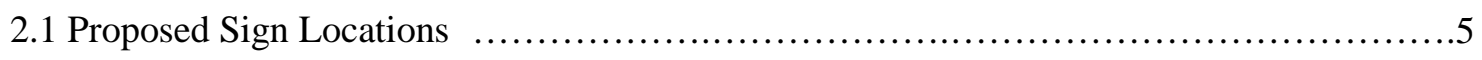

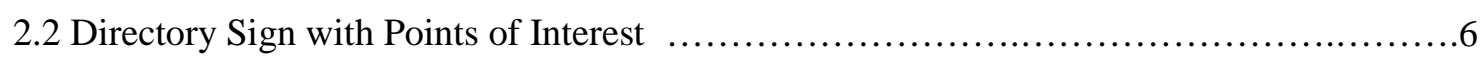

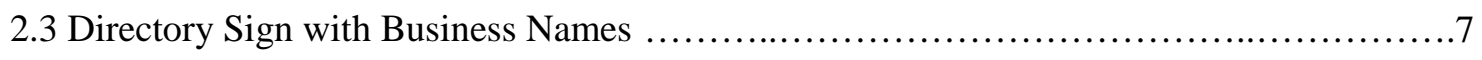

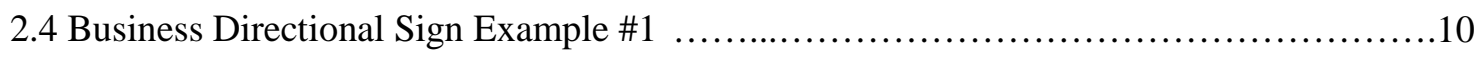

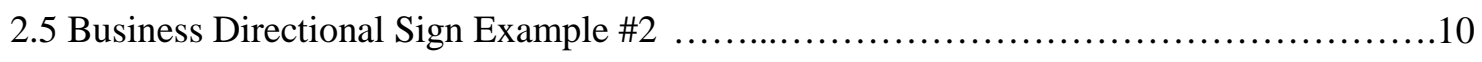

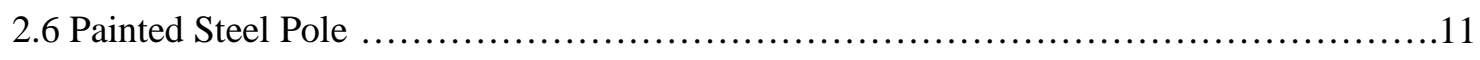

2.7 Flag-topped Steel Pole . .........................................................11 
2.8 Morro Rock / Sunray Pole

2.9 Sign Structure in Healdsburg, CA . .12 
PART A

\section{CITY OF MORRO BAY, CALIFORNIA}

Sign Ordinance Update

\section{BACKGROUND REPORT}

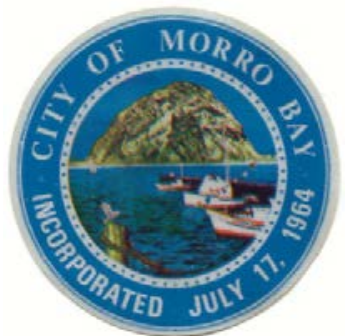

Prepared by

Erik Berg-Johansen, Intern Planner

June 2013 


\section{TABLE OF CONTENTS}

\section{CHAPTER 1: PROJECT BACKGROUND}

1.1 Project Summary................................................

1.2 History of Signs in Morro Bay.....................................2

1.3 Geography and Demographics...................................... 3

1.4 The Four Districts...............................................

\section{CHAPTER 2: SIGNAGE}

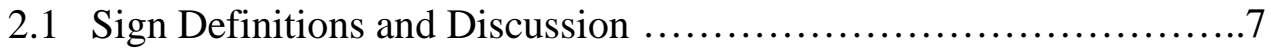

2.2 Signs as Advertising............................................. 14

2.3 A-Frame Signs ............................................... 17

2.4 Digital Signage.................................................. 19

2.5 Illuminated Signs............................................21

\section{CHAPTER 3: SIGN LAW}

3.1 Freedom of Speech...........................................25

3.2 CEQA and Other Environmental Issues ...........................27

3.3 State and Local Law................................................30

3.4 Federal Law........................................................

3.5 Enforcement................................................ 31

3.6 The General Plan and Coastal Land Use Plan .........................34

\section{CHAPTER 4: COMMUNITY OUTREACH}

4.1 Past Public Outreach...............................................38

4.2 Primary Survey Data...........................................43

4.3 Primary Interviews...........................................48

4.4 Outreach Analysis ..............................................50

\section{CHAPTER 5: CASE STUDIES}

5.1 Introduction................................................. 53

5.2 Santa Cruz, California............................................53

5.3 Atascadero, California............................................54

5.4 Carpinteria, California..........................................55

\section{CHAPTER 6: EXISTING SIGN CODES}

6.1 The Current Ordinance.........................................57

6.2 The Old Draft Ordinance..........................................58

6.3 USSC Model Sign Ordinance.................................63

\section{CHAPTER 7: CHANGES TO THE ORDINANCE}

7.1 Introduction ..................................................64

7.2 Allowable Sign Area and Calculations................................64

7.3 Prohibited Signs...............................................65

7.4 Sign Bonuses..................................................66

7.5 Low Impact Signage ..........................................66

7.6 Other Changes ................................................67

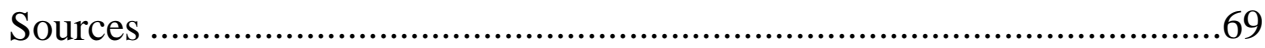




\section{Chapter 1: Project Background}

\subsection{Project Summary}

In 2011, consultants hired by the City of Morro Bay formulated a draft sign ordinance. Due to certain inadequacies within the code and apparent disagreement among decision makers, the ordinance was never approved by the Planning Commission. In fall of 2012 the City decided to make another push towards implementing a new updated sign ordinance. Extensive research was conducted in order to formulate a plan that is clear, concise, and well accepted by the community. The existing draft ordinance has been edited, reorganized, reformatted, and greatly expanded. The new draft ordinance takes an entirely different approach when it comes to calculating allowable sign areas, and also tailors sign regulations to different districts within the City. This background report documents information and evidence gathered, and was used as a tool during the process of making important decisions during the process. The following research was conducted during the creation of this background report:

- Analyzed scholarly journals that discuss marketing, advertising, and theory behind signage and city sign codes

- Gathered ideas by researching sign ordinances from other California cities

- Evaluated Morro Bay’s current sign ordinance and the older 2011 “draft ordinance”

- Conducted surveys to capture the public’s opinion on various sign issues

- Analyzed data from outreach efforts conducted in previous years

- Consulted Morro Bay city staff and planners from other cities to gain knowledge about zoning ordinances and signs

- Reviewed memos, staff reports, and various correspondences regarding the sign ordinance 


\subsection{History of Signs in Morro Bay}

Morro Bay, California is a place that probably has more signs than most other cities of similar size. This phenomenon can be attributed to tourism, which supports a relatively high amount of retail stores, hotels and restaurants within the City (see a map of all businesses in Appendix 1.1). These mentioned business types require signs to advertise their name, as well as offered goods and services. Today Morro Bay has an abundance of businesses for a town of its size, and an economy based primarily on tourism; but when did commercial activity begin to emerge in Morro Bay, and what was the economy based on before the emergence of tourism?

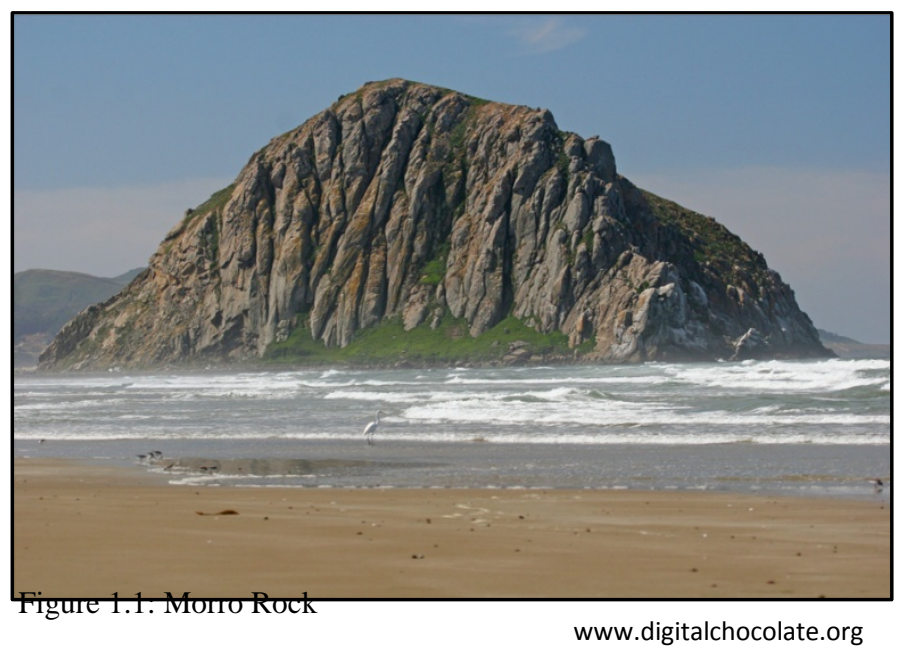

According to Roger Castle’s and Gary

Ream’s book Morro Bay, CA: Images

of America, there were documented

cases of commercial activity in Morro

Bay as early as the 1910s. One of the first was Cornelius Silva, who brought his family to Morro Bay

around 1917. He and his son Alfred started one of the

first commercial fishing operations shortly after moving to the area. Although this example provides evidence of commercial activity in Morro Bay, fishing-based businesses at this time would not have had a storefront or any type of signage (p. 15). There is, however, later evidence of signage from photos and stories related to the developing restaurant business in Morro Bay, which surfaced sometime during the 1920s or early 1930s. One particularly amusing story about signage dates back to 1951, when Lavern and Tommy "Loggie” Loggins reopened the Chat N'Chew restaurant on Main Street. They put up a new sign that read, "Chat N' Chew Terrible 
Food.” According to the source the town was "endlessly amused when the new sign went up" (Castle and Ream, 2006, p. 26).

It seems that some of Morro Bay’s signs today are relics of the past, preserving the playful, dynamic themes jumpstarted by the Chat N' Chew restaurant. In contrast, there are other signs currently existing within the City that are inconsistent with the eclectic beach town character enjoyed by residents and tourists alike. Unappealing signs not only deflate the rich history of this past farming and fishing village, but detract from the natural aesthetic beauties the City prides itself on. An updated sign ordinance will attempt to remedy these issues, and preserve what residents and business owners found so attractive about the City nearly 100 years ago, and what they find so attractive about the City today.

\subsection{Geography and Demographics}

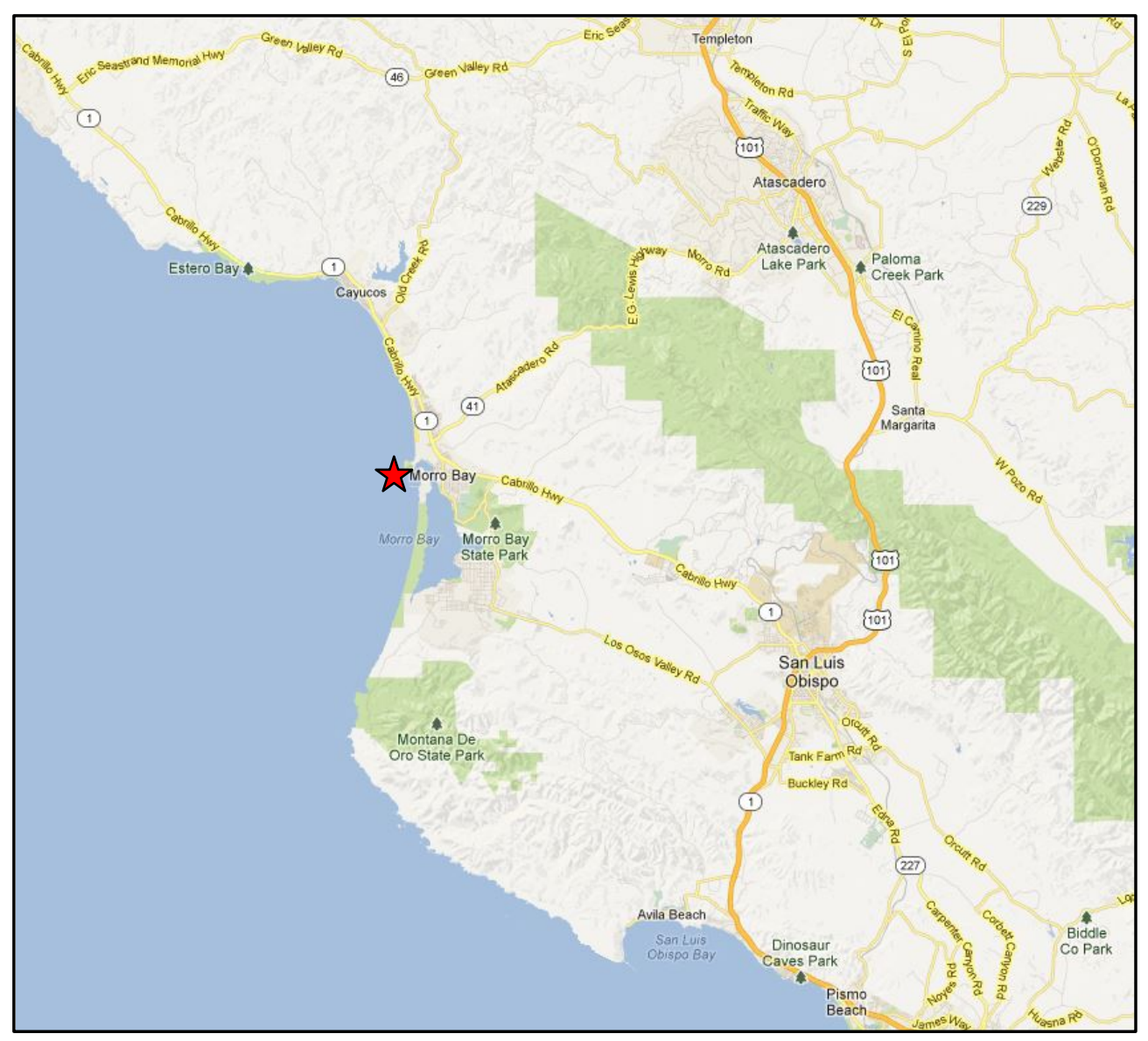

Figure 1.2: Location Map 


\section{Geography:}

The City of Morro Bay, CA is located on California's coastline halfway between San Jose and Los Angeles. The City sits on a hill along Morro Bay, a body of water protected from the Pacific Ocean by a wide sand bar. The bay provides calm waters for recreational kayaking and safe boat mooring. Furthermore, the safety of the bay allows shops, restaurants, and hotels to locate along the waterfront. To the north of Morro Rock lies a large public beach popular with both surfers and sunbathers.

\section{Demographics:}

According to the 2010 U.S. Census, the City of Morro Bay has a population of 10,234 and a median age of 48.9 years old. There are 4,844 permanently occupied households, and 1,125 housing units used for seasonal, recreational, or occasional use. Of the 4,844 permanent households, 2,583 units are owner-occupied, and 2,261 are renter-occupied. According to Morro Bay’s Businsess Database (2013), there are 45 hotels and motels, and 55 restaurants within the City to support the estimated 41,327 motel visitors in July of 2012. (Morro Bay Economic Development Program).

\subsection{The Four Districts}

Instead of organizing the code by zoning district (i.e. commercial, visitor-serving, industrial), discussions with Morro Bay City staff revealed that organizing the ordinance by district was preferable. It must also be noted that survey results (which will be discussed in detail later) support this preference. In contrast to the traditional methods of specifying allowable signage by zoning district or having one set of specifications for the entire city, the four-district organizational strategy bases regulation solely on geographic location. It is hypothesized that this method will work well in Morro Bay because the four distinguished districts are very distinct. That is, businesses in each district, for the most part, exist in a similar economic setting and have 
similar signage needs. Smaller scale tourist-serving businesses located in the Embarcadero District, for example, have certain characteristics that necessitate the need for a customized set of sign regulations. The four districts are as follows: Embarcadero, Downtown, North Main Street, and Quintana Road. Figure 1.3 shows the general location of each district. A more detailed map of the four districts can be found in Appendix 1.2.

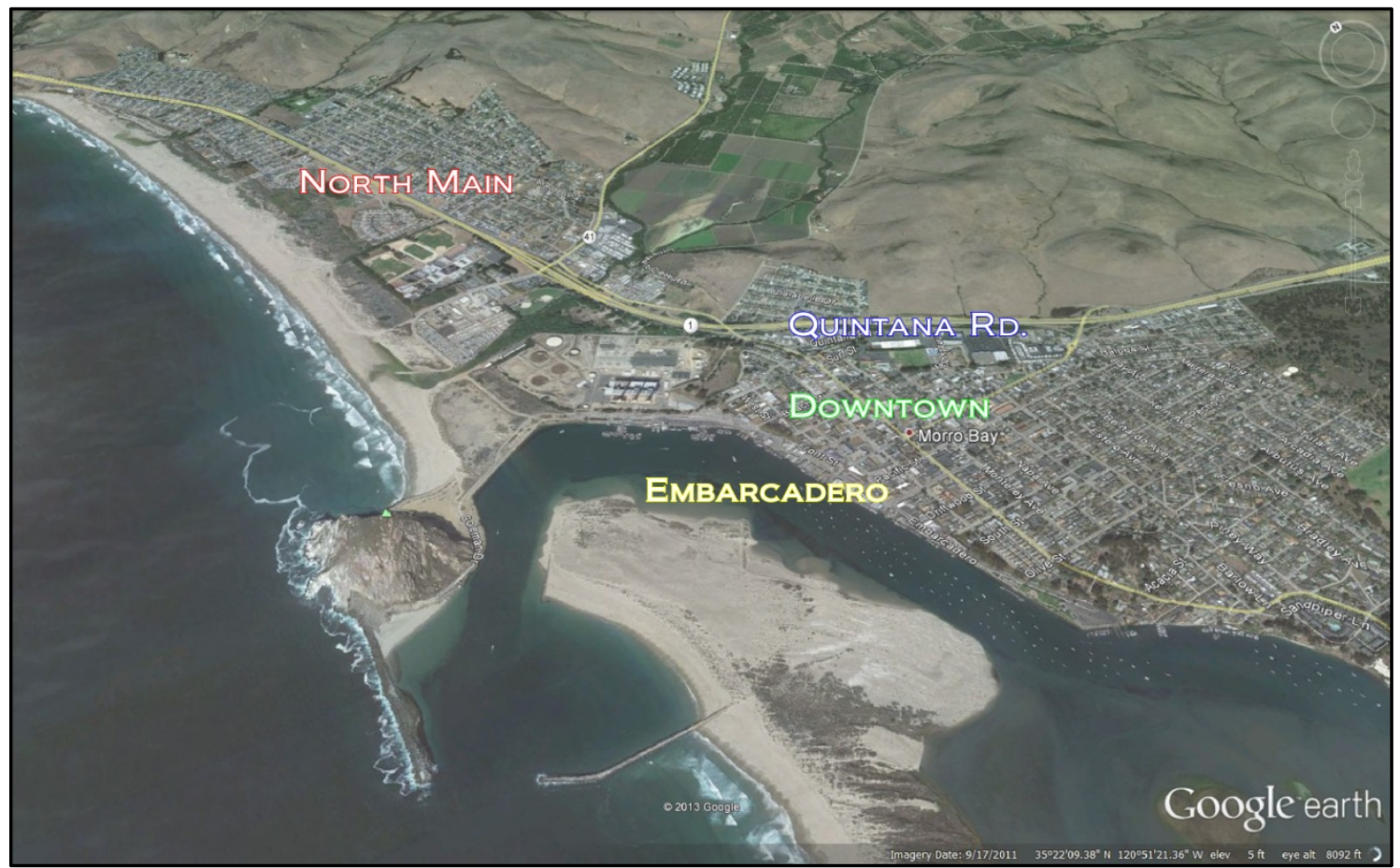

Figure 1.3: The Four Districts Map

\section{Embarcadero District:}

Serving as the City's primary tourist destination, the lively Embarcadero District lines the beautiful waters of the bay. This area is located directly west of the downtown district, and includes some of the city's finest restaurants, cafes, and hotels. The Embarcadero area also houses the majority of tourism-related shops within the City. Candy stores, gift shops, clothes stores, wine tasting rooms, and recreational based businesses (kayak rentals, sport fishing/whale watching tours, etc.) make up the bulk of these tourism-oriented businesses. Including only one narrow road and limited parking, this district is dominated by pedestrian activity.

\section{Downtown Area:}


The Downtown District is at the heart of Morro Bay, existing east of the Embarcadero and southwest of Highway 1. The Downtown Area houses the majority of the City's hotels, banks, churches, offices, parks, and public service buildings. There are also numerous restaurants and other smaller retail establishments such as art boutiques, antique stores, and markets. Morro Bay’s Downtown sees more pedestrian and tourism traffic than the North Main and Quintana Road Districts, but less than the Embarcadero district.

\section{North Main Street District:}

The large North Main Street District runs parallel to Highway 1. This district, which exists north of the Downtown District, is home to restaurants, large supermarket (Spencer's), apartments, single-family homes, industrial uses, and other medium-scale retail businesses. The majority of this district lies within a mixed-use zone, which means both residential and commercial uses are allowed. Currently there is an abundance of pole signs and monument signs in this area designed to attract the attention of drivers traveling on Highway 1. Although pedestrian activity exists in this district, it is dominated by automobile traffic.

\section{Quintana Road District:}

The Quintana Road District spans the northeastern and eastern borders of the Downtown District. Quintana Road is unique because the City's larger commercial buildings exist here (such as the Albertson's/Rite Aid building). It is also important to note that this defined area includes multiple gas stations, which exist on the intersection of Morro Bay Blvd. and Quintana Rd. This district, compared to the other three, is the most auto-oriented (and least pedestrian friendly). 


\section{Chapter 2: Signage}

\subsection{Sign Definitions and Discussion}

Signs are everywhere we look in today's society, and for various reasons, signs are an important aspect in all communities. The United States Sign Council defines signs as "Any device visible from a public place whose essential purpose and design is to convey either commercial or noncommercial messages by means of graphic presentation of alphabetic or pictorial symbols or representations" (USSC, 2011, p. 22).

Signs portray information about businesses, mark landmarks or places of interest, and direct people to their destinations. Signs also keep the roads safe by displaying traffic information for bicyclists and automobiles. Helge Lobler argues that non-verbal signs act as a service, stating that they are "...the application of skills and knowledge for the benefit of another party" (Vargo and Lusch, 2004; retrieved from Lobler, 2010). Signs have long been used on a global scale to communicate messages and information to all people. A list of different sign types are as follows:

A-Frame Signs. A-frame signs are composed of two rectangular pieces of wood or plastic that are attached with a hinge on one side. These signs are mobile, and can be folded flat and stored. See Section 2.3 for more information on A-frame signs.

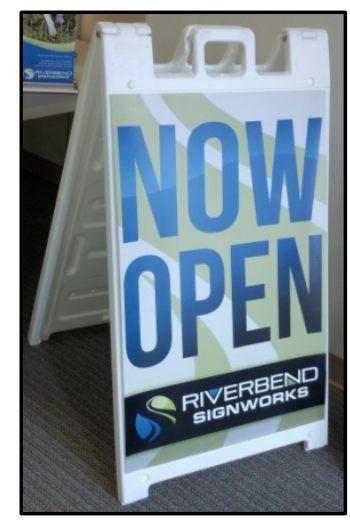

Figure 2.1: A-frame sign (www.riverbendsignworks.com) 


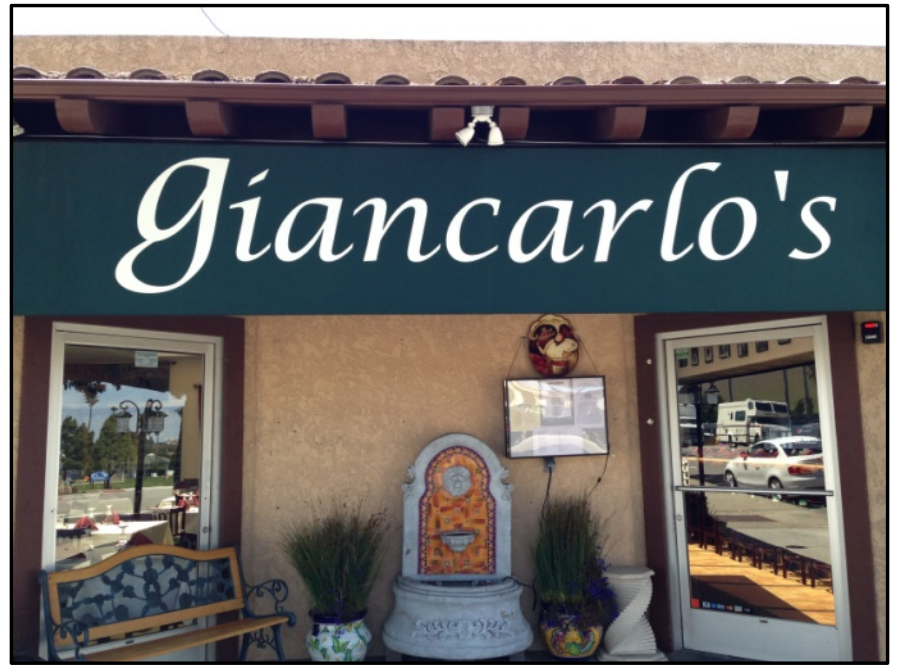

Figure 2.2: Awning Sign

Awning Signs. "A sign displayed on or attached flat against the surface or surfaces of an awning" (USSC, 2011, p. 16). The sign area calculation takes only into account the printed section of the awning, and not the entire area. In a way, this gives awning signs a slight advantage, because the fabric or material used to print on (some which would not count towards total sign area) could perhaps be designed with bright colors to attract attention.

Billboards. Billboards are larger signs placed along the side of highways or freeways, and are designed to display information to fast-traveling motorists. The USSC (2011) defines billboards as an outdoor advertising sign, which are "...permanent sign[s] erected, maintained or used in the

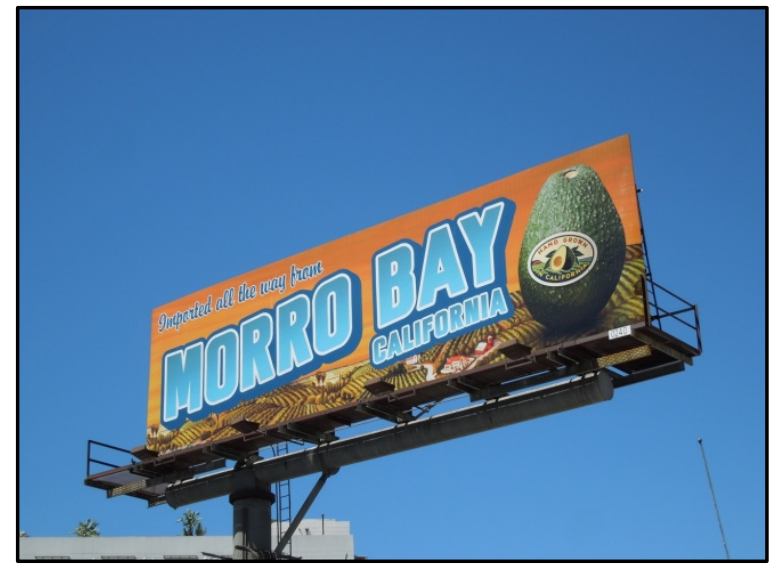

Figure 2.3: Billboard Sign (www.jasoninhollywood.com) 
outdoor environment for the purpose of the display of commercial or noncommercial messages not appurtenant to the use of, products sold on, or the sale or lease of, the property on which it is displayed" (p. 21). The USSC states that off-premise signs and commercial outdoor advertising signs also fall under this definition. Billboards are currently prohibited in the City of Morro Bay.

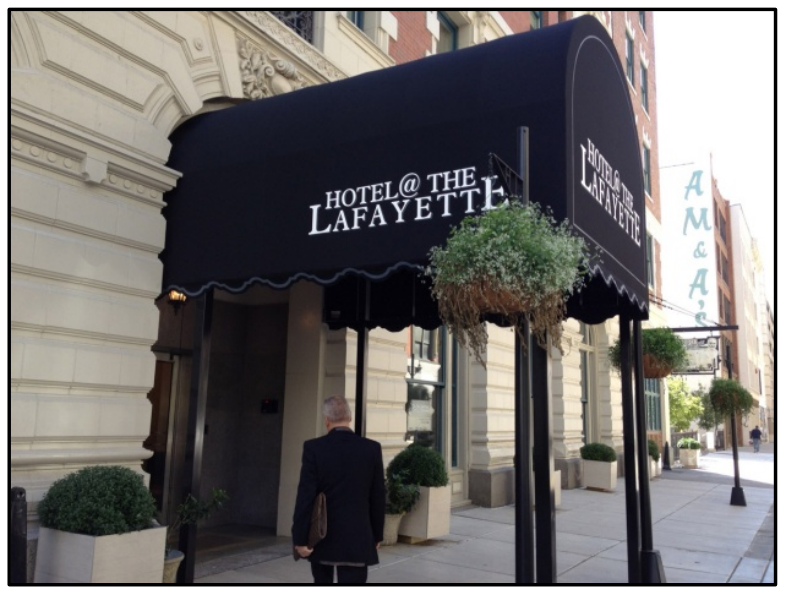

Figure 2.4: Canopy Sign (www.buffalorising.com)

Canopy Sign. "A multi-sided overhead structure or architectural projection supported by attachment to a building on one or more sides and either cantilevered from such building or also supported by columns at additional points. The surface(s) and/or soffit of an attached canopy may be illuminated by means of internal or external sources of light" (USSC, 2011, p. 17). The USSC also states that marquee signs are similar to attached canopy signs.

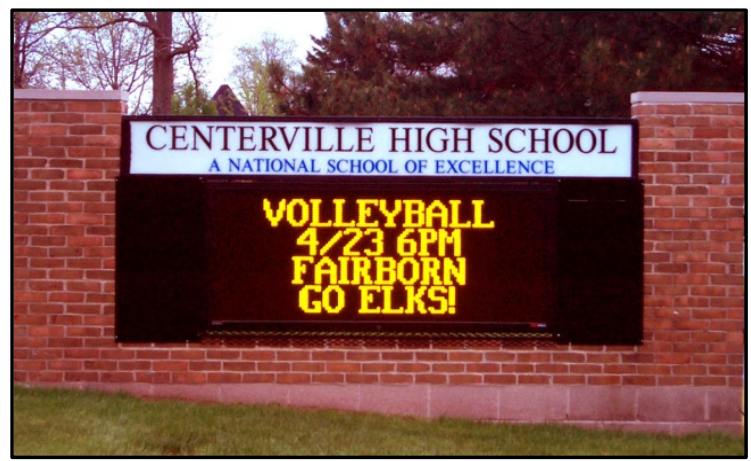

Figure 2.5: Digital Reader Sign (www.ledelectronicsigns.com)
Digital Signs. The USSC defines digital signage as an "electronic message center of sign (EMC)," which is described as "An electrically activated changeable sign whose variable message and/or graphic presentation capability can be 
electronically programmed by computer from a remote location...EMCs typically use light emitting diodes (LEDs) as a lighting source" (USSC, 2011, p. 19). See Section 2.4 for more information on digital signs.

Illuminated Signs. "A sign characterized by the use of artificial light, either projecting through its surface(s) [Internally or trans-illuminated]; or reflecting off its surface(s) [Externally illuminated]" (USSC, 2011, p. 20).

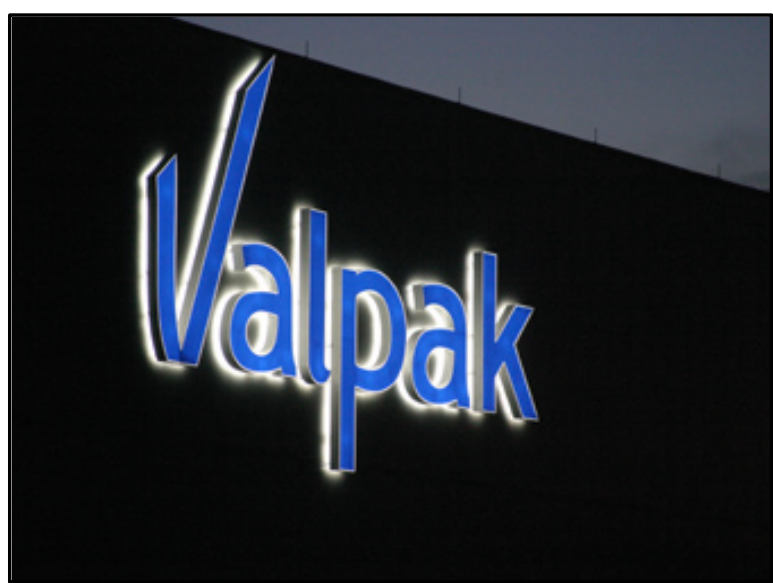

Figure 2.6: Internally Illuminated Sign (www.intlsign.com)

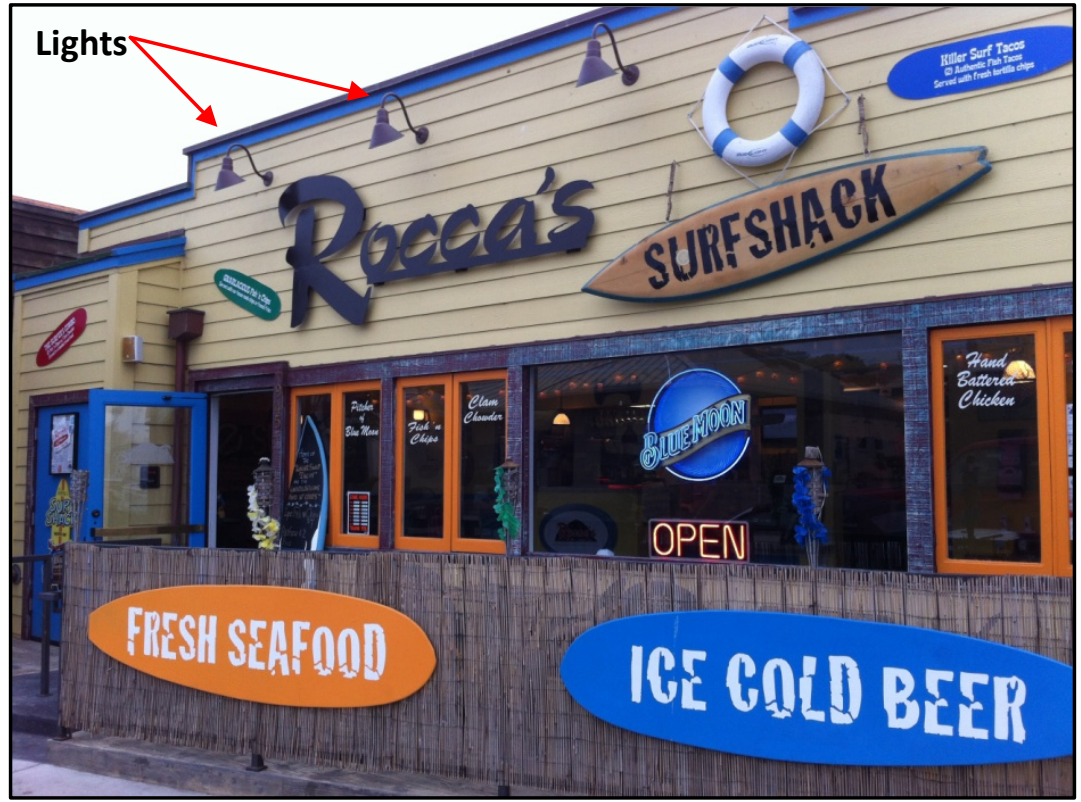

Figure 2.7: Externally Illuminated Sign 
Freestanding Signs. "A sign principally supported by one or more columns, poles, or braces placed in or upon the ground" (USSC, 2011, p. 19). There are two primary types of freestanding signs: monument signs and pole signs.

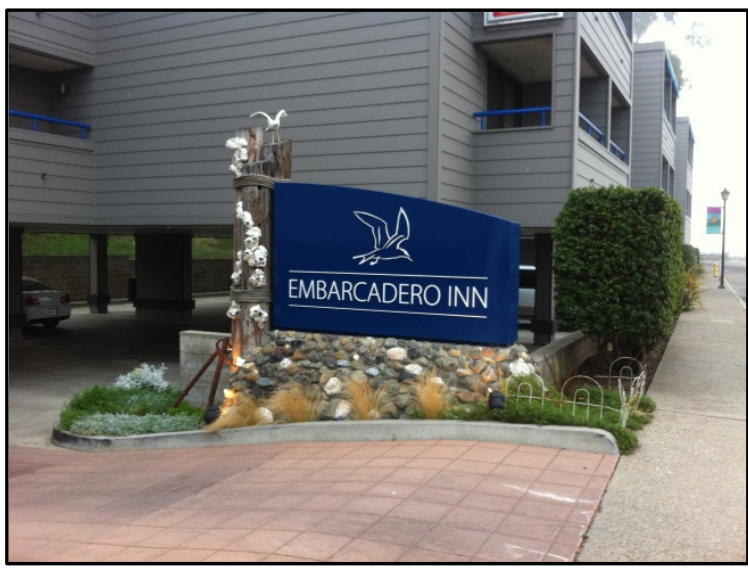

Figure 2.8: Monument Sign

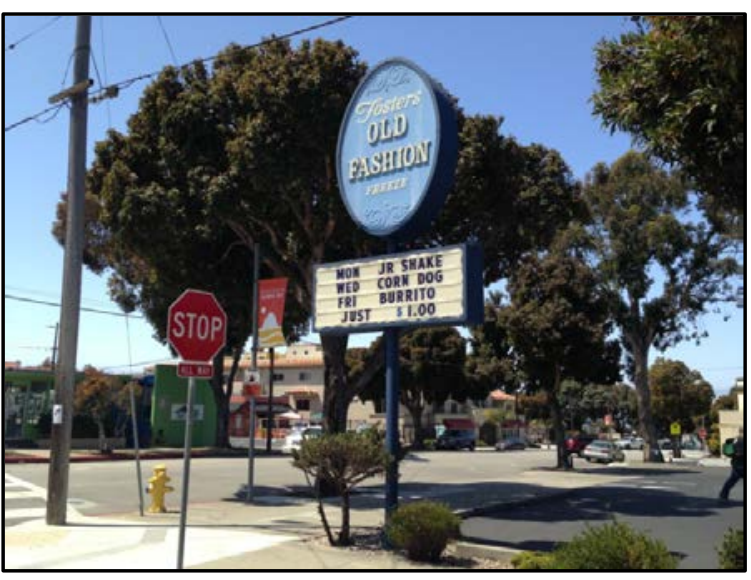

Figure 2.9: Pole Sign

Monument Signs. In general, monument signs are strategically placed in front of businesses to attract motorists, and are positioned in a way that presents sign text or graphics perpendicular to the flow of traffic. This is a benefit that surface signs and window signs may be unable to achieve.

Pole Signs. Pole signs, like monument signs, have the ability to face directly towards incoming travelers. However, they differ in that they display signage higher up. That is, monument signs are generally built relatively close to the ground, and have more than one support structure touching the ground. Pole signs, on the other hand, have a single pole that elevates signage to a height that is visible from farther distances. 


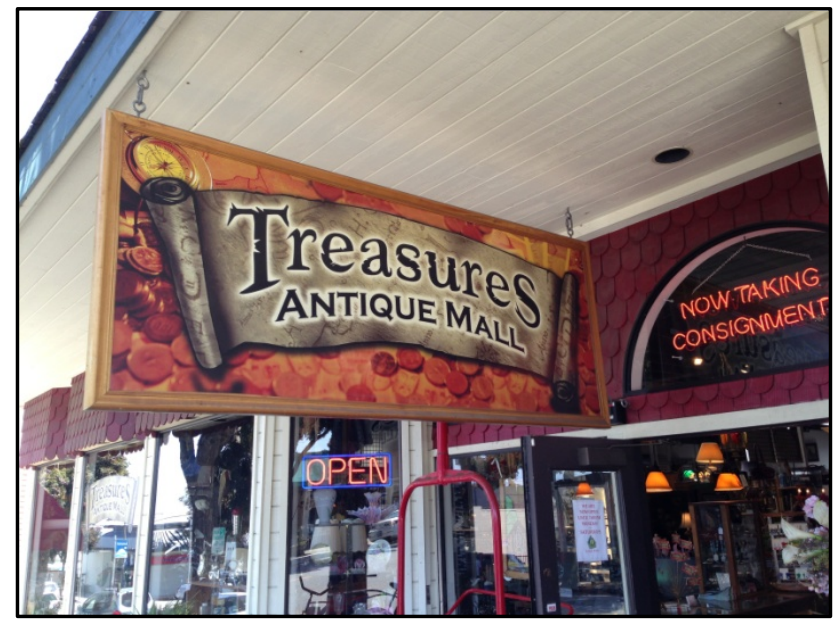

Figure 2.10: Projecting Sign (hanging)

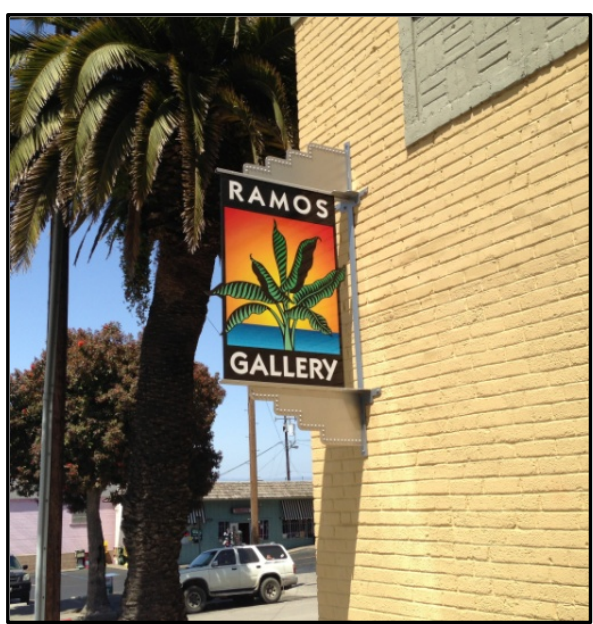

Figure 2.11: Projecting Sign

Projecting (Pub) Sign. A sign that is attached to or projects more than eighteen (18) inches from a building face or wall or from a structure whose primary purpose is other than the support of a sign. Projecting signs are generally hung with chains, or connected to the building with supports.

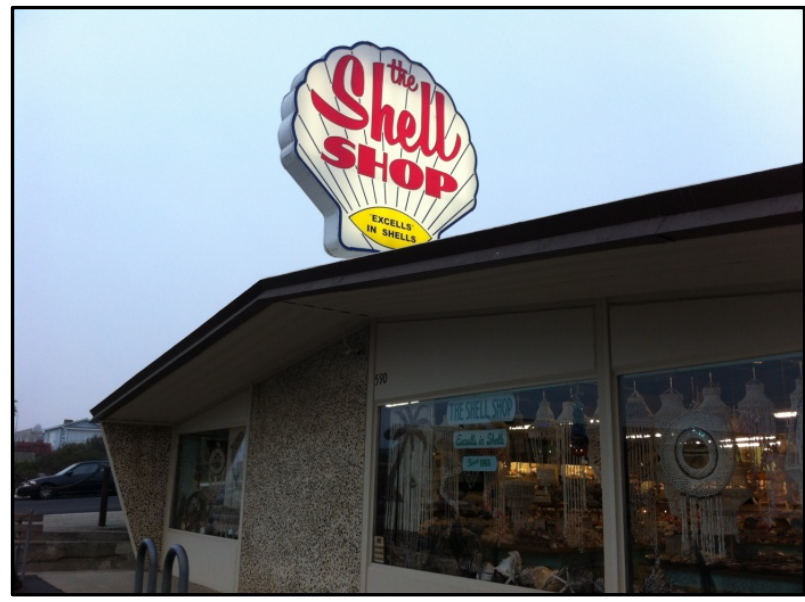

Figure 2.12: Roof Sign
Roof Signs. "A sign mounted on the main roof portion of a building or on the uppermost edge of a parapet wall of a building and which is wholly or partially supported by such building." 


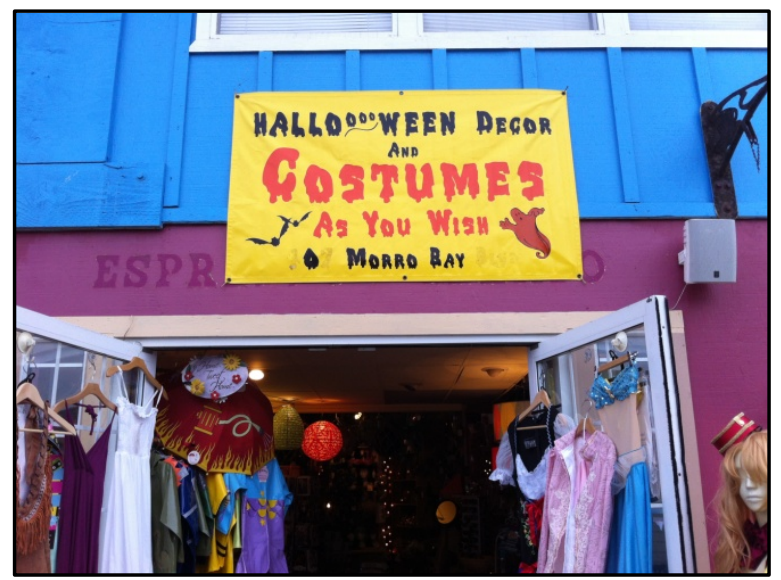

Figure 2.13: Temporary Sign

Temporary Signs. "A sign intended to display either commercial or noncommercial messages of a transitory or temporary nature. Portable signs or any sign not permanently embedded in the ground, or not permanently affixed to a building or sign structure that is permanently embedded in the ground, are considered temporary signs" (USSC, 2011, p. 23).

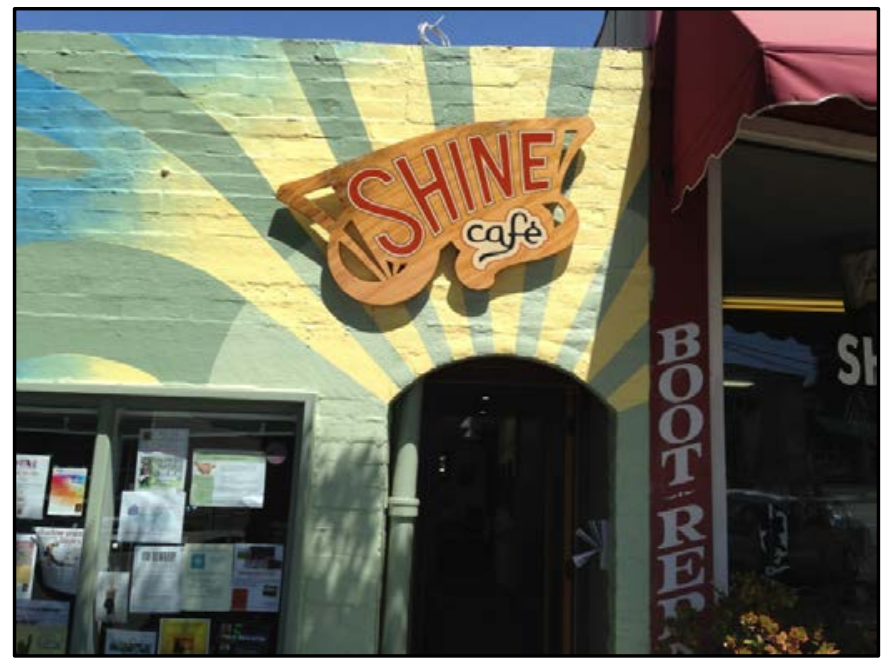

Figure 2.14: Wall Sign

Wall Signs. "A sign that is in any manner affixed to any exterior wall of a building or structure and that projects not more than eighteen (18) inches from the building or structure wall. Also includes signs affixed to architectural projections that project from a building provided the copy area of such signs remains on a parallel plane to the face of the building facade or to the face or faces of the architectural projection to which it is affixed" (USSC, 2011, p. 23). 


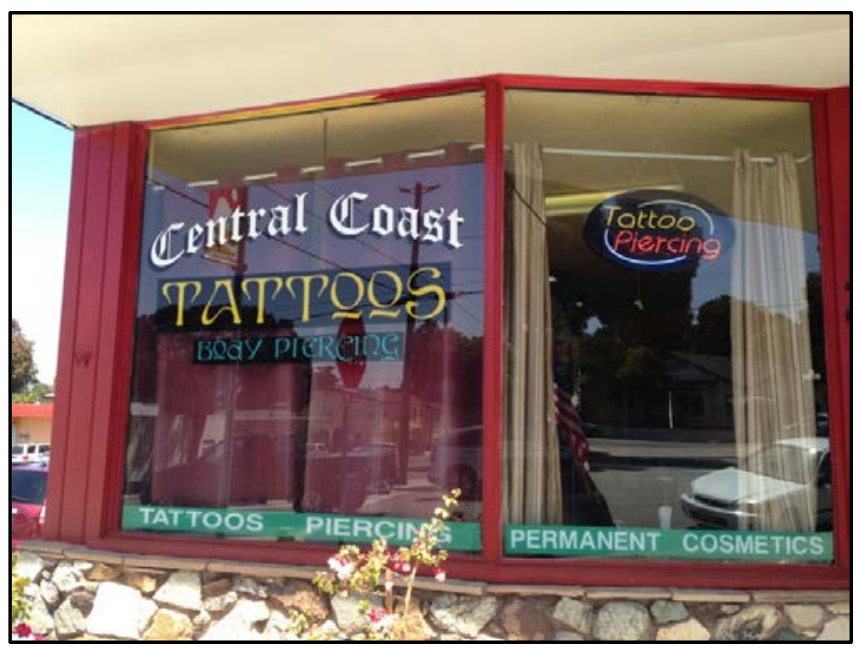

Figure 2.15: Window Sign

Window Signs. "A sign affixed to the surface of a window with its message intended to be visible to the exterior environment" (USSC, 2011, p. 24). Window signs have the ability to advertise the name of a business, but more often than not they are a means of displaying temporary advertisements. An example of this could be a boutique posting a window sign reading "25\% off all furniture!"

\subsection{Signs as Advertising}

\section{Advertising:}

For businesses, on-premise signs serve as advertising tools. A sign allows a store to provide information to potential customers about their goods and services. In his article "How excessive restrictions on signage backfire," Charles Taylor explains that signs have multiple roles, such as "...communicating the location of the business, reinforcing the advertisements as part of integrated marketing communications, branding the site, and enhancing store/brand image" (p. 56). For many businesses, their signage plays a large role in their success, and if sign regulations are too stringent a business may fail to attract enough customers. Taylor offers evidence that sufficient signage is key to a business's success, explaining that a Pier One Imports in Germantown, TN lost 30\% of their sales due to inadequate signage (Taylor, 2006, p. 57). 
Signs are especially important for advertising purposes in Morro Bay because of the high number of tourists (locals do play a large role in supporting businesses, but in a small town like Morro Bay they do not rely on signage to find businesses). Tourists, who are a key component to the success of businesses in Morro Bay, use signage to locate places to dine, shop, and explore. Visible and attractive signs can lure in consumers, and if a business is not allowed to sufficiently portray their company image or character through signage, they may fall short of bringing in customers looking for a specific good or service.

\section{Branding:}

In addition to advertising, building a "brand" through signage is very important for businesses because it creates a sense of attachment between consumer and the business. A successful brand can bring in new customers, but more importantly, it will attract returning customers again and again.

Evidence that branding is important to companies was brought up in the court case Blockbuster Video, Inc. \& Video Update v. The City of Tempe. According to Taylor (2006), Blockbuster Video and Video Update were banned from using their logos in a shopping mall because the color schemes were non-conforming. The two companies won in court, and were therefore granted permission to continue using logos with their original color scheme (p. 57). This case not only proves that recognizable logos are important to businesses, but that courts have identified the significance of branding. This case also establishes that the First Amendment is stronger than aesthetic considerations in a court of law. 


\section{Sign Aesthetics:}

When can signs severely diminish the aesthetic quality of a community? Meg Maguire, President of the non-profit organization Scenic America states, "A drive down an American highway looks like a ride through Vice Valley, with ads for giant-sized booze, strip joints, and casinos. It's sky trash - litter on a stick" (as cited in Duerksen and Goebel, 1999, p. 87). According to the book "Aesthetics, Community Character, and the Law," sixty-nine percent of Missourians, and seventy-nine percent of Houstonians believe that removing billboards would make their surroundings more attractive (Duerksen and Goebel, 1999, p. 88). These sources conclude that while billboards have the potential to make significant economic impacts on businesses and organizations, they are an extreme example of signage that is opposed by the general public.

Signs (which might be harmless individually) can also have compounding effects when they exist in dense collections. Las Vegas, Nevada and Hollywood, California are examples of cities with landscapes dominated by large numbers of bright signs and advertisements. However, in the context of these cities, large and abundant signage is a characteristic that tourists enjoy. For economic and tourism-related reasons, maintaining an unrestrictive sign ordinance might be preferable in cities such as Las Vegas and Hollywood.

On the other side of the spectrum is Carmel, California, a small town located just south of Monterey, California. The City of Carmel allows only one sign per business, and restricts the size and coloration of signs to the point that they are almost unnoticeable. Due to the strict prescriptions, many of the signs throughout the City also look very similar. The City states that their ordinance is designed to maintain the "village character.” As discussed in the Las Vegas/Hollywood example, there is good reason for every town to possess a unique, customized sign ordinance. 
All considered, it is ultimately up to individual communities to decide what kinds of signs are appealing, and what kinds of signs are unappealing. Chapter 4 of this report discusses the outreach efforts completed in Morro Bay that were designed to capture the community's desires in respect to sign aesthetics.

\section{Business Owners:}

Business owners play an integral role in the development of a working sign ordinance. A sign ordinance affects how businesses can advertise on their property, and ultimately, their economic success.

In 2009, one example of business owners revolting against a proposed sign code occurred in Boise, Idaho. The article "Draft of sign ordinance draws protest in Garden City," discusses that The City of Boise desired to update their sign ordinance in order to stay consistent with their vision, and to "...change the way Garden City looks over time - to clean up the town" (Grigg, p.1). Business owners were originally dissatisfied with some of the initial ideas in the draft ordinance, believing it was too restrictive. In response, the City Council agreed to include business owners on the sign ordinance committee. This is an example of city government trying to do their best to please their citizens and not acting on personal interests. It was for this reason that Morro Bay's business owners were asked for their ideas and opinions on the subject.

\subsection{A-Frame Signs}

Morro Bay is a tourist town, and consequently businesses must find ways to attract customers who are not aware of their existence. Along the Embarcadero many businesses make use of Aframe signs to direct visitors to their storefront. A-frame signs generally consist of two plastic rectangles connected at the top. They are cheap to make, easy to store, and can be moved to a 
desired location and set up within seconds. Due to the configuration of the Embarcadero shopping centers, businesses located towards the bay front have a serious disadvantage; someone driving by on Embarcadero Road would never be able to spot their store.

Past survey results and the results from a survey conducted as part of this project (which will be further discussed in Chapter 4), revealed the public's opinion in regards to A-frame signs is fairly divided. A portion of the surveyed Morro Bay residents and business owners believe that A-frame signs are unnecessary, and drastically reduce the aesthetic quality, charm, and natural beauties of the Embarcadero and downtown Morro Bay. Many other respondents (primarily business owners) believe they are a necessity for hidden businesses. All considered, practicality suggests that with today's technologies such as smart phones and pocketsize GPS units, customers can read reviews about a business and then pinpoint the location of the business they wish to visit. Aframe signs and other off-premise signs can still be effective, but there's a strong argument that they may not be as necessary as they were five or ten years ago. See the 2013 Embarcadero District Tourism-Oriented Directional Sign Plan Background Report for more information on Aframe signs.

A-frame signs are currently prohibited in Morro Bay, and are only allowable under a sign exception (which costs $\$ 698.00$ to obtain). Many unpermitted A-frame signs currently exist in great numbers due to lack of enforcement. However, beginning in 1999 A-frame signs were allowed under a special permit called an “A-Frame Sign Exception Permit,” which had a fee of $\$ 20-\$ 25$ (the fee was reduced in later years). This permit was available for a number of years, but is currently unavailable. According to a city staff report dated December 5, 2011 (Appendix 2.1), a letter was sent to all businesses on May 3, 2011 regarding A-frame signs. This letter documents the A-frame sign prohibition, and explained how the City would enforce this prohibition. 


\subsection{Digital Signage}

In today's society digital signage is becoming more popular, and therefore some discussion on the topic is required. According to Dennis et al (2010), “Digital signage has two main objectives: (i) to charge advertisers (beyond our scope); and (ii) to improve atmosphere and image “(p. 157). Digital signs are commonly placed along freeways or in shopping centers for advertising purposes. They are also placed on public buildings or educational facilities to display upcoming events, news reports, and local emergency announcements.

According to the article "Scroll, Roll, and Flash," many local sign ordinances do not address newer types of digital signs. Some modern signs have the ability to "...scroll, roll, and dissolve. The content of such signs can be changed with a click of a computer mouse, and the fanciest of them are capable of full-motion color video" (p. 23). These types of signs attract attention, and have the ability to display a wider range of messages. In a society that is immersed in technology, some might argue that digital signs on storefronts are necessary in order to compete with the advertising we encounter on the internet and television.

\section{Effects on Communities:}

Charles Dennis and his colleagues believe that digital signage has overall positive effects, but also drastically different effects on individuals in different demographic groups. According to Dennis et al (2010), “The more modern local market leader mall is rated higher on overall image and appeals to younger, higher status employment people. This mall has digital signage, which has a more positive effect on Approach for those shoppers” (p. 171). Simply put, the author claims that digital signage has greater appeal to younger shoppers. The article also concludes “...that digital signage is an effective stimulus, adding to positive perceptions of the town environment, emotions and approach behavior such as spending” (p. 172). In this particular 
study, digital signage had an overall positive effect on the shopping center. However, implications from the article also suggest that certain demographic groups are responsible for this positivity. The article summarizes the fact that younger shoppers in a hurry to complete purchases are especially fond of digital signage.

Lastly, it is known that digital signs are sometimes banned due to traffic safety issues. This is a concern that must be explored when deciding if digital signs are appropriate in Morro Bay. Keeping pedestrians, bicyclists, and motorists safe is one of the City's top priorities when considering changes to the sign ordinance.

\section{Digital Signs in Morro Bay:}

Morro Bay's current sign ordinance clearly prohibits "Signs which incorporate, in any manner, any flashing, moving, pulsating or intermittent lighting, with the exception of approved time and temperature displays" (Section 17.68.030). This description could be applied to signs that act as digital television monitors, which would in turn ban anything of the like in Morro Bay. The ordinance does not, however, address signs that can be remotely changed and configured. Nonetheless, an updated sign ordinance should include specific information and regulations about the most modern types of signage available (such as full-motion color video screens). Morro Bay is a small beach town, and it is obvious that large digital signs are not a good fit for the community's relaxed character.

Furthermore, as the U.S Census reports, permanent Morro Bay residents are older when compared to most other towns, and according to this article, less attracted to digital signage. Many younger tourist crowds can be observed within the City on any given day, but these individuals are generally unhurried in shopping situations (like they might be when at home and completing tasks associated with work or daily life). For tourists, shopping is generally a 
leisurely activity where luxury goods such as clothes, art, gifts, and wine are purchased. In regards to digital signage, Morro Bay’s sign ordinance should cater to the preferences of the older generations who make up the bulk of the population.

After analyzing various articles and applying these findings to the circumstances present in City of Morro Bay, it can be concluded that restrictions on new technologies should be explored, and that more lenient regulations on digital signs are inappropriate.

\subsection{Illuminated Signs}

\section{Environmental Effects:}

Apart from digital signage, illuminated signs are one of the most controversial and talked about sign types because of their immediate effect on surrounding environments. When signs are illuminated at night they can be a potential nuisance to neighbors, keeping them awake by polluting the natural darkness with a constant glow. Due to common design features and the transparent plastic materials used to house internal light bulbs, opponents of internally illuminated signs believe that they are aesthetically unpleasing during both nighttime and daytime hours.

Illuminated signs in Morro Bay can also contribute to light pollution. Appendix 2.2 consists of a map showing the magnitude of light pollution in Central Coast cities (International Dark Sky Association, 2013). Although the observed light pollution in Morro Bay is relatively minimal compared to larger cities, night-time lighting restrictions should be addressed in the updated sign ordinance. Requiring hoods on lights used to externally illuminate signs could be one method of reducing light pollution. 
To keep both business owners and residents satisfied, cities find creative ways to regulate illuminated signs. In the City of San Luis Obispo, "Signs shall not be illuminated after 10:00 p.m. or close of business, whichever is later" (City of San Luis Obispo, 2004, p. 8). The City of Morro Bay currently regulates the brightness of illuminated lights, stating that signs shall be designed so that illumination does not exceed 10 foot-candles measured at a distance of 10 feet from the sign. Morro Bay’s draft ordinance also addresses signs at night time hours, stating that “Freestanding and building-mounted signs adjacent to an R district shall be illuminated only during hours when the establishment is open” (17.68.040, E.2).

City staff also suggested that illuminated signs in Morro Bay are perhaps brighter than they need to be. Morro Bay’s General Plan states that “The proliferation of lighted signs that have excessive glare or are offensive to nighttime vision in the Community” is a problem that detracts from the visual quality of the community (IV-10). Staff's suggestions to alter illumination standards are consistent with the City's General Plan, and were therefore considered when drafting the new ordinance.

\section{Suggested Regulations:}

The regulation examples above do help control illuminated signage, but Morro Bay planning staff believe that additional (and more stringent) regulations should be incorporated into the updated ordinance. For example, staff believes that a brightness measured at 10 -foot candles is unreasonably bright, and that any benefits associated with sign illumination could be achieved with less brightness. Furthermore, staff believes that the ordinance should directly address issues associated with the continued operation of illuminated signs after businesses move out. Once a business is no longer operating at a location, all automatic lighting on signs should be disabled until the business begins operating again, or a new business moves in. Possible regulations to 
limit light output serve two purposes: protect community members from glare during night time hours, and to conserve energy.

According to International Dark-Sky Association’s “Model Lighting Ordinance (MLO),” automatic switches with light sensors should be used to “...extinguish all outdoor lighting when sufficient daylight is available” (p. 9). An automatic on/off switch for illuminated signs is not sufficient unless it includes a light senor, because there is more daylight in the summer, and less in the winter. Requiring the use of properly configured automatic switches may be the best and most efficient way of addressing the issues mentioned above.

\section{Safety:}

Businesses prefer illuminated signs because they are visible from longer distances, have the potential to attract more customers, and can increase safety in and around their business.

Illuminated signs are also safer for night time drivers because they are easier to read. Small, dimly lit signs may increase the amount of time drivers need to stare at them before the message is interpreted.

There are also debates over the use of externally illuminated signs versus internally illuminated signs. Garvin, et al. (2004) state that "...past research sponsored by the United States Sign Council Foundation (USSCF) demonstrated that internally illuminated on-premise signs have 40 to 60 percent greater visibility than externally illuminated signs in a controlled test track environment (as cited in Penn State, 2009, p. 1). In their research, Penn State's Transportation Institute conducted an experiment that confirmed this hypothesis (see Figure 2.16 below). 
Figure 2.16: Effect of illumination type on overall sign visibility

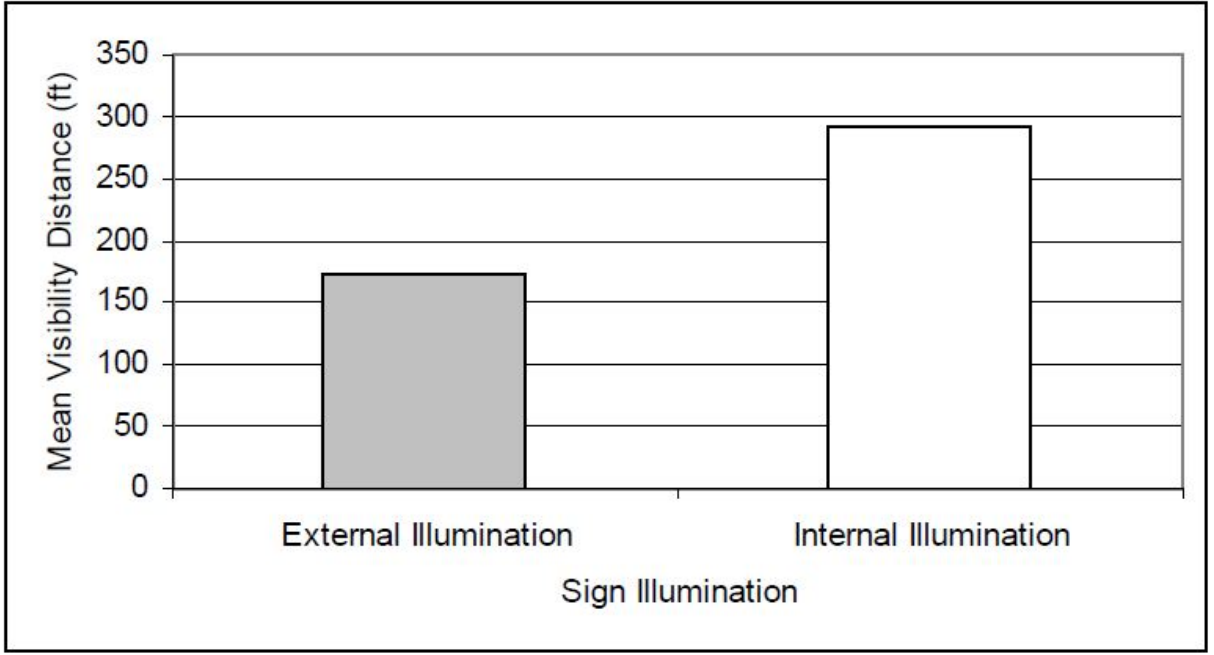

Source: Penn State University, The Thomas D. Larson Pennsylvania Transportation Institute. 2009. "Internal vs. External On-Premise Sign Lighting: Visibility and Safety in the Real World." Retrieved from: http://www.mautc.psu.edu/docs/PSU-2008-02.pdf. 


\section{Chapter 3: Sign Law}

\subsection{Freedom of Speech}

According to Cornell University’s Legal Information Institute, “The First Amendment of the United States Constitution protects the right to freedom of religion and freedom of expression from government interference.” This Amendment brings up many issues in regards to commercial signage, because while businesses should be granted this constitutional right, they also have a certain amount of responsibility to serve the public. If the First Amendment was unregulated, business owners could have the ability to post messages supporting their personal beliefs on signs. A clutter of self-interest signage would defy the original purpose of free market advertising (a tool for commerce), and could ultimately degrade economic vitality. Imagine a street where all of the businesses except for one had signs that included a picture of a certain political figure. That one business without a sign promoting this figure would likely be negatively affected by this scenario. Consumers that support the figure portrayed on the signs may avoid this business, choosing ones that clearly support their party and beliefs. On the other hand, nonsupporter consumers may avoid the area altogether due to an onslaught of signs promoting something they don't believe in.

Furthermore, Duerksen and Goebel (1999) affirm that "...the government may not regulate the content of speech, but may attach reasonable time, place, and manner restrictions on its exercise" (p. 90). In the case of publicly accessible businesses, the government can decide where certain speech content is appropriate, and how it is displayed to the public (size of signs, colors, etc.). In the Supreme Court of California case Metromedia, Inc. v. City of San Diego, business owners brought suit against a city ordinance that imposed "substantial prohibitions on the erection of outdoor advertising displays.” The court held that the new ordinance was an unconstitutional 
exercise of the police power, and that it violated First Amendment rights. In respect to sign ordinances this case was important because it established a precedent for constitutional regulations (Cornell University Legal Information Institute).

However, commercial speech, as opposed to noncommercial speech, is not entirely protected by the First Amendment. For example, unlike residential properties, commercial businesses cannot place signs on their premise advocating for certain religious beliefs. Cornell’s Legal Information Institute defines commercial speech “....as speech where the speaker is more likely engaged in commerce, where the intended audience is commercial or actual or potential consumers, and where the content of the message is commercial in character.” It is also noted that “...commercial speech that is false or misleading is not entitled to any protection under the First Amendment, and therefore can be prohibited entirely” (Cornell University Law School). That is, businesses are not allowed to deceive the public with signage.

The International Sign Association (ISA) believes that the First Amendment should be applied equally to small business signage. On their website they also state that "Government officials and courts recognize that the messages embodied on on-premise signs are protected by the Freedom of Speech clause of the First Amendment and that cities cannot differentiate between noncommercial and commercial messages.” However, this is not the position of American law; in the United States cities make this differentiation on an individual basis.

\section{The Central Hudson Test:}

According to Duerksen and Goebel (1999), courts use the "Central Hudson Test" to determine the constitutionality of commercial sign controls. This four-part test was first applied in the case Central Hudson Gas \& Electric Corp. v. Public Serv. Commission, 447 U.S. 557, 100 S.Ct. 2343 (1980): 
1. As a threshold concern, commercial speech must concern lawful activity and not be misleading in order to be entitled to First Amendment protection.

If commercial speech is entitled to protection, governments may nevertheless regulate that speech if the regulation:

2. Seeks to implement a substantial governmental interest;

3. Directly advances that interest; and

4. Reaches no further than necessary to accomplish the given objective, and leaves open ample alternative means of communication (as cited in Duerkson and Goebel, 1999, p. 91).

\subsection{CEQA and Other Environmental Issues}

\section{CEQA:}

The California Environmental Quality Act requires state and local governments to complete environmental review and public disclosure for all building and land use projects in the State of California. In regard to signs, CalSign.org states the following: "Pursuant to 14 CCR §15311, dealing with Accessory Structures (Class 11), on-premise signs are categorically exempt and a negative declaration should issue. The authority cited for this provision is Public Resource Code sections 21083 and 21087.” As the California Sign Association comments, signs do not generally affect environmental factors. Signs on or around businesses are constructed on built environments, not on vacant land. Therefore any environmental factors have (hopefully) been addressed before the initial alteration of the land for the construction of a structure. 
There are, however, cases when signs are constructed on undeveloped properties. Especially if a sign is particularly large, there can be environmental repercussions that affect wildlife, plants, archeological resources, and view sheds. For example, constructing a large billboard may require the digging of deep holes for the placement of footings. If native species are disturbed by such digging and construction related activities in the vicinity, there could be a need for more extensive CEQA work. If a billboard includes a relatively significant amount of lighting, there can also be potential issues after construction involving light pollution affecting nearby residents.

Under certain circumstances, a full Environmental Impact Report (EIR) may be required for a sign project. In most cases, such projects are initiated by cities. In Milpitas, CA, the City prepared an EIR for the "Interstate 880 Billboards Project.” The report includes seven alternatives, each with unique environmental impacts. The alternatives range from least impactful (“no project”), to implementation of three large digital billboards with the ability to rotate eight different advertisements. The most significant environmental impacts with this project, as expected, are related to aesthetics (light glow, glare, and visual community character).

There was at least one case in Morro Bay when CEQA work was completed for a sign project. Morro Bay’s Planning and Building Manager, Kathleen Wold, commented that the City prepared a Negative Declaration for a project that involved constructing a large digital sign along Highway 41 for a commercial business complex.

\section{CEQA vs. Design Review:}

Another important concept involving signage, aesthetics, and community character is the distinction between design review and “visual impacts” as a part of CEQA review. Barclay (2010) states that “...the court in Guinnane v. San Francisco City Planning Commission held 'the environmental review process is not the same as the permit approval process' such that, where a 
negative declaration found no significant impact for a proposed residence that was 'not in character' and 'significantly more massive and of larger scale than adjoining dwellings,' the city still was justified in disapproving a permit because it 'went beyond environmental concerns and focused instead on the suitability of the project within the affected neighborhood’” (p. 258). Furthermore, Barclay discusses that CEQA is concerned with issues on a community-wide (or even larger) scale, while design review boards have the ability to address impacts in contained areas (p. 258). For example, if a new 10-story apartment complex was proposed, CEQA would require examination of the effects on all residents living in the community. A design review board, on the other hand, could concentrate their analysis on the effects to the immediate neighbors of the proposed development.

Barclay continues to explain that while CEQA review and design review are based on separate and different principles, they may work in harmony to determine whether a project's potential aesthetic effects present a problem within a community.

\section{Other Environmental Issues:}

Although signs are generally exempt from extensive environmental analysis, sustainability should not be ignored when writing and enforcing a sign code. The first issue that can be related to Morro Bay’s current conservation efforts is sign materials. Signs, for the most part, are not made from recycled materials. When they become obsolete or unneeded they generally end up in landfills.

Other components of signs that can have an effect on the environment are illumination systems. Many businesses are beginning to use LED lights in their signs in order to cut down on energy costs while at the same time improving public image. Recently in Morro Bay, the McDonald's restaurant initiated a remodel of their store along with implementation of new signage. In the sign 
proposal they indicated the sole use of LED lights in their new signs, stating they chose this route in an attempt to be more environmentally conscious.

In relation to illumination systems, The International Sign Association discusses mercury-lamp recycling. Due to the fact that mercury is a toxic element to human health, the ISA believes that proper recycling and minimization of mercury use for such illumination systems is very important. However, they state that the “...ISA opposes regulation that arbitrarily prohibit or limit the use of mercury in neon signs.” They believe that certain signs cannot be properly illuminated without the use of mercury. In the case of Morro Bay, proper recycling of neon lighting should be required by all businesses and enforced as best as possible. Furthermore, the City should amend the sign ordinance to require the use of newer, more sustainable technologies such as LEDs.

These three environmental issues were considered during the process of updating the sign ordinance. They will be further discussed in Chapter 6 .

\subsection{State and Local Law}

Most sign issues are dealt with at the State and local level, as opposed to the federal level. According to Duerksen and Goebel (1999), "...most courts are now favorably inclined toward accepting aesthetics as a justification for regulation, and most state legislatures have specifically granted local governments the power to control signs and other items affecting community aesthetics" (p. 89). Unlike federal laws such as prohibiting the sale of liquor to minors, sign regulations are generally formulated at the local level. Every city has their own set of laws and rules regarding signage, and it is unlikely that two cities have the exact same set of regulations. 


\subsection{Federal Law}

\section{Code of Federal Regulations 35.163:}

\section{$\S 35.163$}

Information and Signage:

(a) A public entity shall ensure that interested persons, including persons with impaired vision or hearing, can obtain information as to the existence and location of accessible services, activities, and facilities.

(b) A public entity shall provide signage at all inaccessible entrances to each of its facilities, directing users to an accessible entrance or to a location at which they can obtain information about accessible facilities. The international symbol for accessibility shall be used at each accessible entrance of a facility (Cornell University Legal Information Institute).

\section{On-premise sign size standards:}

The International Sign Association (ISA) states that “...municipal codes which unduly restrict sign sizes defeat the very purpose for which signs exist.” Their website also includes a statement Richard N. Schwab, a former Federal Highway Administration program manager. The statement is as follows: "Traffic safety is not jeopardized by the sign itself or some sort of stimulus overload; instead the culprit is inadequate sign size or lighting, or inappropriate placement, or a combination of these factors.”

\subsection{Enforcement}

Enforcement is a delicate issue because there are so many conflicting opinions throughout communities. Business owners with nonconforming signs dislike the idea because they will be forced to make a monetary investment for a replacement. On the other hand, business owners with conforming signs desire increased enforcement so that all businesses have a fair chance at 
attracting customers. A newspaper article from The Billings Gazette states, "While some businesses have spent thousands to conform to the code, others have ignored it. Many businesses, including some flagrant violators, are biding their time and hoping to catch a break from the city commissioners" (Woolston, p. 1). One reason to have functioning enforcement in a community is to reward all businesses the same amount of signage and not let a select few have a competitive advantage.

One important aspect of enforcement is early outreach to property and business owners. In New Hanover County, North Carolina, a Tribune Business News article discusses this issue. According to the article by Kevin Maurer, a County Commissioner "...was concerned that property owners in the area didn't get proper notice of the sign standard." The Commissioner said that there were news stories and an article in the local newspaper regarding the new rules, however he admitted that "...there wasn't extensive outreach" (Maurer, p. 1). The updated ordinance shall include clear enforcement policies and guidelines to ensure that business owners are aware of changes they may need to make in the future.

\section{Fines:}

Another reason enforcement can be beneficial relates to money acquired through fines. An article by Tia Mitchell in the Tribune Business News discusses how officials in Jacksonville, FL enacted a plan to fine people for "snipe signs" along the highway. The proceeds from fines were used to maintain bus shelters and clean up litter along the highway (p. 1). Sign enforcement allows cities to remove unwanted signage, while at the same time using extra funds to further enhance other elements within the community. 
Due to budgetary reasons, direct enforcement of unpermitted signs is lacking in the City of Morro Bay. Nonetheless, the City of reports the following fines for illegal signage:

1. Temporary, beyond time allowed by Ordinance $-\$ 10.00$ per day after notice

2. Permanently attached signs without permit - $\$ 21.00$ per day after notice (City of Morro Bay Master Fee Schedule for the 2012/13 Fiscal Year).

\section{Amortization:}

In the context of city planning, "amortization” is the process of eliminating nonconforming uses over a period of time that allows the permit holder to recover their initial investment (Barclay, 2010, p. 66). Amortization of non-conforming signs, rather than an order for immediate removal, can help cities avoid paying court-ordered damages to business owners. In 1981 court case Metromedia, Inc. v. City of San Diego, the California Supreme Court created the following rule: "The California cases have firmly declared that zoning legislation may validly provide for the eventual termination of nonconforming uses without compensation if it provides a reasonable amortization period commensurate with the investment involved” (as cited in Barclay, 2010, p. 66).

Later, in the 1987 case City of Salinas v. Ryan Outdoor Adver., Inc., the court held that “...the reasonableness of the amortization period depends on... the depreciated value of the structures to be removed, their remaining useful life, and the harm to the public if they are left standing” (Barclay, 2010, p. 66). Amortization strategies have not been finalized, but it is certain that they will be incorporated into the new draft sign ordinance. 


\subsection{The General Plan and Coastal Land Use Plan}

\section{The General Plan:}

State law requires that every city in California adopt a General Plan that includes the seven required elements: Land Use, Circulation, Housing, Safety, Noise, Conservation, and Openspace. Morro Bay’s current General Plan combines the Land Use, Conservation, and Open-space elements into one broader element, and includes two additional elements. The two additional elements are listed as the Visual Resources and Scenic Highway element, and the Access and Recreation element. These supplementary elements were created to ensure that Morro Bay preserves its natural beauty and community character while also encouraging tourism and recreation.

The “Visual Resources and Scenic Highway Element” within the City’s General Plan discusses signage (see Appendix 3.1). The General Plan includes the following section from the Morro Bay Coastal Land Use Plan:

Signs and Sign Regulations: Signs in Morro Bay have come to be a problem, detracting from the visual quality of the community and in some cases interfering with important views. Among some of the problem associated with signs are:

(1) Failure to remove old, non-functional or nonconforming signs.

(2) The allowable height and size of signs are excessive under the existing ordinance.

(3) The lack of a realistic and enforceable timetable for the amortization of nonconforming signs.

(4) The proliferation of lighted signs that have excessive glare or are offensive to nighttime vision in the Community. 
(5) The lack of appropriate design standards that would better guide the size, type, color, location, lighting, and materials of construction of signs.

(6) Failure to consider views when reviewing applications to erect and light signs. (LCP) (Morro Bay General Plan, p. IV-10 - IV-11)

\section{The Coastal Land Use Plan:}

Chapter XIII Visual Resources of the City’s Coastal Land Use Plan, a document that is part of the City’s Local Coastal Plan, includes policies related to signage. According to the Visual Resources chapter, “Aesthetically viewing an attractive scene can be, for many, a rewarding experience. For other people, scenic views give identity, character, and value to their community. Visually attractive areas are good locations for recreational activities and facilities, and moreover, are good sites for ports, commercial activities and residential developments, all of economic importance” (p. 199). This statement stresses the importance of aesthetics in Morro Bay, which the City acknowledges as a major contributor to the success of tourism. Most cities lack a Visual Resources element within their General Plan, and do not maintain a Local Coastal Plan that further discusses important visual resources. The formulation of new sign regulations must take into account the intentions of the Local Coastal Plan and the associated objectives, policies, and programs.

The following policy within the Coastal Land Use Plan addresses signage:

Policy 12.05 The City shall, as part of the implementation phase of the LCP, adopt new provisions to:

a. Require monument and surface mounted signs and discourage roof mounted and pole signs;

b. Require that view protection and the nighttime characteristics of the sign be mandatory consideration of any sign installation; 

c. Prohibit billboards;
d. Reduce allowable height and size where they interfere with views to and along State Highway One.
e. Develop and adopt sign criteria for signs appropriate for Morro Bay's commercial districts (p. 214-215).
Are these polices addressed in the City's current sign ordinance or draft ordinance? Table 3.1 on the next page links the aforementioned policies to regulations within the current sign ordinance and the old draft sign ordinance.


Table 3.1: Local Coastal Plan Policy Implementation

\begin{tabular}{|c|c|c|c|c|}
\hline LCP Policies & $\begin{array}{l}\text { Addressed in } \\
\text { current code? }\end{array}$ & $\begin{array}{l}\text { Addressed } \\
\text { in draft } \\
\text { code? }\end{array}$ & Position (current ord.) & Position (draft ord.) \\
\hline $\begin{array}{l}\text { Require } \\
\text { monument and } \\
\text { surface mounted } \\
\text { signs and } \\
\text { discourage roof } \\
\text { mounted and } \\
\text { pole signs; }\end{array}$ & Partially & Partially & $\begin{array}{l}\text { Roof signs prohibited (17.68.030, } \\
\text { A.); } \\
\text { Pole signs allowed in commercial } \\
\text { districts (17.68.110, C.4.); } \\
\text { Monument/surface are not } \\
\text { required, but optional } \\
\text { (17.68.110); } \\
\text { Ordinance inconsistent in } \\
\text { reporting allowable height for } \\
\text { pole signs. }\end{array}$ & $\begin{array}{l}\text { Roof signs prohibited (17.68.030, } \\
\text { J.); } \\
\text { Pole signs allowed in commercial } \\
\text { districts (17.68.070, B.2); } \\
\text { Monument/surface are not } \\
\text { required, but optional (17.68.070). }\end{array}$ \\
\hline $\begin{array}{l}\text { Require that } \\
\text { view protection } \\
\text { and the } \\
\text { nighttime } \\
\text { characteristics } \\
\text { of the sign be } \\
\text { mandatory } \\
\text { consideration of } \\
\text { any sign } \\
\text { installation; }\end{array}$ & Partially & Partially & $\begin{array}{l}\text { At city entryways, signs designed } \\
\text { so as not to interfere with view } \\
\text { corridors (17.68.060, E.9.a).; } \\
\text { Signs cannot reflect or emit light } \\
\text { exceeding } 10 \text { foot-candle power } \\
\text { at } 10 \mathrm{ft} \text { from face of sign } \\
(17.68 .050, \mathrm{G} .) \\
\text { Ordinance does not address view } \\
\text { protection in all areas of city; } \\
10 \text { foot-candle too bright. }\end{array}$ & $\begin{array}{l}\text { At city entryways, signs designed } \\
\text { so as not to interfere with view } \\
\text { corridors (17.68.060, E.9.a); } \\
\text { Freestanding and building-mounted } \\
\text { signs adjacent to an R district shall } \\
\text { be illuminated only during hours } \\
\text { when the establishment is open } \\
\text { (17.68.040, E.2) } \\
\text { Signs cannot reflect or emit light } \\
\text { exceeding } 10 \text { foot-candle power at } \\
10 \text { ft. from face of sign (17.68.040, } \\
\text { N.) } \\
\text { Ordinance does not address view } \\
\text { protection in all areas of city; } \\
10 \text { foot-candle too bright. }\end{array}$ \\
\hline $\begin{array}{l}\text { Prohibit } \\
\text { billboards; }\end{array}$ & Yes & Yes & $\begin{array}{l}\text { Billboards prohibited (17.68.030, } \\
\text { G.). }\end{array}$ & $\begin{array}{l}\text { Billboards prohibited (17.68.030, } \\
\text { C). }\end{array}$ \\
\hline $\begin{array}{l}\text { Reduce } \\
\text { allowable height } \\
\text { and size where } \\
\text { they interfere } \\
\text { with views to } \\
\text { and along State } \\
\text { Highway One. }\end{array}$ & No & No & $\begin{array}{l}\text { At city entryways, ordinance } \\
\text { allows even taller signs within } \\
200 \mathrm{ft} \text {. of Highway } 1 \text { (17.68.060, } \\
\text { E.9.b). }\end{array}$ & $\begin{array}{l}\text { At city entryways, ordinance } \\
\text { allows even taller signs within } 200 \\
\text { ft. of Highway } 1 \text {; }(17.68 .090 \text {, } \\
\text { C.4.b). }\end{array}$ \\
\hline $\begin{array}{l}\text { Develop and } \\
\text { adopt sign } \\
\text { criteria for signs } \\
\text { appropriate for } \\
\text { Morro Bay's } \\
\text { commercial } \\
\text { districts }\end{array}$ & Yes & Yes & $\begin{array}{l}\text { Specific regulations exist for } \\
\text { "commercial and industrial } \\
\text { zones” (17.68.110, C.). }\end{array}$ & $\begin{array}{l}\text { Specific regulations exist for } \\
\text { "commercial, mixed-use, and } \\
\text { industrial zones “(17.68.060). }\end{array}$ \\
\hline
\end{tabular}

Sources: City of Morro Bay LCP, City of Morro Bay Current and Draft Sign Ordinances 


\section{Chapter 4: Community Outreach}

\subsection{Past Public Outreach}

\section{Previous Outreach Conducted by the City:}

According to a City of Morro Bay Staff Report dated December 5, 2011, “...City Council directed staff [at the December 13, 2010 meeting] to place the Sign Ordinance as a high priority on the Planning Division’s work program” (see Appendix 2.1). According to the same document, a public workshop was held on February 16, 2011 to receive input from the public about the sign ordinance.

It has been determined that past outreach does provide some important insight into what the community wants to see in an updated sign ordinance. Past surveys and documents related to community outreach were located in the City's computer system, and can be found in Appendices

\section{1-4.2.}

Survey 1 (Appendix 4.1): According to the results, only three business owners and one nonbusiness owner responded. Although only four completed surveys and therefore cannot be used in any significant statistical analysis, it is still worth looking at any themes in the data. Three out of four respondents said that businesses should "be guaranteed a minimum size sign regardless of frontage size” and that there should be "special allowances or exceptions.” Furthermore, all respondents said that murals should not be considered signs, that "sign materials" are important, and that they are unhappy with how signs in Morro Bay look right now.

Other surveys were located within a document titled “12-13-2011 Sign Ordinance Survey Staff Report Attachments” (see Appendix 4.2). The document includes two PowerPoint presentations 
outlining a September 29, 2011 Sign Ordinance Workshop meeting, and an October 6, 2011 Sign Ordinance Workshop meeting. The meetings were facilitated by Chuck Anders. Attached as appendices are the results from four surveys (the first two are related to the workshop held on September 29, 2011, and the second two are related to the workshop held on October 6, 2011).

Survey 2 (Appendix 4.2, p. A-72): The results from the first survey are presented in percentages instead of individual response counts. However, after analyzing the results from one of the questions, it can be determined that there were at least 14 respondents. The results for this particular question were distributed as follows: $14 \%, 14 \%, 43 \%, 21 \%$, and $7 \%$. If $7 \%$ equals an answer from one respondent, one can deduce that two answers would be represented by $14 \%$, three answers by $21 \%$, and so on. Although there could have been 28 respondents (the percentages would be reported the same), this cannot be assumed. For statistical analysis it will be assumed that there were only 14 respondents.

As reported by the PowerPoint presentation from the September 29, 2011 workshop, respondents revealed that $69 \%$ were business owners, $19 \%$ salaried workers, and $13 \%$ other. The first notable result in this survey was the fact that $94 \%$ of respondents were not happy with how the signs in Morro Bay look. Furthermore, 100\% of respondents agree that there should be different rules for different areas of the community, and that "special allowances” should be given to certain businesses.

Survey 3 (Appendix 4.2, p. A-78): This Survey Monkey survey had five respondents; four business owners and one retired resident. Four of the respondents agreed that "businesses be guaranteed a minimum size sign regardless of frontage size," that there should be "special allowances or exceptions,” that they are unhappy with how signs in Morro Bay look right now, and that they were "satisfied with the current rules for reader or changeable message boards.” All 
respondents agreed that murals are not considered signs, and that "sign materials” are important.

Figure 4.1 shows the combined survey results from related surveys 1, 2, and 3. See Appendix 4.2 for the raw data table that contributed to Figure 4.1.

Figure 4.1 Combined Survey Results from Surveys 1, 2, and 3

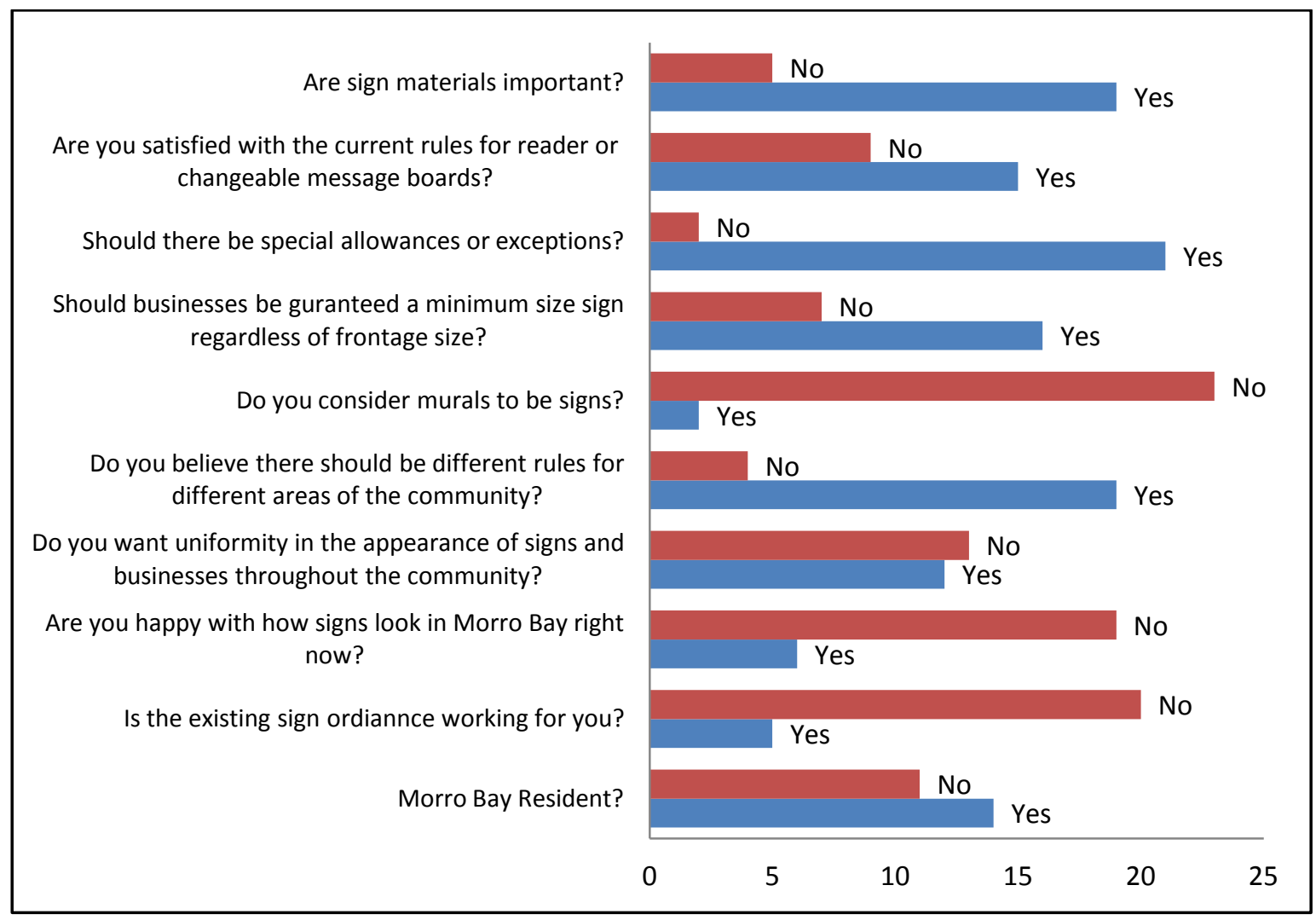

Survey 4 (Appendix 4.2, p. A-93): As reported by the PowerPoint presentation from the October 6, 2011 workshop, fourteen respondents are businesses owners and one is a retired resident of Morro Bay. Of the fifteen total respondents, nine are Morro Bay residents. It must also be noted that seven respondents said they attended the first sign workshop on September 29, 2011. This survey did not ask similar questions to those in the first three surveys, and instead focused on gathering opinions of the preliminary draft ordinance. These opinions will be considered, but are somewhat irrelevant because there will be drastic changes to the previous draft. 
Survey 5 (Appendix 4.2, p. A-50): This online survey was administered via "Zoomerang" and had a total of 93 respondents. This survey focused on gathering opinions about different types of signs in three planning districts: Embarcadero, Downtown Area, and North Morro Bay/Quintana. Respondents were instructed to select signs that they would "approve" for each area in Morro Bay (see Table 4.1). Also found attached to this survey is a list of 34 written comments submitted by respondents.

Table 4.1: Compiled Results from Survey \#5

\begin{tabular}{|l|l|l|}
\hline & \multicolumn{1}{|c|}{$\begin{array}{c}\text { Popular Sign Types (greater than 70\% } \\
\text { respondents approve) }\end{array}$} & $\begin{array}{l}\text { Unpopular Sign Types (less than 40\% } \\
\text { respondents approve) }\end{array}$ \\
\hline Downtown Area & $\begin{array}{l}\text { Awning Signs } \\
\text { Wall Signs } \\
\text { Window Signs }\end{array}$ & $\begin{array}{l}\text { Permanent Banners } \\
\text { Off-Premise Signs }\end{array}$ \\
\hline Embarcadero Area & $\begin{array}{l}\text { Awning Signs } \\
\text { Internally Illuminated Signs } \\
\text { Window Signs }\end{array}$ & $\begin{array}{l}\text { A-Frame Signs } \\
\text { Permanent Banners } \\
\text { Off-Premise Signs }\end{array}$ \\
\hline $\begin{array}{l}\text { North Morro Bay / } \\
\text { Quintana Area }\end{array}$ & $\begin{array}{l}\text { Awning Signs } \\
\text { Internally Illuminated Signs } \\
\text { Wall Signs } \\
\text { Window Signs }\end{array}$ & \\
\hline
\end{tabular}

Analysis of the secondary surveys concludes that a consensus was reached among respondents in regards to some of the questions. The knowledge gained from these results was used to formulate both specific and general ideas within the updated sign ordinance. Themes present in the secondary surveys conducted in the past are summarized as follows:

- Murals should not be considered signs.

- $\quad$ Hanging signs are well liked.

- Bright, colorful signs are preferred.

- $\quad$ Sign materials are important.

- The City should be able to grant special allowances or exceptions.

- Businesses should be granted a guaranteed minimum size sign regardless of frontage. 
- Permanent banner signs, A-frame signs, and off-premise signs are unpopular.

- $\quad$ The existing sign ordinance is not working well.

\section{Cal Poly's Downtown Specific Plan:}

In Spring of 2010, Professor Umut Toker’s City and Regional Planning Master students developed three alternative specific plans for the future of downtown Morro Bay. In an attempt to capture the community's vision for the future Morro Bay, students organized and participated in community meetings and other outreach events during the process of formulating their plans. The following paragraphs summarize the findings documented in these plans related to community character and signs.

According to community meeting data, the public emphasized the following items to "keep out" of Morro Bay: Chain stores, fast food restaurants, adult stores, parking meters, marijuana dispensaries, and vacant storefronts. "Neon signs "and "large signs" were choices, but no residents in attendance marked these as something they strongly wished to keep out of their city. Some residents also contributed that they want to preserve the "small town atmosphere," as well as an "eclectic architectural character" in Morro Bay. Horizontal pub-style signs were the most recommended, as were a common architectural theme for buildings and height limitations for residences (Proposal C, p. 3-3).

Another component of the student's outreach process was organizing an "awareness walk." Participants were given two cameras marked with different colors. One camera was designated the "like camera," and the other the "needs improvement camera.” Residents were instructed to use the "like" camera to take pictures in the downtown of anything they especially liked, and anything they didn't like with the "needs improvement" camera. Common images from the "like" 
cameras included murals, colorful buildings, outdoor seating, mixed use development, public art (murals, bright walls, painted garbage cans, animal topped bollards), landscaping (planter boxes and street trees), and signs (hanging signs, art deco style signs, colorful signs). Common images from the “needs improvement” cameras included bollards, vacant store fronts, unkempt yards/lots, vacant lots, newspaper holders, brightly colored store fronts, inconsistent sidewalk materials, broken sidewalk concrete, unpaved sidewalk sections, free standing signs, tree lights, utility lines, unused poles, and non-retail commercial uses (i.e. hotels and realty offices). (Proposal B, p. 26).

After analyzing what the Cal Poly students gathered, it is evident that the residents who attended these meetings prefer pub-style signs, colorful signs, and are supporters of public art. Participants did not however appreciate free standing (monument) signs and structures that are not well maintained.

Although these views do not represent the entire population, they are a valid source of public input and were considered during the process of updating Morro Bay's sign ordinance.

\subsection{Primary Survey Data}

\section{Business Owner Survey:}

In an effort to supplement the secondary outreach data gathered by the City in 2011, a new survey was designed to target business owners. On March 20, 2013, the survey was sent by mail to every individual with a business license in the City of Morro Bay. Approximately 570 surveys and an attached cover letter were sent. The survey, cover letter, and list of businesses who received the survey can be found in Appendix 4.3. Respondents were also given the opportunity to take the survey online at www.Surveymonkey.com. 
One of the primary issues with the survey was that a single individual could submit their answers twice; both online and on the hard copy. This issue was brought up before the survey was sent out, however it was determined that the benefit of potentially receiving more completed surveys outweighed the cost of undetected duplicate responses. Staff agreed that mailing the survey would reach the most potential respondents, but that the convenience factor of providing an online link would greatly increase the number of responses. To further promote the online survey, the City’s webmaster posted a "news flash” on The City of Morro Bay’s homepage with a link to the business owner survey. The news flash provided information about the project, and urged business owners to take the survey.

A total of 49 respondents took the business sign survey. The majority (33 respondents) filled the survey out by hand, and 16 respondents took the survey online. Results were compiled in an Excel document, and are summarized in graphic form below. The handwritten survey responses, a summary of the Survey Monkey results, and the “comments” made by respondents can be found in Appendix 4.5.

Although business owners were divided on many issues, the following themes emerged after reading comments and analyzing the survey results:

- Many respondents want to lift the ban on A-frame signs, but a portion of these respondents would like to see A-frame signs strictly regulated. That is, they want Aframe signs to be permitted only if business owners can meet certain aesthetic and placement requirements. This information was learned through analysis of multiple questions and through the reading of comments.

- The majority of respondents (73\%) believe that the City's sign code is applied inconsistently. The attached comments reveal that some business owners believe that enforcement is somewhat "selective and inconsistent.” A few respondents also 
commented that corporations are favored, and that they are allowed unfair exceptions. However, despite issues with selective enforcement, $41 \%$ of respondents believe that enforcement of illegal signs is not an issue.

- More than half of respondents are happy with the current signs in Morro Bay; however, survey comments and answers defined under "other” reveal that digital (reader) signs, Aframe signs, window signs, flags/banners, non-professionally made signs and signs made of unappealing materials are among the most disliked types of signs.

- The majority of respondents (86\%) believe that signs are "very important" to the success of their business, and that it would be beneficial to have different sign requirements in different business districts.

- Although some business owners believe that their signs are too small and can't be seen from the street, the majority of respondents (51\%) are happy with their current signage.

- The majority of business owners either support business directional signs on the Embarcadero, or have a neutral stance on the issue.

Figure 4.2: Primary Business Owner Survey Results
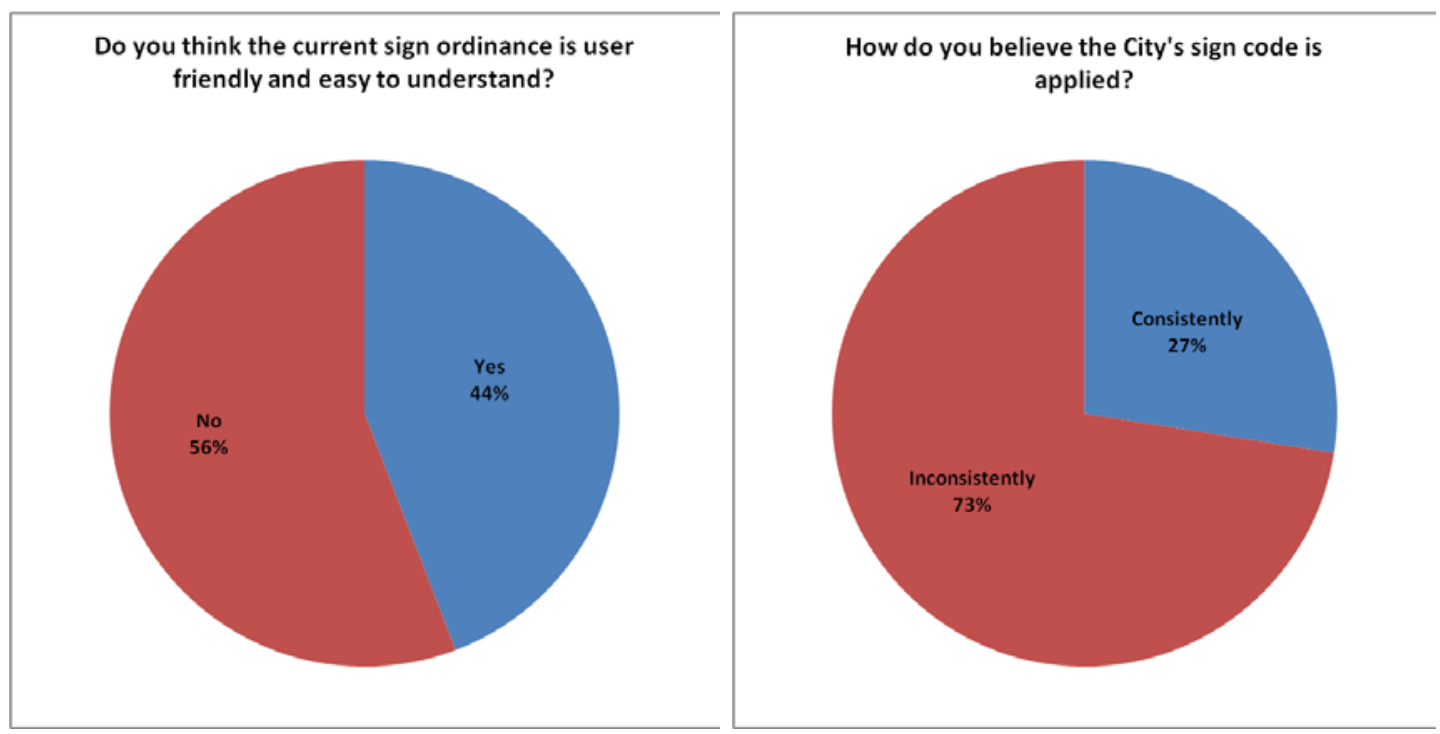
Figure 4.2: Primary Business Owner Survey Results (continued)

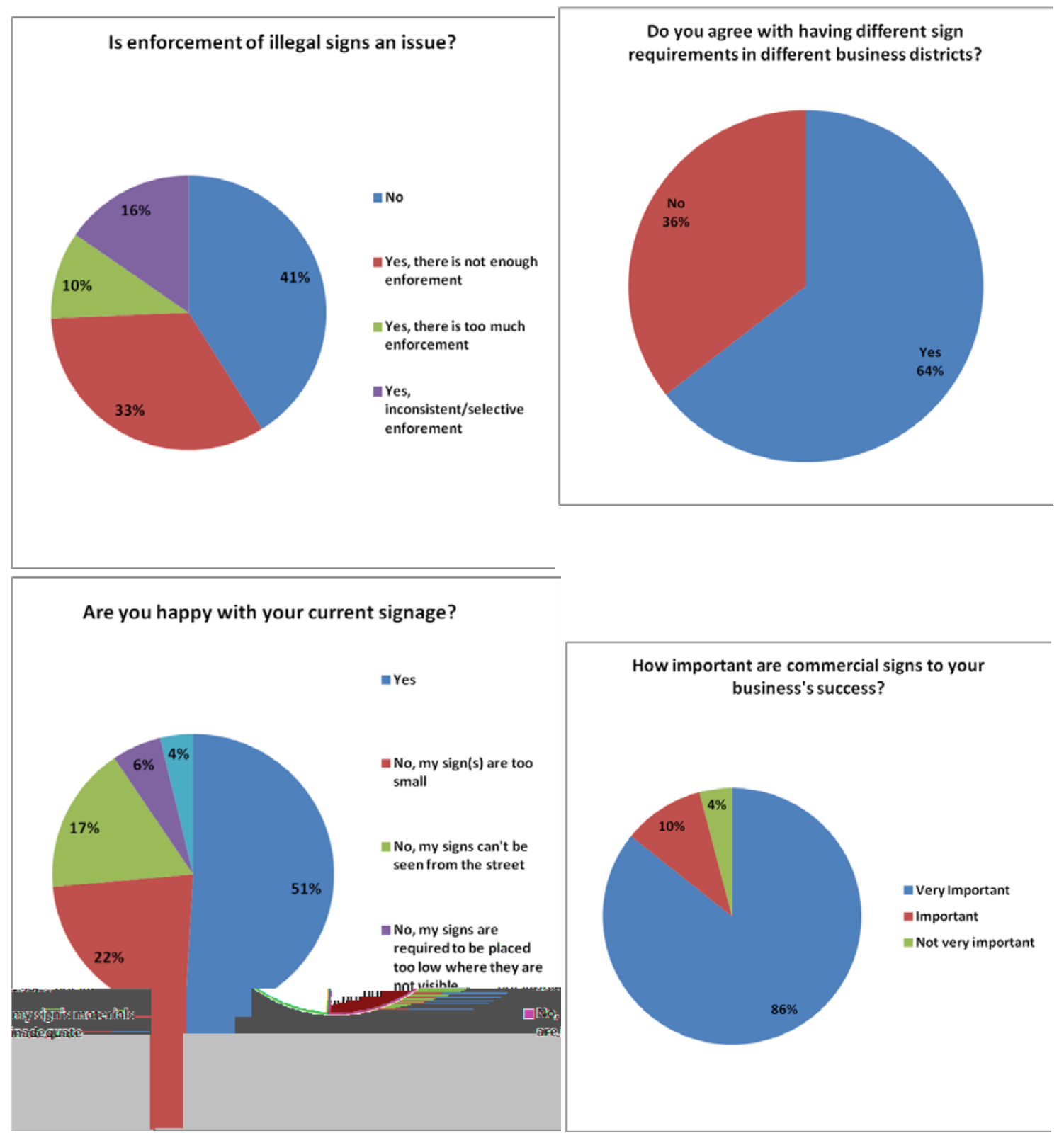


Figure 4.2: Primary Business Owner Survey Results (continued)

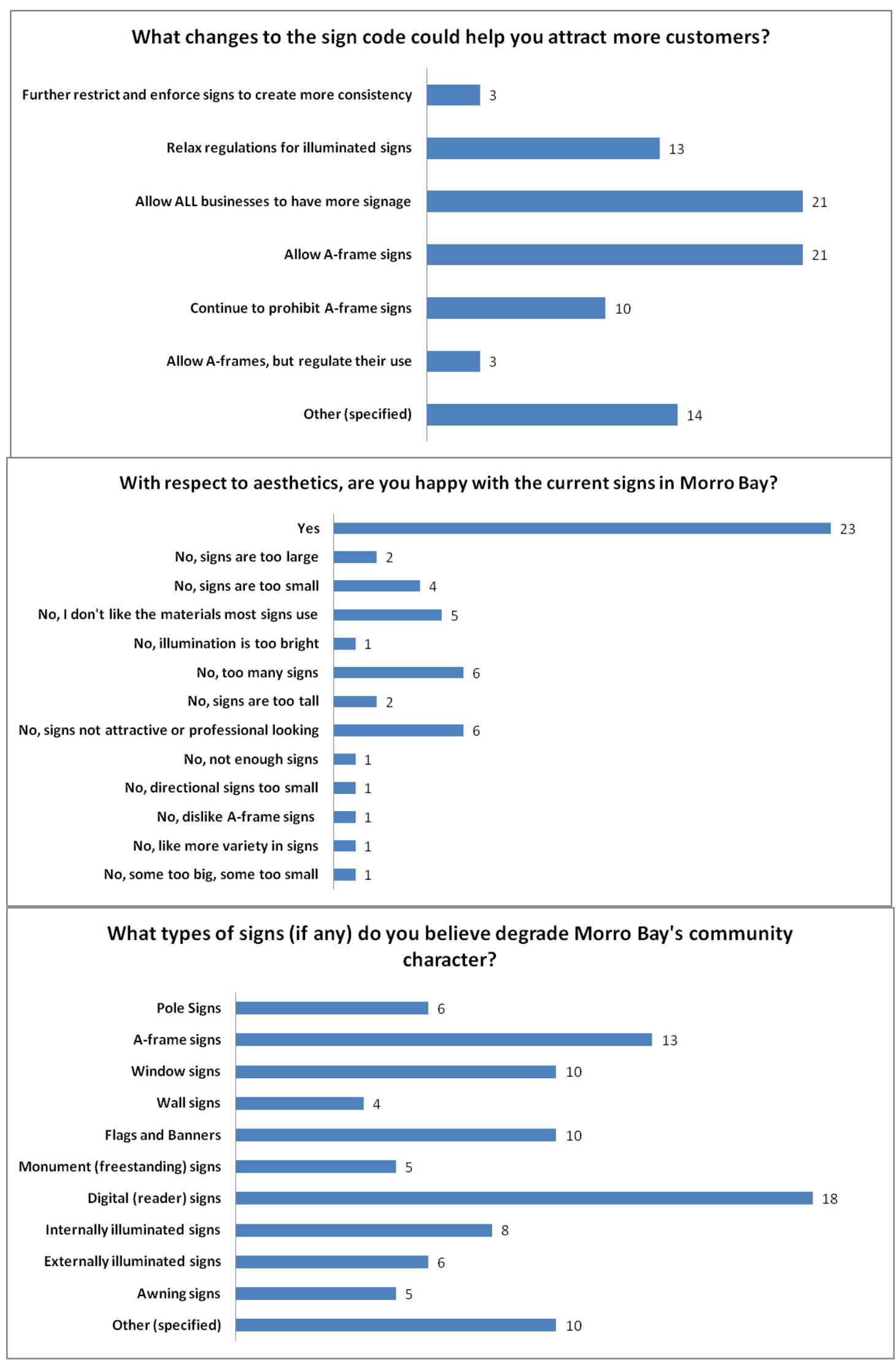




\section{Resident Survey:}

A survey for Morro Bay residents was also administered using Survey Monkey. A link to this survey was included in the previously mentioned news flash. This survey had only four respondents, all of whom reported being Morro Bay residents. All respondents reported that they are happy with the current signs in Morro Bay with respect to aesthetics, and that they would support directional signs on the Embarcadero. Three of the respondents said that businesses should be guaranteed a minimum size sign regardless of frontage size, while one respondent skipped this question. Half of respondents believe that pole signs and A-frame signs degrade community character, and that A-frame signs should be strictly prohibited at all times. Three of four respondents reported that they do not want uniformity in the appearance of signs, and that they would support having different sign requirements for different areas of town. A summary report of the survey results can be found in Appendix 4.6.

\subsection{Primary Interviews}

\section{Interview with Shanna Farley-Judkins, City of Carpinteria, California, Assistant Planner:}

In a previous correspondence, Carpinteria’s Community Development Director, Jackie Campbell, stated that the current sign ordinance in Carpinteria is outdated and that the City is preparing a new draft zoning ordinance. Included in this draft is an updated sign ordinance. Ms. Campbell suggested that staff member Shanna Farley-Judkins be interviewed because she has the most knowledge of the current and draft sign ordinance in Carpinteria. An interview was carried out on April 19 $9^{\text {th }}, 2013$.

Ms. Farley-Judkins provided useful information regarding signs, public outreach and politics. Her insights were used as a tool during the formation of Morro Bay's updated sign ordinance. Some of the key points Ms. Farley-Judkins made during the interview are summarized as follows: 
- The City does not get many complaints about the sign ordinance, but many individuals do not interpret the requirements properly (code is not specific enough). The new code will be more explicit so that confusion, counter staff time, and delays are reduced.

- The new draft ordinance makes use of tables to increase clarity.

- Carpinteria’s new code will require that storefronts reduce signage to allow view of the interior of stores. This is considered in our general plan as an objective for friendly pedestrian commercial frontages.

- Maintenance costs and time must be considered if directional business signs are proposed. With businesses always changing, and new ones arriving, it could be hard to keep up with the changes and make sure there are slots for new businesses.

- When writing a sign ordinance it is especially important to get the Chamber of Commerce and business owners involved with the process. Also, be wary of consultants because they can sometimes push ideas that may not suit smaller communities.

The full interview can be found in Appendix 4.7.

\section{Planning and Building Manager, Kathleen Wold; Associate Planner, Cindy Jacinth:}

Morro Bay Planners Kathleen Wold and Cindy Jacinth were not formally interviewed during this project, but were instead active participants throughout the entire process. Both planners offered their thoughts on what changes needed to be made to the draft sign ordinance. Due to their experience and knowledge of the current sign ordinance, they were able to pinpoint problem areas and offer solutions that could be applied in an updated ordinance. The newly proposed sign ordinance was reviewed, critiqued, approved, and actively worked on by both aforementioned Morro Bay Planners. 


\subsection{Outreach Analysis}

Outreach efforts are a key part of writing zoning ordinances that reflect the desires of the community. Both secondary and primary data were analyzed during the process of this sign ordinance update. When a clear consensus was reached among respondents on a certain question, the knowledge gained from this consensus was used to amend or validate old ideas, and to also form new ideas associated with the proposed ordinance. The issues summarized below highlight the most important issues, but all results and comments were considered during the creation of the sign ordinance update.

\section{Themes observed in all surveys and other outreach efforts:}

Respondents reached a consensus on the following issues:

- The city's sign code is applied inconsistently. The amount of comments on this issue exemplified that fairness is an issue among the community. The sign ordinance update must introduce tools to insure that the codes are applied consistently.

- Signs are very important to businesses in Morro Bay. Only 4\% of respondents stated that their signs are not very important to the success of their business.

- $56 \%$ of respondents stated that the current sign ordinance is not user friendly. While this is not an overwhelming majority, having a clear and easy to understand sign ordinance is a basic necessity. While it may be difficult to please everyone in regards to the regulations within the sign ordinance, these regulations should at least be clear and comprehensible to all residents and business owners.

- As far as attracting more customers, business owners stated that allowing A-frame signs and allowing all businesses to have more signage would be the most important changes.

- “Digital reader signs” was the most popular choice when respondents were asked what types of signs degrade Morro Bay’s community character. A-frame signs, window signs, 
flags/banners and illuminated signs are also disliked by many respondents. Some respondents also used the “other” choice to specify a dislike for temporary and paper signs.

- Secondary surveys reveal that $91 \%$ of respondents believe that businesses should be allowed special allowance or exceptions in regards to the sign ordinance, and $92 \%$ of respondents believe that murals should not be considered signs.

\section{Questions left unanswered:}

After analyzing the survey data it is evident that respondents were divided on some of the questions; that is, a clear consensus was not reached. In these cases it is the job of planners to collaborate with other city staff members, and to use their skills and experience to make the best possible decisions.

Respondents were divided on the following ideas and issues:

- Sign enforcement: while there were many comments regarding selective enforcement, $41 \%$ of respondents believe that enforcement of illegal signs is a non-issue.

- Respondents were split down the middle when asked if they are happy with their current signage. While the majority of "unhappy” respondents claim their signs are too small and cannot be seen from the street, 51\% of respondents are happy with their signs. This means that for more than half of the business owners, the current sign ordinance is allowing them the signage they need.

- Respondents were fairly divided when asked about the aesthetic appearance of signs in Morro Bay. Twenty-three (23) primary survey respondents stated that they are happy with the way signs look around the City. For those who believe aesthetics are unsatisfactory, it was clear that sign materials, professionalism, and the existence of too many signs in general are issues 
that need to be addressed in the new sign ordinance. There were many useful comments concerning sign materials; some respondents pointed out that various handmade signs throughout the City are unappealing, and detract from the overall appearance of the streetscape. Past survey results reported that $76 \%$ of respondents were unhappy with signs in the City, however the reasoning behind this opinion is unclear. 


\section{Chapter 5: Case Studies}

\subsection{Introduction}

This section discusses major themes from sign ordinances currently existing in other cities. The cities included were selected based on their geographic location, community character, demographics, and quality of sign code. For comparison purposes (in terms of demographics) it must be stated that according to the 2010 U.S. Census, the City of Morro Bay has a population of 10,234 and a median age of 48.9 years old. The following sections explain the reasoning behind each selection, and any key ideas or themes observed in each city’s ordinance. The themes examined focus mainly on sign area (which is perhaps the most discussed element of the code and is the most noticeable feature when signs are observed in a community), materials, sign placement, and allowable sign types. Ideas were not taken directly from these ordinances, but instead used for general guidance during the formation of Morro Bay’s updated sign ordinance.

\subsection{Santa Cruz, California}

The City of Santa Cruz, CA was analyzed because like Morro Bay, it is a funky beach community located along California's coast. According to the 2010 U.S. Census, the population of Santa Cruz is 59,946 (nearly six times greater than that of Morro Bay), and has a median age of 29.9 years old. The City of Santa Cruz provides an example of a sign code that exists in a city with similar geographic and community character qualities to Morro Bay, but with a sizeable difference in demographics.

The first noticeable aspect of this code is the unique title; "Part 4: Advertising Devices, Signs, and Billboards.” The code does not include photos or graphics; however it does include two graphs that illustrate allowed sign square footage based on frontages and wall areas (Section 
24.12.390). It must also be mentioned that the code does not include definitions, which is unusual for sign codes. The code is organized uniquely, allocating a different section for each type of sign. For example, Section 24.12.322 is titled "Wall Signs,” and the section includes information about allowable location (on the building) and areas, and how many signs are permitted on the premise.

Unlike the other codes analyzed, it is apparent that Santa Cruz's code does not match allowable sign types with uses. For example, under the "Freestanding Signs” section there is no information about what zones or uses permit this type of sign. If someone reads an individual section such as "Freestanding Signs,” it could be assumed that this type of sign is allowed anywhere. However, the Santa Cruz code states that "There may be permitted for each place of business or occupancy, a combination of not more than two types of signs; freestanding, wall, or projecting” (Section 24.12.334).

\subsection{Atascadero, California}

The City of Atascadero, CA is not a beach town, however Morro Bay City staff stated that Atascadero's code has high quality elements and should be further examined. According to the 2010 U.S. Census, Atascadero has a population of 28,310 and a median age of 41 . The reported population and geographical features are very different in Atascadero; however, of all the cities selected for analyzing, Atascadero has a median age closest to that of Morro Bay. And although it is not a beach town, Atascadero is close to Morro Bay (approximately 17 miles driving) and is part of the Central Coast region of California. These geographic similarities are not present in the other cities used for comparison and research.

One key feature related to Atascadero’s sign ordinance is the existence of a four-page informational handout called “City of Atascadero Sign Guidelines,” which uses images, tables, 
and straightforward text to outline the sign ordinance (see Appendix 5.1). This handout is supplementary to their official Municipal Code. The handout includes minimal amounts of text, which makes finding important sign-related information simple for the user. On the first page the handout includes basic information about the purpose of the sign ordinance, and clearly lists "Exempt Signs” and "Prohibited Signs.” With the help of graphics, the following pages help business owners quickly discover what they can and can't do with their signs.

As far as the content of the sign ordinance, Atascadero's code is quite unique in that it permits the use of large temporary banners. The code exempts large (40 sq. ft.) temporary banners that are in place for a maximum of 30 days. The City of Atascadero also permits the use of window lettering/graphics, A-frame signs, and freeway-oriented signs without the signs counting towards the total allowable sign area for a business. In the smaller city of Morro Bay, allowing free use of large scale signage is not appropriate (even in the freeway-oriented North Main district).

One similarity that can be referenced is Atascadero's specifications for their “downtown districts.” These regulations restrict total signage to 50 sq. ft. per business, and are designed to make storefronts appealing to pedestrians. The City has also implemented design guidelines that must be met before signs are approved. However, despite the strict regulations, businesses in downtown districts are allowed to implement window lettering/graphics, directory signs, "building name” signs, and A-frame signs without the signs counting towards their total allowable sign area.

\subsection{Carpinteria, California}

The City of Carpintaria, CA was analyzed because it has many similarities to the City of Morro Bay. The demographics in Carpinteria are similar to those observed in Morro Bay. The 2010 U.S. Census reports a population of 13,040 and a median age of 39.5 years old. Like both Morro Bay 
and Santa Cruz, Carpintaria is a tourism destination located right on the beach, and is known for being a relaxed and active community. Based on geography, demographics, and community character of the selected cities Carpinteria is perhaps the most similar to Morro Bay. It must also be noted that I was a part of a Cal Poly Planning Studio that worked with the City of Carpinteria in the spring of 2012. I have personal experiences that allowed observations of these similarities first hand.

Carpinteria’s sign code allows signage to be eclectic and unique; however Assistant Planner Shanna Farley-Judkins stated that regulations are tightening in the City's new draft ordinance. See Appendix 4.7 for more information about Carpinteria's draft ordinance.

Another interesting feature of the sign code relates to lodging establishments. The code states, "Price signs for lodging posted outside any hotel, motel, motor court, bed and breakfast inn and like establishment must indicate the range of rates charged, including the highest and lowest rates currently in effect" (Section 14.58.070). With the abundance of hotels and motels in Morro Bay, the implementation of a similar regulation would have wide effects, both positive and negative, throughout the City. While such a regulation would provide tourists with important lodging information, requiring the implementation of such a sign would cost small businesses money. During a time of economic distress it may be unreasonable to impose extraneous costs on hotel and motel owners, and it is likely that such a proposal would be ill received. 


\section{Chapter 6: Morro Bay's Existing Sign Codes}

\subsection{The Current Ordinance}

\section{Issues with the current code:}

Morro Bay’s current sign ordinance was adopted in 1995. In the past eighteen years there have been nationwide changes to marketing strategies, commercial sign design, laws relating to signs, and the way sign ordinances are organized and presented. Changes need to be made to the current sign ordinance to make certain it meets current standards.

In order for Morro Bay's sign ordinance to be successfully updated, it is important to pinpoint the problems with this existing code. According to the community outreach results, the majority of participants are not happy with the way signs currently look in Morro Bay. This is a significant piece of information, but the more important question is, why? A copy of the current sign ordinance is located in Appendix 6.1.

\section{Permit Fees:}

Fees and application format for sign permits affect the willingness of business owners to approach the city for approvals. Sign permit fees according to the "City of Morro Bay Master Fee Schedule for the 2012/13 Fiscal Year” are listed in Figure 6.1.

\begin{tabular}{|l|l|}
\hline Sign Permit & $\$ 84.00$ \\
\hline Sign Exception (CUP) & $\$ 698.00$ \\
\hline Pole Sign (CUP) & $\$ 698.00$ \\
\hline
\end{tabular}

Figure 6.1: Current Fee Schedule 
Permit fees for conforming sign proposals are relatively low in the City of Morro Bay. In other words, it is not the fees that prevent business owners in Morro Bay from obtaining a sign permit. Exception permits, on the other hand, are quite expensive. This high fee has the potential to deter businesses from applying for an exception, and could instead motivate them to take the risk of constructing an unpermitted sign.

\section{Applications:}

Morro Bay’s current sign application forms are being updated along with the sign ordinance. The new applications include detailed instructions and graphics with the hope that additional information will make regulations and requirements clear to readers. The new applications will not be completed until a new sign ordinance is approved by Morro Bay's decision making bodies.

\subsection{The Old Draft Ordinance}

As mentioned, consultants previously developed a sign ordinance update for the City of Morro Bay that was never implemented (see Appendix 6.2). In order to write a successful "new” draft sign ordinance, it is important to discover the changes made by the consultants to the existing (current) sign ordinance. A comparison of the current ordinance with the "old" draft ordinance in matrix form can be found in Appendix 6.3. The following sections will provide a summary of what is included in the "old” draft ordinance, and how this draft differs from the existing sign ordinance. 
There are many differences between the existing sign ordinance and the "old" draft sign ordinance. The changes observed in the "old” draft ordinance are summarized as follows:

- The organization of content is very different.

- Uses graphics to communicate regulations and explain how sign area calculations work.

- Exempts small permanent window signs and other small signs from allowable area calculations.

- Does not determine allowable sign area based on the use of different types of signs.

- $\quad$ Businesses in C1, MCR, CVS, WF, and GC zones are allowed less signage.

- Businesses in industrial zones are granted more allowable sign area per linear ft. of frontage than businesses in commercial zones.

\section{Graphics:}

One of the key aspects of the draft ordinance is the use of graphics to illustrate sign concepts. Most traditional zoning ordinances consist of just text that is organized by sections and subsections. Newer sign ordinances are taking advantage of graphics to make the set of regulations clearer and more user-friendly. A single picture has the ability to replace one or more paragraphs of text, making graphic-based codes simple and more concise. Benefits of using graphics in sign codes are as follows:

- Leaves the public with fewer questions concerning regulations. Fewer questions directed at city planners concerning the regulations, the less staff time needed at the front counter.

- A shorter, organized code reduces the time it takes staff to look up information when questions or uncertainties arise.

- Graphics illustrate a real world example that helps staff explain how a regulation works, and why such a regulation was enacted. 


\section{Exemptions:}

Another key change in the draft ordinance is found at the end of Section 17.68.010 under

“Exempt Signs.” The old draft code aims to exempt "small signs” and relatively small "window

signs” from allowable sign area calculations. The draft code includes the following:

L. Small Signs. Any sign no larger than eight square feet in area, attached to a freestanding sign structure no higher than five feet, a window, or a building wall. This exception may include, but is not limited to, commercial and non-commercial signs, freedom of speech signs, organization identification signs, and commemorative plaques within the required size limits.

N. Window Signs. Window signs not exceeding 20 percent coverage of each glass window or glass door to which the sign is attached or 10 square feet, whichever is greater. Any sign that is hung within three feet of a window, attached to a display located within three feet of a window, or painted on the window is considered a window sign. For temporary window signs, refer to Section 17.68.070.

These exemptions are very interesting proposals. First, allowing a window sign not exceeding 20 percent coverage in every window would allow business owners much more total signage than originally permitted. Would allowing all windows to have signs that were not reviewed by the Planning Department invite the opportunity for business owners to clutter every window within the City's commercial districts?

Secondly and more importantly, allowing an unrestricted number of "small” signs on buildings and freestanding sign structures could provide a loophole that would allow business owners to legally implement excessive amounts of signage.

\section{Allowable Sign Area:}

The draft ordinance includes important changes to allowable sign areas that apply to select commercial, mixed-use, and industrial zones.

1. In the following zones the allowable sign area is reduced to $\mathbf{0 . 5} \mathrm{sq}$. $\mathrm{ft}$. per linear $\mathrm{ft}$. of building frontage: C1, MCR, CVS, GO, WF, and GC. 
2. In the following zones the allowable sign area for awning/canopy signs, window signs, monument signs, and pole signs is increased to 2 sq. $\mathrm{ft}$. per linear $\mathrm{ft}$. of frontage: C2, CF, M1, M2, $\mathrm{H}$ and MMR.

Most of Morro Bay's businesses (and especially those that rely on a storefront to attract customers) are located on the Embarcadero, along North Main St., and in the downtown. C1, MCR, WF and CVS zones are by far the primary zoning designations in these commercial hubs. As proposed in the draft ordinance, the allowable sign area in these zones would effectively be reduced by $50 \%$. If implemented, the draft ordinance would make the majority of signs within the City non-conforming.

\section{Prohibited Signs:}

Another important change observed in the old draft ordinance is the removal of a regulation that prohibits "signs in connection with any home occupation." If implemented in its current state, the draft ordinance would allow signage to be placed in residential neighborhoods. In most communities (and especially in Morro Bay), potentially allowing signs in residential areas would create a sense of anxiety and anger among residents.

Another change is the absence of an A-frame or "sandwich board” sign prohibition. The existing sign ordinance clearly bans A-frame signs, even if they are on a business’s property. A-frame signs in regards to the new draft ordinance will be further discussed in Chapter 7.

\section{Computation of Sign Area:}

One advantage observed in the draft ordinance can be attributed to the graphics dedicated to showing how "allowable sign area” is calculated under different circumstances. In addition to instructions on calculating sign areas for normal rectangular signs, the document includes diagrams showing how to determine areas for circle shaped, “oddly” shaped, and letter-based 
signs. Incorporation of these graphics into a new ordinance would reduce the number of counter questions about area calculations, and also cut down on the number of requested revisions for sign permit applications.

\section{Signs for Lodging:}

The draft ordinance introduces a regulation that applies to lodging-based businesses located in R2 districts. The current ordinance only addresses hotels, motels, and bed/breakfast establishments located in R-3 or R-4 districts. The draft ordinance simply applies the old R-3 regulations to the R-2 regulation, and then moves the sign rules for lodging located in R-3 into the existing R-4 regulation. The draft section is as follows:

\section{B. Hotels, Motels, and Bed and Breakfast Establishments.}

1. R2 Districts. One surface sign or monument sign per bed and breakfast establishment and attraction boards as provided in the Section 17.68.070(C)(5) are permitted with a maximum sign area of 0.5 square feet per linear foot of building frontage.

2. R3 and R4 Districts. Signs may be permitted in accordance with the provisions for commercial zones as provided in Section 17.68 .060 below as well as attraction boards as provided in Section 17.68.070(C)(5).

This change may seem minor, but hotels in Morro Bay are a major land use, as well as a component of the City's tax base. This change would directly affect lodging located in R-3 zones, adhering to "provisions for commercial zones" instead of the regulation allowing $0.5 \mathrm{sq} . \mathrm{ft}$. per linear foot of building frontage. Commercial zones allow many other types of signs in addition to monument and surface signs, the only two allowed in the current ordinance for hotels located in R-3 zones. Furthermore, commercial zones permit surface signs to have an area of 2 sq. ft. per linear foot of building frontage (if not used in conjunction with other types of signs). In some circumstances this change would increase allowable sign area by four times, and could allow certain lodging establishments to construct signs as a large as 200 sq. $\mathrm{ft}$. This change would greatly benefit lodging services located in R-3 and R-4 zones. 


\subsection{USSC Model Sign Ordinance}

In 2011 the United States Sign Council (USSC) published a new model sign code for their subscribers. The document entitled "Model On-Premise Sign Code" is an extremely detailed and dense document that, with slight modifications, can be adopted by cities lacking the resources to create a customized sign code.

The article "New USSC Model Sign Code" by Richard Crawford proves to be an excellent source of information because it summarizes and discusses the relatively new model code. Information and ideas were sourced from this code due to the fact it is so comprehensive. According to Crawford, "A town can simply add its name and make a few cosmetic changes to the document and use the Model Code as presented" (p. 22).

Crawford also points out one of the more interesting elements within the USSC Model Sign Code; allowable sign areas for freestanding signs increase with roadway speed limits. This scheme is based on research regarding traffic safety. The larger the sign, the less time it takes fast moving motorists to focus in on. For example, a freestanding sign in a downtown zoning district along a street with a 25 MPH speed limit has a max area of 24 sq. ft. A sign along a "Limited Access Highway" with a 70 MPH speed limit has an allowable area of 741 sq. ft. (Crawford, p. 23).

In cases of uncertainty among staff in regards to proposed changes, the USSC model code was consulted; analyzing this model code helped maintain consistency in regards to accepted national standards and expectations. 


\section{Chapter 7: Changes to the Sign Ordinance}

Important Note: Further changes will be made to the draft ordinance before it is presented to the Planning Commission during the summer of 2013. All final edits and changes are not included in this report. When the new ordinance is approved, this report will be updated to document future discussion and reasoning behind changes to the final, implemented sign ordinance.

\subsection{Introduction}

After research of scholarly articles, city documents and news articles, the conduction of multiple interviews, participation in city meetings regarding the sign ordinance, and examination of past and present community outreach results, it is apparent that the old draft sign ordinance needs be updated before it is brought to Morro Bay’s Planning Commission for review and discussion. Using the findings presented in this background report, the final chapter discusses the proposed changes to the city's current sign ordinance, and the reasoning behind these changes.

\subsection{Allowable Sign Area and Calculations}

\section{Allowable Sign Area:}

As discussed in Section 5.3 of this report, the draft ordinance proposes a reduction in allowable sign area that would affect the majority of businesses in Morro Bay. Analysis of survey results and comments reveals that signs are very important to business owners in Morro Bay. It is not the intention of the new draft ordinance to further reduce the amount of allowable signage, but allow a fair amount that maximizes effectiveness and aesthetic appearances. 


\section{Sign Calculations:}

The new draft ordinance uses a "percent of frontage” calculation that replaces the traditional "sq. $\mathrm{ft}$. allowable signage per linear sq. ft. of frontage” type calculation. Using the traditional calculation (that appears in Morro Bay's current sign code) leads to the approval of signage that is not proportionate to the building as a whole; only the length of building is considered. On the other hand, the more progressive percentage calculation considers the area of the entire frontage (length $\mathrm{x}$ width). The use of percentages that account for the entire frontage will grant business the appropriate amount of signage that is proportionate to the building.

\subsection{Prohibited Signs}

\section{A-frame Signs:}

After much discussion it was decided that A-frame signs be allowed only in the Downtown District. It is understood that A-frame signs are important to business owners along the Embarcadero; however, with the development of a Tourist-Oriented Directional Sign Plan for the Embarcadero, the need for A-frame signs will decrease. Furthermore, A-frame signs are an issue along the Embarcadero because they crowd the sidewalks and infringe on the pedestrian right-ofway.

Because the new proposed directional sign plan focuses on the Embarcadero, it was decided that business owners in the Downtown be granted the opportunity to use A-frame signs. The use of Aframe signs will be restricted to insure that they do not degrade the aesthetic qualities of Downtown Morro Bay. 


\subsection{Sign Bonuses}

\section{Projecting Signs:}

Projecting signs deserve discussion because, according to outreach efforts conducted by Cal Poly students, they are a type of sign that Morro Bay residents approve of. To be exact, the Cal Poly design studio reported that "pub signs" were liked by participants (pub signs are a type of projecting sign). Furthermore, because projecting signs are oriented in a way that target pedestrians, it is appropriate that the use of projecting signs be encouraged. The Downtown and Embarcadero districts are associated with high volumes of pedestrian traffic, and these districts should therefore have signage that further promotes alternative modes of transportation (such as biking and walking).

After much discussion, it was decided that businesses in the Embarcadero and Downtown districts be allowed a projecting sign that does not count towards the calculated allowable signage. That is, businesses in these districts are granted a "free pass" to implement a small projecting sign. The bonus can also be used towards implementing a larger projecting sign.

\section{Wall Signs with Individual Lettering:}

Bonuses will also be granted to applicants who choose to use wall signs with individual lettering. Individually lettered signs, as opposed to "canned" signs, are generally seen as more aesthetically pleasing. Canned signs will have a greater allowable maximum size, and applicants proposing this type of sign will receive a bonus on top of their allowable signage. 


\subsection{Low Impact Signage}

\section{Low Impact Signage:}

The City of Morro Bay is in the process of adopting a Climate Action Plan, and is also looking for other ways to increase sustainability efforts. Apart from addressing sign illumination and light pollution issues (in Chapter 2), an updated sign ordinance should include regulations that address energy efficiency and sign materials. One idea to promote sustainability in the City could be offering incentives to business owners who have their signs constructed with a certain percentage of recycled materials. One example of an incentive would be offering a $10 \%$ allowable sign area bonus to business owners who can provide proof that their sign(s) were made of sustainable materials (e.g. post-consumer recyclable material).

Impact! Signs is a sign manufacturer based in LaGrange, IL that offers green sign alternatives. Among a long list of environmentally friendly offerings, they sell solar powered illuminated signs that use no electricity. In the relatively sunny climate of Morro Bay, such signs could potentially be very effective in reducing energy consumption. (www.impactsigns.com/green-signs/).

In addition, California Outdoor Design Studio, a company based in Murrieta, CA, provides sustainably produced outdoor furniture and signage. They claim that their signs made out of recycled plastic lumber can withstand any kind of weathering, negating the need to repaint, stain, or seal the surfaces. These signs conserve resources by using recycled materials and also eliminate the need to restore the sign by applying potentially toxic products. (www.outdoordesignstudio.com/signs.html).

These ideas involving low impact signage will not be written into the new draft ordinance; however, they will be mentioned during presentation of the code to the Planning Commission. If the Commission sees that these issues are important, a section will be added to the ordinance 
addressing recycled materials (and some kind of program that awards business owners who take part in making their community more sustainable and environmentally conscious).

\section{Lighting:}

The new ordinance also requires all newly fabricated internally illuminated signs to include energy efficient LED lighting.

\subsection{Other Changes}

\section{Graphics:}

Some of the graphics from the older draft ordinance were used in the new ordinance, however, new ones were also created using Google Sketchup, Adobe Illustrator, and Adobe Photoshop. These new graphics were designed to be both aesthetically attractive and informative.

\section{Organization:}

The new draft ordinance is completely reorganized. The goal of the new organization is to incorporate the Four Districts (discussed earlier in this report), increase clarity, and make the document more user-friendly.

\section{Conclusion}

This report was produced as part of Erik Berg-Johansen’s Masters Project for the Master of City and Regional Planning degree at Cal Poly. This report was used to generate ideas and document progress and decisions during the process of writing the new draft sign ordinance for the City of Morro Bay. Once completed, the draft ordinance will be presented to the Planning Commission during the summer of 2013. At the time of approval this report will be edited to reflect the final state of the approved sign ordinance, and will become an important part of documentation for the City’s sign ordinance update project. 


\section{Sources:}

Armstrong, M. J. (2010, Oct 01). City takes a fresh look at signs. Tribune Business News.

Barclay, Cecily Talbert. (2010). Curtin's California Land Use and Planning Law, Thirteenth Edition. Point Arena, CA: Solano Press Books.

California Sign Association. Retrieved from: www.CalSign.org. Last updated in 2012.

Castle, Roger and Gary Ream. (2006). Images of America Morro Bay. Charleston SC, Chicago IL, Portsmouth NH, San Francisco CA: Arcadia Publishing.

City of Atascadero, CA. Municipal Code, Chapter 15: Signs. Retrieved from: http://qcode.us/codes/atascadero/.

City of Atascadero, CA. "Sign Guidelines Handout.” Retrieved from: http://www.atascadero.org/files/CD/PermitRoadmap/Sign\%20Guidelines.pdf

City of Carmel, CA. (2012). "Carmel-by-the-Sea Municipal Code, Chapter 17.40 Signs." Retrieved from: http://www.codepublishing.com/CA/carmel.html

City of Carpinteria, CA. Municipal Code, Chapter 14.58: Sign Regulations. Retrieved from: http://library.municode.com/index.aspx?clientId=16248\&stateId=5\&stateName=Californ ia

City of Milpitas. (May 2011). "Draft EIR for the Proposed Interstate 880 Billboard Project." Retrieved from: http://mlp010.ci.milpitas.ca.gov/_pdfs/plan_eir_interstate_880_billboards.pdf

City of Morro Bay Economic Development Program. 2013. Developed by: Morro Bay Chamber of Commerce. Retrieved from: http://morrobay.nationbuilder.com/.

City of Morro Bay Public Services Department. (2012). “Master Fee Schedule for the 2012/13 Fiscal Year.”

City of Morro Bay Public Services Department. (2011). Draft Sign Ordinance; Chapter 17.68 Sign Regulations.

City of Morro Bay. The General Plan.

City of Morro Bay. The Coastal Land Use Plan.

City of San Luis Obispo, CA. (2004). Sign Regulations. Retrieved from: www.slocity.org/communitydevelopment/download/signregs.10.07.04.pdf

City of Santa Cruz, CA. Municipal Code, Chapter 24.12: Community Design, Part 4: Advertising Devices, Signs and Billboards. Retrieved from: http://www.codepublishing.com/CA/SantaCruz/html/santacruz24/santacruz2412.html 
Cornell University Law School. Legal Information Institute.

Retrieved From: www.law.cornell.edu/wex/first_amendment. Last Updated: August 19, 2010.

Dennis, Charles, et. al. (2010). The appeal of a town's separately branded environments to market segments and the segmented appeal of digital signage. Place Branding and Public Diplomacy, Special Issue: Places for People in a Turbulent World, pp.156-175.

Drain, David. (2009). Digital Signage Replaces Traditional Signage. Buildings (103, No. 9), p. 34.

Duerksen, Christoper and Matthew Goebel. (1999). Aesthetics, community character, and the law. Chicago, IL: American Planning Association.

Grigg, D. (2009). Draft of sign ordinance draws protest in garden city. The Idaho Business Review.

International Dark Sky Association. (2011). “Model Lighting Ordinance (MLO).” Retrieved from http://www.darksky.org/outdoorlighting/mlo

International Dark-Sky Association. (2011). "Joint IDA - IES Model Light Ordinance (MLO) with User’s Guide.” Retrieved from http://www.darksky.org/assets/documents/MLO/MLO_FINAL_June2011.pdf

International Dark Sky Association. (2013). “Light Pollution Map.” Retrieved from: http://www.blue-marble.de/nightlights/2010

International Sign Association. "Position Statements." Retrieved from: www.Signs.org. Last updated: 2011

Krohe Jr., James. (2009, April). Scroll, Roll \& Flash. Planning.

Lilley, W. III, DeFranco, L.J. and Buffalo, C. (2001). An Analytical Inquiry: Do States that Ban Billboards Have Increased Tourism and Improved Economies? iMapData Inc., Washington, DC.

Lobler, Helge. (2010). Signs and Practices: Coordinating Service and Relationships. J Bus Mark Manag, pp. 217-230.

Lopez, Jesna. (2007). The regulation of signs: an evaluation \& revision of a sign ordinance : a thesis-professional project. San Luis Obispo, Calif.: California Polytechnic University

Maurer, K. (2011, Sep 05). County to consider enforcement of sign ordinance. Tribune Business News.

Mitchell, T. (2010, Jun 08). Sign law changes proposed to help small businesses: The law also proposes more enforcement against 'snipe' signs. Tribune Business New.

Penn State University, The Thomas D. Larson Pennsylvania Transportation Institute. (2009). "Internal vs. External On-Premise Sign Lighting: Visibility and Safety in the Real World." Retrieved from: http://www.mautc.psu.edu/docs/PSU-2008-02.pdf. 
Taylor, Charles. (2006). How excessive restrictions on signage backfire. The Journal of Consumer Marketing (23), pp. 56-57.

Tennyson, Patricia. (2012). Key Steps to Effective Public Outreach. American Water Works Associations (104), pp. 76-83.

U.S. Census Bureau. City of Santa Cruz, City of Atascadero, City of Morro Bay, City of Carpinteria. “2010 Demographic Profile Data (DP-1).” Retrieved from: www.factfinder2.census.gov/

Woolston, C. (1995, Nov 20). Sign code presents dilemma: Businesses that have complied may sue if code is softened. The Billings Gazette, pp. 1-1. 


\section{Chapter 17.68 Sign Regulations}

\section{Sections:}

17.68.010 Purpose

17.68.020 Commercial Signs and Calculations
A. Sign Types
B. Computation of Sign Area
C. Computation of Facades

17.68.030 Standards for ALL Districts and Zones
A. Design Principles
B. Construction, Maintenance, Abandonment, and Removal
C. Provisions for Nonconforming and Illegal Signs
D. General Sign Standards (Commercial and Non-Commercial)
E. Prohibited Signs

17.68.040 Embarcadero District

17.68.050 Downtown District

17.68.060 Quintana Road District

17.68.070 North Main District

17.68.080 Lodging Establishments

17.68.090 Sign Permits

17.68.100 Master Sign Program

17.68.110 Appeals

17.68.120 Definitions

\subsubsection{Purpose}

The purpose of this Chapter is to regulate signs so that they express and enhance the character and environment of the City of Morro Bay and its community. These regulations recognize the importance of business activity to the economic vitality of the City. Specifically, these regulations are intended to:
A. Encourage communications which aid in the identification of businesses and activities.
B. Preserve and enhance the aesthetic character of the City.
C. Restrict signs that overload the public's capacity to receive information or that 
violate privacy.

D. Prohibit signs which increase the probability of automobile accidents.

E. Provide distinct regulations for different districts and lodging establishments.

Morro Bay’s General Plan states, “The commercial areas of Morro Bay are composed of a wide variety of commercial uses as well as motels and some residential uses. There areas include the Downtown, the Embarcadero, Quintana Road, and North Main Street. Each has its own special character and function.” This Chapter provides different sign regulations for each individual district as defined by the General Plan. 
17.68.020 Commercial Signs and Calculations

Figure 17.021: Sign Types

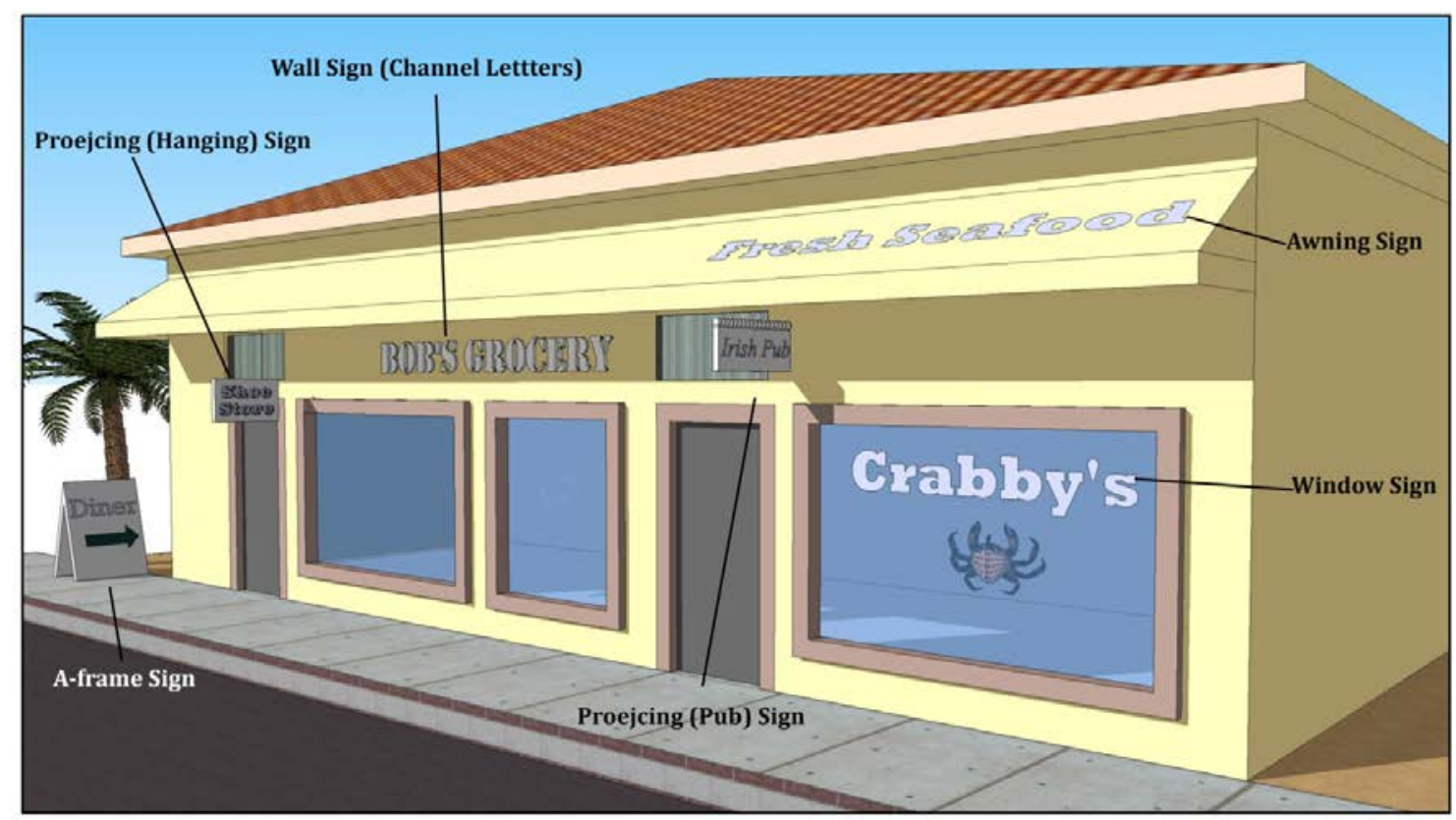

Figure 17.022: Sign Types Continued

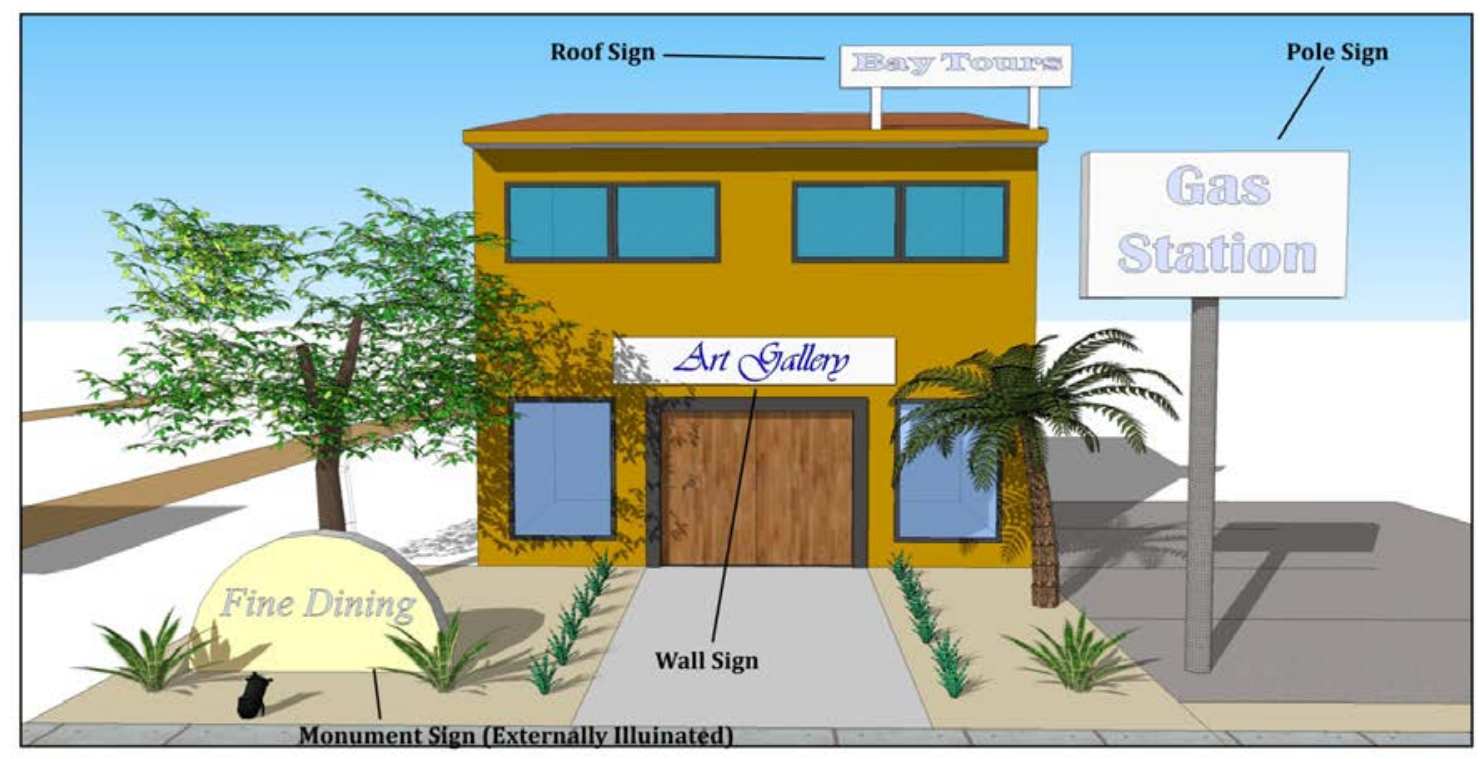




\section{A. Sign Types}

1. A-Frame Signs (Temporary Sidewalk Signs). Signs not permanently attached to the ground or any other permanent supporting structure. Where permitted, Aframe signs are subject to special regulations.

2. Attraction Board means a device used to display information regarding conveniences, services and rates currently offered by facilities providing temporary accommodation.

3. Awning and Canopy Signs. Signs painted on awnings, canopies, arcades, or similar attachments or structures. Sign area for awning and canopy signs is calculated as the area within a single continuous enclosure around only the copy area of the lettering or logo of the sign.

4. Banners. A temporary sign of fabric, plastic, paper or other light pliable material not enclosed in a rigid frame, and which is suspended, mounted, or attached to buildings or poles at two ends or continuously across its longest side so as to allow movements of the sign by atmospheric conditions.

5. Changeable Copy sign means a sign designed so that characters, letters or illustrations can be changed or rearranged without substantially altering the face or the surface of the sign. 
6. Directory Sign. A collection of signs which list names of individual businesses located in a single building, courtyard, or property.

7. Externally Illuminated Signs. A sign that is illuminated by a light source not attached to the sign.

8. Internally Illuminated Signs. A sign which radiates light from any internal source or is backlit.

9. Marquee Sign. A projecting sign that is part of a permanent entryway or canopy and traditionally associated with theaters. A marquee may include a projecting vertical sign extending above the cornice line of a building. See "Projecting Signs" below.

10. Monument Signs. A sign erected on the ground or on a monument base designed as an architectural unit (and not attached to a building). Monument signs shall not interfere with safety sight angles on corners and at driveways.

11. Pole Signs. A freestanding sign erected on top of a pole (and not attached to a building).

12. Projecting Signs (Pub Signs). Signs under canopies or covers in conjunction with pedestrian walkways, or signs projecting from the building wall.

13. Roof Signs. Signs erected upon, over or above the roof of a building or structure, or any sign affixed to the wall of a building so that it projects above the eave line of a roof.

14. Snipe Sign. An off-site sign which is tacked, nailed, posted, pasted, glued or otherwise attached to trees, poles, stakes, fences or to other objects.

15. Temporary Sign. A sign or advertising display designed or intended to be 
displayed for a short period of time.

16. Wall Signs (Surface Signs). Wall surface signs include any sign attached to, erected against or painted upon the wall of a building or structure, the face of which is in a single plane parallel to the plane of the wall. Wall signs also include signs on a false or mansard roof.

17. Window sign means any sign placed inside or upon a window facing the outside and which is intended to be seen from the exterior.

\section{B. Computation of Sign Area}

1. Single-faced Signs. The sign area of signs with sign faces on a single plane and viewable from only one side of the plane shall be measured as the entire area within a single continuous perimeter composed of squares or rectangles that enclose the extreme limits of all sign elements including, but not limited to, sign structures or borders, written copy, logos, symbols, illustrations, and color.

2. Double-faced Signs. Double-faced signs with sign faces that are parallel (backto-back) and a distance of less than three feet apart, or sign faces that have an interior angle of 45 degrees or less, shall be counted as a single sign with only one face measured in calculating sign area. Where the faces are not equal in size, the larger sign face shall be used as the basis for calculating sign area.

3. Multi-faced Signs. The sign area of signs with three or more sign faces, or signs with two sign faces with a distance greater than three feet apart or an interior angle greater than 45 degrees, shall be calculated as the sum of all the sign faces.

4. Three-dimensional Signs. Signs that consist of, or have attached to them, one or 
more three-dimensional objects (i.e., balls, cubes, clusters of objects, sculpture, or statue-like trademarks), shall have a sign area of the sum of two adjacent sides or sign faces.

Allowable sign area and sign types are designated by District. See Figure 17.031 to determine what district your business is located in. 
Figure 17.023: Measurement of Sign Area

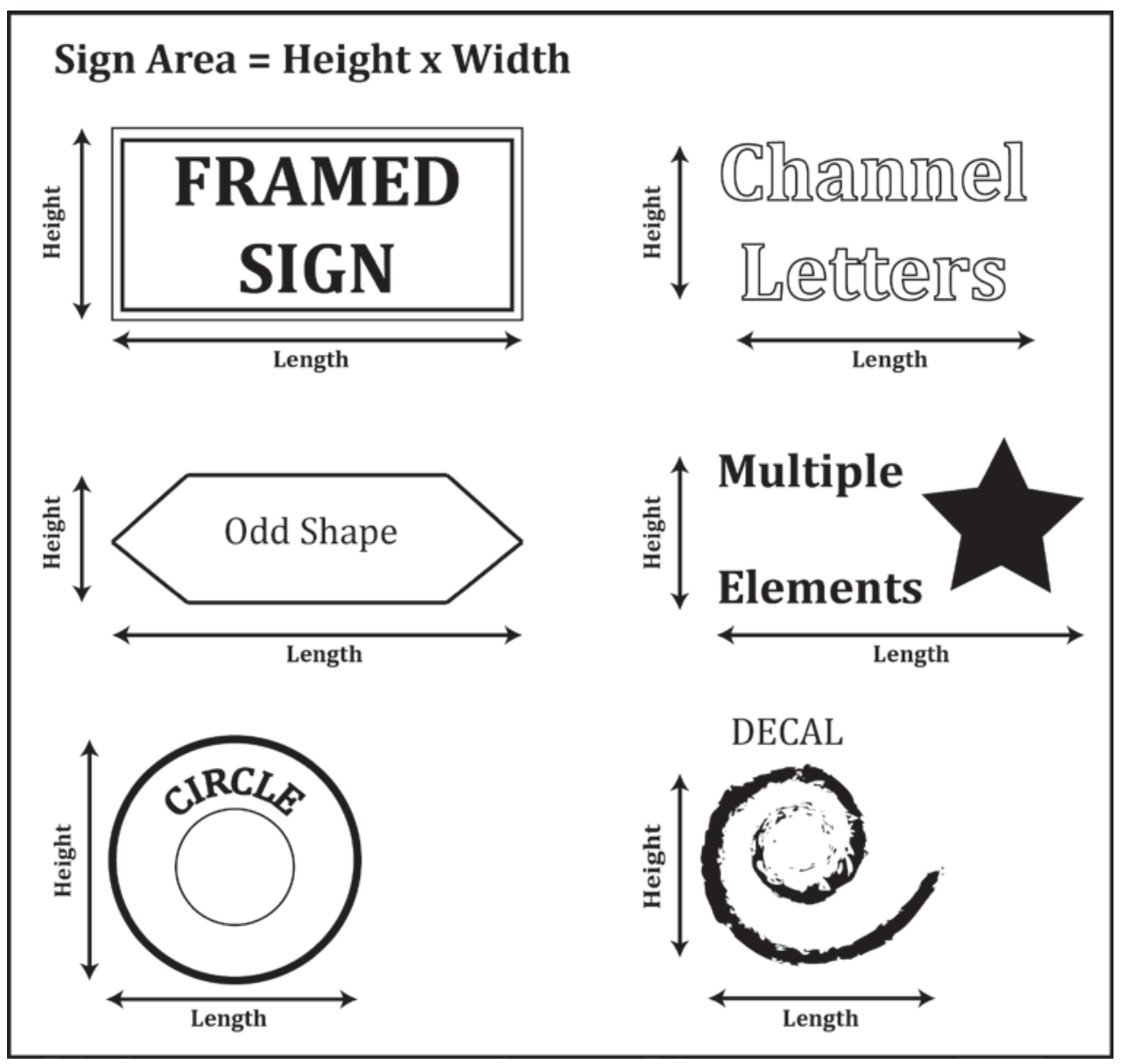

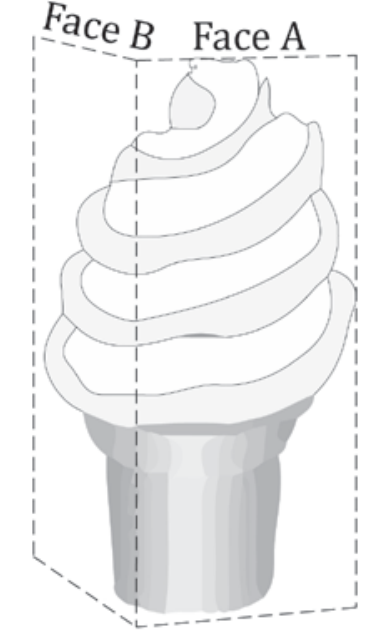

Sign Area $=$ Sum of two adjacent sides

Three-Dimensional Signs

Figure 17.024: Measurement of Double and Multi-Faced Signs

\begin{tabular}{|c|c|}
\hline & Total Sign Area = Sum of All Sign Faces \\
Double-Faced Signs \\
Total Sign Area = One Sign Face \\
\hline
\end{tabular}




\section{Computation of Facades}

"Façade" = (Building Frontage $x$ Building Height)

*For the purposes of this Ordinance, "building height" shall not include the roof

*For definition of "Building Frontage" see Section 17.68.120.
Figure 17.025: Façade Calculations

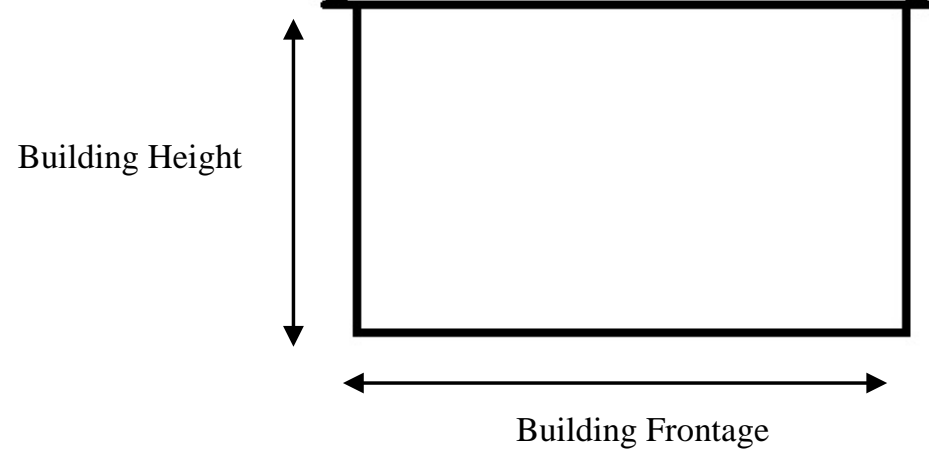

\subsubsection{Standards for ALL Districts and Zones}

The following principles and regulations apply to all districts, zones, and areas within the

City. No area in the City is exempt from the provisions listed in the following section.

See other applicable commercial sign standards: (1) Determine appropriate district (using

Figure 17.031)

(2) View table that applies to the appropriate district (Sections.17.68.040-17.68.070). For Lodging Establishments see Section 17.68.080.

\section{A. Design Principles}

The following principles are general criteria that should be considered in the design of all signs. Creative design is strongly encouraged, and signs should make a positive contribution to the aesthetic appearance of the street or commercial area where they are located. These principles will be used in reviewing and approving proposed signs and 
Master Sign Programs (see Section 17.68.100).

1. Visibility. A sign should be conspicuous and readily distinguished from its surroundings.

2. Legibility. The size and proportion of the elements of the sign's message, including logos, letters, icons and other graphic images, should be selected based on the average distance and average travel speed of the viewer. Sign messages oriented towards pedestrians may be smaller than those oriented towards automobile drivers. Colors chosen for the sign text and/or graphics shall have sufficient contrast with the sign background in order to be easily read during both day and night hours.

3. Readability. A sign message should be easily recognized and designed in a clear, unambiguous and concise manner, so that a viewer can understand or make sense of what appears on the sign. Excessive use of large areas of several colors can create competition for the eye and significantly reduce readability.

4. Architectural Compatibility. A sign (including its supporting structure, if any) should be designed as an integral design element of a building's architecture, and should be architecturally compatible, including color and scale, with any building to which the sign is to be attached and with surrounding structures. A sign which covers a window, or which spills over "natural" boundaries or architectural features and obliterates parts of upper floor of buildings is detrimental to visual order and may not be permitted. 
5. Consistency with Area Character. A sign should be consistent with distinct area or district characteristics and incorporate common design elements such as sign materials or themes. Where signs are located in close proximity with a residential area, the sign should be designed and located so they have little or no impact on adjacent residential neighborhoods.

\section{B. Construction, Maintenance, Abandonment and Removal}

\section{Construction and Maintenance}

a. Unless exempt, signs and supporting structures shall be installed in accordance with the Building Code.

b. All signs, together with all supporting structures, shall be maintained in the following manner:

i. Signs shall be kept free of rust, dirt and chipped, cracked or peeling paint.

ii. All hanging, dangling, torn or frayed parts of signs shall be promptly repaired and graffiti and unauthorized attachments shall be removed.

iii. Burned-out illumination shall be replaced immediately.

iv. Sign areas shall be kept free and clear of all noxious substances, rubbish, and weeds.

c. If a sign is removed from its supporting structure for longer than 60 days, the supporting structure shall be removed.

d. Every sign, including those signs for which no permit is required, together 
with all supports braces, guys and anchors shall be maintained in a safe, presentable and good structural condition at all times. The display surfaces of all signs shall be kept neatly painted, posted or otherwise maintained at all times. The owner of property on which the sign is located shall be responsible for the condition of the area in the vicinity of the sign, and shall be required to keep this area clear, sanitary and free from noxious or offensive substances, rubbish and flammable waste materials.

2. Abandonment. The following signs shall be presumed to be abandoned:

a. Located on Property. Any sign which is located on property that becomes vacant and is unoccupied for a period of 60 days or longer.

b. Unrelated to Property. Any sign which was erected for an occupant or business unrelated to the present occupant or business, except existing, nonconforming outdoor off-site freestanding signs.

c. Time, Event or Purpose Sign. Any sign which pertains to a time, event or purpose which no longer exists.

d. Temporarily Suspended Business. Permanent signs applicable to a business temporarily suspended because of a change of ownership or management of such business shall not be deemed abandoned unless the property remains vacant for a period of 60 days or more.

3. Removal. Abandoned signs are found to be a public nuisance due to their misleading and distracting nature and due to their contributing to visual blight, 
detrimental to surrounding areas and the community generally. An abandoned sign face is prohibited and shall be removed by the property owner.

\section{Provisions for Nonconforming and Illegal Signs}

1. Existing Non-conforming Signs. Signs existing at the time of adoption of this Title, that do not comply with the provisions of this Chapter but that were legally erected pursuant to applicable state and city ordinances in effect at the time of construction, shall be regarded as nonconforming signs, subject to the following:

a. Use Change. Whenever the type of business or use changes with which a nonconforming sign is associated, the nonconforming sign associated with business shall be removed or otherwise made to conform to the provisions of this Chapter. An example of a change in use is a traveler-serving amenity (such as a gas station or convenient store) becoming a resident-serving amenity (such as a furniture or clothes store).

b. Limited Expansion. A nonconforming sign may not be expanded, extended, reconstructed, or altered in any way in its location or orientation to enable it to be read or viewed from a different direction than its original position. Except in the following cases:

i. Changes in sign face, copy, graphic design or color are permitted provided that such sign not be removed.

ii. If change in ownership of the business occurs, without any change to the type of business advertised by a nonconforming sign, the new owner may change any name or names on such sign provided that 
there is no change in the sign size, configuration or orientation.

c. Other Requirements. Nonconforming signs are also subject to the provisions of Chapter 17.56: Nonconforming Uses and Structures.

2. Illegal Signs. Whenever a sign is found to be erected or maintained in violation of any provision of this Chapter, this Title, or any other Federal, State, or local law, and such sign is not a nonconforming sign (e.g. it was a legal sign under the sign regulations in effect prior to adoption of the ordinance codified in this Chapter), the Director shall order that such sign be altered, repaired, reconstructed, demolished or removed, as may be appropriate, to abate such condition or the Director may initiate proceedings to abate the sign as a public nuisance under the provisions of the Business and Professional Code (Sections 5499.1 to 5499.16). Any work required to be done shall be completed within ten days of the date of such order, unless otherwise specified in writing. 


\section{General Sign Standards (Commercial and Non-Commercial)}

\section{Attraction Boards for Hotels. Motels and Bed and Breakfast}

Establishments. An attached or detached attraction board, not to exceed five square feet in sign area, is allowed, provided it is included within the calculation of the maximum allowable sign area for a hotel, motel, or bed and breakfast establishment.

2. Announcement Signs. One sign, not exceeding 16 square feet in area and 6 feet in height, per street frontage on real property where construction, structural alteration or repair is to take place, or is taking place, which contains information regarding the purpose for which the building is intended and the individuals connected with the project, including names of architects, engineers, contractors, developers, finances and tenants. Announcement signs are exempt only for the duration of the construction of the building and shall be removed prior to issuance of a certificate of occupancy.

\section{Awning and Canopy Signs.}

a. Maximum Height. 25 feet above a sidewalk or public right-of-way.

b. Marquee Signs. Removable copy may be changed on the face of permitted marquee signs without securing a sign permit.

c. Maximum Height. Marquee signs may not project above the marquee face.

4. Change of Business Signs. A temporary attachment or covering of wood, plastic, or canvas over a permanent sign indicating a change of ownership or activity may be displayed no longer than 30 days following the change of ownership or activity for which the sign is intended, or up to 90 days following 
issuance of a building permit. The sign shall be no larger than the previously permitted permanent sign.

5. Civic Event Signs. Temporary signs announcing a campaign drive or event of a civic, public, quasi-public, philanthropic, educational or religious organization.

a. Maximum Sign Area. 32 square feet.

b. Maximum Time Period. 30 days. Such signs shall be removed within 15 days after the event.

6. Clearance from Utilities. Signs and their supporting structures shall maintain clearance and not interfere with electrical conductors, communications equipment or lines, surface and underground facilities and conduits for water, sewage, gas, electricity and communications equipment or lines. Signs shall not be placed in public utility easements unless express written permission from the affected public utility is obtained.

7. Directional and Community Promotional Display Programs. Directional and community promotion sign programs advertising, directing or informing pedestrian of business service or community events and services not related to or located on the site shall be permitted on private property in C districts, and on public land with the granting of an encroachment permit.

8. Drainage. The roofs of canopies or marquees exceeding 25 square feet shall be drained to prevent dripping or flow onto public sidewalks or streets and shall be connected to an approved disposal source of adequate conductors.

9. Encroachment into Public Street or Sidewalk. Any sign projecting over a 
public street or sidewalk requires approval of the Director or City Engineer, except that projecting signs and pole signs are allowed a maximum encroachment of 12 inches over a public street or sidewalk subject to approval of an encroachment permit.

10. Equipment Signs. Signs, not more than eight square feet in sign area, incorporated into displays, machinery, or equipment by a manufacturer, distributor, or vendor that identify or advertise only the product or service dispensed by the machine or equipment, such as signs customarily fixed to automated teller machines (ATMs), gasoline pumps, menu boards, and umbrellas. If a vending machine is visible from the street, the sign area shall be included in the total sign area allowed for the use.

11. Flags. Flags and insignia of any government, except when incorporated into a commercial sign, are permitted.

12. Illumination. Signs with any type of illumination are subject to all of the following standards:

a. All lighting is subject to necessary electrical permits.

b. All newly fabricated signs shall incorporate LEDs or equally energy efficient light source.

c. Illuminated signs shall not be switched ON during daylight hours. All newly fabricated signs shall incorporate an automatic on/off switch.

d. All illuminated signs shall be turned off at $10 \mathrm{PM}$ or at the time the business closes.

e. External lighting shall be properly shielded to prevent glare upon an 
adjacent public right-of-way or adjacent property.

f. Illumination shall be constant in intensity and color and shall not consist of flashing, animated or changing lights.

g. Illumination shall not be distracting to pedestrians, motorists, or neighboring property.

h. No sign shall emit or reflect light exceeding ten foot-candle power at ten feet from the face of the sign.

13. Garage Sale Signs. One unlighted sign is permitted for garage sales, provided such sign does not exceed four square feet in area and is displayed on the property where such sale shall take place only on the day of the sale.

14. Materials. All signs shall be made of substantial materials that are not subject to rapid deterioration.

15. Mobile Home Parks. A mobile home park may be allowed one externally illuminated or non-illuminated identification sign, not to exceed the equivalent of one square foot of sign area per ten linear feet of frontage on each right-ofway upon which it takes vehicular access. No sign shall have a surface area of greater than 30 square feet, a height of 8 feet, or be erected at right angles to the right-of-way.

16. Mobile Vendor (Non-permanent Vendor) Signs. Signs fixed to mobile vending carts that identify or advertise the name, product, or service provided by the vendor. Each mobile vending cart is limited to a maximum sign area of eight square feet. 


\section{Monument Signs}

a. Maximum Height 5' (five feet)

b. Minimum Setbacks: One (1) foot from setback line.

c. Landscaping. Signs shall be placed in a landscaped planter or berm. As a condition of any sign permit for a monument sign, additional landscaping of the site may be required to better integrate sign appearance with the site.

\section{Pole Signs}

a. Landscaping. Pole signs shall be placed within a landscaped planter with at least 28 square feet of planting area. As a condition of any sign permit for a pole sign, additional landscaping of the property may be required where needed to better integrate sign appearance with the site through scale and softening effects.

b. Maximum Height. 15 feet; 20 feet within 200 feet of Highway 1, subject to approval of a conditional use permit.

19. Sign Orientation. No sign, other than a projecting sign, shall be permitted that is so oriented as to be viewed primarily across an adjacent private property line. All signs must be visible directly from a public right-of-way, other public open space or parking lot or courtyard on the same site as the sign, without view lines extending over private property different from that on which the sign is located.

20. Subdivision Signs. One sign per frontage, advertising the sale of a subdivision may be displayed on the site of the subdivision upon approval of a final map and initiation of construction for a period of one year. The display period may be extended with written approval of the Director for a reasonable period of 
time, not to exceed one year at any one time.

21. Off-Site Directional Sign. One off-site sign not to exceed 36 square feet, providing direction to real estate available for sale or lease, during daylight hours only. Permission from the property owners of the site where the sign is placed is required.

22. Real Estate and “Open House” Signs. Signs conveying information about the sale, rental, or lease of a property and the identification of the person or firm (agent) handling such sale, lease or rental, provided they comply with the following standards. Real estate and open house signs are exempt only during the period for which the property is offered for sale or lease.

23. Political Campaign Signs. Political campaign signs not to exceed sixty-four square feet in area per site and shall be permitted only on private property;

24. Parking and Directional Signs. On-site parking and directional signs, not exceeding eight square feet in sign area and five feet in height, that do not include any advertising messages or symbols.

\section{Projecting Signs.}

a. Minimum Height. 8 feet above a sidewalk or other public right-of-way. b. Maximum Height. $20 \mathrm{ft}$. above a sidewalk or other public right-of-way, but not above an eave or roof.

26. Special Private Event Displays and Grand Opening Signs. A temporary sign may be erected on the premises of an establishment having a grand opening or special event provided that such signs shall not be displayed for a period exceeding thirty calendar days previous to such event. An establishment shall 
not display such signs more than 60 days each year. Such signs shall be removed immediately after the event.

27. Official Government Signs and Legal Notices. Official notices issued by a court, public body or office and posted in the performance of a public duty; notices posted by a utility or other quasi-public agent in the performance of a public duty; historical markers erected by a governmental body; identification information; directional signs erected by government bodies; or other signs required or authorized by law.

28. Substitution of Sign Message. The owner of a permitted sign may substitute a non-commercial message for a commercial message or a commercial message for a non-commercial message.

29. Vacated Signs. Sign faces shall be removed or made blank within 60 days after the activity, product, business, service, or other use which was being advertised has ceased or vacated the premises.

30. Wall Surface Signs ("Wall” Signs). Wall signs are subject to the standards in the following table. No wall surface sign may cover wholly or partially any required wall opening.

\begin{tabular}{|l|l|}
\hline WALL SURFACE SIGN STANDARDS \\
\hline $\begin{array}{l}\text { Minimum Horizontal and Vertical Separation } \\
\text { Between Signs }\end{array}$ & $3 \mathrm{ft}$. \\
\hline Maximum Projection from Surface of Building & 12 in \\
\hline $\begin{array}{l}\text { Minimum Vertical Separation Between Sign and } \\
\text { Roof Line }\end{array}$ & $\begin{array}{l}1 \mathrm{ft} \text { (8 inches on a fascia or } \\
\text { mansard roof) }\end{array}$ \\
\hline Maximum Height & $\begin{array}{l}20 \mathrm{ft} \text { above a sidewalk or } \\
\text { Above public right-of-way. }\end{array}$ \\
\hline
\end{tabular}




\section{E. Prohibited Signs}

The following signs are prohibited in ALL districts:

1. Animated and Moving Signs. Signs that incorporate, in any manner, any flashing, moving, rotating, pulsating or intermittent lighting, with the exception of approved time and temperature displays.

2. Banners, Streamers, or Pennants. Signs, banners, pennants, valances or any other advertising display constructed of cloth, canvas, light fabric, paper, cardboard, wallboard or other light materials except for awnings and temporary signs as provided for in this Chapter.

3. Billboards. Off premises outdoor advertising signs.

4. Digital Signs. Any electronic sign that resembles a television screen or video monitor, or that can be altered or changed from a remote location.

5. Emissions. Signs that produce noise or sounds in excess of 40 decibels, excluding voice units at drive-through facilities, and signs that emit visible smoke, vapor, particles, or odor.

6. Fence Signs. Signs on fences or free-standing walls, not part of a building.

7. Obscenities. Signs that depict, describe, or relate to "specified sexual activities" or "specified anatomical areas" as defined in Chapter 17.41: Terms and Definitions.

8. Obstruction to Exits. Signs that obstruct any fire escape, required exit, window or door opening intended as a means of egress.

9. Obstruction to Ventilation. Signs that interfere with any opening required for ventilation. 
10. Signs advertising brand names. Any sign that advertises a brand name is prohibited.

11. Signs Creating Traffic Hazards. Signs located in such a manner as to constitute a traffic hazard or obstruct the view of any authorized traffic sign or signal device, or signs that may be confused with any authorized traffic sign, signal, or device; or that makes use of the words "stop”, “look”, “danger”, or any other word, phrase, symbol, or character that interferes with, misleads, or confuses vehicular drivers.

12. Snipe Signs. Off-premise signs advertising a business or service. All commercial signs shall be on property owned or leased by the business owner.

13. Signs on Public Bus Shelters or Benches. Signs located on bus shelters, benches, or similar structures provided for the use of passengers along the route of a bus, not including plaques containing the names of persons or organizations which have made gifts or donations of such street furniture.

14. Vehicle Displays. Signs placed or displayed on vehicles parked in a conspicuous location to be used for on-site or off-site advertising, with the exception of signs advertising such vehicles for sale and vehicle identification signs in locations where sale of vehicles is permitted.

15. Tire Stacks. Signs placed on stacked tires. 


\subsubsection{Embarcadero District}

Purpose. The Embarcadero District is home to many of the tourist-serving businesses in Morro Bay. The Embarcadero District contains a dense collection of restaurants, hotels, bars, museums, gift shops, and recreation-based businesses. The sign regulations for this district are intended to maintain its rustic, beach town character. This area is dominated by pedestrians; the code promotes small scale signs and projecting type signs that are oriented towards pedestrians and bicyclists. With the prohibition of window signs, the code also aims to maximize views of the bay from the street and walkways.

The following chart displays all allowable sign types and specifications for businesses located in the Embarcadero District.

- If a business is near the edge of a district, please consult Planning Staff to confirm appropriate district designation.

- If a sign type does not appear in the following table it is prohibited in this district.

- Signs advertising BRAND NAMES are prohibited in all districts.

- Signs that describe offered products or services COUNT towards total allowed signage.

- If illumination or lighting of ANY kind is proposed on or around signs, see Section 17.68.030, D-12. 
Table 17.041: Embarcadero District Regulations

\begin{tabular}{|c|c|c|c|c|c|}
\hline \multicolumn{6}{|c|}{ Embarcadero District } \\
\hline Sign Type & $\begin{array}{l}\text { Sign Area } \\
\text { Allowed }\end{array}$ & $\begin{array}{l}\text { Max. Sign } \\
\text { Area per } \\
\text { sign (sq. } \\
\text { ft) }\end{array}$ & $\begin{array}{c}\text { Total \# of } \\
\text { signs allowed }\end{array}$ & $\begin{array}{c}\text { Total } \\
\text { Max. } \\
\text { Sign } \\
\text { Area (sq. } \\
\text { ft) }\end{array}$ & $\begin{array}{c}\text { Additional } \\
\text { Regulations }\end{array}$ \\
\hline Awning and Canopy & \multirow{5}{*}{$\begin{array}{c}10 \% \text { of } \\
\text { primary } \\
\text { facade, } 5 \% \text { of } \\
\text { secondary } \\
\text { facade }\end{array}$} & 24 & \multirow{3}{*}{$\begin{array}{l}1 \text { per frontage } \\
\text { (choose one } \\
\text { type) }\end{array}$} & \multirow{5}{*}{60} & $\begin{array}{l}\text { See Section } \\
\text { 17.68.030, D-3 }\end{array}$ \\
\hline Wall (Surface) & & 24 & & & $\begin{array}{l}\text { See Section } \\
17.68 .030, \text { D-30 }\end{array}$ \\
\hline Roof & & 24 & & & $\begin{array}{l}\text { Top of sign must be } \\
\text { below maximum } \\
\text { allowed building } \\
\text { height }\end{array}$ \\
\hline $\begin{array}{l}\text { Monument } \\
\text { (Freestanding) }\end{array}$ & & 25 & 1 per frontage & & $\begin{array}{l}\text { See Section } \\
17.68 .030, \text { D-16 }\end{array}$ \\
\hline Projecting (Pub) & & 16 & 1 per frontage & & $\begin{array}{l}\text { See Section } \\
17.68 .030, \text { D-25 }\end{array}$ \\
\hline \multicolumn{3}{|c|}{ Bonuses } & & & \\
\hline Projecting (Pub) & $\begin{array}{l}\text { PLUS (+) } 8 \\
\text { sq. ft. }\end{array}$ & 16 & & & \\
\hline Wall (Surface) & $\begin{array}{l}\text { PLUS (+) } 4 \\
\text { sq. ft. for } \\
\text { Individual } \\
\text { Lettering }\end{array}$ & 28 & & & \\
\hline
\end{tabular}




\subsubsection{Downtown District}

Purpose. The Downtown District houses a combination of resident-serving and touristserving businesses. While there are many restaurants, gift shops and galleries, the district also contains banks, shopping markets, offices, and service-based businesses such as automobile repair shops. The sign regulations for this district are intended to preserve the small-town character that residents, tourists, and business owners enjoy. The code is designed to eliminate excessive signage while promoting pedestrian-oriented signs. The following chart displays all allowable sign types and specifications for businesses located in the Embarcadero District.

- If a business is near the edge of a district, please consult Planning Staff to confirm appropriate district designation.

- If a sign type does not appear in the following table it is prohibited in this district.

- Signs advertising BRAND NAMES are prohibited in all districts.

- Signs that describe offered products or services COUNT towards total allowed signage.

- If illumination or lighting of ANY kind is proposed on or around signs, see Section 17.68.030, D-12. 
A-frame Signs. The following provisions apply to A-frame signs:

1. One (1) A-frame sign per business is allowed (and will not count towards total allowable signage).

2. Signs must have the following dimensions: 2' $x$ 3' (two feet wide by three feet tall).

3. An illustration of the proposed sign shall be submitted. Signs shall be legible and consistent with other signs on the property.

4. Signs cannot advertise brand names.

5. A site layout map showing the sidewalk, buildings, and proposed A-frame location shall be submitted with the standard sign application. 
Table 17.051: Downtown District Regulations

\begin{tabular}{|c|c|c|c|c|c|}
\hline \multicolumn{6}{|c|}{ Downtown } \\
\hline Sign Type & $\begin{array}{l}\text { Sign Area } \\
\text { Allowed* }\end{array}$ & $\begin{array}{c}\text { Max. } \\
\text { Sign } \\
\text { Area per } \\
\text { sign (sq. } \\
\text { ft) }\end{array}$ & $\begin{array}{l}\text { Total \# of signs } \\
\quad \text { allowed }\end{array}$ & $\begin{array}{l}\text { Total } \\
\text { Max. } \\
\text { Sign } \\
\text { Area } \\
\text { (sq. ft) } \\
\end{array}$ & $\begin{array}{c}\text { Additional } \\
\text { Regulations }\end{array}$ \\
\hline Awning and Canopy & \multirow{5}{*}{$\begin{array}{c}10 \% \text { of } \\
\text { primary } \\
\text { facade, } 10 \% \\
\text { of secondary } \\
\text { facade }\end{array}$} & 48 & \multirow{3}{*}{$\begin{array}{l}1 \text { per frontage } \\
\text { (choose one type) }\end{array}$} & \multirow{5}{*}{100} & $\begin{array}{l}\text { See Section } \\
17.68 .030, \mathrm{D}-3\end{array}$ \\
\hline Marquee & & 80 & & & $\begin{array}{l}\text { See Section } \\
\text { 17.68.030, D-25 }\end{array}$ \\
\hline Wall (Surface) & & 48 & & & $\begin{array}{l}\text { See Section } \\
17.68 .030, \mathrm{D}-30\end{array}$ \\
\hline $\begin{array}{l}\text { Monument } \\
\text { (Freestanding) }\end{array}$ & & 25 & 1 per frontage & & $\begin{array}{l}\text { See Section } \\
17.68 .030, \mathrm{D}-16\end{array}$ \\
\hline Projecting (Pub) & & 16 & 1 per frontage & & $\begin{array}{l}\text { See Section } \\
17.68 .030, \mathrm{D}-25 \\
\end{array}$ \\
\hline \multicolumn{3}{|c|}{ Bonuses } & & & \\
\hline Projecting (Pub) & $\begin{array}{l}\text { PLUS (+) } 8 \\
\text { sq. ft. }\end{array}$ & 16 & & & \\
\hline Wall (Surface) & $\begin{array}{l}\text { PLUS (+) } 4 \\
\text { sq. ft. for } \\
\text { Individual } \\
\text { Lettering }\end{array}$ & 28 & & & \\
\hline A-Frame & \multicolumn{2}{|c|}{$\begin{array}{c}\text { See A-frame sign } \\
\text { specifications below }\end{array}$} & & & \\
\hline
\end{tabular}




\subsubsection{Quintana Road District}

Purpose. The Quintana Road District contains many of the City’s larger commercial buildings, strip malls, and gas stations. Due to the existence of large parking lots and the adjacent Highway 1, this district is auto-oriented. The sign regulations for this zone focus on allowing large-scale commercial and industrial businesses adequate signs that are proportionate to the associated structures. The regulations also promote motorist safety by requiring that signs are clear and legible from the road.

\subsubsection{North Main District}

Purpose. The North Main District is composed of industrial, commercial, and mixed use zones. While pedestrian and bicycle activity is present, this district is auto-oriented. The regulations for this district promote signs that are appealing to pedestrians, bicyclists, and automobiles. The regulations for this district also intend to increase the aesthetic quality of signs that are visible from Highway 1.

\subsubsection{Lodging Establishments}

Purpose. The following regulations apply to lodging establishments in ALL districts. Lodging establishments in the City are located in both residential and commercial zones, and have unique requirements that do not coincide with signage needs of other types of businesses. The regulations in this section are intended to promote signs that attract potential customers and that are also appealing to both residents and tourists 
Attraction Boards for Hotels. Motels and Bed and Breakfast Establishments. An attached or detached attraction board, not to exceed five square feet in sign area, is allowed, provided it is included within the calculation of the maximum allowable sign area for a hotel, motel, or bed and breakfast establishment.

\subsubsection{Sign Permits}

\section{A. Zoning Clearance or Sign Permit Required}

1. Authority. No sign, other than an exempt sign, shall be erected or altered, without first obtaining a zoning clearance or sign permit from the Director. The Director may attach reasonable conditions on the approval of the sign permit to help ensure compliance with this Chapter. These conditions may require the removal, modification or relocation of existing signs where the proposed sign(s) would be located on sites where existing signs are nonconforming.

2. Application Requirements. Applications for a sign permit shall be made in writing upon forms furnished by the Director, accompanied by the required fee and plans drawn to scale and with all of the following information. Where the scale and scope of the sign proposal so warrants, the Director may waive some of the informational requirements listed below, provided all information necessary for adequate review of the proposal is submitted.

a. The proposed design, dimensions, copy, color, lighting methods and location of the sign on the site, including the dimensions of the sign's supporting 
members, and details of all connections, guy lines, supports and footings, and materials to be used.

b. The maximum and minimum height of the sign.

c. The location of off-street parking facilities, including entries and exits where directional signs are proposed.

d. The size and dimension of all signs existing on the site.

e. The location and horizontal frontage of any building(s) on the property, both existing and proposed.

f. Any other information deemed necessary by the Director.

\section{B. Required Findings. In approving a sign permit, the Director must find that:}

1. The sign conforms to the design principles and standards of this Chapter.

2. Signs on all proposed buildings or new additions to existing buildings are designed as an integral part of the total building design.

3. The location of the proposed sign and the design of its visual elements (lettering, words, figures, colors, decorative motifs, spacing and proportions) are legible under normal viewing conditions that prevail where the sign is to be installed.

4. Review of signs at city entryways as defined in the Scenic Highway Element of the General Plan shall also be subject to the following provisions: 
a. Sign area, height and location of signs shall be designed so as not to interfere with view corridors as defined and specified in the General Plan/Local Coastal Plan.

b. Freestanding signs shall not exceed eight feet in height except within two hundred feet of Highway 1 or Highway 41. Where feasible, all freestanding signs within or along city entryways shall be placed within a landscaped planter.

\subsubsection{Master Sign Program}

A. Applicability. Any site having four or more non-residential occupants shall submit a master sign program to be reviewed and approved by the decision-making authority for the use (e.g. the Director or the Planning Commission). Any site having three or fewer non-residential occupants may submit a master sign program to be reviewed and approved by the decision-making authority. Additionally, projects involving construction or renovation of more than 25,000 square feet of space in the commercial and mixed use districts shall submit a master sign program which must be approved prior to issuance of any occupancy permit.

B. Application Requirements. Applications for approval of a master sign program shall be submitted to the Director and shall include the following:

1. Master Sign Program. A Master Sign Program, drawn to scale, delineating the site proposed to be included within the signing program and the location of all 
proposed signs.

2. Drawings and Sketches. Drawings and/or sketches indicating the exterior surface details of all buildings on the site on which wall signs, directory signs, ground signs or projecting signs are proposed.

3. Statement for Modifications. A statement of the reasons for any requested modifications to the regulations or standards of this Chapter.

4. Sign Standards. A written program specifying sign standards, including color, size, construction details, placement, and necessity for City review for distribution to future tenants.

C. Allowable Modifications. A Master Sign Program may provide for additional sign area and other deviations from the standards of this Chapter, provided that the Master Sign Program is consistent with the provisions of all Sections in this Chapter.

D. Required Findings. In approving a Master Sign Program, the decision-making authority shall find that all of the following are met:

1. The proposed signs are compatible in style and character with any building to which the sign is to be attached, any surrounding structures, and any adjoining signage on the site;

2. Future tenants will be provided adequate opportunities to construct, erect or maintain a sign for identification; and

3. All current and future tenants shall be granted adequate advertisement space on the property's primary frontage. 
4. Directional signage and building addressing is adequate for pedestrian and vehicular circulation and emergency vehicle access.

E. Conditions of Approval. The Planning Commission may attach any reasonable conditions necessary to carry out the intent of the Master Sign Program requirement, while still permitting each sign user opportunities for effective identification and communication.

\section{F. Administrative Approval of Signs Consistent with Master Sign Program.}

Following approval of a Master Sign Program, the Director is authorized to issue building permits or other permits, as deemed necessary, to install signs that conform to an approved Master Sign Program. Minor modifications of individual sign area may be approved, provided the maximum allowed by an approved Master Sign Program is not exceeded.

\subsubsection{Appeals}

A. Persons Who May Appeal. Except as provided for elsewhere in this Title, appeals may be made by the following persons, in the following instances:

1. Local Appeals. Appeals to the Planning Commission or City Council may be filed by the applicant, by the owner of property, or by any other person aggrieved by a decision that is subject to appeal under the provisions of this Title. 
B. Final Decision Required. Unless otherwise specified by Federal or State law, an appeal must be brought and a final decision rendered by the hearing body before the matter may be appealed to a court of law.

C. Time Limits. Unless otherwise specified in State or Federal law, all appeals shall be filed within 10 days of the date of action.

D. Proceedings Stayed by Appeal. The timely filing of an appeal shall stay all proceedings in the matter appealed, including, but not limited to, the issuance of City building permits and business licenses.

E. Appeals of Director Decisions. A decision of the Director on any application may be appealed to the Planning Commission by filing a written appeal with the Planning Department. The appeal shall identify the decision being appealed and shall clearly and concisely state the reasons for the appeal.

F. Appeals of Planning Commission Decisions. Decisions of the Planning Commission may be appealed to the City Council by filing a written appeal with the City Clerk. The appeal shall identify the decision being appealed and shall clearly and concisely state the reasons for the appeal.

G. Transmission of Record. The Director, or in the case of appeals to the City Council, 
the City Clerk, shall schedule the appeal for consideration by the authorized appellate body within 60 days of the date the appeal was filed. The Director shall forward the appeal, the Notice of Action, and all other documents that constitute the record to the appellate body. The Director also shall prepare a staff report that responds to the issues raised by the appeal and may include a recommendation for action.

H. Appellate Body Action. The appellate body shall review the appeal, the administrative record, and any written correspondence submitted after the appeal has been filed, and may take one of the following actions:

1. Conduct a public hearing and decide on the action; or

2. Remand the matter to the decision-making body or official to cure a deficiency in the record or the proceedings.

I. No "De Novo" Review. At an appeal or review, the appellate body shall consider only the same application, plans, and related project materials that were the subject of the original decision.

J. Appellate Body Decision. The appellate body shall render its decision within 60 days of the date the hearing is closed unless State law requires a shorter deadline. An action to grant an appeal shall require a majority vote of the appellate body members. A tie vote shall have the effect of rejecting the appeal.

K. Standards of Review. When reviewing any decision on appeal, the appellate body shall use the same standards for decision-making required for the original decision. 
The appellate body may adopt the same decision and findings as were originally approved.

\subsubsection{Definitions}

Abandoned Sign. A sign that no longer applies to a business space, building, or site, due to lack of a valid business license, change of business name, or for any other reason that renders the sign not applicable to the premises involved.

Building Mounted Sign. Any sign mounted or erected on or against any building or façade and includes all walls signs, awning and canopy signs and projecting signs. Business Sign. Any interior or exterior sign which is intended to identify the name or portions of the business name and which is viewable from any exterior area open to the public.

Canopy shall refer to an ornamental roof like structure upon which a sign may be attached or otherwise affixed which is usually located over gasoline pumps.

Construction Sign. A sign displayed by a contractor, subcontractor, or architect on a project site whenever a building permit has been issued for construction, alteration, or repair of a structure and when work is in progress on site pursuant to such permit. Building frontage constitutes for purposes of computing allowable sign area, the linear measurement in feet of the property line directly fronting on a public street, or other public right-of-way to which such sign is oriented, excluding California State Highway One. 


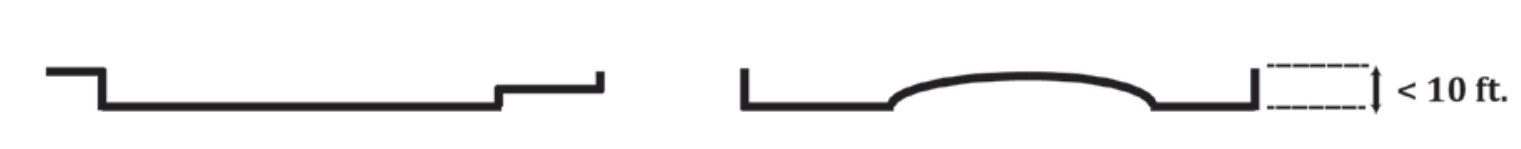

Building frontage is considered continuous if projections are less than $10 \mathrm{ft}$.

Height of a sign means the greatest vertical distance measured from the ground level directly beneath the sign to the top of the sign or from the nearest property line fronting on a public street, whichever is lower.

Master Sign Plan. A coordinated program of all signs, including exempt and temporary signs for a business, or businesses if applicable, located on a development site. The sign program shall include, but not be limited to, indications of the locations, dimensions, colors, letter styles and sign types of all signs to be installed on a site.

Nonconforming Sign. Any sign that existed prior to a change in the municipal code that prohibits such signs or any sign installed without approval from the City that requires approval by the City.

Open House Sign. An open house sign advertises that a house is open for view as part of the sale or exchange of the property.

Billboard (Outdoor-off-site freestanding sign). A sign placed for the purpose of advertising products or services that are not produced, stored or sold on the property or any other subject no related to the property or use of the property, upon which the sign is located.

Real Estate Sign. A sign identifying that a property is for sale, lease, exchange, or rent. The purpose of this sign is to help owners in the sale of their property by providing information on the location of the property to potential buyers without impairing the 
appearance of the community.

Signs. Any object, structure, symbol, emblem, logo, or display, or any combination thereof, which is intended to or does identify, attract attention to, advertise, or communicate information of any kind to the public. See also Chapter 17.68: Signs.

Sign Area. The entire area of a sign calculated for maximum sign area purposes, pursuant to Chapter 17.68:

Sign Face. The surface or surfaces used for the display of a sign message as seen from any one direction. 


\section{PART C}

CITY OF MORRO BAY, CALIFORNIA

Embarcadero District Tourism-Oriented Directional Sign Plan

\section{BACKGROUND REPORT}

Prepared by

Erik Berg-Johansen, Intern Planner

June 2013 
TABLE OF CONTENTS

\section{CHAPTER 1: PROJECT BACKGROUND}

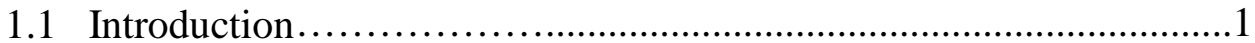

1.2 Directional Signs....................................................................

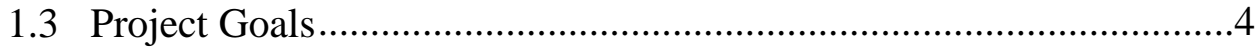

\section{CHAPTER 2: REAL WORLD EXAMPLES}

2.1 Evidence from Scholarly Articles .......................................6

2.2 King City, CA Directional Signage Program..............................8

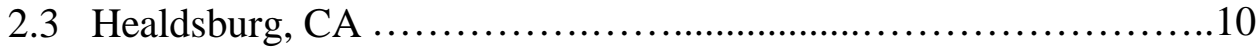

\section{CHAPTER 3: DESIGN AND IMPLEMENTATION}

3.1 Community Outreach............................................13

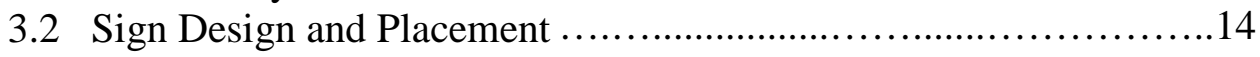

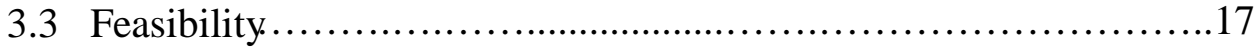

3.4 Implementation .....................................................

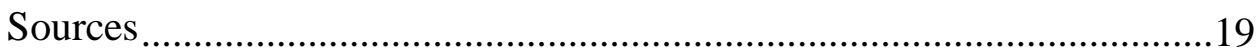




\section{Chapter 1: Project Background}

\subsection{Introduction}

Morro Bay, California is by all standards a desirable tourist destination. Located on an upward sloping hill, residents and tourists enjoy views of the Pacific Ocean, Morro Rock, and a calm bay that houses sail boats, sea lions, and otters. Tourism is an important industry in Morro Bay, and this plan has the potential to further enhance the economic viability of this industry in the future. This document includes research about signs, and also the reasoning behind the decisions made during the process of crafting the "Embarcadero District Tourism-Oriented Directional Sign Plan."

The City of Morro Bay, California is located on California's coastline halfway between San Jose and Los Angeles. The City was founded by farmer, businessman, and politician Franklin Riley, who came to the area in the 1860 s to establish a homestead. In 1872 Riley and his friend Carolan Mathers, a surveyor by trade,

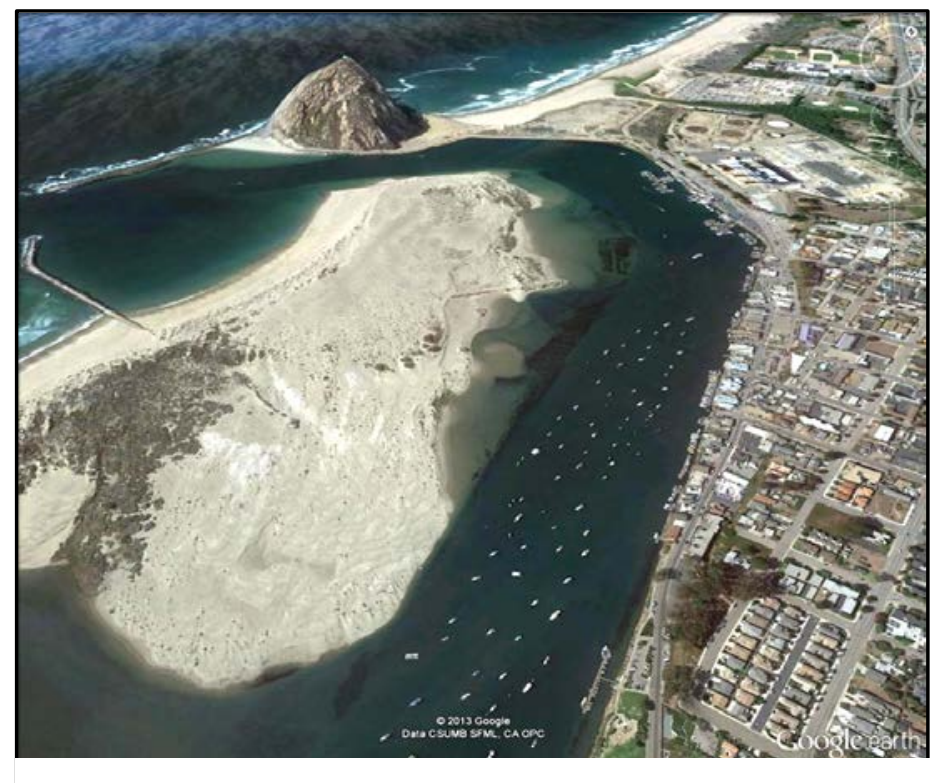

Figure 1.1: Morro Bay, Morro Rock, and the Embarcadero designed the street layout for the future city of Morro Bay. It is said that in the 1920s, Paul and Mary Whitlock discovered the tourism potential of an area with natural beauty and a temperate climate. They built a home, cleared land for a campground, and set up a first-aid station in their home to provide assistance to both locals and visitors (Castle, 2006, p. 9, 21). Perhaps Morro 
Bay’s thriving tourism today is owed to the Whitlock family who discovered Morro Bay nearly 80 years ago.

Today, Morro Bay is a much different place from the farming village it once was. According to the 2010 U.S. Census, the City of Morro Bay has a population of 10,234. This population spikes significantly during the spring and summer seasons when tourists flock to the beaches to escape the heat and enjoy all that Morro Bay has to offer.

According to the City of Morro Bay Chamber of Commerce, the estimated number of motel visitors in July of 2012 was 41,317, more than four times the current population of the City. This spike in motel visitors strongly correlates with the amount of car traffic observed on California State Route 1 where it intersects with Highway 41 in Morro Bay

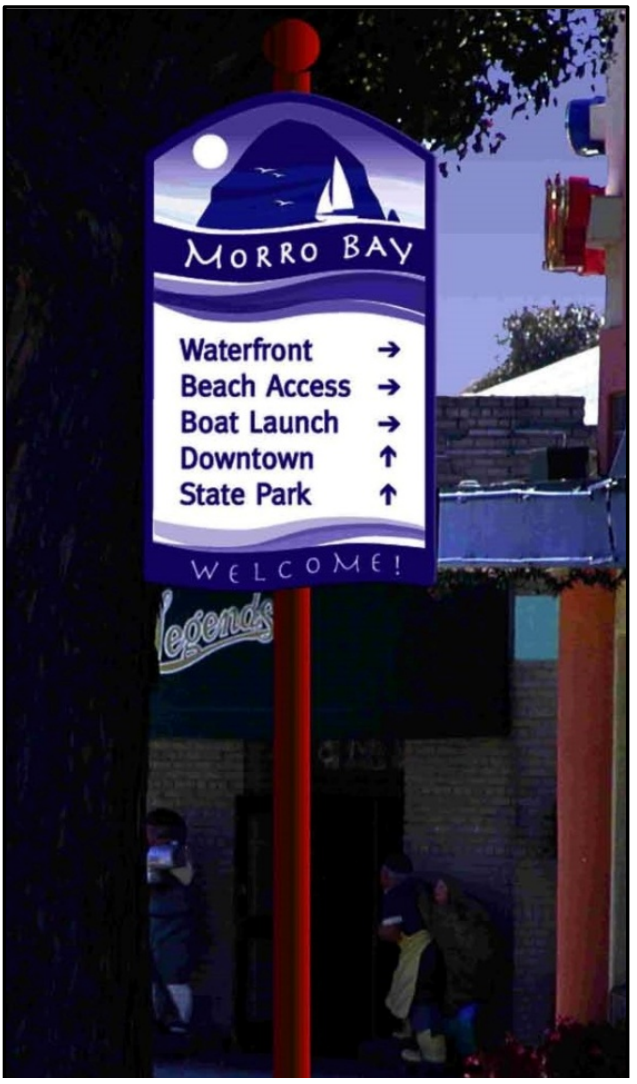

Figure 1.2: Traditional Directional Sign (Appendix 1.1). On the other hand, in January of 2012 it was estimated that only 9,305 visitors stayed in motel rooms, and less than half the volume of car travel observed in July 2012 was present. 

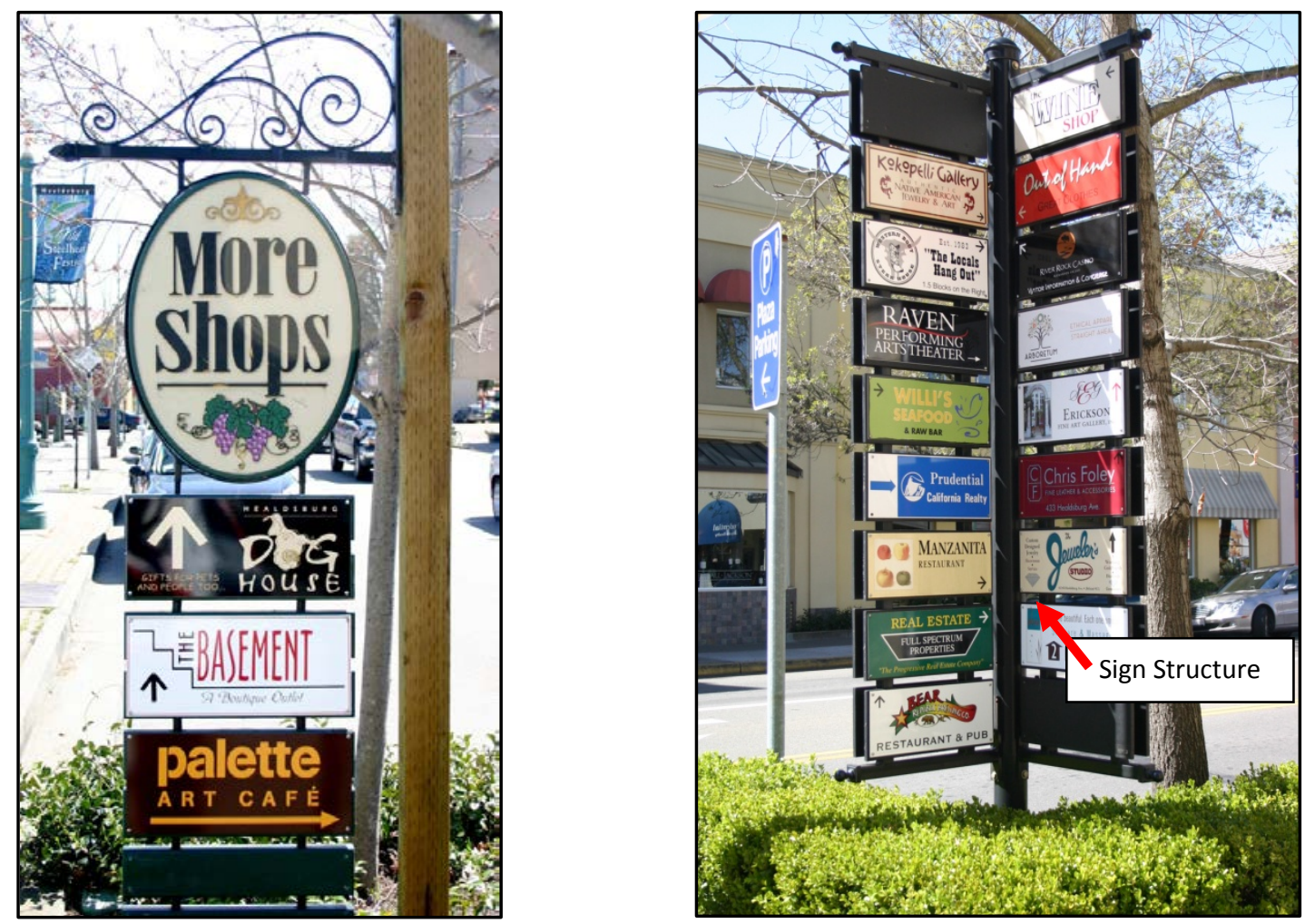

Figure 1.4: Business Directional Signs

\subsection{Directional Signs}

Tourism-oriented directional signs (or wayfinding signs) are used to help tourists navigate through cities. Directional signs are most commonly used to guide tourists towards areas of interest such as beaches, downtown commercial districts, parks, and sites with historic significance (see Figure 1.2 on page 2). Although public directional signs of this kind are discussed, this plan focuses primarily on directional signs that display the names and services of local businesses (see Figures 1.3 and 1.4). According to Morro Bay’s Businsess Database (2013), there are 45 hotels and motels, and 55 restaurants within the City to support tourism (Morro Bay Economic Development Program). These proposed directional signs are designed to make tourists aware of these businesses, and especially ones they may have missed while walking, biking, or driving through Morro Bay’s Embarcadero district. 


\subsection{Project Goals}

The primary goal of the Embarcadero Tourism-Oriented Directional Sign Plan (TODSP) is to improve the overall tourism industry in the City of Morro Bay, CA. Working in tandem with an updated sign ordinance, it is expected that these proposals could benefit the City in the future. Due to the fact that city budgets are tight in the current economic conditions, the main focus of the plan will be to minimize implementation costs while maintaining a certain level of effectiveness. Strategically placing only a few sign posts on the Embarcadero will have a minimal impact on both the budget and the City’s natural aesthetic qualities. Furthermore, Morro Bay's local economy today is partially based on the oyster farming and fishing industries. If overfishing and ocean acidification trends continue, the City may need to rely more heavily on tourism to support the economy. Research themes explored during this project are summarized as follows:

- Sign design features (aesthetics) that fit local character

- International symbology with the ability to convey messages to non-English speakers

- The use of directory signs for wayfinding

- Strategic placement of directional signs

- Key tourism areas and neglected tourist areas (due to poor location)

- Circulation patterns (where do tourists enter the City?)

- $\quad$ Parking areas for visitors

- $\quad$ Signage that targets pedestrians

- Feasibility / implementation costs

The final product of this project is a Tourism-Oriented Directional Sign Plan that focuses on providing geographical information to tourists in regards to businesses and points of interest in the Embarcadero district. These signs will be designed to allow advertisement of businesses and 
their locations at an off-premise location. Although all businesses will be given an opportunity to be featured on a sign, these proposed signs will especially benefit businesses that lack visible storefronts, awarding them an increased chance of being discovered by tourists. Furthermore, implementation of directory maps along the Embarcadero is proposed. The use of directory maps in combination with business directional signs will allow tourists to orient themselves on the Embarcadero and successfully navigate to desired destinations. If implemented successfully, these signs have the potential to negate a need for unpermitted off-premise A-frame signs (which are prohibited in the sign ordinance). Please see the 2013 Embarcadero District TourismOriented Directional Sign Plan for an overview of the three alternative proposals.

The plan is focused on the Embarcadero area because it attracts a high volume of tourists, and has infrastructure designed for pedestrians. These directional signs will be visible from the road, but will be designed to capture the attention of tourists in areas with high levels of pedestrian traffic. The proposed directional signs shall be maintained and managed by the City of Morro Bay, and the City will ultimately decide what businesses are featured on the signs, and what design standards must be followed in order to receive approval. The Embarcadero Tourism-Oriented Sign Plan includes three alternative proposals. 


\section{Chapter 2: Real World Examples}

\subsection{Evidence from Scholarly Articles Success of Directional Sign Plans:}

Tourism-Oriented Directional Sign Plans have proved successful in various cities. An article from the Journal of Travel Research discusses examples of these plans in Oregon and Washington State. According to the article, "Some Washington business operators estimated that as much as $50 \%$ to $80 \%$ of their sales were to highway travelers. Some of the operators of these businesses attributed as much as $50 \%-70 \%$ of their total sales to the influence of their TODS signs.” In Oregon, surveys found that "Of the operators who felt they could estimate the portion of sales attributable to TODS, seven estimated $30 \%$ or less, two estimated $50 \%$, and six estimated $70 \%$ or more of a TODS-generated increase, with a fairly even distribution among wineries and other types of businesses” (Dornbusch and Kawczynska, 1992, p. 4). In a summary of survey results, the authors state that nearly all businesses involved in the study believe that TourismOriented Sign Plans have a positive influence on sales.

The article also includes a bar graph titled "Method of Locating Businesses, Washington and Oregon Combined" that includes nine different methods (Appendix 2.1). The methods on the graph are as follows: Brochure, Map, Visitor Center, Directions, TODS, Other Signs, Guidebook, Drove around, and Don't know. TODS was the obvious winner, followed by "Directions," which was the second most popular method.

\section{Discussion:}

The article summarized above proves success of TODSPs in the Pacific Northwest. Although this is only one study, and conditions are different in Morro Bay, it certainly proves that TODSPs 
have the potential to impact communities in an economically positive way.

For a few reasons, various findings within the article can be applied to the City of Morro Bay.

First, much discussion within the article reveals the importance of targeting highway travelers with a TODSP. Located along Highway 1, Morro Bay is a perfect candidate for a sign plan that aims to attract tourists and travelers driving past the City. Taking Exit 278 for Morro Bay

Boulevard. presents travelers with two convenient gas stations within close proximity of the highway (Valero and Chevron). Morro Bay Blvd. is also one of the City’s most vibrant commercial strips. Directional signs near these two pit stops could potentially attract travelers into the City center for dining, shopping, and sight-seeing. Signs that would attract highway travelers are not proposed in this plan, however, future implementation should be considered.

The second reason the article is relevant to Morro Bay’s situation is its discussion of business types such as gift/crafts, amusement/recreation, museums, and wineries. It is evident that these mentioned business types are abundant throughout the Embarcadero and Downtown districts.

\section{Digital Signage:}

Implementation of digital signage throughout the City on business frontages and billboards would be inconsistent with the General Plan and overall character of the community. Using digital signs to display directional business information could be the way of the future; however, Morro Bay residents and business owners have spoken out against the existence of such signs in their City. Implementation of digital signs also has relatively high upfront costs and additional maintenance costs.

On the other hand, strategically placed digital signs capable of displaying information for tourists could be useful, and could perhaps direct tourists towards businesses they may have missed due to an unfortunate location. The implementation of a single digital sign on the Embarcadero could 
be greatly beneficial for the City of Morro Bay. In the article "Digital Signage Replaces

Traditional Signage," David Drain argues that digital signs are especially useful for wayfinding, emergency notifications, and weather alerts (p. 34). It is advised that the City considers the use of digital signs for emergency notification purposes in the future. If current hypotheses are correct, coastal towns such as Morro Bay may be very susceptible to the future effects of sea level rise and climate change. These changes have the potential to increase the likelihood of natural disasters such as hurricanes and flooding in the coastal regions of California; the City of Morro Bay should prepare for these effects by implementing storm and disaster warning systems on the Embarcadero. A digital sign on the Embarcadero could provide weather alerts and emergency notifications to tourists, residents, business owners, and fisherman.

\subsection{King City, CA Directional Signage Program}

In 2006, Cal Poly Master’s student, Bill Roth, completed a directional sign plan for King City, California. According to Bill Siembieda, a Cal Poly City and Regional Planning Professor, Roth’s project should serve as a reference during the formation of a plan for the City of Morro Bay. King City’s directional sign plan was not “Tourism-Oriented” per say, however some of the theory and concepts related to implementation can be applied to Morro Bay’s plan. Roth’s project also includes proposals for evacuation route signs; proposals for these types of signs will not be included in the potential sign program for Morro Bay.

\section{Key Ideas:}

In the background report Roth expressed ideas that can be applied to a TODSP for the City of Morro Bay. Early on Roth presents “The Guiding Principles for King City Directional Signage.” They are as follows: Unified Style, Cross-cultural communication, Affordability and efficiency, and Safety (p. 4). After discussion with project advisors and Morro Bay City staff, it is evident 
that these guiding principles presented by Roth coincide with the goals of a directional sign plan in Morro Bay.

Unified style, or a theme for the signs, is certainly important. It will be vital that tourists learn what the directional signs look like so they are able to quickly spot others as they navigate the City. Also, a sleek theme shared by directional signs looks more professional, and could improve the overall aesthetic quality of the proposed designs.

Roth's second guideline, cross-cultural communication, is especially important in the case of a tourist town such as Morro Bay. People travel from all over the world to drive up and down California's famous coastline. It must be assumed that some tourists speak and read little to no English, and therefore directional signs must be designed accordingly. Roth comments that "Symbols from the International Standards Organization (ISO) should be used whenever possible” (p. 6). Such symbols allow for graphical representation of ideas rather than textual, which allows the transmission of information to people of different nationalities.

Bringing practicality into the picture is Roth’s third guideline, affordability and efficiency. He discusses efficient use of public funds, along with the use of a phased implementation schedule.

Roth’s final guiding principle is safety, stating that “ $A$ balance between information and readability (at driving speeds) must be maintained” (p. 7). Federal Highway Administration standards were used in the creation of Roth's directional sign plan. These standards ensure that signs will not distract drivers to a point where vehicle-pedestrian and vehicle-vehicle collisions become a problem. 
Apart from the four guiding principles presented in the King City Directional Sign Plan, another theme appears throughout the project; an offering of choices. Instead of assuming that a single design pleases all readers, Roth’s proposal allows decision makers to choose from various design concepts and locations for the proposed signs. For example, each type of proposed sign is presented with a "Style A" and "Style B" choice. Although some may argue that this could cause conflict during the decision process (perhaps during a Planning Commission meeting), it is believed that offering choices can stimulate positive and constructive discussion.

\subsection{Healdsburg, CA}

\section{Morro Bay Chamber of Commerce:}

After a meeting with Morro Bay Chamber of Commerce CEO, Craig Schmidt, it was clear that the Chamber supports the idea of implementing directional signs to help visitors locate businesses in the Downtown and Embarcadero areas. Mr. Schmidt was a member of a team who implemented the Downtown Directional Sign Program in the City of Healdsburg, California (Appendix 2.2). He suggested that the City of Morro Bay use ideas from this successful plan designed for Healdsburg, a city with a similar population to that of Morro Bay.

\section{Key Features from Healdsburg Directional Sign Program:}

The information presented in the Healdsburg Downtown Directional Sign Program - Sign Criteria and Application Requirements handout (Appendix 2.2) is both concise (less than two pages) and user friendly. The following are key features found in the document:

- Designed to feature tourist serving businesses (eligible businesses must be open on weekends).

- The plan offers approval of directional signs for sixteen (16) types of businesses, including clothes stores, hotels, restaurants, spas, and gift shops . 
- The plan bars approval of directional signs for seven (7) types of businesses: exercise and yoga studios, religious establishments, cleaners, general offices, shoe repair, copy and printing shops, and paint stores.

- Businesses must be located within the downtown district or be a destination of general interest.

- $\quad$ Signs cannot include phone numbers or website addresses.

- Each sign shall include a directional arrow oriented towards the business.

- $\quad$ Signs shall measure 7 x 17.5 inches and fabricated from .08 gauge aluminum.

- Offers contact information for local businesses who have the ability to manufacture such signs.

- \$128 Processing fee for sign review.

- $\quad$ Signs shall be installed within 30 days of City’s approval.

\section{Adaptation in Morro Bay}

The Healdsburg, California Directional Sign Program has many well designed features that can be adapted to work in Morro Bay’s proposed program. The following section analyzes key features from Healdsburg's plan, and how these features could be adapted and used in Morro Bay’s proposed Tourism-Oriented Directional Sign Plan.

\section{Allowable Business Types}

One key aspect noted from Healdsburg's plan is that it grants directional signs to sixteen (16) different types of businesses. After multiple meetings with Morro Bay city staff members, it was concluded that Morro Bay's proposed plan should reduce the number of business types eligible for obtaining a directional sign permit. The City of Healdsburg arguably allows businesses not directly associated with tourism to apply for a directional sign permit. These allowances include 
pet stores, beauty salons, banks, and florists. City of Morro Bay staff concluded that pet stores and banks, for example, are not establishments that attract tourists strolling along the Embarcadero on a Saturday afternoon. Instead, these types of businesses are generally sought out beforehand, and then driven to with personal automobiles. Furthermore, it can be argued that business types such as pet stores and banks cater primarily to permanent and part-time residents, not tourists or travelers making a pit stop in Morro Bay.

Morro Bay staff members also believe that Morro Bay has too many businesses in the Embarcadero district for all of them to be featured on a directional sign. To ensure that the plan is consistent and fair, while at the same time optimizing effectiveness, eligible business types shall be limited.

\section{Allowable Number of Signs}

The City of Healdsburg allows businesses to be featured on two different directory signs at different locations. To further increase the chance of permitting all eligible applicants a directional sign in Morro Bay, it is advisable to limit businesses to a total of one sign.

\section{Symbol Signifying Business Type}

Healdsburg’s plan states that each directional sign shall include a “...descriptive line identifying products or services (e.g. art, wine tasting, clothing) that is clearly subordinate to the business name.” Instead of using text to describe services, Morro Bay’s directional business signs will instead include a symbol to be placed in the corner of each sign. Chamber of Commerce representatives and city staff believe that using universal symbols to describe services is preferable because they better accommodate non-English speaking individuals. Furthermore, use of symbols will eliminate excess text on the signs, and in turn, the signs will be easier to read and less cluttered with information. 


\section{Chapter 3: Directional Signs - Design and Implementation}

\subsection{Community Outreach}

As part of the 2013 Sign Ordinance Update for the City of Morro Bay, a survey was sent out to all business owners within the City. Fifty percent of respondents support the idea of "directional signs" on the Embarcadero, while 19\% are neutral. As far as the implementation details, the choice "All businesses should be featured on a directional sign” was most popular ( $27 \%$ of respondents). Because the latter question has no clear winner, and no option had the approval of over $50 \%$ of respondents, the deciding body should consider multiple alternatives for implementation. The alternatives will allow the deciding body the opportunity to examine all viable options

For more information on the survey and survey results, please see the "City of Morro Bay, CA Sign Ordinance Update Background Report.

Figure 3.1: Business Survey Results

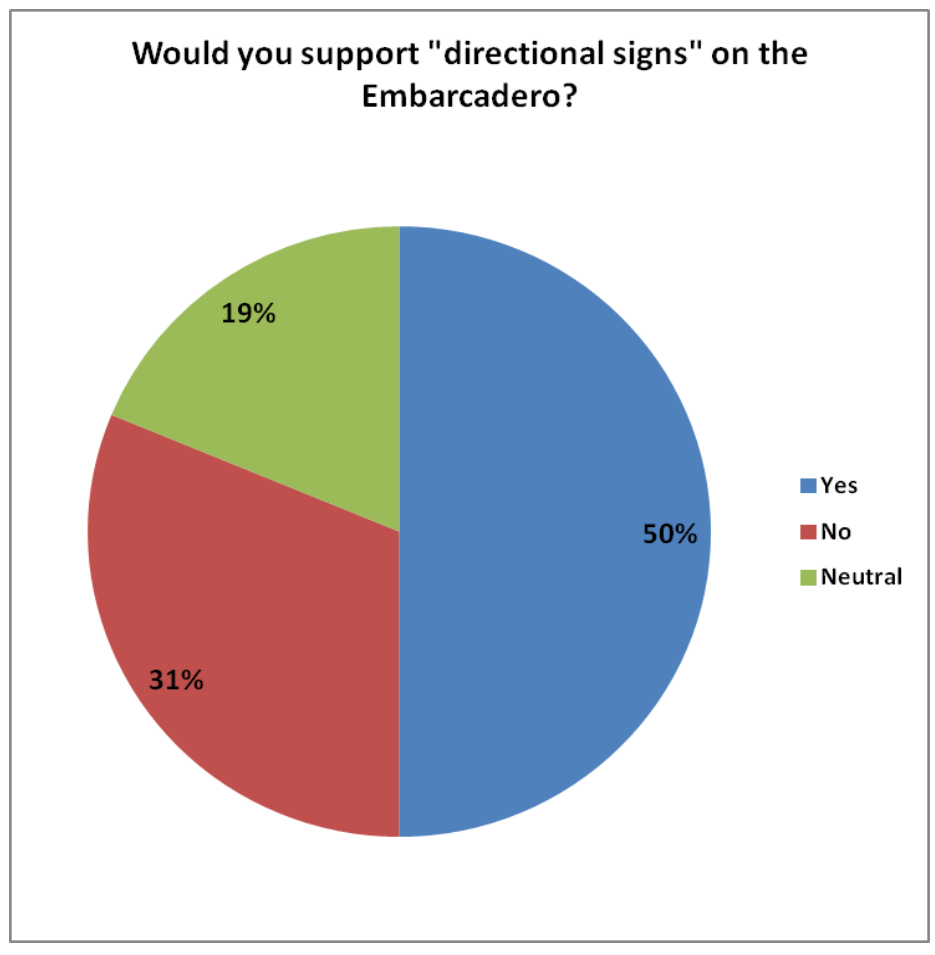


Figure 3.2: Business Survey Results (continued)

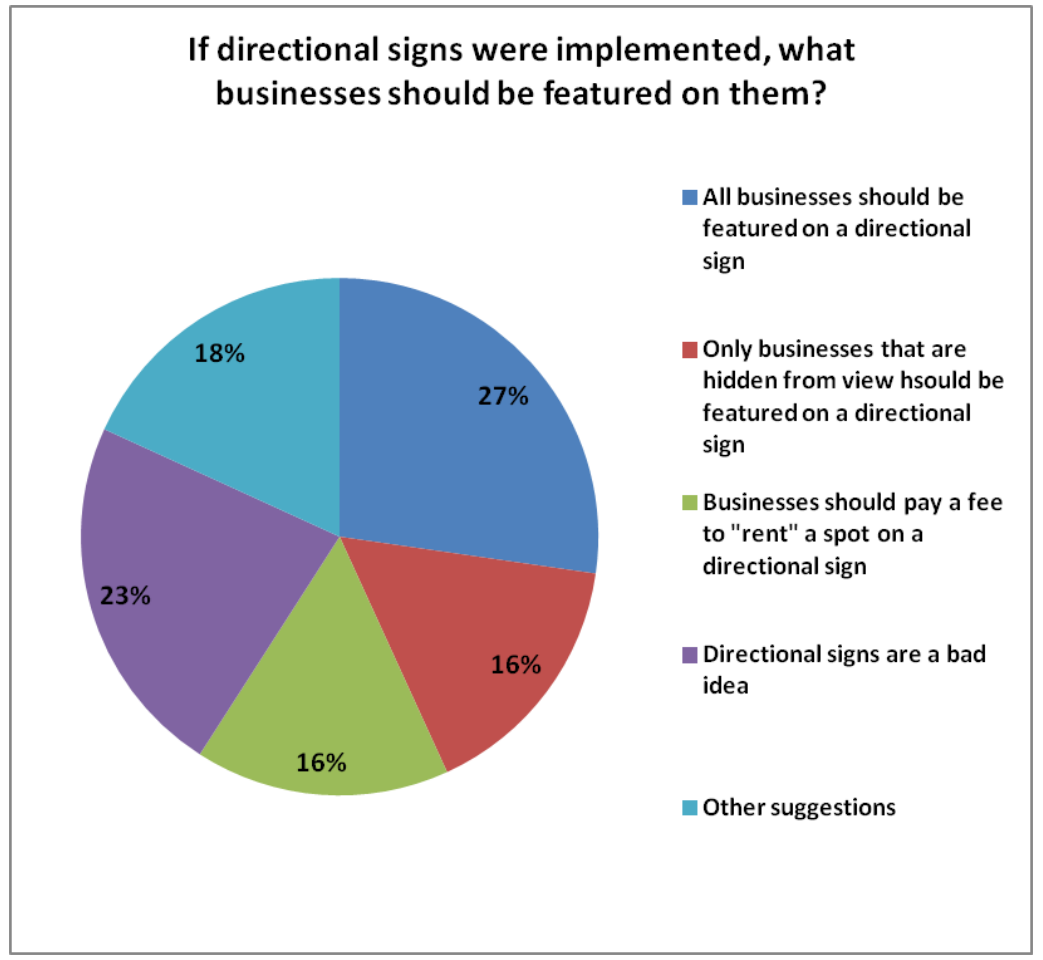

\subsection{Sign Design and Placement}

\section{Design:}

The design guidelines presented in the Tourism-Oriented Directional Sign Plan are a product of extensive background research and discussions with staff and stakeholders in Morro Bay. The sign guidelines have been designed to allow business owners the opportunity to be creative and artistic, while at the same time ensuring that signs are consistent, decipherable and aesthetically pleasing.

The proposed size of the signs and sign structures are other important factors. If the individual business signs are too small they may not be visible to some readers. If the sign structures are too small there may not be enough room to place the needed amount of business signs. The safety of the signs must also be considered; the signs shall not block the view of drivers, and sharp edges on the design should be avoided to prevent injury. 
All alternatives propose that directory maps be implemented. These maps will include a map of the Embarcadero to help tourists navigate. This type of map, which is commonly found in large malls and theme parks, includes a marking and a statement that reads "You are here.” The implementation of such a map on the Embarcadero will supplement the business directional signs (as proposed in Alternative 3), giving tourists a general sense of where they are and where they might want to go. Additional information about the discussed business directional sign and directory sign designs can be found in the 2013 Embarcadero District Tourism-Oriented Directional Sign Plan.

\section{Placement:}

As discussed in Section 2.3 of this report, the proposed TODSP will direct the placement of sign structures in the Embarcadero district. The proposed locations of sign structures were chosen because they meet the following criteria:

- $\quad$ Located in an area with high volumes of pedestrian traffic.

- Located in an area with a high volume of visitor-serving businesses.

- When placed the sign will not completely block the pedestrian right-of-way.

- When placed the sign can be seen from both the road and adjacent sidewalks on both sides of the street.

- When placed the sign will not block desirable viewsheds.

- When placed the sign will not obstruct the visibility of commercial signs.

- When construction activities occur, sensitive natural resources, plants, animals, or habitat will not be disturbed.

Furthermore, a Wayfinding Sign Project was completed in 2005 that proposed traditional directional signs and gateway signs throughout the City (but not directional business signs). This 
project, which proposes 6 directional signs along the Embarcadero (Appendix 3.1), was referenced during the creation of the TODSP. The plan differentiates “directional” and "locational” signs, stating that directional signs are constructed along main streets, while locational signs are mounted along walkways on walls or posts. Both types of signs convey the same kind of information and are only differentiated based on the way they are placed, and where they are placed. As the map in Appendix 3.1 indicates, directional/locational signs were proposed at the following locations:

- The intersection of Marina St. and Embarcadero (Directional)

- The south end of Embarcadero in Anchor Street Park (Locational)

- The south end of Front St. on the corner of Front St. and Embarcadero (Locational)

- On the west side of the intersection of Harbor St. and Embarcadero (Locational)

- $\quad$ On the west side of Embarcadero between Dunes St. and Beach St. (Locational)

- $\quad$ Near the parking lot where the Embarcadero makes a turn towards the NW (Directional)

Using the criteria presented above along with evidence presented in the 2005 Wayfinding Sign Project, the following locations for sign placement are proposed:

1. The NE corner of the Marina St. and Embarcadero intersection.

2. The south end of Front St. on the corner of Front St. and Embarcadero (in the park)

3. The NW corner of the Beach St. and Embarcadero intersection (at the start of the walking path)

\subsection{Feasibility}

Implementation of a relatively small scale sign program in a city like Morro Bay is very feasible. City projects such as creating parks or building community centers may require the purchasing of 
land, and contractors may be required to construct buildings, grade the soil, and complete extensive landscaping. In contrast, costs associated with the manufacturing of sign structures and directory signs, and installation of the structures can be easily estimated. As far as the individual aluminum business signs, applicants will be responsible for the design and fabrication costs.

Furthermore, the financing for such a program in a smaller city like Morro Bay is not overwhelming, and can be partially supported by the processing fee associated with directional business signs. In the case of direction sign plan, a program could be completed solely by Recreation and Parks personnel and sign manufacturers. This means that City funds can be saved by using internal labor, and any other expenditure can be filtered back into the local economy (e.g. hiring a local sign company to make the signs).

\section{Sign Law:}

According to the United States Federal Highway Administration, there are some laws one must consider when proposing a directional sign plan. In Section 2D.50 titled Community Wayfinding Signs, The Manual on Uniform Traffic Control Devices states that “...wayfinding guide signs shall not be installed on freeway or expressway mainlines or ramps.” The Morro Bay TODSP will not propose signs on any kind of freeway or expressway ramp.

Furthermore, there are laws prohibiting signs that have the potential to distract automobile drivers. These laws were considered during the creation of this plan, but because the proposed directional signs are located on a street with low speed limits and abundant stop signs and crosswalks, and will be oriented for pedestrian use, traffic accidents should not be a relevant issue. 


\section{Maintenance:}

Maintenance costs for directional business signs are low, and there are ways the City of Morro Bay can complete maintenance while also helping local non-profit agencies. According to Morro Bay Chamber of Commerce CEO Craig Schmidt, the City of Healdsburg hired a local non-profit to maintain their directional signs. The non-profit, who provides mentally ill individuals work, was contracted by the City to clean the signs every month. If directional business signs are implemented in Morro Bay, and it is feasible to do so, it is advised that the signs be maintained by a local non-profit.

\subsection{Implementation}

The implementation process for Morro Bay’s TODSP is relatively simple. The process consists of the following steps:

1. Submit background report and TODSP to city staff for review, and make any changes associated with their comments.

2. Make proposal public and notify Morro Bay residents.

3. Provide Planning Commission members with a copy of the background report and the sign plan, and then present the proposal at a Planning Commission meeting.

4. If approved, make corrections to the sign plan, and begin formulating a sign program.

5. Implement sign program and begin construction of sign structures and/or directory signs.

6. Alert Embarcadero business owners of the approval and begin accepting applications.

For additional details regarding the proposal, please see the 2013 Embarcadero District TourismOriented Sign Plan. 


\section{Sources:}

City of Healdsburg, CA. "Downtown Directional Sign Program." Retrieved from: http://www.ci.healdsburg.ca.us/Modules/ShowDocument.aspx?documentid=3517

City of Morro Bay Public Services Department. (2012). “Master Fee Schedule for the 2012/13 Fiscal Year.”

Castle, Roger and Gary Ream. 2006. Images of America Morro Bay. Charleston SC, Chicago IL, Portsmouth NH, San Francisco CA: Arcadia Publishing.

City of Morro Bay Economic Development Program. 2013. Developed by: Morro Bay Chamber of Commerce. Retrieved from: http://morrobay.nationbuilder.com/.

Dornbusch, D.M. and Kawczynska, C.J.. 1992. "Tourist Oriented Directional Signs: a selfsupporting program to promote rural business and economic development." Journal of travel research; 31, 1.

Roth, Bill. 2006. “King City Directional Signage Plan and Implementation Program.” Masters Project: California Polytechnic State University, San Luis Obispo, CA.

United States Census Bureau. City of Santa Cruz, City of Atascadero, City of Morro Bay, City of San Clemente. “2010 Demographic Profile Data (DP-1)

United States Department of Transportation, Federal Highway Administration. "Manual on Uniform Traffic Control Devices (MUTCD) - 2009 MUTCD Standard Signs.” Retrieved from: http://mutcd.fhwa.dot.gov/shsm_interim/index.htm\#gss. 


\section{PART D}

CITY OF MORRO BAY, CALIFORNIA

\section{Embarcadero District Tourism-Oriented Directional Sign Plan}

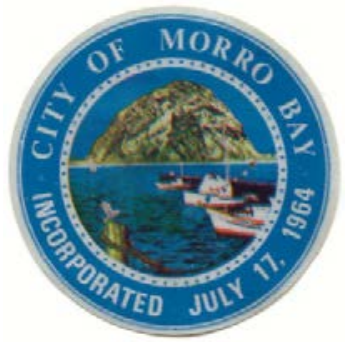

Prepared by

Erik Berg-Johansen, Intern Planner

June 2013 


\section{TABLE OF CONTENTS}

\section{INTRODUCTION}

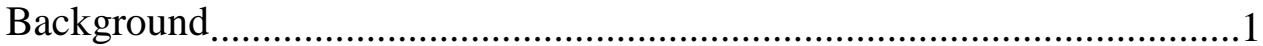

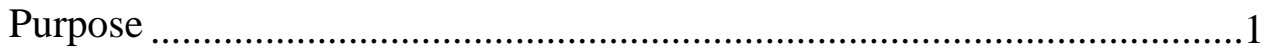

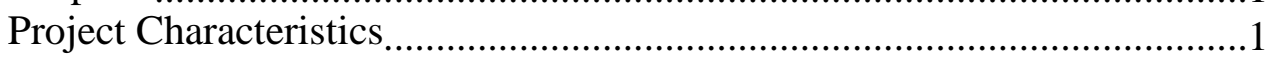

Business Directional Signs ......................................................................2

Traditional Tourism-Oriented Directional Signs ......................................2

\section{PROPOSALS}

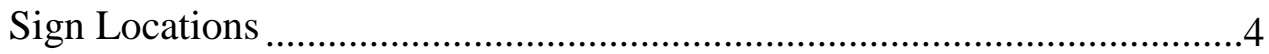

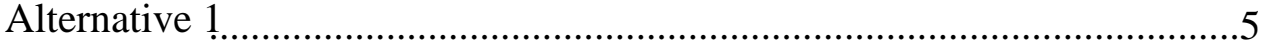

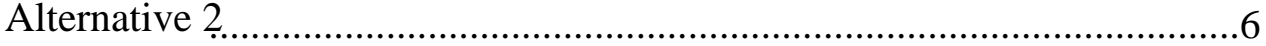

Alternative 3 ..............................................................................

\section{IMPLEMENTATION RECOMMENDATIONS}

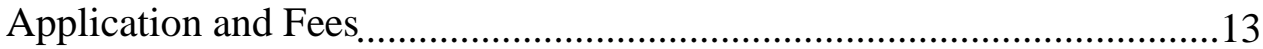

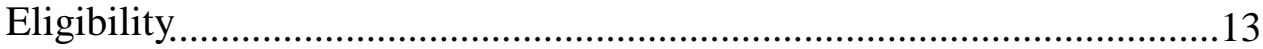

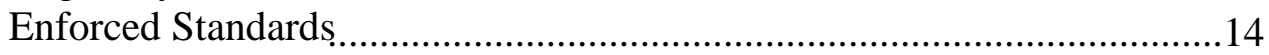

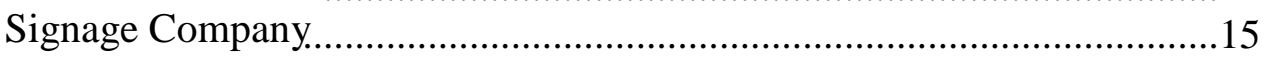

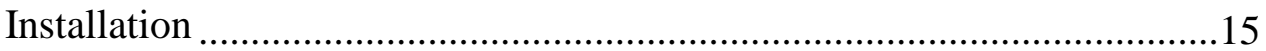

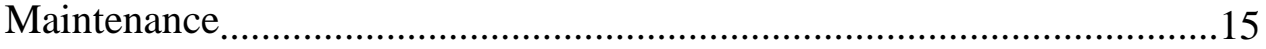




\section{Introduction}

This section outlines the background, purpose, and characteristics associated with the City of Morro Bay Tourism-Oriented Directional Sign Plan.

\section{Background}

This Tourism-Oriented Directional Sign Plan (TODSP) and the City of Morro Bay 2013 Sign Ordinance Update have been prepared simultaneously. This sign plan is designed to work in harmony with the goals presented in the new draft sign ordinance. The Chamber of Commerce, City Staff, and business owners have agreed that business directional signs will be a beneficial asset to the City of Morro Bay.

\section{Purpose}

The purpose of this Plan is to promote tourism and increase the vitality and economic success of businesses in Morro Bay’s Embarcadero district. The proposed signs are designed to make tourists aware of the numerous businesses existing along the Embarcadero, and negate the need for the illegal use of A-frame signs. The directional signs will be especially beneficial for businesses that have a less than ideal location and lack a frontage along the Embarcadero’s primary right-of-way.

\section{Project Characteristics}

The project includes this TODSP and a supplementary background report. The background report serves as supporting document for the decisions made during the formation of the Plan. This TODSP is the product of extensive research, community outreach, and discussion among City staff. The primary goals of the project are as follows:

1. Increase the vitality of all businesses in the Embarcadero district. 
2. Propose aesthetically pleasing signs that match the community's character.

3. Use international symbology on signs to accommodate non-English speakers.

4. Propose placement of directional signs in areas with high volumes of local businesses and pedestrian traffic.

5. Design signs in a manner that increases feasibility and decreases implementation costs.

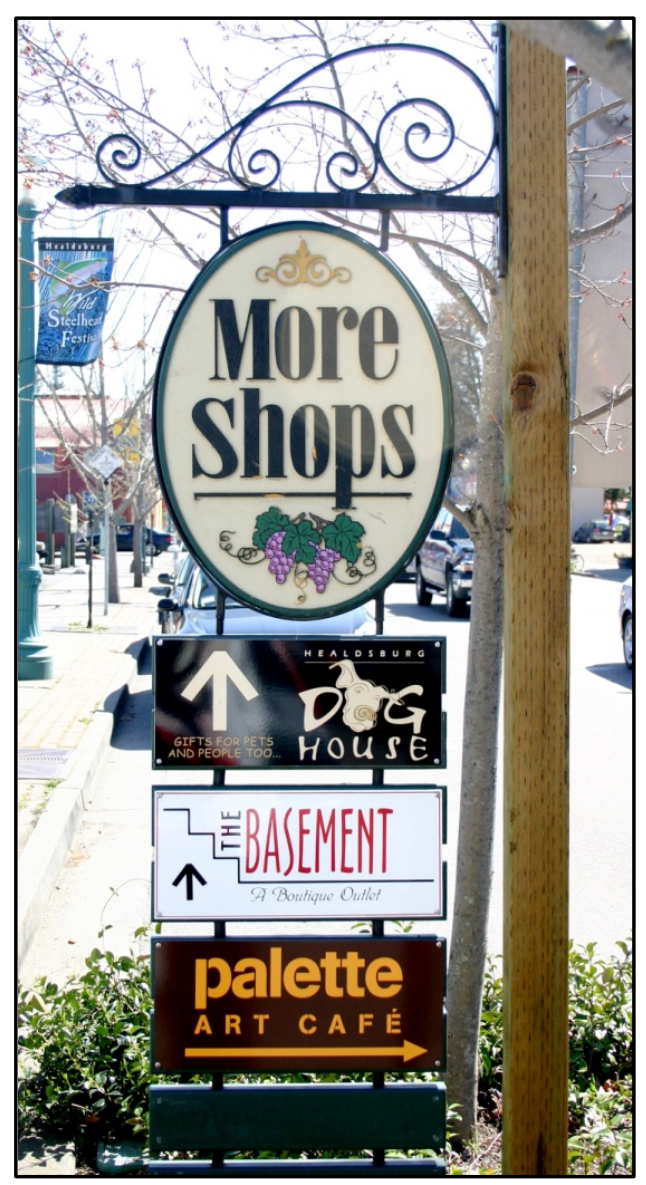

\section{Business Directional Signs}

"Business directional signs," a term coined during the formation of this plan, can be differentiated from traditional tourism-oriented for a number of reasons ${ }^{1}$. First of all, business directional signs portray more specific information about individual businesses. For example, a traditional directional sign might state, “Commercial District This Way.” A business directional sign, on the other hand, includes multiple signs with the names of individual business names “Crabby’s Seafood Restaurant This Way.” Figure 1.2 is an example of a business directional sign existing in Healdsburg, CA.

Figure 1.1: Business Directional Signs

\footnotetext{
${ }^{1}$ Traditional Tourism-Oriented Directional Signs

Tourism-oriented directional signs are traditionally (and most commonly) used to help tourists navigate through cities. These signs can be used to guide tourists towards areas of interest such as beaches, downtown commercial districts, parks, and sites with historic significance. They can also be used for safety purposes, pointing towards hospitals and police stations, or making drivers aware of designated emergency evacuation routes. Figure 1.1 is an example of a tourism-oriented directional sign proposed in Morro Bay’s 2005 Wayfinding Sign Project.
} 


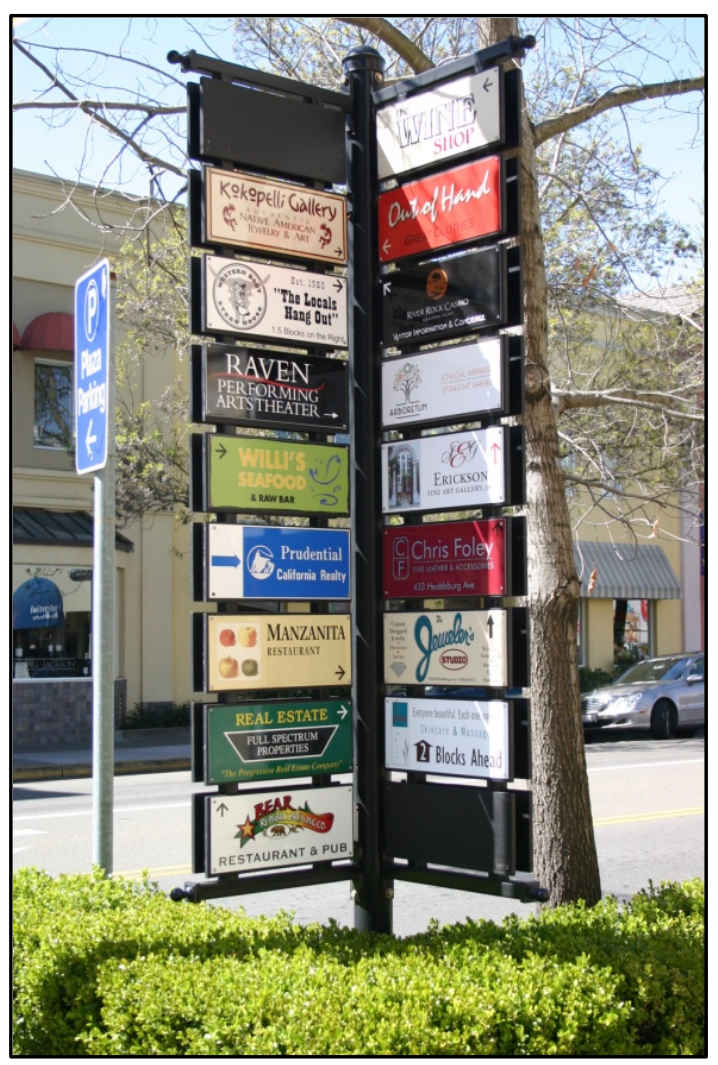

Figure 1.2: Business Directional Sign

Furthermore, business directional signs rely on the creativity of business owners because the included signs, for the most part, are not designed by the City. It is proposed that the City provide a template and specific design guidelines for directional signs, and then allow business owners to create their own signs that include their business name and logo. 


\section{Proposals}

\section{Sign Locations}

Three (3) locations for sign placement are proposed along the Embarcadero:

- On the west side of the Beach Street and Embarcadero intersection. This site was chosen because a directional sign could serve as a gateway to the new pedestrian walkway (Harborwalk) that leads to the north end of the Embarcadero. In addition, there is a large parking lot across the street that attracts arriving tourists.

- In Centennial Parkway at the intersection of Front Street and Embarcadero. This location was chosen because the park (and the public bathroom within the park) attracts tourists. Furthermore, the land is owned by the City and construction will not require consent from a landowner.

- On the NE corner of the Marina Road and Embarcadero intersection. This site was chosen due to the high amount of pedestrian traffic and high concentration of businesses. It may be more appropriate to locate the sign on the west side of the Embarcadero, however crowding in the public right of way could be an issue. 


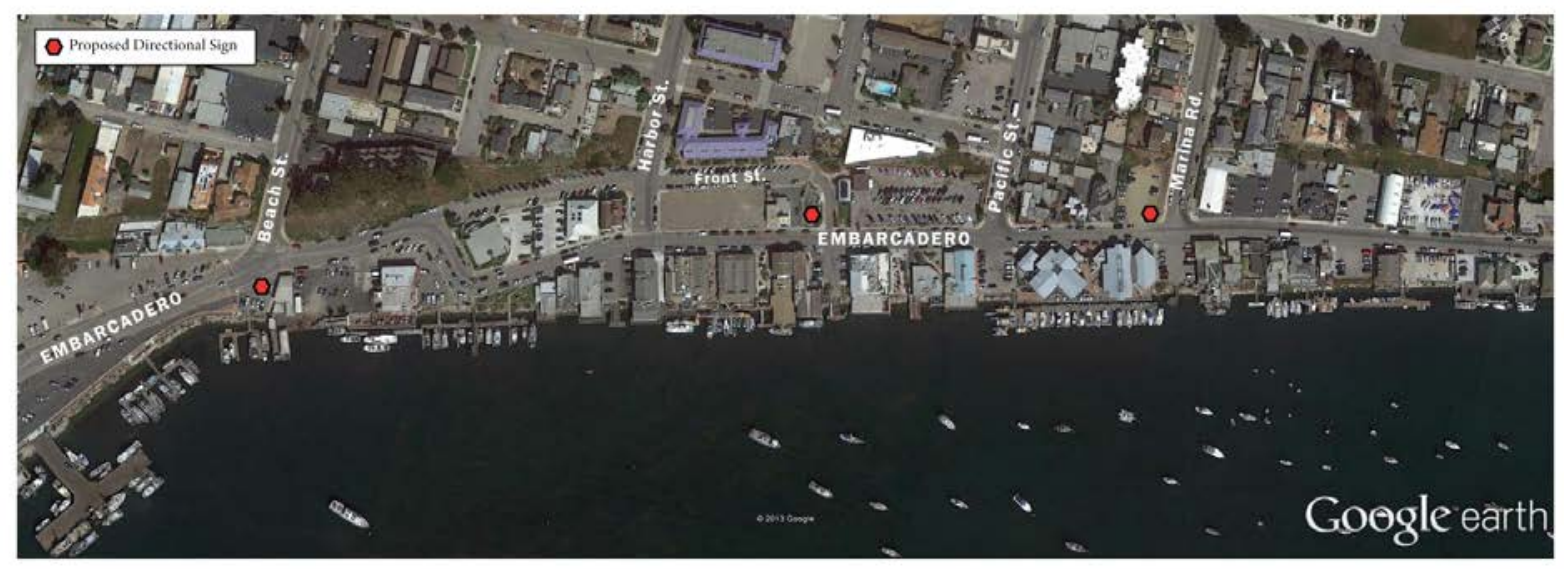

Figure 2.1: Proposed Sign Locations

Three (3) alternatives are presented for the implementation of directional signs on the Embarcadero. All three proposals suggest placement of signs in the three locations specified above, however it could be decided that placement of signs at only one or two of the proposed locations is the only feasible option.

\section{ALTERNATIVE 1}

This alternative is the most basic and feasible option. Each directional sign will include only one

(1) component:

1. A directory map of the Embarcadero district that allows readers to pinpoint their current location. This map will include parking areas, public bathroom locations, and other areas of interest such as viewpoints and ocean access points. This map will not need to be frequently updated. 


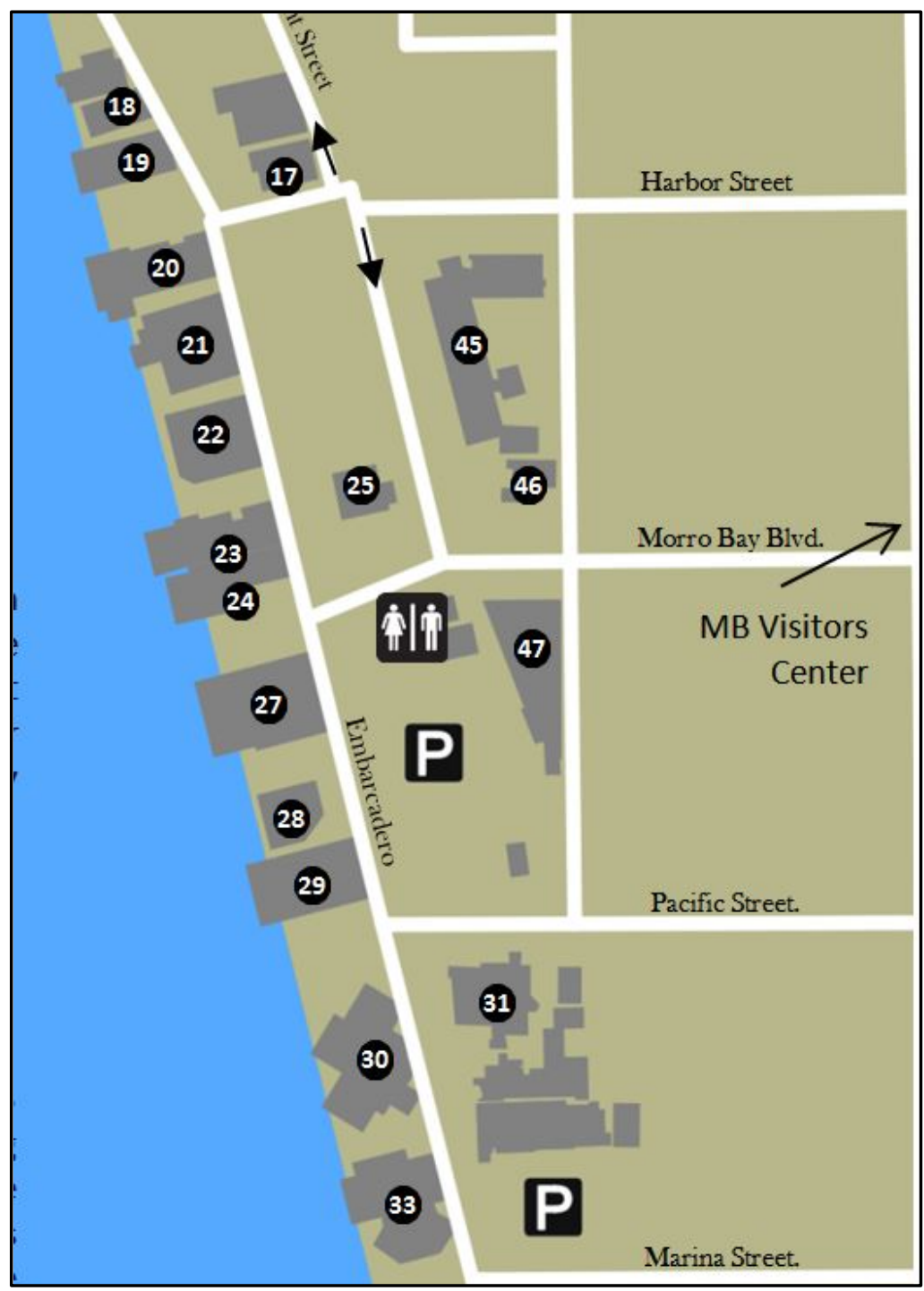

Figure 2.2: Directory Sign with Points of Interest

\section{ALTERNATIVE 2}

This alternative is similar to Alternative 1, however the proposed directory map is more complex.

Each directional sign will include only one (1) component:

1. A large directory map of the Embarcadero that includes everything proposed on the directory map described in Alternative 1, plus the addition of all business names and their locations. With the high turnover rate of businesses in the Embarcadero, this map will need to be updated frequently. This map has the potential to be more effective than the 
map proposed in Alternative 1, however, the cost of printing and installing updated maps must be considered.

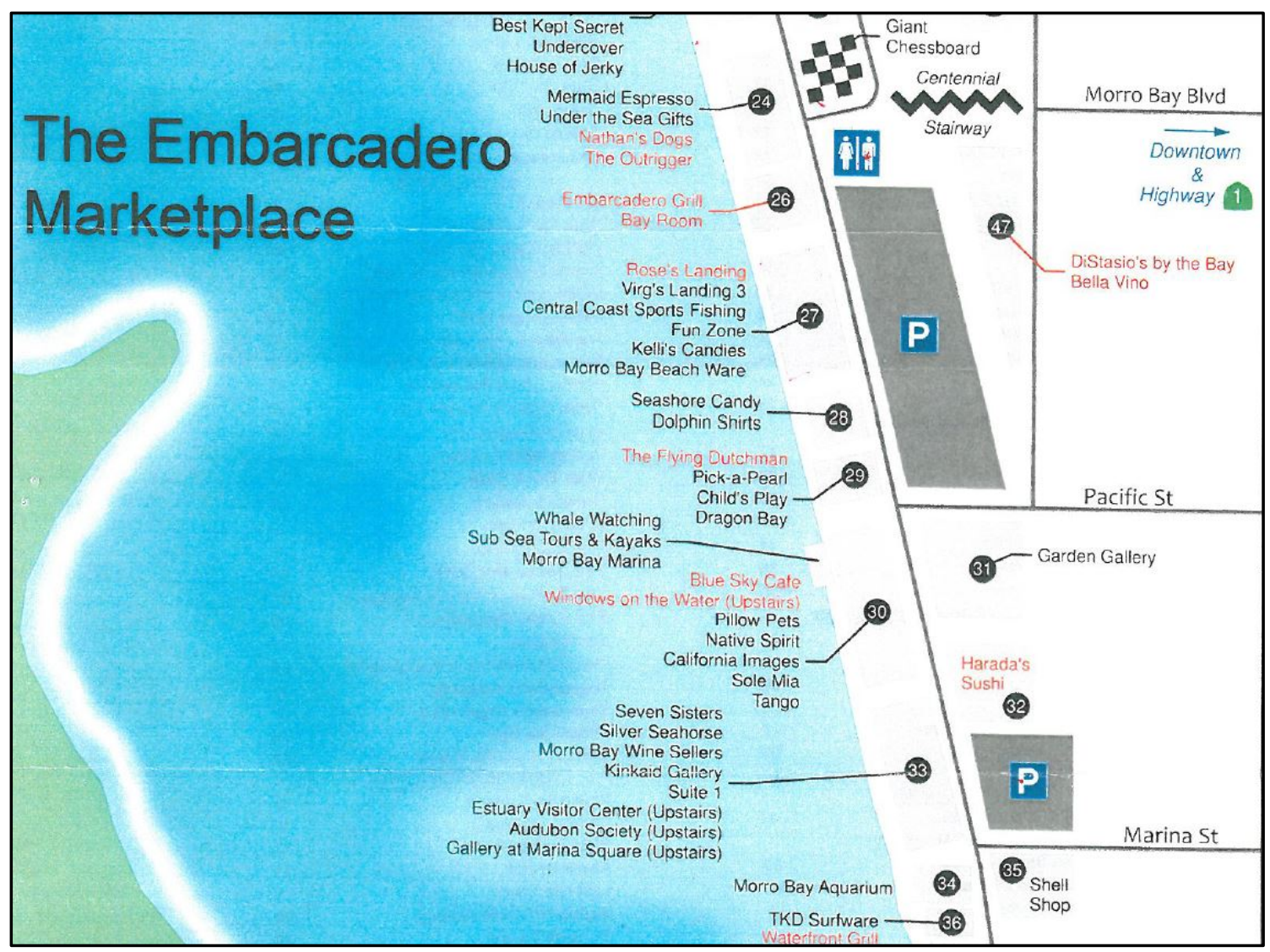

Figure 2.3: Directory Sign with Business Names 


\section{ALTERNATIVE 3}

Alternative 3 is the most complicated alternative, however, if implemented it will provide tourists with the maximum amount of information.

Each directional sign will composed of three main components:

1. A permanent sign structure constructed by the City.

2. A large directory map of the Embarcadero that includes everything proposed on the directory map described in Alternative 1.

3. Multiple business directional signs attached to the sign structure.

\section{Sign Design}

Figures 2.4 and 2.5 are graphical models of how business directional signs would look. The design template includes a space for business owners to create a custom graphic that includes their business name and logo. The template includes two additional spaces where a directional arrow (and accompanying text) and an international symbol can be placed. The arrow is designed to guide tourists towards the business they wish to locate. The international symbol is designed to signify the "type" of business. For example, a knife and fork symbol indicates that the business serves food, and a martini glass indicates that the business is a bar or pub that primarily serves alcoholic beverages.

The proposed business directional signs are designed to:

- Clearly convey business information while allowing for creativity and individuality.

- Include design features that fit local character while also increasing the aesthetic qualities of the Embarcadero. 
- Convey information to non-English speaking tourists.

- Guide tourists towards businesses they would have otherwise passed by.

- Permit off-premise advertisement that will reduce a need for A-frame sign use.

It must also be decided if businesses will be allowed one sign face (front only) or two sign faces (front and back). Due to the high volume of businesses along the Embarcadero, it is recommended that businesses are eligible for only one sign face. This will allow the maximum number of businesses to be represented on the sign structure. The issue with having twice as many different signs on the sign structure is the increased amount of clutter; having too many signs could be overwhelming for the reader.

According to the Chamber of Commerce's Embarcadero Marketplace directory map, there are over 85 businesses (not including hotels) that could be eligible for a directional business sign. For eligibility criteria see Chapter III. 
Figure 2.4: Business Directional Sign Example \#1

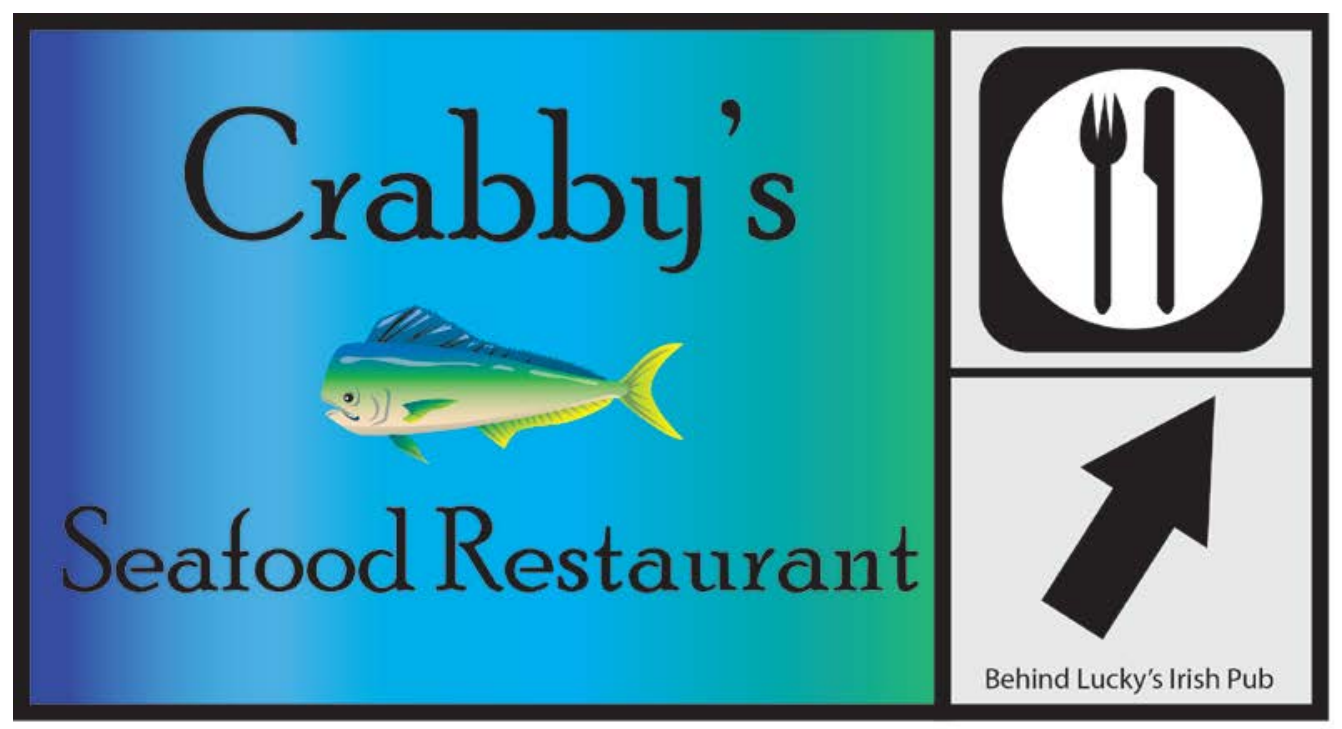

Figure 2.5: Business Directional Sign Example \#2

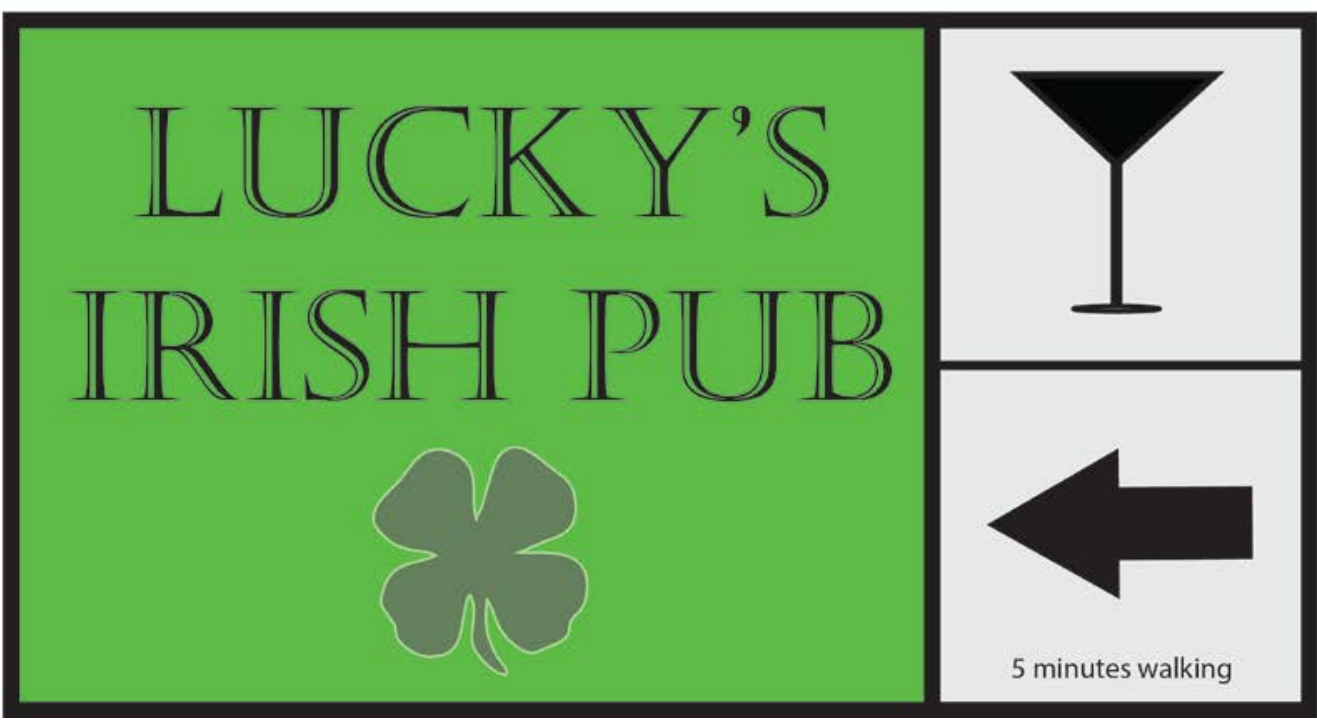




\section{Sign Structure}

Important Note: The following graphics were extracted from the 2005 Wayfinding Sign Project completed by the City of Morro Bay. The Designs were created by Terri Dunivant at Gala Graphics. The following graphics are used to present different "sign structure" designs, and not sign designs (the signs attached to each structure can be ignored).

Alternative 3 also requires the construction of a sign structure. The aluminum business directional signs will be attached to the structure. To reduce the cost of implementation it is recommended that a simple steel pole be used to attach the signs (see Figure 2.6). However, other more attractive designs should be considered and discussed before a final decision is made.

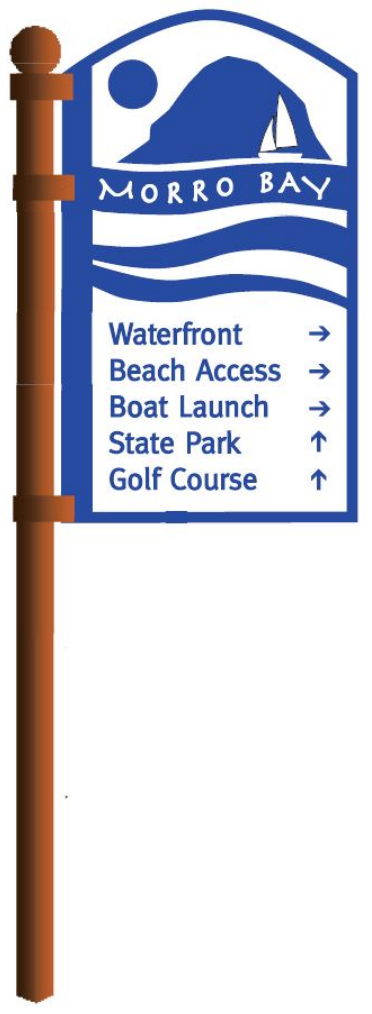

Figure 2.6: Painted Steel Pole

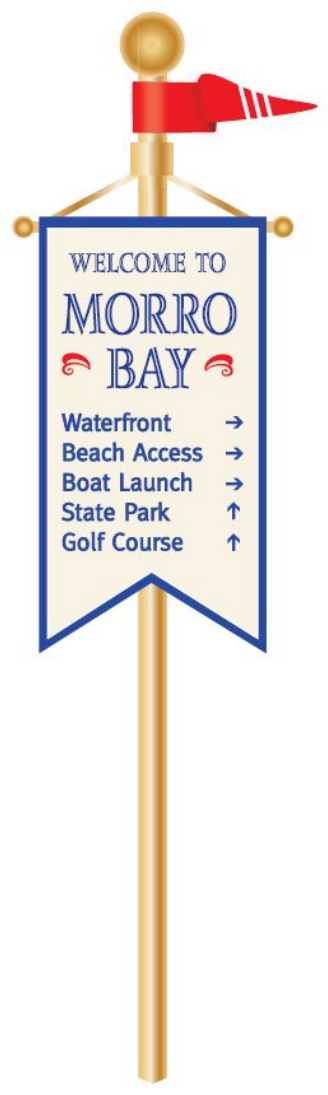

Figure 2.7: Flag-topped Steel Pole

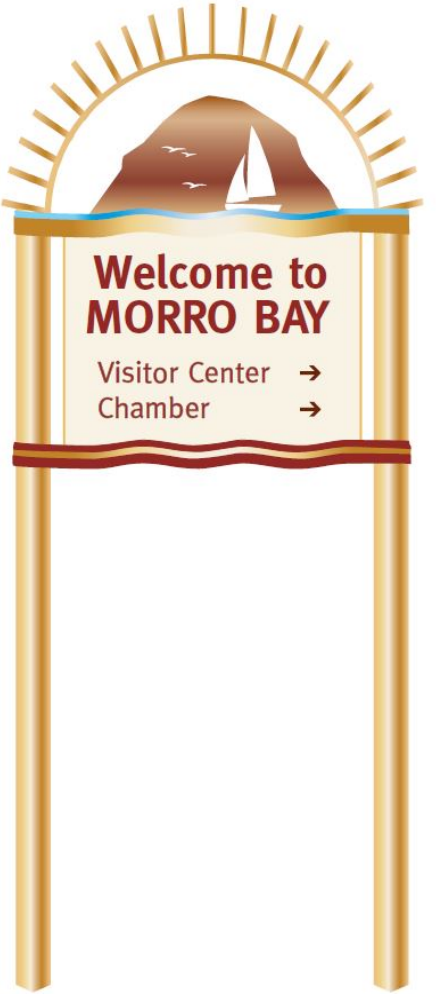

Figure 2.8: Morro Rock/Sunray Pole 
Furthermore, the proposed business directional signs will require additional structural supports that will allow the placement of each individual directional sign. On the directional sign structures in Healdsburg, California, the sturdy aluminum signs are attached using screws in each corner (see Figure 2.9). It is recommended that the signs be made of .08 gauge aluminum, which is what STOP signs and most other road signs are made of (a local sign company was consulted about sign materials). Due to the simplicity of the design, it is proposed that the City of Morro Bay use this method to attach the business directional signs. Using this method of attachment will also make changing the signs relatively quick and easy. To help prevent theft of the signs, custom screws should be used so that ordinary Flathead and Phillips screwdrivers are ineffective at removing signs.

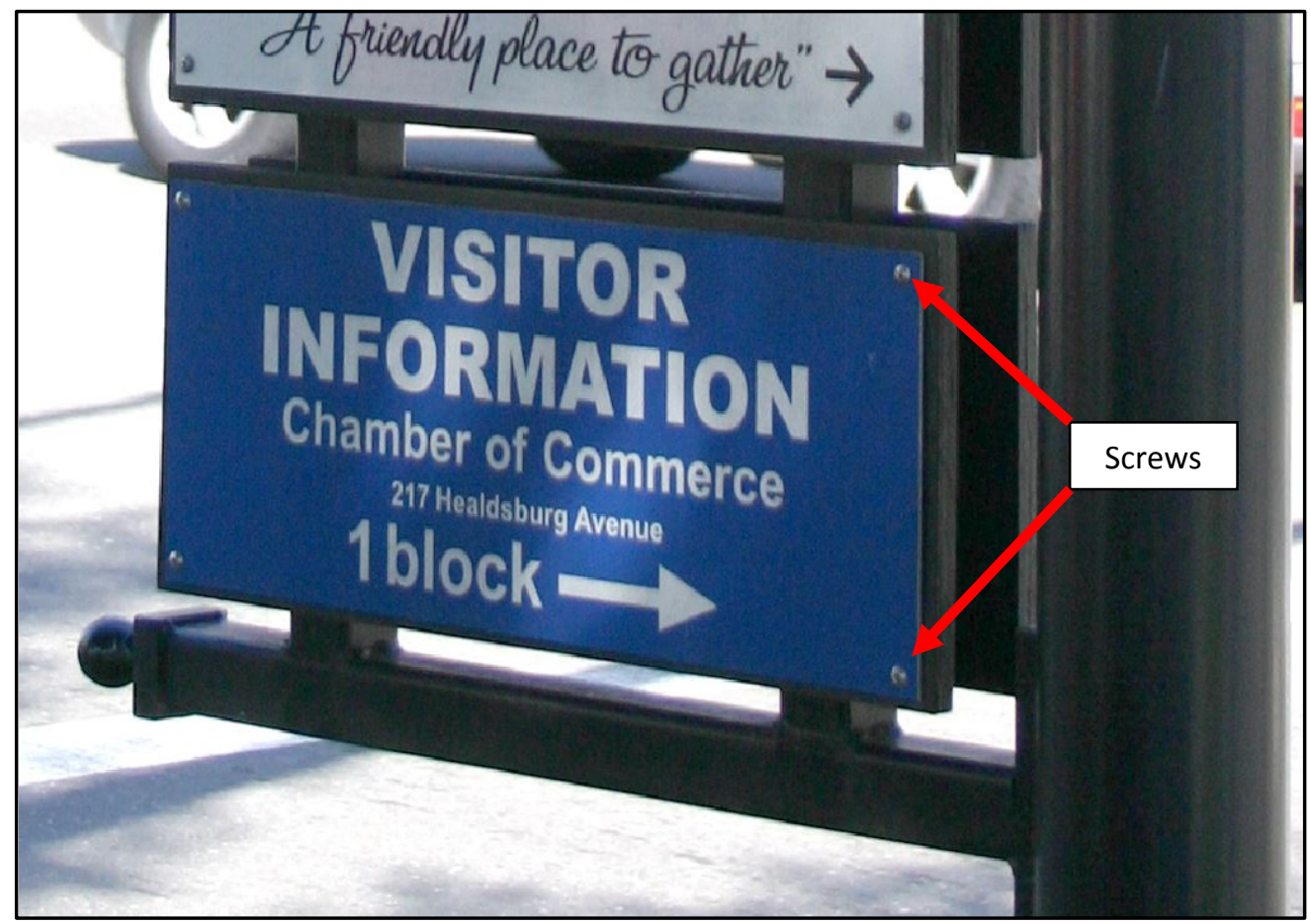

Figure 2.9: Sign Structure in Healdsburg, CA 
Safely should also be considered when designing the sign structure. The structure shall be void of sharp edges that could injure passing pedestrians or bicyclists.

\section{Implementation Recommendations}

The following are recommendations to be considered if Alternative 3 is approved. These standards should be reviewed and critiqued by decision-making bodies before final implementation of a directional sign program.

Note: If Alternatives 1 or 2 are selected, implementation will be straightforward. The City will have the directory signs constructed and then installed by City staff. The following applies mostly to applicants under Alternative 3.

\section{Application and Fees}

Any business owner interested in a directional sign for their business must submit a completed application to the City of Morro Bay Planning Department. Applications will be reviewed by Planning Staff. If an application meets the criteria, the sign application shall be approved. If there are no spaces available on the sign structure, submitted applications will be put on a waiting list. There will be a $\$ 100$ processing fee for sign review.

\section{Eligibility}

The following criteria will be applied to be eligible for a directional sign:

- Business is located within the Embarcadero District.

- Business is open on weekends (Friday-Sunday). 
- The business is tourist-oriented. The following business types meet this description: Clothing and shoe stores, surf shops, restaurants, cafes, pubs, bars, wine shops, hotels/motels, wine tasting rooms, art galleries, museums, gift shops, and recreation/entertainment-based businesses (such as kayak rental shops).

\section{Considerations:}

- Only businesses WITHOUT a storefront on the Embarcadero's main right-of-way are eligible (or favored). There are potentially more than 85 businesses eligible for a sign (allowing a space for all businesses would require placement of 25 or more signs per sign structure).

- Make Hotels/Motels ineligible for a sign because they are generally sought out and reserved beforehand, and due to their larger size they are generally visible from the street.

\section{Enforced Standards}

- Each business is entitled to one (1), one-sided directional business sign.

- Signs shall be fabricated from .08 gauge aluminum. Four drill holes (one in each corner) shall be installed at specified locations.

- Signs shall not include phone numbers, website addresses, obscene language or graphics, or brand names/logos.

- The City shall remove illegal signs (signs that were not approved) from the sign structures immediately.

- If a business closes or moves out of the Embarcadero District, the directional sign shall be removed by the owner within 10 days of their last operational day. If such sign is not removed during this 10 day period, the City shall remove the sign. 
- If a business moves to another location within the Embarcadero District, the previously approved sign may be modified and placed on the appropriate sign structure (if space permits). Before the sign is modified or moved it must be approved by the City, however the processing fee shall be waived.

\section{Signage Company}

To insure consistency, it is advised that one sign company be recommended to fabricate the business directional signs.

\section{Installation}

- $\quad$ Once approved the sign shall be installed by the City.

- Signs shall be given to the City for installation within 10 days after the fabrication of the sign is complete.

\section{Maintenance}

It is suggested that the City contract a local non-profit to complete maintenance duties associated with directional signs. Such a contract could greatly benefit a local organization, and would also be consistent with the City's dedication to the preservation and enhancement of the quality of life. Expected maintenance duties are as follows:

- Clean the directory sign, sign structure, and business signs monthly to prevent rust and corrosion.

- Complete a monthly check to insure that all approved signs are in place and that no illegal signs have been mounted. 


\section{APPENDIX A - TABLE OF CONTENTS}

\section{Appendix 1}

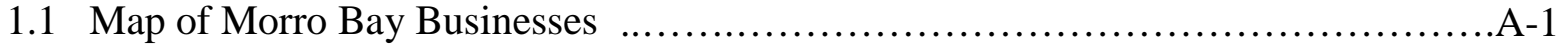

1.2 Map of the Four Sign Ordinance Districts ......................................

\section{Appendix 2}

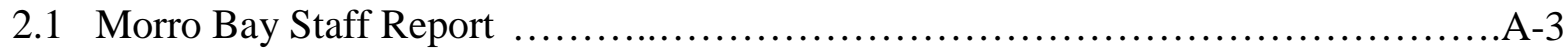

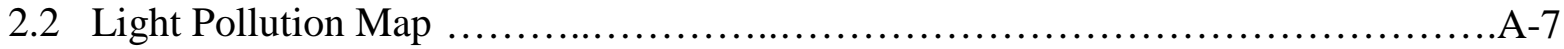

\section{Appendix 3}

3.1 Chapter IV of Morro Bay’s General Plan ..........................................A-8

\section{Appendix 4}

4.1 Past Outreach Survey Monkey Results .........................................

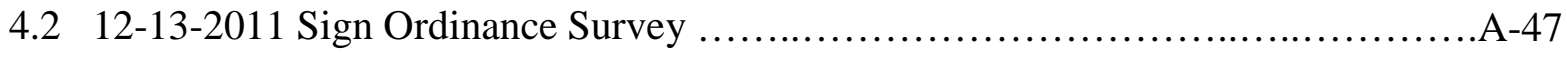

Staff Report Attachments

4.3 Past Outreach Raw Data Table ........................................................A-96

4.4 Primary Business Owner Survey, Cover Letter .......................................9-97 and list of Mail Recipients

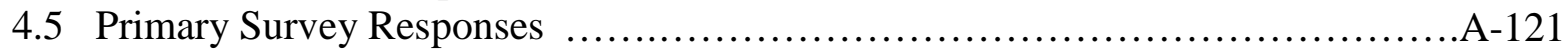

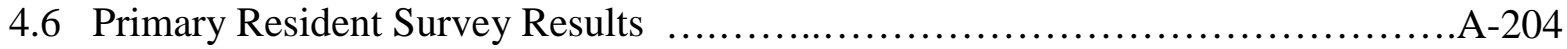

4.7 Interview with Shanna Farley-Judkins .......................................... 210

\section{Appendix 5}

5.1 City of Atascadero Sign Guidelines Handout ....................................A-214

\section{Appendix 6}

6.1 Current Sign Ordinance ......................................................... 218

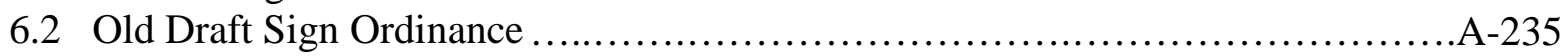

6.3 Current and Draft Ordinance Matrix .........................................-273 


\section{Appendix 1.1}

\section{Map of Morro Bay Businesses}

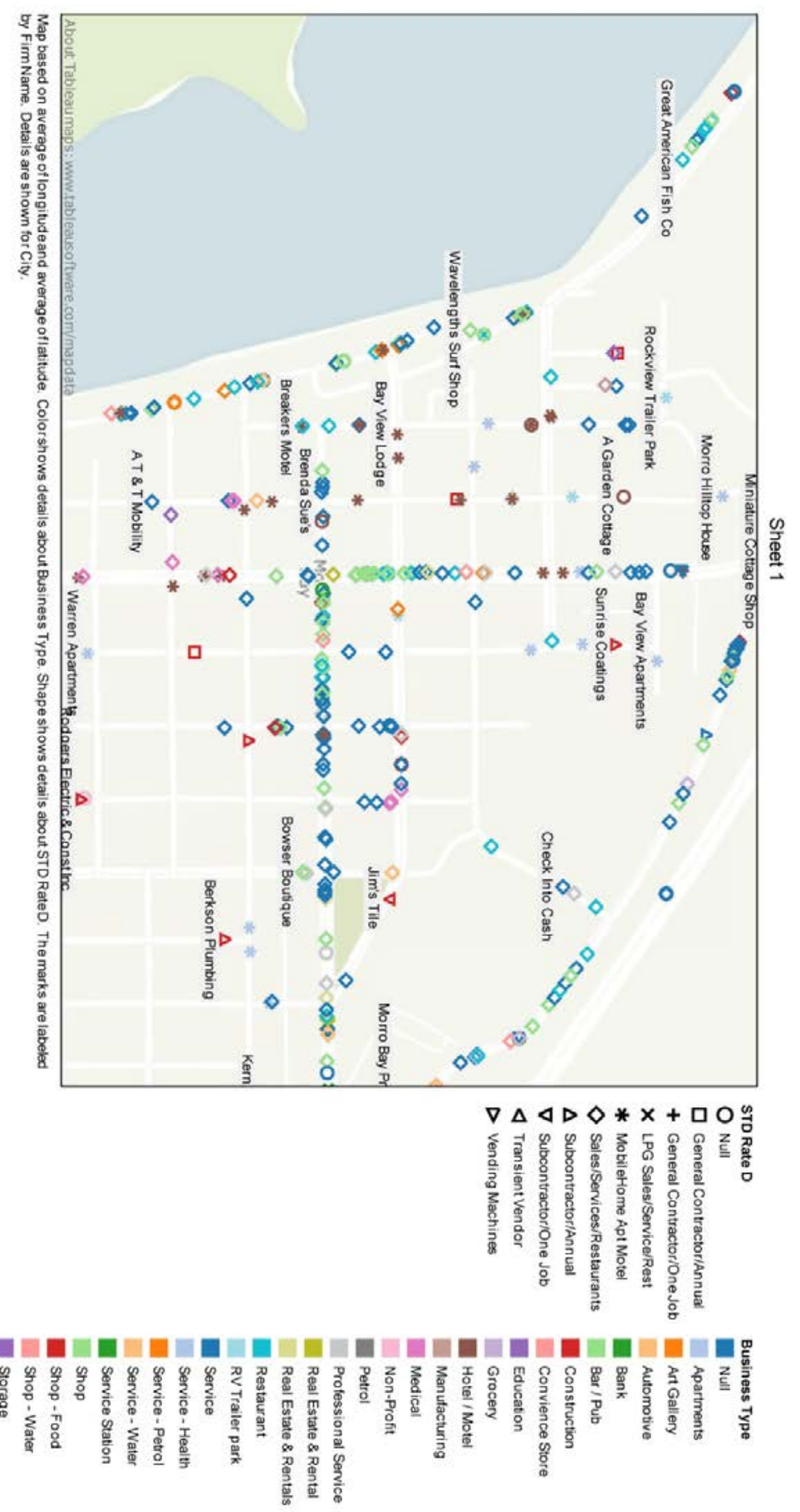




\section{Appendix 1.2}

Map of the Four Sign Ordinance Districts

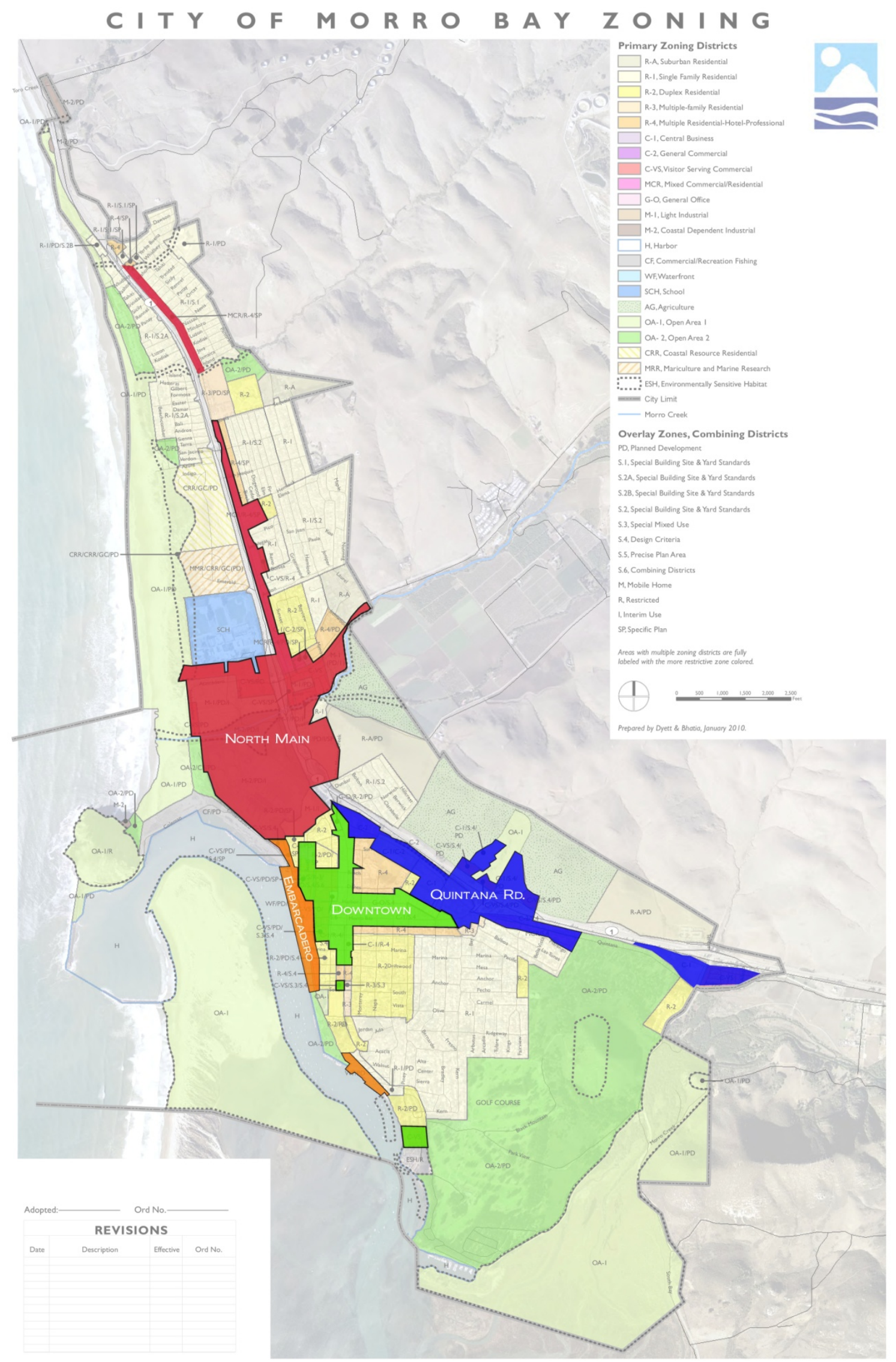




\title{
Appendix 2.1
}

Morro Bay Staff Report

\section{Staff Report}

\author{
TO: $\quad$ Honorable Mayor and City Council $\quad$ DATE: December 5, 2011 \\ FROM: $\quad$ Rob Livick, PE/PLS - Public Services Director/City Engineer \\ Kathleen Wold, AICP - Planning and Building Manager
} SUBJECT: Review and provide recommendations for the City of Morro Bay Sign
Code based on Workshop and Survey Results

\section{RECOMMENDATION:}

Review workshop and survey results and provide direction to staff regarding any modifications to the "Sign Ordinance" to be incorporated into a revised ordinance that will be forwarded to the Planning Commission for review and recommendations back to City Council.

\section{FISCAL IMPACT:}

The processing of this text amendment will require additional staff time associated with processing the amendment through, Planning Commission, City Council and the California Coastal Commission.

\section{BACKGROUND}

At the regularly scheduled City Council meeting on April 12, 2010 the status report on the AFrame Sign Ordinance was presented to the Council for direction. The Council directed staff to bring forward to the Planning Commission a Sign Ordinance Amendment incorporating the Sign Ordinance drafted for the 2004 Zoning Ordinance and new A-frame sign regulations.

Staff worked on the amendment and presented the Sign Ordinance Amendment to the Planning Commission at the regularly scheduled meeting on May 17, 2010. During the meeting, public testimony was received and the ordinance was discussed by the Commission. The ultimate outcome of the meeting was to continue the item to a date uncertain with direction given to staff to hold a workshop on the ordinance to ensure that there was sufficient public input.

At the December 13, 2010 City Council meeting the Council directed staff to place the Sign Ordinance as a high priority on the Planning Division’s work program. On February 16, 2011 a public workshop was held to receive input from the public on the Draft Sign Ordinance. During this meeting input was received from the public and subsequent to this input the Planning 
Commission moved to forward the Draft Sign Ordinance to the City Council with the following changes:

- $\quad$ One A-frame sign per business per frontage during business hours only.

- A-frame or feather sign to be allowed.

- Fee shall be waived until June 2012 for the A-frame signs whereby it would be set at $\$ 40$ as a onetime permit fee.

- Allow for provisions for directional pole signage as brought by Mr. Schmidt of the Chamber of Commerce to include in this ordinance.

- To include corrections of the projection signs section from 12 to 24 inches.

- Include vacation rentals under the Real Estate section.

At the April 19, 2011 City Council meeting an item was brought forth by Mayor Yates and Councilperson Borchard concerning the enforcement of the code prohibiting A-frame signs. At this meeting the Council directed staff to enforce the Sign Ordinance prohibiting A-frame signs and on May 3, 2011 a letter was sent to all businesses within Morro Bay detailing that A-frame signs are prohibited and describing the process by which the City will be enforcing the ordinance.

The draft sign ordinance was scheduled for the May 10, 2011 meeting as a new business item, but at that meeting it was continued to the May 24, 2011 meeting as a public hearing item. At the May 24, 2011 City council held a public hearing and discussed issues regarding the sign ordinance. The City Council adopted an urgency ordinance allowing that established interim rules regulating the approval process and construction of projecting signs pending completion of studies and the preparation of an update to the City's zoning code. Additionally the Council directed staff to hold public workshops and bring the sign ordinance back to the Council for further direction before presenting the proposed sign ordinance to the Planning Commission.

\section{DISCUSSION:}

Public Services staff engaged the services of Chuck Anders of Strategic Initiatives to facilitate two consecutive workshops regarding the sign issues in Morro Bay. The meetings were held on September 29 and October 6, 2011 at the Veteran's Memorial Building. The workshops were attended by representatives of the business community, Chamber and citizens at large. In addition to materials presented at the workshops all of the materials were made available on the City's Website at http://morrobay.ca.us/index.aspx?nid=708.

At the first workshop on September $29^{\text {th }}$, the following items were discussed at the workshop:

- Review history of the existing sign ordinance.

- Discuss structure of ordinance.

- Review the key issues that have been raised in the past.

- Discuss constraints (CCC, general plan, other).

- Review the results from the Tourism Workshop and how BCA is presenting the community.

- Sign ordinance should be aligned with how the community wants to be perceived.

- Discuss how perspectives influence perceptions. 
- Poll each questions to focus discussion on subject.

- Provided some time at end for public comment on related issues.

- Discuss ten different types of signs.

- Current sign rules

- Present results of previous Planning Commission Sign Committee activities.

- Summarize observations and "Takeaways".

- Discuss next steps

o Staff prepares conceptual/preliminary proposals.

o Review alternative concepts and next workshop.

o Discuss implementation methods and timelines.

During the workshop and through the "Survey Monkey" survey tool the consensus of the participants indicated the following:

- The current sign ordinance is not working.

- Not happy with the appearance of signs in Morro Bay.

- Mixed results from respondents regarding having enough signage.

- One hundred percent desired different sign rules for different areas.

- A-Frame signs may be appropriate for some areas.

- Minimize signs in residential areas.

- Allow for exceptions to the sign ordinance for special circumstances.

- Sign materials can be important.

Based on the polling results from the first workshop, staff developed a strategy for a palette of different sign types for different areas in the community, ie Embarcadero, Downtown, and North Morro Bay. North Morro Bay was later designated has "Highway Commercial” to include Quintana Road, which also fronts on Highway 1.

The October $6^{\text {th }}$ workshop built upon the work started at the September $29^{\text {th }}$ workshop ad consisted of the following items:

- Perspective - The sign ordinance should reinforce “The Morro Bay Experience” and promote Morro Bay businesses.

- Reviewed results from first workshop.

- Presented alternative sign ordinance concepts.

- Poll opinions about alternative sign ordinance concepts to focus discussion on pros and cons of alternative concepts:

o Embarcadero Area.

o Downtown.

o North Morro Bay/Highway Commercial (Quintana).

- Presentation by former planning commissioner regarding previous Planning Commission research.

- Conclusions.

In addition to the polling that occurred at the meeting, the Morro Bay Chamber of Commerce assisted staff by polling the entire membership. Ninety-one or 21.6-percent of those (421) emailed responded to the survey. Of those, 10-percent attended both workshops, 80-percent or 73 attended none. One-third of those responding provided comments with their answers. 
Again based on the results of the workshop and polling the participants indicated:

- Desire for different rules for different geographical areas

- A-Frame and Banners may be appropriate for some areas

- No difference between internal and external illumination of signs

Modification of the sign ordinance will require staff time for the writing of new code language and performing the required environmental review. Currently the Planning Division's priority is to focus on current planning activities, i.e. projects that are planned for construction in the near future. In order move the sign ordinance to a higher priority, either a temporary increase in Planning staffing levels or a reprioritization of work load is required; which could result in current projects being delayed.

\section{CONCLUSION}

Based on the approximately 100 plus or minus participants in the sign workshops and survey process, staff can conclude that there is a strong desire for modifications to the sign ordinance to include different rules for different geographical areas, there is still a desire from some participants to allow provisions in the ordinance for A-Frame and flag signs in the "Highway Commercial" areas of North Main and Quintana Road. Staff will refine the sign ordinance based on Council direction and present the revised ordinance to the Planning Commission for their review and consideration. The sign ordinance will then move on to City Council for approval then to the California Coastal Commission for approval. Once all approvals have been received the new sign ordinance can be used and enforced.

\section{ATTACHMENTS}

1. $\quad$ City Council Meeting Minutes from May 24, 2011

2. $\quad$ Presentation from Workshop\#1

3. $\quad$ Sign Ordinance Workshop \#1 Polling Results

4. $\quad$ City (SurveyMonkey) Survey results from Workshop \#1

5. $\quad$ Preliminary Sign Program Prepared for Workshop \#2

6. Sign Ordinance Workshop \#2 Polling Results

7. Chamber of Commerce (Zoomerang) Survey Results from Workshop \#2 


\section{Appendix 2.2 \\ Light Pollution Map}

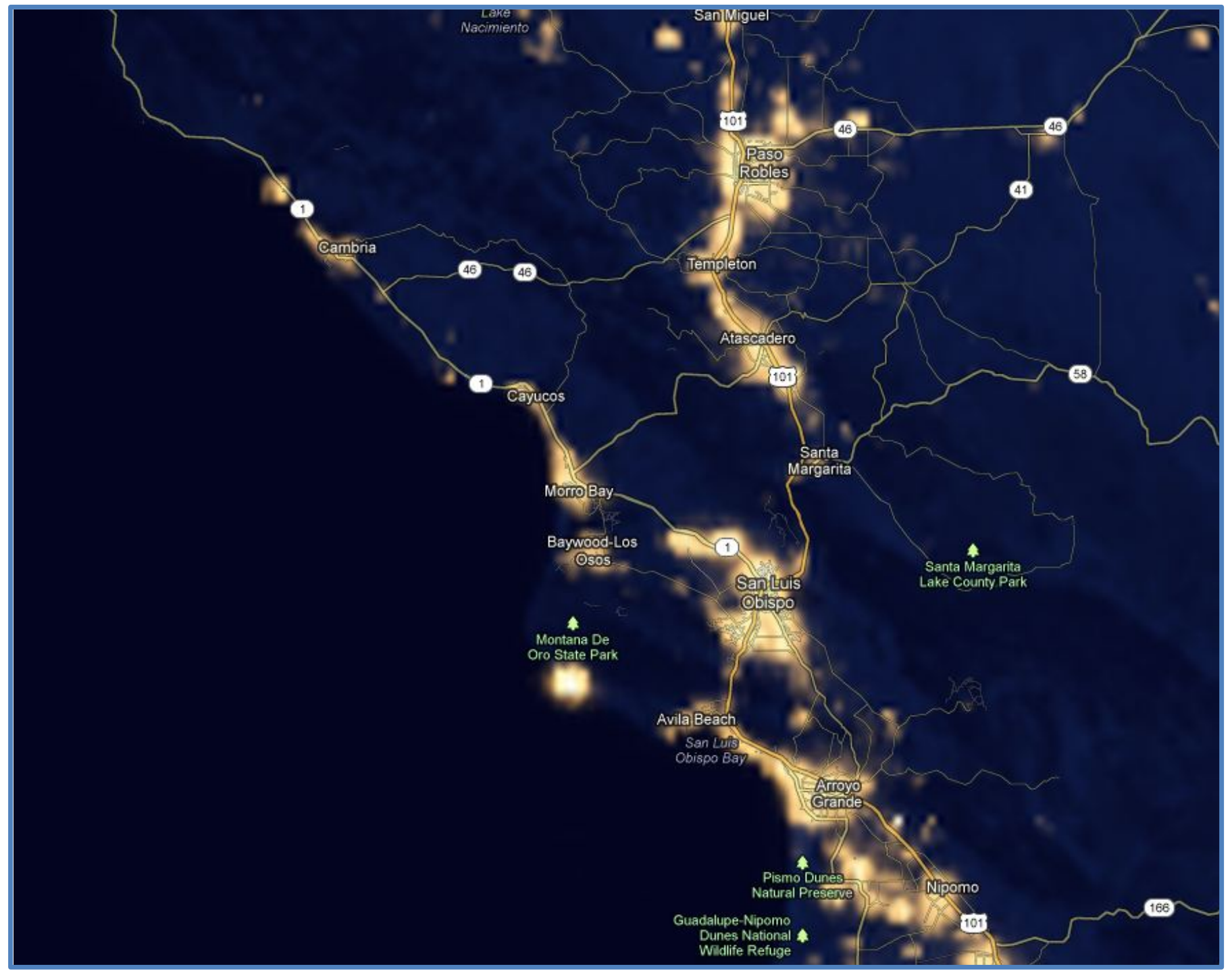

Source: International Dark Sky Association, 2013 


\section{Appendix 3.1}

Chapter IV of Morro Bay's General Plan

(Begins on following page) 
IV

\section{VISUAL RESOURCES}

AND

SCENIC HIGHWAY ELEMENT 
A. Authority and Purpose

IV -1

Assessment of Scenic Values

IV -2

B. Existing Conditions and Issues

IV -6

1. Existing Conditions

IV -6

a. Unique Features

IV -6

b. Waterfront

c. Urban, Commercial and Residential

IV -6

d. Rural

IV -6

e. Scenic Highways

IV -7

2. Issues

IV -7

a. General Visual Resource Issues

IV -10

Property Maintenance

IV -10

Signs and Sign Regulations

IV -10

Overhead Utility Lines

IV -10

IV -11

Landscaping

IV -11

Hillside Development and Grading Practices

IV -12

Protection of Neighborhood Character

IV -12

b. Area Specific Visual Resource Issues

IV -13

Embarcadero

IV -13

Downtown

IV -14

Atascadero Beach Tract

IV -14

Highway 1

IV -14

City "Entryways"

IV -16

C. Objectives, Policies and Programs

IV -17

FIGURE IV

\section{Figure}

VR1

Scenic Views

IV -4

VR2

Areas of Visual Significance

IV -5

VR3

Scenic Highways

IV -9 


\section{IV - VISUAL RESOURCES AND SCENIC HIGHWAY ELEMENT}

\section{A. AUTHORITY AND PURPOSE}

The City of Morro Bay is located in a physical setting with spectacular visual qualities. The visual resources of the community serve as valuable assets to both City residents and visitors, and the protection and enhancement of the resources is one of the foremost policies of the Coastal Act of 1976. (LCP 214)

Scenic views of unique and varied coastal scenes are important to people both in terms of aesthetics and functional qualities. Viewing an attractive scene can be, for many, a rewarding experience. For other people, scenic views give identity, character and value to their community. Visually attractive areas are good locations for recreational activities and facilities, and moreover, are good sites for ports, commercial activities and residential developments, all of economic importance. (LCP Modified 214)

The Visual Resources and Scenic Highway Element Section of the General Plan and Local Coastal Plan establish criteria for the protection, preservation and enhancement of the scenic resources. It also identifies the scenic qualities along major roadways in Morro Bay. (New)

One of the principal purposes of this element is to provide a means for Morro Bay to recognize and protect eligible portions of the state Scenic Highway System within its jurisdiction. An adopted Scenic Highways Element is a prerequisite for official designation of a scenic highway by the California Department of Transportation (Caltrans). A Scenic Highways Element also provides an opportunity for the community to recognize local routes which have unusual scenic quality and to plan for their protection and enhancement. The Scenic Highways Element addresses all of these issues. (SH Modified 6)

The State Scenic Highway System includes the short segment of California Highway One which lies in Morro Bay among the routes eligible for designation as an official scenic highway. This Element examines Highway One's qualifications for official scenic status. A number of local roads were also evaluated for their scenic amenities. From the analysis of Highway one and local scenic roads, policies were developed to help protect and enhance the scenic values of those routes. (SH pg. $26 \mathrm{Co}$. SH Map 11) 
This chapter also addresses the visual quality concerns of the following areas in the community:

(1) Morro Rock

(2) Morro Bay State Park

(3) Morro Rock City Beach/Atascadero State Beach

(4) Morro Creek and the adjacent flatlands

(5) State Highway One

(6) Embarcadero area

(7) Central Morro Bay

(8) PG \& E Power Plant

(9) Coleman Park

(10) Residential Neighborhoods

(11) Undeveloped Land within the City

Additionally, visual concerns relating to the following issues are addressed:

(1) Signs and sign regulations

(2) Landscaping

(3) Utility Lines

(4) Property Maintenance (LCP Modified)

Assessment of Scenic Values

In order to implement the policies of the Coastal Act regarding visual resources, the City identified areas providing significant public views such as Morro Bay, Morro Rock, and the Pacific Ocean.

A scenic view shall be defined as something that is looked at which has significant man-made or natural qualities and which contributes to the identity of a community or area. (LCP Modified 215)

These scenic views can then be further evaluated based upon the following criteria:

(a) the abundance and variety of forms and textures;

(b) the richness and range of color;

(c) the distance and extent of views;

(d) uniqueness of scenic qualities;

(e) the availability of street furniture and public facilities;

(f) the ease of access on foot or by motor vehicle;

(g) the extent of public information.

Because man-made visual quality and natural visual quality are aesthetically pleasing and desirable in different ways, urban views are evaluated under different criteria than natural views. (LCP 215-16) 
Scenic lands are generally more easily described than defined. Nonetheless, the following definitions are useful for the discussion which follows.

Scenic Views: Something looked at which has significantly appealing visual qualities, whether man-made or natural and which contributes to the identity of a community or area. (SH1 Modified)

Scenic corridors: The visible land area adjacent to the highway (or roadway) right-of-way and generally described as "the view from the road". (SH8)

Scenic Backdrop: The element of a view which provides background, e.g. hiliside, bluffs, or ridges. (SH1)

Scenic Vistas: Sweeping views of large visually attractive areas. (SH1)

Official state scenic Highway and official county scenic Highway: Scenic highways officially designated by the California Department of Transportation (CalTrans) after application from local jurisdictions and only if listed with eligible highways in the California Streets and Highways Code. (SH8 Modified)

The criteria used for assessing views of the urban environment include such things as:

(a) the enhancement of the City's character through the use of building materials and scale of the structures;

(b) the compatibility with surrounding structures;

(c) the compatibility with the natural features of the area (i.e. topography);

(d) the preservation of public views;

(e) the enhancement and definition of the City's image;

(f) the uniqueness of the City's image. (LCP 216)

Based upon these criteria, natural open space areas, residential neighborhoods, and commercial zones with significant scenic resources or community character were identified and evaluated. Figures VR-1 and VR-2 show the location of scenic views and identify these areas of visual significance. (These areas are further defined in Volume 2, the Local Coastal Plan.) (LCP Modified) 


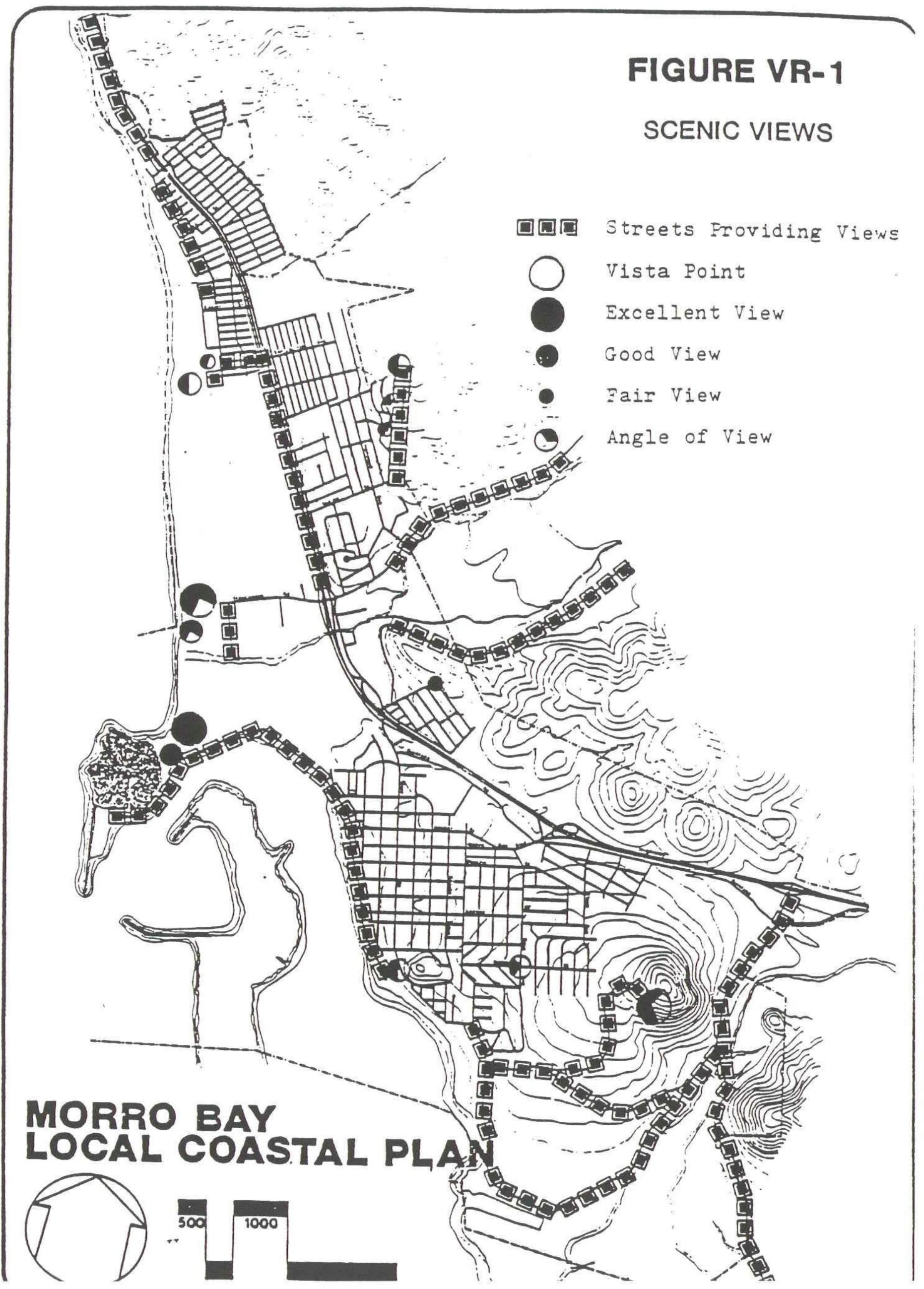




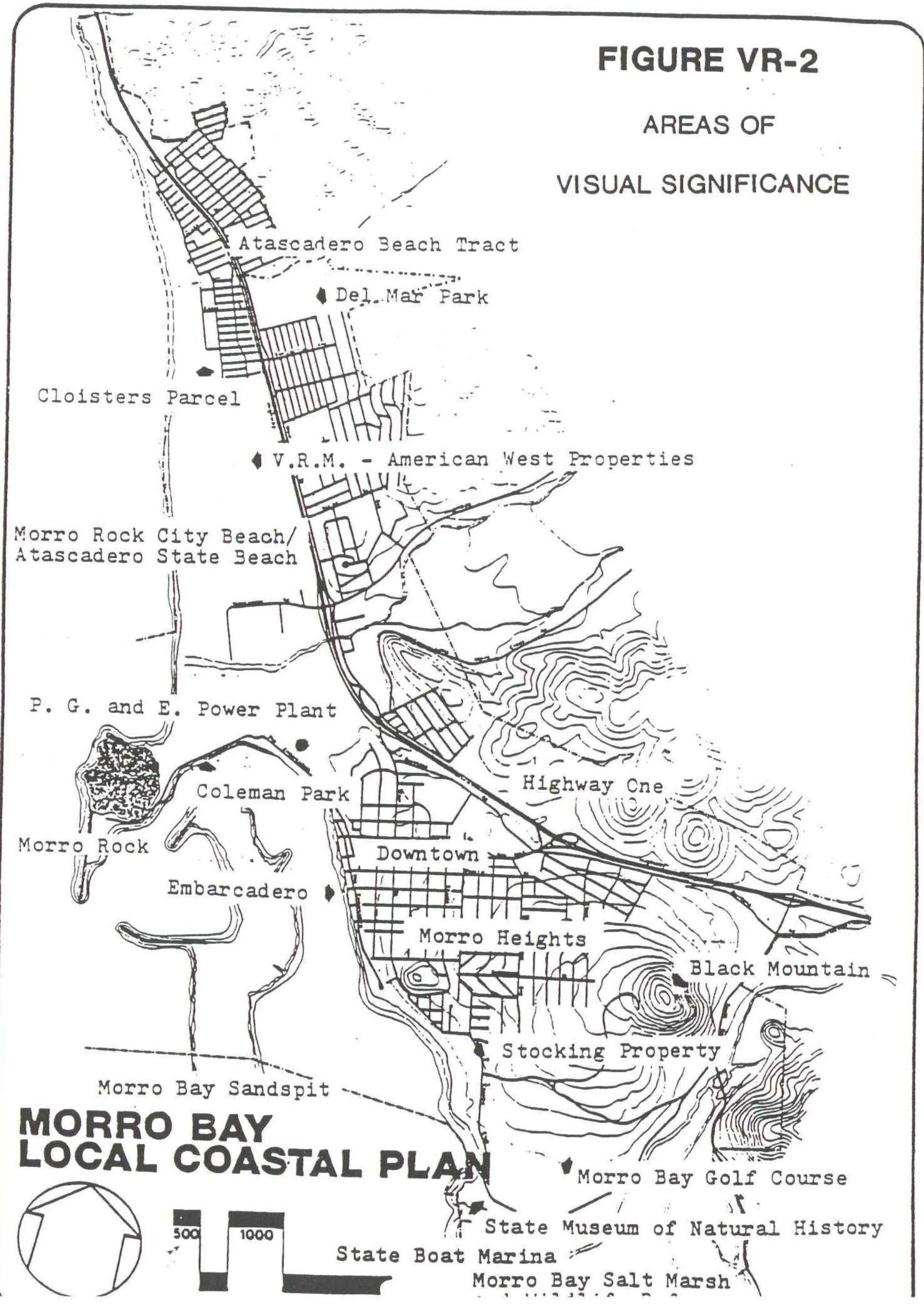




\section{B. EXISTING CONDITIONS AND ISSUES}

\section{EXISTING CONDITIONS}

a. Unique Features: The landmark of the community, Morro Rock, is probably the most significant visual feature of the area and can be seen from almost any location in Morro Bay. (LCP 218)

The massive PG\&E Power Plant is the dominant man-made form in Morro Bay. While its prominent waterfront location at the heart of the community, and other aspects of the installation have significantly detracted from the visual quality of Morro Bay, the facility's three 450 feet high exhaust stacks, visible from miles away, are considered by some to be a familiar, albeit misplaced, local landmark and part of the community's visual character. (LCP 218)

Forming the outer shore of the Bay is the sand spit, a pristine, windblown peninsula visible from the Embarcadero, Coleman Drive, the state Park roads and from bluff and hillside residential areas. (LCP 221)

b. Waterfront: More than half of Morro Bay's physical edge is coastline, and it is this land-sea interface which creates the City's water-oriented character, both natural and urban, both visual and functional. The Pacific Ocean, the "working" harbor and the great saltmarsh at the southern end of the City dominate the landscape, and provide the sweeping vistas of ocean, beach, dune, bluff, and marsh, as well as the quaint harbor-side scenes for which Morro Bay is noted. (SH)

c. Urban, commercial and Residential: Commercial development in Morro Bay is concentrated in three area: the Embarcadero, with its mixture of visitor serving and harbor uses; in the central business district, composed of small businesses with Morro Bay Boulevard as the main artery; and a strip of mostly commercial uses to serve both visitors and residents along Main Street and Quintana Road, parallel with Highway 1.

While some enjoy the jumble of activities at the waterfront and appreciate the resulting visual variety, others lament an "unkempt" appearance which detracts from the area's natural beauty. The downtown area and other commercial corridors are notable for their lack of architectural coordination and sparsity of landscaping.

The character of residential neighborhoods in Morro Bay is largely a reflection of their natural setting. The wellestablished and well-tended charm of Morro Heights and older bluff-top residences is visible from the Embarcadero and Coleman Drive areas. The low-lying Atascadero Beach Tract can be said to harmonize with and capitalize on its prime ocean-front location. 
The residences perched on the City's eastern hillsides are considered attractive by some, and certainly well located for the sweeping views they themselves afford. However, pervasive utility lines and poor property maintenance in some areas detract from the character of some of the City's residential neighborhoods. (SH)

d. Rural: The hills and ridgelines climbing up from the coastal bench and the agricultural flatlands of the Morro and Chorro Valleys provide a scenic backdrop for the community. Their color, texture and shape contrast sharply with the urban areas and coastline, giving a visual definition to the urban form of the City, and reinforcing Morro Bay's image and character as a small- scale town within a rural setting.

The community's country-like character is further established and enhanced by the combination of natural and manmade features in Morro Bay state Park, such as Black Hill, the golf course and campground, which comprise a large portion of the southern part of the City. (SH)

e. Scenic Highways: The State Scenic Highways System (or Master Plan) consists of a list of those segments of state highways which are eligible, should they meet certain standards, for official Scenic Highway designation.

Before one of these eligible routes can be officially designated as a state Scenic Highway, however, the local government whose jurisdiction abuts the highway must act to recognize and protect the scenic quality of the highway's scenic corridor. The city or county must pursue the following steps before the highway is officially designated as scenic:

1. The local legislative body having jurisdiction over lands adjacent to a segment of an eligible scenic highway must adopt a Scenic Highways Element in its General Plan and request the Director of Transportation to make a corridor survey and highway facility study.

2. The local jurisdiction must prepare, adopt and submit to CalTrans for review, a program to protect and enhance the scenic appearance of the corridor. The program shall address, but not be limited to: (1) regulation of land use and intensity (density) of development; (2) detailed land and site planning; (3) control of outdoor advertising; (4) careful attention to and control of earth moving and landscaping; and (5) the design and appearance of structures and equipment.

3. When CalTrans determines that the corridor protection program for a segment of any state highway in the scenic Highway system has been implemented by the local 
jurisdiction and a plan and program has been developed by CalTrans for bringing the highway up to the standards for official Scenic Highways, the familiar "California Poppy" signs are placed along the highway to indicate its official status.

Two state highways lying partially in Morro Bay are eligible for official scenic highway status: Highway one and Highway 41. All but a very small section of Highway 41, however, is outside the City in unincorporated county land. Thus, it is not discussed in this Element, and remains the concern of San Luis Obispo County. Highway one, on the other hand, travels the entire length of the City and issues related to designating the City's portion of the highway as scenic are analyzed in this Element.

County roads may also be designated as Scenic Highways by the same procedure described above. There are presently no roads in Morro Bay, however, which are eligible or designated county Scenic Highways.

While the Scenic Highways Element is principally a city's planning tool for evaluating eligible state scenic highway segments within its boundaries and for meeting the requirements for official state designation, it can also be a mechanism for cities to identify and protect local routes with scenic significance. This Element analyzes some local roads popular with residents and visitors for their scenic significance, and recommends policies for protection and enhancement of their scenic qualities. ( $\mathrm{SH}$ ) Figure VR-3 indicates the locally significant scenic roads as well as state Highway 1.

In addition to Highway one, three routes within Morro Bay have been found to possess especially significant scenic features as well as meet the other criteria for appropriateness as a designated scenic road and have therefore been included in this Element as deserving recognition and protective measures. These routes are the Embarcadero, Coleman Drive, and the Morro Bay State Park road system. The original text of the Scenic Highway Element contained in Volume II provides a description of the scenic qualities, including specific vistas and viewpoints and viewpoints and related facilities. (SH Modified) 


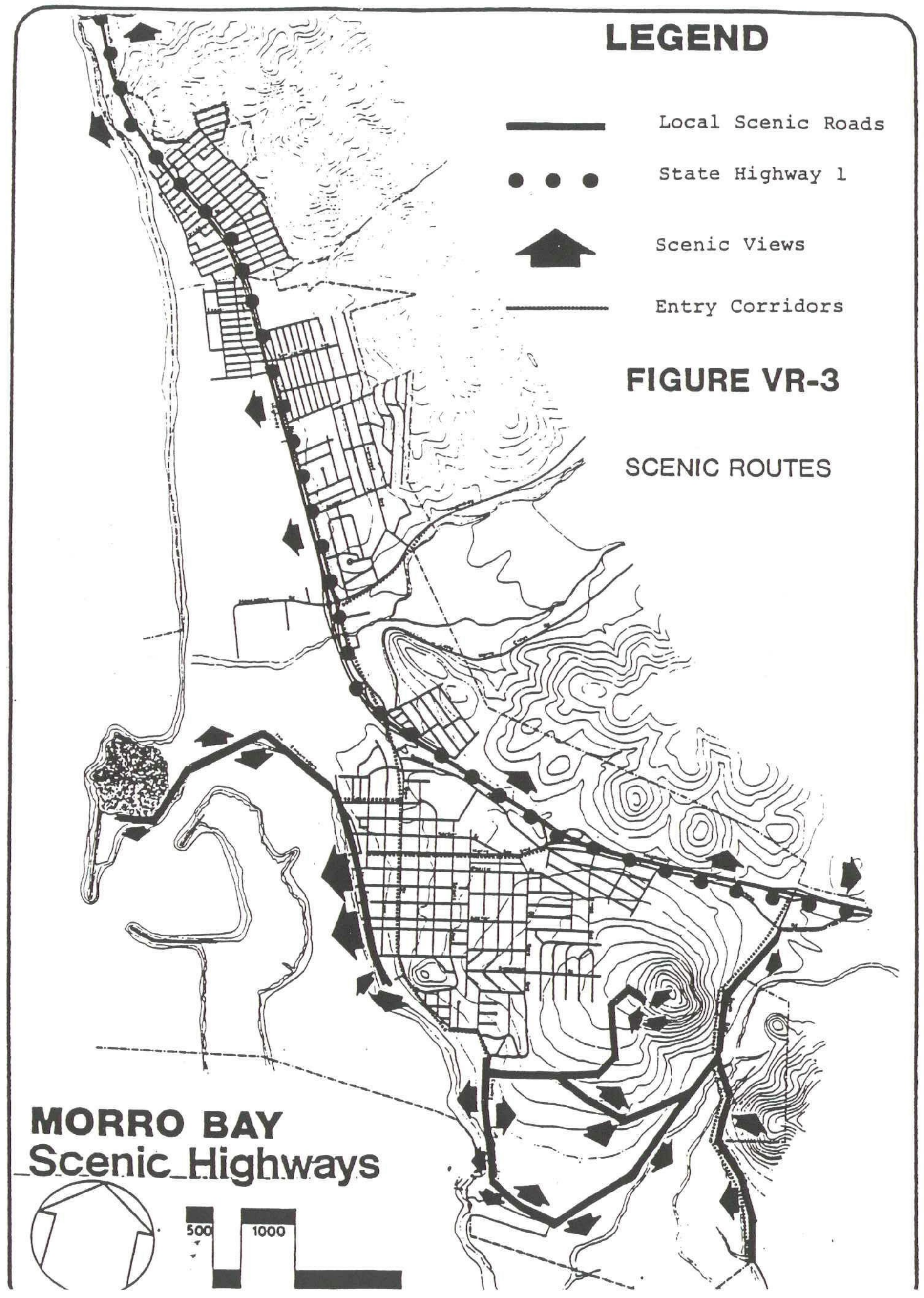


2. ISSUES

While Morro Bay has been blessed with a physical setting of unique and spectacular visual quality, the community can improve, take better advantage of, and prevent abuses to its visual character.

It is desirable to enhance Morro Bay's views. It is equally desirable that the City consciously seek to take better advantage of its visual qualities while attempting to restore and repair the damage that has been done to those qualities. (LCP 221)

\section{a. General Visual Resource Issues}

Property Maintenance: One issue tnat has detracted from the visual character of Morro Bay is poor property maintenance. An inordinate number of abandoned buildings and cars, buildings with peeling pain, accumulated debris and junk, substandard housing, unscreened trash containers, and conflicting nonconforming uses have served to tarnish Morro Bay's natural beauty. It has become such a problem that the City has developed a property maintenance code to designate poor property maintenance as a nuisance and violation of the code subject to formal citation and abatement. The problems of poor property maintenance are particularly acute in the neighborhoods of northern Morro Bay and in the Downtown, Quintana, North Main, and Embarcadero Commercial Areas. The problem areas could be corrected in order that Morro Bay can restore and enhance its visual character. (LCP Modified 221)

Signs and Sign Regulations: Signs in Morro Bay have come to be a problem, detracting from the visual quality of the community and in some cases interfering with important views. Among some of the problems associated with signs are:

(1) Failure to remove old, non-functional or nonconforming signs.

(2) The allowable height and size of signs are excessive under the existing ordinance.

(3) The lack of a realistic and enforceable timetable for the amortization of nonconforming signs.

(4) The proliferation of lighted signs that have excessive glare or are offensive to nighttime vision in the community.

(5) The lack of appropriate design standards that would better guide the size, type, color, location, lighting, and materials of construction of signs. 
(6) Failure to consider views when reviewing applications to erect and light signs. (LCP)

Qverhead Utility Lines: Throughout Morro Bay's residential neighborhoods an $\bar{d}$ most of its commercial areas, there seems to be a maze of overhead utility lines darting in every direction. While this problem is not unique to Morro Bay, it seems particularly acute in this community, particularly in the northern sections of the City. This web of lines serves to both:

(1) create a jumbled, blighted appearance for those areas in which it is most predominant;

(2) interfere with, obstruct, and in some cases render unsightly views that would otherwise be spectacular.

Existing utility lines will continue to plague what is visually pleasant about Morro Bay and detract from property values unless a concerted effort is taken to eliminate this eyesore. (LCP 222)

Landscaping: With the notable exceptions of the Morro Heights area, isolated tree groves in selected areas of the community, and those few locations where a street tree program has been implemented, Morro Bay requires additional landscaping.

Among some of the problems associated with landscaping and the need to provide more landscaping to enhance and/or restore Morro Bay's visual qualities are the following:

(1) The lack of landscaping along Highway One exposes numerous views that detract from Morro Bay's visual qualities.

(2) There are no regulations to prevent the removal of existing trees and vegetation that have helped establish a rural character for some of Morro Bay's neighborhoods.

(3) The City's street tree program has not been progressing and some of the specimens called for by the Master Tree List are inappropriate.

(4) The lack of water will continue to inhibit any attempts to make significant landscaping improvements in Morro Bay.

(5) While there are zoning districts that call for special landscaping and architectural treatment in new developments, there are areas critical to the community's visual quality - i.e. the downtown -- that are not included in these districts. 
(6) The lack of clear regulations and standards for landscaping of buildings and parking lots is inhibiting opportunities to take better advantage of Morro Bay's visual qualities.

(7) Landgrading operations have created unattractive scars and cut faces in hillside areas, and there are no regulations governing the protection of cut slopes with attractive, erosion preventive plant materials. (This can be solved with enforcement of grading ordinance; see Chapter $\mathrm{X}$, Hazards).

Hillside Development and Grading Practices: Some hillside areas within the community have not been developed with regard for the natural topography. Existing subdivisions reflect design criteria more suitable for flat land areas. Some past grading practices also did not take into account the natural topography of the terrain, leading to erosion and scarring of the hillsides. been:

Some of the problems associated with these subdivisions have

(1) Existing development has not followed the natural contours of the hillsides, detracting from the visual qualities this scenic backdrop can provide;

(2) Streets in these portions of the community traverse directly up the hillside, often at ninety degrees to the natural contour.

(3) Ridgelines that help define the eastern edge of the community are not protected from development that would lessen the visual quality of the hillside areas.

(4) Grading practices are not required to reflect as much as possible the natural contours resulting in substantial and unnecessary alteration of the landscape.

For further discussion of hillside concerns see Chapter $\mathrm{X}$, Hazards. (LCP 224)

Protection of Neighborhood Character: One of the priorities of the coastāl Act is the protection of the character of the community and its neighborhoods. Morro Bay recognizes the need to preserve the unique character of its varied neighborhoods and to create a higher quality visual environment within them. Among some of the issues that predicate the establishment of policy to preserve neighborhood character are the following:

(1) New residences and new residential additions are often out of scale and character with other residences in the vicinity. 
(2) The current allowable height and bulk for residential development is not appropriate for some portions of the community. Such buildings would in many cases block important views and conflict with the character of individual neighborhoods.

(3) Standards or guidelines are needed to create buffers between conflicting land uses;

(4) There is a need for a balancing formula governing the allowable height and bulk of residential and commercial buildings.

\section{b. Area Specific Visual Resource_Issues}

There are three neighborhoods which require consideration for neighborhood character protection. These are the Embarcadero, the Downtown and Atascadero Beach Tract (Planning Area I). It should be noted that protection of community character does not mean protection of or continuation of dilapidated buildings, no community improvements or no progress. It means that the enjoyable qualities of the area should be preserved as much as possible. (LCP 224)

Embarcadero: Development of waterfront areas along the Embarcadero, as well as along the bluff above the waterfront is an integral part of the views of the bay and Morro Rock and the views from this area should be enhanced.

The Embarcadero is a random mix of tourist and harborrelated uses that creates certain circulation problems, both vehicular and pedestrian. This random mix does, however, give the area a charm and honesty not found in pre-planned areas. This honesty and individualistic appearance should be encouraged, mindful of a desire for harmony (rather than homogeneity) and its waterfront/bay orientation. Visual problems present on the Embarcadero include:

(1) A lack of landscaping to soften and screen the less pleasing visual impacts of the existing development;

(2) An additional need for public improvements, specifically the paving of parking lots, upgrading restroom facilities and park improvements;

(3) A need to establish standards for signs;

(4) A need to screen rubbish and storage areas; 
(5) A need for underground utility lines on the Embarcadero and along the Bluff;

(6) A need for an effective clean-up and maintenance program.

Circulation problems on the Embarcadero include:

(1) A need to widen sidewalks;

(2) A need to locate long-term parking for sports fishing activities where such use will not create parking congestion. (LCP 225)

Downtown: The downtown business center presents an uninteresting visual appearance to the public. A poor mixture of architectural styles have served to visually fragment this district and sever its connection with the Embarcadero. Other visual concerns facing the downtown are:

(1) A lack of continuity in colors and building materials which lessens visual quality and denies the area character; it also does not emphasize unification and common business goals of the downtown area;

(2) Landscaping is lacking, especially when needed to screen parking areas that lessen scenic qualities;

(3) Overhead utility lines are an eyesore and should be undergrounded;

(4) A lack of design continuity in signs also lessens visual qualities and character. (LCP 225)

Atascadero Beach Tract: This ocean-front neighborhood is visually well defined, consisting mostly of single story residences. Problems facing the protection of this neighborhood's visual qualities are:

(1) Existing zoning would allow new residences with height not in keeping with neighborhood characteristics;

(2) Existing Eucalyptus groves add a visual quality to the neighborhood but can be a problem species;

(3) Development on adjacent vacant property may impact the visual characteristics of the Atascadero Beach Tract. (LCP 226)

Highway 1: The portion of state Highway one in San Luis Obispo County, north of Highway 101 in San Luis Obispo, has been 
recognized as possessing outstanding scenic quality by the state legislature and accordingly, has been declared eligible for official "scenic highway" status. Of the approximately 53 miles of "scenic" Highway one winding through San Luis Obispo County, less than six miles, or about ten percent, lies in Morro Bay. Most of the potential scenic highway is in unincorporated county territory. Consequently, establishment of the highway as "scenic" is properly a greater-than-local project which must be pursued with the cooperation of the county on an area-wide or regional basis. (SH Modified)

Before the highway can be officially designated as "scenic", the local government with land-use jurisdiction for the highway corridor must establish development controls and standards sufficient to ensure that significant scenic resources visible from the road have been protected. In large measure, this has already been done within Morro Bay through the preparation and adoption of the Local Coastal Program. (SH Modified)

Thus, in terms of acquiring official scenic highway status for Highway One, the initial step should be to approach the County to put together a county-wide or regional application to the state. Each jurisdiction should develop appropriate land use controls and standards for its portion of the highway. Once this was accomplished, the jurisdictions could apply together to have the entire eligible length, or a substantial portion of Highway One within the county, designated as "scenic". Therefore, if Morro Bay wishes to pursue scenic highway status for Highway One, it should contact the county to initiate discussion of a joint application. (SH)

In addition to the general issues described for enhancement and protection of visual resources along Highway 1 , a specific landscape program is necessary. Implementation of such a program would be desirable for Highway one in Morro Bay, where the present design of the highway right-of-way itself clearly lacks consideration of visual, aesthetic values. (SH Modified)

From near the Main street exit in the northern City limits, neither the median nor the shoulder areas of this highway are landscaped in any manner. The median should be planted with low-scale shrubs and ground cover. Landscaping should generally not exceed eye-level, to retain views of the sea from northbound lanes. One concept is to place soil in a low-lying median barrier which is planted with low-growing, draping, flowering vegetation, such as bougainvillea. This treatment would dramatically improve the appearance of Highway one in Morro Bay. Trees or taller shrubs should be permitted in the median only if clustered to allow significant view opportunities to the west and where safety could be maintained. (SH Modified)

The portion of the right-of-way outward from the emergency land/shoulder should also be treated, especially in the areas 
from Atascadero Road to Yerba Buena street and south of the Morro Bay Boulevard. On the west side, care should be taken where appropriate so that views to the sea are not blocked. This is generally not a problem because the area between Atascadero Road and San Jacinto street, which currently provides the best views to the sea, is at a significantly lower level than the highway, and roadside landscaping treatment should not affect those views. ( $\mathrm{SH}$ Modified)

On the east side, low roadside landscaping would help make the chainlink fence separating the highway from Main street more aesthetically acceptable. No views of especially important scenic quality would be blocked by this treatment. The pastoral foothills are steep and project above the road, and would, therefore, remain visible. Further study of the best treatment seems to be in order before recommending a preferred solution. It is clear that landscaping improvements to this part of Highway One are needed, and the City should petition CalTrans to instigate such improvements. (SH Modified)

City "Entryways": In addition to the scenic routes, the City's "entryways" are also important with regard to preserving and enhancing visual amenities. If the axiom that first impressions are most important is applied to Morro Bay, then entry corridors should receive considerable attention particularly when one considers that tourism is one of the principal economic bases for the City. The entryways to the City are indicated on Figure VR-3. (SH Modified)

Morro Bay's southernmost entrance is from South Bay Boulevard, leading through Morro Bay state Park; this entryway, along with all the state Park roads, has been recognized as a local scenic route. (SH)

The major entryways from the freeway to the Embarcadero, the Harbor and Morro Rock are from Morro Bay Boulevard, through downtown, and along North Main Street to the waterfront via Beach Street. In both cases, significant improvements to the visual quality of the road corridors should be made. (SH)

The other principal entryway to the city is at the intersection of Routes one and 41. Again, the visual quality of this area is seriously impaired by the lack of landscaping, excessive signs, vacant and unkept properties and overhead utilities. ( $\mathrm{SH})$

The City should exercise strict design control over new development along these corridors to improve architectural coordination and quality. Special sign controls and landscaping requirements should be applied in these areas. Further, establishment of future utility undergrounding districts by the City should focus on these entryways. (SH) 
In addition, better informational signs should be placed along these routes to direct travelers to the numerous visitor services and attractions. These signs should also be designed to improve the aesthetic quality of the routes, and to help establish a sense-of-place, so that people will better recognize and appreciate Morro Bay as a desirable place to visit. (SH)

\section{OBJECTIVES, POLICIES AND PROGRAMS}

OBJECTIVE: To enhance, protect and preserve the existing and potential visual resources of Morro Bay and its surroundings.

POLICY VR-1: The City will establish a system of scenic roadways and a set of mechanisms to protect their scenic values. (New)

Program VR-1.1: The City shall request the county of San Luis Obispo to join with Morro Bay in making application to Caltrans to pursue official scenic highway designation for Highway one. (SH26)

Program VR-1.2: Morro Bay will request that the County and State consider designating state Highway 41 east of the City, State Highway One, South Bay Boulevard, and Main Street in the Morro Bay state Park area as scenic highways when completing the County and City Scenic Highway Elements.

(LCP 231)

Program VR-1.3: The City shall recognize and so designate the local roadways identified in section $A$ of this Element, and shown on Figure VR-3, as "local scenic routes", and take the necessary measures, as provided in this El'ement, to protect and enhance their scenic qualities. (SH 26)

Program VR-1.4: Morro Bay shall request the Division of Highways to develop a plan and program for landscaping the entire length of State Highway one as it traverses through the community that would:
a. Frame and protect important views;
b. Screen unattractive views;
c. Accentuate entrances to the City. (LCP)

POLICY VR-2: The scenic and visual qualities of coastal areas shall be considered and protected as a resource of public importance. Permitted development shall be sited and designed to protect views to and along the ocean and scenic and coastal areas, to minimize the alteration of natural land forms, to be visually compatible with the character of surrounding areas, and where feasible, to restore and enhance visual quality in visually 
degraded areas. New development in highly scenic areas such as those designated on Figure VR-1, shall be subordinate to the character of its setting. (LCP 226)

Program VR-2.1: Permitted development shall be sited and designe $\bar{d}$ to protect views to and along the coast and designated scenic areas and shall be visually compatible with the surrounding areas. Specific design criteria shall be established for the following areas:

a. The Embarcadero (as defined in Policy
b. Downtown commercial area

The criteria shall include the following specific requirements and shall be applied to proposed projects on a case-by-case basis during architectural review:

a. Building height/bulk relationship compatible with existing surrounding uses;

b. Landscaping to restore and enhance visually degraded areas using native and drought resistant plant and tree species;

c. Preservation and enhancement of views of the ocean, bay, sand spit and Morro Rock;

d. Any other requirements applicable from Coastal Commission conceptual approval of the Urban Waterfront Restoration Plan. (LCP 226-27)

Program VR-2.2: New development in areas designated on Figure $\bar{V} R-2$ as having visual significance shall include as appropriate the following:

a. Height/bulk relationships compatible with the character of surrounding areas or compatible with neighborhoods or special communities which, because of their unique characteristics, are popular visitor destination points for recreation uses.

b. Designation of land for parks and open space in new developments which because of their location are popular visitor destination points for recreation uses.

C. View easements or corridors designed to protect views to and along the ocean and scenic and coastal areas. (LCP 230)

POLICY VR-3: The City shall implement the Coastal Land Use Plan/Coastal Element map and policies, through the adoption of 
appropriate ordinances, to protect and enhance the visual resources associated with the corridors of the City's scenic highways and local designated routes. (SH 27)

Program VR-3,1: The City shall enforce current sign regulations which require amortization of non-conforming signs and investigate institution of a new amortization schedule to accompany new sign regulations adopted as part of the Local Coastal Program implementation phase. The length of the amortization period should be such that economic hardships are not placed on present sign owners. (SH 27)

Program VR-3.2: The City shall, as part of the implementation phase of the LCP, adopt new provisions to:

a. Require monument and surface mounted signs and discourage roof mounted and pole signs;

b. Require that view protection and the nighttime characteristics of the sign be mandatory considerations of any sign installations;

c. Prohibit billboards;

d. Reduce allowable height and size where they interfere with views to and along state Highway one.

e. Develop and adopt sign criteria for signs appropriate for Morro Bay's commercial districts. (LCP 230)

Program VR-3.3: The City shall develop special design criteria for the development of the Coleman Drive planning area to include the following:

(1) Development of the landward portion of the area shall be limited to only low profile structures necessary to support development of commercial fishing facilities. Structures shall be sited to protect existing views available to Morro Rock and to and along the ocean and structures shall be subordinate to the character of the setting.

(2) New development shall not encroach within the setback areas of the sensitive habitat located on Morro Rock. (LCP 227)

Program VR-3.4: Industrial development shall be sited and designe $\bar{d}$ in areas specifically designated in the Land Use Plan to protect views to and along the ocean and scenic 
coastal areas, to minimize land alteration, to be visually compatible with the character of the surrounding areas, and where feasible, shall include measures to restore and enhance visually degraded areas. In addition, industrial development shall be subordinate to the character of its setting. (LCP 231)

Program VR-3.5: Development between state Highway One and the ocean in Planning Areas 1,2 and 5 shall provide view corridors as defined in Policy $12.02 \mathrm{~B}$ and by Figure 32 so as not to significantly degrade views to and along the coast from Highway one. New development shall be subordinate to the character of its setting and shall be visually compatible with the surrounding areas. (LCP 229)

Program VR-3.6: The City shall require a detailed development plan for Mixed Use Area G consistent with Policy 12.02.B. Any development shall be subordinate to the unique and sensitive visual character of the area. Design methodology shall include areas of clustered development, varying building heights, roof lines and setbacks, visible common open space areas and landscaping controls which ensure that full grown tree species are selected for heights which do not obscure views. The development plan shall preserve to the maximum extent feasible traditional public visual access from Highway one of the dunes, Morro Rock, and the open ocean and coastal headlands to the north. The plan shall at a minimum include the following visual resource design standards:

1. The public view corridor from Highway one is established as defined in Figure 32. As a condition of future development approval a long term scenic conservation easement agreement shall be entered between the property owners and the City covering the area within the designated public view corridor. Within the view corridor the following development limitations shall apply and these shall be reflected in the scenic conservation easement:

a. no structure shall exceed four (4) feet in height above grade pursuant to Morro Bay Municipal Code Section 17. 12.310 (B) and as hereafter amended except for small public restrooms,

b. landscape screening shall not exceed eight (8) feet in height, or block more than $10 \%$ of the viewshed from Highway One,

c. only open space, lateral access, parking areas, golf, passive recreational uses and mariculture activities shall be allowed in the public view corridor. (LCP 227) 
d. Any development shall be subordinate to the unique and sensitive visual character of the area and shall contain visual corridors and standards as defined in Policy $12.02 \mathrm{~B}$ in the LUP. In addition, development on the parcel outside of defined visual corridors shall be limited to a height of 25 feet, as measured from the lowest possible first finished floor elevation. Design methodology shall include areas of clustered development, varying building heights, roof lines and setbacks, visible common open space areas and landscaping controls which ensure that tree species are selected for maximum heights which do not obscure views. The development plan shall preserve to the maximum extent feasible visual access benefits seen from Highway one through the dunes to Morro rock and vicinity through careful design and siting of structures and site improvements. (LCP Program 1.13b)

Program VR-3.7: Consistent with Policy_, a specific development plan shall be required if and when supplemental uses are found to be consistent with the agricultural policies contained in the LUP and the Coastal Act. Visual resources for the specific plan shall include:

(1) Development shall be sited in clusters on the most level portions of the site adjacent to Highway one. Development shall be compactly clustered onto the portions of the site that have stable slopes of 5 to $15 \%$ and shall not cover more than $2 \%$ of the gross acreage of the property
both within and outside the city.

(2) Prior to the siting of new structures, a detailed geotechnical report shall be prepared in accordance with Policy The report shall define which portions of the site are less suitable for new development due to geologic constraints.

(3) Portions of the site outside of the approved development area shall be retained in open space or of the area.

(4) Structure heights shall not exceed 18 feet above average finished grade of each site pad except that structures designed and approved for visitor-serving lodging may be two stories, not to exceed 25 feet in height, above
existing grade. 
(5) The visual impact of any development on views from Highway one shall be minimized to the maximum extent feasible through the utilization of native plant species indigenous to the area. (LCP 229)

POLICY VR-4: Morro Bay will modify its ordinances so as to:

a. Develop clearer requirements, standards, and criteria for installation of landscaping and retention of existing specimen trees as part of new developments, parking lots, etc.;

b. Prohibit land grading that will create large cut faces, and where minor alteration is necessary, require plantings and appropriate maintenance to conceal and prevent erosion of cut faces. (LCP 231)

Program VR-4.1: The City shall review its zoning districts and revise them as necessary to require appropriate landscaping and the screening of dumpsters, parking lots and other visually obstructive elements as a condition for new development, or redevelopment, especially in all commercial districts. (SH)

Program VR-4.2: The City shall investigate the feasibility of special landscaping requirements for new development or redevelopment along scenic routes and entryways. (SH 28)

Program VR-4.3: The City shall review its existing street tree program to ensure it is adequate. Particular attention shall be given to the following concerns:

- the types of species permitted, especially with regard to their water needs and maintenance costs.

- analysis of the costs for installation and maintenance of street trees and an investigation of funding sources to help offset these costs, such as special appropriations from the general fund, assessment districts or urban forestry grants. Priority for installation of new trees shall be given to the Embarcadero and the entryways designated on Figure 1 .

- an analysis of street tree management plans which could involve non-profit groups. (SH 29)

Program VR-4.4: The City shall develop guidelines regarding the form, height and placement of trees which protect and frame views, and which create canopies where appropriate. ( $\mathrm{SH} 29$ ) 
Program VR-4.5: The City shall initiate methods for screening and landscaping existing parking lots and trashreceptacles along the Embarcadero; such methods may involve both public and private sector participation. (SH 29)

Program VR-4.6: The City shall request CalTrans to install landscaping along Highway One; such landscaping shall not block significant views of the sea, sand dunes or Morro Rock. (SH 29)

Program VR-4.7: The City shall adopt, as appropriate, special design and landscaping requirements for new development or redevelopment along the entryways depicted in Figure _. (SH 30) POLICY VR-5: The City will encourage the continual maintenance
of properties. (LCP Modified 230)

Program VR-5.1: The City shall enforce its Property Maintenānce Code; problems with property maintenance in the Embarcadero and along the entryways designated on Figure 1 shall be given highest priority for ameliorative action. (SH 29)

Program VR-5.2: The City shall identify and work towards the removal or require the mitigation of the effects of those nonconforming uses that cause visual blight or otherwise demean the character of residential neighborhoods and commercial districts. (LCP Modified 230)

POLICY VR-6: Pursuant to Policy 1207 regarding undergrounding of utilities, the City will work toward the undergrounding of utilities where feasible. (New) (230)

Program VR-6.1: In cooperation with PG \& E, the City shall continue implementation of its utility undergrounding district program. (SH 27)

Program VR-6.2: The City shall establish a policy for undergrounding of utilities in connection with new development or major redevelopments. In the event that funding becomes available for the undergrounding of existing utility lines not in connection with new development or major redevelopment, priority shall be given to the undergrounding of lines in the Embarcadero and Downtown areas and entrances to the City. (LCP 231)

PQLICY VR-7: The City should investigate means to install roadside amenities, including informational signs, rest stops, parking areas, scenic pull-outs, bicycle and pedestrian trails and related facilities. (New) 
Program VR-7.1: The City shall investigate the development of an improved informational sign program along its entryways to help direct visitors to commercial districts and points of interest; such signs should be designed to enhance the viewscape of these entryways. (SH 30)

Program VR-7.2: The City should develop a sign program for the Embarcadero to direct visitors to points of interest, e.g. Morro Rock, the T-Piers, the state Park, etc. City parks should also be identified and signs indicating beach access at the end of Coleman Drive near Morro Rock should be in place. (SH 30)

Program VR-7.3: The City shall investigate funding sources for public informational signs. ( $\mathrm{SH} 30$ )

Program VR-7.4: The City shall require as a condition for approving improvements to Morro Bay State Park (1) that scenic pull-outs are adequately identified from the park roads both as a convenience to the traveler and to increase safety on these roads, which are winding and narrow, by alerting to stopping and entering traffic; and (2) that a bicycle/pedestrian path adjacent to the park entrance road from Main street to South Bay Boulevard be provided. (SH 30)

Program VR-7.5: The City shall investigate funding for bike trails and related facilities to be constructed on Coleman Drive and along the state Park roadways. (SH 31)

Program VR-7.6: The City shall implement the LUP/Coastal Element policy regarding provision of a bike path on the parcel West of Highway one between Atascadero Road and San Jacinto Street, as a condition on development there. (SH 31) 


\section{Appendix 4.1}

\section{Past Outreach Survey Monkey Results}

1. Did you find the workshop materials, referenced in http://morro-bay.ca.us/index.aspx? nid $=708$, helpful?

$\begin{array}{rr}\begin{array}{r}\text { Response } \\ \text { Percent }\end{array} & \begin{array}{r}\text { Response } \\ \text { Count }\end{array} \\ 50.0 \% & 2 \\ 25.0 \% & 1 \\ 25.0 \% & 1 \\ \text { a altended the workshop } & \text { answered question } \\ \text { skipped question } & 4\end{array}$

2. Please provide the following information. Contact information will not be distributed. The contact information will only be used should we need to contact you for clarification of your responses.

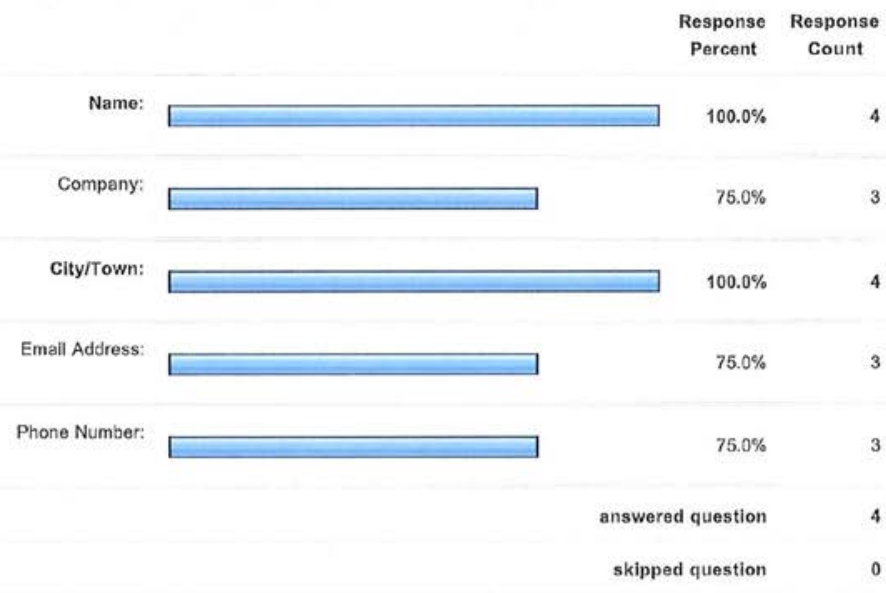

1 of 12 
3. What is your gender?

4. Are you a Morro Bay resident?
Yes

2 of 12 
5. What geographic area of Morro Bay do you represent?

\begin{tabular}{|c|c|c|c|}
\hline & & $\begin{array}{c}\text { Response } \\
\text { Percent }\end{array}$ & $\begin{array}{c}\text { Response } \\
\text { Count }\end{array}$ \\
\hline North Morro Bay & & $0.0 \%$ & 0 \\
\hline Downtown & & $0.0 \%$ & 0 \\
\hline Embarcadero & $\square$ & $25.0 \%$ & 1 \\
\hline North Residential & & $0.0 \%$ & 0 \\
\hline South Residential & & $0.0 \%$ & 0 \\
\hline \multirow[t]{3}{*}{ Other (please specify) } & 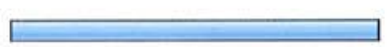 & $75.0 \%$ & 3 \\
\hline & & ed question & 4 \\
\hline & & ad question & 0 \\
\hline
\end{tabular}

6. Which best describes your role?

\begin{tabular}{|c|c|c|c|}
\hline & & $\begin{array}{c}\text { Response } \\
\text { Percont }\end{array}$ & $\begin{array}{c}\text { Response } \\
\text { Count }\end{array}$ \\
\hline Business Owner & $\square$ & $75.0 \%$ & 3 \\
\hline Salaried Worker & & $0.0 \%$ & 0 \\
\hline Retired & $\square$ & $25.0 \%$ & 1 \\
\hline \multirow[t]{3}{*}{ Other (please specify) } & & $0.0 \%$ & 0 \\
\hline & & ed question & 4 \\
\hline & & ed question & 0 \\
\hline
\end{tabular}

3 of 12 
7. Is the existing sign ordinance working for you?

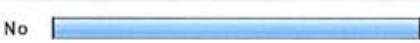

$\begin{array}{rr}\begin{array}{r}\text { Response } \\ \text { Percent }\end{array} & \begin{array}{r}\text { Response } \\ \text { Count }\end{array} \\ 25.0 \% & 1 \\ 75.0 \% & 3 \\ \text { answered question } & 4 \\ \text { skipped question } & 0\end{array}$

8. Are you happy with how the signs in Morro Bay look right now?

$\begin{array}{lrr}\text { Yos } & \begin{array}{r}\text { Response } \\ \text { Percent }\end{array} & \begin{array}{r}\text { Response } \\ \text { Count }\end{array} \\ \text { No } & 0.0 \% & 0 \\ & 100.0 \% & 4 \\ & \text { answered question } & 4 \\ & \text { skipped question } & 0\end{array}$

9. Do you feel that you have enough signage?

$\begin{array}{rrr}\text { Nos } & \begin{array}{r}\text { Response } \\ \text { Percent }\end{array} & \begin{array}{r}\text { Response } \\ \text { Count }\end{array} \\ \text { N/A } & 25.0 \% & 1 \\ & 75.0 \% & 3 \\ & 0.0 \% & 0 \\ & \text { answored question } & 4 \\ & \text { skipped question } & 0\end{array}$


10. Do you want uniformity in the appearance of signs and businesses throughout the community?

Yes $15.0 \%$

11. Do you believe there should be different rules for different areas of the community? (No. Morro Bay - along Hwy 1, Downtown, Embarcadero, Residential)

\begin{tabular}{|c|c|c|}
\hline & $\begin{array}{c}\text { Response } \\
\text { Percent }\end{array}$ & $\begin{array}{c}\text { Response } \\
\text { Count }\end{array}$ \\
\hline Yes $\square$ & $50.0 \%$ & 2 \\
\hline No $\square$ & $50.0 \%$ & 2 \\
\hline & d question & 4 \\
\hline & d question & 0 \\
\hline
\end{tabular}


12. Which of the following types of signs should be allowed in the Downtown Area? (select all that apply)

\begin{tabular}{|c|c|c|c|}
\hline & & $\begin{array}{c}\text { Responso } \\
\text { Percent }\end{array}$ & $\begin{array}{c}\text { Response } \\
\text { Count }\end{array}$ \\
\hline Flag signs & $\square$ & $75.0 \%$ & 3 \\
\hline Banners & $\square$ & $50.0 \%$ & 2 \\
\hline Illuminated/Neon Signs & $\square$ & $75.0 \%$ & 3 \\
\hline A-Frame Signs & $\square$ & $50.0 \%$ & 2 \\
\hline Wall Signs & $\square$ & $75.0 \%$ & 3 \\
\hline Off-Premise Sign & & $0.0 \%$ & 0 \\
\hline Pole/Monument Signs & $\square$ & $50.0 \%$ & 2 \\
\hline Changeable copy signs & $\square$ & $75.0 \%$ & 3 \\
\hline Awning Sign & 口 & $100.0 \%$ & 4 \\
\hline Pub/projecting signs & — & $100.0 \%$ & 4 \\
\hline Other (please specify) & & $0.0 \%$ & 0 \\
\hline \multicolumn{3}{|c|}{ answered question } & 4 \\
\hline \multicolumn{3}{|c|}{ skipped question } & 0 \\
\hline
\end{tabular}

6 of 12 
13. Which of the following types of signs should be allowed in Embarcadero Area? (select all that apply)

\begin{tabular}{|c|c|c|c|}
\hline & & $\begin{array}{c}\text { Response } \\
\text { Percent }\end{array}$ & $\begin{array}{c}\text { Response } \\
\text { Count }\end{array}$ \\
\hline Flag signs & $\square$ & $75.0 \%$ & 3 \\
\hline Banners & $\square$ & $50.0 \%$ & 2 \\
\hline Illuminated/Neon Signs & $\square$ & $75.0 \%$ & 3 \\
\hline A-Frame Signs & & $0.0 \%$ & 0 \\
\hline Wall Signs & $\square$ & $100.0 \%$ & 4 \\
\hline Orf-Premise Sign & & $0.0 \%$ & 0 \\
\hline Pole/Monument Signs & $\square$ & $50.0 \%$ & 2 \\
\hline Changeable copy signs & $\square$ & $50.0 \%$ & 2 \\
\hline Awning Sign & $\square$ & $100.0 \%$ & 4 \\
\hline Pub/projecting signs & $\square$ & $100.0 \%$ & 4 \\
\hline Other (please specify) & & $0.0 \%$ & 0 \\
\hline \multicolumn{4}{|c|}{ answered question } \\
\hline & skippe & d question & 0 \\
\hline
\end{tabular}

7 of 12 
14. Which of the following types of signs should be allowed in Highway-Oriented Commercial Areas? (select all that apply)

\begin{tabular}{|c|c|c|c|}
\hline & & $\begin{array}{c}\text { Response } \\
\text { Percent }\end{array}$ & $\begin{array}{c}\text { Response } \\
\text { Count }\end{array}$ \\
\hline Flag signs & $\square$ & $75.0 \%$ & 3 \\
\hline Banners & $\square$ & $50.0 \%$ & 2 \\
\hline Illuminated/Neon Signs & $\square$ & $75.0 \%$ & 3 \\
\hline A-Frame Signs & $\square$ & $25.0 \%$ & 1 \\
\hline Wall Signs & $\square$ & $100.0 \%$ & 4 \\
\hline Off-Premise Sign & $\square$ & $50.0 \%$ & 2 \\
\hline Pole/Monument Signs & $\square$ & $75.0 \%$ & 3 \\
\hline Changeable copy signs & $\square$ & $75.0 \%$ & 3 \\
\hline Awning Sign & $\square$ & $50.0 \%$ & 2 \\
\hline Pub/projecting sign & $\square$ & $100.0 \%$ & 4 \\
\hline Other (please specify) & & $0.0 \%$ & 0 \\
\hline \multicolumn{3}{|c|}{ answered question } & 4 \\
\hline \multicolumn{3}{|c|}{ skipped question } & 0 \\
\hline
\end{tabular}

8 of 12 
15. Which of the following types of signs should be allowed in Residential Areas? (select all that apply)

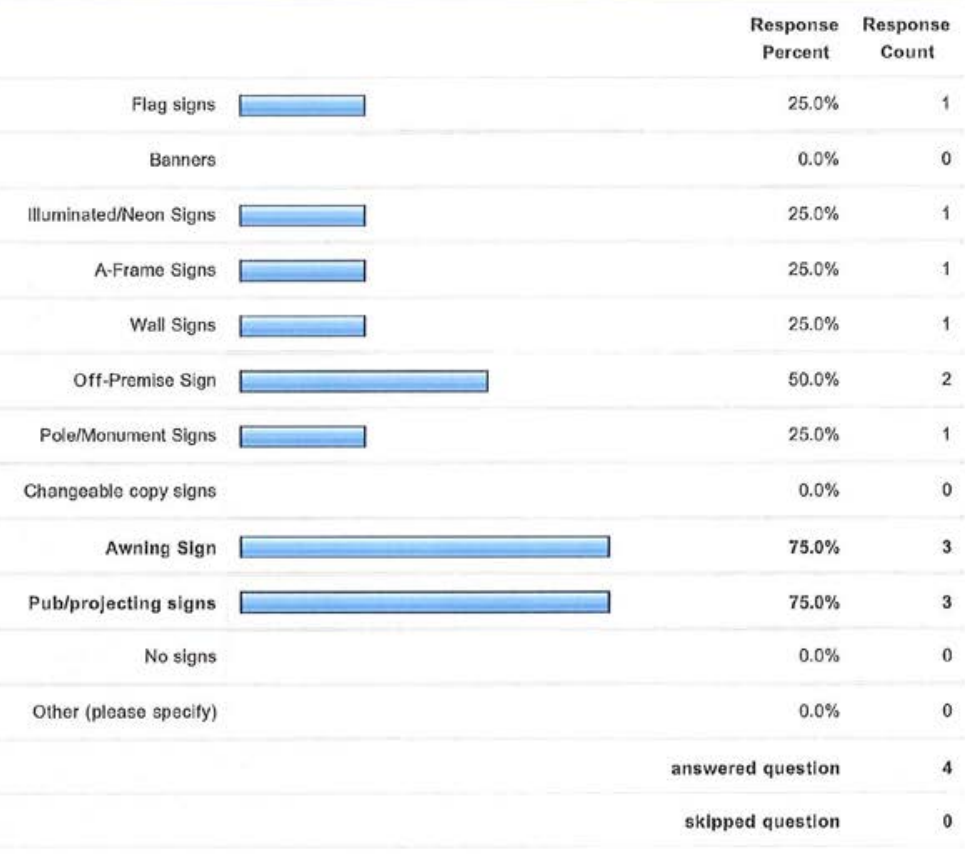

9 of 12 
16. Should multiple types of signs be allowed without penalty? Current regulations apply a reduction in sign area of $50 \%$ if multiple sign types are uses; e.g. wall sign plus a monument sign.

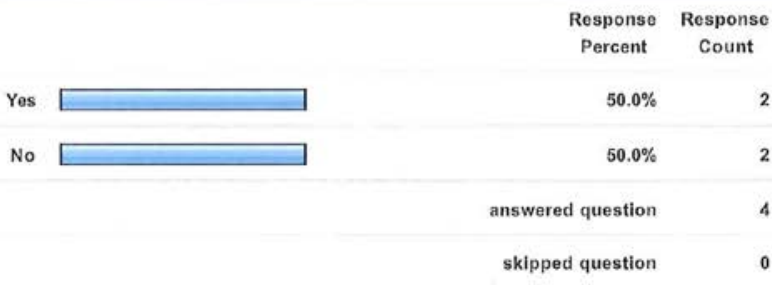

17. Do you consider murals to be signs?

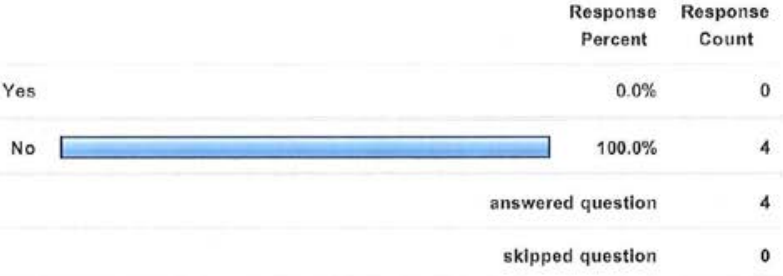

18. Should signage in residential areas be allowed for: (select all that apply)

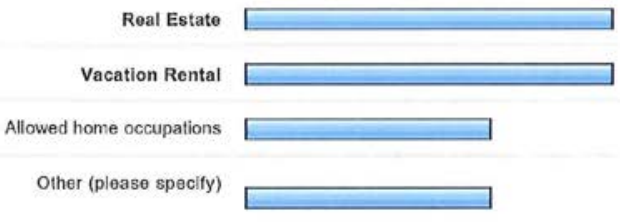

$\begin{array}{rr}\begin{array}{c}\text { Response } \\ \text { Percent }\end{array} & \begin{array}{r}\text { Response } \\ \text { Count }\end{array} \\ 75.0 \% & 3 \\ 75.0 \% & 3 \\ 50.0 \% & 2 \\ 50.0 \% & 2 \\ & 4 \\ \text { answered question } & 4 \\ \text { skipped question } & 0\end{array}$

10 of 12 
19. Should businesses be guaranteed a minimum size sign regardless of frontage size?

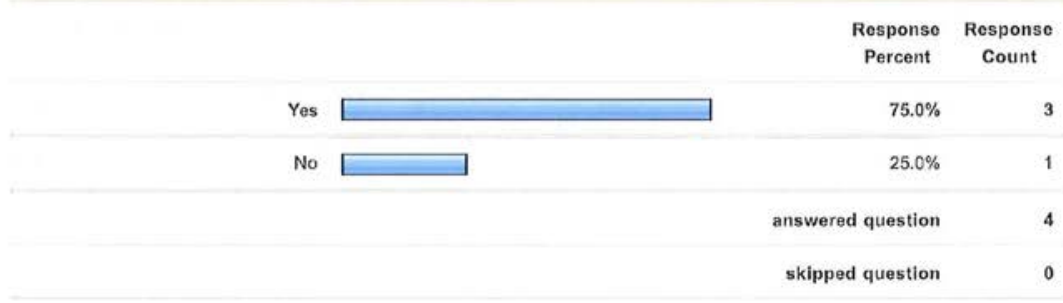

20. Should there be special allowances or exceptions?

Response
Percent $\begin{gathered}\text { Response } \\ \text { Count }\end{gathered}$

21. Are you satisfied with the current rules for reader or changeable message boards? Current code limits the language on such boards for hotel/motels to: a. Winter rate (excluding amount); b. Vacancy; c. Credit cards; d. TV; e. Pool; f. Air conditioning; g. Continental Breakfast; $h$. Any other information as approved by the Director.

\begin{tabular}{|c|c|c|c|}
\hline & & $\begin{array}{c}\text { Response } \\
\text { Percent }\end{array}$ & $\begin{array}{c}\text { Response } \\
\text { Count }\end{array}$ \\
\hline Yes & $\square$ & $75.0 \%$ & 3 \\
\hline & $\square$ & $25.0 \%$ & 1 \\
\hline & & ed question & 4 \\
\hline & & ad question & 0 \\
\hline
\end{tabular}


22. Are sign materials important?

$\begin{array}{ccc}\text { Yes } \quad \text { Why? } & \begin{array}{c}\text { Response } \\ \text { Percent }\end{array} & \begin{array}{c}\text { Response } \\ \text { Count }\end{array} \\ 100.0 \% & 4 \\ & 0.0 \% & 4 \\ & \text { answered question } & 4 \\ & \text { skipped question } & 0\end{array}$

23. Please provide us any additional comments or provide explanation to a question as needed.

$\begin{array}{cr} & \begin{array}{c}\text { Response } \\ \text { Count }\end{array} \\ \text { answered question } & 4 \\ \text { skipped question } & 4\end{array}$




\section{Appendix 4.2}

\section{2_13_2011 Sign Ordinance Survey Staff Report Attachments}

To what extent to you support or oppose the preliminary sign ordinance for the Embarcadero Area

(as presented in preliminary sign matrix)

1. Strongly Agree

2. Agree

3. Neutral

4. Disagree

5. Strongly Disagree

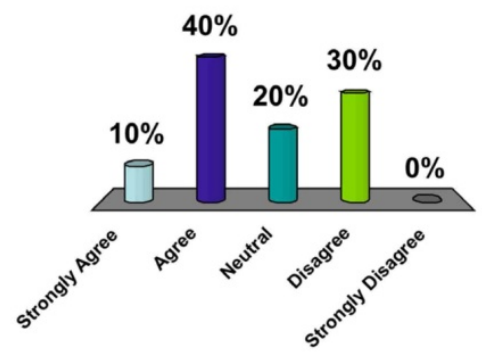

To what extent to you support or oppose the preliminary sign ordinance for the Downtown Area

(allow sidewalk signs and no difference between internal \& external illumination)
1. Strongly Agree
2. Agree
3. Neutral
4. Disagree
5. Strongly Disagree

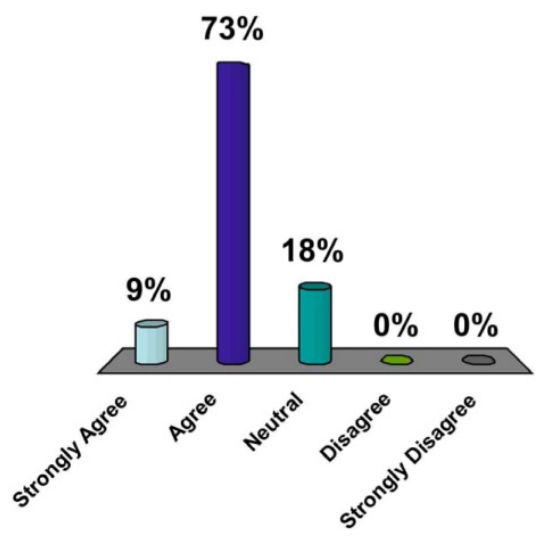


To what extent to you support or oppose the preliminary sign ordinance for the

Embarcadero Area

(allow internal illumination)

1. Strongly Agree

2. Agree

3. Neutral

4. Disagree

5. Strongly Disagree

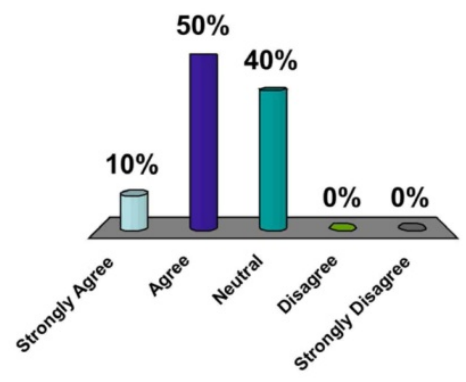

To what extent to you support or oppose the preliminary sign ordinance for the

North Morro Bay Area

(as presented in preliminary sign matrix)

1. Strongly Agree

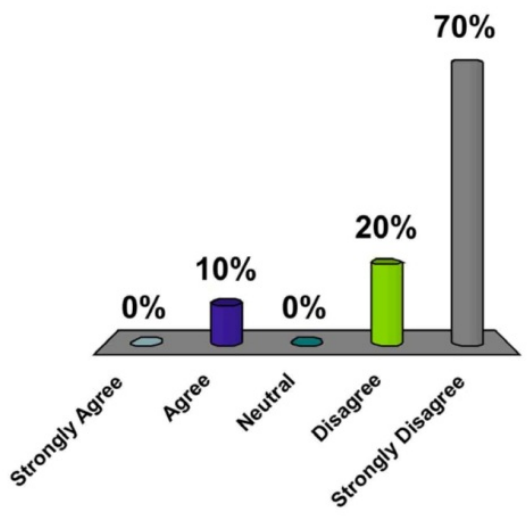

2. Agree

3. Neutral

4. Disagree

5. Strongly Disagree 


\section{To what extent to you support or oppose the preliminary sign ordinance for the \\ North Morro Bay Area \\ (allow flag, sidewalk and banner signs)}

1. Strongly Agree

2. Agree

3. Neutral

4. Disagree

5. Strongly Disagree

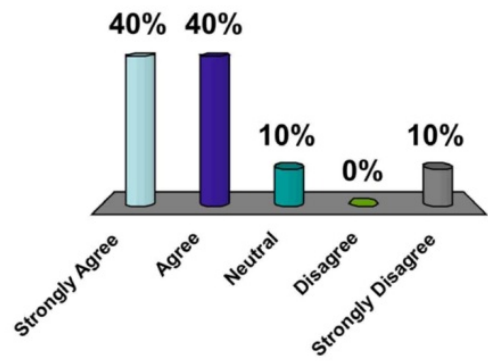

How effective was this workshop to discuss alternative sign ordinance strategies?

1. Very Effective

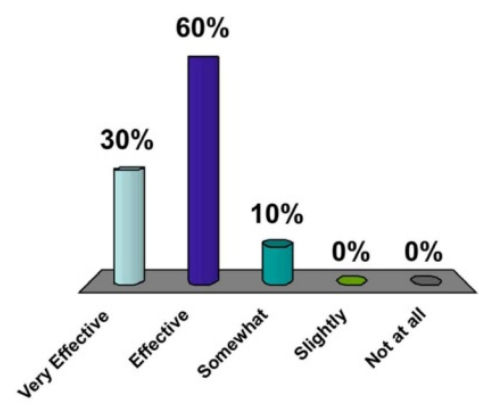

2. Effective

3. Somewhat

4. Slightly

5. Not at all 


\section{City Sign Ordinance Survey Results Overview}

Date: 11/21/2011 12:14 PM PST

Responses: Completes

Filter: No filter applied

1. What best describes your location?

\begin{tabular}{|c|c|c|c|}
\hline Downtown & $\longrightarrow$ & 32 & $35 \%$ \\
\hline Embarcadero & 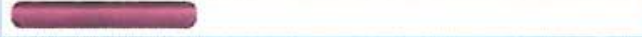 & 24 & $26 \%$ \\
\hline $\begin{array}{l}\text { North Morro } \\
\text { Bay/Quintana }\end{array}$ & & 19 & $21 \%$ \\
\hline $\begin{array}{l}\text { Other, please } \\
\text { specify }\end{array}$ & $\longrightarrow$ & 16 & $18 \%$ \\
\hline & Total & 91 & $100 \%$ \\
\hline
\end{tabular}

2. Did you attend any of the City's Sign Ordinance Workshops?

\begin{tabular}{l|l|l|l|}
\hline $\begin{array}{l}\text { Yes, I attended the } \\
\text { September 29th } \\
\text { workshop, }\end{array}$ & & 6 & $6 \%$ \\
\hline $\begin{array}{l}\text { Yes, I attended the } \\
\text { October 6th } \\
\text { workshop. }\end{array}$ & & 3 & $3 \%$ \\
\hline $\begin{array}{l}\text { I attended both } \\
\text { I did not attend } \\
\text { either one }\end{array}$ & Total & 93 & $10 \%$ \\
\hline
\end{tabular}

3. With regards to business signage in the Downtown area, which of the following signs would you approve? 3. (Check all that apply)

\begin{tabular}{|c|c|c|c|}
\hline A Frame Signs & E & 39 & $43 \%$ \\
\hline Awning Signs & 3 & 69 & $76 \%$ \\
\hline $\begin{array}{l}\text { Banners as a } \\
\text { Permanent Signage }\end{array}$ & 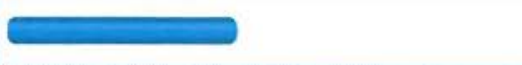 & 30 & $33 \%$ \\
\hline Flag & 3 & 49 & $54 \%$ \\
\hline $\begin{array}{l}\text { Gateway Signs: } \\
\text { Concept would be } \\
\text { to allow a type of } \\
\text { sign at the entrance } \\
\text { at Morro Bay Blvd } \\
\text { to announce the } \\
\text { downtown area. }\end{array}$ & & 55 & $60 \%$ \\
\hline $\begin{array}{l}\text { Illuminated, } \\
\text { Internally }\end{array}$ & 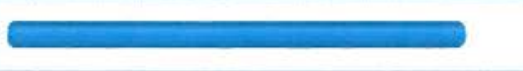 & 63 & $69 \%$ \\
\hline Illuminated, & & 56 & $62 \%$ \\
\hline
\end{tabular}

http://app.zoomerang.com/Report/PrintResultsPage.aspx

$11 / 21 / 2011$ 


\begin{tabular}{|l|l|l|l|}
\hline Externally & & & \\
\hline $\begin{array}{l}\text { Marquee Signs: For } \\
\text { theatres, } \\
\text { nightclubs, } \\
\text { conference } \\
\text { facilities. }\end{array}$ & & 63 & $69 \%$ \\
\hline Monument Signs & & 47 & $52 \%$ \\
\hline Off Premise Signs & & 26 & $29 \%$ \\
\hline Pole Signs & & 38 & $42 \%$ \\
\hline Pub Signs & & 52 & $57 \%$ \\
\hline Wall Signs & & 65 & $71 \%$ \\
\hline Window Signs & & 76 & $84 \%$ \\
\hline
\end{tabular}

4. With regards to business signage in the Embarcadero area, which of the following signs would you approve? 4. (Check all that apply)

\begin{tabular}{|c|c|c|c|}
\hline A Frame Signs & $\Longrightarrow$ & 32 & $36 \%$ \\
\hline Awning Signs & 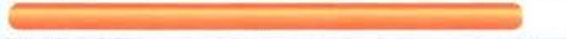 & 69 & $78 \%$ \\
\hline $\begin{array}{l}\text { Banners as a } \\
\text { Permanent Signage }\end{array}$ & 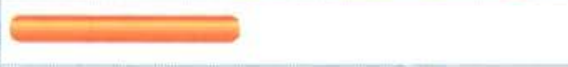 & 29 & $33 \%$ \\
\hline Dock Signs & $\Longrightarrow$ & 59 & $66 \%$ \\
\hline Flag & 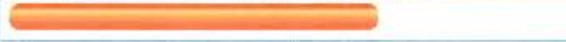 & 49 & $55 \%$ \\
\hline $\begin{array}{l}\text { Gateway Signs: } \\
\text { Concept would be } \\
\text { to allow a type of } \\
\text { sign at the entrance } \\
\text { at Morro Bay Blvd } \\
\text { to announce the } \\
\text { downtown area. }\end{array}$ & 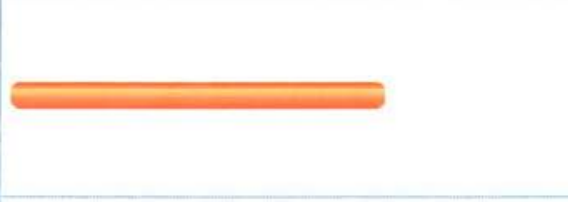 & 50 & $56 \%$ \\
\hline $\begin{array}{l}\text { Illuminated, } \\
\text { Internally }\end{array}$ & $\longrightarrow$ & 65 & $73 \%$ \\
\hline $\begin{array}{l}\text { Illuminated, } \\
\text { Externally }\end{array}$ & $\square$ & 57 & $64 \%$ \\
\hline $\begin{array}{l}\text { Marquee Signs: For } \\
\text { theatres, } \\
\text { nightclubs, } \\
\text { conference } \\
\text { facilities. }\end{array}$ & $\square$ & 49 & $55 \%$ \\
\hline Monument Signs & 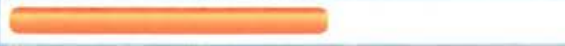 & 42 & $47 \%$ \\
\hline Off Premise Signs & 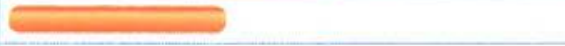 & 28 & $31 \%$ \\
\hline Pole Signs & 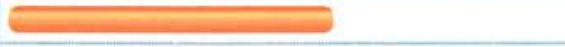 & 43 & $48 \%$ \\
\hline Pub Signs & $\overline{ }$ & 49 & $55 \%$ \\
\hline Wall Signs & 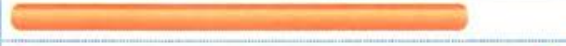 & 61 & $69 \%$ \\
\hline Window Signs & 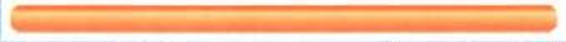 & 74 & $83 \%$ \\
\hline
\end{tabular}




\section{City Sign Ordinance Survey Results Overview}

Date: 11/21/2011 12:16 PM PST

Responses: Completes
Filter: No filter applied

\section{Comments}

\# Response

Many businesses do not have street frontage and need to be able to alert the public to their existance. Perhaps limiting the

1 number of total signs a business can have....wall, window, a-frame, flage...maybe four would be an alternative and keep the clutter down.

2 As a business owner, decisions made regarding signage was not thought through. A frames are effective, now permits need to be applied for and enforced.

The current signage policy put forth by the city has resulted in a $30 \%$ loss of business and our customers tell us they can't find us. We are hidden away from the street and need more options for additional signage including lighting around the sidewalks

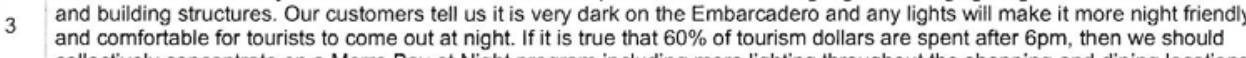
collectively concentrate on a Morro Bay at Night program including more lighting throughout the shopping and dining locations.

4 Local businesses need all the help they can get and should be able to put in signage. I would also support creative signs that are artsy in appearance, as an example the sign at the Sea Shanty in Cayucos is teriffic.

5 All these surveys, etc....as well as meaningless meetings are generally a waste of time. Most merchants, politicians, activists are only interested in their own personal agenda.

6 stop tring to clean up the town by getting rid of businesses do the work the city is paid to do like trim trees fix sidewalks fire prevention along the highway look at the huge sandwich sign on the harbor hut what are you guys thinking

7 Getting rid of the A-frame signs and moving the newsstands has greatly improved the appearance of the Embarcadero area. A uniform sign policy is important. Good job.

8 I don't care for all the sandwich signs that crowd the sidewalks. Makes it look trashy and cluttered.

9 What kind of sign is not as important as how they look, clean, neat, professional, informative, SAFE to people walking by, off sidewalks. Consideration for MOVING/ remodeling/new

10 do a better job removing all banner signs at your deadline. Some businesses removed there signs but jack was done with other business refused. The guy who walked around warning people didn't do his job.

11 The three areas are unique and warrant individual consideration. One size does not fit all. While not a marketing plan, they can tell a story and can make or break a business.

I love the charm of Morro Bay and do not want to see your business closes due to poor exposure due to signage. Some

12 Controls are needed but $i$ think the next step will a survey stating what colors and sytles of fonts on the signs will be acceptable light at night in a business area is always a good idea, the the merchant can afford the pg\&e bill. Jennifer Smith, Harvey's HOney Huts [ we put lights in our units for events that go into the night!

13 Businesses today need any way they can to advertise within reason. If it doesn't distract drivers or affect public safety then they should be able to be creative.

14 Don't know what a Pub Sign is.

15 Without business's profiting there is no infrastructure moneys to run the city. bottom line.

16 Against A-frame signs anywhere...they add clutter, fall over in the wind and become a liability. Against flags and banners because they fade and tatter so quickly and look very tacky.

17 Aren't there more important subjects to address other than signs?

18 lower taxes, too many bureaucrats, support smaller government

19 for people that have more than one address they should be sllowed more than one sign

20 Downtown and Embarcardero should be the only areas which $A$ frames are not permitted.

21 I was going to write a lot of stuff here but decided not to. Because it does not matter anyway. You already have your minds made up.

22 Signs must always be in good taste and represent the business appropriately.

Role of government is not to micro manage people trying to survive in business. If a business owner has "bad signage" it

http://app.zoomerang.com/Report/PrintOpenEndedResponsesPage.aspx?pr... 11/21/2011 


\section{Zoomerang | City Sign Ordinance Survey: Open Ended Report: Question 6 Page 2 of 2}

probably means he/she is a poor business person. They will fail...they don't need the help of a technocrat with some ordinance 23 that has never run a business telling them what sign is appropriate for their business. Oh... how far we have come in this country thinking that it is every bodies "RIGHT" to tell someone how WE (the all important ONE) don't like their sign). If you don't like their sign don't frequent their business...put them out of business and the sign will come down.

24 Without cluttering our city, the businesses need to be visible to the traffic. An attractive sign is the best way to be visible Specially in a non-traffic area as Quintana road.

25 The Embarcadero doesn't need signage that impedes foot traffic, while north Morro Bay needs all the help it can get. Morro Bay downtown could use flags and lights

26 In regards to illuminated signs both internal and external I feel there should be a limit to the number of signs allowed for display.

27 A frame signs stop foot traffic and have been found to disturb drivers enough to cause more accidents in an area. We have limited walk paths as it is. These signs are not standardized and makes an area look like junk.

28 i think the city has bigger issues to worry about then telling business what signage they can use. I understand cleaning things up but In this economy its very tough.

29 Signage should always be determined by individual circumstances. Such as the businesses location to visibility and need for external advertising to enhance foot traffic etc. etc.

30 I only know that not having my a frame with the arrow pointing to Morro Bay Wine Seller has hurt. I can only imagaine how it hurts down town area. they pay for the signs and what ever works for them they be able to choose the two that works the best.

31 I am a visitor to Morro Bay and pretty much like it the way it is.

32 get a real issue

As a business in this economical time, we should be allowed to have signs of all kinds to let people know we are here. We pay all the taxes, and the city doesn't look any better without the signs. Maybe this is not the best of times to try and "clean up the city" by banning struggling businesses from free advertisement. Speaking from a hotels point of view, when we are slow, so

33 are the stores and restaurants, so, we need to try and get people who are here already to spend money. If the people that are here, don't know of the sale we are running, or that we are even here, because they don't see a sign, how are they going to spend? Please let us have signs again. They don't make the town look dumpy, they actually give it more character. thank you for listening.

I love signs. They are information and add to the excitement of the town. Not all businesses are front and center. I feel the

34 signs add action to the town. We also need to have a sign at the freeway exits that indicates DOWNTOWN HARBOR BEACHES other wise how would a guy know we have anything going on or that there is even a town here. Thanks for your time and good luck making everyone happy ;)

Products \& Services | About Us | Support/Help

@ 2011 Copyright MarketTools Inc. All Rights Reserved.| Privacy Policy | Terms Of Use

http://app.zoomerang.com/Report/PrintOpenEndedResponsesPage.aspx?pr... 11/21/2011 


\section{City Sign Ordinance Survey Cross Tab Report}

\begin{tabular}{|c|c|c|c|c|c|}
\hline \multicolumn{6}{|c|}{$\begin{array}{l}\text { With regards to business signage in the Downtown area, which of the following signs would you } \\
\text { approve? (Check all that apply) }\end{array}$} \\
\hline & \multirow{2}{*}{ Total* } & \multicolumn{4}{|c|}{ What best describes your location? } \\
\hline & & Downtown & Embarcadero & North Morro Bay/Quintana & Other, please specify \\
\hline & 91 & 32 & 24 & 18 & 15 \\
\hline A Frame Signs & $\begin{array}{r}38 \\
41.8 \%\end{array}$ & $\begin{array}{r}13 \\
40.6 \%\end{array}$ & $\begin{array}{r}8 \\
33.3 \%\end{array}$ & $\begin{array}{r}10 \\
55.6 \%\end{array}$ & $46.7 \%$ \\
\hline Awning Signs & $\begin{array}{r}68 \\
74.7 \%\end{array}$ & $\begin{array}{r}24 \\
75.0 \%\end{array}$ & $\begin{array}{r}18 \\
75.0 \%\end{array}$ & $\begin{array}{r}13 \\
72.2 \%\end{array}$ & $\begin{array}{r}13 \\
86.7 \%\end{array}$ \\
\hline $\begin{array}{l}\text { Banners as a } \\
\text { Permanent } \\
\text { Signage }\end{array}$ & $\begin{array}{r}29 \\
31.9 \%\end{array}$ & $\begin{array}{r}9 \\
28.1 \%\end{array}$ & $\begin{array}{r}8 \\
33.3 \%\end{array}$ & $\begin{array}{r}6 \\
33.3 \%\end{array}$ & $\begin{array}{r}6 \\
40.0 \%\end{array}$ \\
\hline Flag & \begin{tabular}{r|}
48 \\
$52.7 \%$ \\
\end{tabular} & $\begin{array}{r}12 \\
37.5 \%\end{array}$ & $\begin{array}{r}17 \\
70.8 \%\end{array}$ & $\begin{array}{r}13 \\
72.2 \%\end{array}$ & $\begin{array}{r}6 \\
40.0 \%\end{array}$ \\
\hline $\begin{array}{l}\text { Gateway Signs: } \\
\text { Concept would be } \\
\text { to allow a type of } \\
\text { sign at the } \\
\text { entrance at Morro } \\
\text { Bay Blvd to } \\
\text { announce the } \\
\text { downtown area. }\end{array}$ & $\begin{array}{r}54 \\
59.3 \%\end{array}$ & \begin{tabular}{r|}
20 \\
$62.5 \%$
\end{tabular} & $\begin{array}{r}13 \\
54.2 \%\end{array}$ & \begin{tabular}{r|}
11 \\
$61.1 \%$
\end{tabular} & $\begin{array}{r}10 \\
66.7 \%\end{array}$ \\
\hline $\begin{array}{l}\text { Illuminated, } \\
\text { Internally }\end{array}$ & $\begin{array}{r}61 \\
67.0 \%\end{array}$ & $\begin{array}{r}22 \\
68.8 \%\end{array}$ & $\begin{array}{r}18 \\
75.0 \%\end{array}$ & $\begin{array}{r}13 \\
72.2 \%\end{array}$ & $\begin{array}{r}8 \\
53.3 \%\end{array}$ \\
\hline $\begin{array}{l}\text { Illuminated, } \\
\text { Externally }\end{array}$ & $\begin{array}{r}54 \\
59.3 \%\end{array}$ & $\begin{array}{r}21 \\
65.6 \%\end{array}$ & $\begin{array}{r}14 \\
58.3 \%\end{array}$ & $\begin{array}{r}12 \\
66.7 \%\end{array}$ & $\begin{array}{r}7 \\
46.7 \%\end{array}$ \\
\hline $\begin{array}{l}\text { Marquee Signs: } \\
\text { For theatres, } \\
\text { nightclubs, } \\
\text { conference } \\
\text { facilities. }\end{array}$ & $\begin{array}{r}61 \\
67.0 \%\end{array}$ & $\begin{array}{r}18 \\
56.3 \%\end{array}$ & $\begin{array}{r}16 \\
66.7 \%\end{array}$ & $\begin{array}{r}14 \\
77.8 \%\end{array}$ & $\begin{array}{r}13 \\
86.7 \%\end{array}$ \\
\hline Monument Signs & $\begin{array}{r}46 \\
50.5 \% \\
\end{array}$ & $\begin{array}{r}19 \\
59.4 \%\end{array}$ & $\begin{array}{r}10 \\
41.7 \%\end{array}$ & $\begin{array}{r}11 \\
61.1 \%\end{array}$ & $\begin{array}{r}6 \\
40.0 \%\end{array}$ \\
\hline Off Premise Signs & $\begin{array}{r}25 \\
27.5 \%\end{array}$ & $\begin{array}{r}6 \\
18.8 \%\end{array}$ & $\begin{array}{r}10 \\
41.7 \%\end{array}$ & $\begin{array}{r}6 \\
33.3 \%\end{array}$ & $20.0 \%$ \\
\hline Pole Signs & $\begin{array}{r}36 \\
39.6 \%\end{array}$ & $\begin{array}{r}13 \\
40.6 \%\end{array}$ & $\begin{array}{r}11 \\
45.8 \%\end{array}$ & $\begin{array}{r}9 \\
50.0 \%\end{array}$ & $\begin{array}{r}3 \\
20.0 \% \\
\end{array}$ \\
\hline Pub Signs & $\begin{array}{r}50 \\
54.9 \%\end{array}$ & $\begin{array}{r}15 \\
46.9 \%\end{array}$ & $\begin{array}{r}14 \\
58.3 \%\end{array}$ & $\begin{array}{r}14 \\
77.8 \% \\
\end{array}$ & $\begin{array}{r}7 \\
46.7 \% \\
\end{array}$ \\
\hline Wall Signs & $\begin{array}{r}63 \\
69.2 \%\end{array}$ & $\begin{array}{r}23 \\
71.9 \%\end{array}$ & $\begin{array}{r}17 \\
70.8 \%\end{array}$ & $\begin{array}{r}14 \\
77.8 \%\end{array}$ & $\begin{array}{r}9 \\
60.0 \%\end{array}$ \\
\hline Window Signs & $\begin{array}{r}74 \\
81.3 \%\end{array}$ & $\begin{array}{r}26 \\
81.3 \%\end{array}$ & $\begin{array}{r}19 \\
79.2 \%\end{array}$ & $\begin{array}{r}16 \\
88.9 \%\end{array}$ & $\begin{array}{r}13 \\
86.7 \%\end{array}$ \\
\hline
\end{tabular}




\section{City Sign Ordinance Survey Cross Tab Report}

Date: 11/21/2011 1:03 PM PST

Responses: Completes

Filter: No filter applied

\begin{tabular}{|c|c|c|c|c|c|}
\hline \multicolumn{6}{|c|}{$\begin{array}{l}\text { With regards to business signage in the Embarcadero area, which of the following signs would you } \\
\text { approve? (Check all that apply) }\end{array}$} \\
\hline & \multirow{2}{*}{ Total* } & \multicolumn{4}{|c|}{ What best describes your location? } \\
\hline & & Downtown & Embarcadero & North Morro Bay/Quintana & Other, please specify \\
\hline & 89 & 31 & 24 & 17 & 15 \\
\hline A Frame Signs & $34.8 \%$ & $25.8 \%$ & $\begin{array}{r}8 \\
33.3 \%\end{array}$ & $52.9 \%$ & $40.0 \%$ \\
\hline Awning Signs & $\begin{array}{r}68 \\
76.4 \%\end{array}$ & $67.7 \%$ & $\begin{array}{r}19 \\
79.2 \%\end{array}$ & $\begin{array}{r}15 \\
88.2 \% \\
\end{array}$ & $\begin{array}{r}13 \\
86.7 \% \\
\end{array}$ \\
\hline $\begin{array}{l}\text { Banners as a } \\
\text { Permanent } \\
\text { Signage }\end{array}$ & $\begin{array}{r}28 \\
31.5 \%\end{array}$ & $\begin{array}{r}10 \\
32.3 \%\end{array}$ & $\begin{array}{r}7 \\
29.2 \%\end{array}$ & $\begin{array}{r}4 \\
23.5 \%\end{array}$ & $\begin{array}{r}7 \\
46.7 \%\end{array}$ \\
\hline Dock Signs & $\begin{array}{r}58 \\
65.2 \%\end{array}$ & $\begin{array}{r}20 \\
64.5 \% \\
\end{array}$ & $\begin{array}{r}13 \\
54.2 \% \\
\end{array}$ & $\begin{array}{r}14 \\
82.4 \%\end{array}$ & $\begin{array}{r}11 \\
73.3 \% \\
\end{array}$ \\
\hline Flag & $\begin{array}{r}48 \\
53.9 \% \\
\end{array}$ & $\begin{array}{r}13 \\
41.9 \%\end{array}$ & $\begin{array}{r}17 \\
70.8 \% \\
\end{array}$ & $\begin{array}{r}13 \\
76.5 \% \\
\end{array}$ & $\begin{array}{r}5 \\
33.3 \%\end{array}$ \\
\hline $\begin{array}{l}\text { Gateway Signs: } \\
\text { Concept would be } \\
\text { to allow a type of } \\
\text { sign at the } \\
\text { entrance at Morro } \\
\text { Bay Blvd to } \\
\text { announce the } \\
\text { downtown area. }\end{array}$ & $\begin{array}{r}49 \\
55.1 \%\end{array}$ & $\begin{array}{r}17 \\
54.8 \%\end{array}$ & $\begin{array}{r}12 \\
50.0 \%\end{array}$ & $\begin{array}{r}10 \\
58.8 \%\end{array}$ & $\begin{array}{r}10 \\
66.7 \%\end{array}$ \\
\hline $\begin{array}{l}\text { Illuminated, } \\
\text { Internally }\end{array}$ & $\begin{array}{r}63 \\
70.8 \% \\
\end{array}$ & $\begin{array}{r}23 \\
74.2 \% \\
\end{array}$ & $\begin{array}{r}18 \\
75.0 \% \\
\end{array}$ & $\begin{array}{r}13 \\
76.5 \% \\
\end{array}$ & $\begin{array}{r}9 \\
60.0 \%\end{array}$ \\
\hline $\begin{array}{l}\text { Illuminated, } \\
\text { Externally }\end{array}$ & $\begin{array}{r}55 \\
61.8 \%\end{array}$ & $\begin{array}{r}20 \\
64.5 \%\end{array}$ & $\begin{array}{r}14 \\
58.3 \%\end{array}$ & $\begin{array}{r}14 \\
82.4 \%\end{array}$ & $\begin{array}{r}7 \\
46.7 \%\end{array}$ \\
\hline $\begin{array}{l}\text { Marquee Signs: } \\
\text { For theatres, } \\
\text { nightclubs, } \\
\text { conference } \\
\text { facilities. }\end{array}$ & $\begin{array}{r}47 \\
52.8 \%\end{array}$ & $\begin{array}{r}15 \\
48.4 \%\end{array}$ & $\begin{array}{r}12 \\
50.0 \%\end{array}$ & $\begin{array}{r}11 \\
64.7 \%\end{array}$ & $\begin{array}{r}9 \\
60.0 \%\end{array}$ \\
\hline Monument Signs & $\begin{array}{r}41 \\
46.1 \%\end{array}$ & $\begin{array}{r}17 \\
54.8 \%\end{array}$ & $\begin{array}{r}10 \\
41.7 \%\end{array}$ & $\begin{array}{r}9 \\
52.9 \%\end{array}$ & $\begin{array}{r}5 \\
33.3 \%\end{array}$ \\
\hline Off Premise Signs & $\begin{array}{r}27 \\
30.3 \%\end{array}$ & $\begin{array}{r}9 \\
29.0 \%\end{array}$ & $\begin{array}{r}8 \\
33.3 \%\end{array}$ & $\begin{array}{r}7 \\
41.2 \%\end{array}$ & $\begin{array}{r}3 \\
20.0 \% \\
\end{array}$ \\
\hline Pole Signs & $\begin{array}{r}41 \\
46.1 \%\end{array}$ & $\begin{array}{r}15 \\
48.4 \%\end{array}$ & $\begin{array}{r}11 \\
45.8 \%\end{array}$ & $\begin{array}{r}11 \\
64.7 \%\end{array}$ & $\begin{array}{r}4 \\
26.7 \%\end{array}$ \\
\hline Pub Signs & $\begin{array}{r}47 \\
52.8 \%\end{array}$ & $\begin{array}{r}13 \\
41.9 \%\end{array}$ & $\begin{array}{r}12 \\
50.0 \%\end{array}$ & $\begin{array}{r}14 \\
82.4 \%\end{array}$ & $\begin{array}{r}8 \\
53.3 \% \\
\end{array}$ \\
\hline Wall Signs & $\begin{array}{r}59 \\
66.3 \% \\
\end{array}$ & $\begin{array}{r}20 \\
64.5 \%\end{array}$ & $\begin{array}{r}18 \\
75.0 \%\end{array}$ & $\begin{array}{r}13 \\
76.5 \%\end{array}$ & $\begin{array}{r}8 \\
53.3 \%\end{array}$ \\
\hline Window Signs & $\begin{array}{r}72 \\
80.9 \%\end{array}$ & $\begin{array}{r}25 \\
80.6 \%\end{array}$ & $\begin{array}{r}18 \\
75.0 \%\end{array}$ & $\begin{array}{r}17 \\
100.0 \%\end{array}$ & $\begin{array}{r}12 \\
80.0 \%\end{array}$ \\
\hline
\end{tabular}

http://app.zoomerang.com/Report/PrintCrossTabPage.aspx

$11 / 21 / 2011$ 


\section{City Sign Ordinance Survey Cross Tab Report}

Date: 11/21/2011 1:14 PM PST Responses: Completes Filter: No filter applied

\begin{tabular}{|c|c|c|c|c|c|}
\hline \multicolumn{6}{|c|}{$\begin{array}{l}\text { With regards to business signage in the North Morro Bay/Quintana area, which of the following signs } \\
\text { would you approve? (Check all that apply) }\end{array}$} \\
\hline & \multirow{2}{*}{ Total* } & \multicolumn{4}{|c|}{ What best describes your location? } \\
\hline & & Downtown & Embarcadero & North Morro Bay/Quintana & Other, please specify \\
\hline & 89 & 30 & 23 & 19 & 15 \\
\hline A Frame Signs & $\begin{array}{r}52 \\
58.4 \%\end{array}$ & $\begin{array}{r}17 \\
56.7 \%\end{array}$ & $\begin{array}{r}12 \\
52.2 \%\end{array}$ & $\begin{array}{r}12 \\
63.2 \%\end{array}$ & $\begin{array}{r}11 \\
73.3 \%\end{array}$ \\
\hline Awning Signs & $\begin{array}{r}69 \\
77.5 \%\end{array}$ & $\begin{array}{r}24 \\
80.0 \%\end{array}$ & $\begin{array}{r}18 \\
78.3 \%\end{array}$ & \begin{tabular}{r|r}
14 \\
$73.7 \%$
\end{tabular} & $\begin{array}{r}13 \\
86.7 \%\end{array}$ \\
\hline $\begin{array}{l}\text { Banners as a } \\
\text { Permanent } \\
\text { Signage }\end{array}$ & $\begin{array}{r}36 \\
40.4 \%\end{array}$ & $\begin{array}{r}12 \\
40.0 \%\end{array}$ & $\begin{array}{r}8 \\
34.8 \%\end{array}$ & \begin{tabular}{r|}
8 \\
$42.1 \%$
\end{tabular} & $\begin{array}{r}8 \\
53.3 \%\end{array}$ \\
\hline Flag & $\begin{array}{r}55 \\
61.8 \% \\
\end{array}$ & $\begin{array}{r}16 \\
53.3 \%\end{array}$ & $\begin{array}{r}17 \\
73.9 \%\end{array}$ & $\begin{array}{r}14 \\
73.7 \%\end{array}$ & $\begin{array}{r}8 \\
53.3 \%\end{array}$ \\
\hline $\begin{array}{l}\text { Gateway Signs: } \\
\text { Concept would be } \\
\text { to allow a type of } \\
\text { sign at the } \\
\text { entrance at Morro } \\
\text { Bay Blvd to } \\
\text { announce the } \\
\text { downtown area. }\end{array}$ & $\begin{array}{r}54 \\
60.7 \%\end{array}$ & $\begin{array}{r}21 \\
70.0 \%\end{array}$ & $\begin{array}{r}14 \\
60.9 \%\end{array}$ & $\begin{array}{r}10 \\
52.6 \%\end{array}$ & $\begin{array}{r}9 \\
60.0 \%\end{array}$ \\
\hline $\begin{array}{l}\text { Illuminated, } \\
\text { Internally }\end{array}$ & $\begin{array}{r}64 \\
71.9 \%\end{array}$ & $\begin{array}{r}22 \\
73.3 \%\end{array}$ & $\begin{array}{r}19 \\
82.6 \%\end{array}$ & $\begin{array}{r}14 \\
73.7 \%\end{array}$ & $\begin{array}{r}9 \\
60.0 \%\end{array}$ \\
\hline $\begin{array}{l}\text { Illuminated, } \\
\text { Externally }\end{array}$ & $\begin{array}{r}59 \\
66.3 \%\end{array}$ & $\begin{array}{r}22 \\
73.3 \%\end{array}$ & $\begin{array}{r}16 \\
69.6 \%\end{array}$ & $\begin{array}{r}13 \\
68.4 \%\end{array}$ & $\begin{array}{r}8 \\
53.3 \%\end{array}$ \\
\hline $\begin{array}{l}\text { Marquee Signs: } \\
\text { For theatres, } \\
\text { nightclubs, } \\
\text { conference } \\
\text { facilities. }\end{array}$ & $\begin{array}{r}58 \\
65.2 \%\end{array}$ & $\begin{array}{r}21 \\
70.0 \%\end{array}$ & $\begin{array}{r}16 \\
69.6 \%\end{array}$ & $\begin{array}{r}12 \\
63.2 \%\end{array}$ & $\begin{array}{r}9 \\
60.0 \%\end{array}$ \\
\hline Monument Signs & $\begin{array}{r}49 \\
55.1 \%\end{array}$ & $\begin{array}{r}20 \\
66.7 \%\end{array}$ & $\begin{array}{r}12 \\
52.2 \%\end{array}$ & $\begin{array}{r}9 \\
47.4 \%\end{array}$ & $\begin{array}{r}8 \\
53.3 \%\end{array}$ \\
\hline Off Premise Signs & $\begin{array}{r}36 \\
40.4 \% \\
\end{array}$ & $\begin{array}{r}15 \\
50.0 \%\end{array}$ & $\begin{array}{r}11 \\
47.8 \% \\
\end{array}$ & $\begin{array}{r}7 \\
36.8 \%\end{array}$ & $\begin{array}{r}3 \\
20.0 \%\end{array}$ \\
\hline Pole Signs & $\begin{array}{r}50 \\
56.2 \%\end{array}$ & $\begin{array}{r}15 \\
50.0 \%\end{array}$ & $\begin{array}{r}14 \\
60.9 \%\end{array}$ & $\begin{array}{r}14 \\
73.7 \%\end{array}$ & $\begin{array}{r}7 \\
46.7 \%\end{array}$ \\
\hline Pub Signs & $\begin{array}{r}51 \\
57.3 \%\end{array}$ & $\begin{array}{r}16 \\
53.3 \%\end{array}$ & $\begin{array}{r}14 \\
60.9 \%\end{array}$ & $\begin{array}{r}14 \\
73.7 \%\end{array}$ & $\begin{array}{r}7 \\
46.7 \%\end{array}$ \\
\hline Wall Signs & $\begin{array}{r}67 \\
75.3 \% \\
\end{array}$ & $\begin{array}{r}23 \\
76.7 \%\end{array}$ & $\begin{array}{r}19 \\
82.6 \%\end{array}$ & $\begin{array}{r}14 \\
73.7 \%\end{array}$ & $\begin{array}{r}11 \\
73.3 \%\end{array}$ \\
\hline Window Signs & $\begin{array}{r}74 \\
83.1 \%\end{array}$ & $\begin{array}{r}24 \\
80.0 \%\end{array}$ & $\begin{array}{r}19 \\
82.6 \%\end{array}$ & $\begin{array}{r}19 \\
100.0 \%\end{array}$ & $\begin{array}{r}12 \\
80.0 \%\end{array}$ \\
\hline
\end{tabular}

*Total $=$ The number of respondents for the entire survey who answered the Row question and, if a filter is applied, meet the filter criteria. 
MINUTES - MORRO BAY CITY COUNCIL

CLOSED SESSION - MAY 24, 2011

CITY HALL CONFERENCE ROOM - 4:00 P.M.

Mayor Yates called the meeting to order at 4:00 p.m.

PRESENT:

William Yates

Carla Borchard

Mayor

Nancy Johnson

Councilmember

George Leage

Councilmember

Noah Smukler

Councilmember

Councilmember

STAFF:

Andrea Lueker

Robert Schultz

City Manager

City Attorney

\section{$\underline{\text { CLOSED SESSION }}$}

MOTION: Councilmember Smukler moved the meeting be adjourned to Closed Session. The motion was seconded by Councilmember Leage and unanimously carried. (5-0)

Mayor Yates read the Closed Session Statement

CS-1 GOVERNMENT CODE SECTION 54957.6; CONFERENCE WITH LABOR NEGOTIATOR Conference with City Manager, the City's Designated Representative, for the purpose of reviewing the City's position regarding the terms and compensation paid to the City Employees and giving instructions to the Designated Representative.

CS-2 GOVERNMENT CODE SECTION 54956.8; REAL PROPERTY TRANSACTIONS. Instructing City's real property negotiator regarding the price and terms of payment for the purchase, sale, exchange, or lease of real property as to three (3) parcels:

- Property: Embarcadero Grill - Lease Site 86-86W Negotiating Parties: Caldwell and City of Morro Bay. Negotiations: Sub Lease Terms and Conditions.

- Property: Lease Site 65-66/65W-66W, 571 Embarcadero, Negotiating Parties: Imani and City of Morro Bay. Negotiations: Lease Terms and Conditions.

- Property: Sea One Solutions; Lease Site 124-128/124W-128W and 113W, 1215 Embarcadero.

Negotiating Parties: Sea One Solutions, LLC and City of Morro Bay. Negotiations: Lease Terms and Conditions.

The meeting adjourned at 4:50 p.m.

The City Council adjourned to a Special Open Session meeting to hold interviews to fill vacancies on the City's Planning Commission, Public Works Advisory Board and Community Promotions Committee. The interviews started at 5:00 p.m. and were located at the Veterans' Memorial Building, 209 Surf Street, Morro Bay, CA 
MINUTES - MORRO BAY CITY COUNCIL

REGULAR MEETING - MAY 24, 2011

VETERANS MEMORIAL HALL - 6:00 P.M.

Mayor Yates called the meeting to order at 6:20 p.m.

PRESENT:

William Yates

Carla Borchard

Nancy Johnson

George Leage

Noah Smukler
Mayor
Councilmember
Councilmember
Councilmember
Councilmember

STAFF:

$$
\begin{aligned}
& \text { Andrea Lueker } \\
& \text { Robert Schultz } \\
& \text { Bridgett Kessling } \\
& \text { Eric Endersby } \\
& \text { Rob Livick } \\
& \text { Tim Olivas } \\
& \text { Mike Pond } \\
& \text { Susan Slayton } \\
& \text { Joe Woods }
\end{aligned}
$$

City Manager

City Attorney

City Clerk

Harbor Operations Manager

Public Services Director

Police Chief

Fire Chief

Administrative Services Director

Recreation \& Parks Director

ESTABLISH QUORUM AND CALL TO ORDER

MOMENT OF SILENCE

PLEDGE OF ALLEGIANCE

MAYOR AND COUNCIL MEMBERS REPORTS, ANNOUNCEMENTS \& PRESENTATIONS

CLOSED SESSION REPORT - City Attorney Robert Schultz reported the City Council met in Closed Session; no reportable action under the Brown Act was taken on Item CS-1.

The following action was taken on Item CS-2:

- Property: Embarcadero Grill - Lease Site 86-86W Negotiating Parties: Caldwell and City of Morro Bay. Negotiations: Sub Lease Terms and Conditions.

Councilmember Leage was excused from this discussion due to a conflict of interest; and, no action under the Brown Act was taken on Lease Site 86-86W.

- Property: Lease Site 65-66/65W-66W, 571 Embarcadero, Negotiating Parties: Imani and City of Morro Bay.

Negotiations: Lease Terms and Conditions.

- Property: Sea One Solutions; Lease Site 124-128/124W-128W and 113W, 1215

Embarcadero

Negotiating Parties: Sea One Solutions, LLC and City of Morro Bay.

Negotiations: Lease Terms and Conditions.

Action was taken to correct the administrative error under Section 2.04 (Percentage Rent) to bring the lease agreements in conformance with the Master Lease format for Lease Sites 65-66/65W-66W, and Lease Site 124-128/124W-128W and 113W. 
MINUTES - MORRO BAY CITY COUNCIL

REGULAR MEETING - MAY 24, 2011

\section{PUBLIC COMMENT}

Jeff Eckles, owner of Morro Bay House of Jerky, stated this is a new store on the Embarcadero which carries five different flavors of jerky, as well as a variety of other goods.

Gary Hixson promoted the Gary (Tyler Moore) Hixson Show, and he supports having a Film Commission in Morro Bay. Mr. Hixson spoke on various issues in the City.

Dan Glesmann addressed an article in the Tribune regarding the budget woes in San Luis Obispo. He addressed Morro Bay's upcoming budget and requested the City Council get control of personnel costs and preserve the City's infrastructure.

Stan Trapp thanked the City for its efforts in sprucing up the Embarcadero. He addressed Item A-5 (Resolution Authorizing Monthly Payment Option for Embarcadero Leaseholders) and expressed gratitude to staff for recommending monthly payments for leaseholders. Mr. Trapp also addressed Item B-1 (Consideration of Adoption of Interim Urgency Ordinance Establishing Rules Regulating the Approval Process and Construction of Projecting Signs Pending Completion of Studies and the Preparation of an Update to the City's Zoning Code) and supported the recommendation for approval of Ordinance No. 568 which will bring uniformity to the signs around the City.

Nancy Castle thanked the City for its support of the Central Coast Maritime Museum Association for the display across from the Great American Fish Company which is a part of the history of Morro Bay.

John Weiss discussed the Eco-Rotary Program where the goal is to recycle the food products and reduce the amount of water used at the three local golf courses in the county. He said there will be meetings every second and fourth Tuesdays at the Morro Bay Golf Course regarding this program.

Virginia Hiramatsu announced Relay for Life of Morro Bay will be held on August 6 and 7, 2011 at Morro Bay High School. She said the funds raised at this event will stay to assist victims of cancer in Morro Bay.

George Ross, CPA stated the pension liabilities in the City are the biggest concern and the two-tiered pension benefit is a good idea on reducing future pension liabilities. He said another hole in the City governance is the issuance of business licenses which needs to be enforced. Mr. Ross also stated another annoyance is the theft of recycling goods which could lead to identity theft. He also expressed the need to pursue compliance on the removal of A-frame signs. 
MINUTES - MORRO BAY CITY COUNCIL

REGULAR MEETING - MAY 24, 2011

Betty Winholtz addressed Item A-4 (Adoption of Ordinance No. 567 Repealing, Amending and Reenacting Chapter 14.48 of the City of Morro Bay Municipal Code, Entitled Illicit Discharge and Stormwater Management Control) stating there is not an educational component to this Ordinance, and there needs to be some directive to educate the public. She also noted although the improvements to the Embarcadero are nice, North Main Street also deserves the same improvements to attract customers to the businesses in this part of the City.

Joan Solu addressed Council's future review on tourism and requested the City Council pay close attention to some of the suggestions, and noted there are several visitor-serving contracts. She said tourism brings in \$70-80 million in business revenue annually to the City, and the City does not have a leader or strategy and needs a Director of Tourism. Ms. Solu stated the Morro Bay Tourism Business Improvement District would be happy to discuss paying an administrative fee in place of the Visitor Center contract.

John Barta thanked the City for the removal of the news racks. He referred to Item A-4 and noted the City has no downstream communities that would be caused any harm from storm water pollution. Mr. Barta stated the City should be required to have small traps that will clean storm water discharge however anything larger than that is unnecessary.

Brian Stacy requested the City consider providing assistance to fishermen by giving them an extension on slip rent during salmon season.

Kim Vanerstrand, business owner on Main Street, expressed concern with the City's proposed signage regulations and how it may affect stores off the beaten path.

Mayor Yates closed the hearing for public comment.

\section{A. CONSENT CALENDAR}

Unless an item is pulled for separate action by the City Council, the following actions are approved without discussion. A-1 APPROVAL OF MINUTES FOR THE REGULAR CITY COUNCIL MEETING
OF MAY 10, 2011; (ADMINISTRATION)

RECOMMENDATION: Approve as submitted.

A-2 APPROVAL OF CONTRACT WITH BARNETT COX \& ASSOCIATES FOR ADVERTISING AND MARKETING SERVICES; (CITY ATTORNEY)

\section{RECOMMENDATION: Approve and authorize the Mayor to execute the} contract. 
MINUTES - MORRO BAY CITY COUNCIL

REGULAR MEETING - MAY 24, 2011

A-3 RESOLUTION NO. 35-11 AUTHORIZING SAN LUIS OBISPO COUNTY ASSESSOR TO ASSESS AMOUNTS DUE ON DELINQUENT SOLID WASTE COLLECTION ACCOUNTS AS TAX LIENS AGAINST THE PROPERTIES; (ADMINISTRATIVE SERVICES)

RECOMMENDATION: Adopt Resolution No. 35-11.

A-4 ADOPTION OF ORDINANCE NO. 567 REPEALING, AMENDING AND REENACTING CHAPTER 14.48 OF THE CITY OF MORRO BAY MUNICIPAL CODE, ENTITLED ILLICIT DISCHARGE AND STORMWATER MANAGEMENT CONTROL; (PUBLIC SERVICES)

RECOMMENDATION: Adopt Ordinance No. 567.

A-5 RESOLUTION AUTHORIZING MONTHLY PAYMENT OPTION FOR EMBARCADERO LEASEHOLDERS; (HARBOR)

RECOMMENDATION: Adopt Resolution No. 37-11.

A-6 RESOLUTION AUTHORIZING EXECUTION OF THE "DESIGNATION OF APPLICANT'S AGENT RESOLUTION FOR NON-STATE AGENCIES" FOR THE CITY'S APPLICATION FOR CALIFORNIA DISASTER ASSISTANCE ACT PROGRAM; (HARBOR)

RECOMMENDATION: Adopt Resolution No. 38-11.

Councilmember Leage pulled Item A-3 from the Consent Calendar; Councilmember Borchard pulled Item A-4.

MOTION: Councilmember Borchard moved the City Council approve the Consent Calendar with the exception of Items A-3 and A-4. The motion was seconded by Councilmember Johnson and carried unanimously. (5-0)

A-3 RESOLUTION NO. 35-11 AUTHORIZING SAN LUIS OBISPO COUNTY ASSESSOR TO ASSESS AMOUNTS DUE ON DELINQUENT SOLID WASTE COLLECTION ACCOUNTS AS TAX LIENS AGAINST THE PROPERTIES; (ADMINISTRATIVE SERVICES)

Councilmember Leage asked if there is any other way to collect on a delinquent bill other than placing a lien against property. He said he would prefer another way of collecting on a bill, such as a collection agency rather than attaching the property; Mayor Yates agreed. 
MINUTES - MORRO BAY CITY COUNCIL

REGULAR MEETING - MAY 24, 2011

Administrative Services Director Susan Slayton responded garbage liens are placed only on homeowners based on the delinquency of the bill at the end of the year. She said the Garbage Company makes an effort to collect on the garbage bill and when the bill has been neglected for a long period of time, the Garbage Company has the ability to assess their collection through the property tax bill. Ms. Slayton stated the City receives a $2 \%$ administration fee for pursuing the assessment.

MOTION: Councilmember Borchard moved the City Council approve Item A-3 of the Consent Calendar. The motion was seconded by Councilmember Smukler and carried with Councilmember Leage and Mayor Yates voting no. (3-2)

\section{A-4 ADOPTION OF ORDINANCE NO. 567 REPEALING, AMENDING AND REENACTING CHAPTER 14.48 OF THE CITY OF MORRO BAY MUNICIPAL CODE, ENTITLED ILLICIT DISCHARGE AND STORMWATER MANAGEMENT CONTROL; (PUBLIC SERVICES)}

Councilmember Borchard clarified from her statement at the last City Council meeting instead of "minimum rainfall requirements", she meant "minimum required hydromodification and Low Impact Development Control measures allowed under the City's storm water permit requirements.

MOTION: Councilmember Borchard moved the City Council approve Item A-3 of the Consent Calendar. The motion was seconded by Councilmember Smukler and carried with Mayor Yates voting no. (4-1)

Mayor Yates called for a break at 7:22 p.m.; the meeting resumed at 7:37 p.m.

\section{B. PUBLIC HEARINGS, REPORTS \& APPEARANCES}

B-1 REVIEW OF DRAFT SIGN ORDINANCE AND CONSIDERATION OF ADOPTION OF INTERIM URGENCY ORDINANCE ESTABLISHING RULES REGULATING THE APPROVAL PROCESS AND CONSTRUCTION OF PROJECTING SIGNS PENDING COMPLETION OF STUDIES AND THE PREPARATION OF AN UPDATE TO THE CITY'S ZONING CODE; (CITY ATTORNEY/PUBLIC SERVICES DIRECTOR)

City Attorney Robert Schultz stated staff is beginning to enforce the A-Frame Sign regulations and there have been discussions regarding allowing "Projecting Signs" (commonly referred to as "Pub" signs) to replace A-frame signs. The purpose of this Ordinance is to allow for the issuance of sign permits for projecting signs. Mr. Schultz recommended the City Council adopt Interim Urgency Ordinance No. 568 which would establish interim rules regulating the approval process and construction of projecting signs pending completion of studies and the preparation of an update to the City's zoning code. 
MINUTES - MORRO BAY CITY COUNCIL

REGULAR MEETING - MAY 24, 2011

Mayor Yates opened the hearing for public comment.

John Barta expressed support for the adoption of Interim Urgency Ordinance No. 568.

Mayor Yates closed the hearing for public comment.

MOTION: Mayor Yates moved the City Council adopt Interim Urgency Ordinance No. 568 which would establish interim rules regulating the approval process and construction of projecting signs pending completion of studies and the preparation of an update to the City's zoning code. The motion was seconded by Councilmember Borchard and carried unanimously. (5-0)

City Manager Andrea Lueker read Interim Urgency Ordinance No. 568 by number and title only.

Public Services Director Rob Livick stated the Draft Sign Ordinance is fundamentally the same ordinance approved within the Comprehensive Zoning Ordinance Update 2004; changes have been made to the Sign Ordinance to allow it to be integrated into the existing Ordinance. He said the current and proposed ordinance limits the amount of signage each building and/or business can permanently affix to a building as such a determination should be made if further changes need to be addressed to achieve the Council's goal as they pertain to projecting signs. Mr. Livick recommended the City Council review the Draft Ordinance and changes proposed by the Planning Commission and provide direction to staff regarding the final revised Sign Ordinance.

Council agreed that more work is needed on this Draft Ordinance, and a workshop would be beneficial to receive input from the business community.

Mayor Yates opened the hearing for public comment.

John Barta stated years ago when he served on the Planning Commission, it took several years to develop the concept of the Sign Ordinance. He said he would be happy to share the PowerPoint presentation he has with the information from that time period.

John Weiss, President of Chamber of Commerce, stated it is agreed that the business community would like to reduce clutter; the need of communicating what and where businesses are; the adoption of modest fees; and, it meets the needs of the business as well as City standards. He said a workshop is a great idea.

Mayor Yates closed the hearing for public comment.

Councilmember Smukler stated he would like a better dialogue with the Chamber of Commerce and other interest groups, and that they have an opportunity for input. 


\section{MINUTES - MORRO BAY CITY COUNCIL}

REGULAR MEETING - MAY 24, 2011

Councilmember Johnson made the following suggestions: 1) no A-frame signs anywhere in the City; 2) projecting public signs allowed in all parts of the City; 3) kiosks should be allowed at the corner of Beach and Front Street, along the waterfront and on the corners of Old Town; and 4) feather flags should be allowed in North Morro Bay and Quintana Road. She also noted signs on pick-up trucks should not be allowed and should be enforced.

Mayor Yates stated he agrees there should be no A-frame signs allowed anywhere in town noting there are alternative signs.

Councilmember Borchard stated she would like to exhaust the fact that there are areas that could have alternative signage before disallowing A-frame signs. She said she would like the Planning Commission PowerPoint presentation from 2004 be part of the workshop which could give Council alternative ideas. Councilmember Borchard requested Council consider the appointment of a Sign Review Board.

Council directed staff to schedule a public workshop on the Draft Sign Ordinance within six months, or by the first meeting in November.

No further action was taken on the Draft Sign Ordinance.

\section{B-2 REVIEW AND ADOPTION OF A REVISED TEEN CENTER MASTER PLAN; (RECREATION \& PARKS)}

Recreation \& Parks Director Joe Woods stated the Teen Center Master Plan process started in 2004 with public workshops and concluded in 2006 with a City Council approved Concept Plan. Recent workshops have been held to not only update the Master Plan, but also to fulfill Proposition 84 requirements for public input. Staff held three workshops at the Teen Center in late February 2011. The Recreation \& Parks Commission reviewed four resulting options and requested staff to develop additional options which combined two of the proposed. As a result, Options 5 and 6 are presented to City Council for consideration. At the conclusion of this process, staff will be submitting a grant application to the State Parks Department with the intent to obtain Proposition 84 funding. Mr. Woods recommended the City Council review and discuss the proposed options for the Teen Center Master Plan and adopt either Option 5 or 6 based on public input and consensus.

Mayor Yates opened the hearing for public comment.

Jake stated he has been going to the Teen Center for a few years and it has been a great experience, and he believes this upgrade will be beneficial for future teens. He said Option 6 would provide a lot of space for the community. 


\section{MINUTES - MORRO BAY CITY COUNCIL}

REGULAR MEETING - MAY 24, 2011

John Gutierrez, Program Director for Teen Center, stated this is a home away from home for a lot of teens. He said as part of the Teen Advisory Committee, there are teens that put a lot of time into this Master Plan. Mr. Gutierrez stated he prefers Option 6 generally as the better plan.

Taylor Newton stated he mentors the Gorilla Gardening Club who is mostly teens who are excited about getting involved in the landscape portion of this plan as well as the skate park and fitness area. He stated he prefers Option 6 especially with the fitness center and internet access.

Karen Croley, Recreation \& Parks Commissioner, stated she prefers Option 6 which is more family-oriented with something for different age groups to do in a confined space. She said crime studies show that between 3:00 pm - 5:00 pm is when crime rates are highest because teens are home unsupervised with nothing to do.

Mayor Yates closed the hearing for public comment.

Councilmember Borchard stated she is adamant that this is a Youth Center with multi-age access and recognizing an area for teens. She expressed concern with the maintenance of the skate park area under the trees. Councilmember Borchard also has concern with the unprojected cost of this plan.

Councilmember Johnson stated she prefers Option 6; however, she expressed concern with the placement of the modular skate park in the back and the concrete skate park in the front of the Center. She said she would like the climbing area to be opened to preteens. Councilmember Johnson stated she would like the Center to be renamed because it is intimidating to preteens. She also has concerns with the unprojected costs.

Mayor Yates stated he supports approval of the Master Teen Center Plan (Option 6) as proposed; Councilmember Leage agreed.

Councilmember Smukler stated he supports Option 6 because it gives a buffer from the neighboring property owner. He said he would like renewable energy and water recycling to be included in this plan.

MOTION: Councilmember Smukler moved the City Council adopt Option 6 of the Master Teen Center Plan. The motion was seconded by Councilmember Borchard and carried with Councilmember Johnson voting no. (4-1)

\section{UNFINISHED BUSINESS - NONE}


MINUTES - MORRO BAY CITY COUNCIL

REGULAR MEETING - MAY 24, 2011

\section{NEW BUSINESS}

D-1 RESOLUTION NO. 36-11 APPROVING A COOPERATION AGREEMENT BETWEEN THE COUNTY OF SAN LUIS OBISPO AND THE CITY OF MORRO BAY FOR JOINT PARTICIPATION IN THE COMMUNITY DEVELOPMENT BLOCK GRANT PROGRAM, THE EMERGENCY SOLUTIONS GRANT PROGRAM AND THE HOUSING OPPORTUNITIES FOR PERSONS WITH AIDS PROGRAM FOR FISCAL YEARS 2012-2014; (ADMINISTRATION)

City Manager Andrea Lueker stated the City of Morro Bay has the opportunity to participate with other cities and the County of San Luis Obispo in qualifying as an "Urban County" for fiscal years ending 2012-2014. An Urban County receives annual, formal-based grants from the federal Department of Housing and Urban Development (HUD) under the Community Development Block Grant (CDBG), Home Investment Partnership Act (HOME) and Emergency Solutions Grants (ESG) programs. For the next 3 -year cycle, staff's recommendation is that the City of Morro Bay joins the Urban County rather than apply for funds as an individual city. This recommendation is due to staff reallocations and budget reductions over the past few years. Staff believes this move will provide more funding overall to the City and its residents, than the City attempting to apply for funds as an individual City. If the City decides to become part of the Urban County, the City will receive its CDBG allocation through the county. The estimated amount of the CDGB funding is $\$ 87,000-100,000$. Ms. Lueker recommended the City Council adopt Resolution No. 36-11 approving a Cooperation Agreement between the County of San Luis Obispo and the City of Morro Bay for Joint Participation in the Community Development Block Grant Program, the Emergency Solutions Grant Program, and the Housing Opportunities for Persons with Aids Program for Fiscal Years 2012-2014.

MOTION: Councilmember Leage moved the City Council adopt Resolution No. 3611 approving a Cooperation Agreement between the County of San Luis Obispo and the City of Morro Bay for Joint Participation in the Community Development Block Grant Program, the Emergency Solutions Grant Program, and the Housing Opportunities for Persons with Aids Program for Fiscal Years 2012-2014. The motion was seconded by Councilmember Borchard and carried unanimously. (5-0)

E. DECLARATION OF FUTURE AGENDA ITEMS - NONE.

ADJOURNMENT - The meeting adjourned at 9:19 P.M.

Recorded by:

Bridgett Kessling

City Clerk 

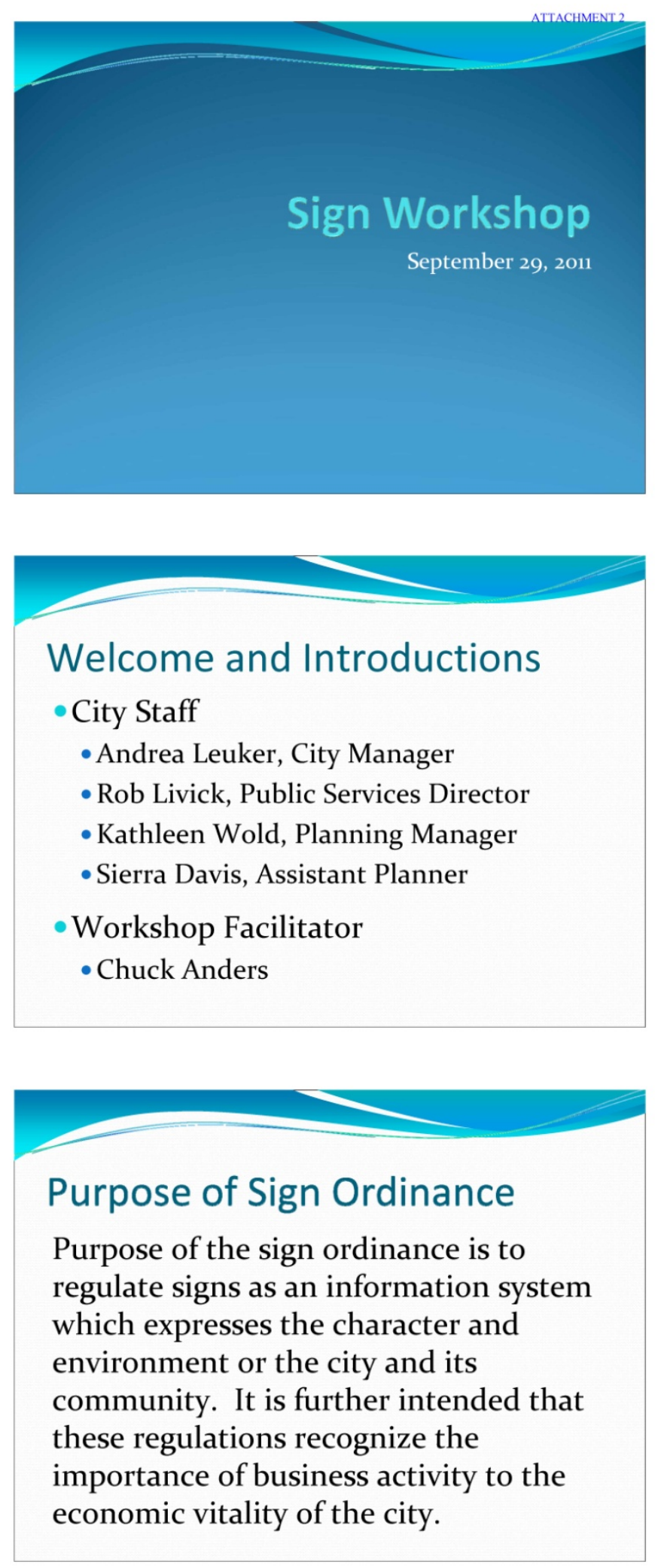

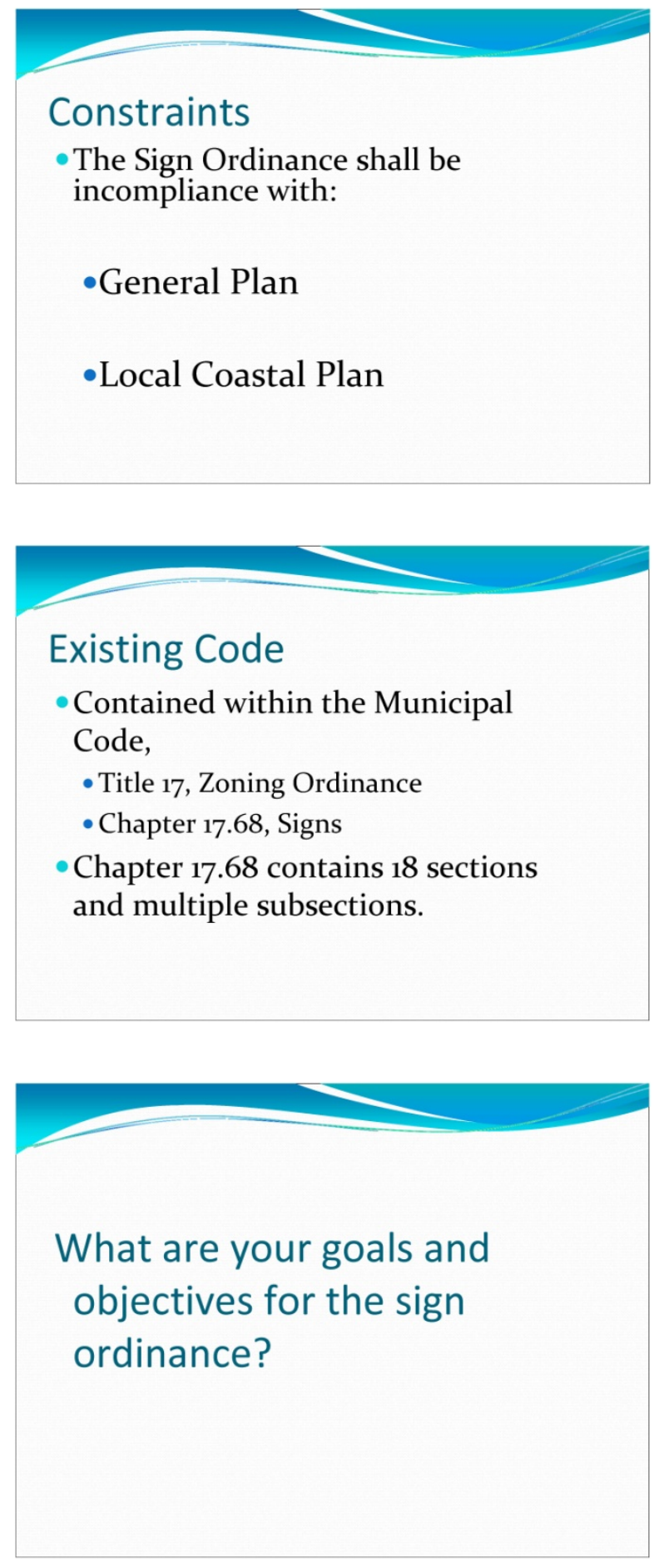

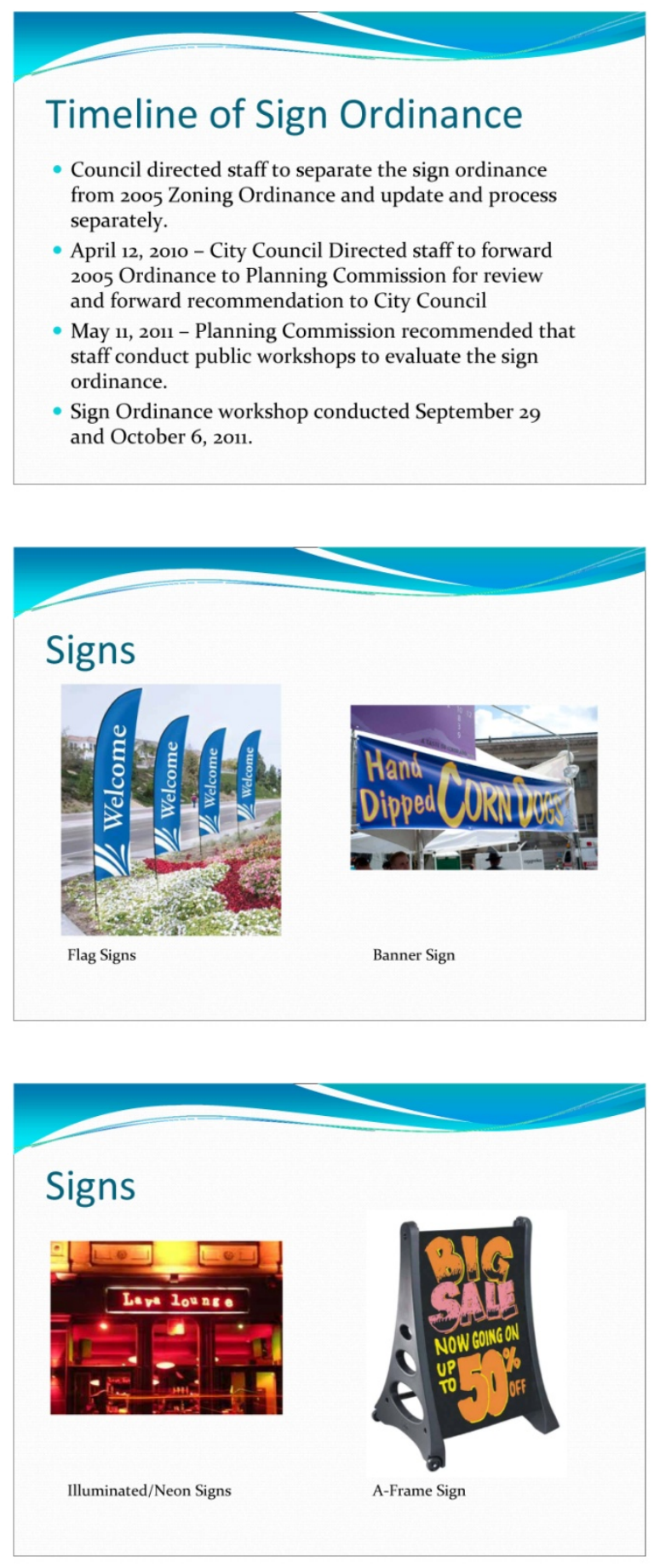

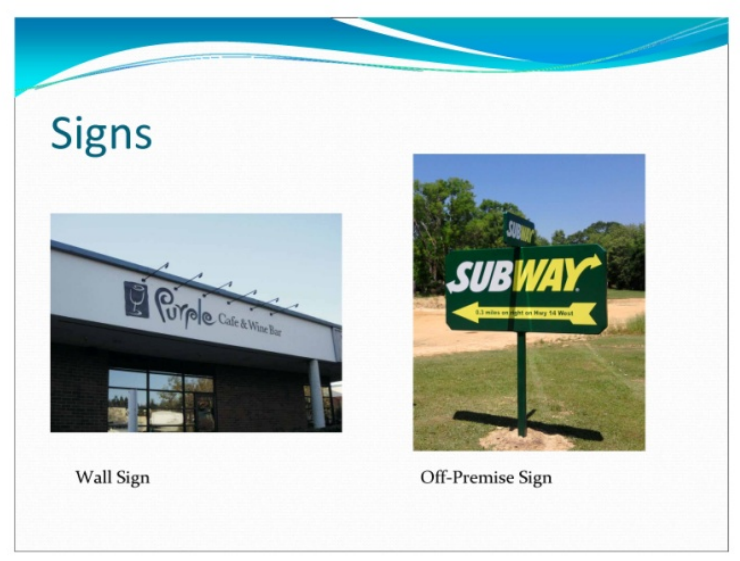



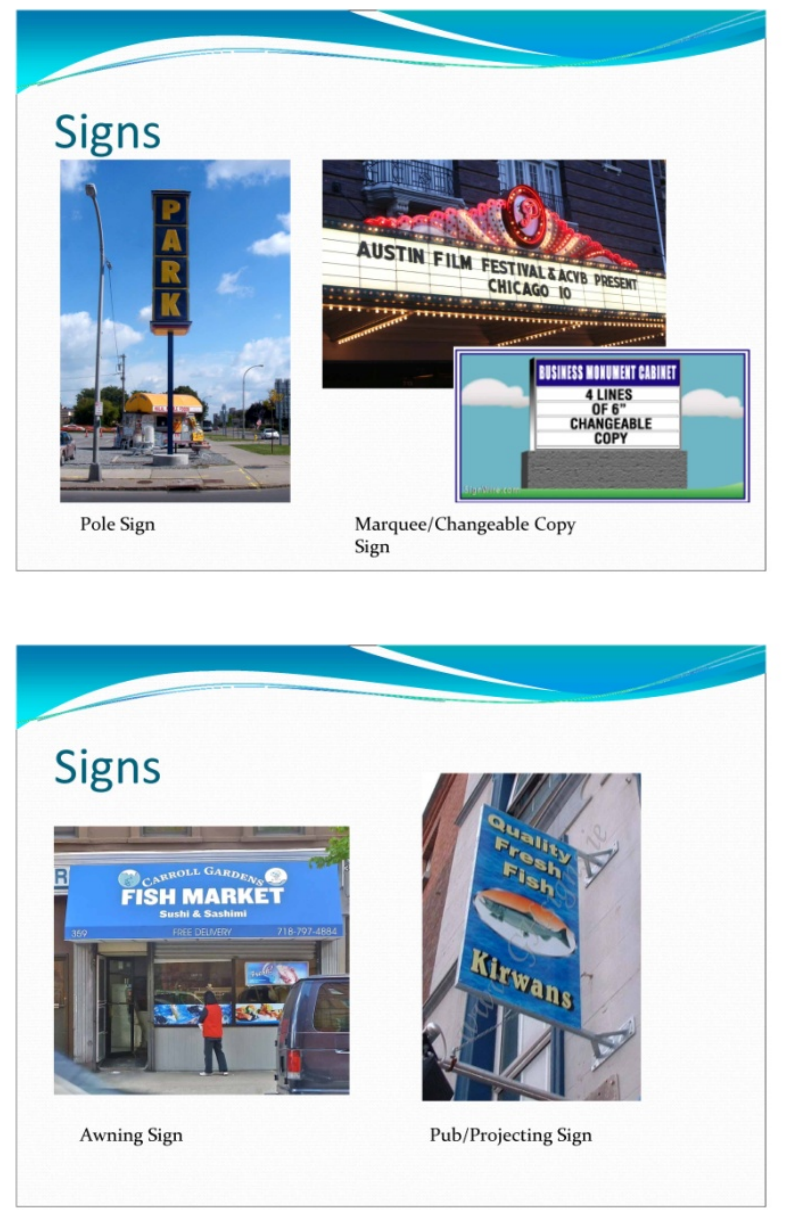

ATTACHMENT

Morro Bay Sign Ordinance Workshop

Thursday

September 29, 2011 


\title{
Morro Bay Sign Ordinance Workshop
}

\author{
Meeting Facilitator \\ Chuck Anders \\ Strategic Initiatives
}

\section{Morro Bay Sign Ordinance Workshop}

- Understand Sign Ordinance and Issues

- Get opinions on key issues

- Evaluate alternatives

\section{Workshop Guidelines}

- Be positive and respectful of others

- Listen - avoid side conversations

- Silence cell phones - take calls outside

- Stay on topic / Be concise

- Raise hand to speak

- Always "Us" (avoid judging others) 

1. Female
2. Male

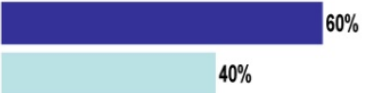

Which best describes your role in this workshop?

\begin{tabular}{ll|l} 
1. Business Owner & \\
2. Salaried Worker & & \\
2. & & \\
3. Retired & $0 \% \%$ \\
4. Other & $13 \%$
\end{tabular}

How many times did the people in the white shirts pass the basketball?

\begin{tabular}{|c|c|}
\hline 1. 12 & $14 \%$ \\
\hline 2. 13 & $0 \%$ \\
\hline 3. 14 & $0 \%$ \\
\hline 4. 15 & $14 \%$ \\
\hline 5. 16 & \\
\hline 6. 17 & $21 \%$ \\
\hline 7. 18 & $7 \%$ \\
\hline 8. 19 & $0 \%$ \\
\hline 9. 20 & $0 \%$ \\
\hline
\end{tabular}

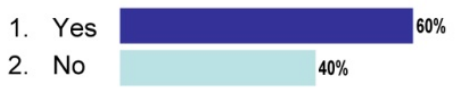

What geographic area of Morro Bay do you represent?

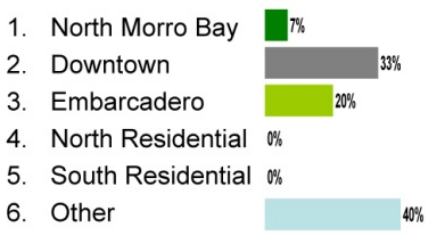

Did you see a gorilla?

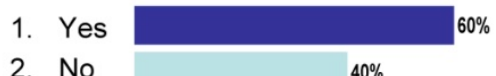

2. No $40 \%$ 
Is the existing sign ordinance working for you?

1. Yes

2. No

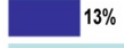

$87 \%$

Do you feel that you have enough signage?

1. Yes

2. No

3. Not applicable

\begin{tabular}{|l|l|}
\hline & $40 \%$ \\
\hline & $47 \%$ \\
\hline $13 \%$ &
\end{tabular}

Do you want uniformity in the appearance of signs and businesses throughout the community?

1. Yes

2. No

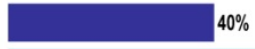

$40 \%$
Are you happy with how the signs in Morro Bay look right now?

1. Yes $6 \%$

2. No

$94 \%$ 
Do you believe there should be different rules for different areas of the community?

(No. Morro Bay - along Hwy 1, Downtown, Embarcadero, Residential)

1. Yes

2. No $0 \%$

Which of the following types of signs should be allowed in the Downtown Area?

(select all that apply)

1. Flag signs

2. Banners

3. Illuminated/Neon Signs

4. A-Frame Signs

5. Wall Signs

6. Off-Premise Sign

7. Pole/Monument Signs

8. Changeable copy signs

9. Awning Sign

10.Pub/projecting signs

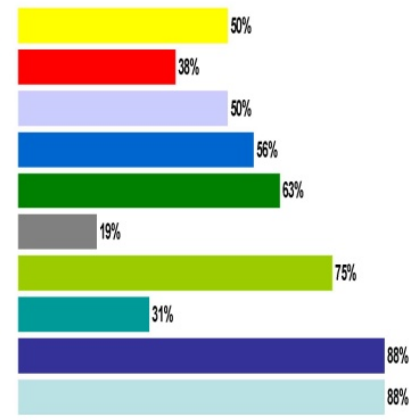

Which of the following types of signs should be allowed in Embarcadero Area? (select all that apply)
1. Flag signs
2. Banners
3. Illuminated/Neon Signs
4. A-Frame Signs
5. Wall Signs
6. Off-Premise Sign
7. Pole/Monument Signs
8. Changeable copy signs
9. Awning Sign
10. Pub/projecting signs

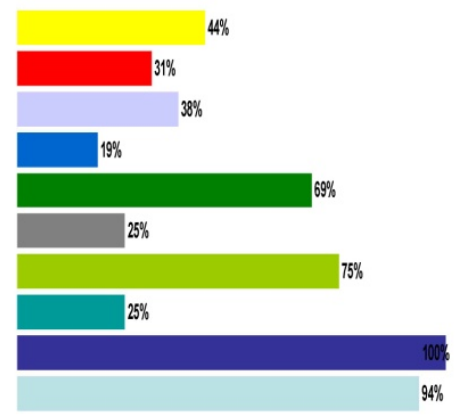


Which of the following types of signs should be allowed in Highway-Oriented Commercial Areas?

(select all that apply)

1. Flag signs

2. Banners

3. Illuminated/Neon Signs

4. A-Frame Signs

5. Wall Signs

6. Off-Premise Sign

7. Pole/Monument Signs

8. Changeable copy signs

9. Awning Sign

10. Pub/projecting signs

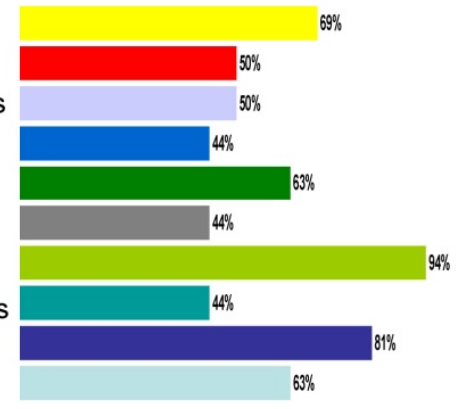

Which of the following types of signs should be allowed in Residential Areas?

(select all that apply)

1. Flag signs

$33 \%$

2. Banners

3. Illuminated/Neon Signs $\%$

4. A-Frame Signs

5. Wall Signs

6. Off-Premise Sign

7. Pole/Monument Signs

8. Changeable copy signs

9. Awning Sign

10. Pub/projecting signs

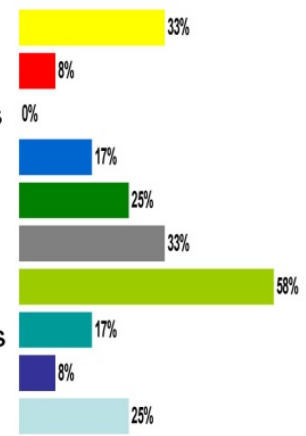

\section{Should multiple types of signs be} allowed without penalty?

1. Yes

2. No

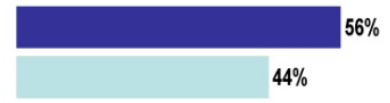


Do you consider murals to be signs?

1. Yes

2. No

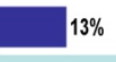

$13 \%$

Should signage in residential areas

be allowed for:

(select all that apply)

1. Real Estate

2. Vacation Rental

3. Allowed home occupations

4. Other

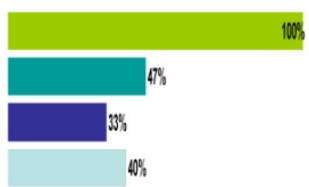

Should businesses be guaranteed a minimum size sign regardless of frontage size?

$\begin{array}{ll}\text { 1. Yes } & \\ \text { 2. No } & 36 \%\end{array}$ 
Should there be special allowances?

1. Yes

2. No $0 \%$

\section{Are you satisfied with the current rules}

for reader boards?

1. Yes

2. No

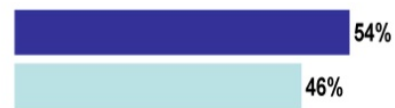

Are sign materials important?
1. Yes
2. No

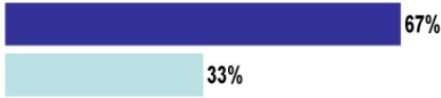


1. Did you find the workshop materials, referenced in http://morro-bay.ca.us/index.aspx? nid=708, helpful?

\begin{tabular}{rrr} 
Yes & $\begin{array}{c}\text { Response } \\
\text { Percent }\end{array}$ & $\begin{array}{c}\text { Response } \\
\text { Count }\end{array}$ \\
\hline No & $40.0 \%$ & 2 \\
\hline I attended the workshop & $40.0 \%$ & 2 \\
\hline & answered question & 5 \\
\hline & skipped question & 0 \\
\hline
\end{tabular}

2. Please provide the following information. Contact information will not be distributed. The contact information will only be used should we need to contact you for clarification of your responses.

\begin{tabular}{|c|c|c|c|}
\hline & & $\begin{array}{c}\text { Response } \\
\text { Percent }\end{array}$ & $\begin{array}{c}\text { Response } \\
\text { Count }\end{array}$ \\
\hline Name: & $\square$ & $100.0 \%$ & 5 \\
\hline Company: & 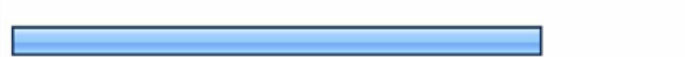 & $80.0 \%$ & 4 \\
\hline City/Town: & $\square$ & $100.0 \%$ & 5 \\
\hline Email Address: & & $80.0 \%$ & 4 \\
\hline Phone Number: & & $80.0 \%$ & 4 \\
\hline \multicolumn{3}{|c|}{ answered question } & 5 \\
\hline \multicolumn{3}{|c|}{ skipped question } & 0 \\
\hline
\end{tabular}


3. What is your gender?

\begin{tabular}{|c|c|c|c|}
\hline & & $\begin{array}{c}\text { Response } \\
\text { Percent }\end{array}$ & $\begin{array}{c}\text { Response } \\
\text { Count }\end{array}$ \\
\hline Male & ${ }^{-}$ & $60.0 \%$ & 3 \\
\hline Female & \begin{tabular}{|r|} 
\\
\end{tabular} & $40.0 \%$ & 2 \\
\hline \multicolumn{3}{|c|}{ answered question } & 5 \\
\hline \multicolumn{3}{|c|}{ skipped question } & 0 \\
\hline
\end{tabular}

4. Are you a Morro Bay resident?

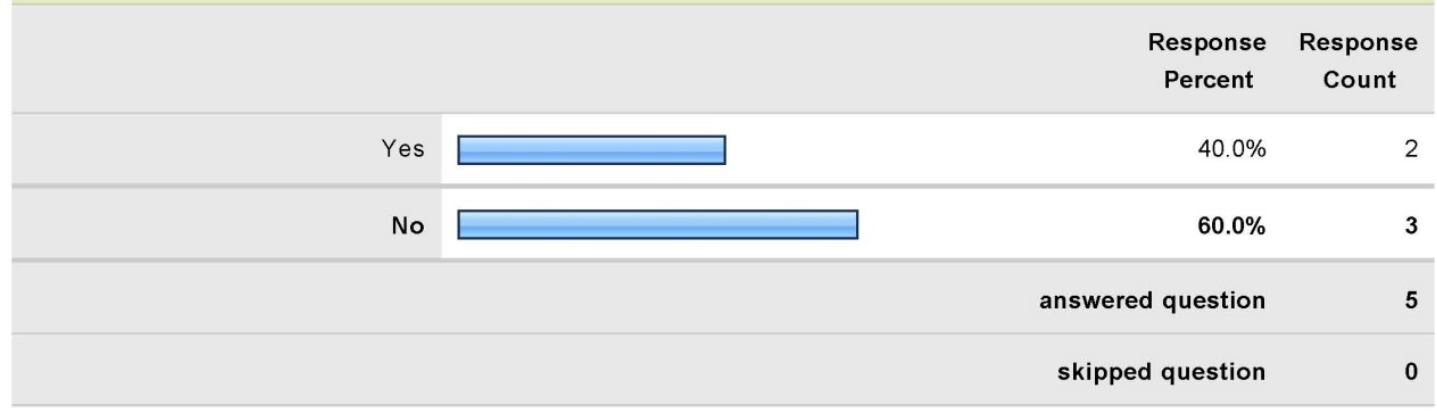




\section{What geographic area of Morro Bay do you represent?}

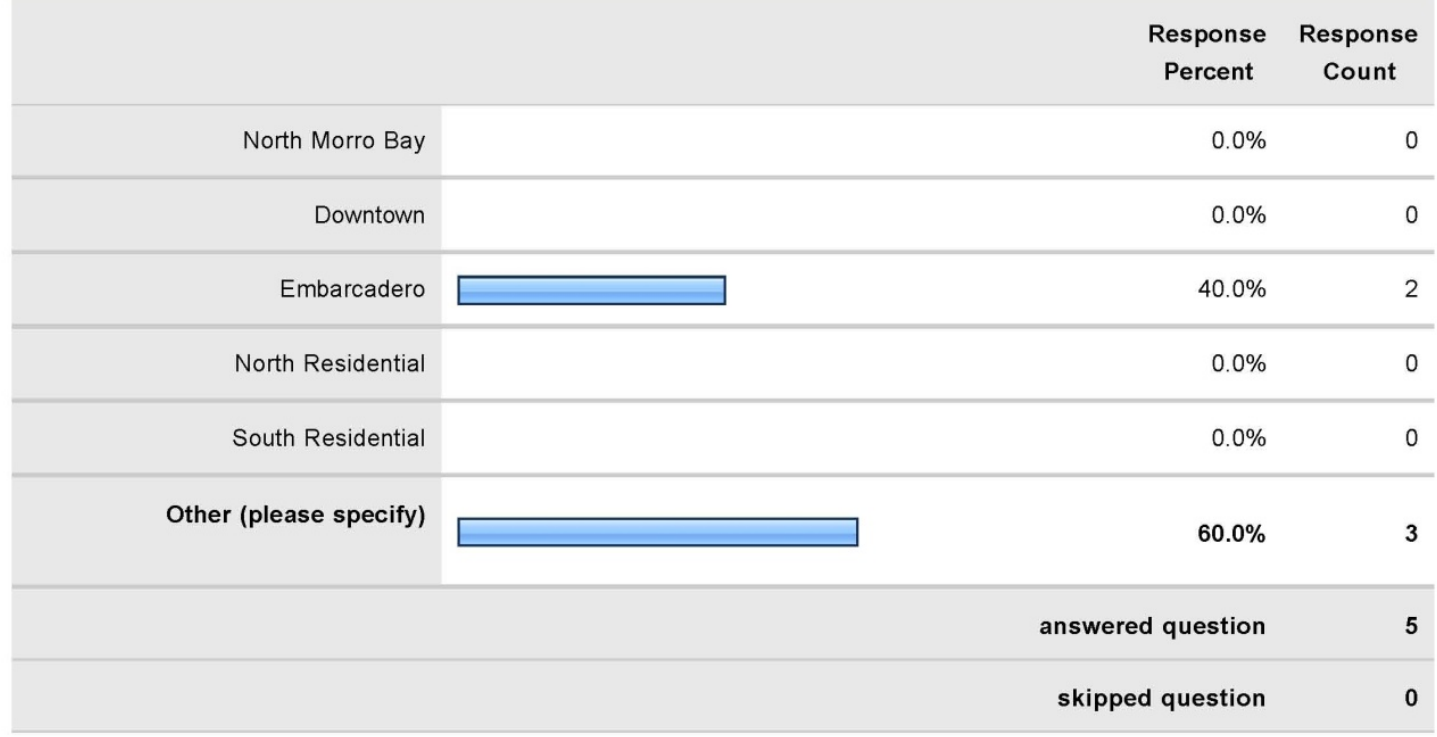

\section{Which best describes your role?}

\begin{tabular}{|c|c|c|c|}
\hline & & $\begin{array}{c}\text { Response } \\
\text { Percent }\end{array}$ & $\begin{array}{c}\text { Response } \\
\text { Count }\end{array}$ \\
\hline Business Owner & $\square$ & $80.0 \%$ & 4 \\
\hline Salaried Worker & & $0.0 \%$ & 0 \\
\hline Retired & $\square$ & $20.0 \%$ & 1 \\
\hline \multirow[t]{3}{*}{ Other (please specify) } & & $0.0 \%$ & 0 \\
\hline & & d question & 5 \\
\hline & & d question & 0 \\
\hline
\end{tabular}


7. Is the existing sign ordinance working for you?

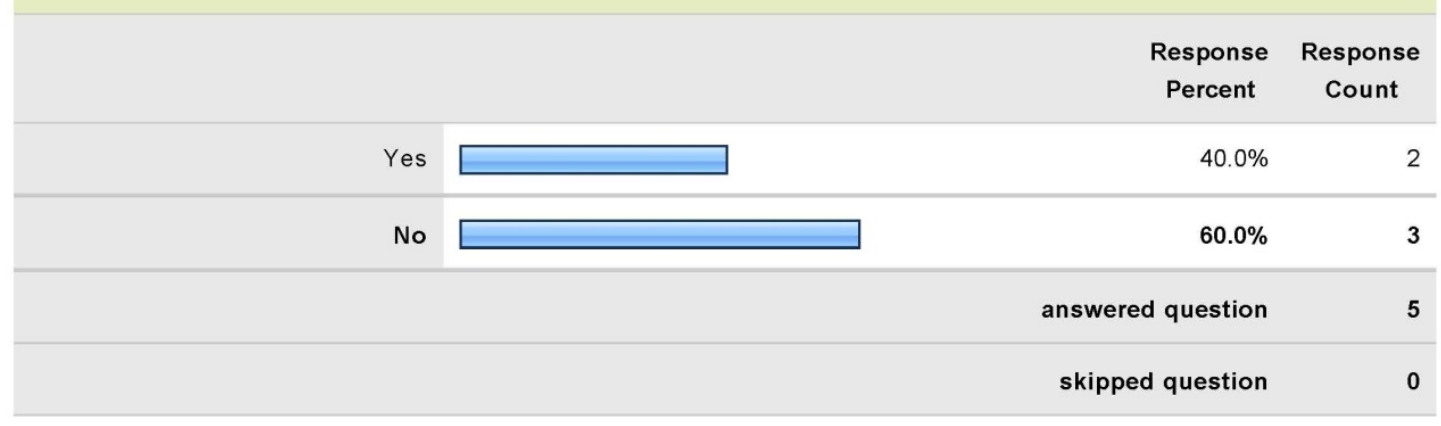

8. Are you happy with how the signs in Morro Bay look right now?

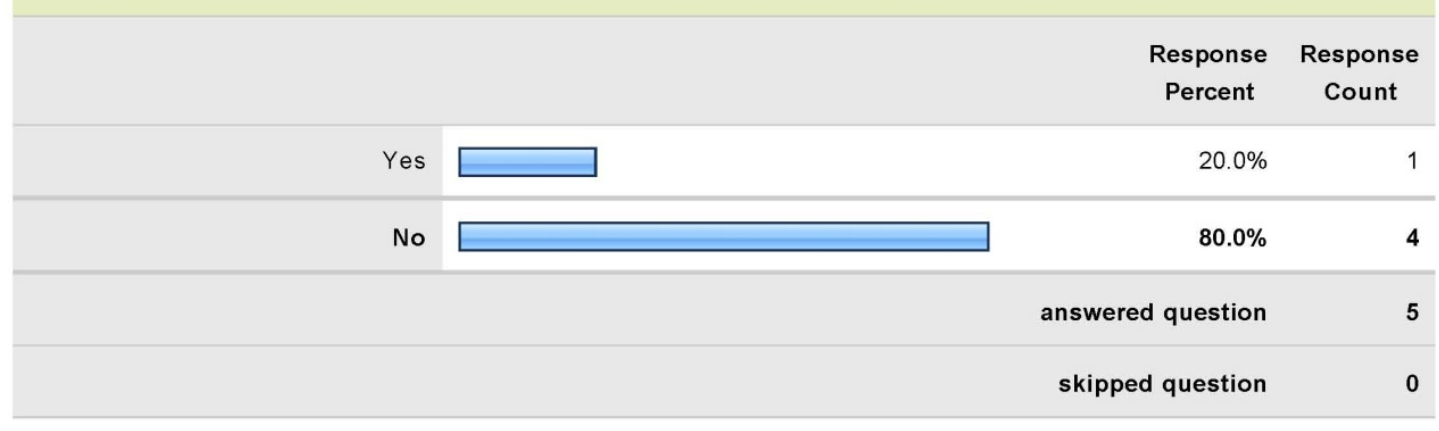

9. Do you feel that you have enough signage?

\begin{tabular}{|c|c|c|c|}
\hline & & $\begin{array}{c}\text { Response } \\
\text { Percent }\end{array}$ & $\begin{array}{c}\text { Response } \\
\text { Count }\end{array}$ \\
\hline Yes & $\square$ & $20.0 \%$ & 1 \\
\hline No & $\square$ & $80.0 \%$ & 4 \\
\hline N/A & & $0.0 \%$ & 0 \\
\hline \multicolumn{3}{|c|}{ answered question } & 5 \\
\hline \multicolumn{3}{|c|}{ skipped question } & 0 \\
\hline
\end{tabular}

4 of 12 
10. Do you want uniformity in the appearance of signs and businesses throughout the community?

\begin{tabular}{rrrr} 
& & $\begin{array}{r}\text { Response } \\
\text { Percent }\end{array}$ & $\begin{array}{c}\text { Response } \\
\text { Count }\end{array}$ \\
\hline Yes & $60.0 \%$ & 3 \\
\hline No & $40.0 \%$ & 2 \\
\hline & answered question & 5 \\
\hline & skipped question & 0 \\
\hline
\end{tabular}

11. Do you believe there should be different rules for different areas of the community? (No. Morro Bay - along Hwy 1, Downtown, Embarcadero, Residential)

\begin{tabular}{|c|c|c|c|}
\hline & & $\begin{array}{c}\text { Response } \\
\text { Percent }\end{array}$ & $\begin{array}{c}\text { Response } \\
\text { Count }\end{array}$ \\
\hline Yes & 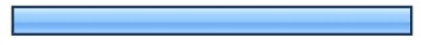 & $60.0 \%$ & 3 \\
\hline No & $\square$ & $40.0 \%$ & 2 \\
\hline \multicolumn{3}{|c|}{ answered question } & 5 \\
\hline \multicolumn{3}{|c|}{ skipped question } & 0 \\
\hline
\end{tabular}




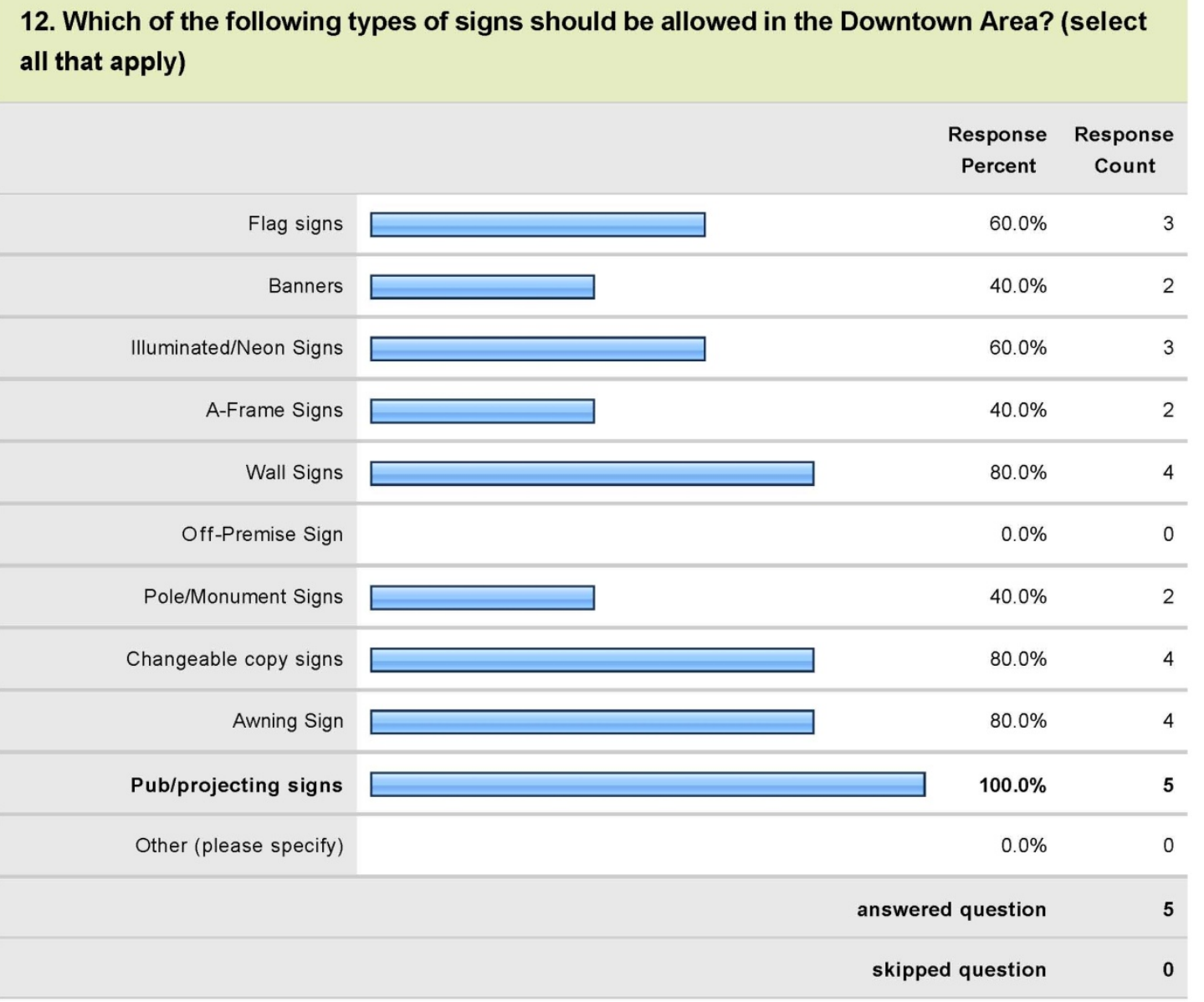




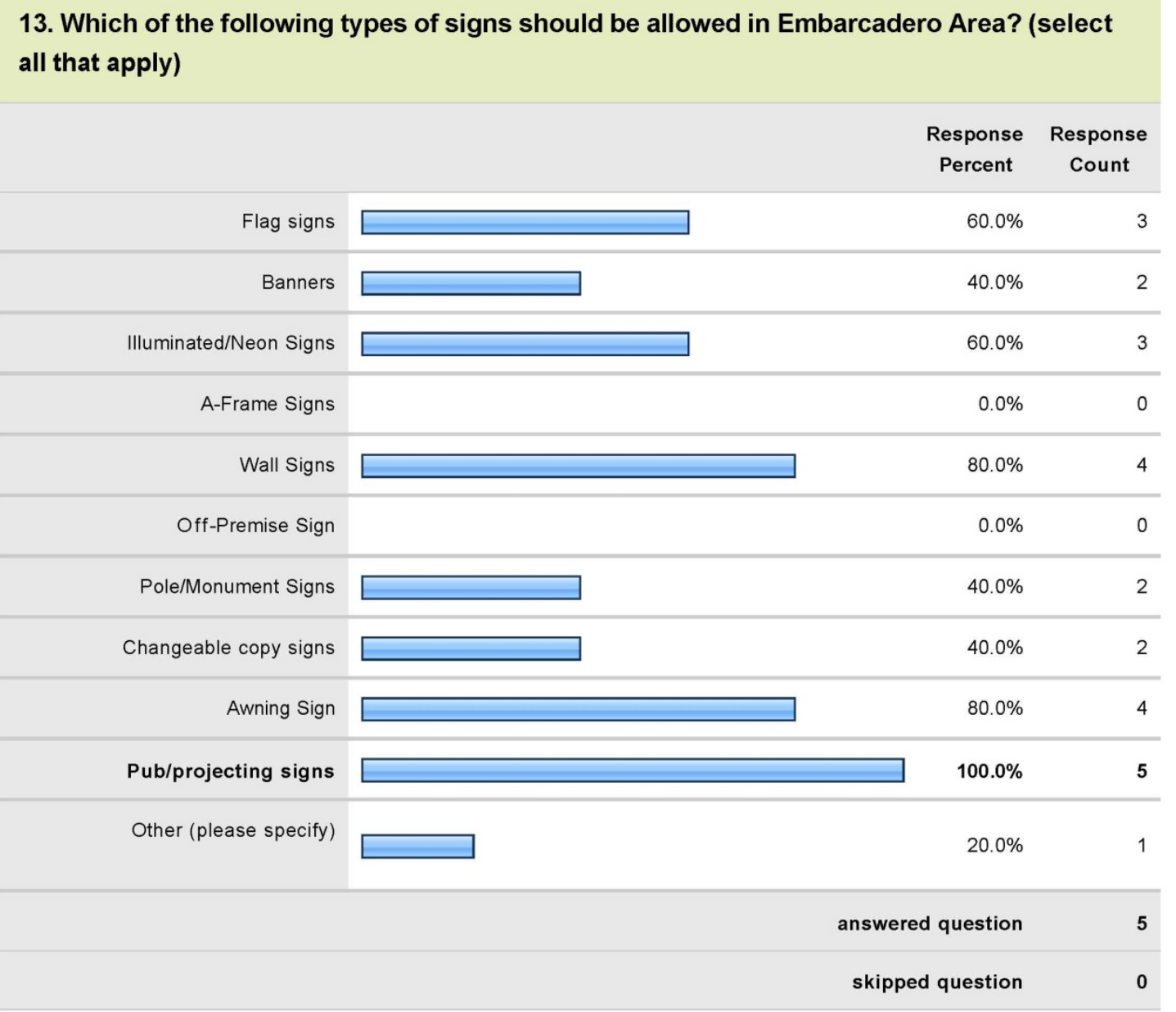


14. Which of the following types of signs should be allowed in Highway-Oriented Commercial Areas? (select all that apply)

\begin{tabular}{|c|c|c|c|}
\hline & & $\begin{array}{c}\text { Response } \\
\text { Percent }\end{array}$ & $\begin{array}{c}\text { Response } \\
\text { Count }\end{array}$ \\
\hline Flag signs & 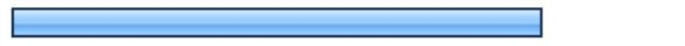 & $80.0 \%$ & 4 \\
\hline Banners & $\square$ & $60.0 \%$ & 3 \\
\hline Illuminated/Neon Signs & $\square$ & $80.0 \%$ & 4 \\
\hline A-Frame Signs & $\square$ & $20.0 \%$ & 1 \\
\hline Wall Signs & $\square$ & $80.0 \%$ & 4 \\
\hline Off-Premise Sign & $\square$ & $60.0 \%$ & 3 \\
\hline Pole/Monument Signs & $\square$ & $80.0 \%$ & 4 \\
\hline Changeable copy signs & $\square$ & $60.0 \%$ & 3 \\
\hline Awning Sign & $\square$ & $40.0 \%$ & 2 \\
\hline Pub/projecting sign & $\square$ & $100.0 \%$ & 5 \\
\hline Other (please specify) & & $0.0 \%$ & 0 \\
\hline \multicolumn{3}{|c|}{ answered question } & 5 \\
\hline \multicolumn{3}{|c|}{ skipped question } & 0 \\
\hline
\end{tabular}




\begin{tabular}{|c|c|c|c|}
\hline & & $\begin{array}{c}\text { Response } \\
\text { Percent }\end{array}$ & $\begin{array}{c}\text { Response } \\
\text { Count }\end{array}$ \\
\hline Flag signs & $\square$ & $20.0 \%$ & 1 \\
\hline Banners & & $0.0 \%$ & 0 \\
\hline Illuminated/Neon Signs & $\square$ & $20.0 \%$ & 1 \\
\hline A-Frame Signs & $\square$ & $20.0 \%$ & 1 \\
\hline Wall Signs & $\square$ & $20.0 \%$ & 1 \\
\hline Off-Premise Sign & $\square$ & $40.0 \%$ & 2 \\
\hline Pole/Monument Signs & $\square$ & $20.0 \%$ & 1 \\
\hline Changeable copy signs & & $0.0 \%$ & 0 \\
\hline Awning Sign & 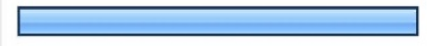 & $60.0 \%$ & 3 \\
\hline Pub/projecting signs & $\square$ & $60.0 \%$ & 3 \\
\hline No signs & & $0.0 \%$ & 0 \\
\hline \multirow[t]{3}{*}{ Other (please specify) } & $\square$ & $20.0 \%$ & 1 \\
\hline & & d question & 5 \\
\hline & & d question & 0 \\
\hline
\end{tabular}


16. Should multiple types of signs be allowed without penalty? Current regulations apply a reduction in sign area of $50 \%$ if multiple sign types are uses; e.g. wall sign plus a monument sign.

\begin{tabular}{|c|c|c|c|}
\hline & & $\begin{array}{c}\text { Response } \\
\text { Percent }\end{array}$ & $\begin{array}{c}\text { Response } \\
\text { Count }\end{array}$ \\
\hline Yes & $\square$ & $40.0 \%$ & 2 \\
\hline No & $\square$ & $60.0 \%$ & 3 \\
\hline \multicolumn{3}{|c|}{ answered question } & 5 \\
\hline \multicolumn{3}{|c|}{ skipped question } & 0 \\
\hline
\end{tabular}

17. Do you consider murals to be signs?

\begin{tabular}{|c|c|c|c|}
\hline & & $\begin{array}{c}\text { Response } \\
\text { Percent }\end{array}$ & $\begin{array}{c}\text { Response } \\
\text { Count }\end{array}$ \\
\hline Yes & & $0.0 \%$ & 0 \\
\hline No & $\square$ & $100.0 \%$ & 5 \\
\hline \multicolumn{4}{|c|}{ answered question } \\
\hline \multicolumn{4}{|c|}{ skipped question } \\
\hline
\end{tabular}

18. Should signage in residential areas be allowed for: (select all that apply)

\begin{tabular}{|c|c|c|c|}
\hline & & $\begin{array}{c}\text { Response } \\
\text { Percent }\end{array}$ & $\begin{array}{c}\text { Response } \\
\text { Count }\end{array}$ \\
\hline Real Estate & E & $80.0 \%$ & 4 \\
\hline Vacation Rental & 口 & $80.0 \%$ & 4 \\
\hline Allowed home occupations & $\square$ & $60.0 \%$ & 3 \\
\hline \multirow[t]{3}{*}{ Other (please specify) } & & $40.0 \%$ & 2 \\
\hline & & answered question & 5 \\
\hline & & skipped question & 0 \\
\hline
\end{tabular}

10 of 12 
19. Should businesses be guaranteed a minimum size sign regardless of frontage size?

\begin{tabular}{|c|c|c|c|}
\hline & & $\begin{array}{c}\text { Response } \\
\text { Percent }\end{array}$ & $\begin{array}{c}\text { Response } \\
\text { Count }\end{array}$ \\
\hline Yes & $\square$ & $80.0 \%$ & 4 \\
\hline No & $\square$ & $20.0 \%$ & 1 \\
\hline \multicolumn{3}{|c|}{ answered question } & 5 \\
\hline \multicolumn{3}{|c|}{ skipped question } & 0 \\
\hline
\end{tabular}

20. Should there be special allowances or exceptions?

\begin{tabular}{rrr} 
Yes & $\begin{array}{r}\text { Response } \\
\text { Percent }\end{array}$ & $\begin{array}{c}\text { Response } \\
\text { Count }\end{array}$ \\
\hline No & $\mathbf{8 0 . 0 \%}$ & 4 \\
\hline & $20.0 \%$ & $\mathbf{5}$ \\
\hline & answered question & 0 \\
\hline
\end{tabular}

21. Are you satisfied with the current rules for reader or changeable message boards? Current code limits the language on such boards for hotel/motels to: $a$. Winter rate (excluding amount); b. Vacancy; c. Credit cards; d. TV; e. Pool; f. Air conditioning; g. Continental Breakfast; $h$. Any other information as approved by the Director.

\begin{tabular}{|c|c|c|c|}
\hline & & $\begin{array}{c}\text { Response } \\
\text { Percent }\end{array}$ & $\begin{array}{c}\text { Response } \\
\text { Count }\end{array}$ \\
\hline Yes & $\square$ & $80.0 \%$ & 4 \\
\hline No & $\square$ & $20.0 \%$ & 1 \\
\hline \multicolumn{3}{|c|}{ answered question } & 5 \\
\hline \multicolumn{3}{|c|}{ skipped question } & 0 \\
\hline
\end{tabular}


22. Are sign materials important?

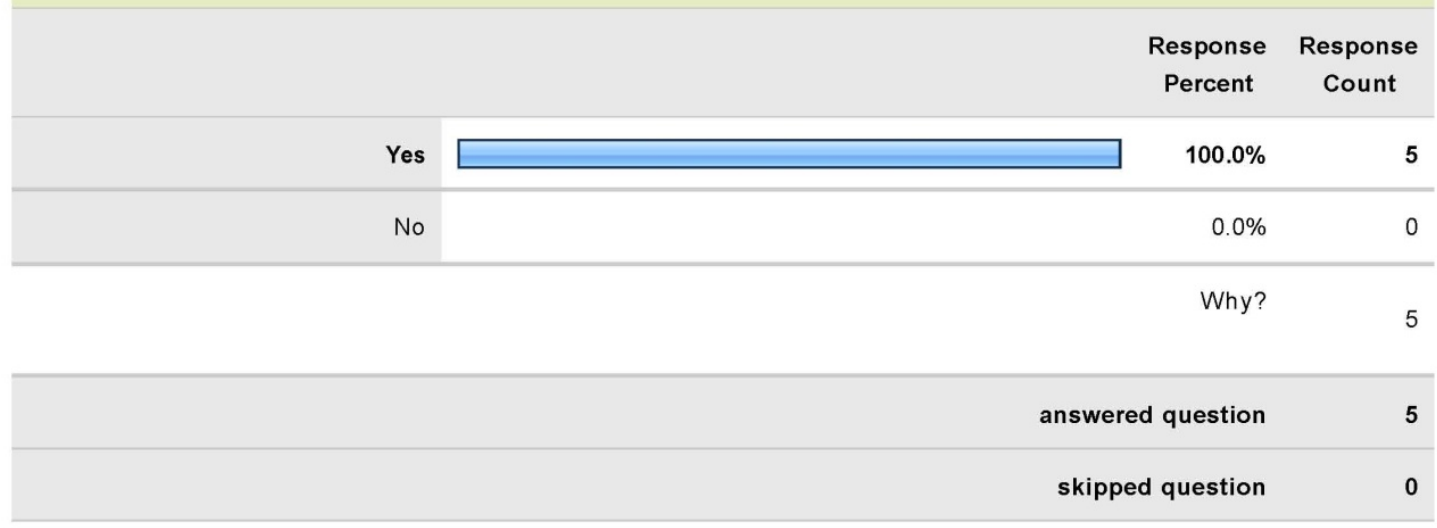

23. Please provide us any additional comments or provide explanation to a question as needed.

Response

Count 


\section{Preliminary Sign Program}

\section{Downtown Area}

General Sign Area Calculations: 2 square feet for each 1 foot of linear building frontage. This represents a $100 \%$ increase in signage allowed when utilizing multiple types of signage.

A Frame Signs: Not Allowed.

Awning Signs: Allowed.

Banners as a Permanent Signage: Not Allowed.

Dock Signs: Not Allowed.

Flag: Not Allowed, see pub signs.

Gateway Signs: Concept would be to allow a type of sign at the entrance at Morro Bay Blvd to announce the downtown area.

Illuminated, Internally: Not Allowed.

Illuminated, Externally: Allowed.

Marquee Signs: Allowed for theatres, nightclubs, conference facilities.

Monument Signs: Allowed, externally illuminated only.

Off Premise Signs: Not Allowed, except for community business directory kiosks and City

Directional Signs.

Pole Signs: Not Allowed.

Pub Signs: Allowed, non illuminated or externally illuminated. Can be utilized to note open or closed and capture visitor business.

Wall Signs: Allowed Downtown with exterior illuminated (such as gooseneck or nonilluminated)

Window Signs: Allowed for relocating businesses with the permission of property owner for a period not to exceed 30 days.

Time limits for nonconforming signs: Remove Section 17.68.155.

\section{Embarcadero Area}

General Sign Area Calculations: 2 square feet for each 1 foot of linear building frontage for single tenant buildings. In addition to the 2 square feet allowed all Multi tenant buildings shall be allowed to have one 16 square foot in size sign facing the Embarcadero identifying the building such as "Marina Square".

A Frame Signs: Not Allowed.

Awning Signs: Allowed.

Banners as a Permanent Signage: Not Allowed.

Dock Signs: Entrances to dock facilities shall be allowed signage to advertise businesses being run from the dock such as commercial fishing and tourist cruises.

Flag: Not Allowed, see pub signs.

Gateway Signs: Concept would be to allow a type of sign at the entrance to the Embarcadero to identify the area.

Illuminated, Internally: Not Allowed.

Illuminated, Externally: Allowed. 
Marquee Signs: Allowed for theatres, nightclubs, conference facilities.

Monument Signs: Allowed externally illuminated, only.

Off Premise Signs: Not Allowed except for community business directory kiosks and City Directional Signs.

Pole Signs: Not Allowed.

Pub Signs: Allowed, non illuminated or externally illuminated Can be utilized to note open or closed and capture visitor business.

Wall Signs: Allowed Embarcadero with exterior illuminated (such as gooseneck or nonilluminated).

Window Signs: Allowed for relocating businesses with the permission of property owner for a period not to exceed 30 days.

Time limits for nonconforming signs: Remove Section 17.68.155.

\section{North Morro Bay}

General Sign Area Calculations: 2 square feet for each 1 foot of linear building frontage. A Frame Signs: Not Allowed.

Awning Signs: Allowed.

Banners as a Permanent Signage: Not Allowed.

Dock Signs: Not Allowed.

Flag: Not Allowed, see pub signs.

Gateway Signs: Concept would be to allow a gateway type of sign at the entrance to North Morro Bay.

Illuminated, Internally: Allowed.

Illuminated, Externally: Allowed.

Marquee Signs: Allowed for theatres, nightclubs, conference facilities.

Monument Signs: Allowed internally or externally illuminated.

Off Premise Signs: Not Allowed except for community business directory kiosks and City

Directional Signs

Pole Signs: Allowed.

Pub Signs: Allowed, non illuminated or externally illuminated. Can be utilized to note open or closed and capture visitor business.

Wall Signs: Allowed.

Window Signs: Allowed for relocating businesses with the permission of property owner for a period not to exceed 30 days.

Time limits for nonconforming signs: Remove Section 17.68.155. 
Morro Bay Sign Ordinance Workshop

Thursday

October 6, 2011

\title{
Morro Bay Sign Ordinance Workshop
}

\author{
Meeting Facilitator \\ Chuck Anders \\ Strategic Initiatives
}

\section{Morro Bay Sign Ordinance Workshop}

- Review results from first workshop

- Review and discuss preliminary sign ordinance concepts

- Next steps 


\section{Workshop Guidelines}

- Be positive and respectful of others

- Listen - avoid side conversations

- Silence cell phones - take calls outside

- Stay on topic / Be concise

- Raise hand to speak

- Always "Us" (avoid judging others)

What is your gender?

1. Female

2. Male

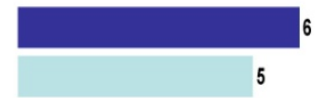

Are you a Morro Bay resident?

1. Yes

2. No

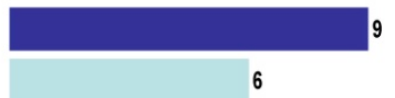


Which best describes your role in this workshop?

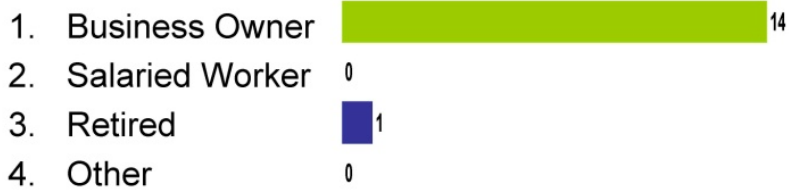

What geographic area of Morro Bay do you represent?

1. North Morro Bay

2. Downtown

3. Embarcadero

4. North Residential 0

5. South Residential 0

6. Other

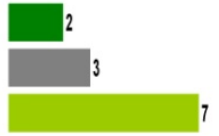

Did you attend the first workshop on

September $\mathbf{2 9}^{\text {th }}$ ?

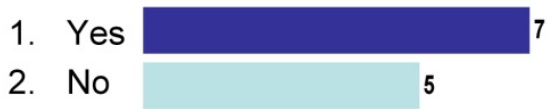


Is a distinction between internal or external illumination important?

1. Yes

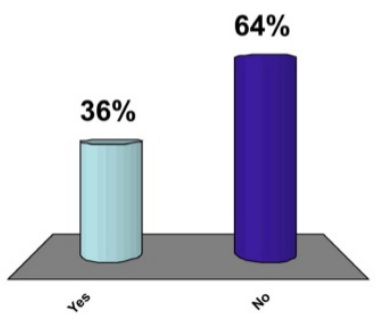

2. No

To what extent to you support or oppose the preliminary sign ordinance for the

$$
\text { Downtown Area }
$$

(as presented in preliminary sign matrix)

1. Strongly Agree

2. Agree

3. Neutral

4. Disagree

5. Strongly Disagree

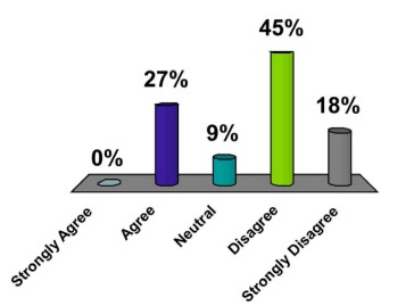




\section{Appendix 4.3}

\section{Past Outreach Raw Data Table}

\begin{tabular}{|c|c|c|c|c|c|c|c|c|}
\hline \multirow[b]{2}{*}{ Questions } & \multirow{2}{*}{$\begin{array}{l}\text { Survey } 1 \\
\text { Yes }\end{array}$} & \multirow[b]{2}{*}{ No } & \multirow{2}{*}{$\begin{array}{l}\text { Survey } 2 \\
\text { Yes }\end{array}$} & \multirow[b]{2}{*}{ No } & \multirow{2}{*}{$\begin{array}{l}\text { Survey } 3 \\
\text { Yes }\end{array}$} & \multirow[b]{2}{*}{ No } & \multicolumn{2}{|c|}{ Survey Totals $(\# 1+\# 2+\# 3)$} \\
\hline & & & & & & & Yes & No \\
\hline Morro Bay Resident? & 2 & 2 & 10 & 6 & 2 & 3 & 14 & 11 \\
\hline Is the existing sign ordiannce working for you? & 1 & 3 & 2 & 14 & 2 & 3 & 5 & 20 \\
\hline $\begin{array}{l}\text { Are you happy with how signs look in Morro Bay right } \\
\text { now? }\end{array}$ & 4 & 0 & 1 & 15 & 1 & 4 & 6 & 19 \\
\hline $\begin{array}{l}\text { Do you want uniformity in the appearance of signs and } \\
\text { businesses throughout the community? }\end{array}$ & 3 & 1 & 6 & 10 & 3 & 2 & 12 & 13 \\
\hline $\begin{array}{l}\text { Do you believe there should be different rules for } \\
\text { different areas of the community? }\end{array}$ & 2 & 2 & 14 & 0 & 3 & 2 & 19 & 4 \\
\hline Do you consider murals to be signs? & 0 & 4 & 2 & 14 & 0 & 5 & 2 & 23 \\
\hline $\begin{array}{l}\text { Should businesses be guranteed a minimum size sign } \\
\text { regardless of frontage size? }\end{array}$ & 3 & 1 & 9 & 5 & 4 & 1 & 16 & 7 \\
\hline Should there be special allowances or exceptions? & 3 & 1 & 14 & 0 & 4 & 1 & 21 & 2 \\
\hline $\begin{array}{l}\text { Are you satisfied with the current rules for reader or } \\
\text { changeable message boards? Current code limits the } \\
\text { language on such boards for hotel/motels? }\end{array}$ & 3 & 1 & 8 & 7 & 4 & 1 & 15 & 9 \\
\hline Are sign materials important? & 4 & 0 & 10 & 5 & 5 & 0 & 19 & 5 \\
\hline
\end{tabular}




\section{Appendix 4.4}

Primary Business Owner Survey, Cover Letter, and List of Mail Recipients

(Begins on following page) 
The City of Morro Bay is in the process of updating their current sign ordinance. Erik Berg-Johansen, a Cal Poly City and Regional Planning graduate student, is assisting the City with this effort as part of a Master's project.

When updating a city ordinance it is important that the public has the opportunity to voice their opinions. Past community outreach has been conducted, however City staff are seeking additional information from business owners to ensure that they are involved with the process.

Please take a few minutes to fill out the attached survey. Completed surveys can be mailed to the City of Morro Bay Public Services Department, or dropped off in person.

\section{Public Services Department}

955 Shasta Ave.

Morro Bay, CA 93442

If you would prefer to fill this survey out online, please access the following link: www.surveymonkey.com/s/morrobaybusinessowners

If you have any other questions, please email Erik Berg-Johansen at: eberg-johansen@morro-bay.ca.us 
1. Do you think the current sign ordinance is user friendly and easy to understand?

- Yes

O No

Comments:

2. How do you believe the City's sign code is applied?

- Consistently

- Inconsistently (please explain below)

Comments:

3. Is enforcement of illegal signs an issue?
O No
O Yes, there is not enough enforcement
- Yes, there is too much enforcement
○ Yes, (please specify):

4. With respect to aesthetics, are you happy with the current signs in Morro Bay? Select one or more.
O Yes
No, illumination is too bright
- No, signs are too large
- No, too many signs
- No, signs are too small
- No, signs are too tall
- No, I don't like the materials most signs use
Other (please specify):

5. What changes to the sign code could help you attract more customers? Select one or more (use the "other" box to offer additional ideas).

- Further restrict and enforce signs to create more consistency

- Allow A-frame signs

- Relax regulations for illuminated signs

- Allow ALL businesses to have more

- Continue to prohibit A-frame signs signage

O Other (please specify):

6. What types of signs (if any) do you believe degrade Morro Bay's community character? Select one or more.
- Pole signs
- A-frame signs
- Window signs
- Wall signs
- Flags and Banners
- Monument (freestanding) signs

- Digital (reader) signs

O Internally illuminated signs

- Externally illuminated signs

- Awning signs

Other (please specify): 
7. Previous City public meetings revealed a preference for having different sign requirements for different areas of town (e.g. North Morro Bay vs. Downtown vs. Embarcadero vs. Quintana). Do you agree with having different sign requirements in different business districts?

o Yes

○ No

Comments

8. Are you happy with your current signage? Select one or more.
○ Yes
No, my sign(s) are too small
- No, my signs can't be seen from the street
O No, my signs are required to be placed too low where they are not visible
O No, my sign's materials are inadequate

9. How important are commercial signs to your business's success?
O Very important
O Important
O Not very important

10. Would you support "directional signs" (also known as wayfinding signs) on the Embarcadero? Directional signs are used to help residents and tourists navigate around cities. In this case, directional signs could be used on the Embarcadero to help tourists locate businesses.
o Yes
○ No
○ Neutral

11. If directional signs were implemented, what businesses should be featured on them?

- All businesses should be featured on a directional sign

O Only businesses that are hidden from view should be featured on a directional sign

- Businesses should pay a fee to "rent" a spot on a directional sign

○ Directional signs are a bad idea

O Other suggestions:

12. Please provide any additional comments about the sign ordinance or signs in general. 
255 MARINA STORAGE

PO BOX 1042

MORRO BAY, CA 93443

3 INK SCREEN PRINTING

349 QUINTANA RD UNIT A

MORRO BAY, CA 93442

888 NAPA AVENUE, L L C

3220 S HIGUERA ST. STE. 201

SAN LUIS OBISPO, CA 93401

A G P VIDEO, INC

390 PRESTON LN

MORRO BAY, CA 93442

A T \& T MOBILITY

1025 LENOX PARK BLVD, 3RD FLR STE 3

ATLANTA, GA 30319

ACTIVE CARE IN-HOME SERVICES

850 SHASTA AVE UNIT A

MORRO BAY, CA 93442

ADA'S FLOOR COVERINGS

366 QUINTANA RD

MORRO BAY, CA 93442

ALBERTSONS \#6345

PO BOX 20

BOISE, ID $83726-0020$

ALL PEOPLE SERVICES

$P O B O X 1533$

MORRO BAY, CA 93443

ALL WAYS CLEAN

P.O. BOX 462

MORRO BAY, CA 93443
ALLAN ARM APARTMENTS

PO BOX 851

TIPTON, CA 93272

ALLESANDRO MINI STORAGE

PO BOX 12060

SAN LUIS OBISPO, CA 93406

ALOHA SHIRT SHOP

458 MORRO BAY BLVD

MORRO BAY, CA 93442

AMERICAN KARATE SCHOOL 400 QUINTANA RD

MORRO BAY, CA 93442

ANDERSON INN

P.O. BOX 1800

MORRO BAY, CA 93443

ANITA'S PILLOW PETS

670 HIGUERA ST. \#B

SAN LUIS OBISPO, CA 93401

ANTIQUES ET CETERA

PO BOX 1207

MORRO BAY, CA 93443

ARCHITECTURAL HOME IMPROVEMENTS

2255 COTTONTAIL CK A

CAYUCOS, CA 93430

ARIANNA'S

525 MORRO BAY BLVD

MORRO BAY, CA 93442

ART EFFECTS GALLERY

435 MORRO BAY BLVD

MORRO BAY, CA 93442
ART SEA

736 MAIN ST A

MORRO BAY, CA 93442

ASAP REPOGRAPHICS

PO BOX 1678

MORRO BAY, CA 93443

ASCOT SUITES

260 MORRO BAY BLVD

MORRO BAY, CA 93442

ASSOC. PACIFIC CONSTRUCTORS IN 495 EMBARCADERO

MORRO BAY, CA 93442

AUTOBODY BUILDERS

340 JAMAICA ST

MORRO BAY, CA 93442

AUTOZONE \# 2805

PO BOX 2198 DEPT 8088

MEMPHIS, TN 38101-9842

AZDUMAZUR

P O BOX 1121

MORRO BAY, CA 93443

AZHIAZIAM

1140 FRONT ST UNIT B

MORRO BAY, CA 93442

B J \& J CONSTRUCTION CO INC PO BOX 1596

MORRO BAY, CA 93443

BABYLONIAN SOAP COMPANY

1328 12TH ST

LOS OSOS, CA 93402 
BACKSTAGE SALON

960 MAIN ST

MORRO BAY, CA 93442

BALI HAI APARTMENTS

1163 MAIN ST

MORRO BAY, CA 93442

BATES CARE MANAGEMENT

PO BOX 1195

MORRO BAY, CA 93443

BAY AUTO \& TIRE

1320 LOS OLIVOS APT 2

LOS OSOS, CA 93402

BAY AUTO MACHINE INC

PO BOX 533

MORRO BAY, CA 93443

BAY PINES MOBILE HOME PARK

6706 PINEDALE CT

BAKERSFIELD, CA 93308

BAY PINES TRAVEL TRAILER

1501 QUINTANA RD

MORRO BAY, CA 93442

BAY STORE

8035 SANTA ROSA RD

ATASCADERO, CA 93422

BAY THEATRE

464 MORRO BAY BLVD

MORRO BAY, CA 93442

BAY VIEW APARTMENTS

888 CRIPPER CREEK

PASO ROBLES, CA 93446
BAY VIEW APARTMENTS

888 CRIPPER CREEK

PASO ROBLES, CA 93446

BAY VIEW LODGE

225 HARBOR ST

MORRO BAY, CA 93442

BAYFRONT INN

1150 EMBARCADEO RD

MORRO BAY, CA 93442

BAYSHORE FISH \& EEL COMPANY

701 EMBARCADERO

MORRO BAY, CA 93442

BAYSHORE REALTY

560 MORRO BAY BLVD

MORRO BAY, CA 93442

BAYSIDE CAFE

10 STATE PARK RD

MORRO BAY, CA 93442

BAYSIDE CARE CENTER

1405 TERESA DR

MORRO BAY, CA 93442

BEACH BUMS MORRO BAY

P O BOX 253

MORRO BAY, CA 93442

BEACH BUNGALOW INN AND SUITES @ A

1050 MORRO AVE

MORRO BAY, CA 93442

BEACH HOUSE BISTRO

1672 9TH ST

LOS OSOS, CA 93402
BEACHWEST STORAGE

1330 VAN BEURDEN DR

LOS OSOS, CA 93402

BEADS BY THE BAY

PO BOX 1534

MORRO BAY, CA 93443

BEAR METAL KUSTOMS, INC.

885 SANTA MARIA

LOS OSOS, CA 93402

BECKER CHIROPRACTIC

580 HARBOR ST

MORRO BAY, CA 93442

BELLA VINO'S

220 ATASADERO RD

MORRO BAY, CA 93442

BELVEDERE APARTMENTS

PO BOX 2107

PISMO BEACH, CA 93448-2107

BENEDICT - RETTEY MORTUARY 1401 QUINTANA RD

MORRO BAY, CA 93442

BERKSON PLUMBING

PO BOX 470

MORRO BAY, CA 93443

BEST KEPT SECRET, L L C 1794 BELLA VISTA CT

PASO ROBLES, CA 93446

BEST WESTERN EL RANCHO

2460 MAIN ST

MORRO BAY, CA 93443 
BEST WESTERN TRADEWINDS MOTEL 225 BEACH ST

MORRO BAY, CA 93442

BLACK MOUNTAIN PET CREMATORY 1401 QUINTANA RD

MORRO BAY, CA 93442

BLUE HERON TERRACE

777 S FIQUEROA ST STE 4850

LOS ANGELES, CA 90017

BLUE SAIL INN

851 MARKET AVE

MORRO BAY, CA 93442

BLUE SKYE COASTAL CAFE

699 EMBARCADERO \#6

MORRO BAY, CA 93442

BODY IN MOTION - FELDENKRAIS METHC 895 NAPA ST STE A-1

MORRO BAY, CA 93442

BOWSER BOUTIQUE

775 PINEY WAY

MORRO BAY, CA 93442

BREAKERS MOTEL

PO BOX 1809

MORRO BAY, CA 93443

BREBES BUILDERS

PO BOX 1602

MORRO BAY, CA 93443

BREE'S CAKES

781 HARBOR ST

MORRO BAY, CA 93442
BRENDA SUE'S

248 MORRO BAY BLVD

MORRO BAY, CA 93442

BROWN'S BARBER SHOP

3118 MAIN ST

MORRO BAY, CA 93442

BRUCE PILNICK WOOD WORKING

1180 LAS TUNAS ST

MORRO BAY, CA 93442

BRUCE TRUBO D. D. S.

747 BERNARDO AVE

MORRO BAY, CA 93442

BUILDING PEACE OF MIND

895 NAPA AVE SUITE B-6

MORRO BAY, CA 93442

BUOY \& GULL TRAILER TERRACE 495 ATASCADERO RD

MORRO BAY, CA 93442

BURGER KING

PO BOX 426

GROVER BEACH, CA 93483-0426

BY THE BAY GALLERY

895 EMBARCADERO

MORRO BAY, CA 93442

C \& R MINI STORAGE

PO BOX 1113

MORRO BAY, CA $93443-1113$

C P LANDSCAPES

P O BOX 446

MORRO BAY, CA 93443
C P PARKER, ARCHITECT

630 QUINTANA RD \#330

MORRO BAY, CA 93442

C P PARKER, CONSTRUCTION 630 QUINTANA RD \#330

MORRO BAY, CA 93442

C RANDALL COOK ATTORNEY 780 PINEY WAY

MORRO BAY, CA 93442-1926

C S BECKER CONSTRUCTION 395 HILLVIEW

MORRO BAY, CA 93442

CALIFORNIA IMAGES

PO BOX 672

MORRO BAY, CA 93443

CAME SECURITY ALARMS

977 LAS TUNAS

MORRO BAY, CA 93442

CAPTAIN STEWS BAY CRUISE

571 EMBARCADERO

MORRO BAY, CA 93442

CARLA'S COUNTRY KITCHEN

213 BEACH ST UNIT C

MORRO BAY, CA 93442

CAROUSEL TAFFY

PO BOX 543

MORRO BAY, CA 93443

CASA DE FLORES

1405 TERESA DR

MORRO BAY, CA 93442 
CASTAWAYS

410 MORRO BAY BLVD

MORRO BAY, CA 93442

CATCH A WAVE BEAUTY SALON

530 QUINTANA

MORRO BAY, CA 93442

CATCH THE WIND SAILING, ELECTRIC BI 845 EMBARCADEO RD \#11

MORRO BAY, CA 93442

CAYUCOS HOME REPAIR \& REMODELINC 350 ORCAS ST

MORRO BAY, CA 93442

CENCAL ROOFING

2030 MAIN ST

MORRO BAY, CA 93442

CENTRAL COAST BBQ CO.

2824 DOGWOOD AVE

MORRO BAY, CA 93442

CENTRAL COAST GLASS

PO BOX 1433

MORRO BAY, CA 93443

CENTRAL COAST LEASING

PO BOX 1921

MORRO BAY, CA 93443

CENTRAL COAST LENDING 601 MORRO BAY BLVD SUITE B MORRO BAY, CA 93442

CENTRAL COAST MONTESSORI 3230 MAIN ST

MORRO BAY, CA 93442
CENTRAL COAST MUSIC

365 MORRO BAY BLVD

MORRO BAY, CA 93442

CENTRAL COAST OPTOMETRIC CENTER 800 QUINTANA RD \#1-D

MORRO BAY, CA 93442

CENTRAL COAST PATHOLOGY LABORAT 3701 S HIGUERA ST

SAN LUIS OBISPO, CA 93401

CENTRAL COAST SPORTFISHING

P O BOX 1706

MORRO BAY, CA 93442

CENTRAL COAST STANDUP PADDLING 501 EMBARCADEO STE 5

MORRO BAY, CA 93442

CENTRAL COAST TATTOOS

501 MORRO BAY BLVD

MORRO BAY, CA 93442

CENTRAL COAST TAX PROFESSIONALS 798 MORRO BAY BLVD SUITE D

MORRO BAY, CA 93442

CENTRAL COAST URGENT

5726 W SWEET DR

VISALIA, CA 93291

CHAMPION APARTMENTS

226 BRADLEY AVE

MORRO BAY, CA 93442

CHARLES L LOE CONSTRUCTION

2622 GREENWOOD AVE

MORRO BAY, CA 93442
CHECK INTO CASH

PO BOX 550

CLEVELAND, TN 37364-0550

CHILD'S PLAY

701 EMBARCADERO UNIT A

MORRO BAY, CA 93442

CHINA DRAGON RESTAURANT

2780 MAIN ST.

MORRO BAY, CA 93442

CHRISTOPHER LUBECK

1116 17TH ST.

LOS OSOS, CA 93402

CHRYSALIS

895 NAPA AVE A-6

MORRO BAY, CA 93442

CIANO REAL ESTATE

360 MORRO BAY BLVD

MORRO BAY, CA 93442

CLASSIC WOODWORKS

730 NAPA AVE

MORRO BAY, CA 93442

COALESCE BOOKSTORE

845 MAIN ST

MORRO BAY, CA 93442

COAST ELECTRONICS

510 QUINTANA RD

MORRO BAY, CA 93442

COAST MANAGEMENT \& RENTALS

PO BOX 229

MORRO BAY, CA 93443 
COAST REALTY

P OBOX 150

MORRO BAY, CA 93443

COASTAL CONSTRUCTION MANAGEMEN 475 MORRO BAY BLVD

MORRO BAY, CA 93442

COASTAL STORAGE

2840 JUNIPER AVE

MORRO BAY, CA 93442

COFFEE COTTAGE 845 EMBARCADEO STE I

MORRO BAY, CA 93442

COFFEE POT RESTAURANT

1001 FRONT ST

MORRO BAY, CA 93442

COLDWELL BANKER PREMIER REAL EST 689 TANK FARM RD STE 230

SAN LUIS OBISPO, CA 93401

COLLINS APARTMENTS

2574 HEMLOCK AVE

MORRO BAY, CA 93442

COMERFORD INC

201 STATE PARK RD

MORRO BAY, CA 93442

COMMUNITY HEALTH CENTER - MORRO I 660 HARBOR ST.

MORRO BAY, CA 93442

COOKIE CROCK WAREHOUSE

1240 KNOLLWOOD CIRCLE

CAMBRIA, CA 93428
CORK N BOTTLE MORRO BAY

396 ATASCADERO RD

MORRO BAY, CA 93442

CRAIG GOSSARD CONSTRUCTION 215 GILBERT ST

MORRO BAY, CA 93442

CRILLS NO 2

903 EMBARCADERO

MORRO BAY, CA 93442

CRILL'S SALT WATER TAFFY

1247 EMBARCADERO

MORRO BAY, CA 93442

CRYE \& SON EXCAVATING

1170 QUINTANA RD

MORRO BAY, CA 93442

CULLIGAN CNTL. WATER COND 355 QUINTANA PLACE

MORRO BAY, CA 93442

CYPRESS MORRO BAY RV \& MH PARK 1121 MAIN ST MORRO BAY, CA 93442

D JACOBSON MARINE SURVEYS 785 QUINTANA RD

MORRO BAY, CA 93442

DALTON MASONRY

694 PONDEROSA

MORRO BAY, CA 93442

DAVID CRYE GENERAL ENGINEERING 1170 QUINTANA RD MORRO BAY, CA 93442
DAVIS \& DAVIS

P O BOX 6243

LOS OSOS, CA 93412

DAYS INN

1095 MAIN ST

MORRO BAY, CA 93442

DEGARIMORES CENTRAL COAST MARIN 1099 EMBARCADERO

MORRO BAY, CA 93442

DEL MAR MARKET

2864 MAIN ST

MORRO BAY, CA 93442

DEV ENTERPRISES

PO BOX 442

CAYUCOS, CA 93430

DIEGO MASONRY \& DESIGN, INC 482 FRESNO AVE MORRO BAY, CA 93442

DISTASIOS ON THE BAY 781 MARKET AVE MORRO BAY, CA 93442

DOGHOUSE PROMOTIONS 1110 QUINTANA RD MORRO BAY, CA 93442

DOLLAR TREE STORES, INC \#3246 500 VOLVO PARKWAY CHESAPEAKE, VA 23320

DOLLY'S DONUTS 1095 KENNEDY WAY MORRO BAY, CA 93442 
DOMINO'S PIZZA

2360 MAIN ST UNIT B

MORRO BAY, CA 93442

DON MARUSKA \& CO., INC.

895 NAPA AVE UNIT A-5

MORRO BAY, CA 93442

DON'S BARBER SHOP

704 MORRO BAY BLVD

MORRO BAY, CA 93442

DORN'S ORIGINAL BREAKERS CAFE

801 MARKET AVE

MORRO BAY, CA 93442

DRAGON BAY

701 EMBARCADERO UNIT B

MORRO BAY, CA 93442

DRAGONFLY BOUTIQUE

5480 OAKHURST DR

CAMBRIA, CA 93428

DUTCHMAN SEAFOOD HOUSE

701 EMBARCADERO

MORRO BAY, CA 93442

DYNEGY FALCON HOLDINGS, INC.

1290 EMBARCADERO

MORRO BAY, CA 93442

ECCLECTIQ

P O BOX 3034

PISMO BEACH, CA 93448

ECONOLODGE

1100 MAIN ST

MORRO BAY, CA 63442
EDDIES CUSTOM CARS

1173 MARKET AVE

MORRO BAY, CA 93442

EDWARD D JONES \& COMPANY

501 HARBOR ST

MORRO BAY, CA 93442

EL MORRO TRAILER COURT

798 MORRO BAY BLVD

MORRO BAY, CA 93442

ELEGANT IMAGE LIMO, INC.

PO BOX 1933

MORRO BAY, CA 93443

EMBARCADERO INN

1148 MARKET AVE

MORRO BAY, CA 93442

EMBARCADO GRILL

801 EMBARCADERO

MORRO BAY, CA 93442

ENSITU ENGINEERING

685 MAIN ST STE A

MORRO BAY, CA 93442

ERIC LUTHI, C.P.A.

645 MAIN ST UNIT B

MORRO BAY, CA 93442

ERIK'S MUFFLER \& WELDING

2190 MAIN ST

MORRO BAY, CA 93442

ESCALANTE'S COASTAL CLEAN-UP

801 LITTLE MORRO CREEK RD

MORRO BAY, CA 93442
ESTERO BAY GRAPHICS 655 MORRO BAY BLVD UNIT B MORRO BAY, CA 93442

ESTERO BAY R. V. PARK PO BOX 1593

ARROYO GRANDE, CA 93421

ESTERO GLASS

1560 MAIN ST

MORRO BAY, CA 93442

ESTERO GLASS

1560 MAIN ST

MORRO BAY, CA 93442

ESTERO INN/HOTEL.

515 MORRO AVE

MORRO BAY, CA 93442

FARMER'S KITES SURREY'S \& MORE 1108 FRONT ST

MORRO BAY, CA 93442

FARMER'S MARKET INSPIRED SOUPS 58 12TH ST

CAYUCOS, CA 93430

FENGZHI YAO

800 MORRO BAY BLVD

MORRO BAY, CA 93442

FIONA BLEU

900 EMBARCADERO RD

MORRO BAY, CA 93442

FIRESIDE INN

730 MORRO AVE

MORRO BAY, CA 93442 
FIRESIDE STYLING SALON

PO BOX 1745

MORRO BAY, CA 93443

FLOORING DISCOUNT CENTER

787 HARBOR ST

MORRO BAY, CA 93442

FOREVER STOKED

P O BOX 6480

LOS OSOS, CA. 93402

FOSTERS FREEZE \#225

801 PINEY WAY

MORRO BAY, CA 93442

FRANKLIN REAL ESTATE \& RENTALS

798 MORRO BAY BLVD

MORRO BAY, CA 93442

FREDERICK NOVY M.D.

895 SHASTA AVE

MORRO BAY, CA 93442

FRENCH PEDDLER

590 MORRO BAY BLVD

MORRO BAY, CA 93442

FRESH KITCHENS \& BATHS

1335 16TH ST

LOS OSOS, CA 93402

FRONT STREET INN \& SPA

1140 FRONT ST

MORRO BAY, CA 93442

FRONTIER ADJUSTERS

PO BOX 1017

MORRO BAY, CA 93443
FUEL DOCK

900 MAIN ST

MORRO BAY, CA 93442

FULL MOON ART STUDIO

345 HARBOR ST

MORRO BAY, CA 93442

G \& B CLEANING SERVICES

PO BOX 112

MORRO BAY, CA 93443

G T H FINANCIAL SERVICES, INC 1052 MAIN ST STE A MORRO BAY, CA 93442-4005

GALLERY AT MARINA SQUARE 915 CARMEL ST

MORRO BAY, CA 93442

GARCIA JR. EXCAVATING, D 2692 ADOBE RD

MORRO BAY, CA 93442

GARDEN GALLERY INC

680 EMBARCADERO

MORRO BAY, CA 93442

GARDEN WEDDING CHAPEL

845 MAIN ST UNIT B

MORRO BAY, CA 93442

GARRY R KOLB M. D.

695 MORRO AVE

MORRO BAY, CA 93442

GEORGE G ROSS CPA PFS CFP

1004 MAIN ST

MORRO BAY, CA 93442
GIANCARLOS RISTORANTE MEDITERRAI

810 MORRO BAY BLVD.

MORRO BAY, CA 93442

GIOVANNI'S FISH MARKET

1001 FRONT ST

MORRO BAY, CA 93442

GLASSWORKS

339 QUINTANA RD

MORRO BAY, CA 93442

GO GO COFFEE

2700 MAIN ST

MORRO BAY, CA 93442

GO GO COFFEE

2700 MAIN ST

MORRO BAY, CA 93442

GOLD COAST REALTY

939 MAIN ST

MORRO BAY, CA 93442

GOLDEN CHINA RESTAURANT

500 EMBARCADERO

MORRO BAY, CA 93442

GOLDEN SHEARS

507 MORRO BAY BLVD

MORRO BAY, CA 93442

GOLDEN STATE SEALING \& STRIPING, IN P.O. BOX 710

ARROYO GRANDE, CA 93421

GOOFY GRAPHICS

925 MAIN ST

MORRO BAY, CA 93442 
GRAY'S INN

2961 JUNIPER AVE

MORRO BAY, CA 93442

GREAT AMERICAN FISH CO

PO BOX 1739

MORRO BAY, CA 93443

GRILL HUT

3637 S DOROTHY ST

BAKERSFIELD, CA 93307

H \& R BLOCK

4801 EL CAMINO REAL

ATASCADERO, CA 93422

HANSON AGGREGATES MID-PACIFIC

PO BOX 71

SAN LUIS OBISPO, CA 93406

HARADA JAPANESE RESTAURANT

PO BOX 929

MORRO BAY, CA 93443-0929

HARBOR ELECTRIC

PO BOX 997

MORRO BAY, CA 93443-0997

HARBOR FLORAL

868 N NAPA AVE

MORRO BAY, CA 93442

HARBOR GUN SHOP INC

PO BOX 81

MORRO BAY, CA 93443

HARBOR HUT

1205 EMBARCADERO RD

MORRO BAY, CA 93443
HARBOR REAL ESTATE

791 PRICE ST \#190

PISMO BEACH, CA 93449

HARBOR VIEWR V PARK

PO BOX 191

ATASCADERO, CA 93423

HARPER'S BOTTLE LIQUOR STORE 999 MAIN ST

MORRO BAY, CA 93442

HARRY'S UPHOLSTERY

1312 MAIN ST

MORRO BAY, CA 93442

HAY PRINTING

3118 MAIN ST UNIT G

MORRO BAY, CA 93442

HEAD-OVER-HEELS GYMNASTICS

365 QUINTANA RD

MORRO BAY, CA 93442

HINSONS TIRE \& AUTO CENTER

839 QUINTANA RD

MORRO BAY, CA 93442

HOFBRAU DER ALBATROSS

PO BOX 1027

MORRO BAY, CA 93443

HOLLAND INN MOTEL

2630 MAIN ST

MORRO BAY, CA 93442

HOT DOGS ON HARBOR

898 MAIN ST STE. D

MORRO BAY, CA 93442
HUNGRY FISHERMAN/RIVACU, INC. 399 BEACH ST MORRO BAY, CA 93442

HWY 41 ANTIQUE EMPORIUM 520 ATASADERO RD MORRO BAY, CA 93442

IMAGES

1180 MAIN ST

MORRO BAY, CA 93442

INTEGRATIVE HEALING ARTS 845 NAPA \#A-B

MORRO BAY, CA 93442

INTEGRITY SECURITY \& INTERGRATED S 9495 LITTLE COUNTRY RD. ATASCADERO, CA 93422

$J \& H$ CAR WASH

P O BOX 826

MORRO BAY, CA 93443

J B G CONSULTING L L C

1243 5TH ST

LOS OSOS, CA 93402

J PETER DOBSON 895 NAPA AVE STE A 4 MORRO BAY, CA 93442

JV ENTERPRISES

418 WHIDBEY ST

MORRO BAY, CA 93442

J.R. TECHNOLOGY

3210 MAIN ST \#1-3

MORRO BAY, CA 93442 
JAMES SEARBY CONSTRUCTION 400 YERBA BUENA ST MORRO BAY, CA 93442

JASCO PLUMBING

224 KERN AVE

MORRO BAY, CA 93442

JASMINE THAI CUISINE

355 MORRO BAY BLVD

MORRO BAY, CA 93442

JEROME TURNER D. D. S.

PO BOX 490

MORRO BAY, CA 93443-0490

JERRY'S MARINE \& TACKLE

9198 WILLOW CT

ATASCADERO, CA 93422

JILL GARMAN L C S W

895 NAPA AVE B-6

MORRO BAY, CA 93442

JIM M BRAY

1050 MORRO AVE

MORRO BAY, CA 93442

JIM'S AUTO.- NEISWANGER AUTO SP 899 PINEY WAY

MORRO BAY, CA 93442

JOE'S SURFBOARD SHOP

431 LA JOLLA ST

MORRO BAY, CA 93442

JOHN HESCH GENERAL CONTRACTOR 454 MAIN ST

MORRO BAY, CA 93442
JOHN RAMOS GALLERY

407 MORRO BAY BLVD

MORRO BAY, CA 93442

JONATHANE. FOW, M.D., INC

200 STATION WAY STE C

ARROYO GRANDE, CA 93420

JOSELLE-ARIEL

450 MORRO BAY BLVD

MORRO BAY, CA 93442

JUDIE FINNEGAN

1801 MAPLE AVE

LOS OSOS, CA 93402

K D CONSTRUCTION INC

PO BOX 162

MORRO BAY, CA 93443

KARMA SUNSHINE - 20TH CENTURY COLI

P O BOX 1432

MORRO BAY, CA 93443

KAYAK HORIZONS

551 EMBARCADERO

MORRO BAY, CA 93442

KEITH GAFFNEY LANDSCAPE INC.

PO BOX 925

MORRO BAY, CA 93443-0925

KELLER WILLIAMS REALTY CENTRAL CO 350 JAMES WAY STE 130

PISMO BEACH, CA 93449

KERN/PACIFIC APARTMENT

8305 BALBOA RD

ATASCADERO, CA 93422
KERN/PACIFIC APARTMENT

8305 BALBOA RD

ATASCADERO, CA 93422

KERN/PACIFIC APARTMENT

8305 BALBOA RD

ATASCADERO, CA 93422

KERN/PACIFIC APARTMENT

8305 BALBOA RD

ATASCADERO, CA 93422

KITTY'S KITCHEN

890 MAIN ST

MORRO BAY, CA 93442

LA CASA MORRO

413 ARBUTUS AVE

MORRO BAY, CA 93442

LA PARISIENNE

1140 FRONT ST

MORRO BAY, CA 93442

LA PETITE

317 MORRO BAY BLVD

MORRO BAY, CA 93442

LA SERENA INN 990 MORRO AVE MORRO BAY, CA 93442

LALEH SHABAN M.D., INC. 665 MAIN ST SUITE B MORRO BAY, CA 93442

LAND/SEA INTERFACE

201 MAIN ST

MORRO BAY, CA 93442 
LARRY T. BLACK CONSTRUCTION 625 MONTEREY AVE

MORRO BAY, CA 93442

LAW OFFICE OF JOAN S. BAUMAN

1163 MAIN ST

MORRO BAY, CA 93442

LAW OFFICE OF SALLY F LA MACCHIA 895 NAPA \#B3

MORRO BAY, CA 93442

LAW OFFICE OF TODD A. PORTER 1052 MAIN STREER STE. D

MORRO BAY, CA 93442

LEGENDS

899 MAIN ST

MORRO BAY, CA 93442

LEMOS FEED \& PET SUPPLY, INC 2527 LOS BERROS RD

ARROYO GRANDE, CA 93420

LEROY RICHARDS PLASTERING

351 OAHU ST

MORRO BAY, CA 93442

LESSI CONSTRUCTION, INC.

PO BOX 4151

SAN LUIS OBISPO, CA 93403

LEWIS PSYCHOLOGICAL SERVICES

365 QUINTANA RD UNIT F-3

MORRO BAY, CA 93442

LIGHTHOUSE LIQUOR

PO BOX 517

MORRO BAY, CA 93442
LINA G'

468 MORRO BAY BLVD

MORRO BAY, CA 93442

LINDA K. HARRIS

325 PACIFIC ST UNIT A

MORRO BAY, CA 93442

LINKER ENTERPRISES

PO BOX 20

MORRO BAY, CA 93443

LOLO'S OF MORRO BAY

2848 MAIN ST

MORRO BAY, CA 93442

LORRAINE'S BEAUTY SALON

PO BOX 1734

MORRO BAY, CA 93443-1734

LUCKY 7 MINI MART \& GAS, INC

1860 MAIN ST

MORRO BAY, CA 93442

LUHR DESIGN \& CONSTRUCTION INC. 2335 NUTMEG AVE MORRO BAY, CA 93442

M \& M GENERAL REFRIGERATION 1287 EMBARCADERO

MORRO BAY, CA 93442

M B PIPER CONSTRUCTION

PO BOX 903

MORRO BAY, CA 93443

M D AIR CONDITIONING \& HEATING

PO BOX 924

MORRO BAY, CA 93442
MAGIC WAND CAR WASH/HANSON FAMI

PO BOX 522

PASO ROBLES, CA 93446

MAIN LIGHTING

3310 MAIN ST

MORRO BAY, CA 93442

MAIN MINI STORAGE

2100 MAIN ST

MORRO BAY, CA 93442

MAIN ST. BOUTIQUE

865 MAIN ST.

MORRO BAY, CA 93442

MARGARITA MAN OF S L O COUNTY

540 ATASCADERO RD

MORRO BAY, CA 93442

MARINA STREET INN B \& B

305 MARINA ST

MORRO BAY, CA 93442

MASSAGE THERAPY TRACEY TUTTLE

PO BOX 1493

MORRO BAY, CA 93443

MASTERPIECE HOTEL

1206 MAIN ST

MORRO BAY, CA 93442

MAYA MEXICAN FOOD

2490 MAIN ST

MORRO BAY, CA 93442

MBFC ACQUISITION CORP

1231 EMBARCADEO RD

MORRO BAY, CA 93442 
MCELHINNEY \& MCELHINNEY 800 QUINTANA RD STE $2 F$ MORRO BAY, CA 93442

MI CASA

650 MORRO BAY BLVD.

MORRO BAY, CA 93442

MIJIT MART

1700 EMBARCADERO

MORRO BAY, CA 93442

MIKE ARMSTRONG

POBOX 118

MORRO BAY, CA 93442

MIKE'S BARBER SHOP

280 MORRO BAY BLVD

MORRO BAY, CA 93442

MIKKELSON'S ANTIQUES

455 MORRO BAY BLVD

MORRO BAY, CA 93442

MINER'S ACE HARDWARE

1056 GRAND AVE

GROVER BEACH, CA 93433

MINIATURE COTTAGE SHOP 1260 MAIN ST

MORRO BAY, CA 93442

MIRTHGIVER INSTANT IMAGES

1848 ASTOR AVE

CAMBRIA, CA 93428

MISSION LINEN SUPPLY

PO BOX 1299

SANTA BARBARA, CA 93102
MOBILITY LIMITED

PO BOX 838

MORRO BAY, CA 93443

MOBILITY MASTERS

358 QUINTANA RD

MORRO BAY, CA 93442

MODICA FINANCIAL \& TAX, INC

1052 MAIN ST SUITE A

MORRO BAY, CA 93442

MOON DANCE BY THE SEA

2600 MAIN ST

MORRO BAY, CA 93442

MOORE, LAUREN

130 HIDALGO AVE

CAYUCOS, CA 93430

MORRO BAY AM/PM

940 MORRO BAY BLVD

MORRO BAY, CA 93442

MORRO BAY APPLIANCE

935 MAIN ST

MORRO BAY, CA 93442

MORRO BAY AQUARIUM INC

PO BOX 129

MORRO BAY, CA 93443

MORRO BAY BARBER SHOP

2300 MAIN ST STE 2

MORRO BAY, CA 93442

MORRO BAY BEACHWEAR

1794 BELLA VISTA CT 101/102

PASO ROBLES, CA 93446
MORRO BAY BOAT YARD

261 MAIN ST

MORRO BAY, CA 93442

MORRO BAY CHEVRON

1798 MAIN ST

MORRO BAY, CA 93442

MORRO BAY CIGARETTES

640 QUINTANA

MORRO BAY, CA 93442

MORRO BAY CUSTOM GOLF

831 MORRO BAY BLVD

MORRO BAY, CA 93442

MORRO BAY DRUG \& GIFT

600 MORRO BAY BLVD SUITE B

MORRO BAY, CA 93442

MORRO BAY FISH CO.

13015 OLD MORRO RD

ATASCADERO, CA 93422

MORRO BAY FRESH

47 16TH ST

CAYUCOS, CA 93430

MORRO BAY FURNITURE

381 QUINTANA RD

MORRO BAY, CA 93442

MORRO BAY HAIR CO.

706 MORRO BAY BLVD

MORRO BAY, CA 93442

MORRO BAY HEARING AID

870 SHASTA AVE

MORRO BAY, CA 93442 
MORRO BAY HOOKERS

875 SANTA YSABEL APT 8

LOS OSOS, CA 93402

MORRO BAY HOUSE OF JERKY

845 EMBARCADERO RD \# $F$

MORRO BAY, CA 93442

MORRO BAY LAUNDERLAND

PO BOX 1627

MORRO BAY, CA 93443

MORRO BAY LAUNDROMAT

111 S HALCYON RD

ARROYO GRANDE, CA 93420

MORRO BAY MAIL CENTER

785 QUINTANA RD

MORRO BAY, CA 93442

MORRO BAY MARINA

699 EMBARCADERO \#10

MORRO BAY, CA 93442

MORRO BAY MARINA, INC

261 MAIN ST

MORRO BAY, CA 93442

MORRO BAY MARKET AND SPIRITS

395 MORRO BAY BLVD

MORRO BAY, CA 93442

MORRO BAY OYSTER COMPANY. L L C 1254 SCOTT ST

MORRO BAY, CA 93442

MORRO BAY PROPANE \& MOVING SUPPL

899 QUINTANA BLVD

MORRO BAY, CA 93442
MORRO BAY R $V$ \& MARINE

1598 MAIN ST

MORRO BAY, CA 93442

MORRO BAY R V TRAILER PARK \& APTS

PO BOX 5189

EL DORADO HILLS, CA 95762

MORRO BAY REALTY

PO BOX 1687

MORRO BAY, CA 93443

MORRO BAY SANDPIPER INN

540 MAIN ST

MORRO BAY, CA 93442

MORRO BAY SELF STORAGE

290 MAPLE CT STE 130

VENTURA, CA 93003

MORRO BAY SKATEBOARD MUSEUM

225 MAIN ST

MORRO BAY, CA 93442

MORRO BAY STOW-AWAY

PO BOX 12060

SAN LUIS OBISPO, CA 93406

MORRO BAY VACATION STAYS

P OBOX 1986

MORRO BAY, CA 93443

MORRO BAY VETERINARY CLINIC

385 QUINTANA RD

MORRO BAY, CA 93442

MORRO BAY WATERFRONT GRILL

571 EMBARCADEO SUITE C

MORRO BAY, CA 93442
MORRO BAY WINE SELLER

601 EMBARCADERO \#5

MORRO BAY, CA 93442

MORRO CREST INN

608 IRONWOOD CT

MORRO BAY, CA 93442

MORRO DOORS

1548 MAIN ST

MORRO BAY, CA 93442

MORRO DUNES REPAIR SERVICE

1700 EMBARCADERO

MORRO BAY, CA 93442

MORRO DUNES TRAILER PARK \& CAMP 1

1700 EMBARCADERO

MORRO BAY, CA 93442

MORRO ENTERPRISES

PO BOX 305

MORRO BAY, CA 93443

MORRO GARDENS MOTEL

411 DEL NORTE RD

OJAI, CA 93023

MORRO HILLTOP HOUSE

PO BOX 13851

SAN LUIS OBISPO, CA 93406

MORRO NAILS

650 QUINTANA RD

MORRO BAY, CA 93442

MORRO PALMS MOBILE LODGE 901 MORRO BAY BLVD \#54

MORRO BAY, CA 93442 
MORRO ROCK GREEN SHOP

P O BOX 6493

LOS OSOS, CA 93412

MORRO SECURE STORAGE

P O BOX 421

ATASCADERO, CA 93423

MORRO SHORES INN \& SUITES

404 SANTA ROSA ST

SAN LUIS OBISPO, CA 93401

MORRO STRAND R V PARK

4087 N HOWARD

KERMAN, CA 93630

MORRO VIEW TRAILER PARK

2482 SEA HORSE LN

LOS OSOS, CA 93402

MOTEL 6 \#04

PO BOX 117508

CARROLLTON, TX 75011

MR GREEN JEANS

365 MORRO BAY BLVD

MORRO BAY, CA 93442

NAOMI CAMILLE MASSAGE

21 6TH ST

CAYUCOS, CA 93430

NATIVE SPIRIT GALLERY

333 BERNARDO

MORRO BAY, CA 93442

NATURE WORKS THERAPY

1028 MAIN ST

MORRO BAY, CA 93442
NEW ASIAN GOURMET

430 MORRO BAY BLVD

MORRO BAY, CA 93442

NEXCYCLE

26021 BUSINESS CENTER DR

REDLANDS, CA 92374

NIBBLE NOOK

410 QUINTANA RD.

MORRO BAY, CA 93442

OASIS EQUIPMENT RENTAL

540 ATASCADERO RD

MORRO BAY, CA 93442

OCEAN ACUPRESSURE

365 QUINTANA RD STE D

MORRO BAY, CA 93442

OCEAN FRONT DONUT SHOP 1130 FRONT ST

MORRO BAY, CA 93442

OCEAN VIEW FURNITURE INC 2200 MAIN ST

MORRO BAY, CA 93442

OGILVIE, INC

PO BOX 373

MORRO BAY, CA 93443

OGLE INC, CHARLES E. PO BOX 720

MORRO BAY, CA 93443

OLSON, LYNNE

PO BOX 775

PALERMO, CA 95968
ONBOARD NAUTICAL EVENTS

840 MORRO AVE B

MORRO BAY, CA 93442

ORIENTAL FOOT MASSAGE 800 MORRO BAY BLVD MORRO BAY, CA 93442

ORIENTAL FOOT MASSAGE 800 MORRO BAY BLVD MORRO BAY, CA 93442

OTTER BAY GIFTS 875 EMBARCADERO MORRO BAY, CA 93442

OTTER ROCK CAFE 885 EMBARCADERO MORRO BAY, CA 93442

OUR COMPUTER GUY 708 MORRO BAY BLVD MORRO BAY, CA 93442

PAC - VUE APARTMENTS 9855 LAUREL RD

ATASCADERO, CA 93422

PACIFIC BEACH PROPERTIES, INC PO BOX 1627 MORRO BAY, CA 93443

PACIFIC BELL 1010 N ST MARY'S ST 9-5-05 SAN ANTONIO, TX 78215

PACIFIC COTTAGE MOTEL 2830 ALDER AVE MORRO BAY, CA 93442 
PACIFIC DANCE CENTER

698 MORRO BAY BLVD

MORRO BAY, CA 93442

PACIFIC EYE SURGEONS, INC.

628 CALIFORNIA BLVD STE. D

SAN LUIS OBISPO, CA 93401

PACIFIC HEATING \& SHEET METAL 1600 MAIN ST

MORRO BAY, CA 93442

PACIFIC LOCKSMITHS

332 MORRO BAY BLVD

MORRO BAY, CA 93442

PACIFIC SHORES INN

890 MORRO AVE

MORRO BAY, CA 93442

PAINTED PIRATE INK

1610 MAIN ST

MORRO BAY, CA 93442

PATRICK J VAUGHAN MD INC 685 MORRO AVE UNIT C MORRO BAY, CA 93442

PATRICK O'GRADY C P A 898 NAPA AVE UNIT A-3 MORRO BAY, CA 93442

PATRICK ROSE CONSTRUCTION 985 MORRO AVE MORRO BAY, CA 93442

PAULA RADKE DICHROICS, INC PO BOX 1088

MORRO BAY, CA 93443
PEDALS \& PADDLES

257 MORRO BAY BLVD

MORRO BAY, CA 93442

PEDERSEN REALTY \& FINANCIAL

1163 MAIN ST

MORRO BAY, CA 93442

PERRY'S AUTOMOTIVE

PO BOX 217

MORRO BAY, CA 93443

PETES MORRO BAY TIRE AND AUTO

375 QUINTANA RD

MORRO BAY, CA 93442

PETTITT COMPANY ELECTRICAL 401 MINDORO ST

MORRO BAY, CA 93442

PHILIP LEE BAUMAN

380 ACACIA ST

MORRO BAY, CA 93442

PLEASANT INN MOTEL

P O BOX 677

SAN LUIS OBISPO, CA 93406

PLEASANT INN MOTEL

1050 MORRO AVE

MORRO BAY, CA 93442

POPPY

911 EMBARCADEO

MORRO BAY, CA 93443

PORTZEL APARTMENTS

PO BOX 701

SAN LUIS OBISPO, CA 93406
PSYCHIC GIFTS

2738 MAIN ST

MORRO BAY, CA 93442

PYRATINE L L C

2950 MAIN ST

MORRO BAY, CA 93442

QUEEN'S CLOSET

325 MORRO BAY BLVD

MORRO BAY, CA 93442

QUINTANA FORGE, THE 353 QUINTANA RD

MORRO BAY, CA 93442

QUINTANA ROAD PROPERTIES LLC PO BOX 12134

SAN LUIS OBISPO, CA 93406

R \& M APARTMENTS

255 MORRO BAY BLVD

MORRO BAY, CA 93442

RANCHO RECREATIONAL VEHICLE PK 355 HARBOR ST

MORRO BAY, CA 93442

RED ANCHOR CHARTERS

51 8TH ST

CAYUCOS, CA 93430

RED ZEPPELIN WINERY

520 ATASADERO RD

MORRO BAY, CA 93442

REED (APARTMENTS), JERRY A

767 N LYNORA ST

TULARE, CA 93274 
REG WHIBLEY

451 EMBARCADERO

MORRO BAY, CA 93442

REGATTA TROPICALS LTD

1742 MANHATTAN AVE STE C

GROVER BEACH, CA 93433

RESIDENTIAL CUSTOM BUILDERS

PO BOX 298

MORRO BAY, CA 93443

RIO

330 MORRO BAY BLVD

MORRO BAY, CA 93442

RITE AID \#5830

PO BOX 3165

HARRISBURG, PA 17105

ROBERT GRAY GALLERY

2961 JUNIPER AVE

MORRO BAY, CA 93442

ROCCA'S

945 EMBARCADERO

MORRO BAY, CA 93442

ROCK KAYAK CO

845 EMBARCADERO \#11

MORRO BAY, CA 93442

ROCK SOLID AUTO

337 A QUINTANA PLACE

MORRO BAY, CA 93442

ROCK SOLID PLUMBING

PO BOX 1363

MORRO BAY, CA 93443
ROCK VIEW REALTY

551 EMBARCADERO RD SUITE A

MORRO BAY, CA 93442

ROCKVIEW INN \& SUITES

3930 BRAE BURN DR.

BAKERSFIELD, CA 93306

ROCKVIEWTRAILER PARK

227 SURF ST

MORRO BAY, CA 93442

RODGERS ELECTRIC \& CONST INC.

542 SHASTA AVE

MORRO BAY, CA 93443-000

ROOTS TOLOCKS SALON

845 NAPA ST STE C

MORRO BAY, CA 93442

ROSE PASLAY

2790 MAIN ST

MORRO BAY, CA 93442

ROSE'S STEAK AND SEAFOOD

725 EMBARCADERO

MORRO BAY, CA 93442

ROSS PROPERTIES

PO BOX 992

MORRO BAY, CA 93443

ROUND TABLE PIZZA

3485 SACRAMENTO DR STE. G

SAN LUIS OBISPO, CA 93401

ROY \& KATHY CINOWALT

3965 E HWY 41

TEMPLETON, CA 93465
RUBY DRAGON

600 MORRO BAY BLVD STE C MORRO BAY, CA 93442

RUTH B LAPP MS L M F T

895 NAPA STE B-6

MORRO BAY, CA 93442

RYAN GARCIA D.D.S. 545 MAIN ST UNIT B-2

MORRO BAY, CA 93442

STAX

1099 EMBARCADEO RD

MORRO BAY, CA 93442

SABETTAS PIZZA \& PASTA

1035 MAGNOLIA DR

ARRYO GRANDE, CA 93420

SALLY DAVIS

P O BOX 862

MORRO BAY, CA 93442

SALON BY THE BAY

735 NAPA AVE

MORRO BAY, CA 93442

SALVAGE A BOUTIQUE

231 MORRO BAY BLVD

MORRO BAY, CA 93442

SAN LUIS AMBULANCE SERVICE INC PO BOX 954

SAN LUIS OBISPO, CA 93406

SAN LUIS OBISPO EYE ASSOCIATES

234 HEATHER CT STE.102

TEMPLETON, CA 93465 
SAN LUIS SPORTS THERAPY

890 SHASTA

MORRO BAY, CA 93442

SAN MARCOS INN, BEST WESTERN

250 PACIFIC ST

MORRO BAY, CA 93442

SANDPRINTS

870 MAIN ST

MORRO BAY, CA 93442

SCENIC COAST ASSOCIATION OF REALTI 830 MORRO BAY BLVD

MORRO BAY, CA 93442

SCOTT CONSTRUCTION

515 MORRO AVE

MORRO BAY, CA 93442

SCOTT TAYLOR, D D S

685 MAIN ST STE C

MORRO BAY, CA 93442

SEA AIR INN

845 MORRO AVE

MORRO BAY, CA 93442

SEACLIFF APARTMENTS

7055 ADELAIDA

PASO ROBLES, CA 93446

SEASIDE REAL ESTATE, INC.

817 MORRO BAY BLVD

MORRO BAY, CA 93442

SEAWIND GALLERY \& FLOWER SPROUT؛

PO BOX 1843

MORRO BAY, CA 93443
SEVEN SISTERS GALLERY, INC

601 EMBARCADERO UNIT 8

MORRO BAY, CA 93442

SHAWN'S ON MAIN

912 MAIN ST

MORRO BAY, CA 93442

SHEAR DIMENSIONS HAIR DESIGNS

1052 MAIN ST UNIT C

MORRO BAY, CA 93442

SHELL SHOP

590 EMBARCADERO

MORRO BAY, CA 93442

SHIRT SHOP

1001 FRONT ST

MORRO BAY, CA 93442

SHORELINE ENGINEERING

505 HARBOR ST

MORRO BAY, CA 93442

SHORTY'S AUTO SERVICE

2190 MAIN ST

MORRO BAY, CA 93442

SILVER CITY RESORT

500 ATASCADERO RD

MORRO BAY, CA 93442

SILVER SEAHORSE

3945 RACE ST

VISALIA, CA 93292

SIMPLY CLEAR MARKETING INC.

1203 MAIN ST

MORRO BAY, CA 93442
SLO ARCHES, INC.

PO BOX 306

ARROYO GRANDE, CA 93421

SLOCO HEATING \& COOLING, INC 540 ATASCADERO RD

MORRO BAY, CA 93442

SMITH'S TRAILER STORAGE

1556 MAIN ST

MORRO BAY, CA 93442

SMOOBAGE

2605 IRONWOOD AVE

MORRO BAY, CA 93442

SOJOURNER SURFBOARDS 986 QUINTANA ROAD UNIT C MORRO BAY, CA 93442

SOLE MIA

699 EMBARCADERO STE. 1

MORRO BAY, CA 93442

SPA BY THE BAY

267 VISTA CT

LOS OSOS, CA 93402

SPENCER'S FRESH MARKETS

2650 MAIN ST

MORRO BAY, CA 93442

SPORTSRIG.COM

354 QUINTANA RD

MORRO BAY, CA 93442

ST. TIMOTHY'S FABULOUS FINDS 962 PINEY WAY

MORRO BAY, CA 93442 
STRANDZ SALON \& SPA

895 NAPA AVE $B 5$

MORRO BAY, CA 93442

STRICTLY P C

3118 MAIN ST UNIT B

MORRO BAY, CA 93442

STUARTS' PETROLEUM

11 4TH ST

BAKERSFIELD, CA 93309

STUDIO FITNESS

630 QUINTANA RD \# 162

MORRO BAY, CA 93442

SUB SEA TOURS

699 EMBARCADERO \#9

MORRO BAY, CA 93442

SUBWAY

660 QUINTANA RD

MORRO BAY, CA 93442

SUITE 1 GALLERY

601 EMBARCADEO RD STE 1

MORRO BAY, CA 93442

SUMMER COTTAGE

863 MAIN ST

MORRO BAY, CA 93442

SUN PACIFIC

PO BOX 1380

MORRO BAY, CA $93443-1380$

SUNDOWN INN

640 MAIN ST

MORRO BAY, CA 93442
SUNFIRE GALLERY

1000 MAIN ST

MORRO BAY, CA 93442

SUN-N BUNS BAKE SHOP

830 EMBARCADERO

MORRO BAY, CA 93442

SUNRISE CHIROPRACTIC

1052 MAIN ST UNIT B

MORRO BAY, CA 93442

SUNRISE COATINGS

1165 MONTEREY AVE

MORRO BAY, CA 93442

SUNSHINE HEALTH FOOD

415 MORRO BAY BLVD

MORRO BAY, CA 93442

SURFWOOD CONSTRUCTION

2462 RENO CT

MORRO BAY, CA 93442

SWIMMING SUPPLY, AQUA WORLD

2198 MAIN ST

MORRO BAY, CA 93442

T K D SURF \& SPORT

291 HARBOR ST

MORRO BAY, CA 93442

TACO BELL \#3499

29889 SANTA MARGARITA PKWY

RANCHO SANTA MARGARITA, CA 92688

TACO DE MEXICO

980 MAIN ST

MORRO BAY, CA 93442
TACO TEMPLE MORRO BAY

2680 MAIN ST

MORRO BAY, CA 93442

TAN DE SOLEIL

670 QUINTANA RD

MORRO BAY, CA 93442

TANGO

699 EMBARCADEO RD STE 5

MORRO BAY, CA 93442

TECHNICAL ENGINEERING, INC

1601 17TH ST

LOS OSOS, CA 93402

THAI BOUNTY

1219 EMBARCADERO

MORRO BAY, CA 93442

THE BUOY

2940 MAIN ST

MORRO BAY, CA 93442

THE COLLECTION

450 MORRO BAY BLVD

MORRO BAY, CA 93442

THE COTTON BALL

1199 MAIN ST

MORRO BAY, CA 93442

THE GALLEY SEAFOOD GRILL \& BAR 899 EMBARCADERO

MORRO BAY, CA 93442

THE GOOD FLEA

335 QUINTANA

MORRO BAY, CA 93442 
THE GREEN GROOMER

1060 QUINTANA RD

MORRO BAY, CA 93442

THE GREEN LOTUS

560 MORRO BAY BLVD

MORRO BAY, CA 93442

THE HOLISTIC MOVEMENT CENTER PO BOX 177

MORRO BAY, CA 93443

THE INN AT MORRO BAY 60 STATE PARK RD

MORRO BAY, CA 93442

THE INN AT MORRO BAY 60 STATE PARK RD

MORRO BAY, CA 93442

THE JOYCUP CO.

P O BOX 392

CAYUCOS, CA 93430

THE LEATHER SHOP 880 MORRO BAY BLVD MORRO BAY, CA 93442

THE OLD POTTING BENCH 630 QUINTANA RD BOX 122 MORRO BAY, CA 93442

THE PARLOUR 241 MORRO BAY BLVD MORRO BAY, CA 93442

THE PIZZA PORT 2 787 MAIN ST MORRO BAY, CA 93442
THE SKIN STOP

270 MARINA ST

MORRO BAY, CA 93442

THE TWIN DOLPHIN

590 MORRO AVE

MORRO BAY, CA 93442

THE UPS STORE \#2702

630 QUINTANA RD

MORRO BAY, CA 93422

THE VINTAGE REBUILDER

364 QUINTANA RD B

MORRO BAY, CA 93442

THE YOGA CENTER OF MORRO BAY 335 DUNES ST

MORRO BAY, CA 93442

THERAPY WORKS - FITNESS WORKS / $F^{\prime}$ 500 QUINTANA RD

MORRO BAY, CA 93442

THREADS

400 MORRO BAY BLVD

MORRO BAY, CA 93442

TIFFANY SMART, O. D.

590 HARBOR

MORRO BAY, CA 93442

TIREWORKS MORRO BAY

339 QUINTANA RD B

MORRO BAY, CA 93442

TJ REYNOLDS CUSTOM WOODWORKS

1152 QUINTANA RD

MORRO BAY, CA 93442
T-N-T COAST BOOT \& SHOE REPAIR 431 MORRO BAY BLVD MORRO BAY, CA 93442

TOBACCO PLUS 385 MORRO BAY BLVD MORRO BAY, CA 93442

TODD'S GARAGE 972 QUINTANA RD MORRO BAY, CA 93442

TOGNAZZINI'S DOCKSIDE 3 1219 EMBARCADERO MORRO BAY, CA 93442

TOGNAZZINI'S DOCKSIDE RESTAURANT 1245 EMBARCADERO MORRO BAY, CA 93442

TOGNAZZINI'S DOCKSIDE TOO 1235 EMBARCADERO MORRO BAY, CA 93442

TOKYO JOE'S SUSHI L L C 3118 MAIN ST MORRO BAY, CA 93442

TOM'S PLUMBING 780 MAR VISTA RD LOS OSOS, CA 93402

TOOBS INC. 347 QUINTANA RD MORRO BAY, CA 93442

TOP DOG COFFEE BAR 1350 PARKHILL RD SANTA MARGARITA, CA 93453 
TOP NAILS SALON

700 MORRO BAY BLVD

MORRO BAY, CA 93442

TRADITIONAL THAI \& THERAPEUTIC MAS

831 MORRO BAY BLVD

MORRO BAY, CA 93442

TRADITIONS JEWERY

898 MAIN ST A

MORRO BAY, CA 93442

TRATEL MORRO BAY

1680 MAIN ST

MORRO BAY, CA 93442

TRAVEL LODGE

220 BEACH ST

MORRO BAY, CA 93442

TRIBE ELATION

520 ESTERO AVE

MORRO BAY, CA 93442

TRUHITTE AUTOMOTIVE, INC.

998 QUINTANA RD

MORRO BAY, CA 93442

TRUHITTE MINI-STORAGE

998 QUINTANA RD

MORRO BAY, CA 93442

TYLOR'S CUSTOM TILE CO

PO BOX 1884

MORRO BAY, CA 93443-1884

U F I

545 MAIN ST UNIT C-2

MORRO BAY, CA 93442
UNDER THE SEA GALLERY

833 EMBARCADERO UNIT B

MORRO BAY, CA 93442

VALERO CORNER STORE \#3556 PO BOX 690007ATTN: LICENSE DEPARTN

SAN ANTONIO, TX 78269

VIAU APARTMENTS

750 W ALLUVIAL APT 1003

CLOVIS, CA 93611

VICTOR BACKHOE SERVICE, INC 991 LITTLE MORRO CREEK RD

MORRO BAY, CA 93442

VIDEO PALACE

7101 EL CAMINO REAL

ATASCADERO, CA 93422

VILLAGE CENTER DRY CLEANERS

750 NAPA AVE

MORRO BAY, CA 93442

VILLAGER MOTEL

1098 MAIN ST

MORRO BAY, CA 93442

VINYL ISLE

781 HARBOR ST

MORRO BAY, CA 93442

VIRG'S LANDING INC

1169 MARKET AVE

MORRO BAY, CA 93442

VIRG'S LANDING INC

1169 MARKET AVE

MORRO BAY, CA 93442
VISITOR TELEVISION L.L.C 699 EMBARCADERO STE 10 MORRO BAY, CA 93442

VITAL DENTAL CERAMICS PO BOX 1078

MORRO BAY, CA 93443

WAGON WHEEL TRAILER COURT PO BOX 1745

MORRO BAY, CA 93442-1745

WALK IN TUBS

3118 N MAIN ST \#A

MORRO BAY, CA 93442

WALKER'S MOBILE HOME PARK, L L C 706 ROANTREE DR

BRENTWOOD, TN 37027

WARREN APARTMENTS

1017 GLEN ARBOR AVE

LOS ANGELES, CA 90041

WATSON CHIROPRACTIC \& WELLNESS ( 800 QUINTANA RD STE $1 B$

MORRO BAY, CA 93442

WAVELENGTHS SURF SHOP 370 O"CONNOR WAY

SAN LUIS OBISPO, CA 93405

WEST COAST LIGHT TACKLE 1124 FRONT ST

MORRO BAY, CA 93442

WEST COAST PROPERTIES

2870 JUNIPER AVE

MORRO BAY, CA 93442 
WESTSIDE LANDSCAPE MANAGMENT 490 LUZON ST

MORRO BAY, CA 93442

WILLIAM P POWELL

1163 MAIN ST

MORRO BAY, CA 93442

WINDOWS ON THE WATER

699 EMBARCADERO \#7

MORRO BAY, CA 93442

WINSTON L ANDERSON JR. M. D.

685 MORRO AVE

MORRO BAY, CA 93442

WIXOM TRUCKING CO., L L C

MORRO BAY

MORRO BAY, CA 93443 


\section{Appendix 4.5}

\section{Primary Surveys Responses (Hard Copies and Survey Monkey)}

12 City of Morro Bay

Sign Ordinance Update - Business Survey

1. Do you think the current sign ordinance is user friendly and easy to understand?

จ Yes

O No

\section{RECEIVED}

Comments:

\section{APR 012013}

City of Morro Bay

Public Services Department

2. Hoyr do you believe the City's sign code is applied?

(1) Consistently

O Inconsistently (please explain below)

Comments:

3. Is enforcement of illegal signs an issue?

$\mathcal{N}$ No

Y Yes, there is not enough enforcement

o Yes, there is too much enforcement

O Yes, (please specify):

4. With respect to aesthetics, are you happy with the current signs in Morro Bay? Select one or more.
c) Yes
No, illumination is too bright
O No, signs are too large
O No, too many signs
O No, signs are too small
O No, signs are too tall
O No, I don't like the materials most signs use
O Other (please specify):

5. What changes to the sign code could help you attract more customers? Select one or more (use the "other" box to offer additional ideas).

O Further restrict and enforce signs to create more consistency

Relax regulations for illuminated signs

$\checkmark$ Allow ALL businesses to have more signage
$Q$ Allow A-frame signs
O Continue to prohibit A-frame signs
O Other (please specify):

6. What types of signs (if any) do you believe degrade Morro Bay's community character? Select one or mgre.

Pole signs

$\checkmark$ A-frame signs

$\alpha$ Window signs

$\mathcal{d}$ Wall signs

$\varnothing$ Flags and Banners

Q Monument (freestanding) signs

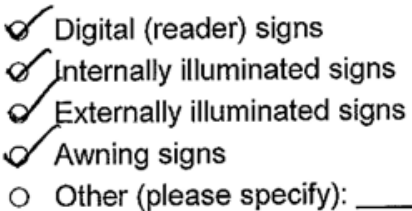

pg. 2 on back $\rightarrow$ 
7. Previous City public meetings revealed a preference for having different sign requirements for different areas of town (e.g. North Morro Bay vs. Downtown vs. Embarcadero vs. Quintana). Do you agree with having different sign requirements in different business districts?

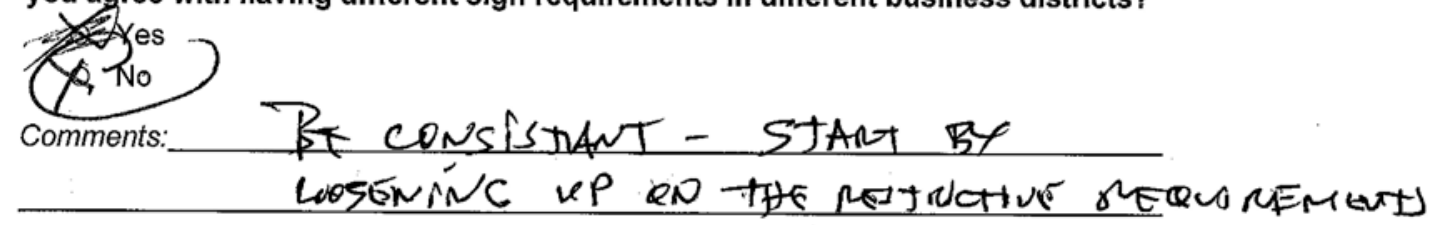

8. Are you happy with your current signage? Select one or more.

O Yes

7 No, my sign(s) are too small

No, my signs can't be seen from the street

6 No, my signs are required to be placed too low where they are not visible

No, my sign's materials are inadequate

9. How important are commercial signs to your business's success?

$\checkmark$ Very important

O. Important

O Not very important

10. Would you support "directional signs" (also known as wayfinding signs) on the Embarcadero? Directional signs are used to help residents and tourists navigate around cities. In this case, directional signs could be used on the Embarcadero to help tourists locate businesises. 0 Yes

O No

O Neutral

11. If directional signs were implemented, what businesses should be featured on them?

C. All businesses should be featured on a directional sign

O Only businesses that are hidden from view should be featured on a directional sign

- Businesses should pay a fee to "rent" a spot on a directional sign

O Directional signs are a bad idea

O Other suggestions: SIOP AU FE'S \& ANES BE Wonk With JHE OW NERS - THEY PAY YQUR CIT BSLS 12. Please provide any additional comments about the sign ordinance or signs in general.

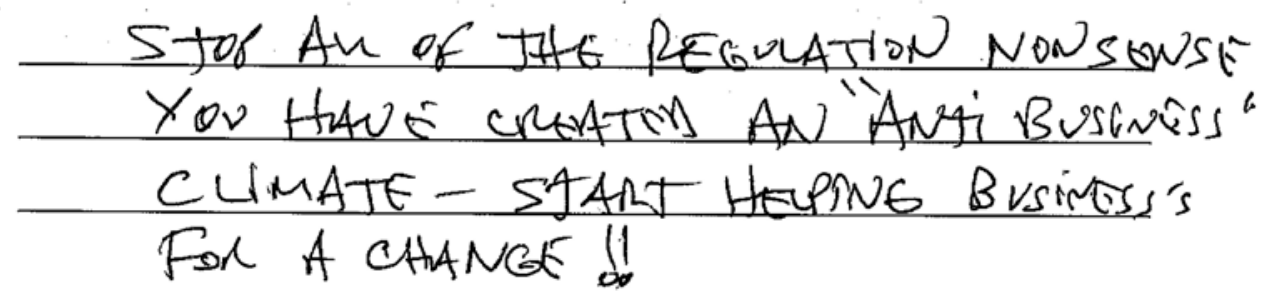

Public Services Department

955 Shasta Ave.

(805)772-6261 
7. Previous City public meetings revealed a preference for having different sign requirements for different areas of town (e.g. North Morro Bay vs. Downtown vs. Embarcadero vs. Quintana). Do you agree with having different sign requirements in different business districts?

O Yes

$\checkmark$ No

Comments:

8. Are you happy with your current signage? Select one or more.

O. Yes

O No, my sign(s) are too small

No, my signs can't be seen from the street

O No, my signs are required to be placed too low where they are not visible

O No, my sign's materials are inadequate

9. How important are commercial signs to your business's success?

Very important

O Important

O Not very important

10. Would you support "directional signs" (also known as wayfinding signs) on the Embarcadero? Directional signs are used to help residents and tourists navigate around cities. In this case, directional signs could be used on the Embarcadero to help tourists locate businesses.

$\$$ Yes

O No

O Neutral

11. If directional signs were implemented, what businesses should be featured on them?

O All businesses should be featured on a directional sign

O Only businesses that are hidden from view should be featured on a directional sign

O Businesses should pay a fee to "rent" a spot on a directional sign

$\varnothing$ Directional signs are a bad idea

O Other suggestions:

12. Please provide any additional comments about the sign ordinance or signs in general. 


\section{City of Morro Bay}

Sign Ordinance Update - Business Survey

1. Do you think the current sign ordinance is user friendly and easy to understand?

$\mathrm{O}$ Yes

No

comments: Its not business finendly

RECEIVED

2. How do you believe the City's sign code is applied?

O Consistently

Inconsistently (please explain below) al wals be reirforreed.

comments: This question is confising are you refierran to the aties signs. or tousiness's signg

3. Is enforcement of illegal signs an issue?

O No

O Yes, there is not enough enforcement

6 Yes, there is too much enforcement

O Yes, (please specify)

4. With respect to aesthetics, are you happy with the current signs in Morro Bay? Select one or more.
q Yes
O No, signs are too large
O No, illumination is too bright
O No, signs are too small
O No, too many signs
O No, I don't like the materials most signs use
O No, signs are too tall

we Whe the eciectic Charm in morro Bay

5. What changes to the sign code could help you attract more customers? Select one or more (use the "other" box to offer additional ideas).

O Further restrict and enforce signs to create more consistency

O Allow A-frame signs

Relax regulations for illuminated signs

f Allow ALL businesses to have more signage

O Continue to prohibit A-frame signs

Other (please specify) to allow aul business's bo do what's nicdea Por eadh

6. What types of signs (if any) do you believe degrade Morro Bay's community character? Select one or more.

O Pole signs

O A-frame signs

X. Digital (reader) signs

O Window signs

O Wall signs

O Flags and Banners

O Monument (freestanding) signs

pg. 2 on back $\rightarrow$ 
7. Previous City public meetings revealed a preference for having different sign requirements for different areas of town (e.g. North Morro Bay vs. Downtown vs. Embarcadero vs. Quintana). Do you agree with having different sign requirements in different business districts?

$\times$ Yes
O No

Comments:

8. Are you happy with your current signage? Select one or more.

$\checkmark$ Yes

O No, my sign(s) are too small

O No, my signs can't be seen from the street

O No, my signs are required to be placed too low where they are not visible

O No, my sign's materials are inadequate

9. How important are commercial signs to your business's success?

X Very important

O Important

O Not very important

10. Would you support "directional signs" (also known as wayfinding signs) on the Embarcadero? Directional signs are used to help residents and tourists navigate around cities. In this case, directional signs could be used on the Embarcadero to help tourists locate businesses.

\& Yes

O No

O Neutral

Not yust on the Embarcadero we need them in downtown also.

11. If directional signs were implemented, what businesses should be featured on them?

O All businesses should be featured on a directional sign

O Only businesses that are hidden from view should be featured on a directional sign

O Businesses should pay a fee to "rent" a spot on a directional sign

O Directional signs are a bad idea

\# Other suggestions: av al able to all and nof Charged for $w$.

12. Please provide any additional comments about the sign ordinance or signs in general.

There need to be gundelues but not so that
business can not thrive in our town


1. Do you think the current sign ordinance is user friendly and easy to understand?

b' Yes

O No

\section{RECEIVED}

Comments:

MAR 282013

City of Morro Bay

2. How do you believe the City's sign code is applied?

Consistently

O Inconsistently (please explain below)

Comments:

3. Is enforcement of illegal signs an issue?

O No

$\varnothing$ Yes, there is not enough enforcement

O Yes, there is too much enforcement

○ Yes, (please specify):

4. With respect to aesthetics, are you happy with the current signs in Morro Bay? Select one or more.
$\varnothing$ Yes
O No, signs are too large
O No, illumination is too bright
O No, signs are too small
O No, too many signs
O No, I don't like the materials most signs use
O No, signs are too tall
Other (please specify):

5. What changes to the sign code could help you attract more customers? Select one or more (use the "other" box to offer additional ideas).

Further restrict and enforce signs to create

more consistency

Relax regulations for illuminated signs

O Allow ALL businesses to have more signage

O Allow A-frame signs

Continue to prohibit A-frame signs

Other (please specify):

6. What types of signs (if any) do you believe degrade Morro Bay's community character? Select one or more.
O Pole signs
O A-frame signs
O Window signs
Wall signs
O Flags and Banners
O Monument (freestanding) signs

O Digital (reader) signs

O internally illuminated signs

O Externally illuminated signs

O Awning signs

O Other (please specify):

pg. 2 on back $\rightarrow$ 
7. Previous City public meetings revealed a preference for having different sign requirements for different areas of town (e.g. North Morro Bay vs. Downtown vs. Embarcadero vs. Quintana). Do you agree with having different sign requirements in different business districts?

○ Yes

$\varnothing$ No

Comments:

8. Are you happy with your current signage? Select one or more.

Q Yes

O No, my sign(s) are too small

O No, my signs can't be seen from the street

O No, my signs are required to be placed too low where they are not visible

O No, my sign's materials are inadequate

9. How important are commercial signs to your business's success?

○ Very important

Important

O Not very important

10. Would you support "directional signs" (also known as wayfinding signs) on the Embarcadero? Directional signs are used to help residents and tourists navigate around cities. In this case, directional signs could be used on the Embarcadero to help tourists locate businesses.
$\not \gamma$ Yes
O No
○ Neutral

11. If directional signs were implemented, what businesses should be featured on them? All businesses should be featured on a directional sign

Only businesses that are hidden from view should be featured on a directional sign

O Businesses should pay a fee to "rent" a spot on a directional sign

D Directional signs are a bad idea

O Other suggestions:

12. Please provide any additional comments about the sign ordinance or signs in general. 
1. Do you think the current sign ordinance is user friendly and easy to understand?

O Yes

O No

Comments:

\section{RECEIVED}

\section{MAO $\& 2013$}

City of Morro Bay

Public Services Department
O Consistently

O Inconsistently (please explain below)
Comments

3. Is enforcement of illegal signs an issue?

O No

Yes, there is not enough enforcement

O Yes, there is too much enforcement

o Yes, (please specify)

4. With respect to aesthetics, are you happy with the current signs in Morro Bay? Select one of
$\begin{array}{ll}\circ \text { Yes } & \bigcirc \text { No, illumination is too bright } \\ \end{array}$
- No, signs are too large
O No, signs are too small

O No, too many signs

- No, I donit like the materials most signs use

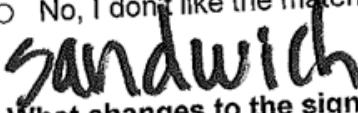

\section{boards}

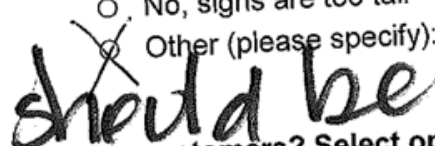

O. No, signs are too tall

5. What changes to the sign coder ideas).

"other" box to restrict and enforce signs to create more consistency

O Relax regulations for illuminated signs

- Allow ALL businesses to have more

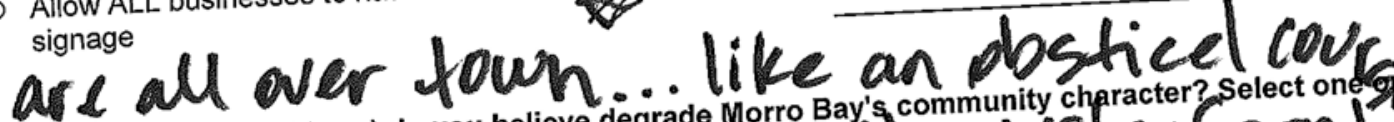

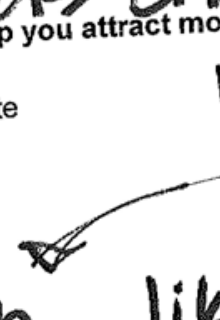

Continue to prohibit A-frame signs

0

Other (please specify): 6. What types of signs (if any) do you believe degrade Morro Bay's community character? Select one?
more. $\mathrm{TH}$ Pole signs

- A-frame sighs

O Window signs

O Wall signs

O Flags and Banners

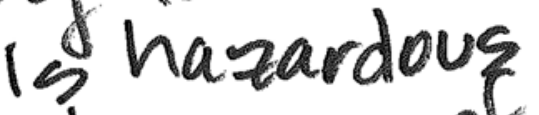

- Internally illuminated signs

O Externally illuminated signs

Monument (freestanding) signs

O Awning signs

O Other (please specify):

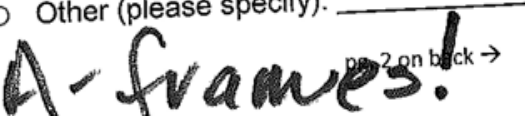


7. Previous City public meetings revealed a preference for having different sign requirements for different areas of town (e.g. North Morro Bay vs. Downtown vs. Embarcadero vs. Quintana). Do you agree with having different sign requirements in different business districts?

O Yes

O No

Comments:

8. Are you happy with your current signage? Select one or more.

Q Yes

O No, my sign(s) are too small

O No, my signs can't be seen from the street

O No, my signs are required to be placed too low where they are not visible

O No, my sign's materials are inadequate

9. How important are commercial signs to your business's success?

Very important

O Important

O Not very important

10. Would you support "directional signs" (also known as wayfinding signs) on the Embarcadero? Directional signs are used to help residents and tourists navigate around cities. In this case, directional signs could be used on the Embarcadero to help tourists locate businesses.
O Yes
$\mathrm{O}$, Nó
O Neutral
is

11. If directional signs were implemented, what businesses should be featured on them?

O All businesses should be featured on a directional sign.

O Only businesses that are hidden from view should be featured on a directional sign

* O Businesses should pay a fee to "rent" a spot on a directional sign

O Directional signs are a bad idea

- $\quad$ Other suggestions:

12. Please provide any additional comments ąbout the sign ordinance or signs in general.

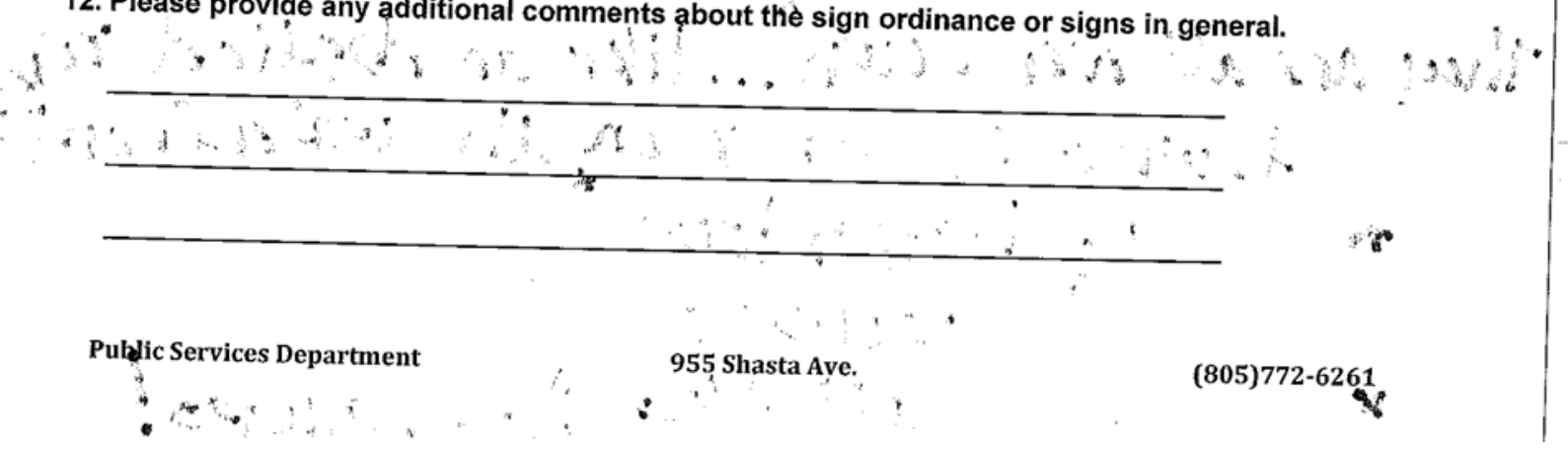




\section{6 \\ City of Morro Bay}

Sign Ordinance Update - Business Survey

1. Do you think the current sign ordinance is user friendly and easy to understand?

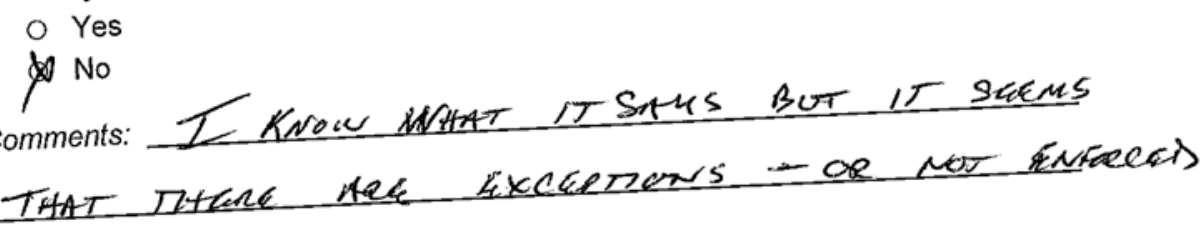

2. How do you believe the City's sign code is applied?

O Consistently

$\varnothing$ Inconsistently (please explain below)

comments: Sout is Above I NOT ENFored

3. Is enforcement of illegal signs an issue?

O No

$\$$ Yes, there is not enough enforcement

- Yes, there is too much enforcement

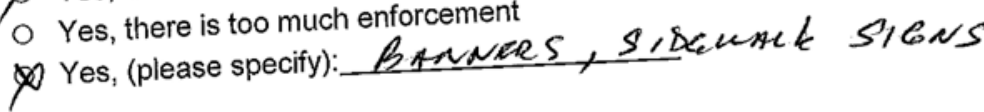

4. With respect to aesthetics, are you happy with the current signs in Morro Bay? Select

O Yes

O No, too many signs

O No, signs are too large

O No, signs are too small

O No, I don't like the materials most signs use

O No, signs are too tall

$\varnothing$ Other (please specify): NO-NOT

elp you attract more customers? Select one or more (use the "other" box to offer additional ideas).

"other" box to offer and restrict and enforce signs to create more consistency

O Relax regulations for illuminated signs

Allow ALL businesses to have more

Allow A-frame signs

O Continue to prohibit A-frame signs

signage

6. What types of signs (if any) do you believe degrade Morro Bay's community character? Select one or more.
- Pole signs
A-frame signs
O Window signs
O Wall signs
O Flags and Banners
O Monument (freestanding) signs

O Digital (reader) signs

O Internally illuminated signs

O Externally illuminated signs

O Awning signs

O Other (please specify):

pg. 2 on back $\rightarrow$ 
7. Previous City public meetings revealed a preference for having different sign requirements for different areas of town (e.g. North Morro Bay vs. Downtown vs. Embarcadero vs. Quintana). Do you agree with having different sign requirements in different business districts?

$\$$ Yes

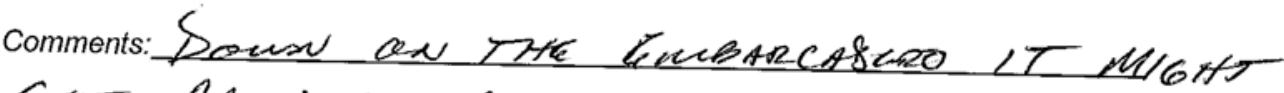

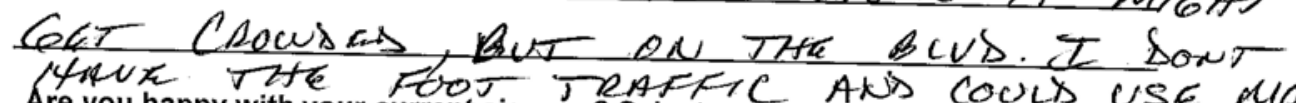

8. Are you happy with your current signage? Select one or more.

O Yes

$316 N+6 E$.

$\$$ No, my sign(s) are too small

No, my signs can't be seen from the street

$\$$ No, my signs are required to be placed too low where they are not visible

No, my sign's materials are inadequate

9. How important are commercial signs to your business's success?

Dery important

O Important

O Not very important

10. Would you support "directional signs" (also known as wayfinding signs) on the Embarcadero? Directional signs are used to help residents and tourists navigate around cities. In this case, directional signs could be used on the Embarcadero to help tourists locate businesses. Y Nos

Neutral

11. If directional signs were implemented, what businesses should be featured on them?

O All businesses should be featured on a directional sign

Only businesses that are hidden from view should be featured on a directional sign

O Businesses should pay a fee to "rent" a spot on a directional sign

Directional signs are a bad idea

O Other suggestions:

12. Please provide any additional comments about the sign ordinance or signs in general.

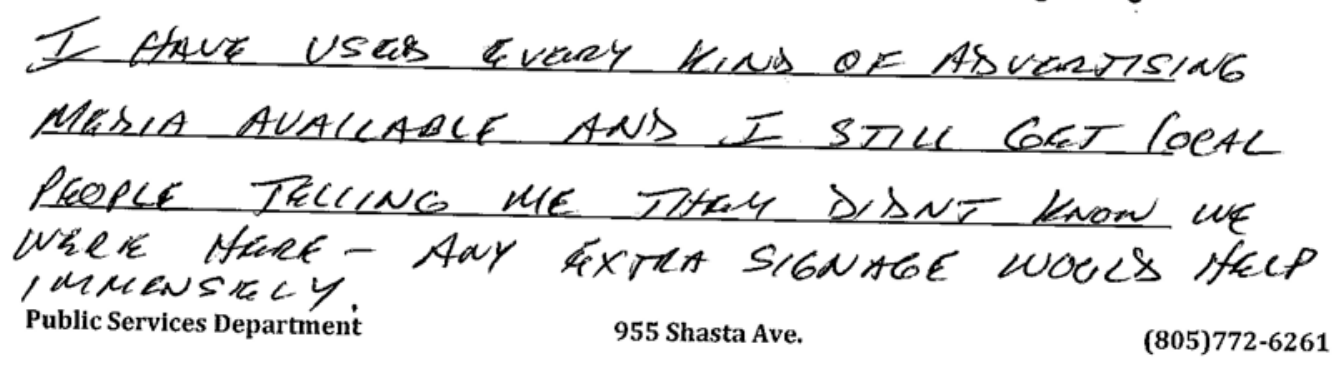


1. Do you think the current sign ordinance is user friendly and easy to understand?

O Yes

$\not$ No

RECEIVED

Comments:

MAR 282013

City of Morro Bay

2. How do you believe the City's sign code is applied?

Public Services Department

O Consistently

Inconsistently (please explain below)

Comments:

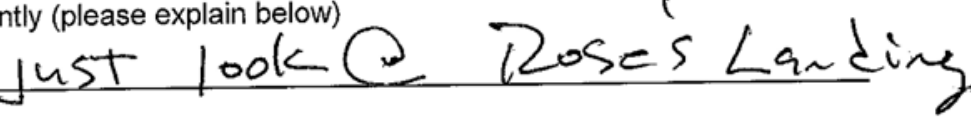

3. Is enforcement of illegal signs an issue?

O No

O Yes, there is not enough enforcement

O Yes, there is too much enforcement,

6 Yes, (please specify)

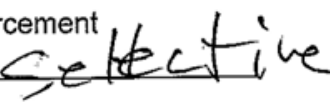

erforcemit

4. With respect to aesthetics, are you happy with the current signs in Morro Bay? Select one or more.
O Yes
No, illumination is too bright
O No, signs are too large
No, signs are too small
O No, I don't like the materials most signs use
No, too many signs
O No, signs are too tall
O Other (please specify):

5. What changes to the sign code could help you attract more customers? Select one or more (use the "other" box to offer additional ideas).

F Further restrict and enforce signs to create more consistency

O Allow A-frame signs

Relax regulations for illuminated signs

O Continue to prohibit A-frame signs

- Allow ALL businesses to have more

O Other (please specify): signage

6. What types of signs (if any) do you believe degrade Morro Bay's community character? Select one or more.
O Pole signs
O A-frame signs
O Window signs
O Wall signs
O Flags and Banners
O Monument (freestanding) signs

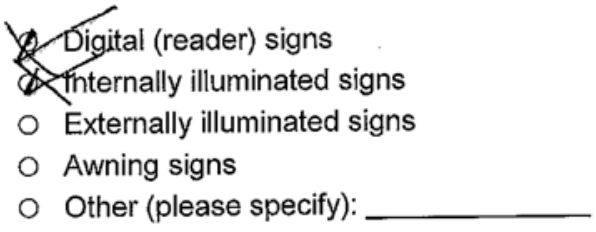

pg. 2 on back $\rightarrow$ 
7. Previous City public meetings revealed a preference for having different sign requirements for different areas of town (e.g. North Morro Bay vs. Downtown vs. Embarcadero vs. Quintana). Do you agree with having different sign requirements in different business districts?

O Yes

No

Comments:

8. Are you happy with your current signage? Select one or more.

Yes

O No, my sign(s) are too small

O No, my signs can't be seen from the street

O No, my signs are required to be placed too low where they are not visible.

O No, my sign's materials are inadequate

9. How jmportant are commercial signs to your business's success?

-Very important
Important

O Not very important

10. Would you support "directional signs" (also known as wayfinding signs) on the Embarcadero? Directional signs are used to help residents and tourists navigate around cities. In this case, directional signs could be used on the Embarcadero to help tourists locate businesses.

O Yes

$\mathcal{L}$ No

6 Neutral

11. If directional signs were implemented, what businesses should be featured on them?

O All businesses should be featured on a directional sign

O Only businesses that are hidden from view should be featured on a directional sign

O Businesses should pay a fee to "rent" a spot on a directional sign

Directional signs are a bad idea

Other suggestions:

12. Please provide any additional comments about the sign ordinance or signs in general. 
18

City of Morro Bay

Sign Ordinance Update - Business Survey

1. Do you think the current sign ordinance is user friendly and easy to understand?

O Yes

(4) No

RECEIVED

Comments:

MAR 282013

City of Morro Bay

2. How do you believe the City's sign code is applied?

O Consistently

Inconsistently (please explain below)

Comments

3. Is enforcement of illegal signs an issue?

O No

O Yes, there is not enough enforcement

o Yes, there is too much enforcement

Yes, (please specify):

are you hapy with the current signs in Morro Bay? Select one or more.

4. With respect to aesthetics, are you happy with the current $O$ No, illumination is too bright
O Yes
O No, signs are too large
O No, signs are too small
O No, I don't like the materials most signs use

No, too many signs

O No, signs are too tall

O Other (please specify):

5. What changes to the sign code could he
"other" box to offer additional ideas).
O Further restrict and enforce signs to create more consistency
O Relax regulations for illuminated signs
O Allow ALL businesses to have more signage

- Allow A-frame signs

O Continue to prohibit A-frame signs

Other (please specify):

6. What types of signs (if any) do you believe degrade Morro Bay's community character? Select one or

\section{more.}

O Pole signs

O A-frame signs

O Window signs

O Wall signs

O Flags and Banners

O Monument (freestanding) signs
- Digital (reader) signs

- Internally illuminated signs

O Externally illuminated signs

O Awning signs

O Other (please specify): 
7. Previous City public meetings revealed a preference for having different sign requirements for different areas of town (e.g. North Morro Bay vs. Downtown vs. Embarcadero vs. Quintana). Do you agree with having different sign requirements in different business districts?

O Yes

No

Comments:

8. Are you happy with your current signage? Select one or more.
- Yes
O No, my sign(s) are too small
O No, my signs can't be seen from the street
O No, my signs are required to be placed too low where they are not visible
O No, my sign's materials are inadequate

9. How important are commercial signs to your business's success?

- Very important

O Important

O Not very important

10. Would you support "directional signs" (also known as wayfinding signs) on the Embarcadero? Directional signs are used to help residents and tourists navigate around cities. In this case, directional signs could be used on the Embarcadero to help tourists locate businesses.
O Yes

No

O Neutral

11. If directional signs were implemented, what businesses should be featured on them?

O All businesses should be featured on a directional sign

Only businesses that are hidden from view should be featured on a directional sign

O Businesses should pay a fee to "rent" a spot on a directional sign

- Directional signs are a bad idea

Other suggestions:

12. Please provide any additional comments about the sign ordinance or signs in general. 
1. Do you think the current sign ordinance is user friendly and easy to understand?<smiles>CC(C)C(=O)O</smiles>

\section{RECEIVED}

Comments:

2. How do you believe the City's sign code is applied?

o Consistently

Inconsistently (please explain below)

Comments:

3. Is enforcement of illegal signs an issue?

No

Yes, there is not enough enforcement

O Yes, there is too much enforcement

O Yes, (please specify):

4. With respect to aesthetics, are you happy with the current signs in Morro Bay? Select one or more.
Ores
O No, signs are too large
O No, signs are too small
O No, I don't like the materials most signs use

O No, illumination is too bright

O No, too many signs

O No, signs are too tall

Other (please specify)

5. What changes to the sign code could help you attract more customers? Select one or more (use the "other" box to offer additional ideas).

O Further restrict and enforce signs to create more consistency

$\chi_{\text {Relax regulations for illuminated signs }}$

O Allow ALL businesses to have more signage

(6) Allow A-frame signs

O Continue to prohibit A-frame signs

O Other (please specify):

6. What types of signs (if any) do you believe degrade Morro Bay's community character? Select one or more.
O Pole signs
O A-frame signs
O Window signs
O Wall signs
O Flags and Banners
O Monument (freestanding) signs

O Digital (reader) signs

O Internally illuminated signs

Externally illuminated signs

A Awning signs

O Other (please specify)

pg. 2 on back $\rightarrow$ 
7. Previous City public meetings revealed a preference for having different sign requirements for different areas of town (e.g. North Morro Bay vs. Downtown vs. Embarcadero vs. Quintana). Do you agree with having different sign requirements in different business districts?

Y Y Yes

Comments:

8. Are fou happy with your current signage? Select one or more.

Yes

O No, my sign(s) are too small

O No, my signs can't be seen from the street

O No, my signs are required to be placed too low where they are not visible

O No, my sign's materials are inadequate

9. How/important are commercial signs to your business's success?

Very important

O Important

O Not very important

10. Would you support "directional signs" (also known as wayfinding signs) on the Embarcadero? Directional signs are used to help residents and tourists navigate around cities. In this case, directional signs could be used on the Embarcadero to help tourists locate businesses.

$\mathrm{O}$ Yes

O No

Neutral

11. If directional signs were implemented, what businesses should be featured on them? All businesses should be featured on a directional sign

O Only businesses that are hidden from view should be featured on a directional sign

O Businesses should pay a fee to "rent" a spot on a directional sign

O Directional signs are a bad idea

O Other suggestions:

12. Please provide any additional comments about the sign ordinance or signs in general. 
1. Do you think the current sign ordinance is user friendly and easy to understand?

O Yes

- No

Comments:
RECEIVED

MAR 282013

City of Morro Bay

Public Services Department

2. How do you believe the City's sign code is applied?

O Consistently

$\Theta$ Inconsistently (please explain below)

Comments:

3. Is enforcement of illegal signs an issue?

O No

O Y.es; there is not enough enforcement

0 Yes, there is too much enforcement

○ Yes, (please specify):

4. With respect to aesthetics, are you happy with the current signs in Morro Bay? Select one or more.
O Yes
O No, illumination is too bright
O No, signs are too large
O No, too many signs
O No, signs are too small
O No, signs are too tall
O No, I don't like the materials most signs use
O Other (please specify):

5. What changes to the sign code could help you attract more customers? Select one or more (use the "other" box to offer additional ideas).

O Further restrict and enforce signs to create more consistency

$\odot$ Relax regulations for illuminated signs

Q. Allow ALL businesses to have more signage

Allow A-frame signs

O Continue to prohibit A-frame signs

O Other (please specify):

6. What types of signs (if any) do you believe degrade Morro Bay's community character? Select one or more.
O Pole signs
A-frame signs
O Window signs
O Wall signs
O Flags and Banners
O Monument (freestanding) signs

O Digital (reader) signs

$O$ Internally illuminated signs

O Externally illuminated signs

O Awning signs

O Other (please specify): 
7. Previous City public meetings revealed a preference for having different sign requirements for different areas of town (e.g. North Morro Bay vs. Downtown vs. Embarcadero vs. Quintana). Do you agree with having different sign requirements in different business districts?

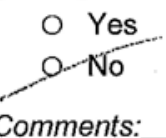

8. Are you happy with your current signage? Select one or more.

O Yes.

$\odot \mathrm{No}$, my sign(s) are too small

No, my signs can't be seen from the street

O No, my-signs are required to be placed too low where they are not visible

$\odot$ No, my sign's materials are inadequate

9. How important are commercial signs to your business's success?
O. Very important
O Important
O Not very important

10. Would you support "directional signs" (also known as wayfinding signs) on the Embarcadero? Directional signs are used to help residents and tourists navigate around cities. In this case, directional signs could be used on the Embarcadero to help tourists locate businesses.

Y Nes
O Noutral

11. If directional signs were implemented, what businesses should be featured on them?

0 All businesses should be featured on a directional sign

O Only businesses that are hidden from view should be featured on a directional sign

O Businesses should pay a fee to "rent" a spot on a directional sign

O Directional signs are a bad idea

O Other suggestions:

12. Please provide any additional comments about the sign ordinance or signs in general.

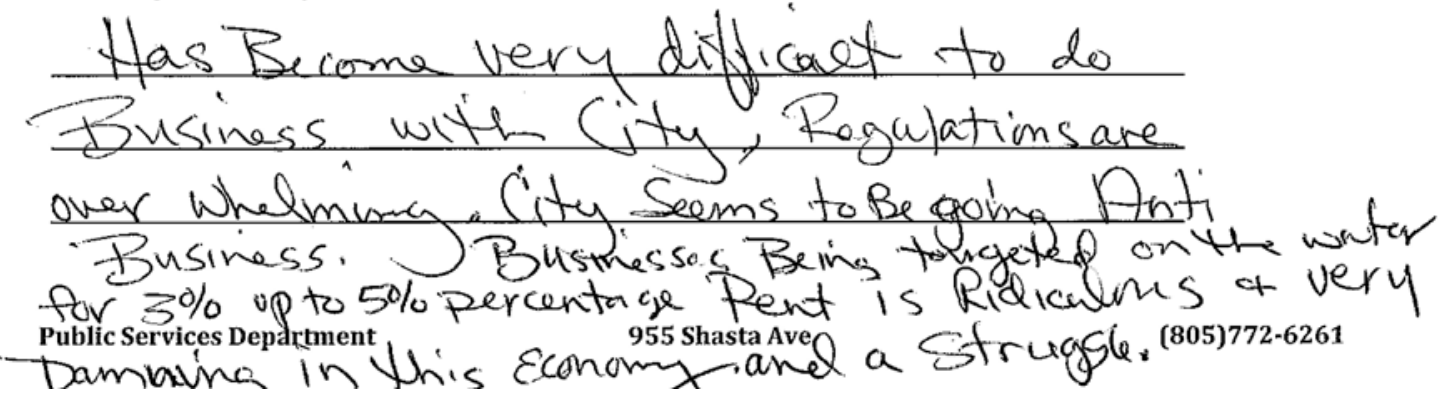


1. Do you think the current sign ordinance is user friendly and easy to understand?
RECEIVED
O Yes
No
MAR 282013

Comments:

2. How do you believe the City's sign code is applied?

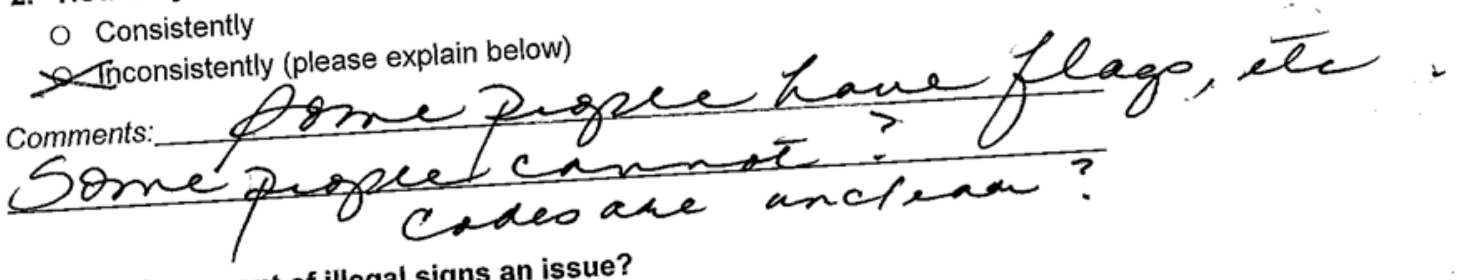

3. Is enforcement of illegal signs an issue?

O No

O Yes, there is not enough enforcement

Y. Yes, there is too much enforcement

O Yes, (please specify):

4. With respect to aesthetics, are you happy with the current signs in Morro Bay? Select

O Yes

O No, signs are too large

O No, signs are too small

- No, I don't like the materials most signs use

O No, too many signs

O No, signs are too tall

Qther (please specify): $N$ D.

We reed mone sigre

5. What changes to the sign code could

"other" box to offer additional ideas).

O Further restrict and
more consistency Relax regulations for illuminated signs

Allow ALL businesses to have more

more customers? Select one or more (usethe

signage

6. What types of signs (if any) do you believe degrade Morro Bay's community charac
more.

O Pole signs

O A-frame signs

O Window signs

O Wall signs

○ Flags and Banners

O Monument (freestanding) signs
CAllow A-frame signs

O Continue to prohibit A-frame signs

O Other (please specify):
O Internally illuminated signs

O Externally illuminated signs

- Awning signs

O Other (please specify): 
7. Previous City public meetings revealed a preference for having different sign requirements for different areas of town (e.g. North Morro Bay vs. Downtown vs. Embarcadero vs. Quintana). Do Y Yes

O No

Comments:

8. Are you happy with your current signage? Select one or more.

O Yes

O No, my sign(s) are too small

2. No, my signs can't be seen from the street

O No, my signs are required to be placed too low where they are not visible

O No, my sign's materials are inadequate

9. How important are commercial signs to your business's success?

$><$ Very important

O Important

O Not very important

10. Would you support "directional signs" (also known as wayfinding signs) on the Embarcadero? Directional signs are used to help residents and tourists navigate around cities. In this case, directional signs could be used on the Embarcadero to help tourists locate businesses.

\& Yes

O No

O. Neutral

11. If directional signs were implemented, what businesses should be featured on them? All businesses should be featured on a directional sign

O Only businesses that are hidden from view should be featured on a directional sign

O Businesses should pay a fee to "rent" a spot on a directional sign

O Directional signs are a bad idea

O Other suggestions:

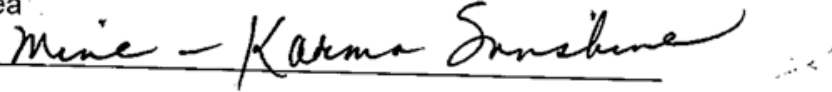

12. Please provide any additional comments about the sign ordinance or signs in general. 


\section{City of Morro Bay}

1. Do you think the current sign ordinance is user friendly and easy to understand?

(ब) Yes

O No

Comments:

\section{RECEIVED}

\section{MAR 282.013}

2. How do you believe the City's sign code is applied?

City of Morro Bay

(D) Consistently

Public Services Department

Inconsistently (please explain below)

Comments:

3. Is enforcement of illegal signs an issue?
$\varnothing$ No
O Yes, there is not enough enforcement
O Yes, there is too much enforcement
O Yes, (please specify):

4. With respect to aesthetics, are you happy with the current signs in Morro Bay? Select one or more.
C) Yes
O No, signs are too large
No signs are too small
No, I don't like the materials most signs use

O No, illumination is too bright

O No, too many signs

O No, signs are too tall

O Other (please specify):

5. What changes to the sign code could help you attract more customers? Select one or more (use the "other" box to offer additional ideas).
Further restrict and enforce signs to create more consistency
Relax regulations for illuminated signs
O Allow ALL businesses to have more signage
O Allow A-frame signs
$\varnothing$ Continue to prohibit A-frame signs
Other (please specify):

6. What types of signs (if any) do you believe degrade Morro Bay's community character? Select one or more.
O Pole signs
- A-frame signs
O Window signs
O Wall signs
O Flags and Banners
O Monument (freestanding) signs
O Digital (reader) signs
O Internally illuminated signs
O Externally illuminated signs
O Awning signs
O Other (please specify):

pg. 2 on back $\rightarrow$ 
7. Previous City public meetings revealed a preference for having different sign requirements for different areas of town (e.g. North Morro Bay vs. Downtown vs. Embarcadero vs. Quintana). Do you agree with having different sign requirements in different business districts?

$$
\begin{gathered}
\infty \text { Yes } \\
\text { O No }
\end{gathered}
$$

Comments:

8. Are you happy with your current signage? Select one or more.
$\varnothing$ Yes
O No, my sign(s) are too small
O No, my signs can't be seen from the street
O No, my signs are required to be placed too low where they are not visible
O No, my sign's materials are inadequate

9. How important are commercial signs to your business's success?
O Very important
$\varnothing$ Important
O Not very important

10. Would you support "directional signs" (also known as wayfinding signs) on the Embarcadero? Directional signs are used to help residents and tourists navigate around cities. In this case, directional signs could be used on the Embarcadero to help tourists locate businesses.

O Yes

O No

\& Neutral

11. If directional signs were implemented, what businesses should be featured on them?

O All businesses should be featured on a directional sign

Of Only businesses that are hidden from view should be featured on a directional sign
O Businesses should pay a fee to "rent" a spot on a directional sign
O Directional signs are a bad idea
Other suggestions:

12. Please provide any additional comments about the sign ordinance or signs in general. 
1. Do you think the current sign ordinance is user friendly and easy to undersfanco 2 EIVED Yes
O No

Comments

2. How do you believe the City's sign code is applied?

\& Consistently

Inconsistently (please explain below)

Comments:

3. Is enforcement of illegal signs an issue?

QNo

O Yes, there is not enough enforcement

O Yes, there is too much enforcement

O Yes, (please specify):

to aesthetics, are you happy with the current signs in Morro Bay? Select one or more. Q $Y$ es

O No, signs are too large

O No, signs are too small

O No, I don't like the materials most signs use

O No, illumination is too bright

O No, too many signs

O No, signs are too tall

O Other (please specify)

5. What changes to the sign code could

Further restrict and enforce signs to create more consistency - Relax regulations for illuminated signs Allow ALL businesses to have more
signage

O Continue to prohibit A-frame signs

6. What types of signs

any) do you believe degrade Morro Bay's community character? Select one or more.
O Pole signs
O A-frame signs
O Window signs
O Wall signs
O Flags and Banners
O Monument (freestanding) signs

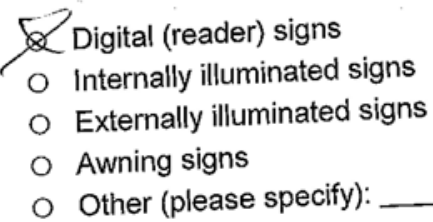

5 Digital (reader) signs

O Internally illuminated signs

O Externally illuminated signs

O Awning signs

O Other (please specify):

pg. 2 on back $\rightarrow$ 
7. Previous City public meetings revealed a preference for having different sign requirements for different areas of town (e.g. North Morro Bay vs. Downtown vs. Embarcadero vs. Quintana). Do you agree with having different sign requirements in different business districts?

ZYes

O No

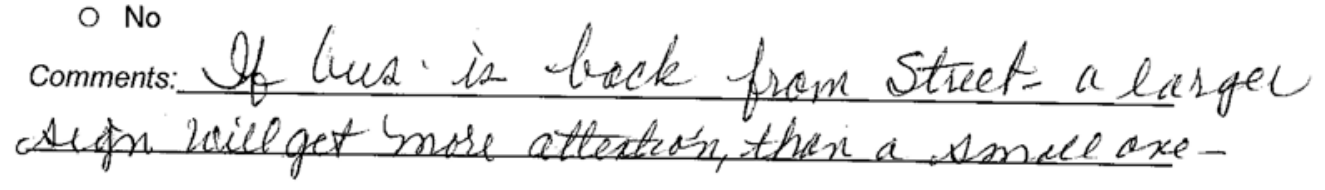

8. Are you happy with your current signage? Select one or more. \& Yes

O No, my sign(s) are too small

O No, my signs can't be seen from the street

O No, my signs are required to be placed too low where they are not visible

$O$ No, my sign's materials are inadequate

9. How important are commercial signs to your business's success?

Q Very important

O Important

O Not very important

10. Would you support "directional signs" (also known as wayfinding signs) on the Embarcadero? Directional signs are used to help residents and tourists navigate around cities. In this case, directional signs could be used on the Embarcadero to help tourists locate businesses.

O Yes

O No

-2 Neutral

11. If directional signs were implemented, what businesses should be featured on them?

All businesses should be featured on a directional sign

22 Only businesses that are hidden from view should be featured on a directional sign

O Businesses should pay a fee to "rent" a spot on a directional sign

O Directional signs are a bad idea

O Other suggestions:

12. Please provide any additional comments about the sign ordinance or signs in general.

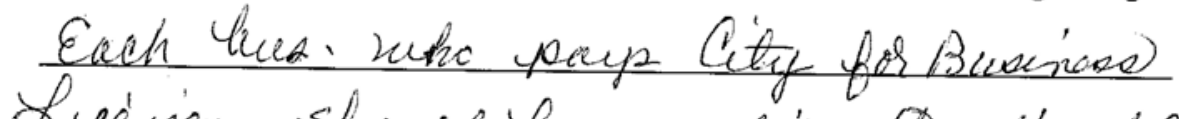

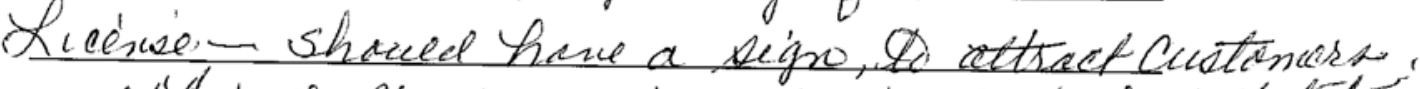

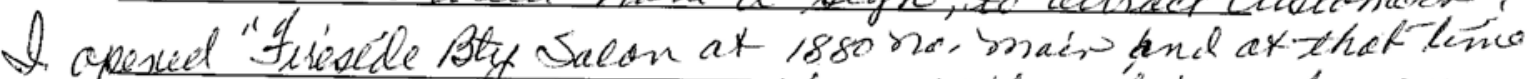

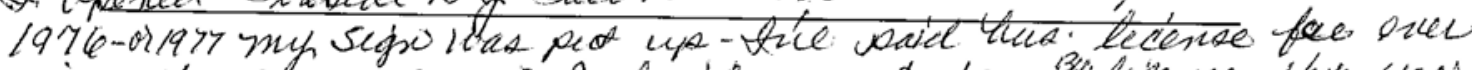

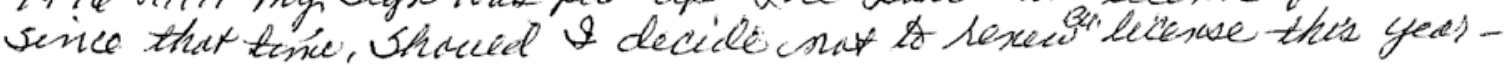

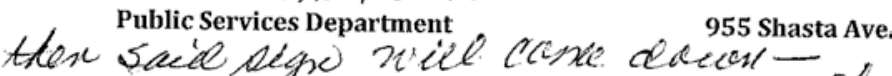

(805)772-6261

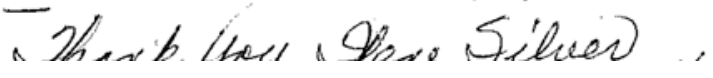


1. Do you think the current sign ordinance is user friendly and easy to understand?

( Yes

RECEIVED

O No

Comments:

MAR 272013

City of Morro Bay

Public Services Department

2. How do you believe the City's sign code is applied?

- Consistently

O Inconsistently (please explain below)

Comments:

3. Is enforcement of illegal signs an issue?
O No
- Yes, there is not enough enforcement
o Yes, there is too much enforcement
O Yes, (please specify):

4. With respect to aesthetics, are you happy with the current signs in Morro Bay? Select one or more.
- Yes
O No, illumination is too bright
O No, signs are too large
O No, too many signs
O No, signs are too small
O No, I don't like the materials most signs use
O No, signs are too tall makeis $\omega_{\text {Toun }}$

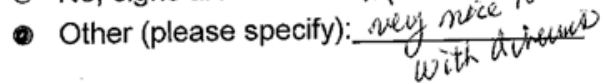

5. What changes to the sign code could help you attract more customers? Select one or more (use the "other" box to offer additional ideas).
F Further restrict and enforce signs to create more consistency
- Relax regulations for illuminated signs
Allow ALL businesses to have more signage

Allow A-frame signs

O Continue to prohibit A-frame signs

O Other (please specify):

6. What types of signs (if any) do you believe degrade Morro Bay's community character? Select one or more.
O Pole signs
A-frame signs
O Window signs
O Wall signs
- Flags and Banners
O Monument (freestanding) signs
O Digital (reader) signs
O Internally illuminated signs
O Externally illuminated signs
- Awning signs
O Other (please specify):

pg. 2 on back $\rightarrow$ 
7. Previous City public meetings revealed a preference for having different sign requirements for different areas of town (e.g. North Morro Bay vs. Downtown vs. Embarcadero vs. Quintana). Do you agree with having different sign requirements in different business districts?

- Yes

O No

Comments:

8. Are you happy with your current signage? Select one or more.

- Yes

No, my sign(s) are too small

No, my signs can't be seen from the street

O No, my signs are required to be placed too low where they are not visible

O No, my sign's materials are inadequate

9. How important are commercial signs to your business's success?

O Very important

- Important

O Not very important

10. Would you support "directional signs" (also known as wayfinding signs) on the Embarcadero? Directional signs are used to help residents and tourists navigate around cities. In this case, directional signs could be used on the Embarcadero to help tourists locate businesses.

O Yes

O No

- Neutral

11. If directional signs were implemented, what businesses should be featured on them?

O All businesses should be featured on a directional sign

- Only businesses that are hidden from view should be featured on a directional sign

O Businesses should pay a fee to "rent" a spot on a directional sign

O Directional signs are a bad idea

Other suggestions:

12. Please provide any additional comments about the sign ordinance or signs in general. 
1. Do you think the current sign ordinance is user friendly and easy to understand?

O Yes

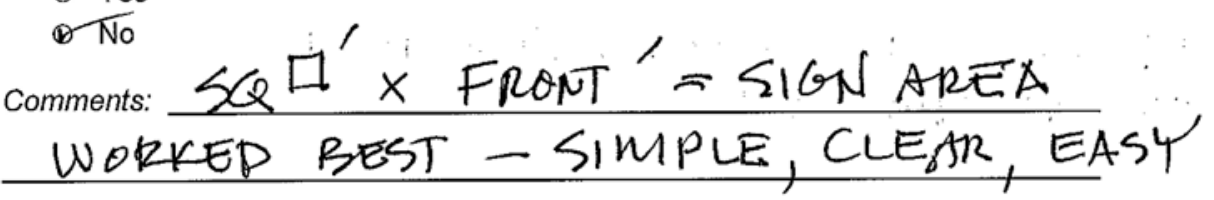

2. How do you believe the City's sign code is applied?

O Consistently

\ Inconsistently (please explain below)

\section{RECEIVED}

MAR 272013

City of Morro Bay

Rublic Services Department

3. Is enforcement of illegal signs an issue?
$\sigma$ No
O Yes, there is not enough enforcement
o Yes, there is too much enforcement
○ Yes, (please specify):

4. With respect to aesthetics, are you happy with the current signs in Morro Bay? Select one or more.
\& Yes
O No, illumination is too bright
O No, signs are too large
O No, too many signs
O No, signs are too small
O No, signs are too tall

O No, I don't like the materials most signs use CoURT 1996 DECISION. FESOM OF EXPRESSUN

5. What changes to the sign code could help you attract more customers? Select one or more (use the "other" box to offer additional ideas).

O Further restrict and enforce signs to create more consistency

O Allow A-frame signs

O Relax regulations for illuminated signs

O Continue to prohibit A-frame signs

O. Allow ALL businesses to have more signage

O Other (please specify): STAY WTHIN BEST FOR THEM, NOT SOME BUREAUCRAT THATS NEVER MADE

6. What types of signs (if any) do you believe degrade Morro Bay's community character? Select one or more.

O Pole signs

0 . A-frame signs

Who DETERMINES THIS WhAT and

Window signs

O Wall signs

O Digital (reader) signs

- Internally illuminated signs

O Flags and Banners

O Monument (freestanding) signs

O Externally illuminated signs

O Awning signs

O Other (please specify): 
7. Previous City public meetings revealed a preference for having different sign requirements for different areas of town (e.g. North Morro Bay vs. Downtown vs. Embarcadero vs. Quintana). Do you agree with having different sign requirements in different business districts?

$\varnothing$ Yes

O No

Comments: VISUAL MEEDS ARE DIFPEMENT IN
SECTIONS OF THE CITY

8. Are you happy with your current signage? Select one or more.

$\$$ Yes

O No, my sign(s) are too small

O No, my signs can't be seen from the street

O No, my signs are required to be placed too low where they are not visible

○o, my sign's materials are inadequate

9. How important are commercial signs to your business's success?

$\not$ Very important

O Important

O Not very important

10. Would you support "directional signs" (also known as wayfinding signs) on the Embarcadero? Directional signs are used to help residents and tourists navigate around cities. In this case, directional signs could be used on the Embarcadero to help tourists locate businesses.
$\ngtr$ Yes
O No
O Neutral

11. If directional signs were implemented, what businesses should be featured on them?

- All businesses should be featured on a directional sign

O Only businesses that are hidden from view should be featured on a directional sign

O Businesses should pay a fee to "rent" a spot on a directional sign

O Directional signs are a bad idea

O Other suggestions: SIMPLE, GENERIC ARER SIGNAGE BUSINESES SETANGE, ONGOING UPDATING BELONES

12. Please provide any additional comments about the sign ordinance or signs in general.

\section{ASK PROS WHAT WORKS. ASK RMSINESS}

$\therefore$ :GWNERS FOR NEEDS. REAL EXPERIENLE

COUNTS IN THE SIGN BUSINESS. OPINIONS ARE

ARGUEABLE... EXPERIENCE IS NOT.

$$
\text { SARY RYAN - } 772-5785
$$

Public Services Department 


\section{City of Morro Bay \\ Sign Ordinance Update - Business Survey}

1. Do you think the current sign ordinance is user friendly and easy to understand?

O Yes

- No

\section{RECEIVED}

Comments:

MAR 202013

City of Morro Bay

2. How do you believe the City's sign code is applied?

Public Services Department

- Consistently

- Inconsistently (please explain below)

Comments:

3. Is enforcement of illegal signs an issue?
O No
- Yes, there is not enough enforcement
- Yes, there is too much enforcement
o Yes, (please specify):

the current signs in Morro Bay? Select one or more.

4. With respect to aesthetics, are you happy with the current signs in Morro Bamination is too bright
O Yes
O No, too many signs
O No, signs are too large
O No, signs are too tall
O No, signs are too small
No, I don't like the materials most signs use
- Other (please specify): Som Brepen hoow so chepp !

more customers? Select one or more (use the

5. What changes to the sign code could

"other" box to offer additional ideas). more consistency

O Relax regulations for illuminated signs

Allow ALL businesses to have more signage

- Allow A-frame signs

Continue to prohibit A-frame signs

O Other (please specify):

6. What types of signs (if any) do you believe degrade Morro Bay's community character? Select one or more.

(2) Pole signs

A-frame signs

O Window signs

O Wall signs

(1) Flags and Banners

Monument (freestanding) signs

Digital (reader) signs

(1) Internaily illuminated signs

- Externally illuminated signs

O Awning signs
Other (please specify): Skinnfy Pole Fis pg. 2 on back $\rightarrow$ are
Wong 
7. Previous City public meetings revealed a preference for having different sign requirements for different areas of town (e.g. North Morro Bay vs. Downtown vs. Embarcadero vs. Quintana). Do you agree with having different sign requirements in different business districts?

O Yes

O No

Comments:

8. Are you happy with your current signage? Select one or more.
1) Yes
O No, my sign(s) are too small
O No, my signs can't be seen from the street
O No, my signs are required to be placed too low where they are not visible
O No, my sign's materiais are inadequate

9. How important are commercial signs to your business's success?
- Very important
O Important
O Not very important

10. Would you support "directional signs" (also known as wayfinding signs) on the Embarcadero? Directional signs are used to help residents and tourists navigate around cities. In this case, directional signs could be used on the Embarcadero to help tourists locate businesses.

- Yes

O No

O Neutral

11. If directional signs were implemented, what businesses should be featured on them?

- All businesses should be featured on a directional sign

O Only businesses that are hidden from view should be featured on a directional sign

O Businesses should pay a fee to "rent" a spot on a directional sign

O Directional signs are a bad idea

O Other suggestions:

12. Please provide any additional comments about the sign ordinance or signs in general.

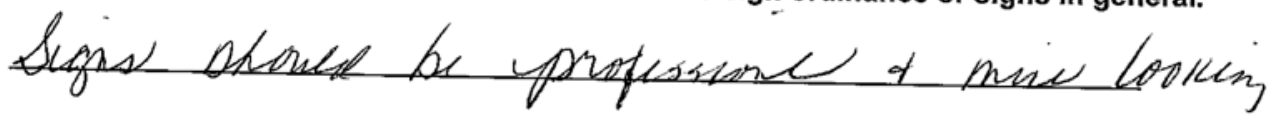




\section{City of Morro Bay}

Sign Ordinance Update - Business Survey

1. Do you think the current sign ordinance is user friendly and easy to understand?
$\varnothing$ Yes
RECEIVED
O No

HAR 222013

Comments:

try of Morro Bay

Public Services Department

2. How do you believe the City's sign code is applied?

O Consistently

¿ Inconsistently (please explain below)

comments: I see new businesses with for nore signaige

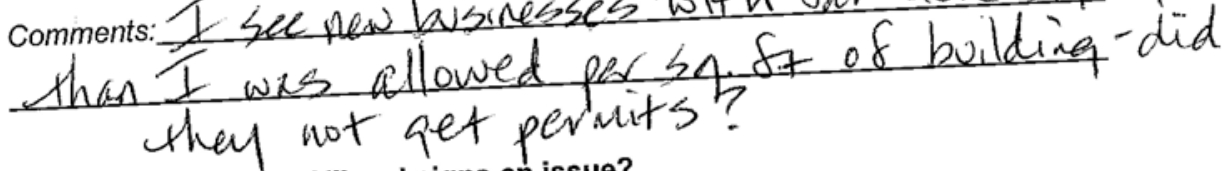

3. Is enforcement of illegal signs an issue?

O No

2 Yes, there is not enough enforcement

O Yes, there is too much enforcement

O Yes, (please specify):

are you happy with the current signs in Morro Bay? Select one or more.
O Yes
O No, signs are too large
O No, signs are too small
$\varnothing$ No, I don't like the materials most signs use

$$
\text { cheap tacky bualy }
$$

O No, illumination is too bright

5. What changes to the sign code could

"other" box to offer additional ideas)
- Further restrict and enforce signs to create more consistency
O Relax regulations for illuminated signs
O Allow A-frame signs
$\not$ Continue to prohibit A-frame signs

Q Allow ALL businesses to have more

O No, too many signs

O No, signs are too tall

Other (please specify)

6. What types of signs (if any) do you believe degrade Morro Bay's community character? Select one or more.

\&) Pole signs

ॠ A-frame signs

O Wall signs

O Flags and Banners

O Monument (freestanding) signs

O Digital (reader) signs

entive 10 Internally illuminated signs

O Awning signs

Other (please specify):

pg. 2 on back $\rightarrow$ 
7. Previous City public meetings revealed a preference for having different sign requirements for different areas of town (e.g. North Morro Bay vs. Downtown vs. Embarcadero vs. Quintana). Do you agree with having different sign requirements in different business districts?

$\varnothing$ Yes

O No

Comments

8. Are you happy with your current signage? Select one or more.
$\Varangle$ Yes.
O No, my sign(s) are too small
O No, my signs can't be seen from the street
No, my signs are required to be placed too low where they are not visible
O No, my sign's materials are inadequate

9. How important are commercial signs to your business's success?

$\infty$ Very important

O Important

Not very important

10. Would you support "directional signs" (also known as wayfinding signs) on the Embarcadero? Directional signs are used to help residents and tourists navigate around cities. In this case, directional signs could be used on the Embarcadero to help tourists locate businesses.

O Yes

$\otimes$ No

O Neutral

11. If directional signs were implemented, what businesses should be featured on them? * All businesses should be featured on a directional sign not just EMbrochdero businesses

O Only businesses that are hidden from view should be featured on a directional sign

O Businesses should pay a fee to "rent" a spot on a directional sign

O Directional signs are a bad idea

Other suggestions:

12. Please provide any additional comments about the sign ordinance or signs in general.

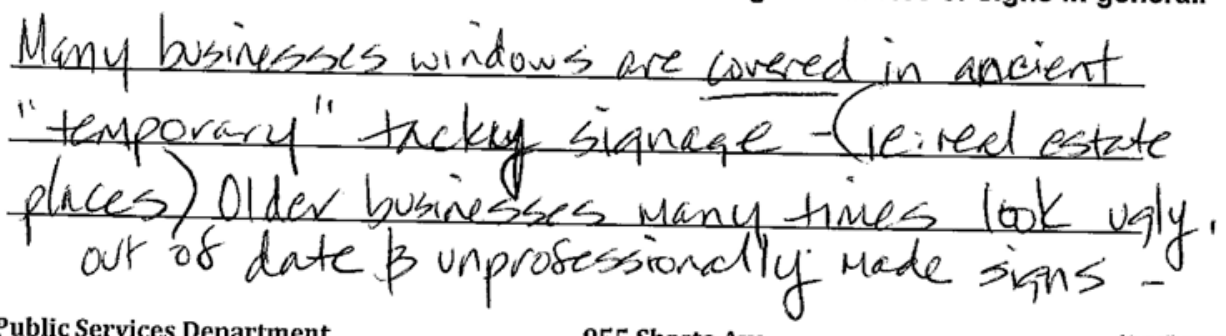

Public Services Department

955 Shasta Ave.

(805)772-6261 
28

City of Morro Bay

Sign Ordinance Update - Business Survey

1. Do you think the current sign ordinance is user friendly and easy to understand?

o Yes

KECEIVED

MAR 252013

Comments:

City of Morro Bay

Public Services Department

2. How do you believe the City's sign code is applied?

O Consistently

Inconsistently (please explain below)

Comments:

3. Is enforcement of illegal signs an issue?
O No
(1) Yes, there is not enough enforcement
O Yes, there is too much enforcement
O Yes, (please specify):

4. With respect to aesthetics, are you happy with the current signs in Morro Bay? Select one or more.
O Yes
(5) No, signs are too large
(1) No, illumination is too bright
O Mo, signs are too small
No, I don't like the materials most signs use
(1) No, too many signs
D. No; signs are too tall (please specify): Nel owe the
peve hue in mP

5. What changes to the sign code could help you attract more customers? Select one or more (use the "other" box to offer additional ideas).

(b) Further restrict and enforce signs to create more consistency

O Relax regulations for illuminated signs

O Allow ALL businesses to have more signage

- Allow A-frame signs

(1) Continue to prohibit A-frame signs

O Other (please specify):

6. What types of signs (if any) do you believe degrade Morro Bay's community character? Select one or more.

(1) Pole signs

(1) A-frame signs

(5) Window signs

d Wall signs

(1) Elags and Banners

$\Phi$ Monument (freestanding) signs

Digital (reader) signs

O Internally illuminated signs

(1) Externally illuminated signs

(1) Awning signs

O Other (please specify):

pg. 2 on back $\rightarrow$ 
7. Previous City public meetings revealed a preference for having different sign requirements for different areas of town (e.g. North Morro Bay vs. Downtown vs. Embarcadero vs. Quintana). Do you agree with having different sign requirements in different business districts?

O Yes

(1) No

Comments:

8. Are you happy with your current signage? Select one or more.

b. Yes

O No, my sign(s) are too small

O No, my signs can't be seen from the street

O No, my signs are required to be placed too low where they are not visible

O No, my sign's materials are inadequate

9. How jmportant are commercial signs to your business's success?

6) Very important

O Important

O Not very important

10. Would you support "directional signs" (also known as wayfinding signs) on the Embarcadero? Directional signs are used to help residents and tourists navigate around cities. In this case, directionalsigns could be used on the Embarcadero to help tourists locate businesses.
o Yes
(1) No

O Neutral

11. If directional signs were implemented, what businesses should be featured on them?

O All businesses should be featured on a directional sign

O Only businesses that are hidden from view should be featured on a directional sign

O Businesses should pay a fee to "rent" a spot on a directional sign

(1) Directional signs are a bas idea

12. Please provide any additional comments about the sign ordinance or signs in general.

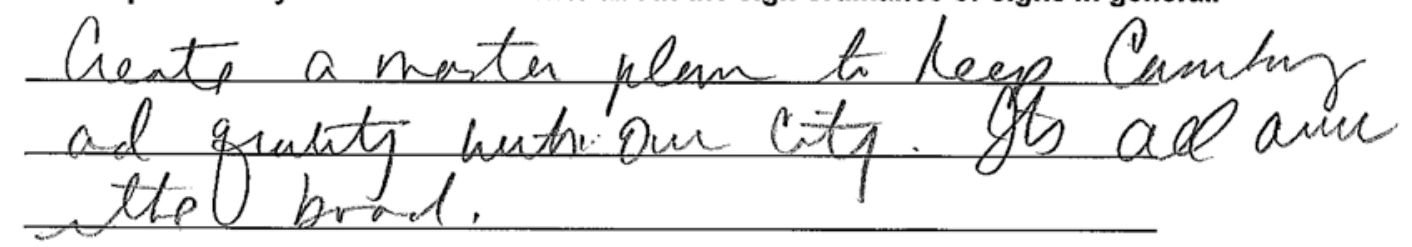

(805)772-6261 
sign ordinance is user friendly and easy to understand?

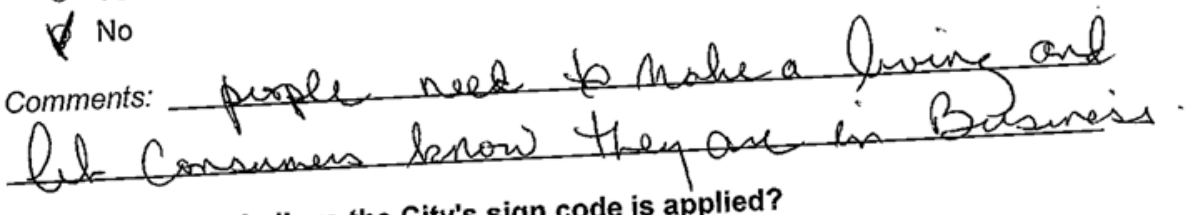

2. How do you believe the City's sign code is applied?

O Consistently

O Inconsistently (please explain below)

Comments:

3. Is enforcement of illegal signs an issue?

O No

O Yes, there is not enough enforcement

Yes, there is too much enforcement

○ Yes, (please specify):

4. With respect to aesthetics, are you happy with the current signs in Morro Bay? Select on
more Signso
No, too many signs
- No, signs are too large
O No, signs are too tall
O No, signs are too small
O No, I don't like the materials most signs use
O Other (please specify):

5. What changes to the sign code could
"Further restrict and enforce signs to create more consistency
O Relax regulations for illuminated signs
Allow ALL businesses to have more
signage
Allow A-frame signs
O Continue to prohibit A-frame signs
O Other (please specify):

O Pole signs

- A-frame signs

O Window signs

O Wall signs

O Flags and Banners

O Monument (freestanding) signs

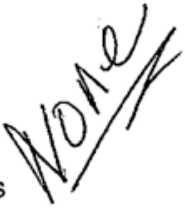

- Digital (reader) signs

O Internally illuminated signs

O Externally illuminated signs

O Awning signs

O Other (please specify): 
7. Previous City public meetings revealed a preference for having different sign requirements for different areas of town (e.g. North Morro Bay vs. Downtown vs. Embarcadero vs. Quintana). Do you agree with having different sign requirements in different business districts?

Comments: No
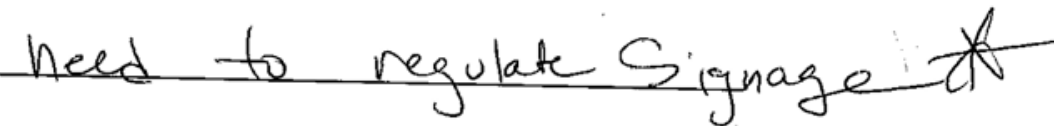

8. Are you happy with your current signage? Select one or more.

O Yes

No, my sign(s) are too small

O No, my signs can't be seen from the street

O No, my signs are required to be placed too low where they are not visible

O No, my sign's materials are inadequate

9. How important are commercial signs to your business's success?

Very important

O Important

O Not very important

10. Would you support "directional signs" (also known as wayfinding signs) on the Embarcadero? Directional signs are used to help residents and tourists navigate around cities. In this case, directional signs could be used on the Embarcadero to help tourists locate businesses.

Y Yes

$r_{O}$ No

O Neutral

11. If directional signs were implemented, what businesses should be featured on them?

A All businesses should be featured on a directional sign

$O$ Only businesses that are hidden from view should be featured on a directional sign

O Businesses should pay a fee to "rent" a spot on a directional sign

O Directional signs are a bad idea

O Other suggestions:

12. Please provide any additional comments about the sign ordinance or signs ingeneral.

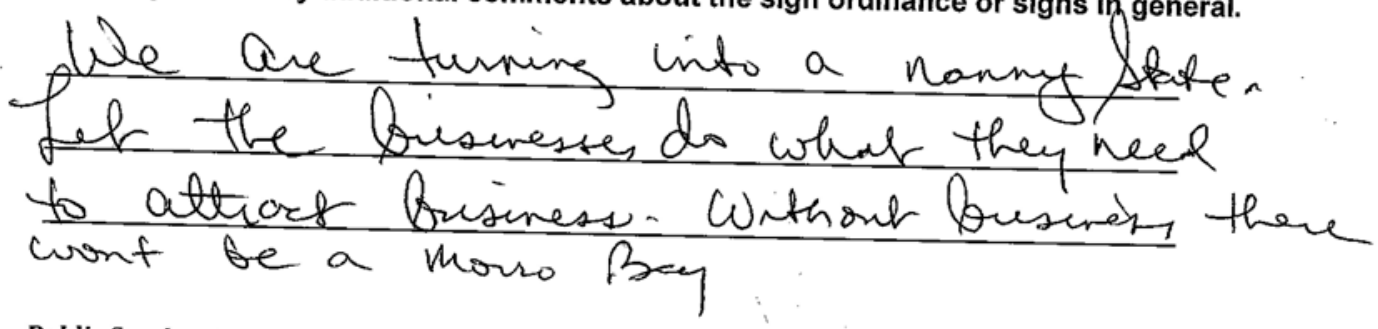

Public Services Department

955 Shasta Ave.

(805)772-6261 
1. Do you think the current sign ordinance is user friendly and easy to $4 \ln ^{2}$ derstand?
- Yes
City of Morro Bay
O No
Public Services Department

Comments:

2. How do you believe the City's sign code is applied?

O Consistently

- Inconsistently (please explain below)

Comments:

3. Is enforcement of illegal signs an issue?
O No
Y Yes, there is not enough enforcement
- Yes, there is too much enforcement
○ Yes, (please specify):

4. With respect to aesthetics, are you happy with the current signs in Morro Bay? Select one or more.
- Yes
O No, illumination is too bright
O No, signs are too large
O No, too many signs
O No, signs are too small
O No, signs are too tall
O No, I don't like the materials most signs use
O Other (please specify):

5. What changes to the sign code could help you attract more customers? Select one or more (use the "other" box to offer additional ideas).

F Further restrict and enforce signs to create more consistency

- Allow A-frame signs

- Relax regulations for illuminated signs

- Continue to prohibit A-frame signs

O Allow ALL businesses to have more

O Other (please specify):

6. What types of signs (if any) do you believe degrade Morro Bay's community character? Select one or more.
Pole signs
O A-frame signs
Window signs
O Wall signs
O Flags and Banners
O Monument (freestanding) signs

O Digital (reader) signs

O Internally illuminated signs

O Externally illuminated signs

O Awning signs

- Other (please specify): Nole

pg. 2 on back $\rightarrow$ 
7. Previous City public meetings revealed a preference for having different sign requirements for different areas of town (e.g. North Morro Bay vs. Downtown vs. Embarcadero vs. Quintana). Do you agree with having different sign requirements in different business districts?

- Yes

O No

Comments:

8. Are you happy with your current signage? Select one or more.

O Yes

- No, my sign(s) are too small

- No, my signs can't be seen from the street

O No, my signs are required to be placed too low where they are not visible

O No, my sign's materials are inadequate

9. How important are commercial signs to your business's success?

O Very important

- Important

O Not very important

10. Would you support "directional signs" (also known as wayfinding signs) on the Embarcadero? Directional signs are used to help residents and tourists navigate around cities. In this case, directional signs could be used on the Embarcadero to help tourists locate businesses.
O Yes
- No
O Neutral

11. If directional signs were implemented, what businesses should be featured on them?

O All businesses should be featured on a directional sign

O Only businesses that are hidden from view should be featured on a directional sign

O Businesses should pay a fee to "rent" a spot on a directional sign

- Directional signs are a bad idea

O Other suggestions:

12. Please provide any additional comments about the sign ordinance or signs in general. 


\section{City of Morro Bay}

Sign Ordinance Update - Business Survey

1. Do you think the current sign ordinance is user friendly and easy to understand?

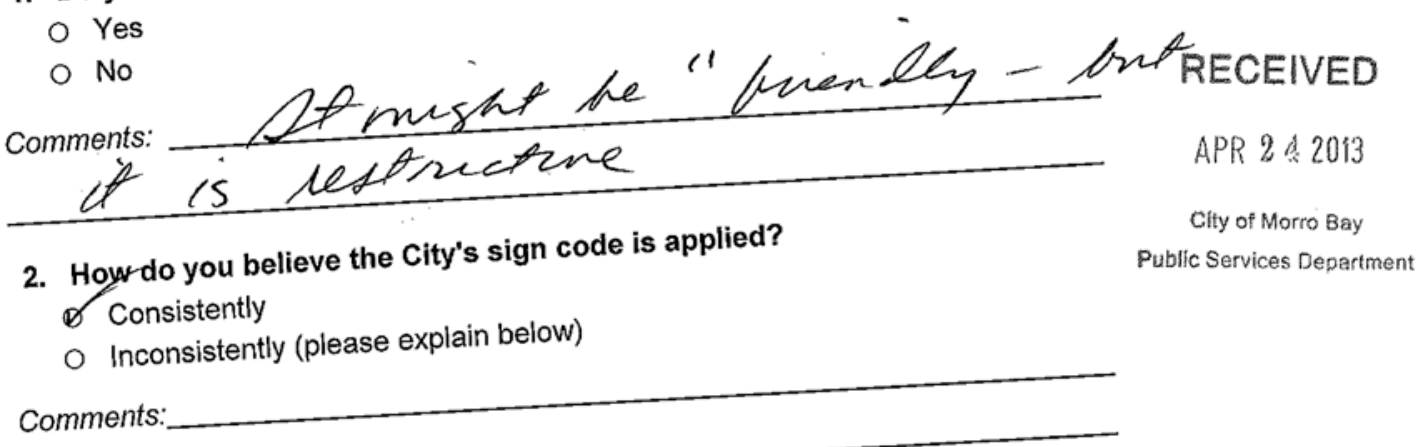

3. Is enforcement of illegal signs an issue?

(2) No

O Yes, there is not enough enforcement

Yes, there is too much enforcement

O Yes, (please specify):

4. With respect to aesthetics, are you happy with the current signs in Morro Bay? Select ond

O Yes

O No, too many signs

O No, signs are too large

O No, signs are too small No, I don't like the materials most signs use What changes to the sign code could hitional ideas) "other" box to offer additional ideas).

Further restrict and enforce signs to create hrore consistency

- Relax regulations for illuminated signs

- Allow ALL businesses to have more signage
Q. Allow A-frame signs
- Continue to prohibit A-frame signs
Other (please specify):

6. What typ
O Pole signs
O A-frame signs
O Window signs
O Wall signs
O Flags and Banners
- Monument (freestanding) signs
O Digital (reader) signs
O Internally illuminated signs
O Externally illuminated signs
of Awning signs pigns pg. 2 on back $\rightarrow$


7. Previous City public meetings revealed a preference for having different sign requirements for different areas of town (e.g. North Morro Bay vs. Downtown vs. Embarcadero vs. Quintana). Do Yes

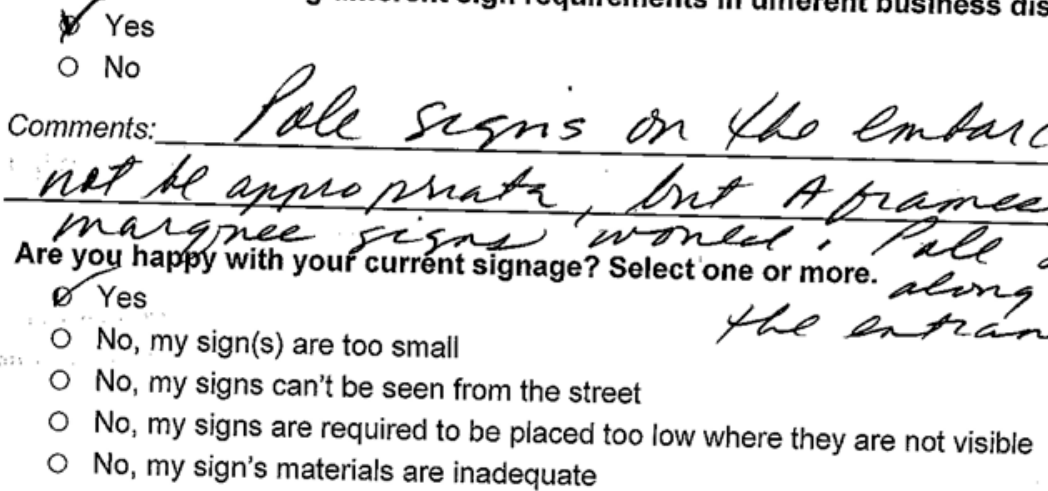

9. How important are commercial signs to your business's success?

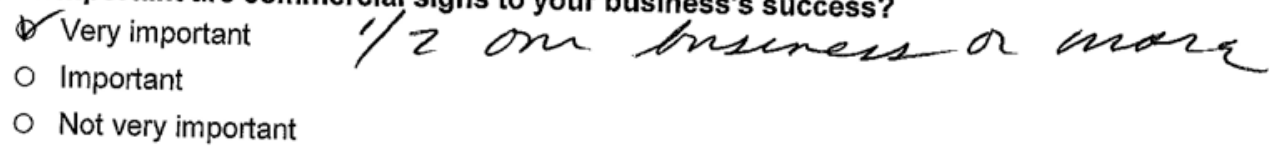

10. Would you support "directional signs" (also known as wayfinding signs) on the Embarcadero? Directional signs are used to help residents and tourists navigate around cities. In this case, 10 Yes

O No

O Neutral

11. If directional signs were implemented, what businesses should be featured on them?

O All businesses should be featured on a directional sign

O Only businesses that are hidden from view should be featured on a directional sign

O Businesses should pay a fee to "rent" a spot on a directional sign

D Directional signs are a bad idea

O Other suggestions:

$$
\text { ad idea }
$$

$$
\text { el coolsaing/ Pounts }
$$

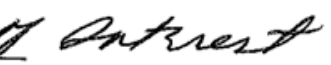

12. Please provide any additional comments about the sign ordinance or signs in general.

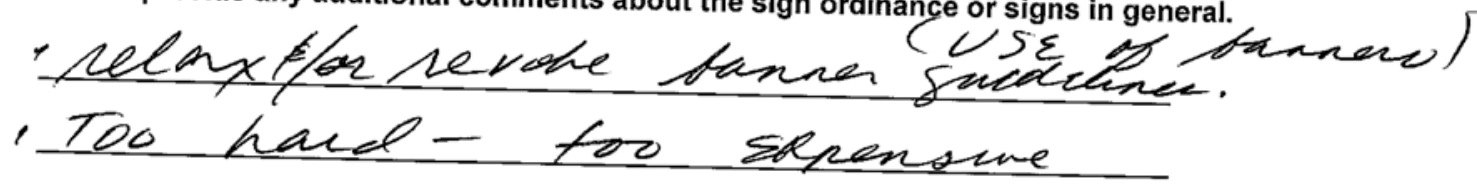


32

City of Morro Bay

Sign Ordinance Update - Business Survey

1. Do you think the current sign ordinance is user friendly and easy to understand?

Yes

RECEIVED

O No

MAR 252013

Comments:

City of Morro Bay

Public Services Department

2. How do you believe the City's sign code is applied?

- Consistently

\Inconsistently (please explain below)

comments: savetumes unareed

sametwmes wot

3. Is enforcement of illegal signs an issue?

O No

O Yes, there is not enough enforcement

Yes, there is too much enforcement

O Yes, (please specify):

4. With respect to aesthetics, are you happy with the current signs in Morro Bay? Select one or more.

O Yes

O No, signs are too large

O No, illumination is too bright

\% No, signs are too small

O No, I don't like the materials most signs use

O No, too many signs

O No, signs are too tall

O Other (please specify)

5. What changes to the sign code could help you attract more customers? Select one or more (use the "other" box to offer additional ideas).

O Further restrict and enforce signs to create more consistency

- Relax regulations for illuminated signs

Allow ALL businesses to have more signage

QXAllow A-frame signs

O Continue to prohibit A-frame signs

O Other (please specify):

6. What types of signs (if any) do you believe degrade Morro Bay's community character? Select one or more.
O Pole signs
O A-frame signs
O Window signs
O Wall signs
Flags and Banners
Oonument (freestanding) signs

O Digital (reader) signs

O Internally illuminated signs

O Externally illuminated signs

O Awning signs

O Other (please specify): Wowe

pg. 2 on back $\rightarrow$ 
7. Previous City public meetings revealed a preference for having different sign requirements for different areas of town (e.g. North Morro Bay vs. Downtown vs. Embarcadero vs. Quintana). Do you agree with having different sign requirements in different business districts?

क. Yes

O No

Comments:

8. Are you happy with your current signage? Select one or more.

O Yes

No, my sign(s) are too small

No, my signs can't be seen from the street

O No, my signs are required to be placed too low where they are not visible

O No, my sign's materials are inadequate

9. How important are commercial signs to your business's success?

$\$$ Very important

O Important

O Not very important

10. Would you support "directional signs" (also known as wayfinding signs) on the Embarcadero? Directional signs are used to help residents and tourists navigate around cities. In this case, directional signs could be used on the Embarcadero to help tourists locate businesses.

Q Yes

O No

O Neutral

11. If directional signs were implemented, what businesses should be featured on them?

O All businesses should be featured on a directional sign

$O$ Only businesses that are hidden from view should be featured on a directional sign

Businesses should pay a fee to "rent" a spot on a directional sign

O Directional signs are a bad idea

O Other suggestions:

12. Please provide any additional comments about the sign ordinance or signs in general.

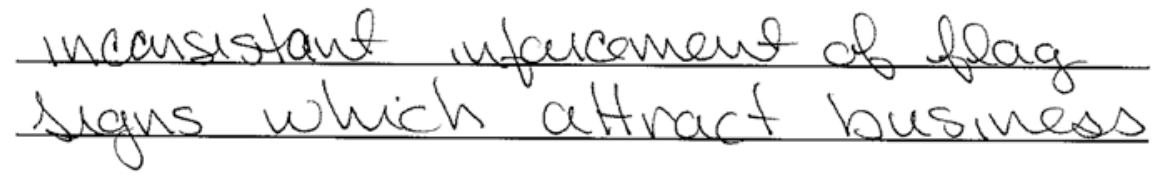


31

City of Morro Bay

Sign Ordinance Update - Business Survey

1. Do you think the current sign ordinance is user friendly and easy to understand?
O Yes
MAR 252013
O No
City of Morro Bay

Comments:

Have not used euttic Services Department

2. How do you believe the City's sign code is applied?

O Consistently

$\otimes$ Inconsistently (please explain below)

Comments:__ Just drive down the Embarcadero.......

3. Is enforcement of illegal signs an issue?

O No

$\otimes$ Yes, there is not enough enforcement

o Yes, there is too much enforcement

Yes, (please specify): Example: 571 Embarcadero-there are over 16 signs on one small lease site. Even the Pub signs are probably over size.

4. With respect to aesthetics, are you happy with the current signs in Morro Bay? Select one or more.
O Yes
O No, signs are too large
O No, signs are too small
O No, I don't like the materials most signs use part signs are okey; there should be variety.

O No, illumination is too bright

O No, too many signs

O No, signs are too tall

$\varnothing$ Other (please specify): For the most

5. What changes to the sign code could help you attract more customers? Select one or more (use the "other" box to offer additional ideas).

O Further restrict and enforce signs to create more consistency

Relax regulations for illuminated signs

- Allow ALL businesses to have more signage

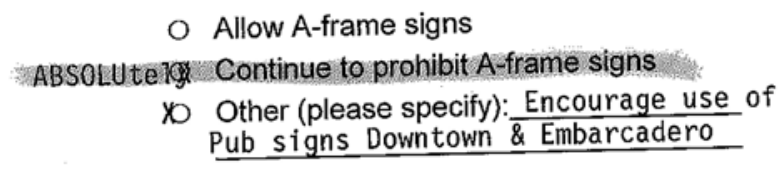

6. What types of signs (if any) do you believe degrade Morro Bay's community character? Select one or more.
O Pole signs
$\bowtie$ A-frame signs
O Digital (reader) signs
$\otimes$ Window signs should be off when business is closed
O Wall signs
Internally illuminated signs when chusiness
$\bowtie$ Flags and Banners
O Awning signs
O Other (please specify):

O Monument (freestanding) signs

pg. 2 on back $\rightarrow$ 
7. Previous City public meetings revealed a preference for having different sign requirements for different areas of town (e.g. North Morro Bay vs. Downtown vs. Embarcadero vs. Quintana). Do you agree with having different sign requirements in different business districts?

$\otimes$ Yes

O No

Comments: North Morro Bay \& Quintana should be the same (larger signs, lit?

Downtown \& Embarcadero thessame,but,smaller size, Pub signs?

8. Are you happy with your current signage? Select one or more.
$\$$ Yes
O No, my sign(s) are too small
O No, my signs can't be seen from the street
O No, my signs are required to be placed too low where they are not visible
O No, my sign's materials are inadequate

9. How important are commercial signs to your business's success?
ぬ Very important
New business really need signs.
O Important
O Not very important

10. Would you support "directional signs" (also known as wayfinding signs) on the Embarcadero? Directional signs are used to help residents and tourists navigate around cities. In this case, directional signs could be used on the Embarcadero to help tourists locate businesses.
O Yes
O No
d Neutral

11. If directional signs were implemented, what businesses should be featured on them?

O All businesses should be featured on a directional sign

O Only businesses that are hidden from view should be featured on a directional sign

$\alpha$ Businesses should pay a fee to "rent" a spot on a directional sign

O Directional signs are a bad idea

Other suggestions:

12. Please provide any additional comments about the sign ordinance or signs in general.

Canvas signs tied on venicles, front \& back, parked on public streets should be banned and ticketed immediately. There is nothing that looks more taky than this form of advertising, i.e. 500 block of the Embarcadero. 


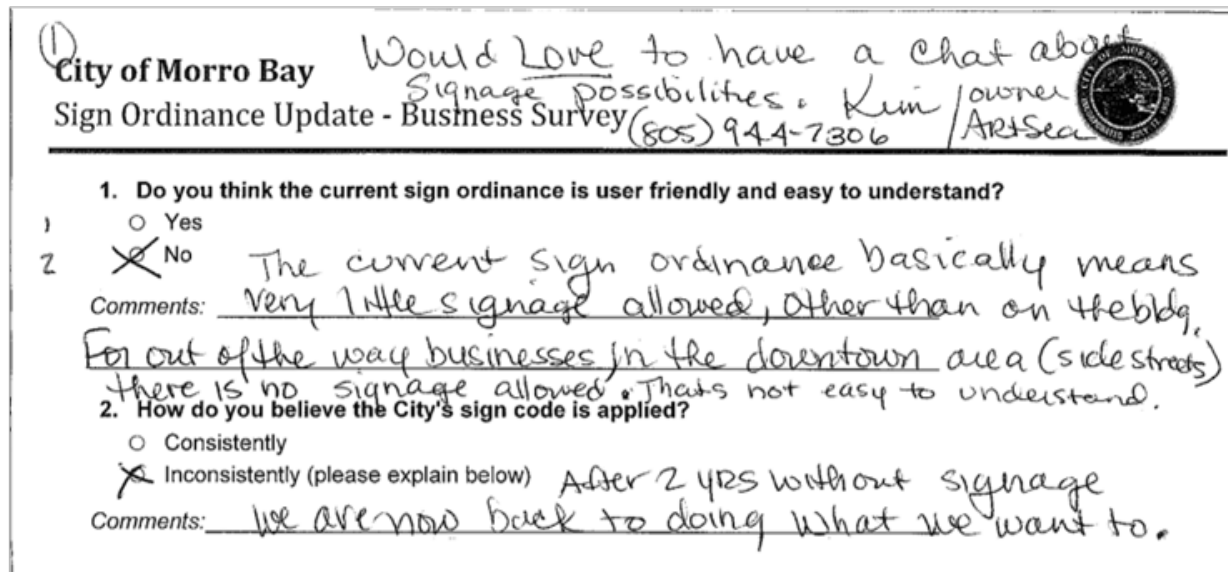

3. Is enforcement of illegal signs an issue?

* No There is no enforement at this timerECEIVED

O Yes, there is not enough enforcement

o Yes, there is too much enforcement

Y Yes, (please specify)

4. With respect to aesthetics, are you happy with the current signs in Morro Bay? Select one or more.
\&Yes city signs
O No, signs are too large
No, illumination is too bright
No, signs are too small-Business shop sighs 0 No, signs are too tall

O No, I don't like the materials most signs use $\quad$ Other (please specify):

5. What changes to the sign code could help you attract more customers? Select one or more (use the "other" box to offer additional ideas).

Further restrict and enforce signs to create more consistency

Allow A-frame signs

- Relax regulations for illuminated signs $\quad$ Continue to prohibit A-frame signs

- Allow ALL businesses to have more

Other (please specify). Ild like to $\cdot \frac{5}{3}$ signage See signage that is eneatuve artistic unique $\vec{s}$ for the businesses, yet heid up to a bigh standardof or

6. What types of signs (if any) do you believe degrade Morro Bay's community character? Select one or more.

○ Pole signs

A-frame signs

O Window signs

O Wall signs

$\varnothing$ Flags and Banners

Monument (freestanding) signs

Digital (reader) signs

Q Internally illuminated signs

$\not$ Externally illuminated signs

- Awning signs

O Other (please specify) 
7. Previous City public meetings revealed a preference for having different sign requirements for different areas of town (e.g. North Morro Bay vs. Downtown vs. Embarcadero vs. Quintana). Do you agree with having different sign requirements in different business districts?

$$
\text { \& Yes example ArtSea (2) } 76 \text { mavivist. }
$$

comments: Also downtom has Rery Diran.

comments: Also, downtoon has side streets where small businesses constantly fail. These areas need addotonal signs

8. Are you happy with your current signage? Select one or more.

○ Yes

No, my sign(s) are too small

No, my signs can't be seen from the stre

opper halt of bidg a cais

- No, my sign's materials are inadequate

9. How important are commercial signs trateic eíthere

$$
\begin{aligned}
& \text { trathid eithere } \\
& \text { Hew important are commercial signs to your business's success? }
\end{aligned}
$$

O Important

- Not very important

10. Would you support "directional signs" (also known as wayfinding signs) on the Embarcadero? directional signs could be used residents and tourists navigate around cities. In this case, directional signs could be used on the Embarcadero to help tourists locate businesses.

Q. Yes - dorentown

$$
\text { \& No Waste of timed resources. (embarcaderi) }
$$

11. If directional signs were implemented, what businesses should be featured on them?

All businesses should be featured on a directional sign

O Only businesses that are hidden from view should be featured on a directional sign

- Businesses should pay a fee to "rent" a spot on a directional sign

O Directional signs are a bad idea

- Other suggestions: Because 'downtown' is so spread out 12. Please provide any additional comments about the sign ordinance or signs in 4 SO be cause doontowh is not requiated with designated furpose (such refail). Id like to see clever signage with a varefical flavor to both qive MB. Chalacter as a whole and create a"gublic aut" aspeet. For example, my shop Artsea uses $\begin{array}{ll}\text { Public Services Department } 955 \text { Shasta Ave. } & \text { (805)772-6261 }\end{array}$ the Cambria Scarecrowhermaid as my signage and I pken 

Would Love to have a chat alog
Signage posscbilites. Lin owner
Sign Ordinance Update-Bustness Survey $(805) 944-7306$ Sign Ordinance Update - Business Survey (805) 944-7306

1. Do you think the current sign ordinance is user friendly and easy to understand?

1 O Yes

2 No The current sign ordinance basically means comments: very 1 Alle signage allowed, other than on thebleq. For out of the way businesses in the downtown are a (side streets)

there is no signage allowed Thats not easy to understand. 2. How do you believe the City's sign code is applied?

O Consistently

Y Inconsistently (please explain below) Adter 2 yrs with out sighage comments: We are now back to doing what we want to.

3. Is enforcement of illegal signs an issue?
\& No There is no enforement at this fimerecEIVED
O Yes, there is not enough enforcement
O Yes, there is too much enforcement
APR 082013
O Yes, (please specify):
City of Morro Bay
Public Services Department

4. With respect to aesthetics, are you happy with the current signs in Morro Bay? Select one or more.
\& Yes city signs
O No, illumination is too bright
O No, signs are too large
O No, too many signs
* No, signs are too small-Bustress shop signs
No, signs are too tall
O No, I don't like the materials most signs use
O Other (please specify)

5. What changes to the sign code could help you attract more customers? Select one or more (use the "other" box to offer additional ideas).

F Further restrict and enforce signs to create more consistency

O Relax regulations for illuminated signs

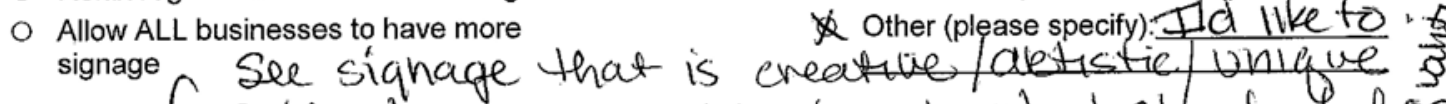
for the businesses, yet held up to a bigh standard of oo

6. What types of signs (if any) do you believe degrade Morro Bay's community character? Select one or more.
O Pole signs
O A-frame signs
O Window signs
O Wall signs
$\$$ Flags and Banners
O Monument (freestanding) signs

Digital (reader) signs
$\$$ Internally illuminated signs
$\$$ Externally illuminated signs
Awning signs
0 Other (please specify):

pg. 2 on back $\rightarrow$ 
7. Previous City public meetings revealed a preference for having different sign requirements for different areas of town (e.g. North Morro Bay vs. Downtown vs. Embarcadero vs. Quintana). Do you agree with having different sign requirements in different business districts?

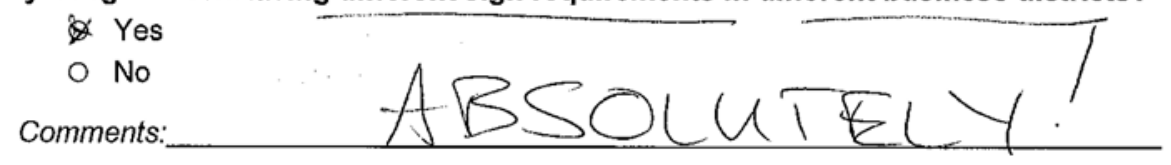

8. Are you happy with your current signage? Select one or more.

O Yes

O No, my sign(s) are too small

O No, my signs can't be seen from the street

O No, my signs are required to be placed too low where they are not visible

O No, my sign's materials are inadequate

7 USMALLY DOMBLE MY BOSINESS WiteN a PUT MY \&IDEUAL \&IGN OXT.

9. How important are commercial signs to your business's success?

$\$$ Very important

O Important

Not very important

10. Would you support "directional signs" (also known as wayfinding signs) on the Embarcadero? Directional signs are used to help residents and tourists navigate around cities. In this case, directional signs could be used on the Embarcadero to help tourists locate businesses.

\&) Yes

O No

O Neutral

11. If directional signs were implemented, what businesses should be featured on them? O. All businesses should be featured on a directional sign

QC. Only businesses that are hidden from view should be featured on a directional sign

\& Businesses should pay a fee to "rent" a spot on a directional sign

0 Directional signs are a bad idea

o Other suggestions: I wonld let Eubarcadero businesses decide this- elearly invisible businesses have a greaber

12. Please provide any additional comments about the sign ordinance or signs in general.

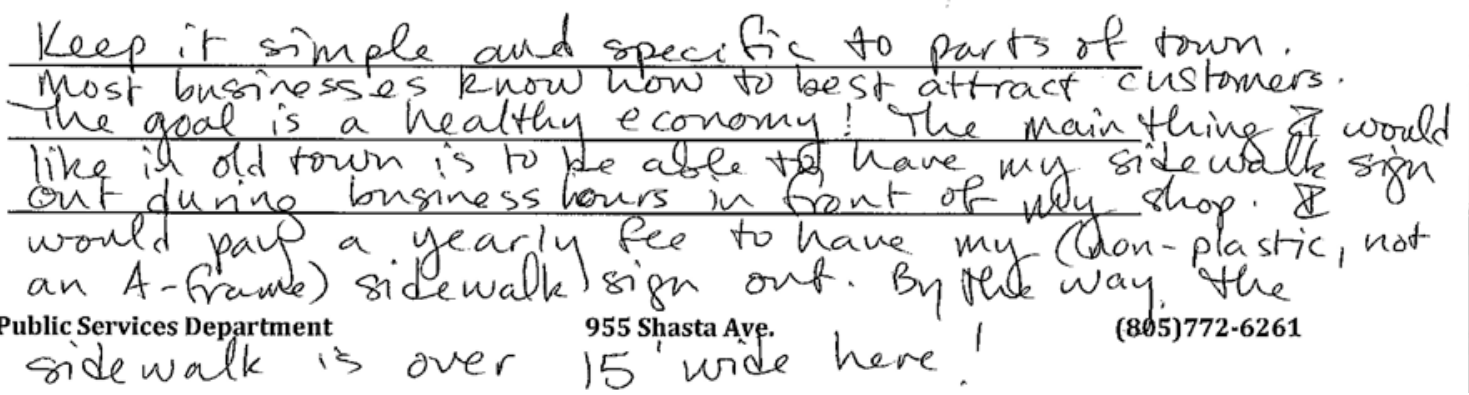




\section{City of Morro Bay}

\section{Sign Ordinance Update - Business Survey}

1. Do you think the current sign ordinance is user friendly and easy to understand?

O Yes

O No

Comments: Not fam:liar with it

2. How do you believe the City's sign code is applied?

O Consistently

Inconsistently (please explain below)

Comments:

Not enough information to have an opinion

3. Is enforcement of illegal signs an issue?
O No
O Yes, there is not enough enforcement
O Yes, there is too much enforcement
O Yes, (please specify):

4. With respect to aesthetics, are you happy with the current signs in Morro Bay? Select one or more.
- Yes
O No, illumination is too bright
O No, signs are too large
O No, too many signs
O No, signs are too small
O No, signs are too tall
O No, I don't like the materials most signs use
O Other (please specify):

5. What changes to the sign code could help you attract more customers? Select one or more (use the "other" box to offer additional ideas).

O Further restrict and enforce signs to create more consistency

O Allow A-frame signs

O Relax regulations for illuminated signs

- Continue to prohibit A-frame signs

O Allow ALL businesses to have more

- Other (please specify): signage

some business'es need more signage than othars. i.e. tourisr/highway travelers destivations need bigger, tallersigns than a" local "lousiness.

6. What types of signs (if any) do you believe degrade Morro Bay's community character? Select one or more.
O Pole signs
- A-frame signs
- Window signs
O Wall signs
- Flags and Banners
O Monument (freestanding) signs

O Digital (reader) signs

O Internally illuminated signs

O Externally illuminated signs

O Awning signs

O Other (please specify):

pg. 2 on back $\rightarrow$ 
7. Previous City public meetings revealed a preference for having different sign requirements for different areas of town (e.g. North Morro Bay vs. Downtown vs. Embarcadero vs. Quintana). Do you agree with having different sign requirements in different business districts?

- Yes

O No

Comments:

8. Are you happy with your current signage? Select one or more.

O Yes

- No, my sign(s) are too small

No, my signs can't be seen from the street

- No, my signs are required to be placed too low where they are not visible

O No, my sign's materials are inadequate

9. How important are commercial signs to your business's success?

- Very important

O Important

O Not very important

10. Would you support "directional signs" (also known as wayfinding signs) on the Embarcadero? Directional signs are used to help residents and tourists navigate around cities. In this case, directional signs could be used on the Embarcadero to help tourists locate businesses.
- Yes
O No
O Neutral
Tourists contribute tax dollars, helping them navigate
helps us all.

11. If directional signs were implemented, what businesses should be featured on them?

O All businesses should be featured on a directional sign

O Only businesses that are hidden from view should be featured on a directional sign

O Businesses should pay a fee to "rent" a spot on a directional sign

O Directional signs are a bad idea

O Other suggestions:

$$
\text { Good guestion! }
$$

12. Please provide any additional comments about the sign ordinance or signs in general.

$$
\begin{aligned}
& \text { Easy to read signs that are large enough for an aging popiation } \\
& \text { to read and re-act to drises revenue and tax collections. }
\end{aligned}
$$




\title{
City of Morro Bay \\ Sign Ordinance Update - Business Survey
}

The City of Morro Bay is in the process of updating their current sign ordinance. Erik Berg-Johansen, Cal Poly City and Regional Planning graduate student, is assisting the City wiect.
Master's project

When updating a city ordinance it is important that the public has the opportunity to voice their opinions. Past community outreach has been conducted, how the process.

business owners to ensure that they are

Please take a few minutes to fill out the attached survey. Completed

\section{Public Services Department} 955 Shasta Ave.

Morro Bay, CA 93442

\section{RECEIVED}

\author{
APR 082013 \\ City of Morro Bay \\ Public Services Department
}

If you would prefer to fill this survey out online, please access the following link:
www.surveymonkey.com/s/morrobaybusinessowners

If you have any other questions, please email Erik Berg-Johansen at:

eberg-johansen@morro-bay.ca.us

Public Services Department

955 Shasta Ave.

(805)772-6261 
A-173 


\section{City of Morro Bay}

Sign Ordinance Update - Business Survey

1. Do you think the current sign ordinance is user friendly and easy to understand?

Yes

O No

Comments:

2. How do you believe the City's sign code is applied?

Consistently

O Inconsistently (please explain below)

\section{RECEIVED}

$$
\text { APR } 042013
$$

City of Morro Bay

Public Services pepartment

Comments:

3. Is enforcement of illegal signs an issue?
$\Phi$ No
Yes, there is not enough enforcement
O Yes, there is too much enforcement
○ Yes, (please specify):

4. With respect to aesthetics, are you happy with the current signs in Morro Bay? Select one
Yes
- No, signs are too large
O No, signs are too small
- No, I don't like the materials most signs use

o No, too many signs

O No, signs are too tall

O Other (please specify):

5. What changes to the sign code could
O Further restrict and enforce signs to create more consistency
O Relax regulations for illuminated signs
A Allow ALL businesses to have more

6. What types of signs (if any) do you
more.
O Pole signs
O A-frame signs
O Window signs
O Wall signs
O Flags and Banners
O Monument (freestanding) signs

anding) signs

$\varnothing$ Allow A-frame signs

O Continue to prohibit A-frame signs

O Other (please specify):
- Digital (reader) signs
O Internally illuminated signs
O Externally illuminated signs
O Awning signs
Other (please specify):

pg. 2 on back $\rightarrow$ 
7. Previous City public meetings revealed a preference for having different sign requirements for different areas of town (e.g. North Morro Bay vs. Downtown vs. Embarcadero vs. Quintana). Do you agree with having different sign requirements in different business districts?

O Yes

$\$$ No

Comments:

8. Are you happy with your current signage? Select one or more.
- Yes
O No, my sign(s) are too small
O No, my signs can't be seen from the street
O No, my signs are required to be placed too low where they are not visible
O No, my sign's materials are inadequate

9. How important are commercial signs to your business's success?
$\otimes$ Very important
O Important
O Not very important

10. Would you support "directional signs" (also known as wayfinding signs) on the Embarcadero? directional signs could be used residents and tourists navigate around cities. In this case,
Y Yes
O No
O Neutral

11. If directional signs were implemented, what businesses should be featured on them?
- All businesses should be featured on a directional sign
O Only businesses that are hidden from view should be featured on a directional sign
O Businesses should pay a fee to "rent" a spot on a directional sign
O Directional signs are a bad idea
O Other suggestions:

12. Please provide any additional comments about the sign ordinance or signs in general. 


\section{City of Morro Bay}

Sign Ordinance Update - Business Survey

1. Do you think the current sign ordinance is user friendly and easy to understand?

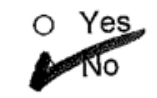

Comments:

\section{RECEIVED}

2. How do you believe the City's sign code is applied?

O Consitently

nconsistently (please explain below)

Comments:
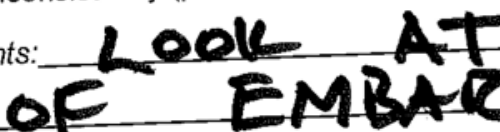

3. Is enforcement of illegal signs an issue?
O No
O Yes, there is not enough enforcement
O Yes, there is too much enforcement
es, (please specify):
WH.
SEARCTIVE

, are you happy with the current signs in Morro Bay? Select one or more.
O Yes
O No, illumination is too bright
O Yes
- No, signs are too large
O No, signs are too small
O No, I don't like the materials most signs use
No, too many signs
O No, signs are too tall
O Other (please specify):

5. What changes to the sign code could
"other" box to offer additional ideas).

"other" box to offer additional ideas). more consistency

O Relax regulations for illuminated signs

- Allow ALL businesses to have more signage

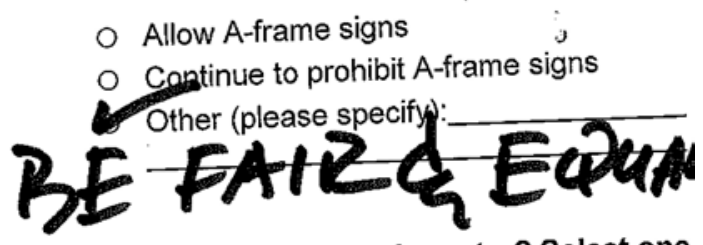

signs (if any) do you believe degrade Morro Bay's community character? Select one
more.
○ Pole signs
O A-frame signs
Window signs
O Wall signs
O Flags and Banners
O Monument (freestanding) signs

Digital (reader) signs

Internally illuminated signs

O Externally illuminated signs

O Awning signs

O Other (please specify):

pg. 2 on back $\rightarrow$ 
7. Previous City public meetings revealed a preference for having different sign requirements for different areas of town (e.g. North Morro Bay vs. Downtown vs. Embarcadero vs. Quintana). Do you agree with having different sign requirements in different business districts?

O Yes.

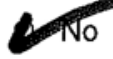

Comments:

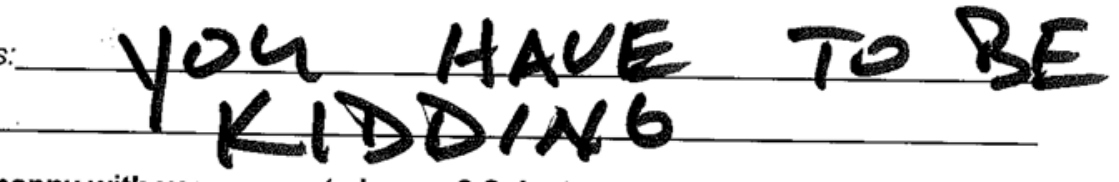

8. Are you happy with your current signage? Select one or more.

Yes

O No, my sign(s) are too small

O No, my signs can't be seen from the street

O No, my signs are requitred to be placed too low where theysare not visible

O No, my sign's materials are inadequate.

9. How impontant are commercial signs to your business's success?

Nery important

O Important

O Not very important

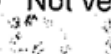

\section{3}

. Would you support "directional signs" (also known as wayfinding signs) on the Embarcadero? Directional signs are used to help residents and tourists navigate around cities. In this case, directional signs could be used on the Embarcadero to help tourists locate businesses.

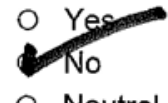

11. If directional signs were implemented, what businesses should be featured on them?

O All businesses should be featured on a directional sign

O Only businesses that are hidden from view should be featured on a directional sign

O Busineses should pay a fee to "rent" a spot on a directional sign

Orectional signs are a bad idea

Other suggestions:

12. Please provide any additional comments about the sign ordinance or signs in general. 


\section{City of Morro Bay}

Sign Ordinance Update - Business Survey

1. Do you think the current sign ordinance is user friendly and easy to understand?

OYes
O No

Comments:

2. How do you believe the City's sign code is applied?

8 Consistently

Inconsistently (please explain below)

\section{RECEIVED}

Comments:

3. Is enforcement of illegal signs an issue?
O No
Yes, there is not enough enforcement
- Yes, there is too much enforcement
o Yes, (please specify):

4. With respect to aesthetics, are you happy with the current signs in Morro Bay? Select on
of Yes
- No, signs are too large
O No, too many signs
O No, signs are too small
O No, 1 don't like the materials most signs use
O No, signs are too tall
O Other (please specify):

5. What changes to the sign code could
"other" box to offer additional ideas).

O Further restrict and enforce signs to create more consistency

- Relax regulations for illuminated signs

- Allow ALL businesses to have more signage

- Allow A-frame signs

(1) Continue to prohibit A-frame signs

O Other (please specify):

6. What types of signs (if any) do you believe degrade Morro Bay's community character? Select one mgre.

(1) Pole signs

(1) A-frame signs

W Window signs

O Wall signs

O Flags and Banners

O Monument (freestanding) signs

O Digital (reader) signs

O Internally illuminated signs

O Externally illuminated signs

O Awning signs

O Other (please specify):

pg. 2 on back $\rightarrow$ 
7. Previous City public meetings revealed a preference for having different sign requirements for different areas of town (e.g. North Morro Bay vs. Downtown vs. Embarcadero vs. Quintana). Do you agree with having different sign requirements in different business districts?

$\varpi$ Yes

O No

comments: Dapending on location some bulswesses are set back and not vey usible

8. Are you happy with your current signage? Select one or more.

(6) Yes

O No, my sign(s) are too small

- No, my signs can't be seen from the street

O No, my signs are required to be placed too low where they are not visible

O No, my sign's materials are inadequate

9. How important are commercial signs to your business's success?

V Very important

Q Important

O Not very important

10. Would you support "directional signs" (also known as wayfinding signs) on the Embarcadero? Directional signs are used to help residents and tourists navigate around cities. In this case, directional signs could be used on the Embarcadero to help tourists locate businesses.

O Yes

(1) No

O Neutral

11. If directional signs were implemented, what businesses should be featured on them?

O All businesses should be featured on a directional sign

$\bowtie$ Only businesses that are hidden from view should be featured on a directional sign

O Businesses should pay a fee to "rent" a spot on a directional sign

O Directional signs are a bad idea

O Other suggestions:

12. Please provide any additional comments about the sign ordinance or signs in general. 


\section{City of Morro Bay}

Sign Ordinance Update - Business Survey

current sign ordinance is user friendly and easy to understand?
O Yes
$\not \$$ No
Comments:
APR 022013
City of Morro Bay
Public Services Department

RECEIVED

2. How do you believe the City's sign code is applied?

O Consistently

Inconsistently (please explain below)

Comments

3. Is enforcement of illegal signs an issue?
O No
O Yes, there is not enough enforcement
Yes, there is too much enforcement
o Yes, (please specify):

With respect to aesthetics, are you happy with the current signs in Morro Bay? Select one or more.
- Yes
O No, signs are too large
O No, signs are too smal
No, I don't like the materials most signs use

O No, too many signs

O No, signs are too tall

O Other (please specify):

5. What changes to the sign code could he

"other" box to offer additional ideas).

Further restrict and
more consistency

Q Relax regulations for illuminated signs

Allow ALL businesses to have more signage

6. What types of signs (if any) do you believe degrade Mor
more.
d. Pole signs
A-frame signs
Window signs
$\varnothing$ Wall signs
$\varnothing$ Flags and Banners
$\not 2$ Monument (freestanding) signs

O Allow A-frame signs

O Continue to prohibit A-frame signs

O Other (please specify) 
7. Previous City public meetings revealed a preference for having different sign requirements for different areas of town (e.g. North Morro Bay vs. Downtown vs. Embarcadero vs. Quintana). Do you agree with having different sign requirements in different business districts?

* Yes

O No

Comments:

8. Are you happy with your current signage? Select one or more.

Yes

O No, my sign(s) are too small

O No, my signs can't be seen from the street

O No, my signs are required to be placed too low where they are not visible

O No, my sign's materials are inadequate

9. How important are commercial signs to your business's success?

Very important

O Important

O Not very important

10. Would you support "directional signs" (also known as wayfinding signs) on the Embarcadero? Directional signs are used to help residents and tourists navigate around cities. In this case, directional signs could be used on the Embarcadero to help tourists locate businesses.

O Yes

O No

Neutral

11. If directional signs were implemented, what businesses should be featured on them?

O All businesses should be featured on a directional sign

O Only businesses that are hidden from view should be featured on a directional sign

O Businesses should pay a fee to "rent" a spot on a directional sign

$\not$ Directional signs are a bad idea

O Other suggestions:

12. Please provide any additional comments about the sign ordinance or signs in general. 
1. Do you think the current sign ordinance is user friendly and febsy/todunderstan
Public Services Department
Yes

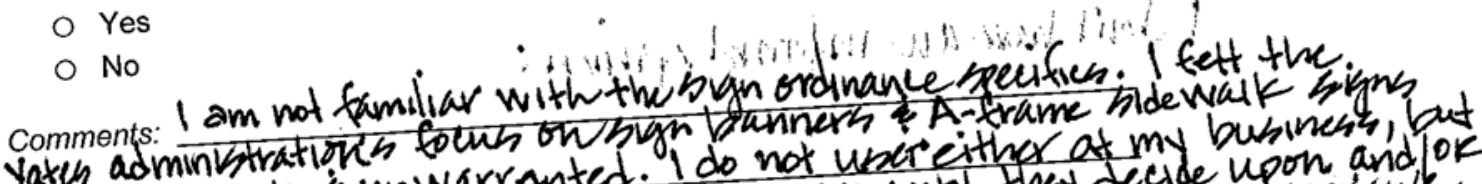

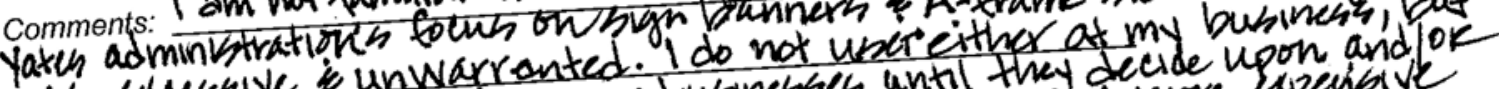

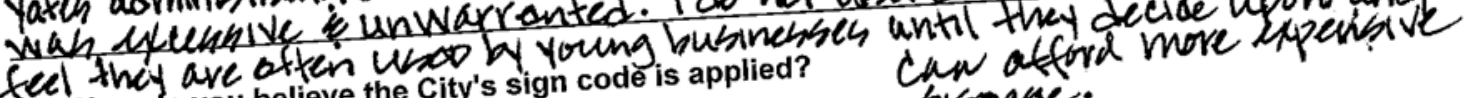
Xee How do you believe the City's sign code is applied?

O Consistently

O Inconsistently (please explain below)

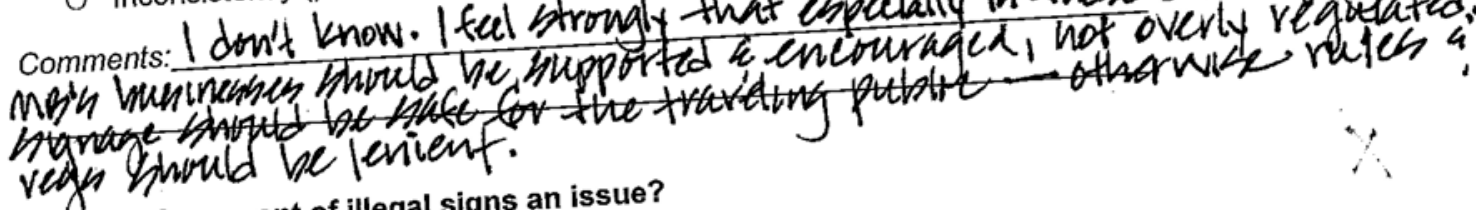

3. Is enforcement of illegal signs an issue?

O No

O Yes, there is not enough enforcement

Yes, there is not enough enforcement
Yes, there is too much enforcement
O Yes, (please specify): Ge gentle - we re all fighting a hard battle

4. With respect to aesthetics, are you happy with the current signs in Morro Bay? Select on
$\begin{array}{ll}\propto \text { Yes } & \bigcirc \text { No, illumination is too bright. }\end{array}$
No, signs are too large
O No, signs are too small
O No, I don't like the materials most signs use
O No, too many signs

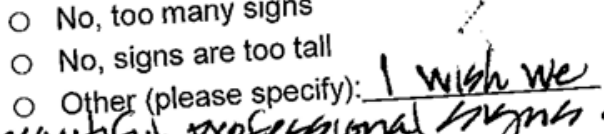 could all afford beutifut proferhional hynn.

$\because$

5. What changes to the sign code could hel

"other" box to offer additional ideas).
more consistency more consistency

O Relax regulations for illuminated sig

- Allow ALL businesses to have more signage character? Select on

6. What types of signs (if any) do you believe degrade Wiorro Bay's col more.
O Pole signs
O A-frame signs
Window signs
O Wall signs
O Flags and Banners
- Monument (freestanding) signs

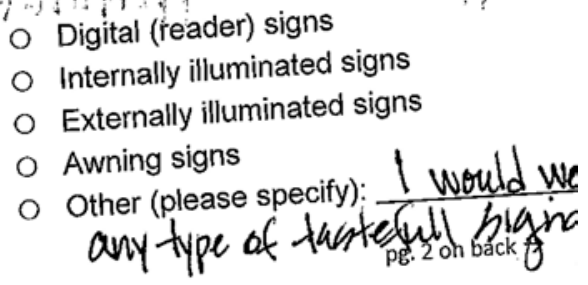


7. Previous City public meetings revealed a preference for having different sign requirements for different areas of town (e.g. North Morro Bay vs. Downtown vs. Embarcadero vs. Quintana). Do you agree with having different sign requirements in different business districts?

O Yes

O No

comments: 1 don't have an informed opinion:

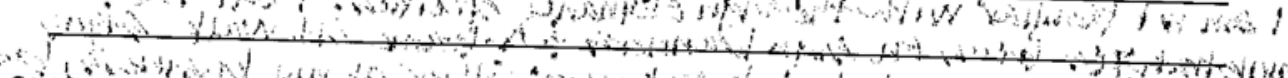

8. Are you happy with your current signag

A Yess

O No, my sign(s) are to small s.

O No, my signs can't be seen from the street

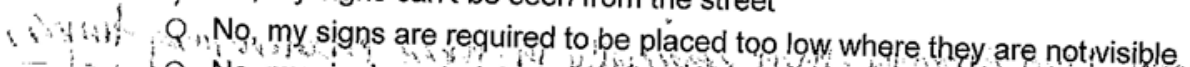

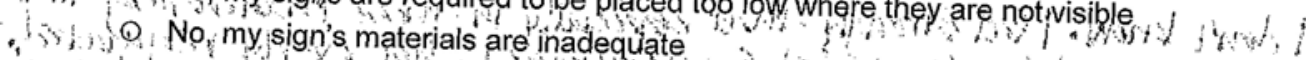

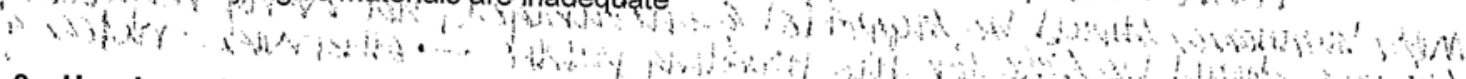

9. How important are commercial signs to your business's success?

\ery important

O Important

O Not very important

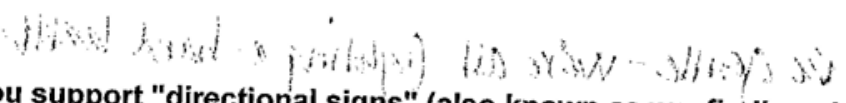

10. Would you support "directional signs" (also known as wayfinding signs) on the Embarcadero? directional signs could be used on the Embarcand tourists navigate around cities. In this case,

o Yes

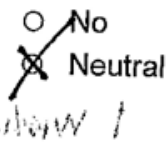

11. If directional signs weré implemented, what businésses should be featured on them?

O All businesses should be featured on a directional sign

O Only businesses that are hidden from view should be featured on a directional sign

O Businesses should pay a fee to "rent" a spot on a directional sign

O Directional signs are a bad idea

O Other suggestions:

Oajin - no informed opinuon

12. Pleáséprovide any additional

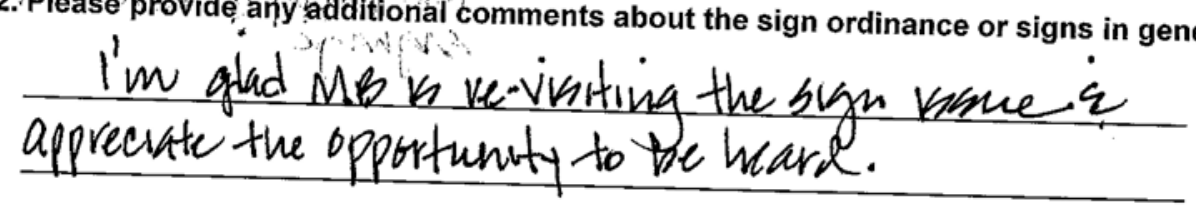

$\therefore$ Publicsertices

Public Services Department

H

955 Shasta Ave.

(805)772-6261 


\section{City of Morro Bay \\ Sign Ordinance Update - Business Survey}

1. Do you think the current sign ordinance is user friendly and easy to undor

O Yes

City of Morro Bay

No

APR 01 PAID

Comments:

Finance Department

2. How do you believe the City's sign code is applied?

O Consistently

Inconsistently (please explain below)

comments:

3. Is enforcement of illegal signs an issue?

- No

- Yes, there is not enough enforcement

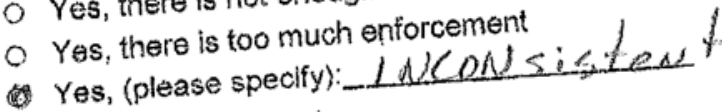

4. With respect to aesthetics, are you happy with the current signs in Mlorro Bay? Select on
- Yes
- No, signs are too large
o No, signs are too smiall
- No, I don't like the materials most signs use

o No, too many signs

- No, signs are too tall

O Other (please specify):

5. What changes to the sign code could he

"other" box to offer additional ideas).
Further restrict and enforce signs to create

more consistency

- Relax regulations for illuminated signs

- Allow AlL businesses to have more

signage

- Allow A-frame signs

O Continue to prohibit A-frame signs

Other (please specify): 6. What types of signs (if any) do you believe degrade Morro Eay's commulity charac (reader) signs
more.

- Pole signs

- A-frame signs

- Window signs

- Wail signs

- Flags and Banners

- Monument (freestanding) signs

pg. 2 on back $\rightarrow$ 
7. Previous City public meetings revealed a preference for having different sign requirements for different areas of town (e.g. North Morro Bay vs. Downtown vs. Embarcadero vs. Quintana). Do you agree with having different sign requirements in different business districts?

(1) Yes

O No

Comments:

8. Are you happy with your current signage? Select one or more.

- Yes

- No, my sign(s) are too smail

- No, my signs can't be seen from the street

- No, my signs are required to be placed too low where they are not visibie

O No, my sign's materials are inadequate

9. How important are commercial signs to your business's success?

(-) Very important

O Important

- Not very important

10. Would you support "directional signs" (also known as wayfinding signs) on the Embarcadero? Directional signs are used to help residents and tourists navigate around cities. In this case, directional signs could be used on the Embarcadero to help tourists locate businesses.

- Yes

(1) No

O Neutral

11. If directional signs were implemented, what businesses should be featured on them?

- Ail businesses should be featured on a directional sign

O Only businesses that are hidden from view should be featured on a directional sign

O Businesses should pay a fee to "rent" a spot on a directional sign

- Directional signs are a bad idea

O Other suggestions:

12. Please provide any additional comments about the sign ordinance or signs in general. 


\section{City of Morro Bay}

Sign Ordinance Update - Business Survey

1. Do you think the current sign ordinance is user friendly and easy to understand? 18. Yes

O No

Comments:

\section{RECEIVED}

\section{APR 012013}

City of Morro Bay

2. How do you believe the City's sign code is applied?

O Consistently

O Inconsistently (please explain below)

Comments

3. Is enforcement of illegal signs an issue?
O No
O Yes, there is not enough enforcement
O Yes, there is too much enforcement
O Yes, (please specify):

4. With respect to aesthetics, are you happy with the current signs in Morro Bay? Select one or more.
O Yes
O No, illumination is too bright
No, signs are too small-Directorial City Signs
O No, too many signs
O No, signs are too tall
O No, I don't like the materials most signs use
O Other (please specify):

5. What changes to the sign code could help you attract more customers? Select one or more (use the "other" box to offer additional ideas).

O Further restrict and enforce signs to create more consistency

F $f$ A Allow A-frame signs

1 Relax regulations for illuminated signs

- Allow ALL businesses to have more signage

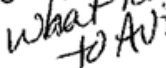

"Consistency"

$\frac{\text { coweates boring }}{\text { tows }}$

Like Carmet montergy $\longleftrightarrow$ Creative, unigue signs ARE BES

6. What types of signs (if any) do you believe degrade Morro Bay's community character? Select one or more.
O Polesigns
8. A-frame signs
Window signs
O Wall signs
O Flags and Banners
O Monument (freestanding) signs

O Digital (reader) signs

O Internally illuminated signs

O Externally illuminated signs

$O$ Awning signs

O Other (please specify):

pg. 2 on back $\rightarrow$ 
7. Previous City public meetings revealed a preference for having different sign requirements for different areas of town (e.g. North Morro Bay vs. Downtown vs. Embarcadero vs. Quintana). Do you agree with having different sign requirements in different business districts?

b) Yes

O No

comments: Businesses with majority 0 drial-by tratfic)

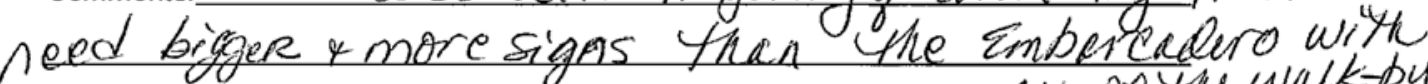

8. Are you happy with your current signage? Select one or more. ALL ox Yhe walk-by e. Yes

O No, my sign(s) are too small

O No, my signs can't be seen from the street

O No, my signs are required to be placed too low where they are not visible

O No, my sign's materials are inadequate

9. How important are commercial signs to your business's success?

Q Very important

O Important

O Not very important

10. Would you support "directional signs" (also known as wayfinding signs) on the Embarcadero? Directional signs are used to help residents and tourists navigate around cities. In this case, directional signs could be used on the Embarcadero to help tourists locate businesses.

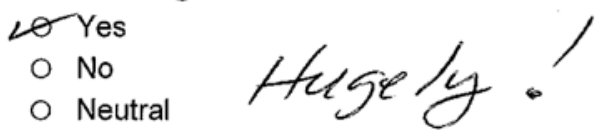

11. If directional signs were implemented, what businesses should be featured on them?

O All businesses should be featured on a directional sign

O Only businesses that are hidden from view should be featured on a directional sign

6 Businesses should pay a fee to "rent" a spot on a directional sign

O Directional signs are a bad idea

$\odot$ Other suggestions:

12. Please provide any additional comments about the sign ordinance or signs in general.

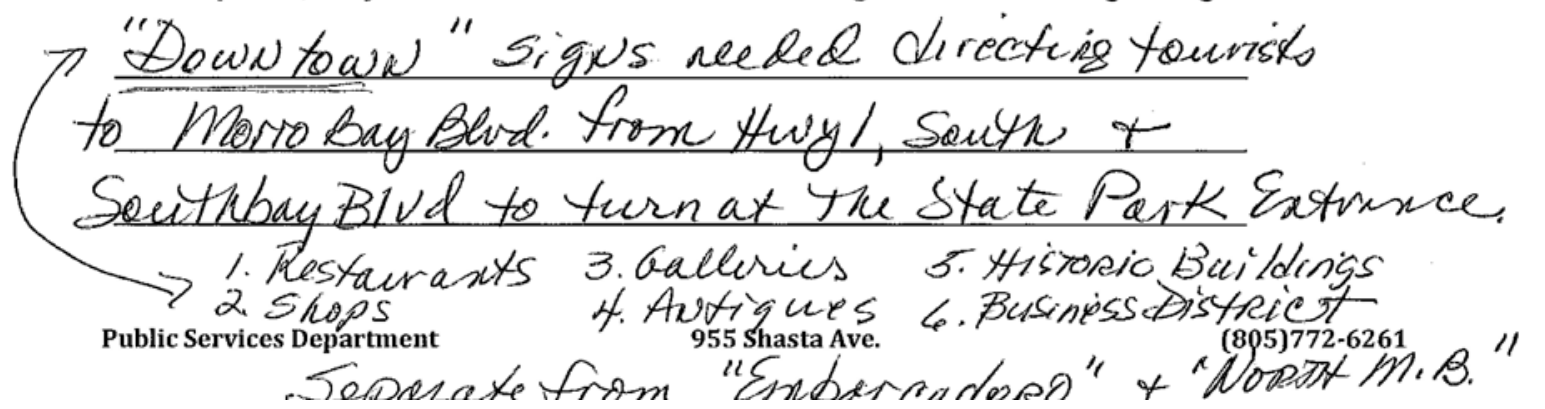




\section{U City of Morro Bay}

Sign Ordinance Update - Business Survey

1. Do you think the current sign ordinance is user friendly and easy to understand?

O Yes

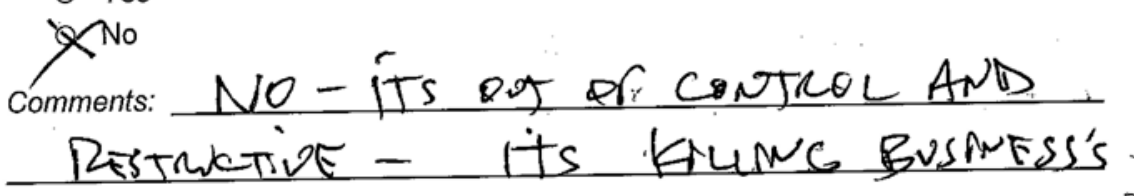

RECEIVED

APR 012013

City of Morro Bay

Public Services Department

2. How do you believe the City's sign code is applied?

O Consistently

76 inconsistently (please explain below)

Comments:- T00 lastrigive - DROS MOT

Promate Busteness f ColowtH - LOUSEY COSA: THAnd to Make A LiVinc with AK TAS RESTNCTIONS,

3. Is enforcement of illegal signs an issue?

O No

- Yes, there is not enough enforcement

\&4 Yes, there is too much enforcement
O Yes, (please specify): THS CROAting A CLMATE WHEV your visitars ARE Down. CIFY USE TO BE GUN-NOS AMY MOPE BAD CLIMATE EXSTS होIWITH ?

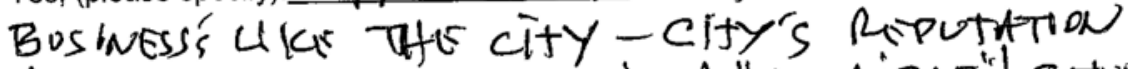
AMONG BUSINESS OWNAR is A "TERRiBLE"I STUATION

4. With respect to aesthetics, are you happy with the current signs in Morro Bay? Select one or more.
o Yes
O No, signs are too large
O No, signs are too small

O No, illumination is too bright

O No, too many signs Ho, I don't like the materials most signs use

5. What changes to the sign code could help you attract more customers? Select one or more (use the "other" box to offer additional ideas).

Further restrict and enforce signs to create more consistency

Relax regulations for illuminated signs

Allow ALL businesses to have more signage

$$
\text { city is Biting THE }
$$

Allow A-frame signs
Continue to prohibit A-frame signs
Other (please specify):

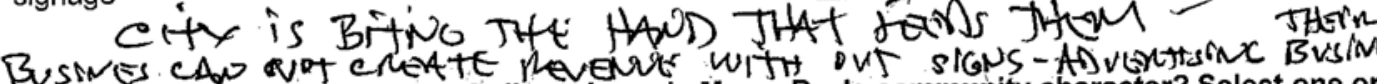

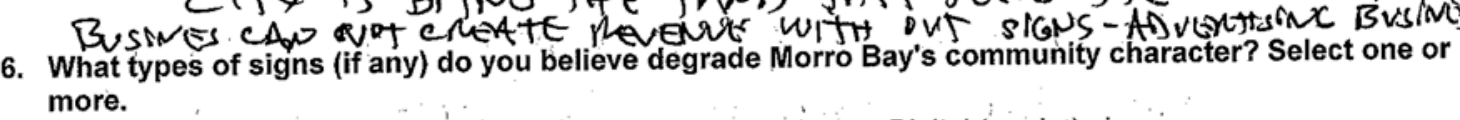
O Pole signs
O A-frame signs
O Window signs
O Wall signs
O Flags and Banners
O Monument (freestanding) signs 
Business Owner Sign Survey

SurveyMonkey

1. Do you think the current sign ordinance is user friendly and easy to understand?

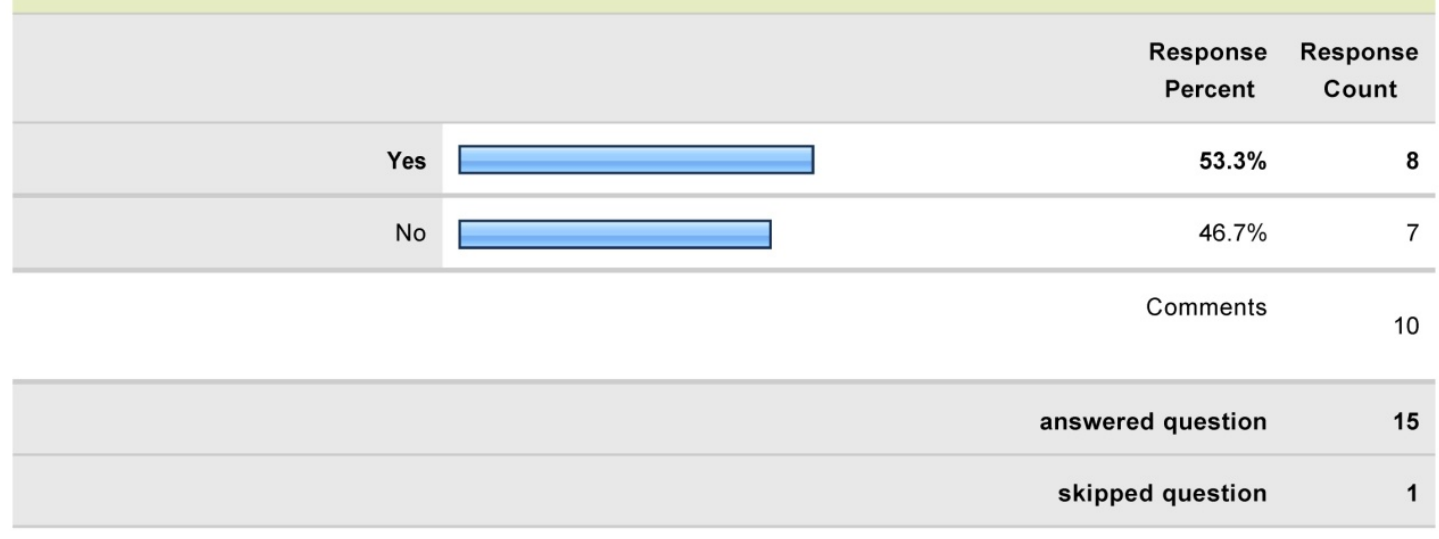

2. How do you believe the City's sign code is applied?

\begin{tabular}{|c|c|c|c|}
\hline & & $\begin{array}{l}\text { Response } \\
\text { Percent }\end{array}$ & $\begin{array}{l}\text { Response } \\
\text { Count }\end{array}$ \\
\hline Consistently & $\square$ & $25.0 \%$ & 3 \\
\hline \multirow[t]{4}{*}{$\begin{array}{r}\text { Inconsistently (please explain } \\
\text { below) }\end{array}$} & & $75.0 \%$ & 9 \\
\hline & & Other (please specify) & 12 \\
\hline & & answered question & 12 \\
\hline & & skipped question & 4 \\
\hline
\end{tabular}

1 of 15 
3. Is enforcement of illegal signs an issue?

\begin{tabular}{|c|c|c|c|}
\hline & & $\begin{array}{c}\text { Response } \\
\text { Percent }\end{array}$ & $\begin{array}{c}\text { Response } \\
\text { Count }\end{array}$ \\
\hline No & $\square$ & $61.5 \%$ & 8 \\
\hline $\begin{array}{r}\text { Yes, there is not enough } \\
\text { enforement }\end{array}$ & & $23.1 \%$ & 3 \\
\hline \multirow[t]{4}{*}{$\begin{array}{r}\text { Yes, there is too much } \\
\text { enforcement }\end{array}$} & $\square$ & $15.4 \%$ & 2 \\
\hline & & Other (please specify) & 7 \\
\hline & & answered question & 13 \\
\hline & & skipped question & 3 \\
\hline
\end{tabular}

\section{With respect to aesthetics, are you happy with the current signs in Morro Bay? Select one or more.}

\begin{tabular}{|c|c|c|c|}
\hline & & $\begin{array}{c}\text { Response } \\
\text { Percent }\end{array}$ & $\begin{array}{c}\text { Response } \\
\text { Count }\end{array}$ \\
\hline Yes & $\square$ & $46.7 \%$ & 7 \\
\hline No, signs are too large & $\square$ & $6.7 \%$ & 1 \\
\hline No, signs are too small & $\square$ & $13.3 \%$ & 2 \\
\hline $\begin{array}{r}\text { No, I don't like the materials most } \\
\text { signs use }\end{array}$ & $\square$ & $20.0 \%$ & 3 \\
\hline No, illumination is too bright & & $0.0 \%$ & 0 \\
\hline No, too many signs & $\square$ & $13.3 \%$ & 2 \\
\hline No, signs are too tall & $\square$ & $6.7 \%$ & 1 \\
\hline \multirow[t]{3}{*}{ Other (please specify) } & 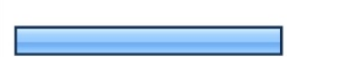 & $40.0 \%$ & 6 \\
\hline & & answered question & 15 \\
\hline & & skipped question & 1 \\
\hline
\end{tabular}

2 of 15 


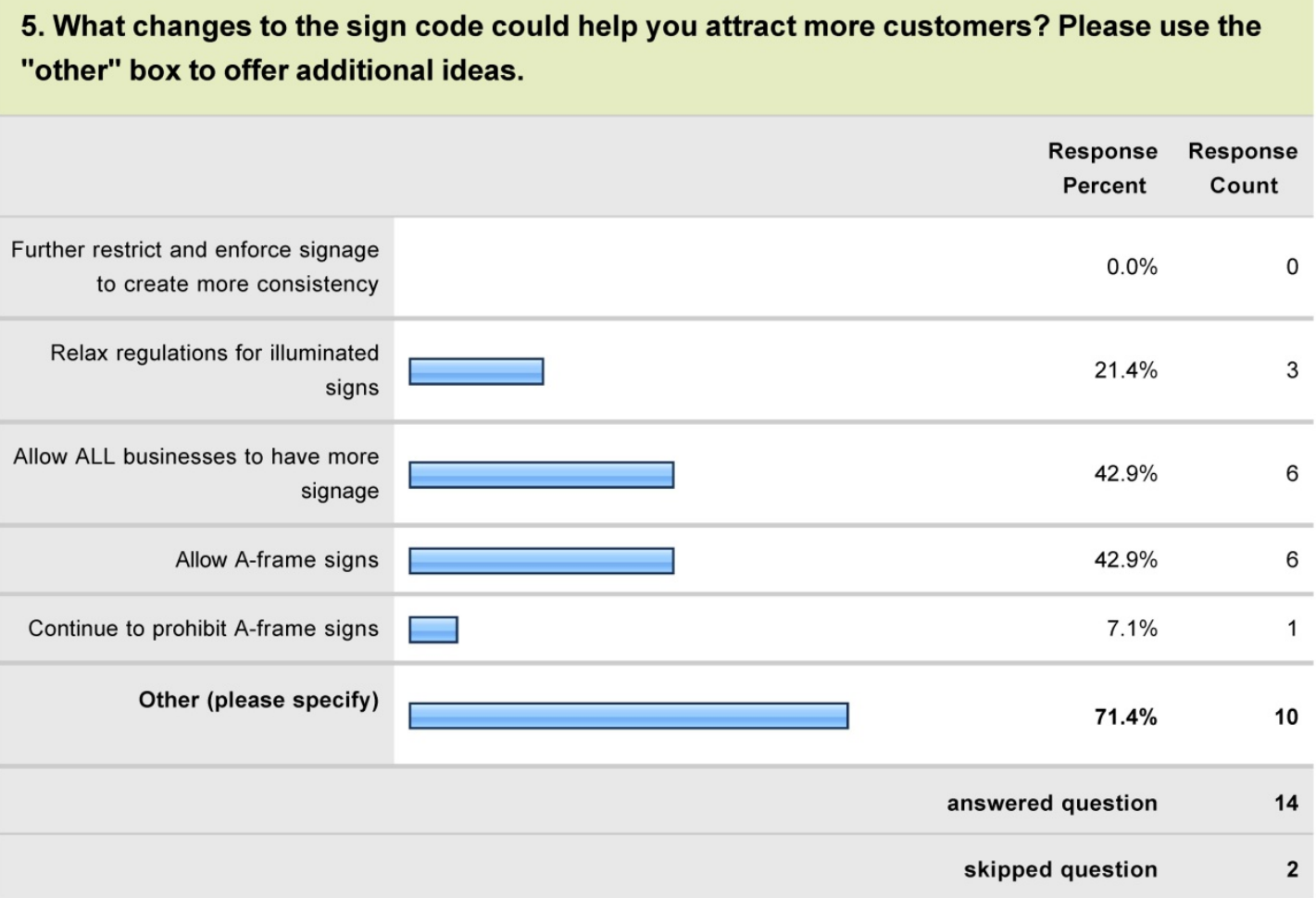


6. What types of signs (if any) do you believe degrade Morro Bay's community character? Select one or more.

\begin{tabular}{|c|c|c|c|}
\hline & & $\begin{array}{c}\text { Response } \\
\text { Percent }\end{array}$ & $\begin{array}{c}\text { Response } \\
\text { Count }\end{array}$ \\
\hline Pole signs & & $0.0 \%$ & 0 \\
\hline A-frame signs & $\square$ & $26.7 \%$ & 4 \\
\hline Window signs & $\square$ & $26.7 \%$ & 4 \\
\hline Wall signs & & $0.0 \%$ & 0 \\
\hline Flags and Banners & $\square$ & $6.7 \%$ & 1 \\
\hline Monument (freestanding) signs & & $0.0 \%$ & 0 \\
\hline Digital (reader) signs & 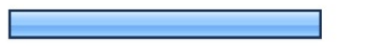 & $46.7 \%$ & 7 \\
\hline Internally illuminated signs & $\square$ & $6.7 \%$ & 1 \\
\hline Externally illuminated signs & $\square$ & $13.3 \%$ & 2 \\
\hline Awning signs & $\square$ & $13.3 \%$ & 2 \\
\hline \multirow[t]{3}{*}{ Other (please specify) } & $\square$ & $53.3 \%$ & 8 \\
\hline & & answered question & 15 \\
\hline & & skipped question & 1 \\
\hline
\end{tabular}

4 of 15 
7. Previous City public meetings revealed a preference for having different sign requirements for different areas of town (e.g. North Morro Bay vs. Downtown vs. Embarcadero vs. Quintana). Do you agree with having different sign requirements in different business districts?

\begin{tabular}{|c|c|c|c|}
\hline & & $\begin{array}{c}\text { Response } \\
\text { Percent }\end{array}$ & $\begin{array}{c}\text { Response } \\
\text { Count }\end{array}$ \\
\hline Yes & $\square$ & $66.7 \%$ & 10 \\
\hline No & $\square$ & $33.3 \%$ & 5 \\
\hline
\end{tabular}

\begin{tabular}{rr} 
Comments & answered question \\
\hline 15 & skipped question $\quad 1$ \\
\hline
\end{tabular}

\section{Are you happy with your current signage? Select one or more.}

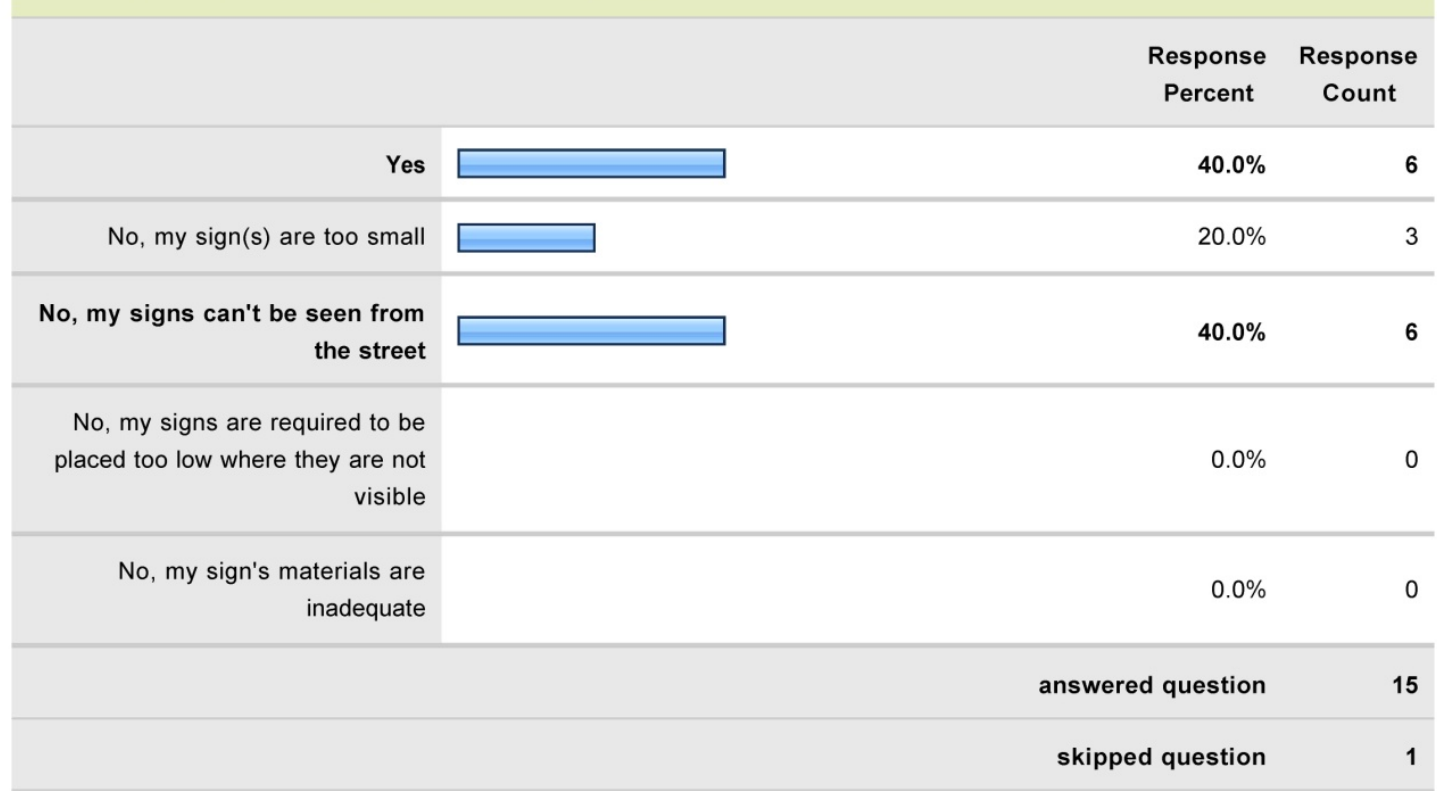


9. How important are signs to your business's success?

\begin{tabular}{|c|c|c|c|}
\hline & & $\begin{array}{c}\text { Response } \\
\text { Percent }\end{array}$ & $\begin{array}{c}\text { Response } \\
\text { Count }\end{array}$ \\
\hline Very important & $\square$ & $87.5 \%$ & 14 \\
\hline Important & & $0.0 \%$ & 0 \\
\hline Not very important & $\square$ & $12.5 \%$ & 2 \\
\hline \multicolumn{3}{|c|}{ answered question } & 16 \\
\hline \multicolumn{3}{|c|}{ skipped question } & 0 \\
\hline
\end{tabular}

10. Would you support "directional signs" (also known as directional signs) on the Embarcadero? Directional signs are used to help residents and tourists navigate around cities. In this case, directional signs could be used on the Embarcadero to help tourists locate businesses.

\begin{tabular}{|c|c|c|c|}
\hline & & $\begin{array}{c}\text { Response } \\
\text { Percent }\end{array}$ & $\begin{array}{c}\text { Response } \\
\text { Count }\end{array}$ \\
\hline Yes & $\square$ & $56.3 \%$ & 9 \\
\hline No & $\square$ & $37.5 \%$ & 6 \\
\hline \multirow[t]{3}{*}{ I'm indifferent } & $\square$ & $6.3 \%$ & 1 \\
\hline & & answered question & 16 \\
\hline & & skipped question & 0 \\
\hline
\end{tabular}


11. If directional signs were implemented, what businesses should be featured on the signs?

\begin{tabular}{|c|c|c|c|}
\hline & & $\begin{array}{c}\text { Response } \\
\text { Percent }\end{array}$ & $\begin{array}{l}\text { Response } \\
\text { Count }\end{array}$ \\
\hline $\begin{array}{r}\text { All businesses should be featured } \\
\text { on a directional sign }\end{array}$ & & $15.4 \%$ & 2 \\
\hline $\begin{array}{r}\text { Only businesses that are hidden } \\
\text { from view should be featured on a } \\
\text { directional sign }\end{array}$ & $\square$ & $15.4 \%$ & 2 \\
\hline $\begin{array}{l}\text { Businesses should pay a fee to } \\
\text { "rent" a spot on a directional sign }\end{array}$ & E & $30.8 \%$ & 4 \\
\hline \multirow[t]{4}{*}{ Directional signs are a bad idea } & $\square$ & $38.5 \%$ & 5 \\
\hline & & Other suggestions? & 8 \\
\hline & & answered question & 13 \\
\hline & & skipped question & 3 \\
\hline
\end{tabular}

12. Please provide any additional comments about the current sign ordinance or signs in general.

Response

Count 
Q1. Do you think the current sign ordinance is user friendly and easy to understand?

\begin{tabular}{|c|c|c|}
\hline 1 & To confusing for small business owners. & Apr 11, 2013 10:21 PM \\
\hline 2 & $\begin{array}{l}\text { I have only looked at it briefly. I'm not sure if it has different rules for different } \\
\text { areas. }\end{array}$ & Apr 2, 2013 1:28 PM \\
\hline 3 & $\begin{array}{l}\text { Relatively, make suree there is a distinct clarification between "Building" frontage } \\
\text { and "Lot" frontage as it relates to allowable sign area }\end{array}$ & Mar 29, 2013 5:10 PM \\
\hline 4 & $\begin{array}{l}\text { It was written for a different city. it is over restrictive and harms business. it } \\
\text { favors Embarcadero owners and completely ignores the problems of businesses } \\
\text { that are not on a main street. }\end{array}$ & Mar 24, 2013 12:32 PM \\
\hline 5 & I dont know anything about it & Mar 23, 2013 1:28 PM \\
\hline 6 & $\begin{array}{l}\text { While it is easy to understand it is strict and unfair to all of our cities business } \\
\text { need. }\end{array}$ & Mar 23, 2013 11:29 AM \\
\hline 7 & $\begin{array}{l}\text { I have no idea, where is the ordinance in the first place. May I see a copy before } \\
\text { I answer correctly. }\end{array}$ & Mar 21, 2013 5:41 PM \\
\hline 8 & $\begin{array}{l}\text { It seems it applied subjectively. One business is allowed a huge sign and the } \\
\text { one next door is limited to } 2 \text { ' by } 2^{\prime} \text {. }\end{array}$ & Mar 21, 2013 4:28 PM \\
\hline 9 & $\begin{array}{l}\text { Some simplification in the process especially the appeals process for denied } \\
\text { signage }\end{array}$ & Mar 21, 2013 3:10 PM \\
\hline 10 & Had a hard time finding it on the website. & Mar 21, 2013 12:28 PM \\
\hline
\end{tabular}


Q2. How do you believe the City's sign code is applied?

\begin{tabular}{|c|c|c|}
\hline 1 & $\begin{array}{l}\text { Some businesses have very large signs given the size of their street fronts when } \\
\text { looking at the ordinance specs for sign size. }\end{array}$ & Apr 11, 2013 10:21 PM \\
\hline 2 & $?$ & Apr 2, 2013 1:28 PM \\
\hline 3 & Not familiar with other parts of town & Mar 29, 2013 5:10 PM \\
\hline 4 & North of town seems to have A-frames still. & Mar 26, 2013 1:42 PM \\
\hline 5 & There is no control & Mar 26, 2013 12:42 PM \\
\hline 6 & $\begin{array}{l}\text { Mayor Yates and City Attorney Schultz went around and took signs belonging to } \\
\text { businesses who opposed the ordinance. Everything favors the Embarcadero, } \\
\text { who need no signs }\end{array}$ & Mar 24, 2013 12:32 PM \\
\hline 7 & unknown & Mar 23, 2013 1:28 PM \\
\hline 8 & $\begin{array}{l}\text { The code is totally out of touch with the needs of the business community. Some } \\
\text { business have huge signage and too much but it has been approved by the city. } \\
\text { Maybe the city should physically go out and look at the proposed location and } \\
\text { ask a few questions. }\end{array}$ & Mar 23, 2013 11:29 AM \\
\hline 9 & $\begin{array}{l}\text { Has become more consistant over the past year however it seems that at first } \\
\text { the city was only enforcing law unto local small business while letting major } \\
\text { corporations to continue to use prohibited signage (ie McDonalds and Burger } \\
\text { King) }\end{array}$ & Mar 22, 2013 11:22 AM \\
\hline 10 & $\begin{array}{l}\text { Some people have advantage of big signs while others do not. Some people } \\
\text { block other peoples signs on purpose. Like mine. }\end{array}$ & Mar 21, 2013 5:41 PM \\
\hline 11 & $\begin{array}{l}\text { Some businesses are scrutinized while others are overlooked. Example; The } \\
\text { photography store on Main st. has a } 8 \text { ' sign on the roof that can be seen for } \\
\text { several blocks, the photography store on the Embarcadero is allowed a 2' by 2' } \\
\text { sign only??? }\end{array}$ & Mar 21, 2013 4:28 PM \\
\hline 12 & $\begin{array}{l}\text { Albertson's gets away with many flag type signs, big banners; small businesses } \\
\text { get hassled for having one. }\end{array}$ & Mar 21, 2013 12:28 PM \\
\hline
\end{tabular}


Q3. Is enforcement of illegal signs an issue?

\begin{tabular}{|clc}
\hline 1 & $? ? ?$ & Mar 29, 2013 5:10 PM \\
\hline 2 & Too many windows covered in Ads & Mar 26, 2013 12:42 PM \\
\hline 3 & Not to me it isn't & Mar 23, 2013 1:28 PM \\
\hline 4 & $\begin{array}{l}\text { There are parts of town that need A frames not Pub Signs. Sending out the city } \\
\text { officials and letters is counter productive. There are areas that need A frame } \\
\text { signage since those business would go otherwise unnoticed }\end{array}$ & Mar 23, 2013 11:29 AM \\
\hline 5 & $\begin{array}{l}\text { Again, enforcement seemed inconsistant at first but have now noticed an } \\
\text { improvement }\end{array}$ & Mar 22, 2013 11:22 AM \\
\hline 6 & it is COMPLETELY inconsistent. & Mar 21, 2013 4:28 PM \\
\hline 7 & Waste of City Attorney's time and energy & Mar 21, 2013 12:28 PM
\end{tabular}

Q4. With respect to aesthetics, are you happy with the current signs in Morro Bay? Select one or more.

\begin{tabular}{|c|c|c|}
\hline 1 & too many window sticker signs & Apr 21, 2013 12:30 PM \\
\hline 2 & see Number 6 & Apr 2, 2013 1:28 PM \\
\hline 3 & the rules are too restrictive. most of us cannot have any signs. & Mar 24, 2013 12:32 PM \\
\hline 4 & Some signage location is totally incorrect and inconsiderate to business owners & Mar 23, 2013 11:29 AM \\
\hline 5 & $\begin{array}{l}\text { Some are to small and it's to hard to find a business while others are huge or } \\
\text { ugly. }\end{array}$ & Mar 21, 2013 4:28 PM \\
\hline 6 & $\begin{array}{l}\text { Happy is a loaded word, particularly in a survey. Signage is needed for many } \\
\text { businesses to attract busienss...some are better than others. }\end{array}$ & Mar 21, 2013 12:28 PM \\
\hline
\end{tabular}

10 of 15 
Q5. What changes to the sign code could help you attract more customers? Please use the "other" box to offer additional ideas.

\begin{tabular}{|c|c|c|}
\hline 1 & $\begin{array}{l}\text { continue to prohibit A-Frame signs and prohibit window sticker signs below the } \\
\text { top } 12 \text { inches of the window running horizontal }\end{array}$ & Apr 21, 2013 12:30 PM \\
\hline 2 & $\begin{array}{l}\text { not sure what the original problem } w \text { the A frame signs were. It seems like with } \\
\text { some guidelines...this could look fine. Not all A-Frame (or any other) signs are } \\
\text { equal...there could be nice ones and lame ones. }\end{array}$ & Apr 2, 2013 1:28 PM \\
\hline 3 & Consistency without unique restrictions & Mar 29, 2013 5:10 PM \\
\hline 4 & But proper signage. $1 \mathrm{~A}$ frame or & Mar 26, 2013 12:42 PM \\
\hline 5 & $\begin{array}{l}\text { City should erect sign posts at major intersections with arrows pointing to shops } \\
\text { that are no on the main street. We are invisible and cannot do anything to attract } \\
\text { attention. }\end{array}$ & Mar 24, 2013 12:32 PM \\
\hline 6 & don't use signage except on my truck & Mar 23, 2013 1:28 PM \\
\hline 7 & $\begin{array}{l}\text { We need to have different restrictions for different parts of town. Some of our } \\
\text { businesses would go totally unnoticed with out A frames Feather flags etc. }\end{array}$ & Mar 23, 2013 11:29 AM \\
\hline 8 & Allow certain types of flags and banners & Mar 22, 2013 11:22 AM \\
\hline 9 & $\begin{array}{l}\text { Allow but limit } A \text { frames and require permits for them and they can not be used } \\
\text { on a sidewalk neede for foot traffic. }\end{array}$ & Mar 21, 2013 4:28 PM \\
\hline 10 & $\begin{array}{l}\text { I checked A-frames for other businesses, not mine. I have adequate signage for } \\
\text { my type of business. }\end{array}$ & Mar 21, 2013 12:28 PM \\
\hline
\end{tabular}


Q6. What types of signs (if any) do you believe degrade Morro Bay's community character? Select one or more.

\begin{tabular}{|lll|}
\hline 1 & $\begin{array}{l}\text { Unrigid vinyl banners make the town look junky. Printed photo type signs look } \\
\text { cheesy too (although rigid, the limo place on Quintana (sorry guys) }\end{array}$ & Apr 2, 2013 1:28 PM \\
\hline 2 & $\begin{array}{l}\text { morro bay is a tourist town and needs to have a friendly playful character. } \\
\text { People love coming to a community that is not full of chain stores. we need to } \\
\text { allow indiviuality }\end{array}$ & Mar 24, 2013 12:32 PM \\
\hline 3 & none & Mar 23, 2013 1:28 PM \\
\hline 4 & $\begin{array}{l}\text { Excessive window signage like in the grocery stores, Dollar store and Gas } \\
\text { stations. }\end{array}$ & Mar 23, 2013 11:29 AM \\
\hline 5 & none & Mar 22, 2013 9:26 AM \\
\hline 6 & handmade & Mar 21, 2013 5:41 PM \\
\hline 7 & Bad materials, not custom made, cheap looking, old and not maintained. & Mar 21, 2013 4:28 PM \\
\hline 8 & The older paper pricing that supermarkets used to use & Mar 21, 2013 12:28 PM \\
\hline
\end{tabular}

Q7. Previous City public meetings revealed a preference for having different sign requirements for different areas of town (e.g. North Morro Bay vs. Downtown vs. Embarcadero vs. Quintana). Do you agree with having different sign requirements in different business districts?

1 Embarcadero is so crowded less or smaller signs would be better. N. MB is so Apr 11, 2013 10:21 PM bad for business they would need lager signs as everyone just rushes by.

2 my business is on a side street off of Morro Bay Blvd. I should be able to have signs that attract attention from people on Morro Bay Blvd.

3 Absolutely, in North Morro Bay traffic whizzes by on the highway at at least 55 mph giving any business about 5 seconds to see, process and think about using that business. On the Quintana corridor the shopping center is invisible on the west end. It really needs some more signage allowances to get folks to look up there while in the next shopping center the signage is blinding.

4 If the distinctions are clear and the reasons behind them sound and vetted in the public and business community input

$5 \quad$ May also need to address sub-sets where businesses can't be seen from the street, like the Cookie Crock shopping center.

Mar 24, 2013 12:32 PM

Mar 23, 2013 11:29 AM

(1)

Mar 21, 2013 3:10 PM

Mar 21, 2013 12:28 PM 
Q11. If directional signs were implemented, what businesses should be featured on the signs?

1 You are opening up a new area for the preception of discrimination and

Apr 21, 2013 12:30 PM favoritisim.

2 Upper MB Blvd and N. Main gets lost as all the tourist end up on the

Apr 11, 2013 10:21 PM Embarcadero and were left watch the cars drive by.

3 I'm not sure...I would need to see info on each idea. Intriguing idea.

Apr 2, 2013 1:28 PM

4 Only public access businesses such as the Museum, the Harbor Master, the

Mar 26, 2013 12:42 PM Visitor's Center, the Chamber of Commerce

5 Directional signs are a great idea for ALL BUSINESSES in Morro Bay. Why are you just asking about the Embarcadero. They don't need signs. those of us off the beaten path need directional signs

6 Great money maker for the city.

Mar 23, 2013 11:29 AM

$7 \quad$ They look cluttered and people don't stop to read them on the Embarcadero but

Mar 21, 2013 4:28 PM they would be helpful on Quintana where you can't see the stores in the strip malls and in North Main directing from the off ramps.

8 Bad idea if set-up by the City, waste of worker time. Also probably, regrettably, be out of date all to quickly and therfore worthless. Add to clutter.

Mar 24, 2013 12:32 PM

Mar 21, 2013 12:28 PM 
14 of 15 
Q12. Please provide any additional comments about the current sign ordinance or signs in general.

1 Getting rid of the A-frame signs and blow ups was an excellent idea. The town is

Apr 21, 2013 12:30 PM cleaner and has a charm based on the buildings and people and natural surroundings. The pub signs look wonderful. They present well on the Embarcadero and the Down Town area where the foot traffic is. There needs to be regulation regarding window signs. Some windows are completely covered. This type of sinage degrades the look of the windows and the buildings it is in. It is mostly done in restaurants and shows prices for drinks and specials such as fish and chips and beer. At the very least there should be no prices associated with window sticker signs. Hotels are not allowed to display prices to avoid price wars. The same should be true of restaurants. It makes town look bad.

2 I will restate how terrible floppy vinyl type signs look. thank you !!

Apr 2, 2013 1:28 PM

3 Street Signage (hangings and street signs) in areas should identify an area -

Mar 26, 2013 12:42 PM such as Oldtown should be in one color, Embarcadero should be in one color North Morro Bay, etc. Additionally, there is no signage for lodging or food for anyone to exit off Morro Bay Blvd., etc.

$4 \quad$ Please come visit my shop to understand what we are dealing with. Ruby

Mar 24, 2013 12:32 PM Dragon 600 Morro Bay Blvd, Suite C on Shasta. Closed Sun, Mon, Wednesday. $10=4$ remaining days. Penny

$5 \quad$ Why are we doing this again? The City hosted 2 workshops on this subject. As I

Mar 23, 2013 11:29 AM remember we all pretty much agreed the sign ordinance was totally controlling and not good for the Business Community. We also have other issues with the City's signage. For example the blue signs all over town direct for the most part to the Embarcadero. The cal trans signs on the highway ,coming from the north, say Morro Bay next 3 exits at the $41 /$ high School exit. What about Yerba Buena or San Jacinto? No beach access signs either.

$6 \quad$ My sign is hidden by neighbors trees and I am not that visible. Can we either raise my sign or chop off those trees?

7 It needs to be consistent. I would like to see a committee to approve designs to

Mar 21, 2013 4:28 PM ensure a basic quality level and make allowances only when it is particularly esthetically pleasing as in a piece of art.

$8 \quad$ Like most business centered discussions in Morro Bay the Embarcadero gets an

Mar 21, 2013 3:10 PM disproportionate amount of attention. While the Embarcadero may drive tourist centered revenue businesses out of the Embarcadero zone deserve more representation. I very much support the differentitation stated in question 7. My business caters exclusively to the resident population of Morro Bay and is located out of the Embarcadero. My signage needs to attract drive by traffic to become aware of my location and services.

$9 \quad$ Signs are a necessary part of doing business, and Morro Bay needs healthy businesses. The current onerous sign ordinace that eliminated a-frames and flag signs hampers business's ability to attract customers.

Mar 21, 2013 12:28 PM 
Appendix 4.6

\section{Primary Resident Survey Results}

Resident Sign Ordinance Survey

mo SurveyMonkey

1. Are you a Morro Bay resident?

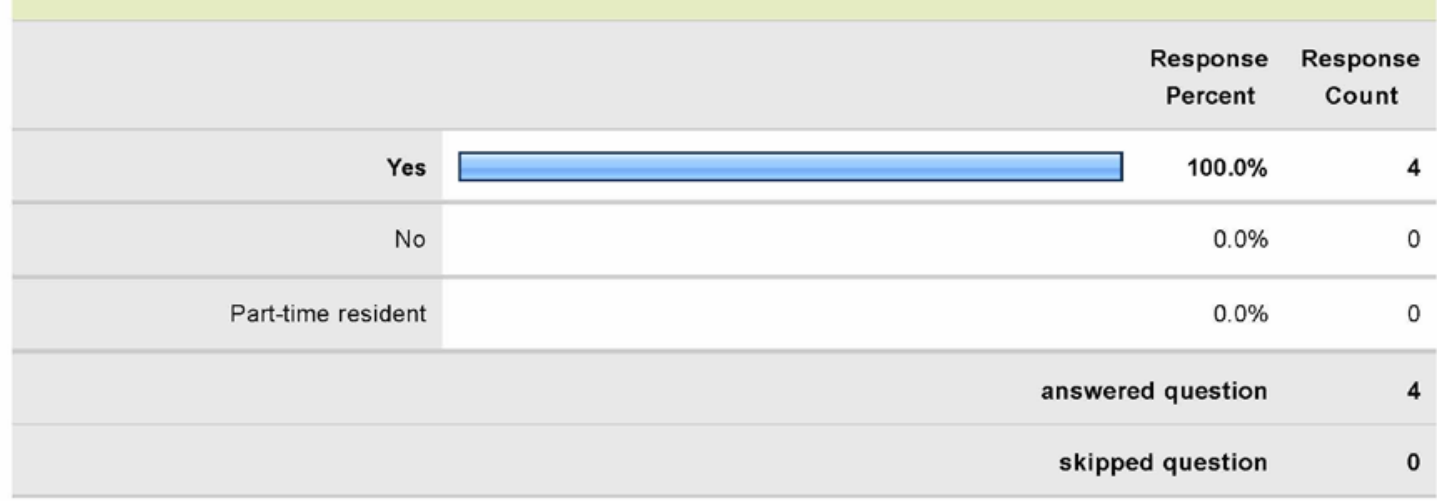

2. With respect to aesthetics, are you happy with the current signs in Morro Bay? Select one or more.

\begin{tabular}{|c|c|c|c|}
\hline Yes & $\square$ & $100.0 \%$ & 4 \\
\hline No, signs are too large & & $0.0 \%$ & 0 \\
\hline No, signs are too small & & $0.0 \%$ & 0 \\
\hline $\begin{array}{r}\text { No, I don't like the materials most } \\
\text { signs use }\end{array}$ & & $0.0 \%$ & 0 \\
\hline No, signs are too tall & & $0.0 \%$ & 0 \\
\hline \multicolumn{3}{|c|}{ Other (please specify) } & 0 \\
\hline \multicolumn{3}{|c|}{ answered question } & 4 \\
\hline \multicolumn{3}{|c|}{ skipped question } & 0 \\
\hline
\end{tabular}

1 of 6 
3. What types of signs (if any) do you believe degrade Morro Bay's community character? Select one or more.

\begin{tabular}{|c|c|c|c|}
\hline & & $\begin{array}{c}\text { Response } \\
\text { Percent }\end{array}$ & $\begin{array}{c}\text { Response } \\
\text { Count }\end{array}$ \\
\hline Pole signs & $\square$ & $66.7 \%$ & 2 \\
\hline A-frame signs & $\square$ & $66.7 \%$ & 2 \\
\hline Window signs & $\square$ & $33.3 \%$ & 1 \\
\hline Wall signs & & $0.0 \%$ & 0 \\
\hline Flags and Banners & & $0.0 \%$ & 0 \\
\hline Monument (freestanding) signs & & $0.0 \%$ & 0 \\
\hline Digital (reader) signs & $\square$ & $33.3 \%$ & 1 \\
\hline Internally illuminated signs & & $0.0 \%$ & 0 \\
\hline Externally illuminated signs & & $0.0 \%$ & 0 \\
\hline Awning signs & & $0.0 \%$ & 0 \\
\hline \multicolumn{4}{|c|}{ Other (please specify) } \\
\hline \multicolumn{4}{|c|}{ answered question } \\
\hline \multicolumn{4}{|c|}{ skipped question } \\
\hline
\end{tabular}


4. Would you support "directional signs" (also known as wayfinding signs) on the Embarcadero? Directional signs are used to help residents and tourists navigate around cities. In this case, directional signs could be used on the Embaradero to help tourists locate businesses.

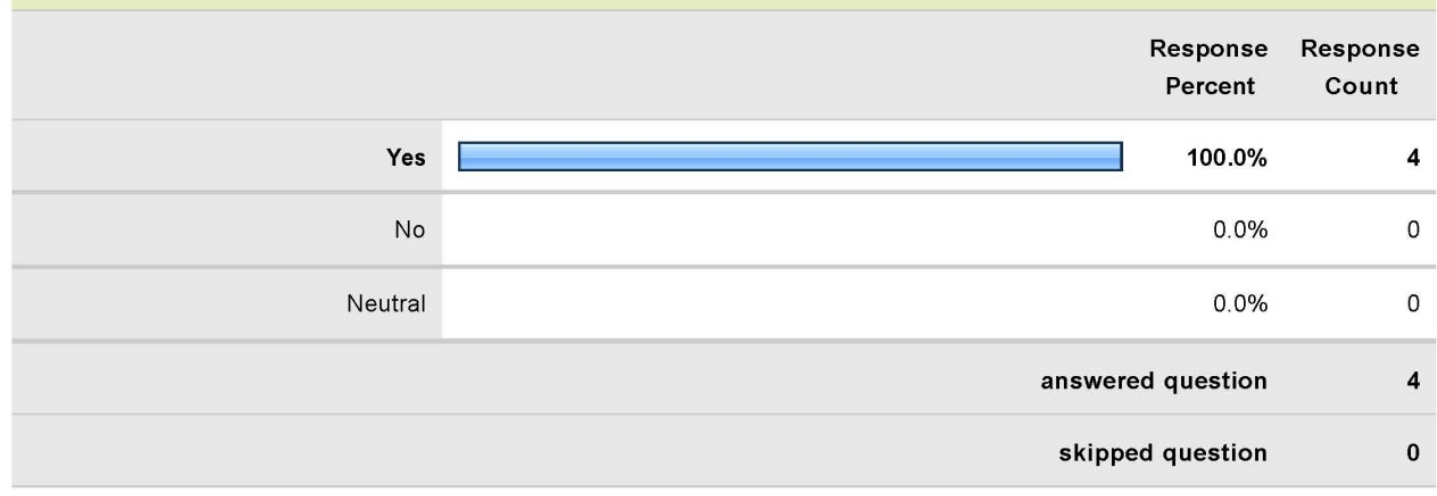

5. Should businesses be guranteed a minimum size sign regardless of frontage size?

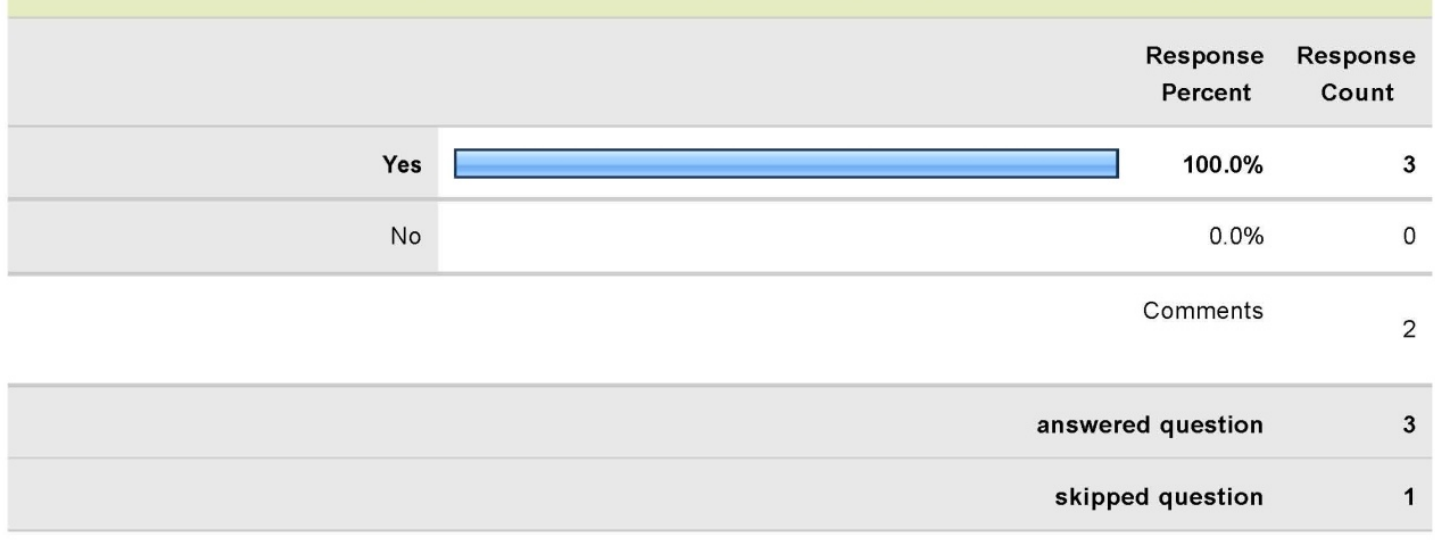




\section{A-frame signs should be:}

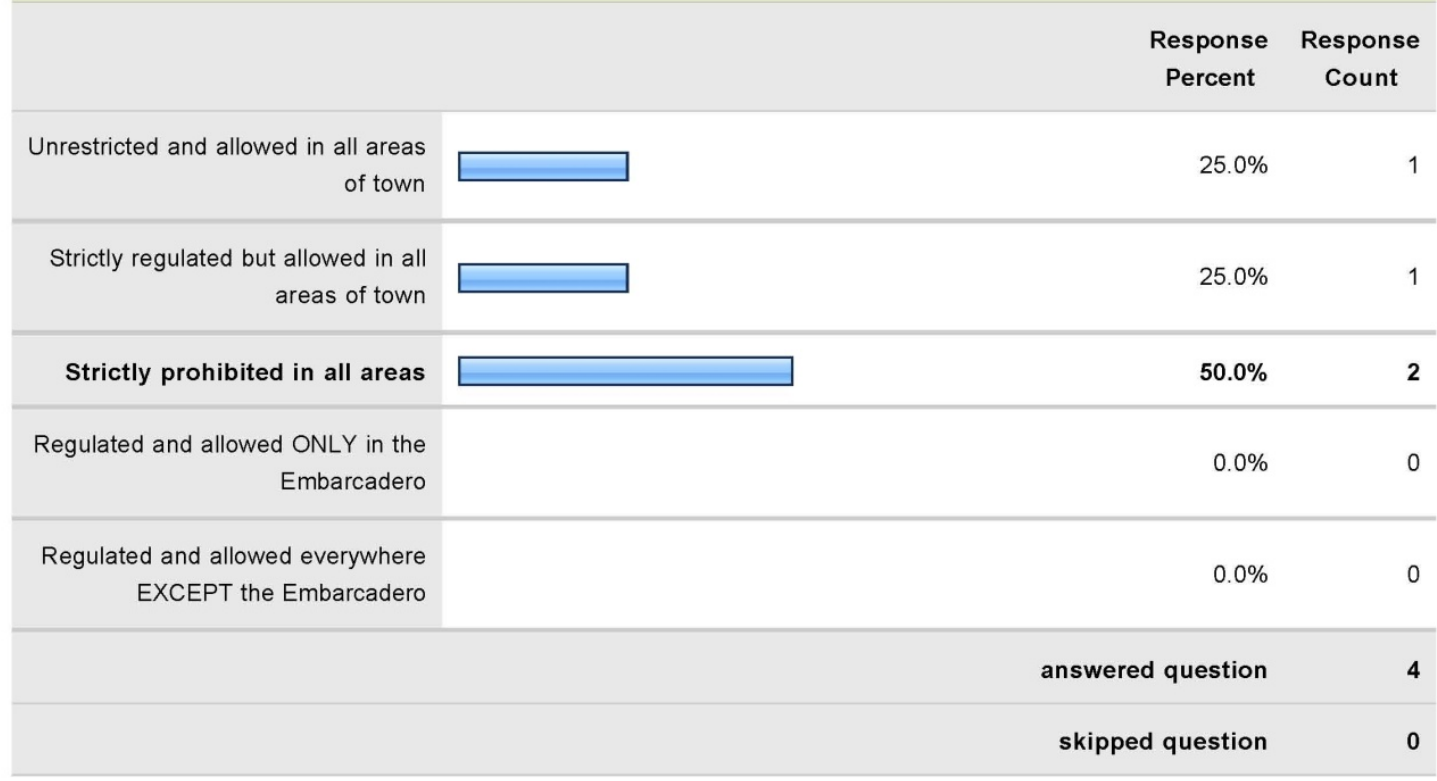

7. Do you want uniformity in the appearance of signs and businesses throughout the community?

\begin{tabular}{|c|c|c|c|}
\hline & & $\begin{array}{c}\text { Response } \\
\text { Percent }\end{array}$ & $\begin{array}{c}\text { Response } \\
\text { Count }\end{array}$ \\
\hline Yes & $\square$ & $25.0 \%$ & 1 \\
\hline \multirow[t]{3}{*}{ No } & ⿷ & $75.0 \%$ & 3 \\
\hline & & answered question & 4 \\
\hline & & skipped question & 0 \\
\hline
\end{tabular}

4 of 6 
8. Previous City public meetings revealed a preference for having different sign requirements for different areas of town (e.g. North Morro Bay vs. Downtown vs. Embarcadero vs. Quintana). Do you agree with having different sign requirements in different business districts?

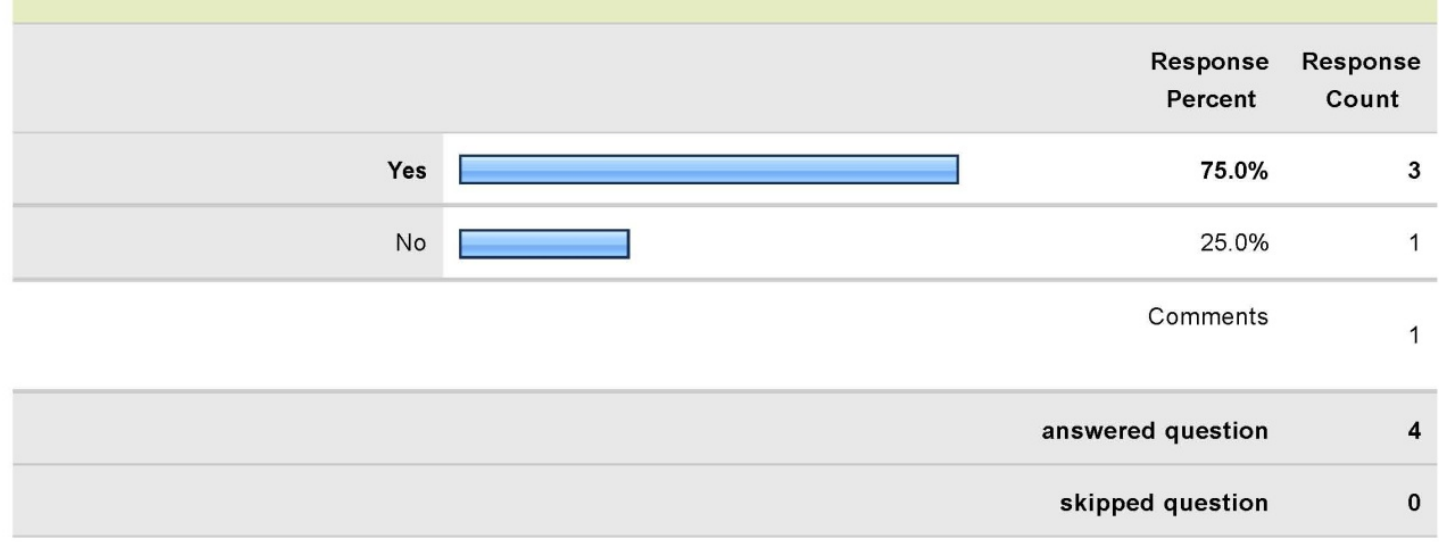

9. Please provide any additional comments about the sign ordinance or signs in general.

Response

Count 
Q3. What types of signs (if any) do you believe degrade Morro Bay's community character? Select one or more.

Q5. Should businesses be guranteed a minimum size sign regardless of frontage size?

1 I don't understand this question, so I won't comment. Frontage size where, and

Apr 17, 2013 10:35 AM where would the sign be posted if not on a storefront?

2 It should be tasteful and consistent in size - i.e., all business signs on buildings

of certain height and size will be so high, and so on.

Apr 9, 2013 3:19 PM

Q8. Previous City public meetings revealed a preference for having different sign requirements for different areas of town (e.g. North Morro Bay vs. Downtown vs. Embarcadero vs. Quintana). Do you agree with having different sign requirements in different business districts?

Q9. Please provide any additional comments about the sign ordinance or signs in general.

1 Signs are a great way of providing communication to residents, tourists and outside communities of what is happening around town. As long as they are tasteful and have a specific guideline of what is expected, they should be allowed. Thank you. 


\section{Appendix 4.7 \\ Interview with Shanna Farley-Judkins}

1. What are the main complaints about your current sign ordinance? From business owners? From residents? From staff?

Shanna: We don't get as many obvious complaints about the sign ordinance, but I know that most people do not interpret the requirements properly. I find I often spend a good deal of time with each applicant explaining the permit process and requirements. I think this is partially due to the small business owners doing this for the first time and being new to the process. Most sign companies are easy to work with and have few questions. Some people simply dislike paying a fee or getting a permit in the first place.

Some concerns from staff are that the code is not specific enough or failed to deal with certain elements that now cause a problem.

2. What key changes to the current ordinance have been requested by the community, staff, and you personally?

Shanna: In our new code we are looking at more specific language under the prohibited signs section, to make it obvious the types of signs we do not want like neon signs, motion signs, human signs, offsite signs, tall pole signs, etc... We also clarified the size limitations and types of signs allowed in each zone district, including residential zones, where we allow home occupations or home businesses.

Our new code is also better formatted with tables to simplify the code for applicants and staff.

We recently updated our fee study to better account for time required to take applications to Architectural Review Board and time to work out the details with applicants. In the past the fee was very low and did not account for staff time to review the permits, especially when the code is not followed and staff helps the applicants redesign.

3. Does the current sign ordinance promote the preservation of Carpinteria's eclectic, beach town character that residents and business owners enjoy? If not, what kinds of considerations were made during the formation of the draft ordinance to address the preservation of community character?

Shanna: The sign code does not speak to the preservation of the city's character in the rules and regulations, but the historic chapter will hopefully address existing non-conforming historic signs. We tend to lean on either the design guidelines or the general plan for more general direction for the goals of the city, which encourage and guide development to maintain the quality $\mathrm{f}$ the small beach town character of Carpinteria. In addition, we have a non-conforming chapter which allows applicants to preserve existing elements that otherwise are not compliant newer regulations. We would usually require some discretionary hearing for a CUP to process such a request with the Planning Commission. We have more recently reviewed and older motel / motor inn with the ARB which allowed the maintenance and continued use of an old non-conforming pole sign, which is non-conforming to today's code. 
4. What types of signs or sign materials will be encouraged by the draft ordinance's regulations, and what types of signs or sign materials will be strongly discouraged or newly prohibited? What was the reasoning for these preferences?

Shanna: The proposed code will newly propose the prohibition of Animated signs., Signs with open and/or unshielded light bulbs and light bulb strings, including rope lighting, Roof signs or any signs extending above the primary roofline or roof eave, unless no other location exists on the site for proper identification, Off-premises signs. Signs shall not advertise a business, accommodation, service or activity not provided on the premises on which the sign is located, except with approval of an Encroachment Permit in compliance with Chapter 12.08 (Street and Sidewalk Obstructions) of the Municipal Code, Pole signs, Mobile signs, Signs in the public right-of-way, except with approval of an Encroachment Permit in compliance with Chapter 12.08 (Street and Sidewalk Obstructions) of the Municipal Code, Tethered inflatable advertising signs/objects, Obscene signs as defined in State law, and Human Signs.

These signs are viewed as less appropriate at our small scale. The code already encourages smaller scale size, reducing the heights of signs and reducing the quantity of signage. Our new code will also require that storefronts maintain reduce signage to allow view of the interior of stores. This is considered in our general plan as an objective for friendly pedestrian commercial frontages.

5. If different at all, would you say the draft ordinance is more restrictive overall, or less restrictive overall? Were there specific reasons for making the draft ordinance more or less restrictive? Shanna: The proposed code would appear more restrictive, since it is more clear and explicit in its language. In reality, the code will better explain and codify the generalities outlined in the general plan and design guidelines, hopefully to make it easier to design and get signs approved. I think that my making the code more explicit, say for explain signs that are prohibited, staff can determine more easily what signs can be permitted and avoid confusion or delays for applicants. I think it will also help with Code Enforcement, so there is fewer questions about what is allowed and what is not.

6. Morro Bay does not currently have a code enforcement officer, and it is evident that illegal signs exist within the City. Besides hiring an enforcement officer, are there more creative ways of expelling illegal, non-conforming signage, or perhaps preventing them in the first place? How does Carpinteria deal with illegal signs?

Shanna: We do use our code enforcement office for newly installed illegal signs. We have not done much to abate older existing signs, as we tend to deal with them with changes to signs or new tenants. We do not have direction to abate old signs at this time unless they are worn and dilapidated. This seems to be a self correcting concern and we have not needed to get too involved in repairs and maintenance. We deal with complaints typically, through code enforcement.

I could see that planning staff could send letters, as our code division does and state the same codes and facts. I assume there is some function that Morro uses to deal with other violations, like building without permit. I would ask how they deal with violations of other codes and see if that mechanism can be mimicked by other staff. 
We also clarified what signs avoid permits or are exempt from permits. This helps to allow some flexibility for certain signage that is small or serves a specific function. We also include a temporary banner permit for special events that allows for larger / special signs that otherwise would not be permissible.

7. What was the toughest decision you and the Carpinteria staff had to make during the creation of the draft sign ordinance? Was there a lack of community consensus, disagreement among staff, or something else that made the decision so hard?

Shanna: We have not yet presented the draft code to the public. We hope to present the whole of our revised zone code sometime this summer. Since the whole code will be reviewed, I expect that signs will get less attention than would if reviewed alone as a chapter. We will have to see where the community is most concerned.

I know many of the items addressed have come from concerns of the Planning Commission, Architectural Review Board and staff as signs have been permitted over the last few years.

8. I am also developing a tourism-oriented directional sign plan for the Downtown and Embarcadero districts in Morro Bay. The plan will focus on the implementation of signs featuring business names and their location (see photo on right). If you were to implement signs like this in Carpinteria, what key advantages and disadvantages would you immediately identify?

Shanna: I had previously encouraged our Public Works Department in Carpinteria to develop a tourism or directional sign program for the City and downtown. We have not spent any real time on the program and instead have a temporary sidewalk sign program for the downtown until a formal program is designed. The temporary program has been in place for many years and allows businesses on side streets to place a sidewalk sign at one of our main streets

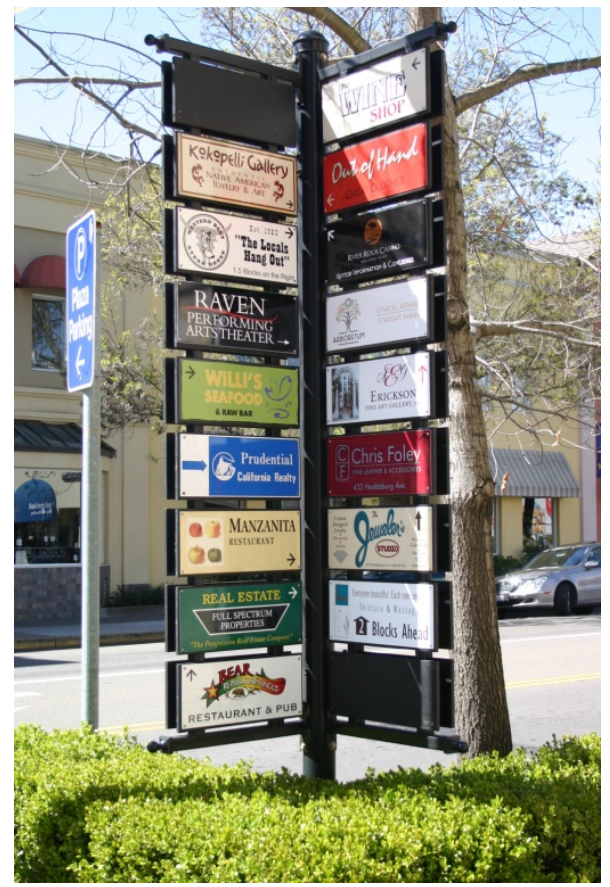
for more pedestrian visibility.
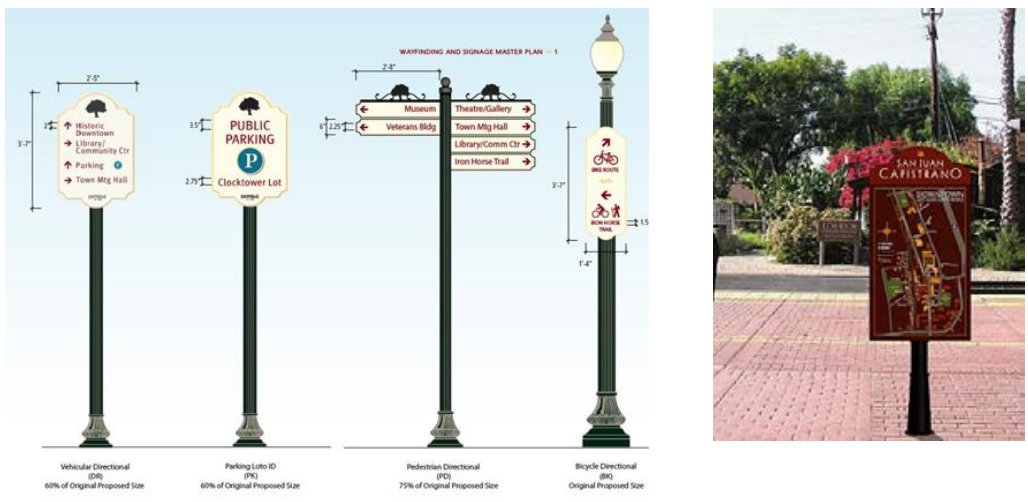
In discussions of the directory sign program, we looked at signs that would help direct pedestrians to businesses off the main streets along side streets and alleys that have less street presence. I would suggest working with the local business community and chamber of commerce to ask about their desires. I think that signs that are more general may be easier to manage, than a sign above. I would want to know if there are fees and rules that limit the use of the sign or if a new business comes in and doesn't fit. I like the idea of a kiosk sign in the public parking lots that are like a mall directory. These signs can have a printed page that is cheaper and easier to change with changes in the business community. The signs above ate more general and civic in nature. I think this is a program that once installed requires little management. Some City's will advertise a district or restaurants, but avoid specific business names on the street signage. Our temporary sidewalk sign program is very time consuming and seemed to generate more code compliance as signs were permitted, more were placed without permits.

9. Do you have any final advice or insight in regards to writing sign ordinances or zoning ordinance in general?

Shanna: I suggest getting the business community involved to find out what their issues and concerns are. I would avoid designing a program without that general guidance first. Our City Council also guided our street sign programs and had very distinct opinions about the program. I am a big believer in outreach before you spend a bunch of time gather information and data. So many different ideas are out there and should be narrowed down to be more manageable. I spent many hours creating idea boards, simply to have them scrapped for a temporary program. I wished we had better direction before spending so much time which seemed to go to waste.

Has there been direction already to head in a particular direction. Consultants can help, but often appear to push for a program that generates more signs and can be overwhelming for a small community. I think a staff person can do much the same work, by looking to find a good program to mimic and then contracting for sign manufacturing only. We looked into consultants in the past, before I worked here, and they went overboard and scared the past council away from any program and therefore nothing was ever adopted. 


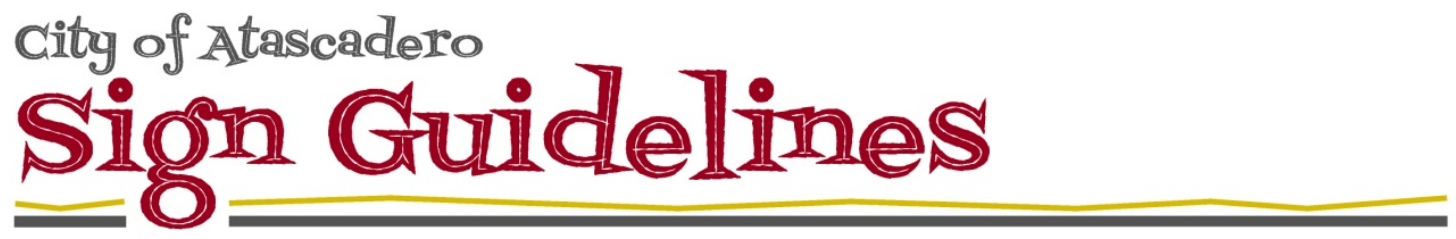

The purpose of the Atascadero Sign Ordinance is to maintain and improve the appearance of the City's business districts. The consistent use of signage is important in maintaining a vibrant business district to attract local customers and tourists.

The following guidelines have been developed to promote economic growth and development, to encourage effective communication, and to enhance the appearance of the City of Atascadero.

\section{Do You Need a Permit?}

$(9-15.003(b))$

Most proposed signs will require a building permit (please refer to Exempt Signs and Prohibited Signs listed below).

If you have additional questions, please contact the Community Development Department at (805) 461-5035.

When submitting your application, please include the following information for Community Development review:

1. Building Permit Application. Available online at www.atascadero.org and at the City Hall Permit Center.

2. Site Plan. Identify the location of all existing structures, existing signs, and proposed signs on site.

3. Construction Plans. Construction plans must be submitted with a building permit application and must include details on how the sign will be attached to the building. Electrical signs must include a wiring diagram. Any new or modified electrical sign must include a completed State Title 24 Electrical Sign Energy Compliance Form (SLTG-IC).

4. Elevations. Provide building elevations where signs are proposed. Include sign dimensions, lettering, length, height, and width. Building elevations should show location of all existing and proposed signs. Be sure to note the size and number of proposed signs.

5. Colors/Materials Board. Provide samples/images of proposed colors and materials for all signs. Include manufacturer's color and material names.

\section{Exempt Signs}

$(9-15.003(c))$

Not all signs will require a sign permit. The following signs may be installed without a permit; however, these signs are still subject to regulations, such as size and display time.

- Real estate signs maximum area: 6 square feet, removed 14 days after sale

- Official government flags

- Banner/temporary signs maximum area: 40 square feet / maximum time: 30 days (please refer to banner handout for specific regulations)
- Residential area signs maximum 4 square feet

- Window lettering not to exceed $50 \%$ of window area

- Construction signs maximum area: 40 square feet / maximum height: 8 feet

\section{Prohibited Signs}

$(9-15.003(d))$

Certain sign types are not permitted within Atascadero's city limits.

Help preserve the aesthetic character of Atascadero by avoiding the use of these signs for your business!

$\begin{array}{llll}\text { - Off-site / billboard signs } & - \text { Feather/advertising flags } & - \text { Roof signs } & \text { - Permanent banner signs } \\ \text { - Signs on vehicles* } & - \text { Animated signs } & - \text { Snipe signs } & \text { - Inflatable signs }\end{array}$

* It is not considered a sign when a message is painted directly upon the vehicle, printed on a vinyl sheet magnet and placed directly upon the vehicle, or when permanently affixed to the body or other integral part of the vehicle.

For specific information on sign regulations and guidelines, please refer to the Atascadero Sign Ordinance available online at www.atascadero.org in the Atascadero Municipal Code and at the City Hall Permit Center. If you would like to talk to a planner about your proposed signs, stop in at City Hall or call the Community Development Department at (805) 461-5035. 


\section{Citg of Atascadero

Banner signs are an effective way to promote business but they must comply with City regulations to provide effective communication and to enhance the appearance of the City of Atascadero.

A banner is defined as any sign of non-permanent, lightweight fabric or similar material (such as paper, canvas, vinyl, etc.) that is attached to a building or other structure erected for another purpose. Banners are permitted within the City of Atascadero, and do not require a building permit, provided they comply with the following regulations.

If you have additional questions regarding the regulation of banners throughout Atascadero, please contact the Community Development Department at (805) 461-5035.

Category

Size / Number

Duration

Exemptions

\section{Banner Regulations}

Businesses may have one (1) banner per public street frontage, with a maximum area of forty (40) square feet

\begin{tabular}{ll}
\hline $\begin{array}{l}\text { Duration } \\
\text { Attachment }\end{array}$ & $\begin{array}{l}\text { Banners may be displayed for a maximum of thirty (30) days. Before any new } \\
\text { banner may be placed, the previous banner must have been down for a period } \\
\text { of sixty (60) days }\end{array}$ \\
\hline Exemptions & $\begin{array}{l}\text { All banners must be secured flat against a building or structure. Fences and } \\
\text { block walls are not considered buildings or structures for banner placement. }\end{array}$ \\
\hline Non-profit events are exempt from the size and number of banners. Contact \\
the Community Development Department to make sure your event qualifies.
\end{tabular}

\section{Banner Examples}

These images provide examples of common violations and permitted banners.

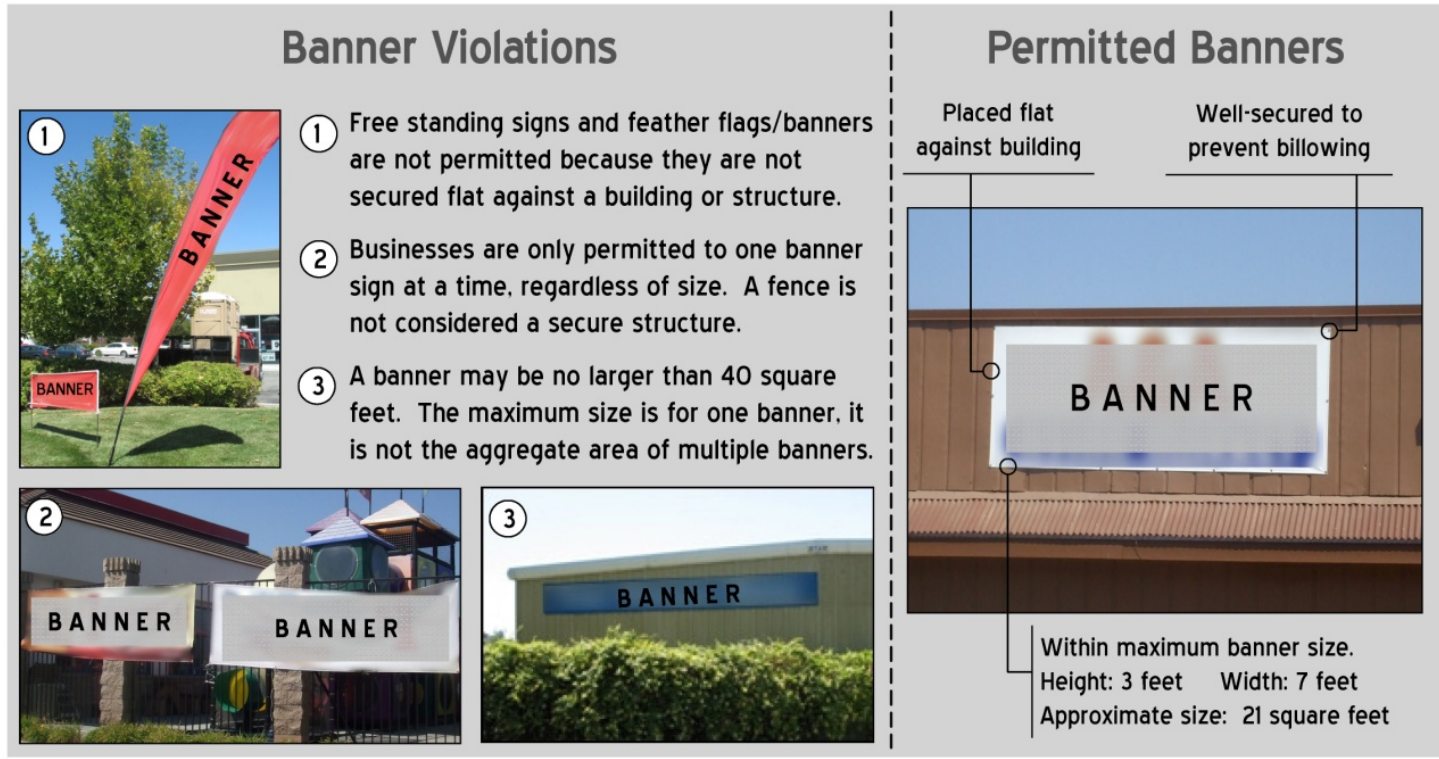




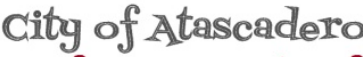 \\ Sigin Guidelines: Commercial/Industrial Zones}

Businesses located in the commercial and industrial zones are permitted up to 125 square feet of signage per site. Check to see if there is an approved sign program for your commercial or industrial site; there may be different regulations for individual centers.

The sign area may be divided between multiple sign types, provided the total square footage does not exceed individual regulations (see below) and total allowed sign area. Remember that color banding and logos are considered to be signs.

For specific regulations on sign types, please refer to the Atascadero Sign Ordinance

\section{Sign Type \\ Regulations \\ Size}

Aggregate area of following signs not to exceed 125 square feet

Standard Wall Sign One sign per building face with One square foot per lineal foot 9-15.005(a)(1)

- or -

Multi-Tenant Signs

9-15.005(a)(5) public street or parking lot frontage

of business frontage

(Maximum size: 40 square feet)

Centers with $3^{+}$tenants may One square foot per lineal foot have 1 tenant wall sign per of business frontage business street frontage (Maximum size: 20 square feet) One sign per 200 lineal feet of public street frontage per site with a landscaped base

Maximum 60 square feet (Maximum height: 10 feet)

9-15.005(a)(2) One sign per business (minimum 8 foot ground clearance)

Maximum 15 square feet Projecting Sign 9-15.005(a)(3)(4)

Sign types not counted toward 125 square feet maximum

\section{Window Lettering}

\& Graphics

9-15.005(c)(10)

\begin{tabular}{|c|c|}
\hline Portable/A-Frame & $\begin{array}{l}\text { One sign per street frontage } \\
\text { (requires Encroachment Permi }\end{array}$ \\
\hline $9-15.00$ & Nalk) \\
\hline
\end{tabular}

\section{Freeway-oriented}

Wall Signs

9-15.005(a)(6)(ii)(iii)

\section{Highway 101 street frontage may}

have a sign

lineal feet of building frontage
(Maximum size: 60 square feet)

Restaurants, service stations, hotels/motels, and new

Freeway-oriented

Pole Signs

9-15.005(a)(6)(i)

automobile dealerships
Maximum width: 2 feet

Maximum height: 5 feet

Minimum height: 3 feet
One square foot per lineal foot of freeway-oriented business frontage

(Maximum size: 150 square feet adjacent to Highway 101 or

Highway 101 street frontage may have one sign

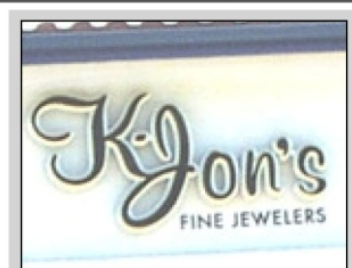

The K-Jon's wall sign is clean against the wall and easy to read. The gold outline against the navy coloring adds depth to the sign.

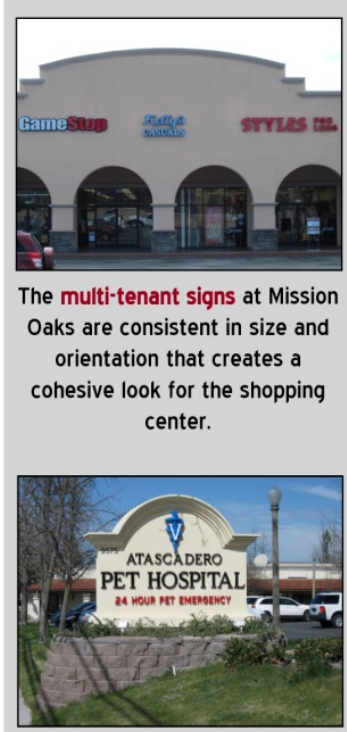

The Atascadero Pet Hospital monument sign clearly identifies the business. The addition of landscaping and a decorative base create a positive sign aesthetic. Maximum height: 50 feet) 
Businesses located in the downtown districts are permitted one square foot of sign area per lineal foot of business street frontage. Total signage cannot exceed 50 square feet and all businesses are permitted at least 20 square feet of sign area.

The sign area may be divided between multiple sign types, provided the total square footage does not exceed individual regulations (see below) and total allowed sign area.

The design, materials, illumination, and location of signs in the downtown districts will be reviewed for consistency with the Downtown Design Guidelines, available online at www.atascadero.org and at the City Hall Permit Center.

For specific regulations on sign types, please refer to the Atascadero Sign Ordinance.

\begin{tabular}{ccc|} 
Sign Type & Regulations & Size \\
\hline $\begin{array}{c}\text { Aggregate area of following signs not to exceed } 50 \text { square feet } \\
\text { 9-15.005(b)(4)(i) }\end{array}$ & $\begin{array}{c}\text { One sign per business (corner } \\
\text { buildings may have two signs, } \\
\text { can/box signs are not allowed) }\end{array}$ & $\begin{array}{c}\text { One square foot per lineal foot } \\
\text { of business street frontage } \\
\text { (Maximum: } 50 \text { square feet) }\end{array}$ \\
$\begin{array}{c}\text { Awning Sign } \\
\text { 9-15.005(b)(4)(ii) }\end{array}$ & $\begin{array}{c}\text { May be used in place of allowed } \\
\text { wall signs (business may not } \\
\text { have both) }\end{array}$ & $\begin{array}{c}\text { Maximum 25\% coverage of the } \\
\text { awning face }\end{array}$ \\
$\begin{array}{c}\text { Projecting Sign } \\
\text { 9-15.005(b)(4)(iii) }\end{array}$ & One sign per business & $\begin{array}{c}\text { Maximum } 9 \text { square feet per side } \\
\text { (if double-sided, both sides } \\
\text { counted in total sign area) }\end{array}$ \\
\hline
\end{tabular}

Sign types not counted toward 50 square feet maximum

\section{Window Lettering \\ \& Graphics}

9-15.005(b)(4)(v)

Signs should be directly painted, or affixed by decal, on window

Maximum $20 \%$ coverage of the window area, or 20 square feet. whichever is less

$\begin{array}{cc}\text { Multi-Tenant } & \begin{array}{c}\text { Design must be consistent with } \\ \text { architectural style and features of Maximum } 72 \text { inches per tenant } \\ \text { Directory Sign } \\ 9-15.005(\text { b)(4)(vi) }\end{array} \\ \text { building facade }\end{array}$

Building Name
Sign
$9 \cdot 15.005(\mathrm{~b})(4)(\mathrm{vii})$$\quad \begin{gathered}\text { Sign permitted on buildings with } \\ 3^{+} \text {tenants }\end{gathered}$

\begin{tabular}{ccc} 
Portable/ & One sign per street frontage & Maximum width: 2 feet \\
"A-Frame" Signs & (requires Encroachment Permit & Maximum height: 5 feet \\
$9-15.005($ b)(4)(vii) & when placed on sidewalk) & Minimum height: 3 feet \\
\hline
\end{tabular}

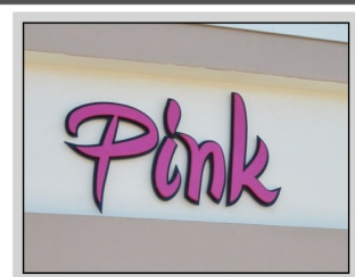

Pink Salon's vibrant wall sign creates a bold look against the building and draws attention to the business.

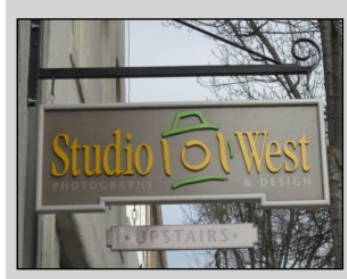

The projecting sign for Studio 101 West is fun and expresses the type of business. The curve on the bracket adds an artful decoration.

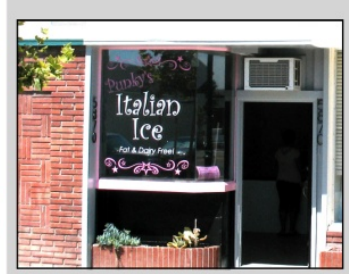

Punky's Italian Ice window lettering projects a fun vibe. The pink and white contrast nicely with the darker window.

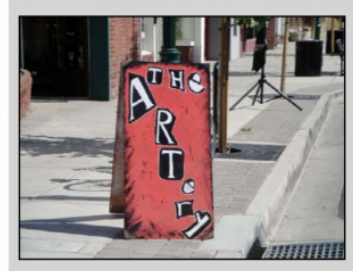

The portable sign for The Artery has vibrant colors and good contrast. The size is appropriate for both pedestrians and automobiles. 


\section{Appendix 6.1 \\ Current Sign Ordinance}

Chapter 17.68 - SIGNS

\section{Sections:}

$\underline{17.68 .010 \text { - Purpose and intent. }}$

$\underline{17.68 .015}$ - Findings.

17.68 .020 - Definitions.

$\underline{17.68 .030 \text { - Prohibited signs. }}$

17.68.040 - Advertising on city property.

$\underline{17.68 .050 ~-~ M i s c e l l a n e o u s ~ s p e c i f i c a t i o n s . ~}$

$\underline{17.68 .060 \text { - Permits. }}$

$\underline{17.68 .070 \text { - Exceptions. }}$

17.68 .080 - Minor adjustments.

$\underline{17.68 .090 \text { - Planning commission interpretation. }}$

17.68.100 - Exception permits.

$\underline{17.68 .110 ~-~ S i g n s ~ i n ~ v a r i o u s ~ z o n e s . ~}$

17.68.120 - Miscellaneous signs and their regulations.

$\underline{17.68 .130 ~-~ M a i n t e n a n c e . ~}$

17.68.140 - Abandoned signs.

$\underline{17.68 .150}$ - Existing nonconforming signs.

17.68.155 - Time limits for nonconforming signs.

$\underline{17.68 .160 ~-~ P e n a l t i e s ~ f o r ~ v i o l a t i o n . ~}$

\subsubsection{0 - Purpose and intent.}

It is the purpose of this chapter to regulate signs as an information system which expresses the character and environment of the city and its community. It is further intended that these regulations recognize the importance of business activity to the economic vitality of the city. Standards shall attempt to:
A. Encourage communications which aid orientation and identify activities;
B. Preserve and enhance the aesthetic character of the surroundings;
C. Relate signing to basic principles of good design, encouraging pleasing community appearance; and 
D. Restrict signs which overload the public's capacity to receive information, violate privacy or which increase the probability of accidents by distracting attention or obstructing vision.

(Ord. 445 \& 3 (part), 1995)

\subsubsection{5 - Findings.}

In adopting the regulations for signs, the city council does find the following:

A. That an excessive amount of signage, both in terms of number and size, as well as improper shape or design, can be distracting to motorists and pedestrians and this condition adversely effects the public safety by creating a potential traffic hazard;

B.That excessive and poorly designed signs are confusing and reduce the effectiveness of all signs; this condition reduces the ability of residents and visitors to readily locate public facilities as well as businesses and services. Consequently, this condition not only adversely affects public safety by interfering with safe travel but also affects the public welfare by reducing convenience to residents and visitors and the viability of commercial districts; C.That signs provide important information to the public for a variety of purposes: excessive and poorly designed signs interfere with the effective transmitting of this information to the detriment of the public welfare;

D.That excessive and poorly designed signs detract from the city's appearance and visual environment: this fact is recognized both in the city's general plan as well as its certified local coastal program. The visual environment is important to the property values and pleasant, enjoyable quality of life for residents and, therefore, signs which degrade that environment adversely affect the public welfare. Furthermore, the visual quality of the coastal zone, which encompasses virtually the entire city, is recognized in the California Coastal Act as a resource of statewide importance and, therefore, regulation of the size, shape, design and other features of signs which become part of the visual environment and which can detract from it if not carefully controlled is important for protecting this public resource. Also, the visual quality of the city enhances its appeal to the tourists who contribute significantly to the local economy; therefore, protection and enhancement of the visual environment is important to the vitality of the local economy.

(Ord. $445 \& 3$ (part), 1995)

\subsubsection{0 - Definitions.}

For purposes of this chapter, the following definitions shall apply:

"Area of sign" means and shall be computed as the entire area measured in square feet, within a single continuous perimeter enclosing the extreme limits of lettering, representations, emblems, logos or any figure or integral part of the display or used to differentiate such sign from the background against which it is placed (exclusive of a background panel the same color as the wall to which it is attached). Only one face of a double-faced sign shall be considered in determining sign area provided both sides are of essentially similar design and not more than twelve inches apart and on planes parallel to each other. The support, uprights or structure on which any sign is supported shall not be included in determining the sign area unless such supports, uprights or structures are designed 
in such a manner as to form an integral part of the sign display. Where a sign consists of a series of individual letters, numerals, symbols or other similar components and is painted or attached flat against the wall of a building or structure, and where such components are without integrated background definition and are not within a circumscribed or framed area, the total area of the sign shall be defined as the sum of the area within not more than eight straight lines enclosing such components plus twenty percent of the area within the lines. Stripes or designs on the building whose principal purpose is to accentuate, highlight or exaggerate sign(s) shall be construed as part of such signs(s) when calculating area of sign(s).

"Attraction board" means a device used to display information regarding conveniences, services and rates currently offered by facilities providing temporary accommodation.

"Bench sign" means a sign located on any part of the surface of a bench or seat placed on or adjacent to a public right-of-way.

"Billboard" means the same as outdoor off-site freestanding sign.

"Canopy" means an ornamental rooflike structure upon which a sign may be attached or otherwise affixed which is usually located over gasoline pumps.

"Changeable copy sign" means a sign designed so that characters, letters or illustrations can be changed or rearranged without substantially altering the face or the surface of the sign.

"Director" means the community development director or his authorized representative(s).

"Display structures" for pedestrian viewing mean and include enclosed display of products sold, bulletin type advertising stands such as racks or directory signs as defined in this section.

"Display surface" means the area made available by the sign structure for the purpose of making visible the advertising message.

"Freestanding sign" means any sign which is supported by one or more uprights, poles or braces in or upon the ground which are not a part of any building or enclosed within the exterior walls of any building, and are separated therefrom by a distance of a least six inches.

"Frontage" means, for purposes of computing allowable sign area, the linear measurement in feet of the property line directly fronting on a public street, or other public right-of-way to which such sign is oriented, excluding California State Highway One.

"Height of a sign" means the greatest vertical distance measured from the ground level directly beneath the sign to the top of the sign or from the nearest property line fronting on a public street, whichever is lower.

"Illuminated sign" means a sign which uses an artificial light source to make the message readable. 
"Marquee" means a permanent roof structure attached to and supported by a building and projecting therefrom. A "marquee sign" is any sign affixed to a marquee.

"Monument sign" means a freestanding sign not exceeding eight feet in height and relating to the design and building materials and the architectural theme of the buildings on the same property.

"Outdoor-off-site freestanding sign" means a sign placed for the purpose of advertising products or services that are not produced, stored or sold on the property or any other subject not related to the property or use of the property, upon which the sign is located.

"Pole sign" means any freestanding sign exceeding eight feet in height.

"Projecting sign" or "pedestrian sign" means a sign other than a surface sign which extends outwards, suspended from or supported by a building or structure.

"Roof sign" means a sign erected upon, over or above the roof of a building or structure, or any sign affixed to the wall of a building so that it projects above the eave line of a roof.

"Sign" means any medium, including its structure and component pans, which is primarily used for, or having the effect of attracting attention from streets, parking lots, sidewalks or other outside public private areas.

"Temporary sign" means any sign, banner, pennant, valance or advertising display constructed of cloth, canvas, light fabric, cardboard, wallboard, paper or other light materials, with or without frames, intended to be displayed for a limited period of time only.

"Wall sign" means any sign attached to, erected against or painted upon the wall of a building or structure, the face of which is in a single plane parallel to the plane of the wall. Such sign shall not project from the building more than twelve inches, or extend above the roofline or parapet line.

"Wind sign" means banners or objects of plastic or other light material designed to move and attract attention for purposes of advertising upon being subjected to pressure by wind or breeze.

"Window sign" means any sign placed inside or upon a window facing the outside and which is intended to be seen from the exterior.

(Ord. $445 \& 3$ (part), 1995)

\subsubsection{0 - Prohibited signs.}

The following types of signs are prohibited:

A.Roof signs, except as otherwise provided in this section;

B.Signs which incorporate, in any manner, any flashing, moving, pulsating or intermittent lighting, with the exception of approved time and temperature displays;

C.Signs in connection with any home occupation; 
D.Bench signs or advertising signs located on other similar structures provided for the use of passengers along the route of a bus, not including plaques containing the names of persons or organizations which have made gifts or donations of such street furniture;

E.Signs which make noise;

F.Signs placed or displayed on vehicles parked in a conspicuous location to be used for onsite or off-site advertising, with the exception of signs advertising such vehicles for sale and vehicle identification signs in locations where sale of vehicles is permitted;

G.Billboards;

H.Tire stacks;

I.Signs incorporating the words "stop," "look," or "danger;"

J.Illuminated signs of red, green or yellow within a view of a signalized intersection, or any unofficial sign, signal or device which purports to be or is an imitation of or resembles, any official traffic sign or signal, or which attempts to direct the movement of traffic, or which interferes with the visibility of any official traffic control device or warning signal;

K.Sandwich board or A-frame signs, and other portable signs or posters of a miscellaneous or temporary character which are tacked, painted, pasted or otherwise placed or affixed and made visible from a public way, on the walls of buildings, on barns, sheds, trees, fences, utility poles or other structures, sidewalks or patios, except as otherwise provided in this section;

L.Signs which move or rotate in whole or in part, except for barber poles or clocks;

M.Signs, banners, pennants, valances or any other advertising display constructed of cloth, canvas, light fabric, paper, cardboard, wallboard or other light materials except for awnings and temporary signs as provided for in this chapter;

N.Signs on fences or free standing walls not part of a building.

(Ord. $445 \S 3$ (part), 1995)

\subsubsection{0 - Advertising on city property.}

No person, except a public officer in performance of a public duty, shall paste, post, print, nail, tack, suspend or otherwise affix or place any card, banner, handbill, sign, poster, flag, advertisement or notice of any kind over any sidewalk, alley, street, land, park or other public place or property of the city, except as may be required by other city, county, state or national regulations, or without first obtaining the approval of the planning director. Application for such approval shall be made in writing stating the manner of intended use the method of erection and the purpose of intended use and the length of time requested. The director may require an exception permit or such other required permit prior to approving such uses.

(Ord. $445 \& 3$ (part), 1995)

\subsubsection{0 - Miscellaneous specifications.}

A.Obstruction to Exits. No sign shall be erected so as to obstruct any fire escape, required exit, window or door opening intended as a means of egress. 
B.Obstruction to Ventilation. No sign shall be erected which interferes with any opening required for ventilation.

C.Clearance from Electrical Power Lines and Communication Lines. Signs shall maintain all clearances from electrical conductors in accordance with the regulations of the California Public Utilities Commission and the orders of the Division of Industrial Safety, state of California, and from all communications equipment or lines located within the city.

D.Clearance from Surface and Underground Facilities. Signs and their supporting structures shall maintain clearance and noninterference with all surface and underground facilities and conduits for water, sewage, gas, electricity and communications equipment or lines. Signs shall not be placed in public utility easements unless express written permission from the affected public utility is obtained for the sign.

E.Drainage. The roofs of canopies or marquees exceeding twenty-five square feet shall be drained to prevent dripping or flow onto public sidewalks or streets and shall be connected to an approved disposal source of adequate conductors.

F.Visible Supports. Visible angle iron or other frames supporting projecting signs and canopy signs as well as chain supports are prohibited, except those structures of an artistic nature which are integral to the sign's aesthetic design.

G.Glare Prohibited. No sign shall be permitted to emit undue reflection or glare on surrounding property. No sign shall emit or reflect light exceeding ten foot-candle power at ten feet from the face of the sign.

H.Sign Orientation. No sign shall be permitted which is so oriented as to be viewed primarily across an adjacent private property line; all signs must be visible directly from a public right-of-way, other public open space or parking lot or courtyard on the same site as the sign, without view lines extending over private property different from that on which the sign is located.

I.Lighting. Light sources shall be steady and stationary. Lighting shall not be distracting to pedestrians, motorists and neighboring property. No sign shall emit or reflect light exceeding ten footcandle power at ten feet from the face of the sign.

J.Projecting Signs and Rooflines. No projecting sign shall extend above the roofline or parapet of the building or structure to which it is attached.

(Ord. 445 \& 3 (part), 1995)

\subsubsection{0 - Permits.}

A.Required. No sign shall be erected or altered, including painted signs, without first obtaining a permit to do so from the director or his authorized representative, except as otherwise provided in this chapter. No permit shall be issued for any sign which does not conform to adopted sections of the Uniform Building Code and Uniform Sign Code and to other applicable provisions of the construction standards of the city. The director may apply reasonable conditions to the approval of a sign permit to help ensure compliance with this chapter.

B.Application. Application for a sign permit shall be made in writing upon forms furnished by the community development department. Such application shall include a sign plan as required in this section. 
C.Fees. Applications for a sign permit shall be accompanied by a fee in the amount set by resolution of the city council.

D.Sign Plan Required. Application for a sign permit as required by this chapter shall be accompanied by a plan or plans drawn to scale, which includes the following:

1 .The proposed design, dimensions, copy, color, lighting methods and location of the sign on the property, including the dimensions of the sign's supporting members, and details of all connections, guy lines, supports and footings, and materials to be used;

2.The maximum and minimum height of the sign;

3. The method of attachment to any structure;

4. The position (orientation) of the proposed sign and its relation to adjacent buildings and structures, property lines and public rights-of-way;

5. The size and color relationships of such sign to the appearance and design of existing or proposed buildings and structures on the property;

6. The location of off-street parking facilities, including major points of entry and exit for motor vehicles where directional signs are proposed;

7. The sizes and dimensions of all other signs existing on the property;

8.The location and size of any building(s) or structure(s) on the property, both existing and proposed;

9.A statement of sign valuation;

10.Such other information as the community development director may reasonably require to secure compliance with this chapter and the ordinances of the city;

11.Where the scale and scope of the sign proposal so warrants, the director may waive some of the informational requirements above, provided all information necessary for adequate review of the proposal is submitted.

E.Sign Review Criteria. The allowed number and area of signs as outlined in this chapter are intended to be maximum standards which do not necessarily ensure architectural compatibility. Therefore, in addition to the enumerated standards, consideration shall be given to a sign's relationship to the overall appearance of the subject property. Simplicity and sign effectiveness shall be considered along with the following criteria in review of signs. In approving a sign permit or sign exception permit as provided for in Section 17.68.070 the reviewing body must find that these criteria are met:

1.The sign is consistent with the intent and purpose of this chapter;

2.The sign does not constitute a detriment to public health, safety and welfare;

3.The size, shape, color, materials, design and location of the sign are compatible with and bear harmonious relationship to all signs on a parcel and to the use, as well as to the neighborhood and surroundings;

4.Signs on all proposed buildings or new additions to existing buildings are designed as an integral part of the total building design;

5.The location of the proposed sign and the design of its visual elements (lettering, words, figures, colors, decorative motifs, spacing and proportions) are legible under normal viewing conditions prevailing where the sign is to be installed;

6.The location and design of the proposed sign does not obscure from view or unduly detract from existing or adjacent signs; 
7.The location and design of the proposed sign, its size, shape, illumination, and color does not detract from or interfere with or intrude upon adjacent properties or their occupants; 8.The location and design of a proposed sign in close proximity to any residential district does not adversely affect the value or character of the adjacent residential district;

9.Review of signs at city entryways as defined in the city's scenic highway element shall also be subject to the following provisions:

a.Sign area, height and location shall be designed so as not to interfere with view corridors as defined and specified in the coastal plan/coastal element; b.Freestanding signs shall not exceed eight feet in height except within two hundred feet of Highway One or Highway 41 where the provisions of Section 17.68.110 shall apply. Where feasible, all freestanding signs within or along city entryways shall be placed within a landscaped planter.

(Ord. 445 \& 3 (part), 1995)

\subsubsection{0 - Exceptions.}

The following signs or modifications to signs shall not require a sign permit. These exceptions shall not be construed as relieving the owner of the sign from the responsibility of its safe erection and safe and attractive maintenance, and its compliance with applicable provisions of this chapter or any other law or chapter regulating same:

A.Changing Copy. The changing of the advertising copy or message of an approved sign specifically designed for the use of replaceable copy;

B.Maintenance. The electrical, repainting or cleaning maintenance of a sign;

C.Nameplates. Signs not exceeding one square foot in area and bearing only property numbers, post box numbers, or names of the occupants of premises;

D.Government Flags. Flags and insignia of any government, except when displayed in connection with commercial promotion;

E.Legal Notices. Legal notices, identification information, or directional signs erected by government bodies;

F.Architectural Features. Integral decorative or architectural features of buildings except letters, trademarks, moving parts or lights;

G.Traffic Direction Signs. Signs directing and guiding traffic and parking on private property, not exceeding three square feet in area but bearing no advertising matter;

H.Announcement Signs. One sign per street frontage on real property where construction, structural alteration or repair is to take place, or is taking place, which contains information regarding the purpose for which the building is intended and the individuals connected with the project, including names of architects, engineers, contractors, developers, finances and tenants, provided the area of such sign shall not exceed sixteen square feet in area; I.Real Estate and "Open House" Signs. During the period which real estate is offered for sale or lease, one sign per frontage not exceeding four square feet in area in R-l or R-2 residential districts, or eight square feet in other districts, advertising the sale, lease, or rent of the 
property upon which it is located and the identification of the person or firm (agent) handling such sale, lease or rental. Such signs shall not exceed six feet in height. No flags or banners are permitted. One off-site "Open House" sign, not to exceed eighteen inches by twenty-four inches in area for providing direction to real estate which is available for inspection and sale, during daylight hours only, for a period not to exceed thirty days and with permission of property-owners of site on which such sign is placed;

J.Subdivision Signs. One sign per street frontage, signs not exceeding fifty square feet in aggregate area, for the advertising of the sale of a subdivision may be displayed on the site of the subdivision upon approval of a final map and initiation of construction for a period of one year. The display period may be extended by written approval of the planning director for a reasonable period of time, not to exceed one year at any one time;

K.Plaques. Commemorative plaques placed by historical agencies recognized by the city of Morro Bay and county of San Luis Obispo or the state of California, consisting of noncombustible material (e.g. bronze or stone);

L.Political Campaign Signs. Political campaign signs not to exceed sixty-four square feet in area per site shall be permitted only on private property;

M.Signs on Awnings, Etc. Painted, nonilluminated or indirectly lighted signs may be permitted on the borders of canopies, awnings, arcades or similar attachments or structures if located and, erected in a manner satisfactory to the director or an authorized representative.

Such signs shall be included in the total permitted sign area;

N.Decorative Wind Socks. Decorative wind socks not exceeding six feet in length, not advertising any location, business, goods or services and not extending over public property. Such signs extending over public property shall obtain a sign permit prior to installation; O.Garage Sale Signs. One unlighted sign shall be permitted for garage sales, provided such sign shall not exceed four square feet in area and shall be displayed on the property where such sale shall take place and only on the day of said sale.

(Ord. 493, 2002; Ord. 445 § 3 (part), 1995)

\subsubsection{0 - Minor adjustments.}

The director may grant for either new or existing signs, minor adjustments to sign colors, landscaping requirements or height, or authorize deviations from sign area not to exceed twenty percent; and on sloping roofs, the allowance of roof signs not to extend above the ridge line, for existing buildings only, when it is determined that no other possible, reasonable method of sign is available. In granting adjustments, the director may apply reasonable conditions to help ensure that the provisions of this chapter are met.

(Ord. $445 \& 3$ (part), 1995)

\subsubsection{0 - Planning commission interpretation.}

The planning commission shall have authority and duty to interpret the provisions of this chapter at the request of the planning director, or when a written appeal from a decision of the director is filed with the planning commission. Decisions made by the planning commission may be appealed to the city council within ten days of that decision. 
(Ord. 445 \& 3 (part), 1995)

\subsubsection{0 - Exception permits.}

Exception permits for signs not conforming with the provisions of this chapter may be granted by the planning commission, pursuant to the following provisions:

A.Application. Application for an exception permit shall be made by the sign owner or by the lessee if approved by the property owner in writing, on a form prescribed by the city, and shall be accompanied by a fee as established by resolution of the city council;

B.Public Hearing. Upon receipt of the required application and fee, a public hearing shall be held by the planning commission. Notice of such hearing shall be given by publication in the official newspaper of the city at least ten days prior to the hearing and by mailing the notice, postage prepaid, at least five days prior to the hearing to all property owners whose names and addresses appear on the latest adopted tax roll as owning property within a distance of three hundred feet from the exterior boundaries of the applicant's property; C.Provisions for Granting. Exception permits may be granted if the commission finds that the sign will not be contrary to the purposes of this chapter, will not be materially detrimental to the health, safety, comfort or general welfare of persons residing in the neighborhood or detrimental or injurious to property or improvements in the neighborhood or to the general welfare of the city, and that adverse effects can be prevented with the imposition of conditions. The planning commission may impose conditions on the approval of a sign exception permit to ensure that the above listed provisions are met; D.Imitating Traffic Signs. Exception permits shall not be granted for signs imitating traffic signs or affecting visibility of traffic-control devices, as prohibited in this chapter. No exception permit shall be granted for illuminated signs of red, green or yellow within view of a signalized intersection;

E.Appeal. In cases where the applicant or any other person is not satisfied with the action of the planning commission, they may within ten days, appeal the decision of the commission to the city council on forms provided by the city. Notice shall be given to the planning commission of such appeal and the commission shall submit a report to the city council setting forth the reasons for the action taken. The city council shall render its decision within sixty days after the filing of such appeal.

(Ord. 445 \& 3 (part), 1995)

\subsubsection{0 - Signs in various zones.}

The following regulations regarding signs shall apply to the specified zoning districts as provided below: sign permits shall be required for the sign types described in the following zones unless expressly exempted:

A.Agriculture Zone. One unlighted sign per street frontage for the purpose of advertising the sale of products grown on the premises may be allowed in the agriculture zone and shall not require a sign permit. The aggregate area of such signs shall not exceed eight square feet per property.

B.Residential Zones. The following signs may be permitted in residential zones: 
1.Surface Signs. One identification surface sign not to exceed twenty square feet in area shall be permitted on any multifamily dwelling of more than four attached units; 2.One surface sign or monument sign not to exceed .5 square feet per one linear foot of frontage or twenty-four square feet, whichever is less, shall be permitted for other allowable nonresidential uses, except as otherwise provided in this chapter;

3.For hotels, motels and bed and breakfast establishments in R-4 districts, signs may be permitted in accordance with the provisions for commercial and industrial zones as provided in subsection I of this section as well as attraction boards as provided in Section 17.68.120

4.For bed and breakfast establishments in R-3 districts, one surface sign or monument sign not to exceed .5 square feet for each linear foot of frontage, and attraction boards as provided in the Section 17.68.120

5.Subdivision or Tract Name Signs. One nonilluminated sign not to exceed twentyfour square feet in area or one nonilluminated sign not to exceed twelve square feet each per exclusive entrance to a subdivision or tract name with a maximum of four per tract shall be permitted;

6.Mobile Home Parks. A mobilehome park may be allowed one externally illuminated or nonilluminated identification sign, not to exceed the equivalent of one square foot of sign area per ten linear feet of frontage on each right-of-way upon which it takes vehicular access. No sign shall have a surface area of greater than thirty square feet or be erected at right angles to the right-of-way. Such signs shall not exceed eight feet in height.

C.Commercial and Industrial Zones. The following signs may be permitted in commercial and industrial zones, except the G-O zone:

1.Surface signs and aggregate allowable area per site:

a.Provided no other types of signs are erected on the property, surface signs may be permitted to a maximum area of two square feet for each one linear foot of building frontage on the site.

b.Where surface signs are used in conjunction with other types of signs on the same site, the aggregate area allowed for all signs shall not exceed one square foot for each one linear foot of building frontage on the site.

c.Any sign, or the aggregate of all signs for any one property shall require an exception permit if such signs exceed two hundred square feet in area, or except if the sign program is approved pursuant to a conditional use permit or coastal development permit.

2.Monument Signs. One monument identification sign not to exceed six feet six inches in height may be permitted per site. Monument signs set back at least five feet from the property line(s) may be eight feet in height provided, however, such sign is placed in a landscaped planter or berm subject to approval by the director. Monument signs may be placed in required setback areas but must be a minimum of one foot from the property line. Monument signs shall not interfere with safety sight angles on corners and at driveways. As a condition of any sign permit for a monument sign, 
additional landscaping of the site may be required to better integrate sign appearance with the site.

3.Projecting Signs. The total area of a projecting identification sign shall not exceed one square foot for each one linear foot of building frontage on the site. No projecting sign shall encroach more than twelve inches over a public right-of-way. In addition such signs shall be a minimum of eight feet in height above a sidewalk or other public pedestrian right-of-way and shall otherwise comply with applicable provisions of Title 14 of this code.

4.Pole Signs. One pole sign for identification purposes only may be allowed per business site or per shopping center, subject to the following conditions:

a.For a shopping center the total area of the sign shall not exceed one square foot for each linear foot of property frontage, or one hundred square feet, whichever is less;

b.Such signs shall not encroach more than twelve inches over a public rightof-way;

c.Such signs shall not exceed fifteen feet in height; except within two hundred feet of Highway One where twenty-five feet may be approved subject to a conditional use permit approved pursuant to Chapter 17.60 d.Such signs shall be placed within a landscaped planter; e.As a condition of any sign permit for a pole sign additional landscaping of the property may be required where needed to better integrate sign appearance with the site through scale and softening effects; f.Such signs and their supporting elements shall be designed so as to be harmonious with any building or structures on the site, including architectural style, colors and scale; g.Other provisions of this section notwithstanding, no pole sign shall be permitted on a property which fronts on a street right-of-way (excluding Highway One) which directly faces an R-l, R-2 or R-3 zoning district. 5.Marquee Signs. One marquee sign may be permitted in conjunction with theaters, museums, galleries and similar uses subject to obtaining a sign exception permit. One identification sign not to exceed twelve inches in the vertical dimension or six inches in thickness (width) may be placed immediately below the marquee sign. Such sign shall not project beyond the marquee face, nor be less than eight feet above a sidewalk or other public pedestrian right-of-way. Removable copy may be changed on the face of permitted marquee signs without securing a sign permit; 6.Restaurant Menus. In addition to those signs permitted by this chapter, a restaurant may display a sign not to exceed three square feet in area on a wall or window, which displays the menu and/or daily specials;

7.Temporary Signs within Window Area. Temporary informational signs and posters including sale, special events and other similar signs, which do not exceed twentyfive percent of the window area, or ten square feet, whichever is greater may be 
located on the inside of the window, or painted on said window for a period not to exceed thirty days;

8.Frontage and Placement.

a.A business in a building facing on more than one public right-of-way shall be allowed the full authorized sign area on one street and one-half the authorized sign area on the other street(s);

b.Any sign shall be oriented toward the public street on which they are located, or where no such public right-of-way exists, signs shall orient towards a common use parking lot or interior courtyard;

c.Where the principal sign for a business is located so that it cannot be seen by pedestrian traffic, an identification sign, in addition to that otherwise allowed by this chapter may be permitted by the director.

D.General Office Zone. The following signs may be permitted in the general office (G-O) zone: Monument or surface signs may be permitted as provided in subsection $\mathrm{C}$ of this section, except that the total area of all signs on a site shall not exceed one square foot per one linear foot of frontage, and provided however, freestanding signs exceeding eight feet in height are expressly prohibited.

(Ord. 445 \& 3 (part), 1995)

\subsubsection{0 - Miscellaneous signs and their regulations.}

A.Display Structure. Display structures for pedestrian viewing as defined in this chapter shall be permitted in any commercial district upon granting of an exception permit as provided in this chapter. Such display structures shall comply with building setback requirements, shall have a total area not to exceed fifty percent of the sign area requirements as prescribed in the section on commercial and industry zones for surface signs and shall be illuminated only by indirect light, semidirect light or diffused light.

B.Special Private Event Displays and Grand Opening Signs. Temporary signs and wind signs may be erected on the premises of an establishment having a grand opening or special event, provided that such signs shall be displayed for a period not to exceed thirty calendar days previous to such event. Such signs shall be removed within seven days after the event. Such signs may be used for not more than two periods each calendar year for any property or business.

C.Directional and Community Promotional Display Programs. Directional and community promotion sign programs advertising, directing or informing pedestrian of business service or community events and services not related to or located on the site shall be permitted on private property in commercial use areas of the city, and on public lands or rights-of-way upon granting of an exception permit.

D.Civic Event Signs on Private Property. Temporary signs not to exceed thirty-two square feet in area announcing a campaign drive or event of a civic, public, quasi-public, philanthropic, educational or religious organization shall be permitted on private property for a period not to exceed thirty days. Such signs shall be removed within fifteen days after the event.

E.Civic Event Signs on Public Property. Temporary signs announcing a civic, public, quasi public, philanthropic, educational or religious organization purposes may extend over public property subject to obtaining an exception permit as provided in this chapter. Such signs may extend across a public street only by permission of the city council and shall maintain a minimum vertical clearance of fourteen feet six inches. No 
temporary sign may be displayed for a period exceeding thirty days, for each of two periods each calendar year.

F.Attraction Boards for Hotels, Motels and Bed and Breakfast Establishments. An attraction board may be included in the design and allowable sign area for a hotel, motel, or bed and breakfast establishment, subject to the following:

1.The attraction board shall be designed and located so that it is made an integral part of the principal sign except as provided in this section;

2.If the principal sign is designed and located on a building or in such a manner that an attached attraction board sign would detract from the appearance of the sign, a detached attraction board sign shall be allowed provided:

a.That the size of the detached attraction board sign shall be counted as pan of the total allowable sign area;

b.That the maximum allowed size for a detached attraction board sign shall be five square feet;

c.The name of the hotel or motel shall not be indicated on the attraction board sign.

3.The following information shall be allowed on an attraction board sign:

a.Winter rate (excluding amount);

b.Vacancy;

c.Credit cards;

d.TV;

e.Pool;

f.Air conditioning;

g.Continental Breakfast;

h.Any other information as approved by the Director.

G.Signs on Awnings and Similar Overhangs. Painted, nonilluminated or indirectly lighted signs may be permitted on the borders of marquees, canopies, awnings, arcades or similar attachments or structures, but not including mansard-style roofs or eaves, if located and erected in a manner satisfactory to the planning director or an authorized representative. Such signs shall be included in the total permitted sign area.

(Ord. 445 \& 3 (part), 1995)

\subsubsection{0 - Maintenance.}

Every sign, including those signs for which no permit is required, together with all supports braces, guys and anchors shall be maintained in a safe, presentable and good structural condition at all times. The display surfaces of all signs shall be kept neatly painted, posted or otherwise maintained at all times. The owner of property on which the sign is located shall be responsible for the condition of the area in the vicinity of the sign, and shall be required to keep this area clear, sanitary and free from noxious or offensive substances, rubbish and flammable waste materials.

(Ord. $445 \S 3$ (part), 1995) 


\subsubsection{0 - Abandoned signs.}

Any sign which is located on property that becomes vacant and is unoccupied for a period of three months or longer, or any sign which was erected for an occupant or business unrelated to the present occupant or business, except existing, nonconforming outdoor off-site freestanding signs, or any sign which pertains to a time, event or purpose which no longer exists shall be presumed to be abandoned. Permanent signs applicable to a business temporarily suspended because of a change of ownership or management of such business shall not be deemed abandoned unless the property remains vacant for a period of six months or more. An abandoned sign is prohibited and shall be removed, such removal shall be the responsibility of the property owner. Abandoned signs are found to be a public nuisance due to their misleading and distracting nature and due to their contributing to visual blight, detrimental to surrounding areas and the community generally.

\section{(Ord. $445 \& 3$ (part), 1995)}

\subsubsection{0 - Existing nonconforming signs.}

Signs existing at the time of adoption of the ordinance codified in this chapter, which do not comply with the provisions hereof but which were legally erected pursuant to applicable state and city ordinances and policies in effect at the time of construction, shall be regarded as nonconforming signs, and are subject to the following:

A.Whenever there occurs a change in the type of business or use with which a sign is associated, such existing signs for the prior business shall be removed or otherwise made to conform to the provisions of this chapter. B.A nonconforming sign may not be expanded, extended, reconstructed, or altered in any way in its location or orientation to enable it to be read or viewed from a different direction than its original position, except in the following cases:

1.Such sign may be removed for purposes of repair and routine maintenance, including painting, provided such sign is replaced within sixty days of its removal; 2.Minor sign face changes not involving changes in graphic design or color are permitted;

3.Such sign may be removed for the purpose of remodeling a building provided replacement occurs within thirty days after remodeling is completed;

4.If change of ownership of the business occurs, and no change to the type of business advertised by any nonconforming sign, the new owner may change any name or names on such sign provided there is no change in the sign size, configuration or orientation.

C.A nonconforming sign destroyed by the elements, fire or other accidental cause, to an extent exceeding fifty percent of its original valuation shall not be replaced as a nonconforming sign.

(Ord. 445 \& 3 (part), 1995)

\subsubsection{5 - Time limits for nonconforming signs.}

The city council incorporates the time limits for compliance for nonconforming signs as originally adopted by ordinance and modified by Ordinance 242: 
A. Time Limits. There are declared to be the following time periods commencing six months from October 1, 1972, within which all nonconforming signs within the city shall be altered, removed, or otherwise made to comply with the provisions of this chapter:

1.All signs not in conformance with the requirements provided by Chapter 14.64 as in effect on October 1, 1972, eleven years from said October 1, 1972.

2.Exception: The following time period shall apply to signs legally erected pursuant to a valid sign permit issued within two years immediately preceding October 1 , 1972: All signs not in conformance with Chapter 14.64 as in effect on October 1, 1972, fifteen years from permit date.

B. List of Nonconforming Signs.

1.Within six months of October l, 1972, the building official shall compile a list of signs which as of said date do not conform to the provisions of this Chapter 14.64 and are subject to amortization in accordance with subsection A of this section, and file the same in his office.

2.Notification.

a.Within three months after the filing, the building official shall cause to be mailed to the owners of property and the proprietor of premises on which nonconforming signs are located, notice of the existence of such nonconforming signs and the time within which the same must be made to conform or be abated;

b.For purposes of such notification, the last known name and address of the owner of the property in question shall be used, as shown on the last equalized assessment roll of the county of San Luis Obispo;

c.Notification to such owner of the property shall be deemed to be notification to the owner of the sign in question;

d.The mailing of such notice shall be done by certified mail. The failure of the owner to receive the same shall in no way impair the effectiveness of the provisions of this section or the validity of any proceedings taken for the abatement of any such sign.

C.Abatement.

1.Nonconforming signs listed in subsection A of this section, shall either be made to conform with the provisions of this chapter, or abated within the applicable period of time set forth in subsection A of this section.

2.In the event a sign is not abated in accordance with subsection (C)(1) of this section the building official shall order the same abated by the owner of the property and any other person known to be responsible for the maintenance of the sign. It is thereafter unlawful for any such person to maintain or suffer to be maintained any such sign on any property owned or controlled by him.

3.Unless some other mode of abatement is approved by the building official in writing, abatement of nonconforming signs shall be accomplished in the following manner 
a.Movable Signs—-Rotations Exceeding Eight R.P.M. By reducing rate of rotation to eight r.p.m. or less or by removing the sign.

b.Other Signs. By removal of the sign, including its dependent structures and supports; or pursuant to a sign permit dully issued, by modification, alteration or replacement thereto, in conformity with the provisions of this chapter.

(Ord. $445 \S 3$ (part), 1995)

\subsubsection{0 - Penalties for violation.}

A.Whenever a sign is found to be erected or maintained in violation of any provision of this chapter or of any other chapter or law, the director shall order that such sign be altered, repaired, reconstructed, demolished or removed as may be appropriate to abate such condition. Any work required to be done shall be completed within ten days of the date of such order, unless otherwise specified in writing. B.Failure, neglect or refusal to comply with such order of the director shall be sufficient basis for the revocation of any permit granted under this chapter.

C.The director shall have the power and authority to remove or cause to be removed, at the owner's expense, any sign erected or maintained in violation of the provisions of this chapter.

D.The installation and/or maintenance of a sign in violation of this chapter or in violation of any conditions affixed to a sign permit shall be deemed a misdemeanor.

(Ord. 445 \& 3 (part), 1995) 


\section{Appendix 6.2}

Old Draft Sign Ordinance

\section{Chapter 17.68 Sign Regulations}

Sections:

17.68.010 Purpose

17.68.020 Exempt Signs

17.68.030 Prohibited Signs

17.68.040 General Sign Standards

17.68.050 Regulations for Residential Districts

17.68.060 Regulations for Commercial Districts, Mixed-Use and Industrial Districts

17.68.070 Specific Sign Types and Standards

17.68.080 General Design Principles

17.68.090 Zoning Clearance or Sign Permit Required

17.68.100 Master Sign Program

17.68.110 Maintenance, Abandonment, and Removal

17.68.120 Provisions for Nonconforming and Illegal Signs

17.68.130 Appeals

17.68.010 Purpose

The purpose of this Chapter is to regulate signs as an information system that expresses the character and environment of the City of Morro Bay and its community. These regulations recognize the importance of business activity to the economic vitality of the City. Specifically, these regulations are intended to:

A. Encourage communications which aid orientation and identify businesses and activities. 
B. Preserve and enhance the aesthetic character of the City.

C. Apply basic principles of good design and sensitivity to community appearance to signage.

D. Restrict signs that overload the public's capacity to receive information, violate privacy or which increase the probability of accidents by distracting driver's attention or obstructing a driver's vision.

\subsubsection{Exempt Signs}

The following signs or modifications to signs do not require zoning conformance review, nor shall the area of such signs be included in the maximum allowable sign area measurement for the purposes of this Chapter. These exceptions shall not be construed as relieving the owner of the sign from the responsibility of the safe erection and safe and attractive maintenance of the sign, of obtaining a building permit where applicable, or of compliance with applicable provisions of this Chapter or any other requirement of this Title.

A. Announcement Signs. One sign, not exceeding 16 square feet in area and 6 feet in height, per street frontage on real property where construction, structural alteration or repair is to take place, or is taking place, which contains information regarding the purpose for which the building is intended and the individuals connected with the project, including names of architects, engineers, contractors, developers, finances and tenants. Announcement signs are exempt only for the duration of the construction of the building and shall be removed prior to issuance of a certificate of occupancy. FIGURE 17.25-A: ANNOUNCEMENT SIGN STANDARDS

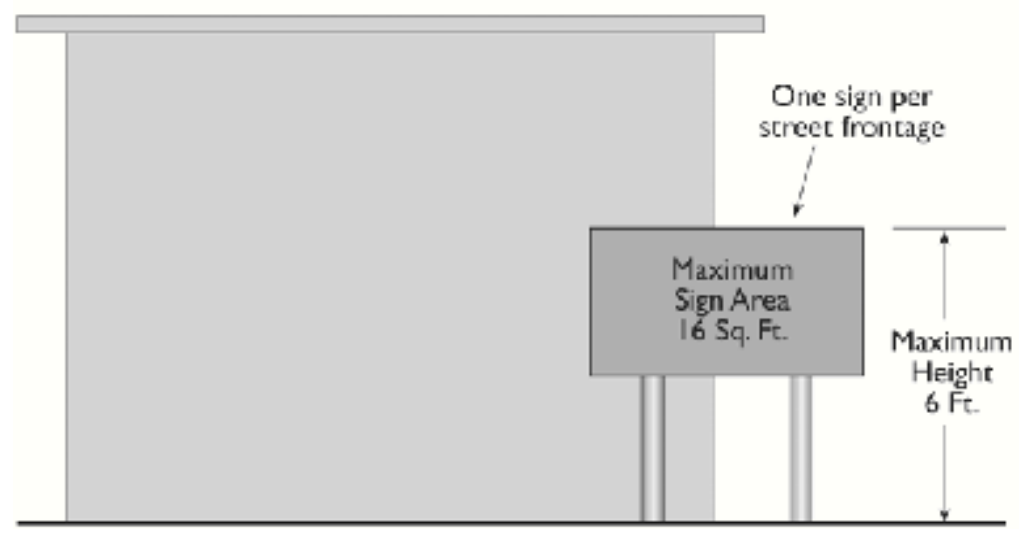


B. Change of Business Signs. A temporary attachment or covering of wood, plastic, or canvas over a permanent sign indicating a change of ownership or activity may be displayed no longer than 30 days following the change of ownership or activity for which the sign is intended, or up to 90 days following issuance of a building permit. The sign shall be no larger than the previously permitted permanent sign.

C. Equipment Signs. Signs, not more than eight square feet in sign area, incorporated into displays, machinery, or equipment by a manufacturer, distributor, or vendor that identify or advertise only the product or service dispensed by the machine or equipment, such as signs customarily fixed to automated teller machines (ATMs), gasoline pumps, menu boards, and umbrellas. If a vending machine is visible from the street, the sign area shall be included in the total sign area allowed for the use.

D. Flags. Flags and insignia of any government, except when incorporated into a commercial sign.

E. Garage Sale Signs. One unlighted sign is permitted for garage sales, provided such sign does not exceed four square feet in area and is displayed on the property where such sale shall take place only on the day of the sale.

F. Mobile Vendor (Non-permanent Vendor) Signs. Signs fixed to mobile vending carts that identify or advertise the name, product, or service provided by the vendor. Each mobile vending cart is limited to a maximum sign area of eight square feet. 


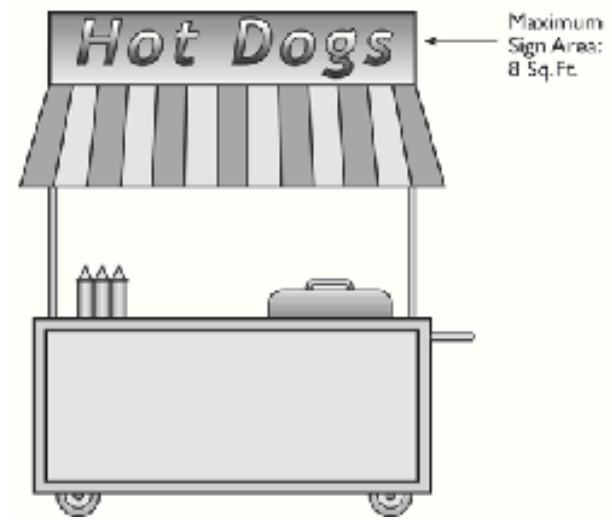

G. Official Government Signs and Legal Notices. Official notices issued by a court, public body or office and posted in the performance of a public duty; notices posted by a utility or other quasi-public agent in the performance of a public duty; historical markers erected by a governmental body; identification information; directional signs erected by government bodies; or other signs required or authorized by law.

H. Parking and Directional Signs. On-site parking and directional signs, not exceeding eight square feet in sign area and five feet in height, that do not include any advertising messages or symbols.

I. Political Campaign Signs.. Political campaign signs not to exceed sixty-four square feet in area per site and shall be permitted only on private property;

J. Real Estate and "Open House" Signs. Signs conveying information about the sale, rental, or lease of a property and the identification of the person or firm (agent) handling such sale, lease or rental, provided they comply with the following standards. Real estate and open house signs are exempt only during the period for which the property is offered for sale or lease.

1. Maximum Number. One on-site per frontage. 
2. Maximum Sign Area.

a. RS or RD Districts. 4 square feet.

b. Other Districts. 8 square feet.

3. Maximum Height. 6 feet.

FIGURE I7.25-C: REAL ESTATE SIGN STANDARDS

RS or RD Districts

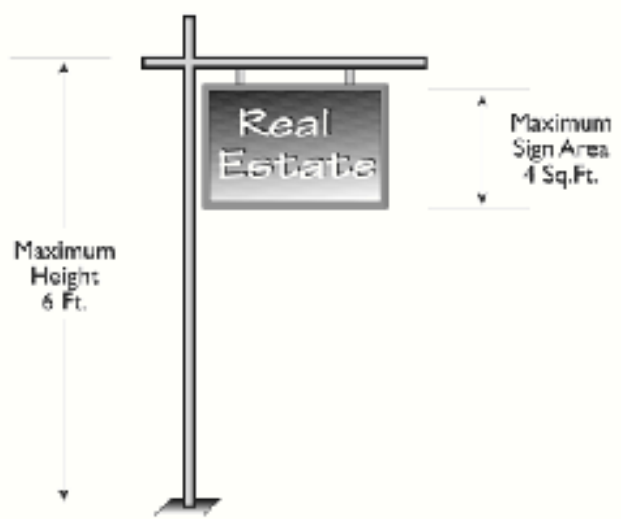

Other Districts

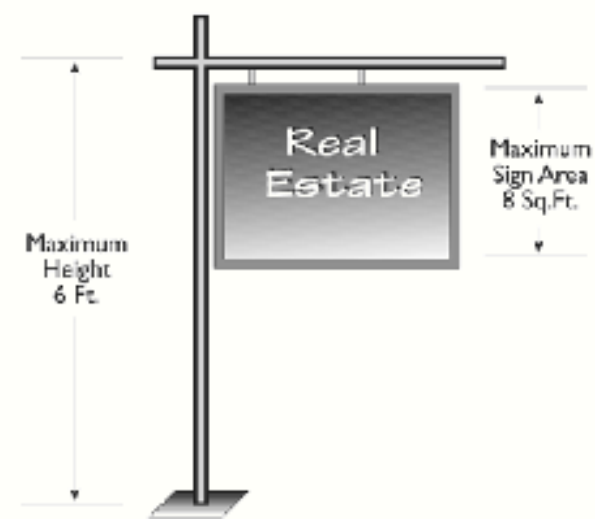

K. Off-Site Directional Sign. One off-site sign not to exceed 36 square feet, providing direction to real estate available for sale or lease, during daylight hours only. Permission from the property owners of the site where the sign is placed is required.

L. Small Signs. Any sign no larger than eight square feet in area, attached to a freestanding sign structure no higher than five feet, a window, or a building wall. This exception may include, but is not limited to, commercial and non-commercial signs, freedom of speech signs, organization identification signs, and commemorative plaques within the required size limits.

M. Subdivision Signs. One sign per frontage, advertising the sale of a subdivision may be displayed on the site of the subdivision upon approval of a final map and initiation of construction for a period of one year. The display period may be extended with written 
approval of the Director for a reasonable period of time, not to exceed one year at any one time.

\begin{tabular}{|l|l|}
\hline TABLE $17.68-$ A: SUBDIVISION SIGNS \\
\hline Maximum Height & $8 \mathrm{ft}$. \\
\hline Maximum Sign Area & $24 \mathrm{sq} . \mathrm{ft}$. \\
\hline $\begin{array}{l}\text { Maximum Number per } \\
\text { Subdivision or Tract }\end{array}$ & 4 \\
\hline
\end{tabular}

N. Window Signs. Window signs not exceeding 20 percent coverage of each glass window or glass door to which the sign is attached or 10 square feet, whichever is greater. Any sign that is hung within three feet of a window, attached to a display located within three feet of a window, or painted on the window is considered a window sign. For temporary window signs, refer to Section 17.68.070.

FIGURE 17.25-D:WINDOW SIGNS
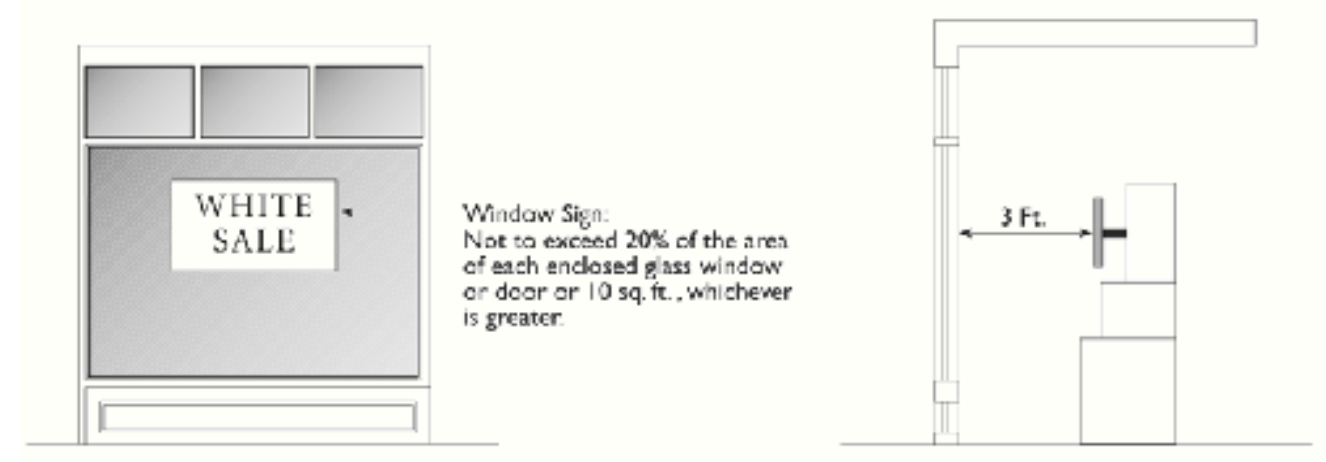

Sign con display setback up to $3 \mathrm{ft}$
from a wincow is cansidered a window sign.

\subsubsection{Prohibited Signs}

The following types of signs, materials, designs, messages, and locations are prohibited: 
A. Animated and Moving Signs. Signs that incorporate, in any manner, any flashing, moving, rotating, pulsating or intermittent lighting, with the exception of approved time and temperature displays.

B. Banners, Streamers, or Pennants. Signs, banners, pennants, valances or any other advertising display constructed of cloth, canvas, light fabric, paper, cardboard, wallboard or other light materials except for awnings and temporary signs as provided for in this Chapter.

C. Billboards. Off premises outdoor advertising signs.

D. Emissions. Signs that produce noise or sounds in excess of 40 decibels, excluding voice units at drive-through facilities, and signs that emit visible smoke, vapor, particles, or odor.

E. Fence Signs. Signs on fences or free-standing walls, not part of a building.

F. Obscenities. Signs that depict, describe, or relate to "specified sexual activities" or "specified anatomical areas" as defined in Chapter 17.41: Terms and Definitions.

G. Obstruction to Exits. Signs that obstruct any fire escape, required exit, window or door opening intended as a means of egress.

H. Obstruction to Ventilation. Signs that interfere with any opening required for ventilation.

I. Posters and Snipe Signs. Posters of a miscellaneous or temporary character that are tacked, painted, pasted or otherwise placed or affixed and made visible from a public way, on the walls of buildings, on barns, sheds, trees, fences, utility poles or other structures, sidewalks or patios, except as otherwise provided in this Chapter. 
J. Roof Signs. Signs erected upon, over or above the roof of a building or structure, or any sign affixed to the wall of a building so that it projects above the eave line of a roof. No projecting sign shall extend above the roofline or parapet of the building or structure to which it is attached.

FIGURE I 7.25-E: PROHIBITED ROOF SIGNS
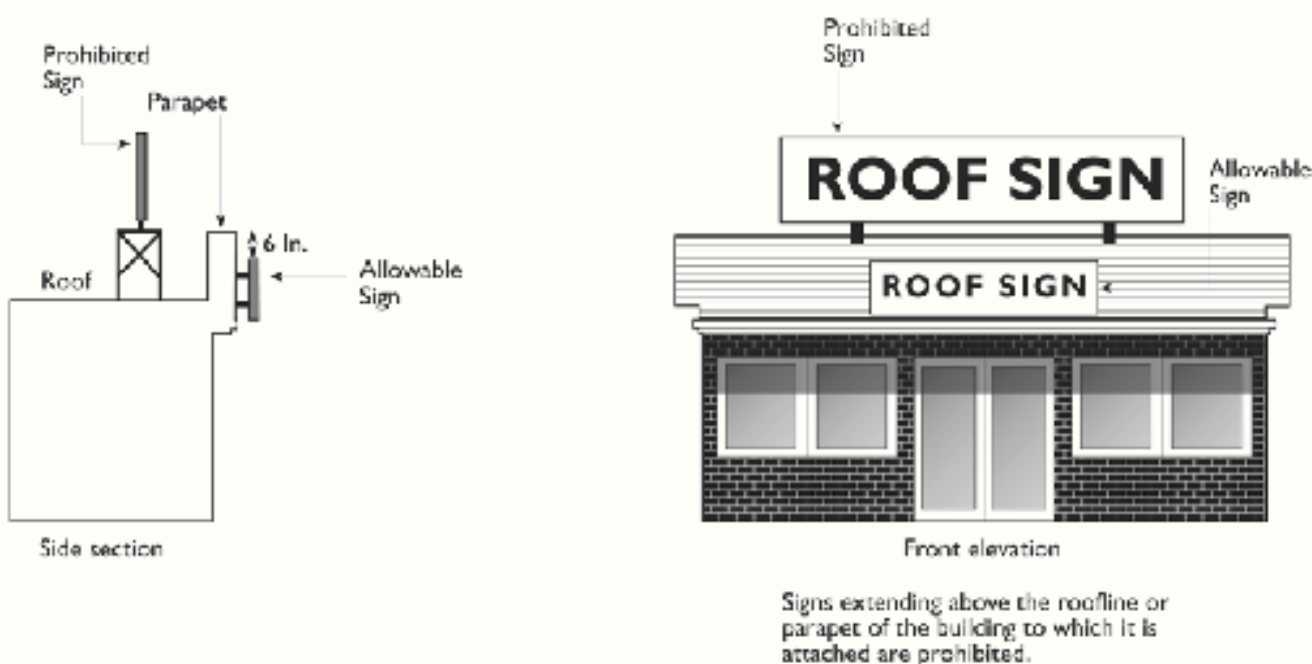

K. Signs Creating Traffic Hazards. Signs located in such a manner as to constitute a traffic hazard or obstruct the view of any authorized traffic sign or signal device, or signs that may be confused with any authorized traffic sign, signal, or device; or that makes use of the words "stop", "look", "danger", or any other word, phrase, symbol, or character that interferes with, misleads, or confuses vehicular drivers.

L. Signs on Public Bus Shelters or Benches. Signs located on bus shelters, benches, or similar structures provided for the use of passengers along the route of a bus, not including plaques containing the names of persons or organizations which have made gifts or donations of such street furniture.

M. Vehicle Displays. Signs placed or displayed on vehicles parked in a conspicuous location to be used for on-site or off-site advertising, with the exception of signs advertising such 
vehicles for sale and vehicle identification signs in locations where sale of vehicles is permitted.

N. Tire Stacks. Signs placed on stacked tires.

\subsubsection{General Sign Standards}

This Section establishes rules for measuring sign area, general physical standards, and requirements applicable to all signs and the districts in which they are located. More detailed standards applicable to specific sign types (e.g. building mounted, freestanding, and other sign types) in each zoning districts follow this Section.

A. Maximum Allowable Sign Area. The maximum allowable total sign area per property shall be as specified under the regulations in Section 17.68.050 and 17.68.060 for specific districts, unless a different limit is approved under a

Master Sign Program (see Section 17.68.100) or approved by the Planning Commission.

B. Computation of Sign Area. The methodology for computing the sign area of all sign types shall be as follows:

1. Single-faced Signs. The sign area of signs with sign faces on a single plane and viewable from only one side of the plane shall be measured as the entire area within a single continuous perimeter composed of squares or rectangles that enclose the extreme limits of all sign elements including, but not limited to, sign structures or borders, written copy, logos, symbols, illustrations, and color.

2. Double-faced Signs. Double-faced signs with sign faces that are parallel (back-to-back) and a distance of less than three feet apart, or sign faces that have an interior angle of 45 degrees or less, shall be counted as a single sign with only one face measured in calculating sign area. Where the faces are not equal in size, the larger sign face shall be used as the basis for calculating sign area. 
3. Multi-faced Signs. The sign area of signs with three or more sign faces, or signs with two sign faces with a distance greater than three feet apart or an interior angle greater than 45 degrees, shall be calculated as the sum of all the sign faces.

4. Three-dimensional Signs. Signs that consist of, or have attached to them, one or more three-dimensional objects (i.e., balls, cubes, clusters of objects, sculpture, or statue-like trademarks), shall have a sign area of the sum of two adjacent sides or sign faces. 
FIGURE 17.25-F: MEASUREMENT OF SIGN AREA

Sign Area $=$ Height $\times$ Widch
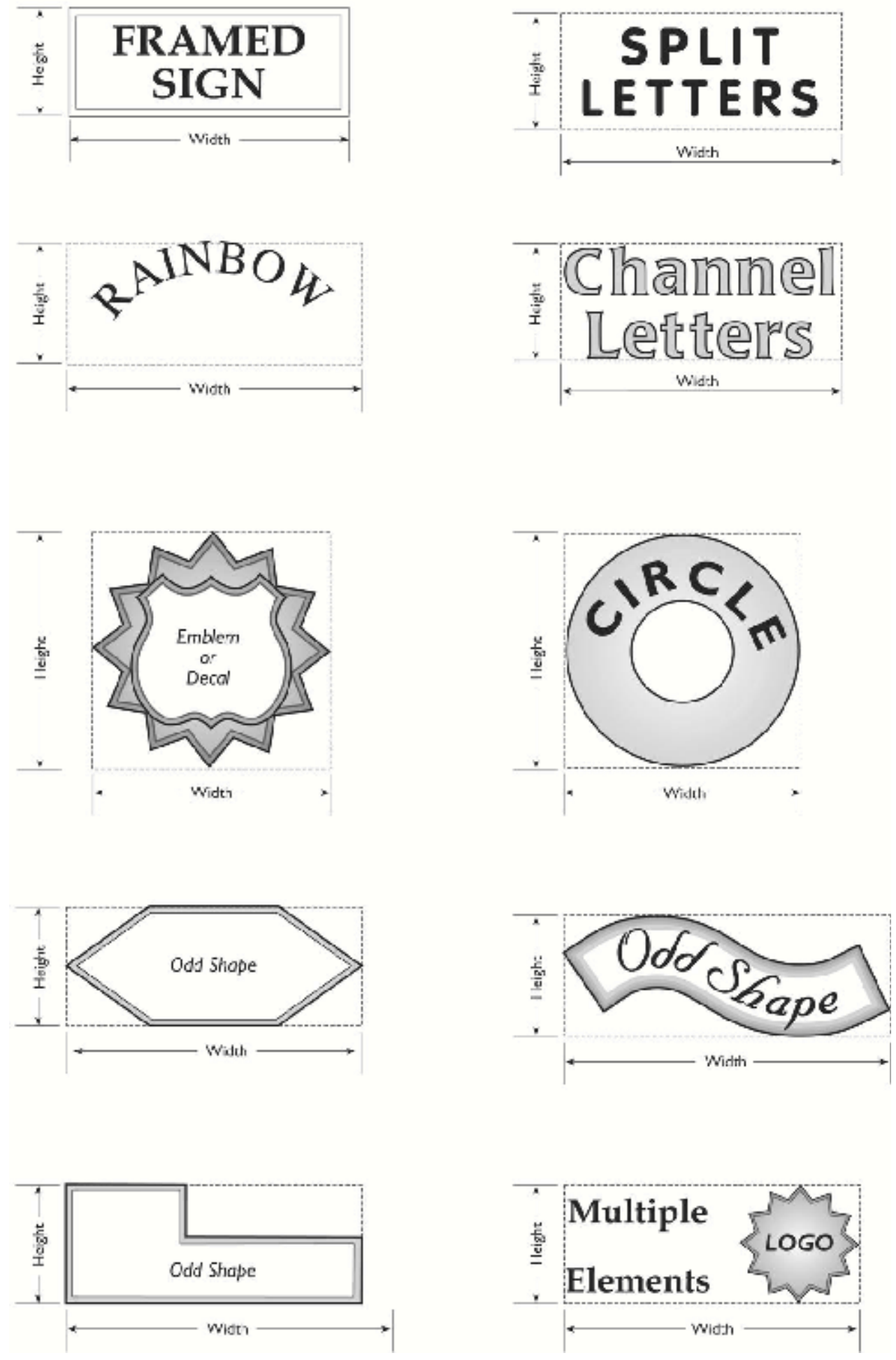


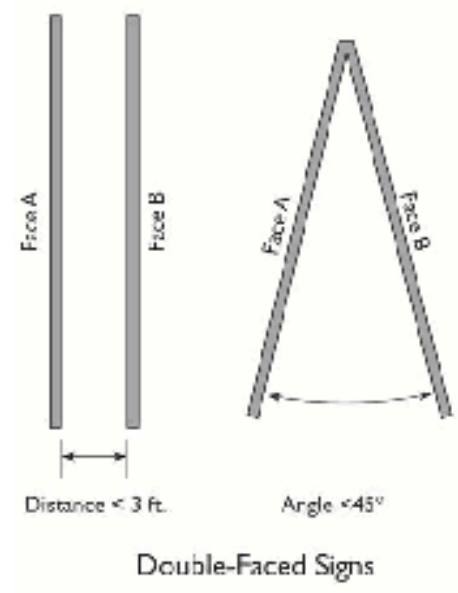

Total Sign Area $=$ One Sign Face

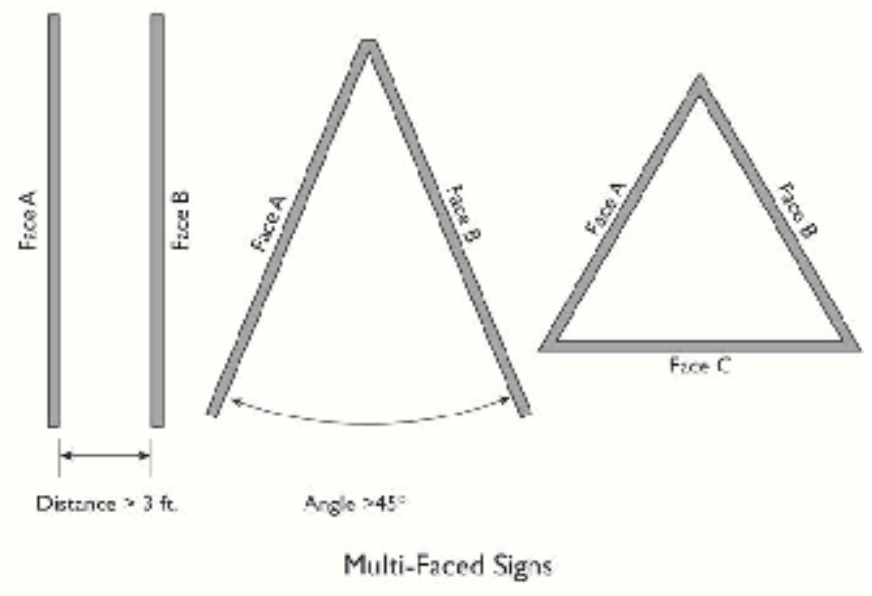

Total Sign Area $=$ Sum Of All Sign Faces

FIGURE 17.25-H: MEASUREMENT OF THREE-DIMENSIONAL SIGNS

Sign Area $=$ sum of two adjacent sides

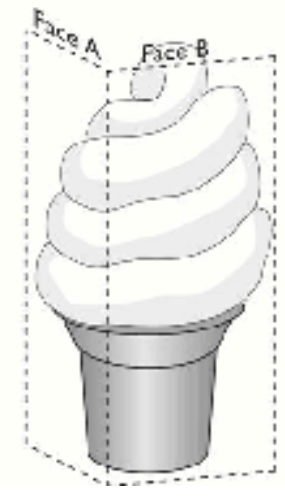


C. Building Frontage. A building's frontage is considered continuous if projections or recesses in a building wall do not exceed ten feet in any direction.

FIGURE 17.25-I: BUILDING FRONTAGE

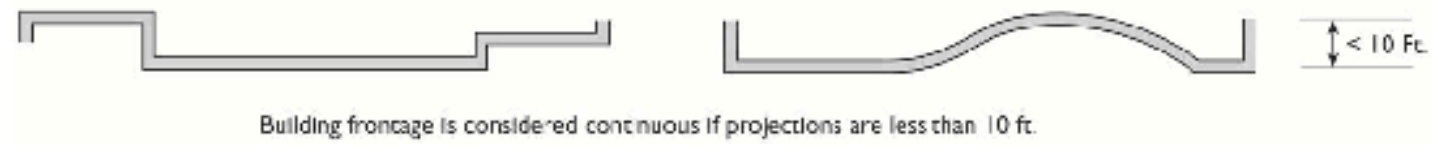

D. Materials. Paper, cardboard, or other material subject to rapid deterioration shall be limited to signs displayed for no more than 30 days.

E. Illumination. Signs may be illuminated subject to all of the following standards:

1. All lighting is subject to necessary electrical permits.

2. Freestanding and building-mounted signs adjacent to an $\mathrm{R}$ district shall be illuminated only during hours when the establishment is open for business.

3. External lighting shall be properly shielded to prevent glare upon an adjacent public right-of-way or adjacent property.

4. Illumination shall be constant in intensity and color and shall not consist of flashing, animated or changing lights.

F. Changeable Copy. Changeable copy shall cover no more than 25 percent of the total sign area, except for the following uses which are exempt from this restriction: churches and establishments for religious assembly, cinemas, gas station gas price signs, indoor theaters, schools, colleges, and signs that flash the time and temperature.

\section{G. Construction and Maintenance.}


1. Unless exempt, signs and supporting structures shall be installed in accordance with the Building Code.

2. All signs, together with all supporting structures, shall be maintained in the following manner:

a. Signs shall be kept free of rust, dirt and chipped, cracked or peeling paint.

b. All hanging, dangling, torn or frayed parts of signs shall be promptly repaired and graffiti and unauthorized attachments shall be removed.

c. Burned-out illumination shall be promptly replaced.

d. Sign areas shall be kept free and clear of all noxious substances, rubbish, and weeds.

3. If a sign is removed from its supporting structure for longer than 90 days, the supporting structure shall be removed.

H. Abandoned Signs. Sign faces shall be removed or made blank within 60 days after the activity, product, business, service or other use which was being advertised has ceased or vacated the premises. Any signs not removed or made blank within this time shall be removed pursuant to the removal procedures set forth in Section 17.68.110 of this Chapter.

I. Substitution of Sign Message. The owner of a permitted sign may substitute a noncommercial message for a commercial message or a commercial message for a noncommercial message.

J. Encroachment into Public Street or Sidewalk. Any sign projecting over a public street or sidewalk requires approval of the Director or City Engineer, except that projecting signs and pole signs are allowed a maximum encroachment of 12 inches over a public street or sidewalk subject to approval of an encroachment permit.

K. Clearance from Utilities. Signs and their supporting structures shall maintain clearance and not interfere with electrical conductors, communications equipment or lines, surface and underground facilities and conduits for water, sewage, gas, electricity and communications 
equipment or lines. Signs shall not be placed in public utility easements unless express written permission from the affected public utility is obtained.

L. Drainage. The roofs of canopies or marquees exceeding 25 square feet shall be drained to prevent dripping or flow onto public sidewalks or streets and shall be connected to an approved disposal source of adequate conductors.

M. Sign Orientation. No sign, other than a projecting sign, shall be permitted that is so oriented as to be viewed primarily across an adjacent private property line. All signs must be visible directly from a public right-of-way, other public open space or parking lot or courtyard on the same site as the sign, without view lines extending over private property different from that on which the sign is located.

N. Lighting. Light sources shall be steady, and stationary lighting shall not be distracting to pedestrians, motorists and neighboring property. No sign shall emit or reflect light exceeding ten foot-candle power at ten feet from the face of the sign.

\subsubsection{Regulations for Residential Districts.}

The following regulations shall apply to all $\mathrm{R}$ districts, as well as residential dwellings located in nonresidential districts. Sign permits shall be required for the sign types described in the following zones unless expressly exempted.

A. Multi-family Dwellings. One building-mounted sign or monument sign per multi-family dwelling complex of four or more units is permitted, with a maximum sign area of 20 square feet.

B. Hotels, Motels, and Bed and Breakfast Establishments. 
1. R2 Districts. One surface sign or monument sign per bed and breakfast establishment and attraction boards as provided in the Section $17.68 .070(C)(5)$ are permitted with a maximum sign area of 0.5 square feet per linear foot of building frontage.

2. R3 and R4 Districts. Signs may be permitted in accordance with the provisions for commercial zones as provided in Section 17.68 .060 below as well as attraction boards as provided in Section 17.68.070(C)(5).

C. Subdivision or Tract Name Signs. One non-illuminated sign not to exceed 24 square feet in area or one non-illuminated sign not to exceed 12 square feet in area, per exclusive entrance to a subdivision or tract name with a maximum of four per tract is permitted.

1. Maximum Sign Area. 30 square feet.

2. Maximum Height. 8 feet.

D. Mobile Home Parks. A mobile home park may be allowed one externally illuminated or nonilluminated identification sign, not to exceed the equivalent of one square foot of sign area per ten linear feet of frontage on each right-of-way upon which it takes vehicular access. No sign shall have a surface area of greater than 30 square feet or be erected at right angles to the right-of-way.

1. Maximum Sign Area. 30 square feet.

2. Maximum Height. 8 feet.

E. Non-residential Uses. One building-mounted sign or monument sign per each allowable non-residential uses is permitted.

1. Maximum Sign Area. 0.5 square feet per linear foot of building frontage up to 24 square feet. 
2. Maximum Height. 15 feet above finished grade for building-mounted signs and eight feet for monument signs.

\subsubsection{Regulations for Commercial, Mixed-Use and Industrial Districts}

The following standards apply to signs in commercial, mixed-use and industrial zones.

A. Sign Area and Allowable Signs. Signage in Commercial, Mixed-Use, and Industrial zoning districts shall comply with the standards in Table 17.68 - B.

1. Calculation of Sign Area. For individual signs, the sign area of the proposed sign shall be multiplied by the sign factor specified in Table 17.68 - B to calculate the sign area to be applied towards the maximum sign area allowed.

2. Minimum Sign Area. All commercial, mixed-use, and industrial uses shall be allowed a minimum sign area of 20 square feet.

B. Sign Placement. Signs shall be oriented towards the public street or the harbor frontage on which they are located, or where no such public right-of-way or harbor frontage exists, signs shall be oriented towards a common use parking lot or interior courtyard. Where the principal sign for a business is located so that it cannot be seen by pedestrian traffic, an identification sign, in addition to that otherwise allowed by this Chapter, may be permitted. 


\begin{tabular}{|c|c|c|c|c|c|c|c|c|}
\hline $\begin{array}{l}\text { Zoning Districts } \\
\text { Frontage: }\end{array}$ & \multicolumn{2}{|c|}{$\begin{array}{l}\text { Sign Area Allowed } \\
\text { (sq. ft. per } 1 \text { linear ft. of } \\
\text { building frontage) }\end{array}$} & $\begin{array}{l}\text { Total } \\
\text { Maximum Sign } \\
\text { Area (sq. ft.) }\end{array}$ & $\begin{array}{l}\text { Permitted Sign } \\
\text { Types }\end{array}$ & $\begin{array}{l}\text { Sign } \\
\text { Type } \\
\text { Factor }\end{array}$ & $\begin{array}{l}\text { Maximum } \\
\text { Number of Signs }\end{array}$ & $\begin{array}{l}\text { Maximum } \\
\text { Sign Area Per (sq. ft.) }\end{array}$ & Additional Regulations \\
\hline \multirow[t]{5}{*}{$\begin{array}{l}\text { C1, MCR, CVS, } \\
\text { GO, WF, and } \\
\text { GC }\end{array}$} & 0.5 & & 100 & $\begin{array}{l}\text { Awning and } \\
\text { Canopy }\end{array}$ & 1 & & 24 & Section 17.68.070(A)(1) \\
\hline & & & & Wall & 2 & 2 per frontage & 24 & Section $17.68 .070(A)(4)$ \\
\hline & & & & Marquee & 1 & & $\begin{array}{l}1.5 \text { per linear } \mathrm{ft} \text {. Section of } \\
\text { building frontage }\end{array}$ & Section 17.68.070(A)(2) \\
\hline & & & & Monument & 3 & 1 per site & 24 & Section $17.68 .070(\mathrm{~B})(1)$ \\
\hline & & & & $\begin{array}{l}\text { Temporary } \\
\text { Sidewalk }\end{array}$ & 1 & 1 per site & 12 & Section 17.68.070(B)(3) \\
\hline \multirow{4}{*}{$\begin{array}{l}\mathrm{C} 2, \mathrm{CF}, \mathrm{M} 1, \mathrm{M} 2 \\
\mathrm{H} \& \mathrm{MMR}\end{array}$} & & & & Wall & 1 & $\begin{array}{l}1 \text { per building or } \\
\text { tenant space }\end{array}$ & 25 & Section 17.68.070(A)(4) \\
\hline & & & & Window & 2 & 2 per frontage & & Section 17.68.070(A) \\
\hline & & & & Monument & 2 & 1 per frontage & 60 & Section 17.68.070(B)(1) \\
\hline & & & & Pole & 3 & $\begin{array}{l}1 \text { per site or } \\
\text { shopping center }\end{array}$ & 60 & Section 17.68.070(B)(2) \\
\hline
\end{tabular}




\subsubsection{Specific Sign Types and Standards}

A. Building-Mounted Signs. Building-mounted signs consist of wall signs, awning and canopy signs, projecting signs, and marquee signs. There is no limit on the maximum number of building mounted signs, provided that the total size of all such signs does not exceed the total maximum signage area permitted for all signs in the zoning district where the sign is located, established by Sections 17.68.050 and 17.68.060.

\section{FIGURE |7.25-]: BUILDING-MOUNTED SIGN TYPES}

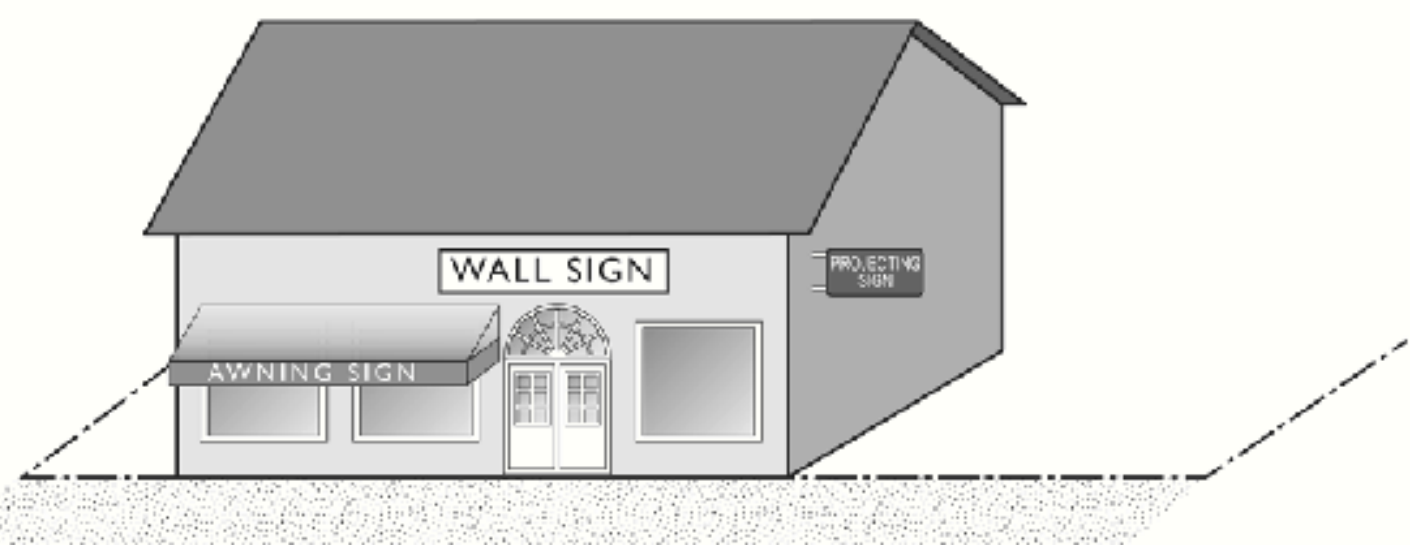

1. Awning and Canopy Signs. Signs painted on awnings, canopies, arcades, or similar attachments or structures. Sign area for awning and canopy signs is calculated as the area within a single continuous enclosure around only the copy area of the lettering or logo of the sign. Awning and canopy signs are also subject to the specific zoning district standards in 17.68.050 and 17.68.060.

a. Maximum Height. 25 feet above a sidewalk or public right-of-way.

b. Marquee Signs. A sign permanently affixed to a marquee is allowed in conjunction with theaters, museums, galleries, and similar uses. Removable copy may be changed on the face of permitted marquee signs without securing a sign 
permit. Marquee signs are subject to the specific zoning district standards in 17.68.050 and 17.68.060.

c. Maximum Height. Marquee signs may not project above the marquee face.

FIGURE 17.25-K: AWNING AND CANOPY SIGNS

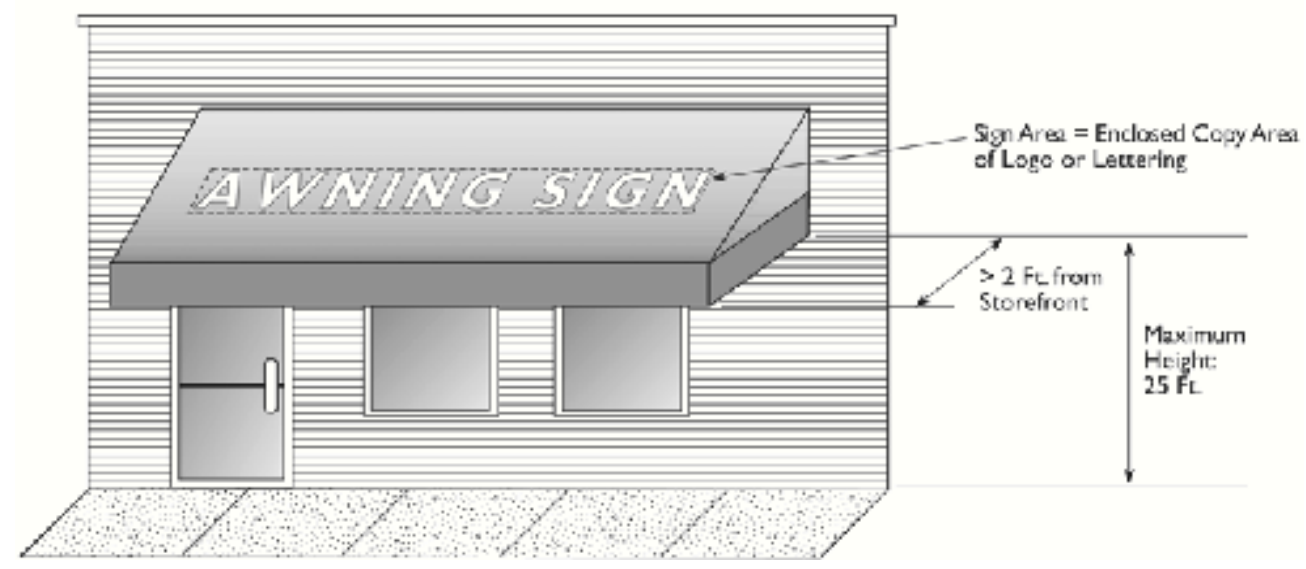

2. Projecting Signs. Signs under canopies or covers in conjunction with pedestrian walkways, or signs projecting from the building wall. Projecting signs are subject to the specific zoning district standards in 17.68.080.

a. Minimum Height. 8 feet above a sidewalk or other public right-of-way.

b. Maximum Height. $20 \mathrm{ft}$. above a sidewalk or other public right-of-way, but not above an eave or roof. 


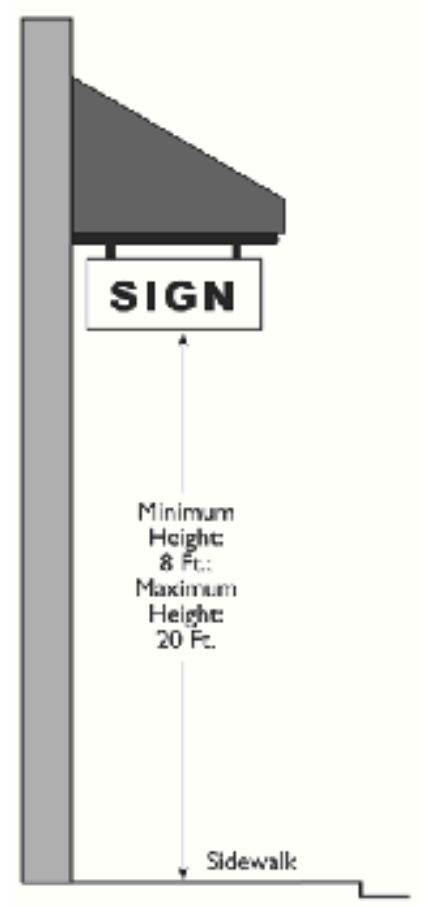

Projecting Under Awning Sign

3. Wall Surface Signs ("Wall" Signs). Wall surface signs include any sign attached to, erected against or painted upon the wall of a building or structure, the face of which is in a single plane parallel to the plane of the wall. Wall signs also include signs on a false or mansard roof. Wall signs are subject to the standards in Table $17.68-$ C. No wall surface sign may cover wholly or partially any required wall opening. Wall signs are also subject to the specific zoning district standards in 17.68.050 and 17.68.060.

\begin{tabular}{|l|l|}
\hline TABLE 17.68 - C: WALL SURFACE SIGN STANDARDS \\
\hline $\begin{array}{l}\text { Minimum Horizontal and Vertical Separation } \\
\text { Between Signs }\end{array}$ & $3 \mathrm{ft}$. \\
\hline Maximum Projection from Surface of Building & $12 \mathrm{in}$ \\
\hline $\begin{array}{l}\text { Minimum Vertical Separation Between Sign and } \\
\text { Roof Line }\end{array}$ & $\begin{array}{l}1 \mathrm{ft} . \text { (8 inches on a fascia or } \\
\text { mansard roof) }\end{array}$ \\
\hline Maximum Height & $\begin{array}{l}20 \mathrm{ft} . \text { above a sidewalk or } \\
\text { Above public right-of-way. }\end{array}$ \\
\hline
\end{tabular}


B. Freestanding Signs. Freestanding signs consist of signs not attached to a building or structure, including monument signs and pole signs. Freestanding signs shall not interfere with safety sight angles on corners and at driveways. No more than one freestanding sign is allowed on a site.

1. Monument Signs. Freestanding signs erected on the ground or on a monument base designed as an architectural unit. Monument signs are also subject to the specific zoning district standards in 17.68.050 and 17.68.060.

a. Maximum Height. six feet six inches. eight feet if setback a minimum of five feet from property line.

b. Minimum Setbacks - C1 and C2, CVS, and MCR Districts. one foot from setback line.

c. Landscaping. Signs higher than six feet six inches shall be placed in a landscaped planter or berm. As a condition of any sign permit for a monument sign, additional landscaping of the site may be required to better integrate sign appearance with the site.

\section{Pole Signs.}

a. Landscaping. Pole signs shall be placed within a landscaped planter with at least 28 square feet of planting area. As a condition of any sign permit for a pole sign, additional landscaping of the property may be required where needed to better integrate sign appearance with the site through scale and softening effects.

b. Design. Such signs and their supporting elements shall be designed so as to be harmonious with any building or structures on the site, including architectural style, colors and scale.

c. Maximum Height. 15 feet; 25 feet within 200 feet of Highway 1, subject to approval of a conditional use permit.

d. Other Requirements. Pole signs are subject to the specific zoning district standards in 17.6.050 and 17.68.060. 
3. Temporary Sidewalk Signs. Signs not permanently attached to the ground or any other permanent supporting structure, such as "A-frame" or sandwich type sign, and sidewalk or curb signs. Temporary sidewalk signs shall not impede safe pedestrian circulation.

Temporary sidewalk signs are subject to the specific zoning district standards in $\mathbf{1 7 . 6 8 . 0 5 0}$ and

FIGURE I7.25-M: FREESTANDING SIGN TYPES
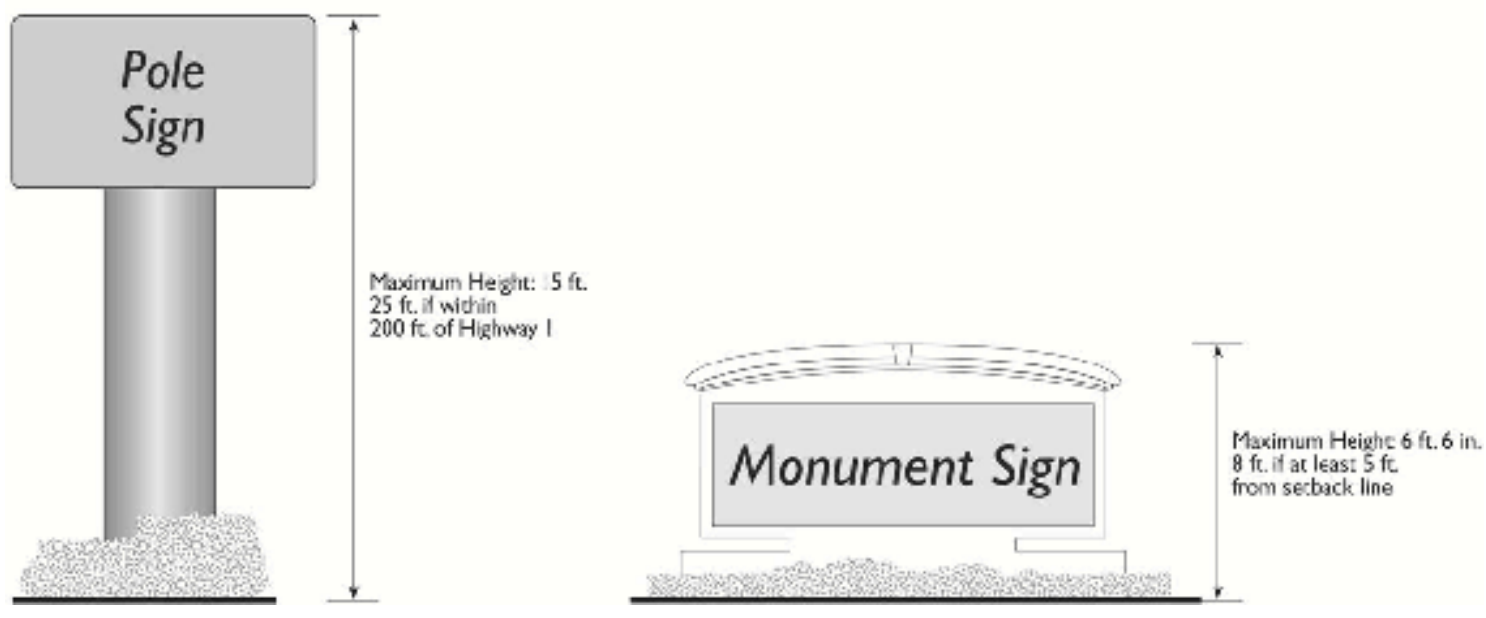

\subsubsection{Other Sign Types.}

1. Display Structures. Display structures for pedestrian viewing, as defined in this Chapter, are permitted in any commercial district. Such display structures must comply with building setback requirements, and shall be illuminated only by indirect light or diffused light. The maximum sign area is 50 percent of the maximum building mounted sign area allowance for the building and frontage with which they are associated.

2. Special Private Event Displays and Grand Opening Signs. Temporary signs and wind signs may be erected on the premises of an establishment having a grand opening or special event provided that such signs shall be displayed for a period not to exceed thirty calendar days previous to such event. These signs shall be removed within seven days after the event, and 
such signs may be used for not more than two periods each calendar year for any property or business.

3. Directional and Community Promotional Display Programs. Directional and community promotion sign programs advertising, directing or informing pedestrian of business service or community events and services not related to or located on the site shall be permitted on private property in $\mathrm{C}$ districts, and on public land with the granting of an encroachment permit.

4. Civic Event Signs. Temporary signs announcing a campaign drive or event of a civic, public, quasi-public, philanthropic, educational or religious organization.

a. Maximum Sign Area. 32 square feet.

b. Maximum Time Period. 30 days. Such signs shall be removed within 15 days after the event.

5. Attraction Boards for Hotels. Motels and Bed and Breakfast Establishments. An attached or detached attraction board, not to exceed five square feet in sign area, is allowed, provided it is included within the calculation of the maximum allowable sign area for a hotel, motel, or bed and breakfast establishment.

\subsubsection{General Design Principles}

The following principles are general criteria that should be considered in the design of all signs. Creative design is strongly encouraged, and signs should make a positive contribution to the aesthetic appearance of the street or commercial area where they are located. These principles will be used in reviewing and approving proposed signs and Master Sign Programs (see Section 17.68.100).

A. Visibility. A sign shall be conspicuous and readily distinguished from its surroundings. 
B. Legibility. The size and proportion of the elements of the sign's message, including logos, letters, icons and other graphic images, shall be selected based on the average distance and average travel speed of the viewer. Sign messages oriented towards pedestrians may be smaller than those oriented towards automobile drivers. Colors chosen for the sign text and/or graphics shall have sufficient contrast with the sign background in order to be easily read during both day and night hours.

C. Readability. A sign message should be easily recognized and designed in a clear, unambiguous and concise manner, so that a viewer can understand or make sense of what appears on the sign. Excessive use of large areas of several colors can create competition for the eye and significantly reduce readability.
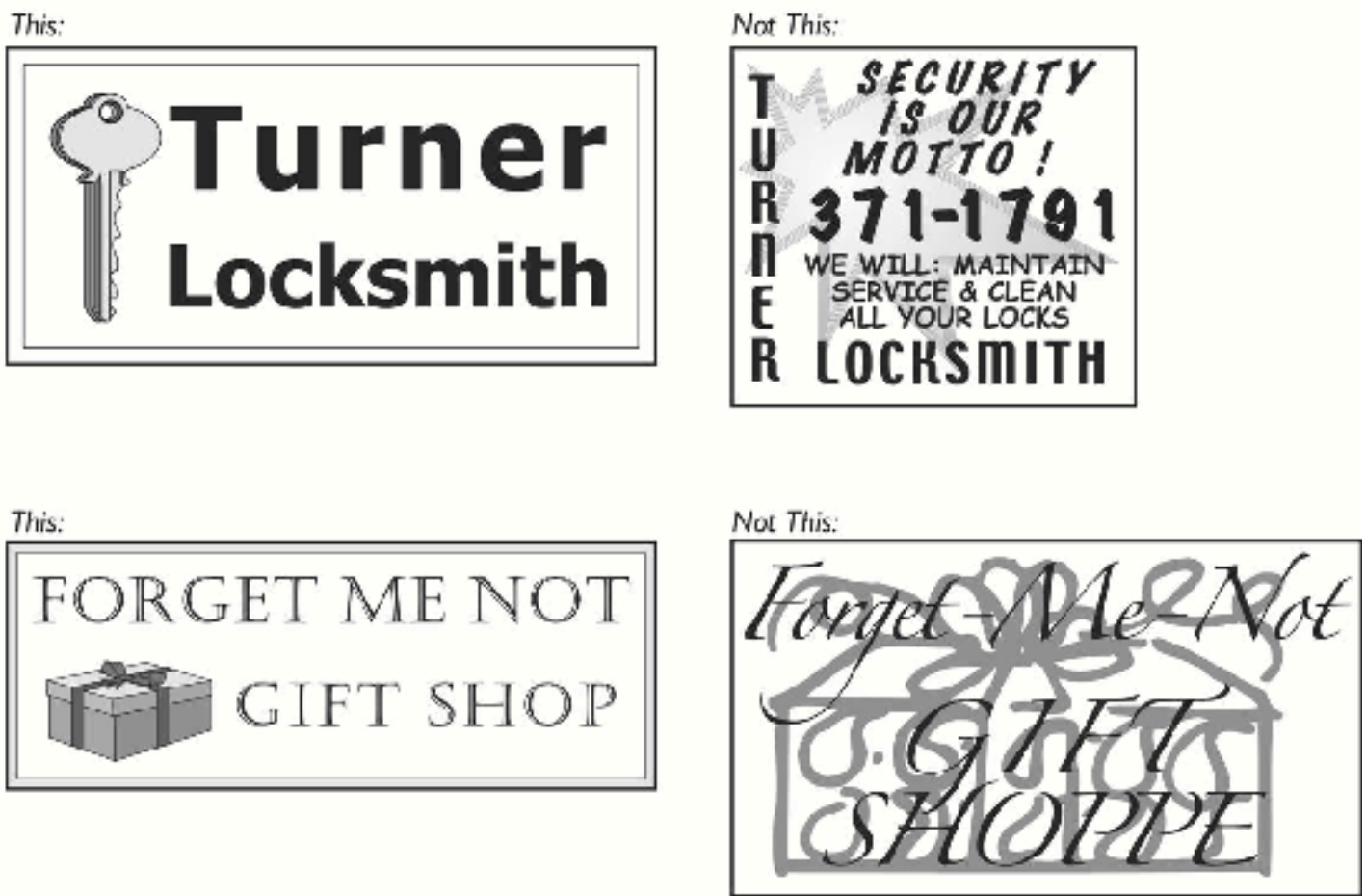
D. Architectural Compatibility. A sign (including its supporting structure, if any) shall be designed as an integral design element of a building's architecture, and shall be architecturally compatible, including color and scale, with any building to which the sign is to be attached and with surrounding structures. A sign which covers a window, or which spills over "natural" boundaries or architectural features and obliterates parts of upper floor of buildings is detrimental to visual order and may not be permitted.

E. Consistency with Area Character. A sign should be consistent with distinct area or district characteristics and incorporate common design elements such as sign materials or themes. Where signs are located in close proximity with a residential area, the sign should be designed and located so they have little or no impact on adjacent residential neighborhoods.

FIGURE 17.25-O: ARCHITECTURAL COMPATIBILITY

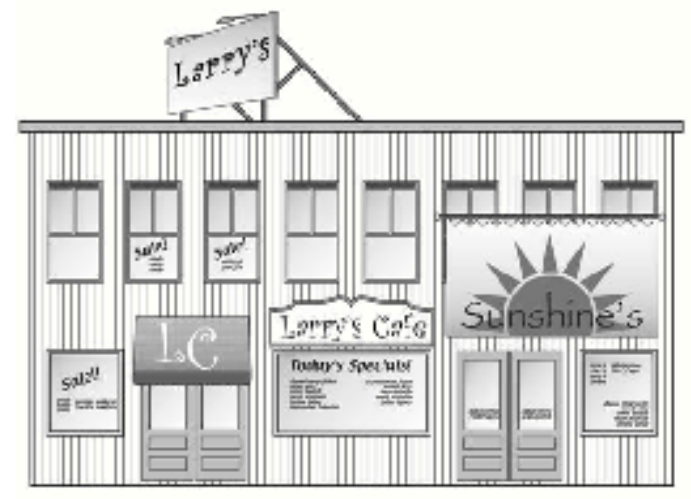

These signs block building's elements and create a chaotic image.

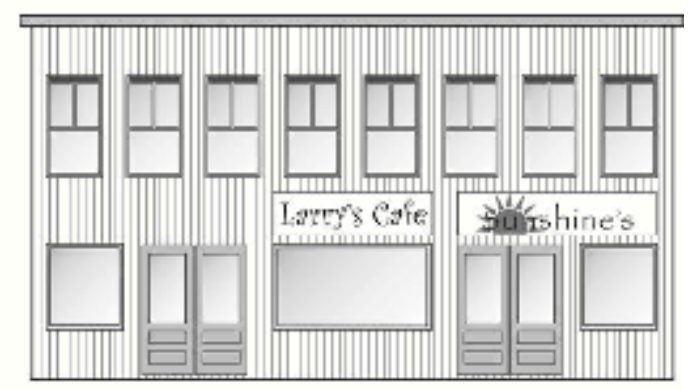

These signs complement dhe building's form and creete a more orderly appearance.

\subsubsection{Zoning Clearance or Sign Permit Required}

A. Authority. No sign, other than an exempt sign, shall be erected or altered, without first obtaining a zoning clearance or sign permit from the Director. The Director may attach reasonable conditions on the approval of the sign permit to help ensure compliance with this Chapter. These conditions may require the removal, modification or relocation of 
existing signs where the proposed sign(s) would be located on sites where existing signs are nonconforming.

B. Application Requirements. Applications for a sign permit shall be made in writing upon forms furnished by the Director, accompanied by the required fee and plans drawn to scale and with all of the following information. Where the scale and scope of the sign proposal so warrants, the Director may waive some of the informational requirements listed below, provided all information necessary for adequate review of the proposal is submitted.

1. The proposed design, dimensions, copy, color, lighting methods and location of the sign on the site, including the dimensions of the sign's supporting members, and details of all connections, guy lines, supports and footings, and materials to be used.

2. The maximum and minimum height of the sign.

3. The location of off-street parking facilities, including entries and exits where directional signs are proposed.

4. The size and dimension of all signs existing on the site.

5. The location and horizontal frontage of any building(s) on the property, both existing and proposed.

6. Any other information deemed necessary by the Director.

\section{Required Findings. In approving a sign permit, the Director must find that:}

1. The size, shape, color, materials, design and location of the sign conforms to the design principles and standards of this Chapter. 
2. Signs on all proposed buildings or new additions to existing buildings are designed as an integral part of the total building design.

3. The location of the proposed sign and the design of its visual elements (lettering, words, figures, colors, decorative motifs, spacing and proportions) are legible under normal viewing conditions that prevail where the sign is to be installed.

4. Review of signs at city entryways as defined in the Scenic Highway Element of the General Plan shall also be subject to the following provisions:

a. Sign area, height and location of signs shall be designed so as not to interfere with view corridors as defined and specified in the General Plan/Local Coastal Plan.

b. Freestanding signs shall not exceed eight feet in height except within two hundred feet of Highway 1 or Highway 41. Where feasible, all freestanding signs within or along city entryways shall be placed within a landscaped planter.

\subsubsection{Master Sign Program}

A. Applicability. Any site having four or more non-residential occupants shall submit a master sign program to be reviewed and approved by the decision-making authority for the use (e.g. the Director or the Planning Commission). Any site having three or fewer nonresidential occupants may submit a master sign program to be reviewed and approved by the decision-making authority. Additionally, projects involving construction or renovation of more than 25,000 square feet of space in the commercial and mixed use districts shall submit a master sign program which must be approved prior to issuance of any occupancy permit.

B. Application Requirements. Applications for approval of a master sign program shall be submitted to the Director and shall include the following:

1. Master Sign Program. A Master Sign Program, drawn to scale, delineating the site proposed to be included within the signing program and the general location of all signs. 
2. Drawings and Sketches. Drawings and/or sketches indicating the exterior surface details of all buildings on the site on which wall signs, directory signs, ground signs or projecting signs are proposed.

3. Statement for Modifications. A statement of the reasons for any requested modifications to the regulations or standards of this Chapter.

4. Sign Standards. A written program specifying sign standards, including color, size, construction details, placement, and necessity for City review for distribution to future tenants.

C. Allowable Modifications. A Master Sign Program may provide for additional sign area and other deviations from the standards of this Chapter, provided that the Master Sign Program is consistent with the provisions of Sections 17.68.040 and 17.68.080.

D. Required Findings. In approving a Master Sign Program, the decision-making authority shall find that all of the following are met:

1. The proposed signs are compatible in style and character with any building to which the sign is to be attached, any surrounding structures, and any adjoining signage on the site;

2. Future tenants will be provided adequate opportunities to construct, erect or maintain a sign for identification; and

3. Directional signage and building addressing is adequate for pedestrian and vehicular circulation and emergency vehicle access.

E. Conditions of Approval. The Planning Commission may attach any reasonable conditions necessary to carry out the intent of the Master Sign Program requirement, while still permitting each sign user opportunities for effective identification and communication. 
F. Administrative Approval of Signs Consistent with Master Sign Program. Following approval of a Master Sign Program, the Director is authorized to issue building permits or other permits, as deemed necessary, to install signs that conform to an approved Master Sign Program. Minor modifications of individual sign area may be approved, provided the maximum allowed by an approved Master Sign Program is not exceeded.

\subsubsection{Maintenance, Abandonment and Removal}

A. Maintenance. Every sign, including those signs for which no permit is required, together with all supports braces, guys and anchors shall be maintained in a safe, presentable and good structural condition at all times. The display surfaces of all signs shall be kept neatly painted, posted or otherwise maintained at all times. The owner of property on which the sign is located shall be responsible for the condition of the area in the vicinity of the sign, and shall be required to keep this area clear, sanitary and free from noxious or offensive substances, rubbish and flammable waste materials.

B. Abandonment. The following signs shall be presumed to be abandoned:

1. Located on Property. Any sign which is located on property that becomes vacant and is unoccupied for a period of three months or longer.

2. Unrelated to Property. Any sign which was erected for an occupant or business unrelated to the present occupant or business, except existing, nonconforming outdoor off-site freestanding signs.

3. Time, Event or Purpose Sign. Any sign which pertains to a time, event or purpose which no longer exists.

4. Temporarily Suspended Business. Permanent signs applicable to a business temporarily suspended because of a change of ownership or management of such business shall not be deemed abandoned unless the property remains vacant for a period of six months or more. 
C. Removal. Abandoned signs are found to be a public nuisance due to their misleading and distracting nature and due to their contributing to visual blight, detrimental to surrounding areas and the community generally. An abandoned sign is prohibited and shall be removed by the property owner.

17.68.120 Provisions for Nonconforming and Illegal Signs

A. Existing Non-conforming Signs. Signs existing at the time of adoption of this Title, that do not comply with the provisions of this Chapter but that were legally erected pursuant to applicable state and city ordinances in effect at the time of construction, shall be regarded as nonconforming signs, subject to the following:

1. Use Change. Whenever the type of business or use with which a nonconforming sign is associated changes, the nonconforming sign associated with business shall be removed or otherwise made to conform to the provisions of this Chapter.

2. Limited Expansion. A nonconforming sign may not be expanded, extended, reconstructed, or altered in any way in its location or orientation to enable it to be read or viewed from a different direction than its original position. Except in the following cases:

a. Such sign may be removed for purposes of repair and routine maintenance, including painting, provided such sign is replaced within 60 days of its removal;

b. Changes in sign face, copy, graphic design or color are permitted.

c. Such sign may be removed for the purpose of remodeling a building provided replacement occurs within 30 days after remodeling is completed.

d. If change in ownership of the business occurs, without any change to the type of business advertised by a nonconforming sign, the new owner may change any name or names on such sign provided that there is no change in the sign size, 
configuration or orientation.

3. Other Requirements. Nonconforming signs are also subject to the provisions of Chapter 17.68: Nonconforming Uses and Structures.

B. Illegal Signs. Whenever a sign is found to be erected or maintained in violation of any provision of this Chapter, this Title, or any other Federal, State, or local law, and such sign is not a nonconforming sign (e.g. it was a legal sign under the sign regulations in effect prior to adoption of the ordinance codified in this Chapter), the Director shall order that such sign be altered, repaired, reconstructed, demolished or removed, as may be appropriate, to abate such condition or the Director may initiate proceedings to abate the sign as a public nuisance under the provisions of the Business and Professional Code (Sections 5499.1 to 5499.16). Any work required to be done shall be completed within ten days of the date of such order, unless otherwise specified in writing.

\subsubsection{Appeals of Sign Permits}

\subsubsection{A Rights of Appeal}

A. Persons Who May Appeal. Except as provided for elsewhere in this Title, appeals may be made by the following persons, in the following instances:

1. Local Appeals. Appeals to the Planning Commission or City Council may be filed by the applicant, by the owner of property, or by any other person aggrieved by a decision that is subject to appeal under the provisions of this Title.

B. Final Decision Required. Unless otherwise specified by Federal or State law, an appeal must be brought and a final decision rendered by the hearing body before the matter may be appealed to a court of law. 


\subsubsection{Time Limits}

Unless otherwise specified in State or Federal law, all appeals shall be filed within 10 days of the date of action.,

\subsubsection{Local Appeals}

A. Proceedings Stayed by Appeal. The timely filing of an appeal shall stay all proceedings in the matter appealed, including, but not limited to, the issuance of City building permits and business licenses.

B. Appeals of Director Decisions. A decision of the Director on any application may be appealed to the Planning Commission by filing a written appeal with the Planning Department. The appeal shall identify the decision being appealed and shall clearly and concisely state the reasons for the appeal.

C. Appeals of Planning Commission Decisions. Decisions of the Planning Commission may be appealed to the City Council by filing a written appeal with the City Clerk. The appeal shall identify the decision being appealed and shall clearly and concisely state the reasons for the appeal.

D. Transmission of Record. The Director, or in the case of appeals to the City Council, the City Clerk, shall schedule the appeal for consideration by the authorized appellate body within 60 days of the date the appeal was filed. The Director shall forward the appeal, the Notice of Action, and all other documents that constitute the record to the appellate body. The Director also shall prepare a staff report that responds to the issues raised by the appeal and may include a recommendation for action. 
E. Appellate Body Action. The appellate body shall review the appeal, the administrative record, and any written correspondence submitted after the appeal has been filed, and may take one of the following actions:

1. Conduct a public hearing and decide on the action; or

2. Remand the matter to the decision-making body or official to cure a deficiency in the record or the proceedings.

F. No "De Novo" Review. At an appeal or review, the appellate body shall consider only the same application, plans, and related project materials that were the subject of the original decision.

G. Appellate Body Decision. The appellate body shall render its decision within 60 days of the date the hearing is closed unless State law requires a shorter deadline. An action to grant an appeal shall require a majority vote of the appellate body members. A tie vote shall have the effect of rejecting the appeal.

H. Standards of Review. When reviewing any decision on appeal, the appellate body shall use the same standards for decision-making required for the original decision. The appellate body may adopt the same decision and findings as were originally approved.

\subsection{Definitions}

Abandoned Sign. A sign that no longer applies to a business space, building, or site, due to lack of a valid business license, change of business name, or for any other reason that renders the sign not applicable to the premises involved. 
Attraction Board means a device used to display information regarding conveniences, services and rates currently offered by facilities providing temporary accommodation.

Banners. A temporary sign of fabric, plastic, paper or other light pliable material not enclosed in a rigid frame, and which is suspended, mounted, or attached to buildings or poles at two ends or continuously across its longest side so as to allow movements of the sign by atmospheric conditions.

Bench sign means a sign located on any part of the surface of a bench or seat placed on or adjacent to a public right-of-way.

Billboard means the same as outdoor off-site freestanding sign.

Building Mounted Sign. Any sign mounted or erected on or against any building or façade and includes all walls signs, awning and canopy signs and projecting signs.

Business Sign. Any interior or exterior sign which is intended to identify the name or portions of the business name and which is viewable from any exterior area open to the public.

Canopy shall refer to an ornamental roof like structure upon which a sign may be attached or otherwise affixed which is usually located over gasoline pumps.

Changeable Copy sign means a sign designed so that characters, letters or illustrations can be changed or rearranged without substantially altering the face or the surface of the sign.

Construction Sign. A sign displayed by a contractor, subcontractor, or architect on a project site whenever a building permit has been issued for construction, alteration, or repair of a structure and when work is in progress on site pursuant to such permit. 
Directory Sign. A collection of signs which list names of individual businesses located in a single building, courtyard, or property. Directories are located on private property at one or more entrance(s) facing or near the public right of way.

Freestanding sign means any sign which is supported by one or more uprights, poles or braces in or upon the ground which are not a part of any building or enclosed within the exterior walls of any building, and are separated there from by a distance of a least six inches.

Frontage constitutes for purposes of computing allowable sign area, the linear measurement in feet of the property line directly fronting on a public street, or other public right-of-way to which such sign is oriented, excluding California State Highway One

Height of a sign means the greatest vertical distance measured from the ground level directly beneath the sign to the top of the sign or from the nearest property line fronting on a public street, whichever is lower.

Illuminated Sign. A sign which radiates light from any internal source or is backlit and is visible from any public right-of-way or from any area open to the public.

Marquee Sign. A projecting sign that is part of a permanent entryway or canopy and traditionally associated with theaters. A marquee may include a projecting vertical sign extending above the cornice line of a building.

Master Sign Plan. A coordinated program of all signs, including exempt and temporary signs for a business, or businesses if applicable, located on a development site. The sign program shall include, but not be limited to, indications of the locations, dimensions, colors, letter styles and sign types of all signs to be installed on a site. 
Monument Sign. A freestanding sign not erected on one or more poles or similar structures but erected to rest on the ground or to rest on a monument base designed as an architectural unit.

Nonconforming Sign. Any sign that existed prior to a change in the municipal code that prohibits such signs or any sign installed without approval from the City that requires approval by the City.

Open House Sign. An open house sign advertises that a house is open for view as part of the sale or exchange of the property.

Outdoor-off-site freestanding sign means a sign placed for the purpose of advertising products or services that are not produced, stored or sold on the property or any other subject no related to the property or use of the property, upon which the sign is located.

Real Estate Sign. A sign identifying that a property is for sale, lease, exchange, or rent. The purpose of this sign is to help owners in the sale of their property by providing information on the location of the property to potential buyers without impairing the appearance of the community.

Roof Sign. Any sign erected, constructed, and maintained wholly upon or over the roof of any building.

Signs. Any object, structure, symbol, emblem, logo, or display, or any combination thereof, which is intended to or does identify, attract attention to, advertise, or communicate information of any kind to the public. See also Chapter 17.68: Signs.

Sign Area. The entire area of a sign calculated for maximum sign area purposes, pursuant to Chapter 17.68: 
Sign Face. The surface or surfaces used for the display of a sign message as seen from any one direction.

Snipe Sign. An off-site sign which is tacked, nailed, posted, pasted, glued or otherwise attached to trees, poles, stakes, fences or to other objects.

Temporary Sign. A sign or advertising display designed or intended to be displayed for a short period of time.

Wall Sign. Any sign that is fastened, affixed, or attached to and erected parallel to a building wall.

Window sign means any sign placed inside or upon a window facing the outside and which is intended to be seen from the exterior. 


\section{Appendix 6.3}

\section{Current and Draft Ordinance Matrix}

\begin{tabular}{|c|c|c|c|c|}
\hline & & & MB Current Ordinance & MB Draft Ordinance \\
\hline \multirow[t]{10}{*}{$\begin{array}{l}\text { Allowable } \\
\text { Sign Area by } \\
\text { Zone }\end{array}$} & Commercial & & $\begin{array}{l}\text { Only surface signs: } 2 \text { s.f. per } \\
\text { linear ft. frontage. Two or more } \\
\text { types of signs: } 1 \text { s.f. per linear } \\
\text { ft. frontage }\end{array}$ & $\begin{array}{l}\text { C1, MCR, CVS, WF, and GC } \\
\text { zones: } 0.5 \text { s.f. per linear ft. } \\
\text { frontage (100 s.f max) ; C2, CF, } \\
\text { H, MMR zones: } 2 \text { s.f. per linear } \\
\text { ft. frontage ( } 200 \text { s.f. max) }\end{array}$ \\
\hline & Industrial & & Same as Commercial & $\begin{array}{l}2 \text { s.f. per linear ft. frontage; } 200 \\
\text { s.f. } \max \end{array}$ \\
\hline & Agriculture & & 8 s.f. max per property & NA \\
\hline & \multirow[t]{5}{*}{ Residential } & $\begin{array}{l}\text { Multifamily dwelling of more } \\
\text { than four attached units: }\end{array}$ & 20 s.f. & 20 s.f. \\
\hline & & Other non-residential uses & $\begin{array}{l}0.5 \text { s.f. per linear ft., or } 24 \text { s.f. } \\
\text { (whichever is less) }\end{array}$ & $\begin{array}{l}0.5 \text { s.f. per linear ft. ; } 24 \text { s.f. } \\
\max .\end{array}$ \\
\hline & & Hotels, motels, bed/breakfast & See Commercial zone standards & $\begin{array}{l}\text { R2: } 0.5 \text { s.f. per linear ft.; R3/R4: } \\
\text { See Commercial zone standards }\end{array}$ \\
\hline & & Subdivision or tract name signs & $\begin{array}{l}24 \text { s.f. max, or up to four } 12 \text { s.f. } \\
\text { signs at entrances }\end{array}$ & $\begin{array}{l}24 \text { s.f. max, or up to four } 12 \text { s.f. } \\
\text { signs at entrances }\end{array}$ \\
\hline & & Mobile home parks & $\begin{array}{l}1 \text { s.f. per } 10 \text { linear ft. of } \\
\text { frontage on each right-of-way. } \\
30 \text { s.f. max }\end{array}$ & $\begin{array}{l}1 \text { s.f. per } 10 \text { linear ft. of } \\
\text { frontage on each right-of-way. } \\
30 \text { s.f. max }\end{array}$ \\
\hline & General Office & & 1 s.f. per linear ft. & $\begin{array}{l}0.5 \text { s.f. per linear ft. ; } 100 \text { s.f. } \\
\max \end{array}$ \\
\hline & Other Zones & & NA & $\begin{array}{l}\text { Harbor: } 2 \text { s.f. per linear ft. } \\
\text { frontage; } 200 \text { s.f. max }\end{array}$ \\
\hline $\begin{array}{l}\text { Temporary } \\
\text { Commercial } \\
\text { Signs }\end{array}$ & & & $\begin{array}{l}25 \% \text { of window area or } 10 \text { s.f., } \\
\text { whichever less. All lowed for } 30 \\
\text { days, }\end{array}$ & NA \\
\hline \multirow{6}{*}{$\begin{array}{l}\text { Sign } \\
\text { Allowances }\end{array}$} & Billboards & & Not allowed & Not Allowed \\
\hline & A-Frame & & Not allowed & Not Allowed \\
\hline & Digital Signs & & Not allowed & Not Allowed \\
\hline & Pole Signs & & $\begin{array}{c}\text { Allowed in } \\
\text { commercial/industrial zones }\end{array}$ & $\begin{array}{l}\text { Allowed in C2, CF, M1, M2, H, } \\
\text { MMR zones }\end{array}$ \\
\hline & Cloth Banners & & Not allowed & Not Allowed \\
\hline & Roof Signs & & Not allowed & Not Allowed \\
\hline $\begin{array}{l}\text { Approximate } \\
\text { Length of } \\
\text { code's text }\end{array}$ & & & 7,600 words & 7,900 \\
\hline
\end{tabular}

